\title{
Modelo de Gestão do Processo de Venda e Desenvolvimento de Software On-Demand para MPE's
}

\author{
Andrea Padovan Jubileu
}

Tese apresentada à Escola de Engenharia de São Carlos, da Universidade de São Paulo, como parte dos requisitos para obtenção do título de Doutor em Engenharia de Produção.

Orientador: Professor Titular Henrique Rozenfeld

\author{
São Carlos
}

2008 
AUTORIZO A REPRODUCCÃO E DIVULGAÇÃO TOTAL OU PARCIAL DESTE TRABALHO, POR QUALQUER MEIO CONVENCIONAL OU ELETRÔNICO, PARA FINS DE ESTUDO E PESQUISA, DESDE QUE CITADA A FONTE.

Ficha catalográfica preparada pela Seçăo de Tratamento da Informação do Serviço de Biblioteca - EESC/USP

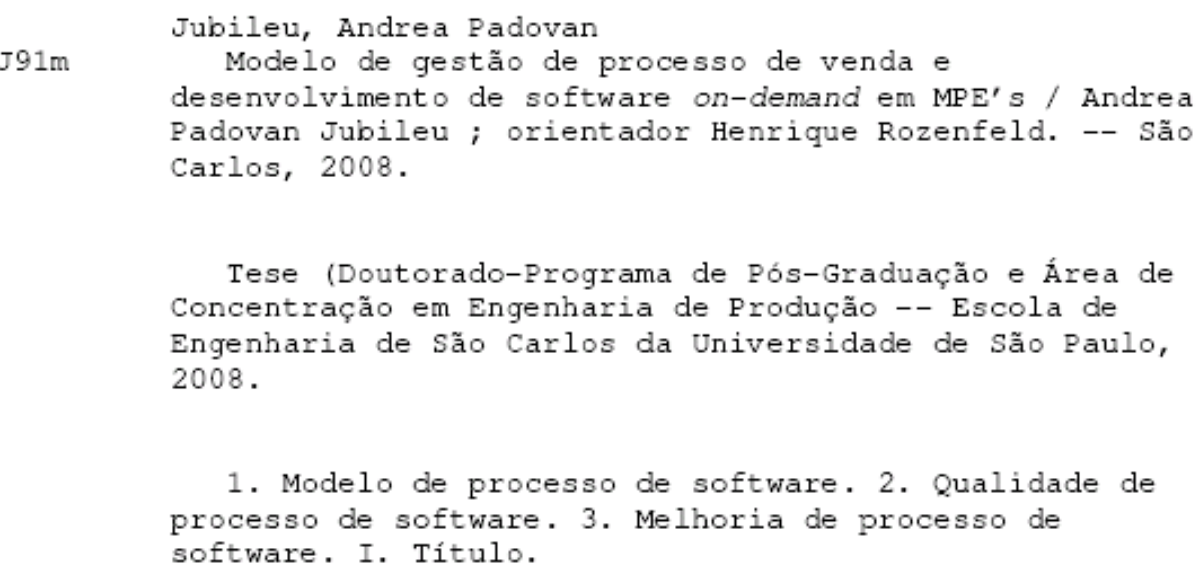




\section{FOLHA DE NULGAMENTO}

Candidata: Bacharel ANDREA PADOVAN JUBILEU

Tese defendida e julgada em 16:122008 perante a Comissâo Julgadora:

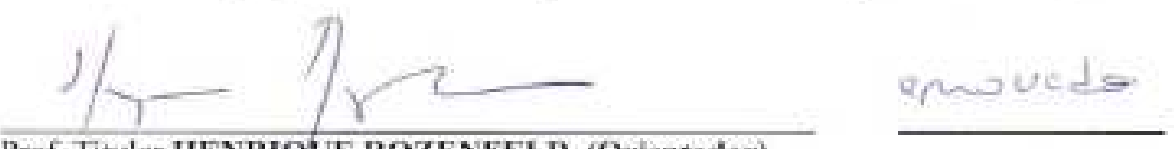

Prof. Titular HENRIQUE ROZENFELD (Orientador)

(Escola de Engenharia de Sâo Carlos,USP)

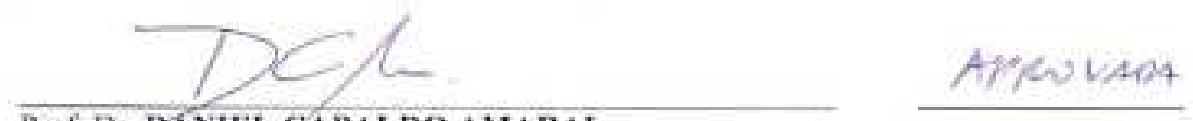

Prof DE DANIEL CAPALDO AMARAL

(Escola de Engenharia de Sầo CarlosiUSP)
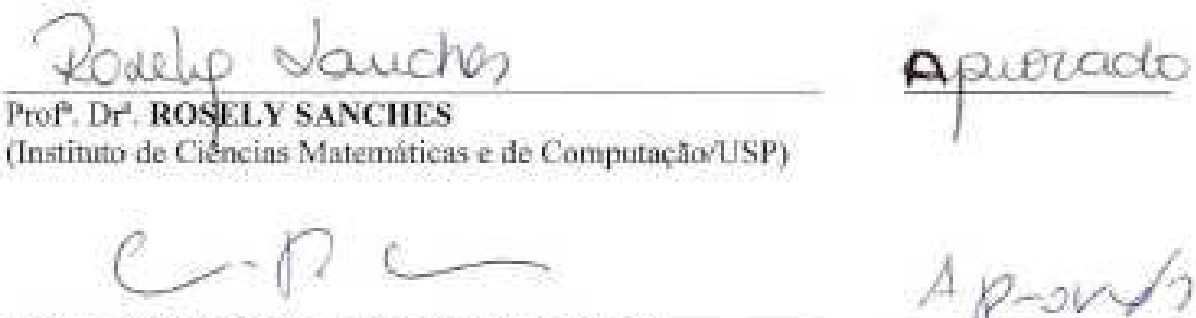

Prof. Di ClêNIO FIGUEIREDO SALVIANO

(Centro de tecnologia da Informaçāo/CTI)

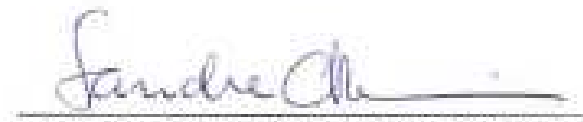

Prof. Dr". SANDRA CAMARGO PINTO FERRAZ FABBRI

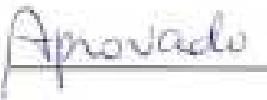

(Universidade Federal de Sáo Carlos.UFSCar)

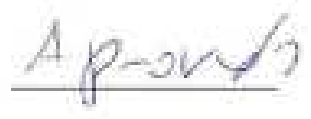

Romato 5 . Wriso Prof. Asgociado REGINALDO TEIXEIRA COELHO

Coondenador do Programa de Pós-Graduação em Engenharia de Produçào

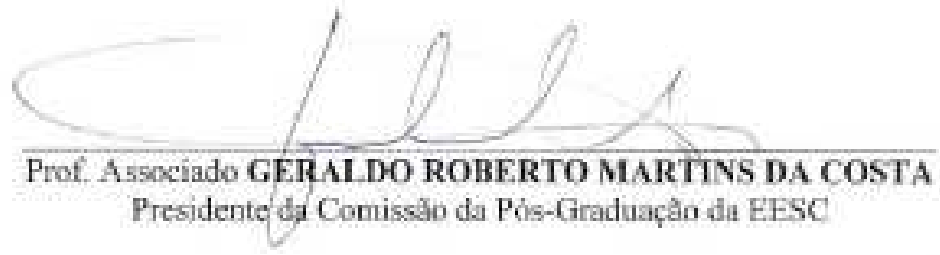


Ao meu esposo Renato e aos meus pais Geraldo e Matilde. 


\section{AGRADECIMENTOS}

A Deus, por guiar os meus passos.

Ao Renato, meu grande amor e companheiro, grande incentivador desse trabalho.

A toda minha família, em especial aos meus pais (Geraldo e Matilde) que sempre me apoiaram em todos os momentos de minha vida, aos meus irmãos (Cassiano, Adriano), minha tia Ivanilde, meu sogro (Alceu) e minha sogra (Elvira), minhas sobrinhas (Lavínia e Lorena), meu sobrinho (Igor) e minhas cunhadas (Haline e Adriane) que estiveram sempre ao meu lado e souberam compreender as minhas ausências quando necessário.

A todos que colaboraram direta ou indiretamente para que fosse possível a realização desse trabalho: Moacir, Haroldo, Robson, Douglas e, em especial, à Sayuri, Jana, Aglaê, Maria José, Marcelo (Mão), Emerson, Rogério, Marcos, Ana Cristina e Márcio.

A todos os amigos que me incentivaram durante a realização desse trabalho: Ana Lúcia, Francis, Sayuri, Jana, Simone, Ana Claudia, Helien, Eve, Eduardo, Dani, Ana Paula, Cris, Leandro, Mão, Aglaê, Maria José, Emerson, Roger, Débora, Gisele e Ivani.

A todos os professores que encontrei durante minha vida acadêmica. Em especial, à Rosely que com seu conhecimento e experiência enriqueceu minha vida profissional e pessoal, e ao prof. Henrique que me deu a oportunidade de desenvolver esse trabalho de pesquisa e, conseqüentemente, contribuiu para o meu crescimento profissional.

Aos proprietários das empresas onde foi realizada a pesquisa-ação, Paulo e Marcos, e aos funcionários dessas empresas.

Aos funcionários e docentes do Departamento de Engenharia de Produção da EESC, em especial ao Zé Luis. 


\section{RESUMO}

JUBILEU, A. P. Modelo de Gestão do Processo de Venda e Desenvolvimento de Software On-demand para MPEs. 2008. 330p. Tese (Doutorado) - Escola de Engenharia de São Carlos, Universidade de São Paulo, São Carlos, 2008.

A maioria das micro e pequenas empresas (MPEs) de desenvolvimento de software brasileiras são voltadas para o desenvolvimento de software on-demand. Normalmente, essas MPEs têm dificuldades em formalizar um processo de software padrão. O presente trabalho de pesquisa tem por objetivo apresentar uma proposta de integração de modelos/normas de capacidade de processo com modelos de ciclo de vida de software, em um contexto de gestão de processos de negócio. Como resultado, obteve-se o Modelo de Gestão do Processo de Venda e Desenvolvimento de Software On-demand para MPEs (ProcSoftVD - Gestão), composto pelo Método de Melhoria de Processo de Software (ProcSoftVD - Melhoria) e pelo Modelo de Processo de Venda e Desenvolvimento de Software On-demand para MPEs (ProcSoftVD). O Método de Melhoria de Processo de Software foi criado a partir de abordagens existentes e complementares, voltadas às MPEs. O ProcSoftVD foi originado com base no framework Unified Process, possibilitando a visualização do processo em duas perspectivas - fases e áreas de conhecimento, e nos modelos/normas de capacidade de processo CMMI-DEV e ISO/IEC 15504-5, elaborado em um processo iterativo e evolutivo de pesquisa-ação com a participação de duas MPEs. Um diferencial dessa proposta é a consideração de atividades de comercialização do software junto ao processo de desenvolvimento de software, o que auxilia na delimitação do escopo do projeto de desenvolvimento de software para um acordo contratual. Outro diferencial é o detalhamento das atividades do processo por meio de tarefas, sugestão de papéis desempenhados pelos responsáveis das atividades e disponibilização de templates com exemplos para cada um dos artefatos elaborados na execução da atividade.

Palavras-chave: Modelo de Processo de Software, Qualidade de Processo de Software, Melhoria de Processo de Software. 


\begin{abstract}
JUBILEU, A. P. Management Model of Selling and On-demand Software Development Process. 2008 PhD Thesis - Sao Carlos Engineering School, Sao Paulo University, Sao Carlos, 2008.
\end{abstract}

The majority of the software development micro and small companies are turned to the development of on-demand software. Usually, for these small companies the formalization of a standard process for software development is very difficult. For that reason the goal of this research is to propose an integration of capability processes models/standards within software life cycle models, in a perspective of business process management. The main result of this research is a Management Model of Selling and Ondemand Software Development Process, which embraces the Software Process Improvement Method and the Selling and on-demand Software Development Process Model. The Software Process Improvement Method was build from complementary and existents tailored approaches for micro and small companies. The Selling and on-demand Software Development Process Model was created based on the models/standards of process capability CMMI-DEV and ISO/IEC 15504-5 and on the Unified Process Framework, allowing the process view from two perspectives - phases and knowledge areas. The model was elaborated in an iterative and evolutionary action-research process carried out within two micro and small companies. The originality of this proposal is the consideration of software sale activities jointly with software development process, assisting the scope delimitation of a software development project for contractual agreement. Other aspect of this research which makes it distinctive is the detail of the process activities by mean of tasks, suggestions of people roles for each activities and provision of templates with examples for each artifact created during the activities.

Key words: Software Process Model, Software Quality Process, Software Process Improvement. 


\section{Lista de Figuras/Tabelas/Quadros}

Figura 2.1 - Modelo de Processo de Software Clássico (Cascata) ....................................................26

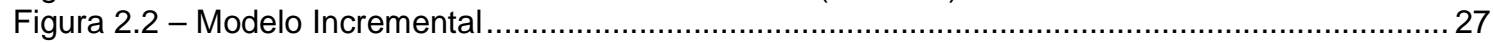

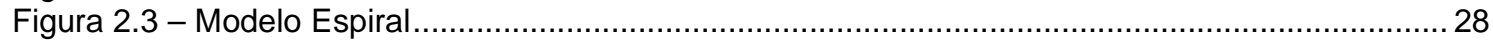

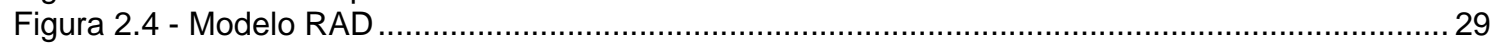

Figura 2.4 - Unified Process. Fonte: Traduzido de (AMBLER, 2005) …......................................... 31

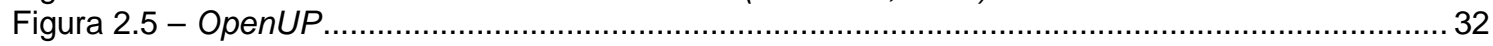

Fonte: Traduzido de (Eclipse Process Framework Community, 2008) ............................................. 32

Figura 2.6 - ISO/IEC 12207 - Processos de Ciclo de Vida de Software .......................................... 34

Fonte: Traduzido de (INTERNATIONAL ORGANIZATION FOR STANDARDIZATION, 2001)............34

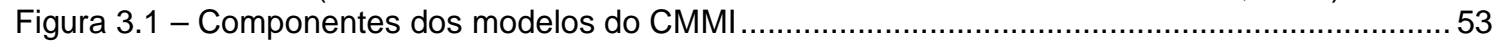

Fonte: Traduzido de (SOFTWARE ENGINEERING INSTITUTE, 2006) .......................................... 53

Figura 5.1 - Modelo de Gestão do Processo de Venda e Desenvolvimento de Software On-demand

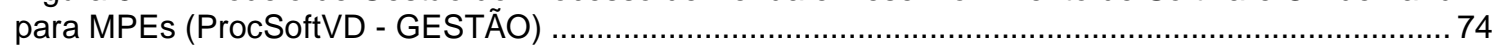

Figura 5.2 - Primeira Versão do Modelo Genérico Do PV\&DS On-demand ………...........................76

Figura 5.3 - Instância do Modelo Genérico Do PV\&DS on-demand para a Empresa 1 ..................... 78

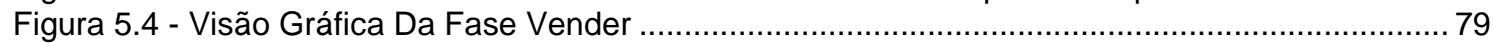

Figura 5.5- Visualização gráfica do conteúdo dos artefatos do processo proposto.............................. 80

Figura 5.6 - Visualização gráfica do conteúdo do artefato "documento de requisitos" ...........................81

Figura 5.7 - Detalhamento de uma Atividade do Modelo de Processo Proposto .................................. 82

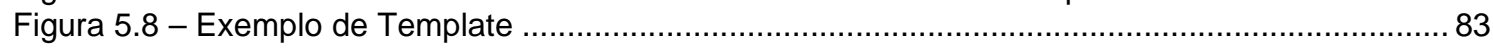

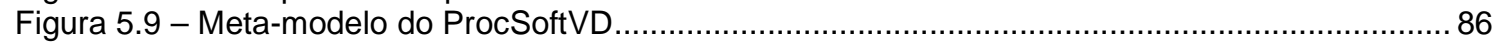

Quadro 5.11- Associação das áreas de conhecimento do ProcSoftVD com outros modelos .............91

Figura 5.12- Atividades da Área de Gestão de Conhecimento do Modelo ProcSoftVD ..................... 96

Quadro 5.13 - Quadro Comparativo dos Métodos de Melhoria de Processo ..................................... 97

Tabela 5.14 - Pontuação para as áreas de conhecimento (SALVIANO, 2006) ................................100

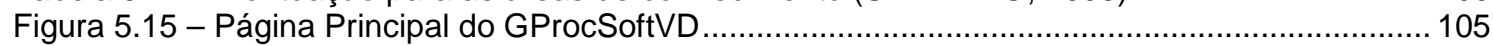

Figura 5.16 - Exemplo de Visão Gráfica - fase de prospecção ...................................................106

Figura 5.17 - Visão Textual: Perspectiva por Fases e por Áreas de Conhecimento.......................... 107

Figura 5.18 - Exemplo de uma Atividade - fase de prospecção ......................................................108

Figura 5.19 - Exemplo de Detalhamento de Atividade .............................................................. 109

Figura 5.20 - Atividades da Área de Conhecimento "Gestão de Conhecimento" ..............................110

Figura 5.21 - Mapeamento do ProcSoftVD com CMMI e ISO/IEC 15504-5 …..............................111

Figura 5.22 - Exemplo de Mapeamento da Atividade "Definir escopo do Projeto" .............................112

Quadro 6.1 - Características de qualidade do Modelo ProcSoftVD ............................................... 120

Figura 6.2 - Gráfico de relação entre as respostas dos profissionais ...........................................120

Figura A1.1 - Planilha de Relevância (Descrição do processo) ……..........................................135

Figura A1.2 - Planilha de Relevância (Comentário referente à cada questão) …............................136

Figura A1.3 - Planilha de Relevância (Seleção de alternativas) .................................................136

Figura A2.1 - Tabulação da Importância versus Risco das Áreas de Conhecimento para a Empresa

Quadro A3.1 - Entradas, Atividades e Saídas da fase Prospeccão.

Quadro A3.2 - Entradas, Atividades e Saídas da fase Concepção...................................................... 140

Quadro A3.2 - Entradas, Atividades e Saídas da fase Concepção (Cont.).......................................141

Quadro A3.3 - Entradas, Atividades e Saídas da fase Negociação .............................................. 142

Quadro A3.3 - Entradas, Atividades e Saídas da fase Negociação (Cont.) ....................................143

Quadro A3.4 - Entradas, Atividades e Saídas da fase Elaboração................................................143

Quadro A3.4 - Entradas, Atividades e Saídas da fase Elaboração (Cont.) ........................................ 144

Quadro A3.5 - Entradas, Atividades e Saídas da fase Construção .............................................. 144

Quadro A3.5 - Entradas, Atividades e Saídas da fase Construção (Cont.) ..................................... 145

Quadro A3.6 - Entradas, Atividades e Saídas da fase Transição ................................................... 145

Quadro A3.6 - Entradas, Atividades e Saídas da fase Transição (Cont.) ........................................146

Quadro A3.7 - Entradas, Atividades e Saídas da Área de Conhecimento Comercialização ..............147

Quadro A3.7 - Entradas, Atividades e Saídas da Área de Conhecimento Comercialização (Cont.). 148

Quadro A3.8 - Entradas, Atividades e Saídas da Área de Conhecimento Modelagem de Negócio . 149

Quadro A3.9 - Entradas, Atividades e Saídas da Área de Conhecimento Produção de Requisitos . 149 
Quadro A3.9 - Entradas, Atividades e Saídas da Área de Conhecimento Produção de Requisitos

(Cont.)

Quadro A3.10 - Entradas, Atividades e Saídas da Área de Conhecimento Projeto, Codificação \&

Integração de Produto.

Quadro A3.11 - Entradas, Atividades e Saídas da Área de Conhecimento Verificação \& Validação 152

Quadro A3.11 - Entradas, Atividades e Saídas da Área de Conhecimento Verificação \& Validação

(Cont.).

Quadro A3.12 - Entradas, Atividades e Saídas da Área de Conhecimento Implantação........................ 153

Quadro A3.13 - Entradas, Atividades e Saídas da Área de Conhecimento Aquisição....................... 153

Quadro A3.14 - Entradas, Atividades e Saídas da Área de Conhecimento Medição........................ 154

Quadro A3.14 - Entradas, Atividades e Saídas da Área de Conhecimento Medição (Cont.)............ 155

Quadro A3.14 - Entradas, Atividades e Saídas da Área de Conhecimento Medição (Cont.)............ 156

Quadro A3.15 - Entradas, Atividades e Saídas da Área de Conhecimento Garantia da Qualidade de

Produto e Processo

Quadro A3.15 - Entradas, Atividades e Saídas da Área de Conhecimento Garantia da Qualidade de

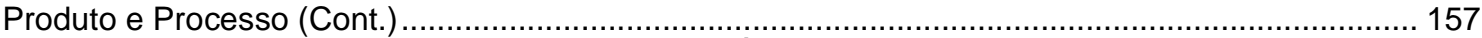

Quadro A3.16 - Entradas, Atividades e Saídas da Área de Conhecimento Gestão de Requisitos ... 158

Quadro A3.17 - Entradas, Atividades e Saídas da Área de Conhecimento Gestão de Mudanças e

Configuração

158

Quadro A3.17 - Entradas, Atividades e Saídas da Área de Conhecimento Gestão de Mudanças e

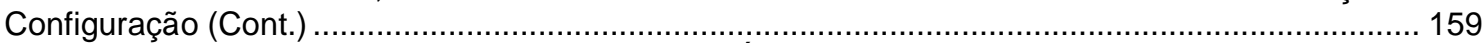

Quadro A3.18 - Entradas, Atividades e Saídas da Área de Conhecimento Gestão de Projetos ...... 159

Quadro A3.18 - Entradas, Atividades e Saídas da Área de Conhecimento Gestão de Projetos (Cont.)

Quadro A3.18 - Entradas, Atividades e Saídas da Área de Conhecimento Gestão de Projetos (Cont.)

161

Quadro A3.18 - Entradas, Atividades e Saídas da Área de Conhecimento Gestão de Projetos (Cont.)

162

Quadro A3.18 - Entradas, Atividades e Saídas da Área de Conhecimento Gestão de Projetos (Cont.)

163

Quadro A3.18 - Entradas, Atividades e Saídas da Área de Conhecimento Gestão de Projetos (Cont.)

Quadro A3.19 - Entradas, Atividades e Saídas da Área de Conhecimento Gestão de Conhecimento

Figura A3 20 - Visão Gráfica - Fase: Prospecção

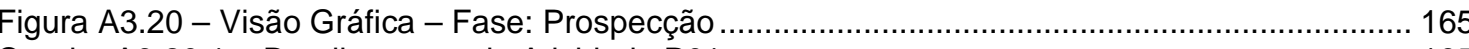

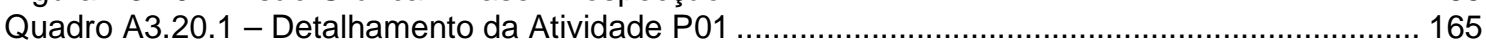

Quadro A3.20.2 - Detalhamento da Atividade P02 …............................................................ 166

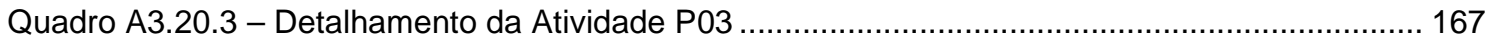

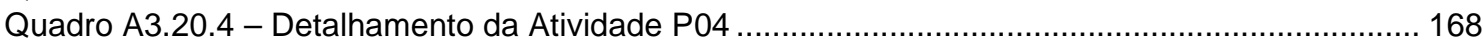

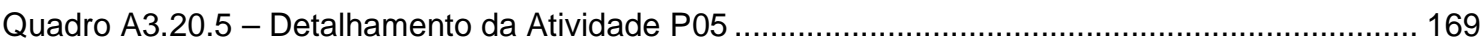

Figura A3.21 - Visão Gráfica - Fase: Concepcção ………....................................................... 170

Quadro A3.21.1 - Detalhamento da Atividade Cp01 …............................................................ 171

Quadro A3.21.1 - Detalhamento da Atividade Cp01 (Cont.) ……................................................ 172

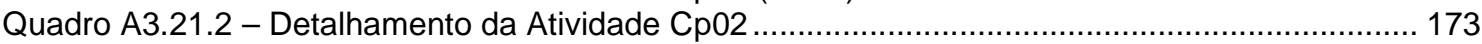

Quadro A3.21.3 - Detalhamento da Atividade Cp03 …......................................................... 174

Quadro A3.21.4 - Detalhamento da Atividade Cp04 ….......................................................... 175

Quadro A3.21.5 - Detalhamento da Atividade Cp05 ................................................................. 176

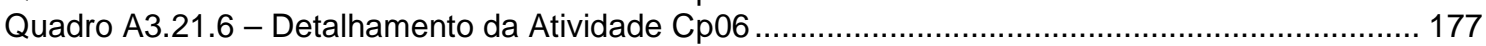

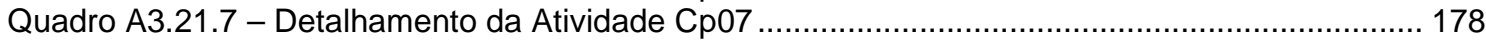

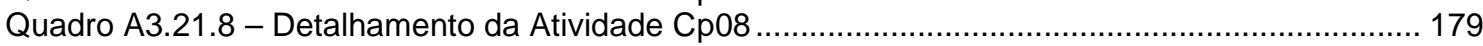

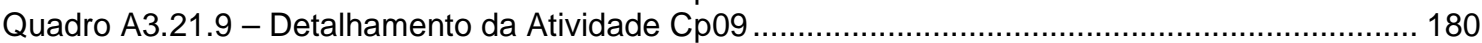

Quadro A3.21.10 - Detalhamento da Atividade Cp10 …....................................................... 181

Quadro A3.21.11 - Detalhamento da Atividade Cp11 …........................................................... 182

Quadro A3.21.12 - Detalhamento da Atividade Cp12 …............................................................... 183

Quadro A3.21.13 - Detalhamento da Atividade Cp13 …......................................................... 183

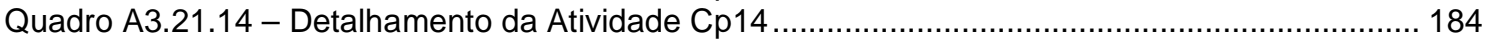

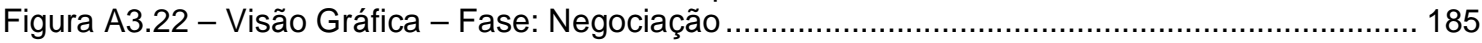

Quadro A3.22.1 - Detalhamento da Atividade N01 …....................................................... 186

Quadro A3.22.2 - Detalhamento da Atividade N02 …........................................................... 187

Quadro A3.22.3 - Detalhamento da Atividade N03 .................................................................... 187 


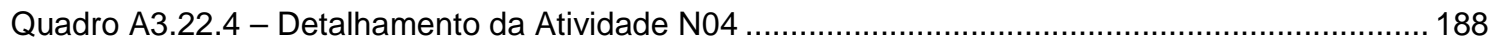

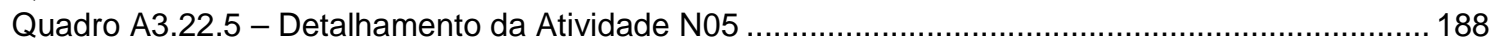

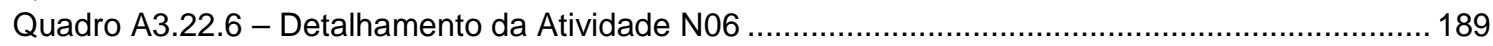

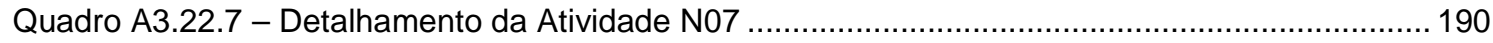

Quadro A3.22.8 - Detalhamento da Atividade N08 …......................................................... 190

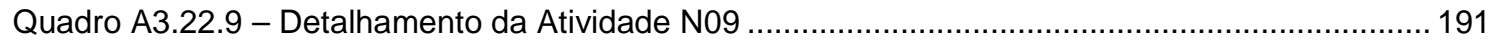

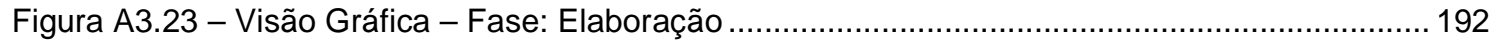

Quadro A3.23.1 - Detalhamento da Atividade E01 …............................................................. 193

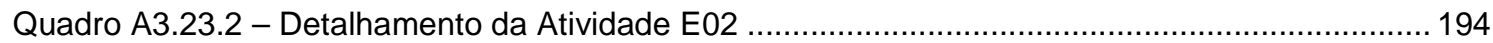

Quadro A3.23.3 - Detalhamento da Atividade E03 ….................................................................... 195

Quadro A3.23.4 - Detalhamento da Atividade E04 …............................................................ 196

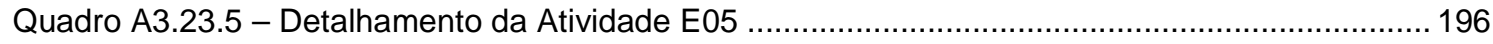

Quadro A3.23.5 - Detalhamento da Atividade E05 (Cont.) ......................................................... 197

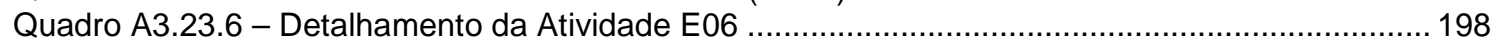

Quadro A3.23.7 - Detalhamento da Atividade E07 ……......................................................... 199

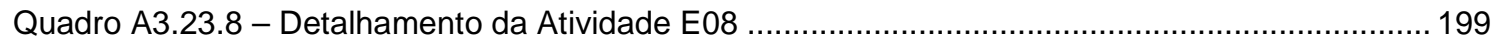

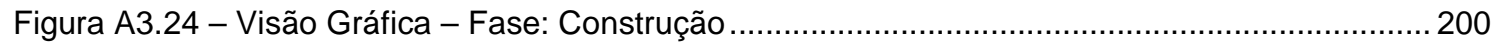

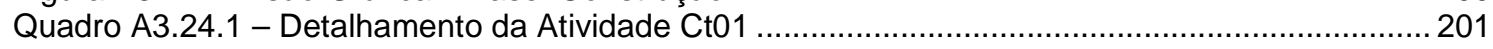

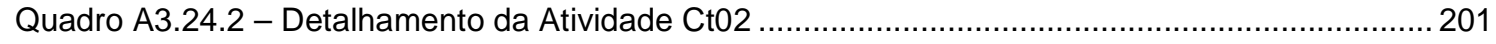

Quadro A3.24.2 - Detalhamento da Atividade Ct02 (Cont.) …......................................................202

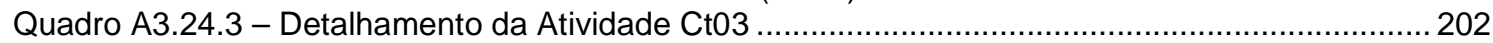

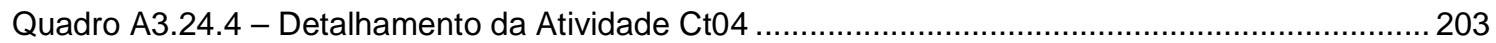

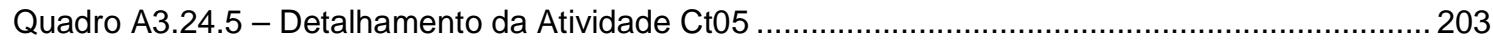

Quadro A3.24.5 - Detalhamento da Atividade Ct05 (Cont.) .........................................................204

Quadro A3.24.6 - Detalhamento da Atividade Ct06 …................................................................... 204

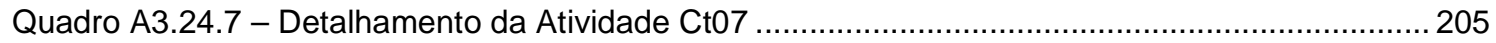

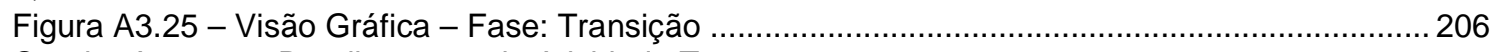

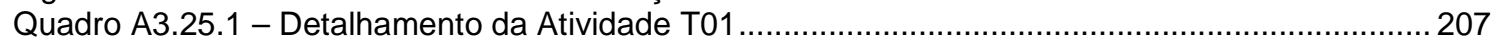

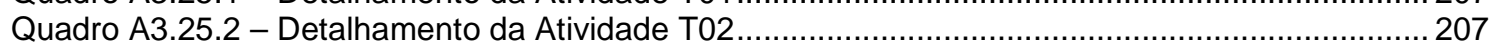

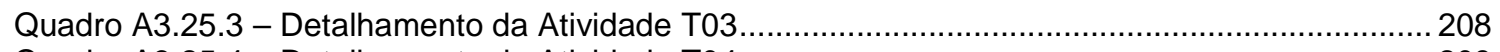

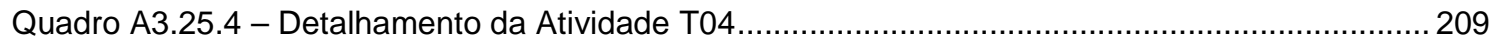

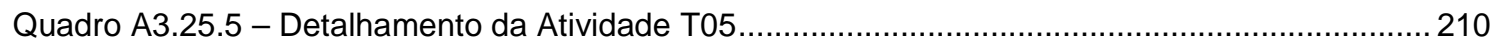

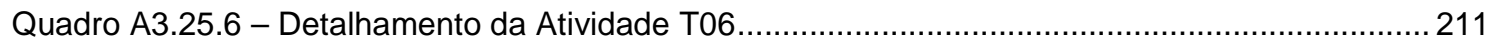

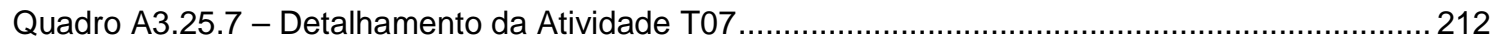

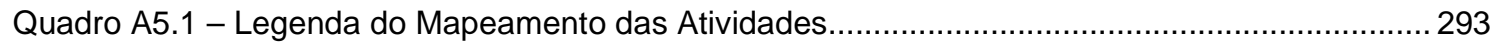

Quadro A5.1 - Legenda do Mapeamento das Atividades (Cont.) ................................................. 294

Quadro A5.2 - Mapeamento das Atividades da Fase de Prospecção ............................................ 294

Quadro A5.3 - Mapeamento das Atividades da Fase de Concepção ...............................................295

Quadro A5.3 - Mapeamento das Atividades da Fase de Concepção (Cont.) ..................................... 296

Quadro A5.3 - Mapeamento das Atividades da Fase de Concepção (Cont.) ...................................... 297

Quadro A5.3 - Mapeamento das Atividades da Fase de Concepção (Cont.) ....................................298

Quadro A5.3 - Mapeamento das Atividades da Fase de Concepção (Cont.) ..................................... 299

Quadro A5.4 - Mapeamento das Atividades da Fase de Negociação ............................................... 299

Quadro A5.4 - Mapeamento das Atividades da Fase de Negociação (Cont.) ................................... 300

Quadro A5.4 - Mapeamento das Atividades da Fase de Negociação (Cont.) ..................................... 301

Quadro A5.5 - Mapeamento das Atividades da Fase de Elaboração ................................................ 302

Quadro A5.5 - Mapeamento das Atividades da Fase de Elaboração (Cont.) ……............................ 303

Quadro A5.5 - Mapeamento das Atividades da Fase de Elaboração (Cont.) ................................... 304

Quadro A5.5 - Mapeamento das Atividades da Fase de Elaboração (Cont.) …….............................. 305

Quadro A5.6 - Mapeamento das Atividades da Fase de Construção ..................................................306

Quadro A5.6 - Mapeamento das Atividades da Fase de Construção (Cont.) ..........................................307

Quadro A5.6 - Mapeamento das Atividades da Fase de Construção (Cont.) ...................................... 308

Quadro A5.7 - Mapeamento das Atividades da Fase de Transição .................................................... 309

Quadro A5.7 - Mapeamento das Atividades da Fase de Transição (Cont.)..........................................310

Quadro A5.7 - Mapeamento das Atividades da Fase de Transição (Cont.) ...................................... 311

Quadro A8.1 - Transcrição das Respostas - Área de Conhecimento Produção de Requisitos........... 321

Quadro A8.2 - Transcrição das Respostas - Área de Conhecimento Modelagem de Negócios ....... 321

Quadro A8.3 - Transcrição das Respostas - Área de Conhecimento Comercialização.......................322

Quadro A8.4 - Transcrição das Respostas - Área de Conhecimento ……..................................... 322

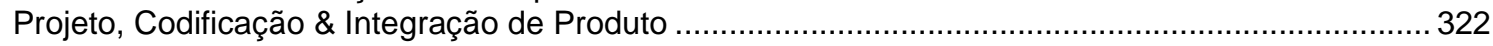


Quadro A8.5 - Transcrição das Respostas - Área de Conhecimento Aquisição ............................ 323

Quadro A8.6 - Transcrição das Respostas - Área de Conhecimento Medição ............................... 323

Quadro A8.7 - Transcrição das Respostas - Área de Conhecimento Implantação ........................ 323

Quadro A8.8 - Transcrição das Respostas - Área de Conhecimento V\&V ................................. 324

Quadro A8.9 - Transcrição das Respostas - Área de Conhecimento Garantia da ......................... 324

Qualidade de Produto e Processo ............................................................................. 324

Quadro A8.10 - Transcrição das Respostas - Área de Conhecimento Gestão de Conhecimento ... 324

Quadro A8.11 - Transcrição das Respostas - Área de Conhecimento Gestão de Requisitos ......... 325

Quadro A8.12 - Transcrição das Respostas - Área de Conhecimento Gestão de Projetos ............. 325

Quadro A8.13 - Transcrição das Respostas - Área de Conhecimento Gestão de Mudanças e

Configuração 


\title{
Lista de Abreviaturas e Siglas
}

\author{
ASPE/MSC \\ Approach for Software Process Establishment in Micro and Small Companies \\ BPM \\ Business Process Management \\ BPR \\ Business Process Reengineering \\ CMMI \\ Capability Maturity Model Integration \\ CMMI-DEV \\ CMMI for Development \\ IDEAL \\ Initiating, Diagnosing, Establishing, Acting, Learning \\ ISO/IEC 12207 \\ ISO/IEC 15504 \\ Information technology -- Software life cycle processes \\ Information technology -- Process assessment \\ ISO/IEC 15504-5 \\ Information technology -- Process assessment - Part 5: An exemplar Process \\ Assessment Model \\ $\mathrm{KM}$ \\ Knowledge Management \\ MPES \\ Micro e Pequenas Empresas \\ MPS \\ Melhoria do Processo de Software \\ MPS.BR \\ Melhoria de Processos do Software Brasileiro \\ MSC \\ Micro and Small Companies \\ PA \\ Process Area (CMMI) \\ PDCA \\ Plan, Do, Check, Action \\ PDS \\ Processo de Desenvolvimento de Software \\ ProcSoftVD \\ Modelo do Processo de Venda e Desenvolvimento de Software On-demand \\ para MPEs \\ ProcSoftVD - Gestão \\ Modelo de Gestão do Processo de Venda e Desenvolvimento de Software \\ On-demand para MPEs \\ ProcSoftVD - Melhoria \\ Método de Melhoria do Processo de Venda e Desenvolvimento de Software \\ On-demand para MPEs \\ PRO2PI \\ Perfil de Capacidade de Processo para Melhoria de Processo \\ PRO2PI-WORK \\ PRO2PI Establishment Workshop Method \\ PSEE \\ PV\&DS \\ Process-Centered Software Engineering Environment \\ Processo de Venda e Desenvolvimento de Software \\ RAD \\ Rapid Application Development \\ RUP \\ Rational Unified Process \\ $S G$ \\ Specific Goal \\ SOFTEX \\ Associação para Promoção da Excelência do Software Brasileiro \\ $\mathrm{SPI}$ \\ Software Process Improvement \\ $\mathrm{TI}$ \\ Tecnologia da Informação \\ TQM \\ Total Quality Management \\ UP \\ Unified Process
}




\section{SUMÁRIO}

LISTA DE FIGURAS/TABELAS/QUADROS ................................................................................................

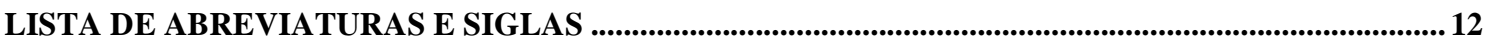

1. INTRODUÇÃO........................................................................................................................................ 15

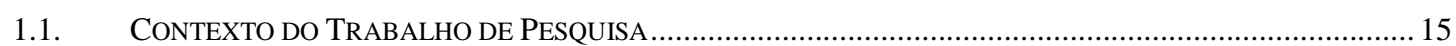

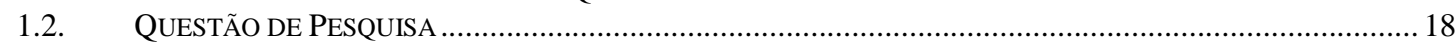

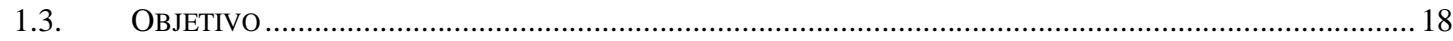

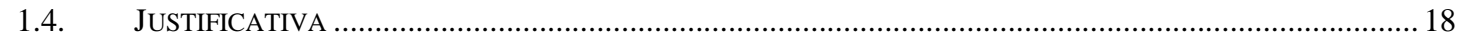

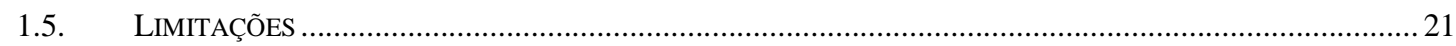

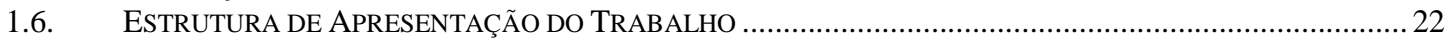

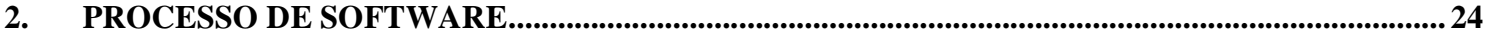

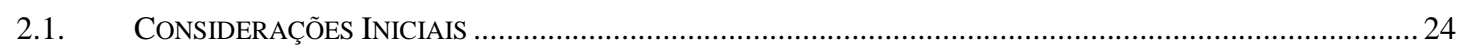

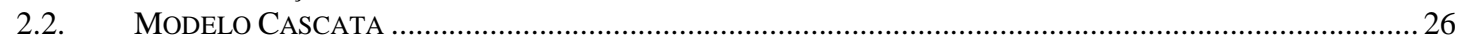

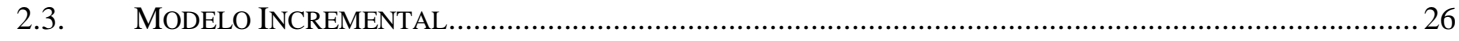

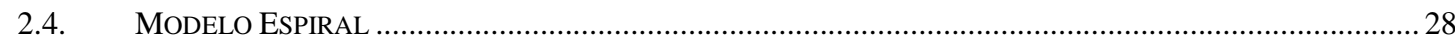

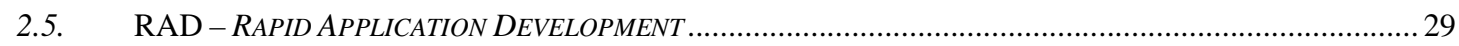

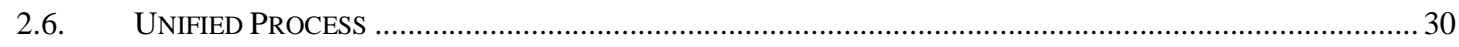

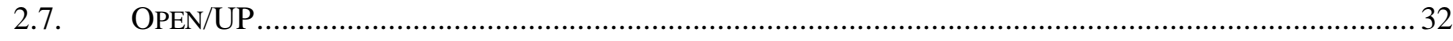

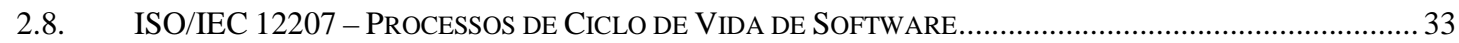

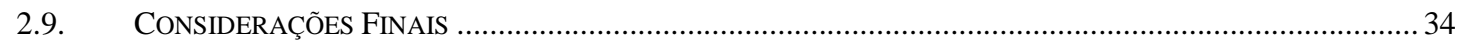

3. MELHORIA DE PROCESSO DE SOFTWARE ...............................................................................37

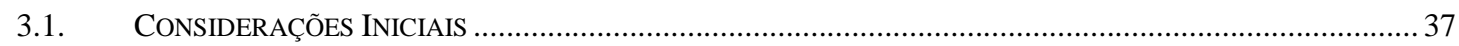

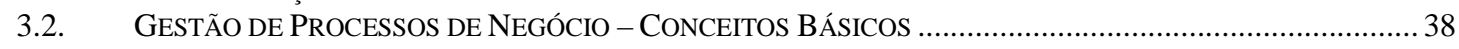

3.3. Algumas AboRdagens PARA MelHoria de Processo............................................................... 41

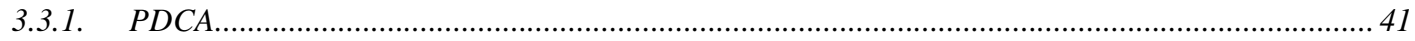

3.3.2. IDEAL

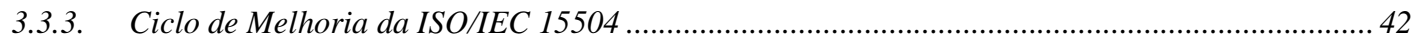

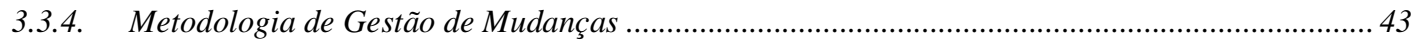

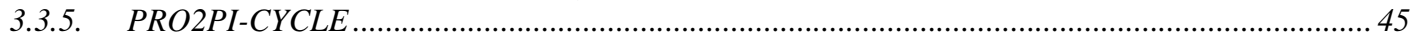

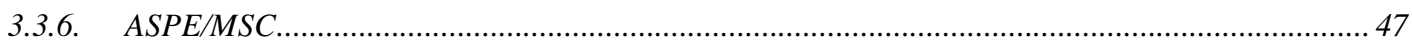

3.4. MODELOS DE REFERÊNCIA UTILIZADOS PARA MELHORIA DE PROCESSO ………................................ 48

3.4.1. Framework ISO/IEC 15504 e Modelo 15504-5 ……............................................................... 48

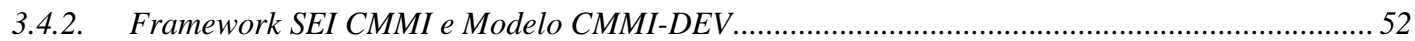

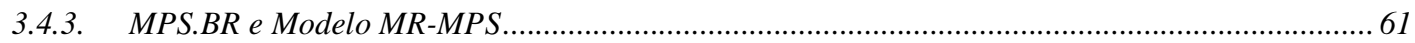

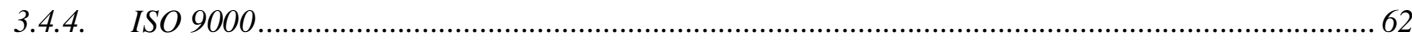

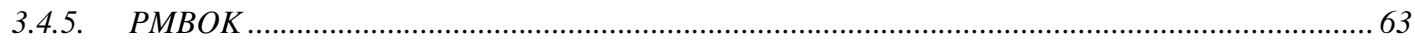

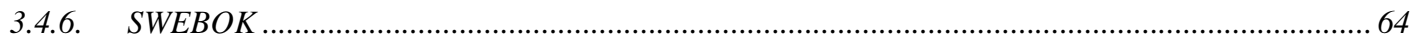

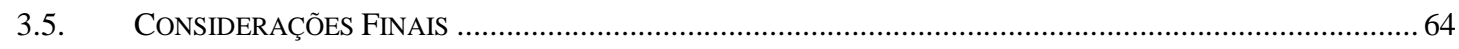

4. METODOLOGIA DE PESQUISA.....................................................................................................65

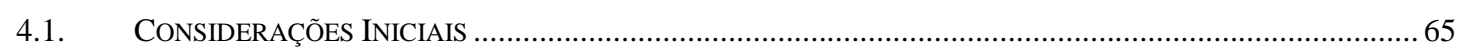

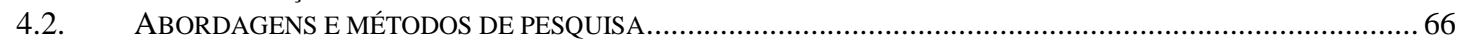

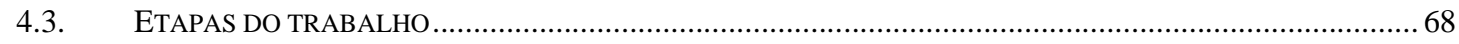

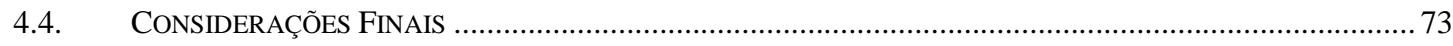

5. MODELO DE GESTÃO DO PROCESSO DE VENDA E DESENVOLVIMENTO DE SOFTWARE ON-DEMAND PARA MPES (PROCSOFTVD - GESTÃO) ............................................................................74

5.1. CONSIDERAÇÕES INICIAIS ………………………………………………………………….... 74

5.2. EVolução do Modelo de Processo de Venda e Desenvolvimento de SoftWare $O N$-DEMAND

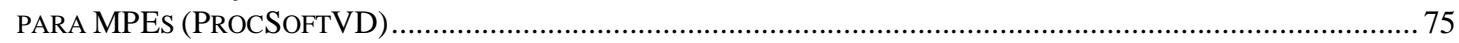

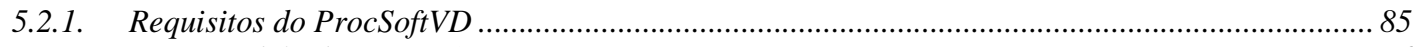

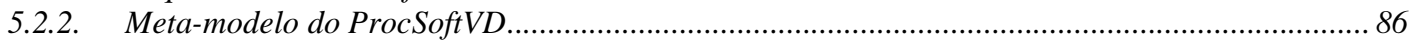

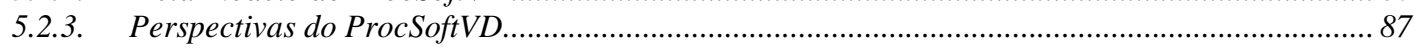


5.3. Método de Melhoria do Processo de Venda e DesenVolvimento de Software ON-DEMAND PARA MPES (PROCSOFTVD - MELHORIA)

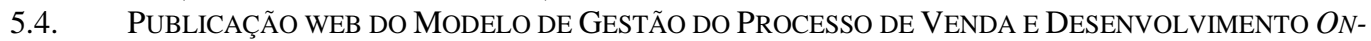

DEMAND PARA MPES

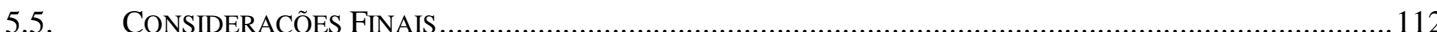

6. APLICAÇÕES E RESULTADOS DO MODELO PROCSOFTVD - GESTÃO..................................113

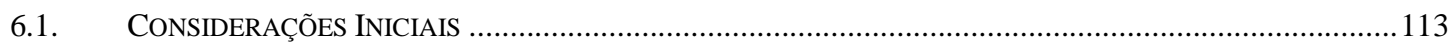

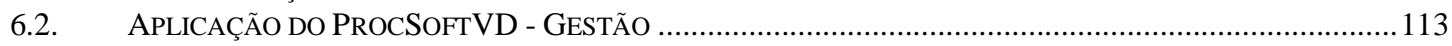

6.3. ANÁliSE dos Pontos Fortes E Fracos do ModElo ProcSoftVD ............................................114

6.4. ANÁLISE DAS CARACTERÍSTICAS DE QUALIDADE DO MODELO PROCSOFTVD.....................................119

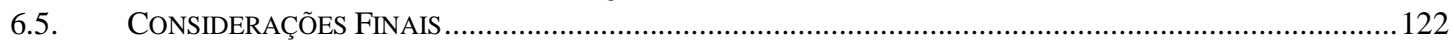

7. CONCLUSÕES E TRABALHOS FUTUROS.................................................................................123

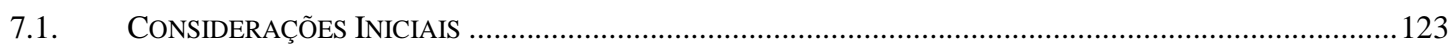

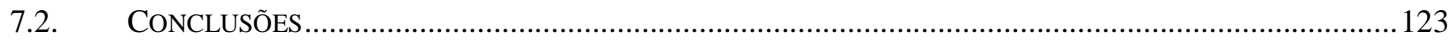

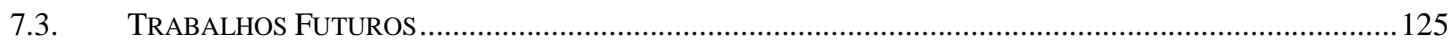

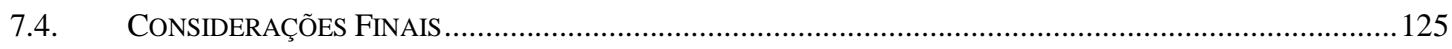

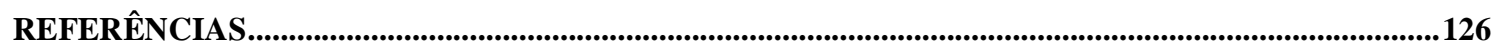

APÊNDICE 1 - QUESTIONÁRIO PARA LEVANTAMENTO DE ÁREAS DE CONHECIMENTO

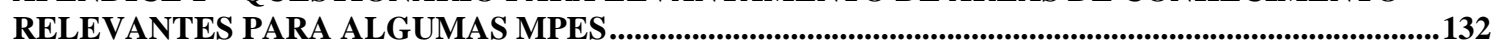

APÊNDICE 2 - RESULTADO DA ANÁLISE DO QUESTIONÁRIO DEFINIDO NO APÊNDICE 1....137

APÊNDICE 3 - MODELO PROCSOFTVD (ATIVIDADES) ..................................................................139

APÊNDICE 4 - MODELO PROCSOFTVD (TEMPLATES) .................................................................213

APÊNDICE 5 - MODELO PROCSOFTVD (MAPEAMENTO COM O CMMI E ISO/IEC 15504)........293

APÊNDICE 6 - APLICAÇÃO DO PROCSOFTVD - MELHORIA..............................................................312

APÊNDICE 7 - QUESTIONÁRIO DE AVALIAÇÃO DO PROCSOFTVD.............................................317

APENDICE 8 - PONTOS FORTES E FRACOS TRANSCRITOS DAS RESPOSTAS DO

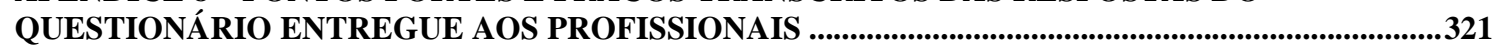

APÊNDICE 9 - RESPOSTAS DO QUESTIONÁRIO RESPONDIDO PELOS PROFISSIONAIS...........327 


\section{INTRODUÇÃO}

\subsection{Contexto do Trabalho de Pesquisa}

Segundo uma pesquisa realizada pelo Ministério da Ciência e Tecnologia (MCT, 2005) sobre população alvo constituída por empresas desenvolvedoras de software (de pacote, sob encomenda (on-demand), embarcado e para uso próprio) e por empresas distribuidoras ou editoras de software de terceiros, no total de 488 empresas, 396 são empresas que desenvolvem software on-demand (81,1\%). Adotando-se o critério aplicado à força de trabalho efetiva - microempresas (de 1 a 9 pessoas), pequenas (de 10 a 49 pessoas), médias (de 50 a 99 pessoas) e grandes (100 ou mais pessoas) - 80,9\% das micro empresas e $85,9 \%$ das pequenas empresas desenvolvem software on-demand, confirmando-se a predominância de micro e pequenas empresas (MPEs) no cenário de desenvolvimento de software on-demand no Brasil.

Em busca de melhorar tanto a qualidade de seus produtos de software quanto a produtividade do desenvolvimento de software, cada vez mais as MPEs estão percebendo a importância da existência de um processo $^{1}$ de software $^{2}$ formalizado na empresa e investindo na melhoria do processo de software. Essa afirmação é pautada nos resultados de uma revisão sistemática, elaborada por PINO et al. (2008), realizada nas fontes: Science Direct, Wiley InterScience, IEEE Digital Library, ACM Digital Library e um relatório especial "Proceedings of the First International Research Workshop for Process Improvement in Small Settings" da SEI (Software Engineering Institute). No contexto brasileiro, comprova-se um aumento do desempenho de processos de software o que auxilia na melhoria da qualidade de produtos de software e no aumento das vantagens competitivas das empresas brasileiras tanto no mercado nacional quanto internacional (ROCHA et al., 2005).

\footnotetext{
${ }^{1}$ Processo: segundo a ABNT (Associação Brasileira de Normas Técnicas), um conjunto de atividades interrelacionadas ou interativas, que transforma insumos (entradas) em produtos (saídas).

2 Processo de Software: segundo a IEEE (Institute of Electrical and Electronics Engineers), trata-se de uma abordagem sistemática, disciplinada e quantificável para o desenvolvimento, operação e manutenção do software.
} 
Um processo de software bem estabelecido, compreendido e controlado auxilia aos desenvolvedores obter um produto final com qualidade (SOFTWARE ENGINEERING INSTITUTE, 2006).

Para o estabelecimento de um processo de desenvolvimento de software podem ser usados como referências: modelos $^{3}$ de processo $^{4}$ que descrevem atividades, como o Modelo Cascata, Incremental, Espiral e RAD (Rapid Application Development) (PRESSMAN, 2006; SOMMERVILLE, 2007); um framework de processo, tal como o UP (Unified Process) (JACOBSON et al., 1999); uma norma, como a ISO/IEC 12207 (INTERNATIONAL ORGANIZATION FOR STANDARDIZATION, 2001), que define as atividades, objetivos e resultados de processos relacionados ao ciclo de vida do software e/ou, ainda, modelos e normas de capacidade de processo ${ }^{5}$ que prescrevem melhores práticas, tais como CMMI (SOFTWARE ENGINEERING INSTITUTE, 2002), ISO/IEC 15504 (INTERNATIONAL ORGANIZATION FOR STANDARDIZATION, 2003) e MPS.BR (WEBER et al., 2005a), metodologias ágeis, como Extreme Programming (WELLS, 2006) entre outras referências.

De acordo com os dados disponibilizados pelo PBQP Software ${ }^{6}$ (WEBER et al., 2006): 63,3\% conhecem, mas não usam o CMMI (SOFTWARE ENGINEERING INSTITUTE, op. cit); 65\% conhecem, mas não usam a norma ISO/IEC 12207 (INTERNATIONAL ORGANIZATION FOR STANDARDIZATION, op. cit) e 71,1\% conhecem, mas não usam a norma ISO/IEC 15504 (INTERNATIONAL ORGANIZATION FOR STANDARDIZATION, op. cit).

\footnotetext{
${ }^{3}$ Segundo Vernadat (1996), um modelo é uma representação útil de algum objeto. É uma abstração da realidade expressa em termos de algum formalismo (ou linguagem) definido por um método de modelagem em função do objetivo do usuário.

${ }_{4}^{4}$ Modelos de processo de software: podem ser prescritivos, quando enfatizam a definição, identificação e aplicação detalhada de atividades e tarefas de processo, e podem ser ágeis, quando enfatizam a adaptabilidade (PRESSMAN, 2006). Neste trabalho de pesquisa, são chamados "modelos de processo de software" aqueles a partir dos quais se pode definir, identificar e aplicar detalhadamente atividades e tarefas de processo. Já os de caráter ágil são denominados "metodologias ágeis" e não modelos.

${ }^{5}$ Modelos/Normas de capacidade de processo: segundo a ISO/IEC 15504, capacidade de processo é uma caracterização da habilidade do processo atingir aos objetivos de negócio atuais ou futuros. Sendo assim, neste trabalho de pesquisa são denominados "modelos/normas de capacidade de processo" aqueles que possibilitam a determinação da capacidade de um determinado processo.

6 Programa Brasileiro da Qualidade e Produtividade em Software que tem por objetivo atingir padrões internacionais de Qualidade e Produtividade no Setor de Software no Brasil. O PBQP Software é composto por voluntários, interessados na melhoria da qualidade e produtividade em software, ligados ao Governo, Academia e Indústria.
} 
Devido à dificuldade e alto custo de implantação e avaliação de modelos, como o CMMI, pelas MPEs e a necessidade de expandir o mercado de software brasileiro, a Associação para Promoção da Excelência do Software Brasileiro (SOFTEX) iniciou um programa mobilizador denominado MPS.BR - Melhoria de Processo de Software Brasileiro (WEBER et al., 2005a) - com o intuito de melhorar continuamente a qualidade de software no Brasil a um custo acessível (WEBER \& ARAUJO, 2006; ROCHA et al., 2006).

O Modelo MPS.BR (Melhoria de Processos do Software Brasileiro) teve como bases de construção as normas ISO/IEC 12207 e a ISO/IEC 15504 e as melhores práticas da engenharia de software, além de manter compatibilidade com o CMMI. A sua originalidade não está no conteúdo, mas sim na estratégia de implementação, criada para a realidade brasileira (SOFTEX, 2007).

Apesar da estratégia de implementação do MPS.BR ser mais adequada às MPEs brasileiras, os relatos de implantação/melhoria de processos (em vários níveis de maturidade estabelecidos pelo MPS) por parte das MPEs citam o auxílio de consultores e parcerias com universidades (BORSSATTO, 2008; MONTEIRO et al., 2008; OLIVEIRA et al., 2008; PORTO et al., 2008; SCHEID et al., 2008; VARGAS, et al., 2008). Este fato evidencia certa dificuldade por parte dessas MPEs em definir, implantar e melhorar seus processos.

Melhorar continuamente os processos de negócio é um dos objetivos da Gestão de Processos de Negócio (BPM) - uma fonte de vantagem competitiva para a empresa (HUNG, 2006). Segundo Jeston \& Nelis (2008) BPM tem por princípio alcançar os objetivos estratégicos da organização por meio da melhoria, gestão e controle de processos de negócio essenciais.

Considerando esse contexto, seria bastante útil alguma maneira de permitir às próprias MPEs definirem, implantarem e melhorarem seu processo de software, atendendo a modelos de capacidade de processo tais como o CMMI e a ISO/IEC 15504-5, de modo a minimizar a necessidade de consultorias externas. 


\subsection{Questão de Pesquisa}

De acordo com o exposto anteriormente, foi originada a seguinte questão de pesquisa - a cuja resposta se pretende contribuir:

"Considerando o contexto de gestão de processos de negócio, é possível criar um modelo que auxilie as MPEs a definir seu processo padrão ${ }^{7}$ de venda e desenvolvimento de software on-demand, minimizando suas dificuldades em utilizar modelos/normas de capacidade de processo, tais como CMMI, ISO/IEC 15504-5 e MPS.BR, e minimizando a necessidade de consultorias externas?"

\subsection{Objetivo}

Considerando a questão de pesquisa, este trabalho tem como principal objetivo criar um modelo que oriente uma MPE, de maneira mais detalhada do que a sugerida pelos modelos de capacidade de processo, na definição de seu processo padrão de venda e desenvolvimento de software on-demand, considerando o contexto de melhoria de processo.

O objetivo secundário do trabalho é possibilitar que o modelo a ser criado permita que a empresa selecione as áreas de conhecimento que serão abordadas em cada ciclo de melhoria do processo, de acordo com as suas prioridades.

\subsection{Justificativa}

Em busca de melhorar a qualidade de seus produtos de software e de ter maior visibilidade das atividades do projeto de desenvolvimento de software, cada vez mais as empresas estão enxergando a importância de melhorar o seu processo de software e ter um

\footnotetext{
${ }^{7}$ Processo padrão: segundo o estabelecido no CMMI, é uma definição operacional dos processos básicos que guiam o estabelecimento de um processo comum em uma organização. Um processo padrão descreve os elementos de processo fundamentais que se espera serem incorporados em algum processo definido (processo adaptado a partir do conjunto de processo padrão, de acordo com as diretrizes de adaptação da organização).
} 
processo formalizado que sirva de guia para todos os envolvidos em um projeto, permitindo uma visão comum entre eles.

Para auxiliar nessa missão, há na literatura, os chamados modelos de processo de software, frameworks e normas de processo de software que têm por objetivo orientar na definição de um processo de software e, também, os métodos, modelos e abordagens para orientarem na melhoria do processo de software.

Quanto aos métodos, modelos e abordagens que orientam na melhoria do processo de software, há vários na literatura, como Ciclo PDCA (DEMING, 1986), Abordagem IDEAL $^{\text {SM }}$ (MCFEELEY, 1996), Ciclo de Melhoria da ISO/IEC 15504 (INTERNATIONAL ORGANIZATION FOR STANDARDIZATION, 2003), Metodologia de Mudanças (COSTA, 2006) e alguns voltados para MPEs por serem mais detalhados, como PRO2PI-CYCLE (SALVIANO, 2006) e ASPE/MSC (WEBER et al., 2005b).

Quanto aos modelos de processo de software, normalmente, eles prescrevem apenas as atividades a serem realizadas sem fornecer detalhes, que facilitariam 0 entendimento e uso do modelo por parte das MPEs. Alguns exemplos desses detalhes são: os responsáveis pelas atividades, suas tarefas, os artefatos de entrada necessários para a realização das atividades, os artefatos resultantes da execução das atividades, recursos que podem ser utilizados e templates que fornecem informações do conteúdo de cada um dos artefatos.

A maioria dos modelos de processo de software existentes na literatura foca o desenvolvimento do software. Entretanto, neste trabalho de pesquisa considera-se que a comercialização do software é uma área relevante, no caso de desenvolvimento on-demand (sob encomenda), pois a elicitação dos requisitos do produto a ser desenvolvido é inicialmente realizada durante as atividades de comercialização, a fim de se ter subsídio para negociar um contrato. Assim, essa área deve ser considerada juntamente ao desenvolvimento de software.

Algumas limitações dos modelos de processo de software existentes na literatura são: não abordar a área de comercialização junto ao desenvolvimento de software on- 
demand e não dar ênfase nas atividades de gestão de conhecimento e gestão de habilidades e competência em meio ao desenvolvimento do software. Por isso, como meta para o modelo proposto buscou-se incorporar as atividades relacionadas às áreas de comercialização, gestão de conhecimento e gestão de habilidades e competências.

Existem processos, tal como o RUP (Rational Unified Process) - embutido em algumas ferramentas da Rational (KRUTCHEN, 2004) e o OpenUP (ECLIPSE PROCESS FRAMEWORK COMMUNITY, 2008) - um processo unificado ágil embutido na ferramenta free EPF Composer (Eclipse Process Framework) - que atendem às necessidades anteriormente descritas e poderiam servir como modelo a ser utilizado pelas MPEs, mas também não incluem atividades relacionadas à comercialização de software, o que auxiliaria as MPEs durante a negociação da venda do software para o cliente e acompanhamento do fluxo de caixa e, também, não incluem atividades relacionadas ao gerenciamento da memória organizacional da empresa - Gestão de Conhecimento - e nem atividades relacionadas à gestão de habilidades e competências dentro da empresa o que auxilia a criar a sua memória organizacional.

A engenharia de software pode ser vista como um processo de intensivo conhecimento (BOGEN et al., 2005). Isso porque ela consiste de diferentes campos de conhecimento, tais como análise de requisitos, projeto de software, teste de software e gestão de configuração de software (SWEBOK, 2004), e todos esses campos de conhecimento têm em comum a existência de uma grande variedade de fontes, uma alta demanda por comunicação, um período de vida curto de conhecimento e alto custo no processo.

É importante para uma organização de software saber trilhar quem conhece "o quê" para fazer uso do conhecimento não documentado (conhecimento tácito). Uma boa solução para esse problema é a gestão de competências ou gestão de habilidades. O aprendizado a partir da experiência requer uma memória de projeto e produto. $\mathrm{O}$ ambiente no qual o engenheiro de software conduz seu trabalho diário dá suporte à criação da memória. $\mathrm{O}$ controle de versão, gestão de mudanças, documentação de decisões de projeto (design 
rationale) e rastreabilidade de requisitos são exemplos de práticas de engenharia de software que auxiliam a construir memórias como uma forma efetiva de desenvolvimento de software (RUS \& LINDVALL, 2002).

Apesar de algumas barreiras para o uso efetivo de gestão de conhecimento (KM Knowledge Management) na engenharia de software (DeSOUZA, 2003), foram encontradas na literatura várias abordagens de KM no PDS que relatam sobre experiências bem sucedidas (MONTONI et al., 2004a, 2004b, 2005 e 2007; FALBO et al., 2004 e SEGRINI et al., 2006; LIMA et al., 2006). Um exemplo de barreira é a resistência de ser conhecido como um especialista: alguns especialistas têm receio de serem alocados somente em projetos relacionados às suas experiências no passado ao invés de serem lançados a ele desafios intelectuais (oportunidade de aprendizado) (DeSOUZA, 2003).

Pode-se dizer que, um processo de software também deve considerar, além das atividades de desenvolvimento propriamente ditas, outras atividades relacionadas aos processos organizacionais e de apoio, tais como gestão de projeto, gestão de conhecimento, gestão de requisitos e gestão de mudanças e de configuração. Essas atividades são abordadas em modelos e normas, tais como ISO/IEC 12207, CMMI, ISO/IEC 15504 e MPS.BR, que prescrevem melhores práticas com o intuito de auxiliar na definição e melhoria de processos de software. Contudo, para as MPEs, definir seu processo padrão a partir desses modelos é uma tarefa árdua, pois requer especialistas com conhecimento em qualidade de software e em modelagem de processo.

\subsection{Limitações}

O modelo proposto neste trabalho de pesquisa tem as seguintes limitações:

- Não está inserido em um Ambiente de Engenharia de Software Centrado em Processo (PSEE), o que facilitaria para as MPEs a adequação do modelo para a sua realidade. Um PSEE (Process-Centered Software Engineering Environment) também é conhecido por PCE (Process Centered Environments), PSE (Process 
Sensitive Environments) ou PSS (Process Support System) (ARBAQUI et al., 2002). PSEE constitui um tipo especial de ambiente de desenvolvimento de software para apoiar a definição de processos de software, objetivando automatizar a gerência do desenvolvimento. Esses ambientes provêem serviços para análise, simulação, execução e reutilização das definições de processos, que cooperam no aperfeiçoamento contínuo de processos.

- Atende somente às áreas de processo definidas para se alcançar o nível 2 de maturidade do CMMI e às áreas de processo da categoria Engenharia para se alcançar o nível 3 de maturidade. Sendo assim, processos como suporte e manutenção do software não são abordados pelo modelo elaborado neste trabalho de pesquisa.

- Não está mapeado diretamente com os resultados esperados definidos pelo MPS.BR. Entretanto, uma vez que o MPS.BR foi elaborado em consonância com os modelos internacionais CMMI e ISO/IEC 15504-5 e o modelo elaborado neste trabalho de pesquisa está mapeado com os objetivos específicos do CMMI-DEV e com as práticas-base da ISO/IEC 15504-5, pode-se dizer que o modelo elaborado atende aos resultados esperados do MPS.BR.

- Não atende aos princípios definidos por metodologias ágeis, como Extreme Programming (XP), SCRUM, FDD, entre outras.

- Para ser utilizado como meio de certificação da empresa em nível 2 de maturidade CMMI-DEV, toda vez que o CMMI-DEV for atualizado, o mapeamento das atividades do ProcSoftVD em relação ao CMMI e, se necessário, as atividades do ProcSoftVD devem ser atualizadas.

\subsection{Estrutura de Apresentação do Trabalho}

Este trabalho está organizado em capítulos. No Capítulo 2 são apresentados alguns modelos de processo de software que auxiliam as empresas a definirem os processos e 
atividades que farão parte do seu processo padrão e a norma ISO/IEC 12207 que define os processos de ciclo de vida do software.

O Capítulo 3 apresenta alguns conceitos básicos relacionados à gestão de processos de negócio (que tem como um dos objetivos a melhoria dos processos) e algumas abordagens, métodos e modelos que podem ser utilizados na melhoria de processo de software. Apresenta, também, alguns modelos de capacidade de processo utilizados como referência pelas empresas para definirem o seu processo de software padrão e os outros modelos que poderiam ser utilizados como referência.

No Capítulo 4 são apresentados as abordagens e métodos de pesquisa, e as etapas realizadas no trabalho.

O Capítulo 5 apresenta o Modelo de Gestão do Processo de Venda e Desenvolvimento de Software On-Demand em MPE's (ProcSoftVD - Gestão), resultante desse trabalho de pesquisa.

No Capítulo 6 são apresentadas as aplicações e análises realizadas no ProcSoftVD Gestão, além dos resultados das aplicações. E, finalmente, no Capítulo 7 são apresentados as conclusões e trabalhos futuros, as referências bibliográficas e os apêndices. 


\section{PROCESSO DE SOFTWARE}

\subsection{Considerações Iniciais}

Segundo a IEEE, a engenharia de software é a aplicação de uma abordagem sistemática, disciplinada e quantificável para o desenvolvimento, operação e manutenção do software. Sistemática por partir do princípio de que existe um processo de desenvolvimento definindo as atividades que deverão ser executadas. Disciplinada, pois parte do princípio de que os processos definidos serão seguidos. Quantificável por que se deve definir um conjunto de medidas a serem extraídas do processo durante o desenvolvimento, de forma que as tomadas de decisão relacionadas ao desenvolvimento do software (por exemplo, melhoria de processo) sejam embasadas em dados reais (SPÍNOLA \& ÁVILA, 2008). Essa abordagem refere-se a um processo de software.

Segundo Paulk et al. (1995), para um processo de software funcionar satisfatoriamente, deve possuir: procedimentos e métodos que descrevam a relação entre as tarefas; ferramentas e equipamentos que dêem suporte à realização das tarefas, simplificando e automatizando o trabalho; pessoas com perfil adequado, treinadas nos métodos e nas ferramentas para poderem realizar as atividades adequadamente.

Para Salviano (2006), "processo de software é o que as pessoas fazem para um determinado propósito, utilizando suas habilidades e conhecimento, com o apoio de artefatos, ferramentas e outros recursos, para produzir software e seus produtos associados".

Devido à alta rotatividade de pessoas na indústria de software, há uma grande probabilidade dos desenvolvedores originais não estarem disponíveis quando surgirem os problemas e forem necessárias modificações (FIGUEIREDO et al., 2006). Esse é um dos motivos pelo qual se justifica a importância de utilizar processos como guias 
de condução das atividades fundamentais de processo de desenvolvimento de software (PDS) e das atividades gerenciais, organizacionais e de apoio relacionados ao PDS.

Há na literatura vários modelos de processo de software que surgiram na tentativa de auxiliar na definição de processos de software com qualidade - cada um deles com suas peculiaridades (PRESSMAN, 2006). Modelos de processo de software são abstrações do processo de software descritos com uma linguagem formal ou semi-formal denominada PML (Process Modeling Language or Formalism) (CONRADI et al., $1992^{8}$ apud ARBAQUI et al., 2002; LONCHAMP, $1993^{9}$ apud ARBAQUI et al., 2002). Podem ser entendidos como uma representação simplificada do processo de software.

A fim de fornecer mecanismos de apoio aos realizadores de processo de software, surgiram os Ambientes de Engenharia de Software Orientados a Processos (PSEE - Process-Centered Software Engineering Environment). Esses ambientes permitem a customização de um modelo de processo para um projeto específico por meio do refinamento e adaptação de um modelo de processo genérico (ARBAQUI et al., 2002). Alguns exemplos de PSEE são: Eclipse Process Framework - EPF (ECLIPSE FOUNDATION, 2008), Rational Method Composer (IBM, 2006), Visual Studio Team System - VSTS (MICROSOFT, 2006), TABA (MONTONI et al., 2004a, 2004b, 2005 e 2007), Ontology-based Development Environment - ODE (FALBO et al., 2004; SEGRINI et al., 2006) e WebAPSEE (LIMA et al., 2006).

Neste capítulo serão abordados alguns modelos de processo de software, um framework e uma norma que define os processos de ciclo de vida do software. Esses

\footnotetext{
${ }^{8}$ CONRADI, R. C.; FERNSTROM, A.; FUGGETA, A.; SNOWDON, B. (1992). Towards a Reference Framework for Process Concepts. In: Proceedings of the $2^{\text {nd }}$ European Workshop on the Software Process Technology, Lecture Notes in Computer Science, vol. 635, Trondheim, Norway.

${ }^{9}$ LONCHAMP, J. (1993). A Structured Conceptual and Terminological Framework for Software Process Engineering. In: Proceeding of the $2^{\text {nd }}$ International Conference on the Software Process, IEEE Computer Society Press, Berlin, Germany.
} 
foram investigados para servirem de guia para uma MPE definir o seu processo padrão ${ }^{10}$.

\subsection{Modelo Cascata}

Trata-se do modelo mais antigo da engenharia de software (PRESSMAN, 2006; SOMMERVILLE, 2007) o qual sugere uma abordagem sistemática e seqüencial ao desenvolvimento de software (Figura 2.1). O enfoque desse modelo está nos documentos e nos artefatos.

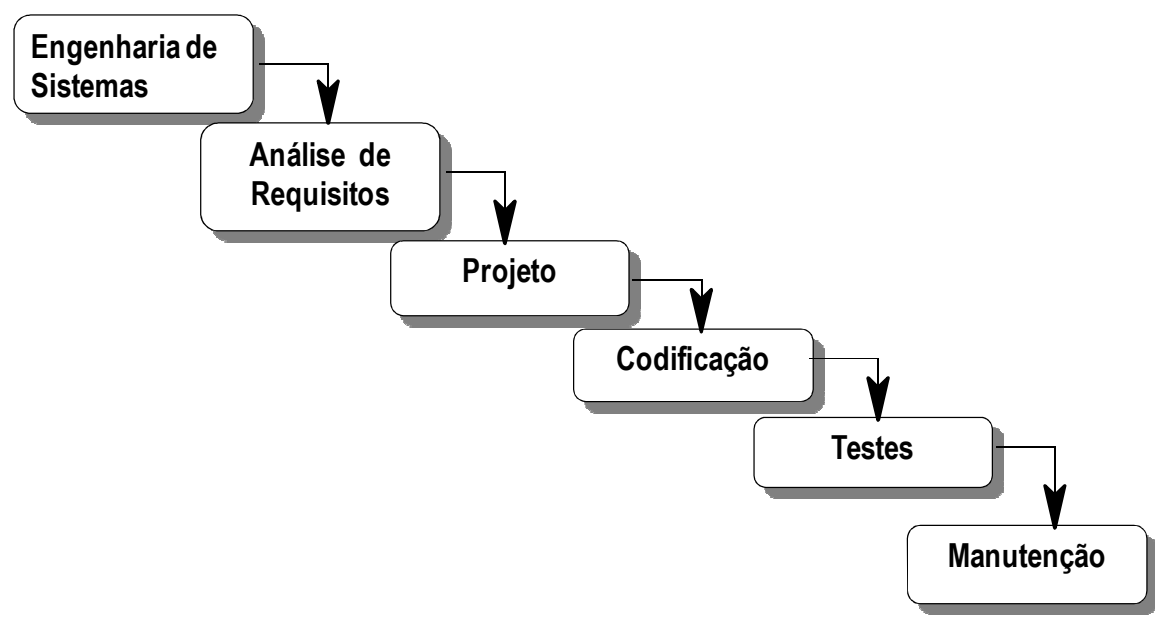

Figura 2.1 - Modelo de Processo de Software Clássico (Cascata)

Porém, apesar de ser bastante conhecido, a utilização dele apresenta alguns problemas: projetos reais raramente seguem o fluxo seqüencial que o modelo propõe; logo no início é difícil estabelecer explicitamente todos os requisitos, pois no começo dos projetos sempre existe uma incerteza natural; o cliente deve ter paciência, pois uma versão executável do software só fica disponível em uma etapa avançada do desenvolvimento.

\subsection{Modelo Incremental}

O Modelo Incremental combina elementos do modelo cascata de maneira iterativa. Essa abordagem foi sugerida por Mills et al. $(1987)^{11}$ apud (PRESSMAN,

\footnotetext{
${ }^{10}$ Segundo o CMMI, Processo Padrão refere-se à definição operacional do processo básico que guia o estabelecimento de um processo comum na organização.
} 
2006) como um meio de reduzir o re-trabalho no processo de desenvolvimento de software e de proporcionar aos clientes algumas oportunidades de adiar decisões sobre seus requisitos detalhados, até que eles tenham alguma experiência com o sistema.

Os clientes identificam, em um esboço, as funções a serem fornecidas pelo sistema (Figura 2.2). Eles identificam quais funções são mais prioritárias e, em seguida, é definida uma série de estágios de entrega, com cada estágio fornecendo um subconjunto das funcionalidades do sistema, de acordo com a priorização do cliente.

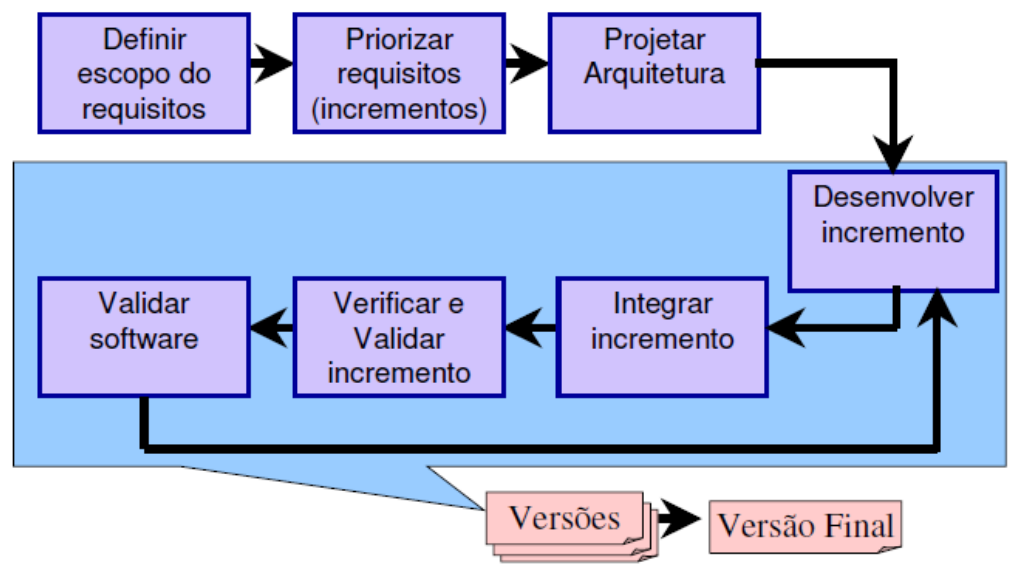

FIGURA 2.2 - MODELO INCREMENTAL

As vantagens desse modelo são:

- os clientes não precisam esperar que a versão final do software seja entregue para usá-lo;

- os clientes podem utilizar os primeiros incrementos desenvolvidos como um protótipo, de forma a definir melhor alguns requisitos do software;

- existe um risco menor de fracasso do software;

- como as funções prioritárias são entregues primeiro, é inevitável que estas passem por um período de testes mais intensivo.

\footnotetext{
11 MILLS, H. D.; DYER, M.; LINGER, R. (1987). Cleanroom Software Engineering. IEEE Software,
} setembro de 1987, p. 19-25. 


\subsection{Modelo Espiral}

O Modelo Espiral (Figura 2.3), originalmente proposto por Boehm $(1988)^{12}$ apud (BOEHM et al., 1998), usa uma abordagem cíclica para desenvolver um sistema, resultando em entregas incrementais da capacidade operacional do sistema.

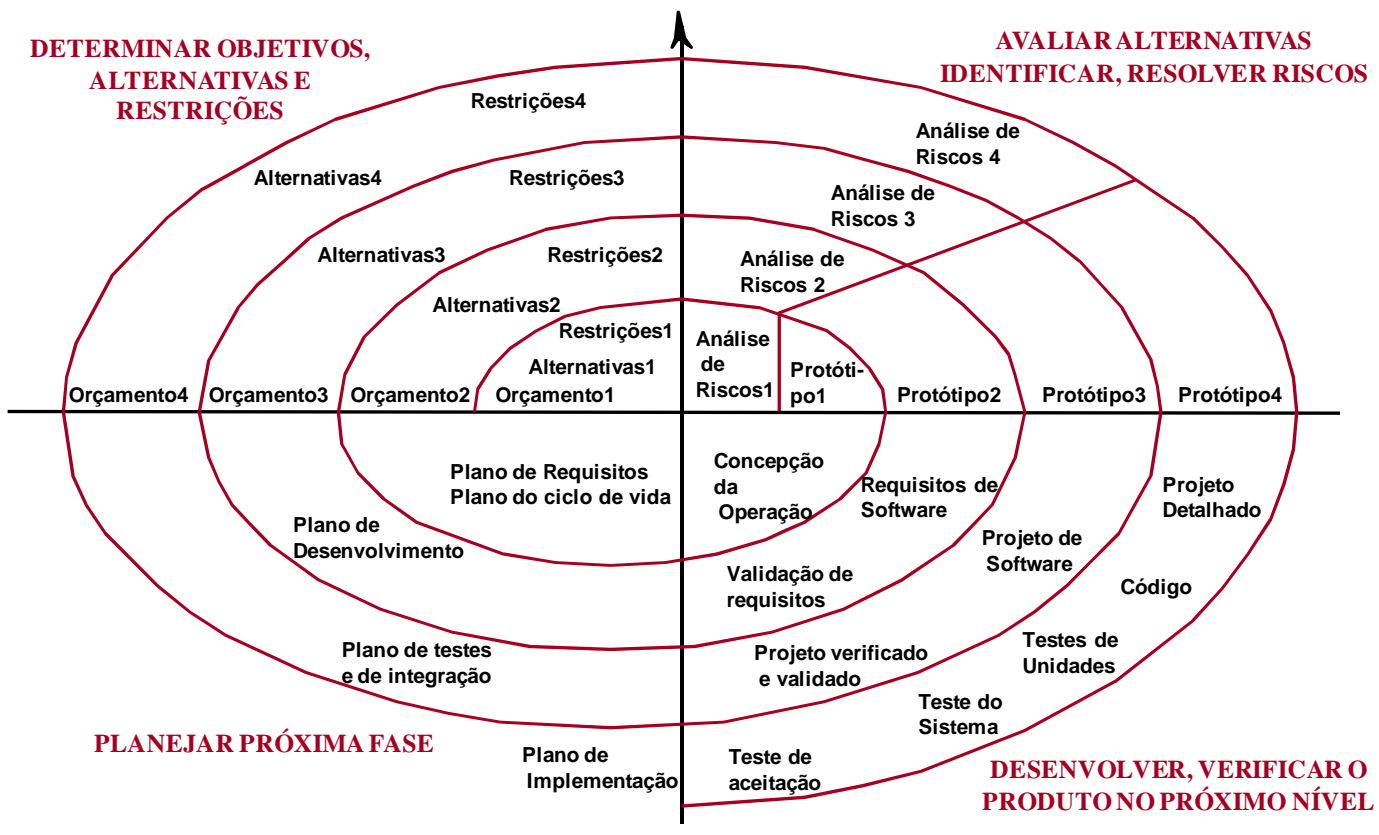

FIGURA 2.3 - MODELO ESPIRAL

Cada ciclo envolve quatro principais atividades:

- Elaborar os objetivos de processo e produto, restrições e alternativas.

- Avaliar as alternativas em relação aos objetivos e restrições; identificar e solucionar as principais fontes de risco do processo e produto.

- Elaborar a definição do produto e processo.

- Planejar o próximo ciclo e alterar o plano de ciclo de vida, incluindo a partição do sistema em subsistemas para ser distribuída em ciclos paralelos.

Pode-se dizer que o modelo espiral engloba os elementos do modelo cascata, com a característica de iteração do modelo incremental, adicionando um novo

\footnotetext{
${ }^{12}$ Boehm, B.W. (1988). A Spiral Model of Software Development and Enhancement. Computer 21, 5, 6172.
} 
elemento: a Análise de Risco. Pode ser criado um protótipo em qualquer etapa da evolução do produto, como mecanismo de redução de riscos (SOMMERVILLE, 2007).

\subsection{RAD - Rapid Application Development}

Trata-se de um modelo de processo de software incremental que enfatiza um ciclo de desenvolvimento curto (MARTIN, $1991^{13}$ apud SOMMERVILLE, 2007). Podese dizer que é uma adaptação do modelo cascata, onde o desenvolvimento rápido (em um período de 60 a 90 dias) é obtido devido à abordagem de construção ser realizada com base em componentes junto ao desenvolvimento realizado por várias equipes trabalhando em paralelo (Figura 2.4).

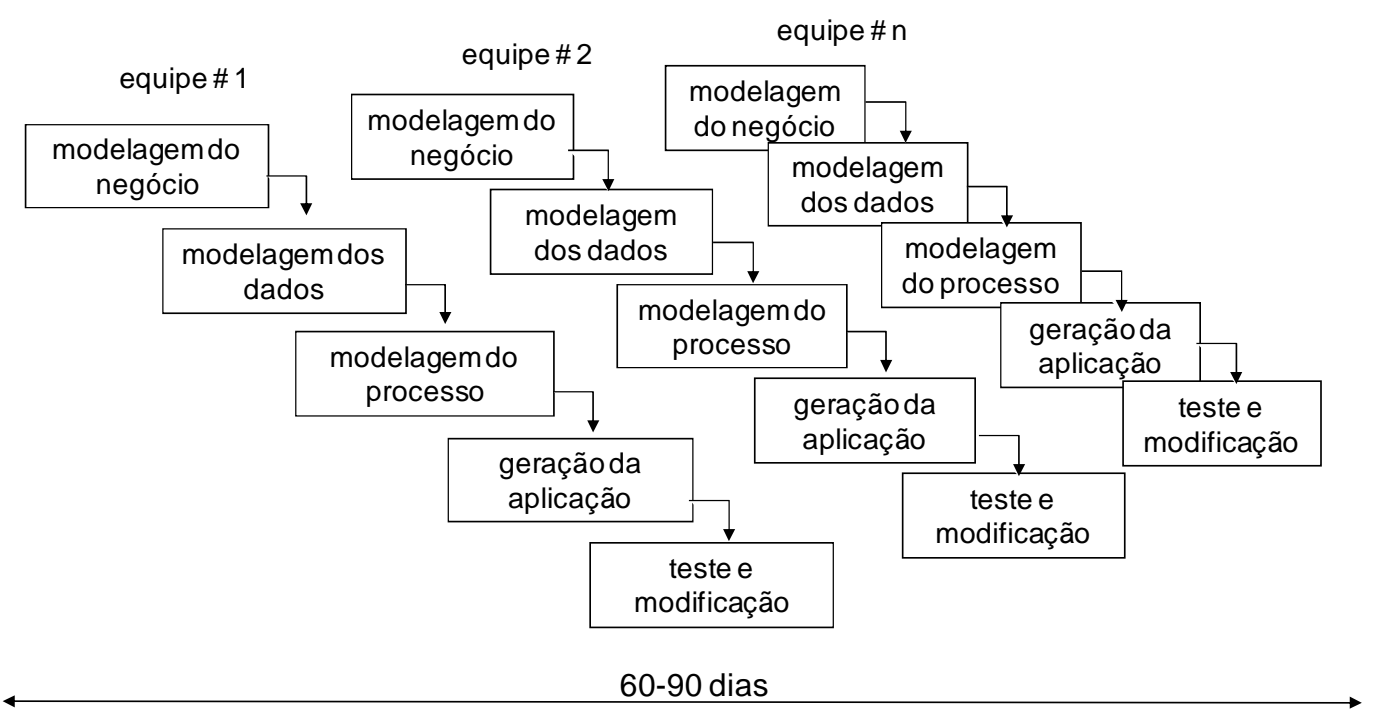

FIGURA 2.4 - MODELO RAD

Entretanto, para utilizar esse modelo é necessário que os requisitos sejam bem compreendidos, antes de iniciar a construção do software. Algumas desvantagens desse modelo: (1) para projetos grandes, o RAD exige recursos humanos suficientes para criar um número adequado de equipes RAD; (2) se os desenvolvedores e clientes não estiverem comprometidos com as atividades continuamente rápidas, o projeto

${ }^{13}$ MARTIN, J. (1991). Rapid Application Development. Prentice-Hall. 
falhará; (3) se o sistema não puder ser adequadamente modularizado, a construção dos componentes necessários será problemática; (4) o RAD pode não ser adequado quando riscos técnicos são altos (PRESSMAN, 2006).

\subsection{Unified Process}

O Unified Process (UP) é um framework genérico para o desenvolvimento de software que pode ser customizado para empresas ou projetos específicos. Esse framework é fundamentado em um conjunto de seis melhores práticas: desenvolver software de forma iterativa, gerenciar os requisitos, utilizar arquitetura baseada em componentes, modelar o software de forma visual, verificar a qualidade do software e controlar as mudanças do software (JACOBSON et al., 1999). O RUP (Rational Unified Process) foi originado do UP - elaborado pela Rational Software Corporation que foi adquirida pela IBM (KRUCHTEN, 2004).

Um dos princípios fundamentais do UP (Figura 2.4) é o fato de ser iterativo e incremental. Por isso, o projeto para desenvolvimento de sistema deve ser dividido em “mini-projetos”, chamados iterações.

Uma iteração é uma seqüência completa de disciplinas (workflows), sendo que o resultado de uma iteração é um artefato ou uma série de artefatos. Um artefato pode ser um código-fonte, um modelo, etc. Uma vez que os artefatos para uma fase específica foram completados ocorre a passagem para a próxima fase. 


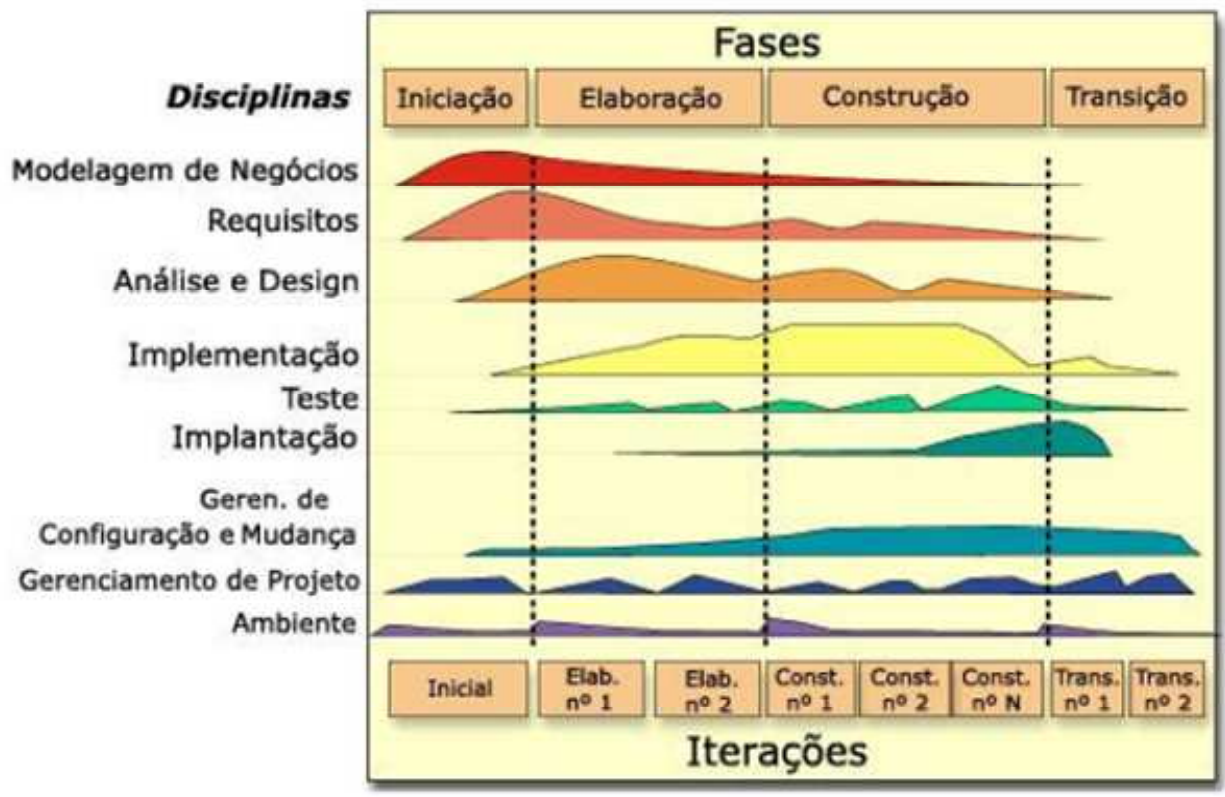

Figura 2.4 - Unified Process. Fonte: Traduzido de (AMBLER, 2005)

As fases do UP são (AMBLER, 2005):

- Concepção: nessa fase define-se o escopo do projeto, avalia-se a tecnologia, os principais riscos são relacionados, as áreas mais críticas a serem tratadas são detectadas, verifica-se a viabilidade do projeto e é desenvolvido um planejamento para a natureza incremental e iterativa do projeto.

- Elaboração: nessa fase os requisitos são especificados em detalhes e a arquitetura do software é identificada e avaliada.

- Construção: nessa fase o produto é construído e as suas versões beta são testadas.

- Transição: a versão do produto para entrega ao cliente é testada e o sistema é implantado. 


\subsection{Open/UP}

OpenUP (ECLIPSE PROCESS FRAMEWORK COMMUNITY, 2008) é um Processo Unificado enxuto que aplica as abordagens iterativas e incrementais dentro de um ciclo de vida estruturado. Incorpora uma filosofia ágil e que foca a natureza colaborativa de desenvolvimento de software.

Em um projeto que utiliza OpenUP os esforços pessoais são organizados em micro-incrementos. Esses representam pequenas unidades de trabalho produzidas em poucas horas ou dias que fornecem feedback para direcionar decisões adaptativas em cada iteração (Figura 2.5).

OpenUP utiliza um ciclo de vida de iteração que estrutura como os microincrementos são aplicados para produzir entregas estáveis do sistema em semanas. Essas iterações são planejadas em um ciclo de vida de projeto composto por quatro fases: concepção, elaboração, construção e transição.

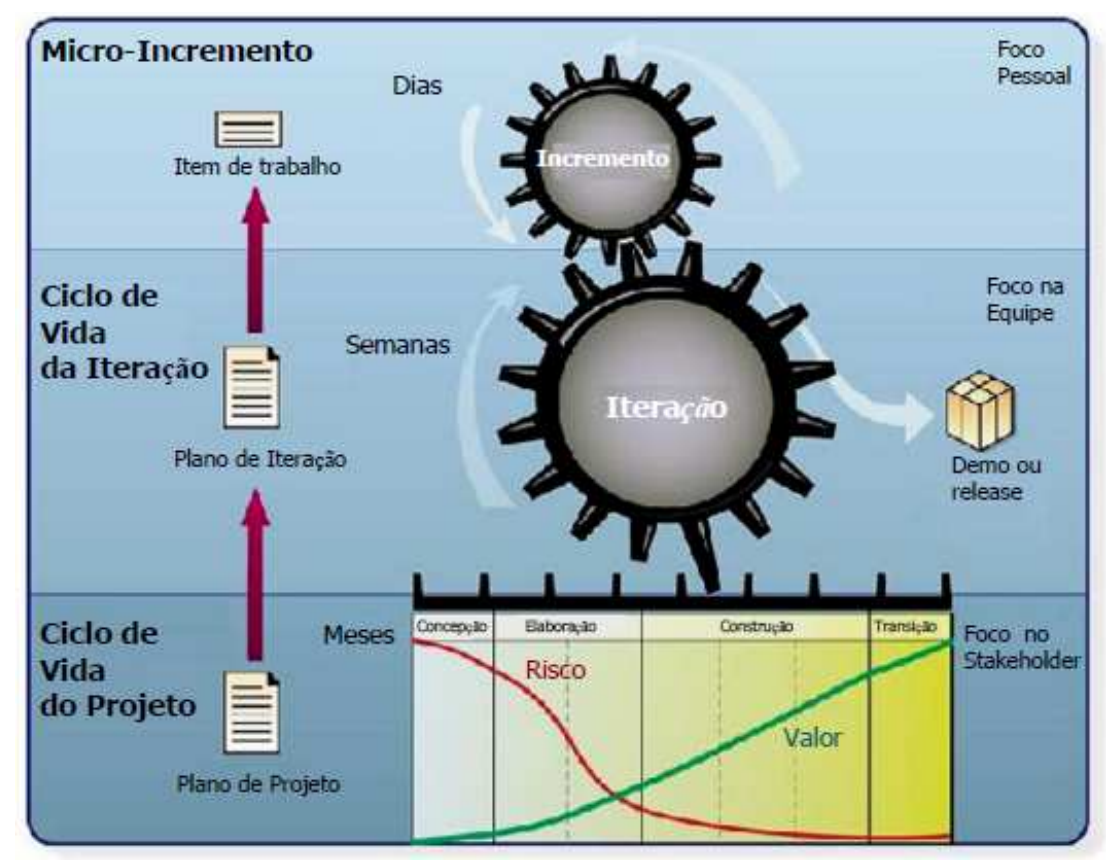

FiguRA 2.5 - OPENUP

Fonte: Traduzido de (Eclipse Process Framework Community, 2008) 


\subsection{ISO/IEC 12207 - Processos de Ciclo de Vida de Software}

Essa norma junto às suas emendas - ISO/IEC 12207 AMD1 e AMD2 (INTERNATIONAL ORGANIZATION FOR STANDARDIZATION, 2001) - estabelece uma estrutura comum para os processos de ciclo de vida de software, que pode ser referenciada pela indústria de software. A estrutura contém processos, atividades e tarefas que servem para ser aplicadas durante (a) a aquisição de um sistema que contém software, de um produto de software independente ou de um serviço de software; (b) o fornecimento, desenvolvimento, operação e manutenção de produtos de software.

A norma não especifica o como implementar ou executar as atividades e tarefas, não determina um modelo de processo de software ou método de desenvolvimento e deve ser adaptada de acordo com o organização e projetos específicos.

Os processos de ciclo de vida estão organizados em categorias de processos fundamentais, processos de apoio e processos organizacionais (Figura 2.6). Cada categoria é subdividida em grupos de processo.

Os Processos Fundamentais de Ciclo de Vida constituem um conjunto de quatro grupos de processo que atendem as partes fundamentais (pessoa ou organização) durante o ciclo de vida de software: aquisição, fornecimento, engenharia e operação.

Os Processos Organizacionais de Ciclo de Vida constituem um conjunto de quatro grupos de processo que são empregados por uma organização para estabelecer e implementar uma estrutura subjacente, constituída de processos de ciclo de vida e pessoal associado, e melhorar continuamente a estrutura e os processos. Os grupos de processos organizacionais são: gerência, melhoria de Processo, recursos e infra-estrutura, e reuso.

Os Processos de Apoio de Ciclo de Vida constituem um conjunto de processos que auxiliam a um outro processo contribuindo para o sucesso e qualidade do projeto 
de software. Um processo de apoio é empregado e executado, quando necessário, por outro processo. Os processos de apoio são: controle de configuração e garantia da qualidade.

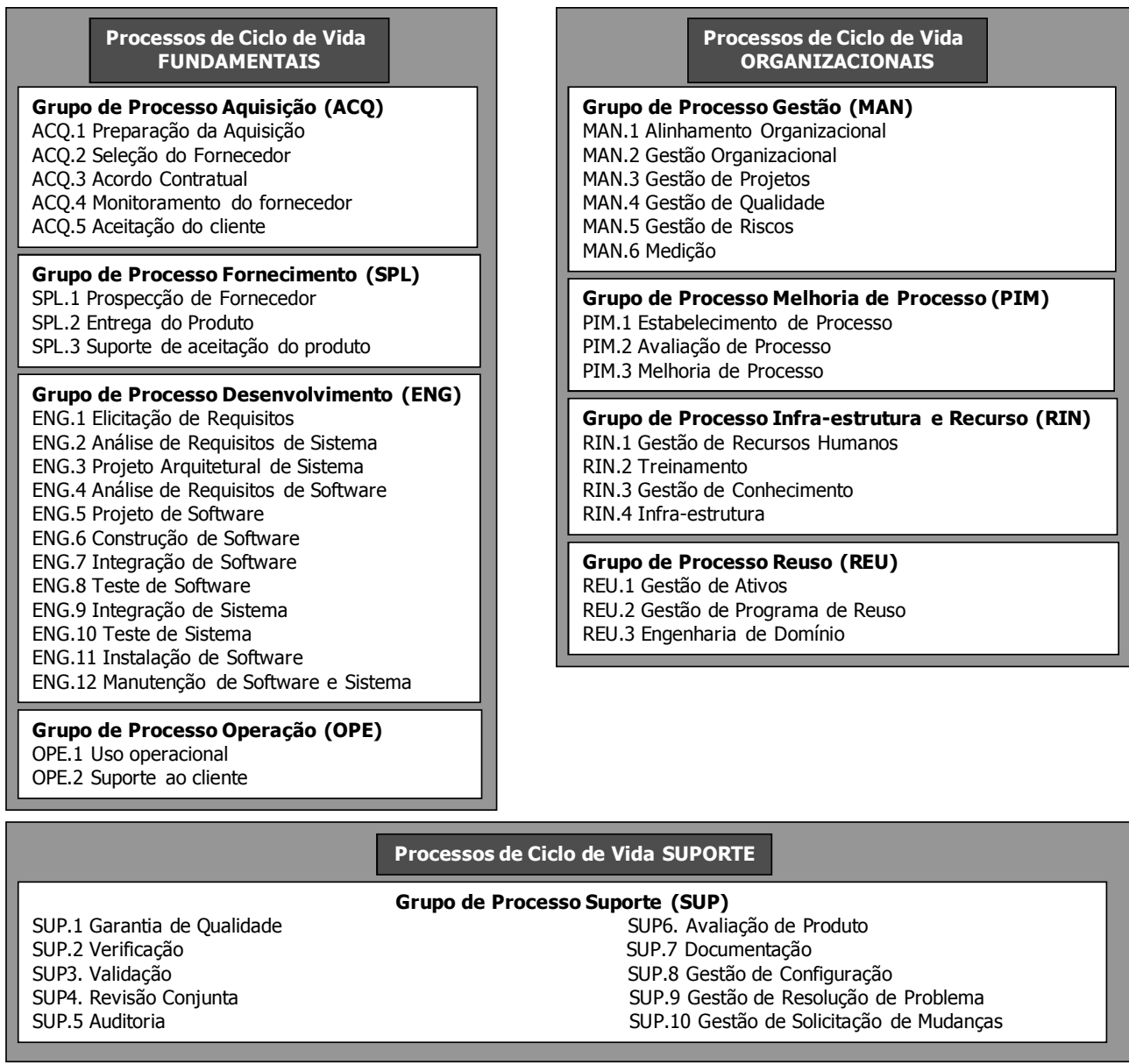

Figura 2.6 - ISO/IEC 12207 - Processos DE CICLO de VIDA DE SofTWARE

FONTE: TRADUZIDO DE (INTERNATIONAL ORGANIZATION FOR STANDARDIZATION, 2001)

\subsection{Considerações Finais}

Os modelos cascata, espiral, incremental e RAD (PRESSMAN, 2006; SOMMERVILLE, 2007) são considerados modelos tradicionais e têm características de modelos prescritivos - modelos que prescrevem um conjunto de elementos de processo e tem ênfase em documentação e controles.

O Modelo Cascata não retrata fielmente o que acontece no desenvolvimento de projetos reais, devido sua característica de desenvolvimento seqüencial (conclui-se 
uma fase para posteriormente iniciar a próxima). Essa deficiência foi suprida pelos modelos incremental e espiral que foram utilizados como base do framework de processo UP (Unified Process) (JACOBSON et al., 1999), pois sugere que o processo seja realizado de forma incremental e iterativa.

O modelo RAD é útil em situações peculiares: quando o desenvolvedor compreende todos os requisitos do software e re-utiliza componentes para agilizar o processo de desenvolvimento que deve ser realizado em um período de 60 a 90 dias.

Todos esses modelos (cascata, incremental, espiral e RAD), apesar de serem prescritivos, prescrevem apenas as atividades a serem realizadas sem fornecer mais detalhes (como os responsáveis pelas atividades, suas tarefas, os artefatos de entrada necessários para a realização das atividades, os artefatos resultantes da execução das atividades, recursos que podem ser utilizados e templates que fornecem informações do conteúdo de cada um dos artefatos), o que facilitaria o entendimento e uso do modelo por parte das MPEs.

O RUP - Rational Unified Process (KRUTCHEN, 2004) - embutido em algumas ferramentas da Rational e o OpenUP (ECLIPSE PROCESS FRAMEWORK COMMUNITY, 2008) - um processo unificado ágil embutido na ferramenta free EPF Composer (Eclipse Process Framework) - prescrevem elementos além das atividades a serem realizadas e poderiam servir como modelo a ser utilizado pelas MPEs, mas não incluem atividades relacionadas à comercialização de software, o que auxiliaria as MPEs durante a negociação da venda do software para o cliente e acompanhamento do fluxo de caixa e, também, não incluem atividades relacionadas ao gerenciamento da memória organizacional da empresa - Gestão de Conhecimento e nem atividades relacionadas à gestão de habilidades e competências dentro da empresa.

A norma ISO/IEC 12207 (INTERNATIONAL ORGANIZATION FOR STANDARDIZATION, 2001) prescreve as atividades do processo de ciclo de vida de software, porém não define a seqüência de execução das atividades (por exemplo, linear ou evolutiva), o que é definido pelos modelos cascata, espiral, incremental, 
framework UP e outros. Entretanto, pode ser utilizada como referência para a definição do processo de software padrão de uma empresa. 


\section{MELHORIA DE PROCESSO DE SOFTWARE}

\subsection{Considerações Iniciais}

Melhorar continuamente os processos de negócio é um dos objetivos da Gestão de Processos de Negócio (BPM) - uma fonte de vantagem competitiva para a empresa (HUNG, 2006). Segundo Jeston \& Nelis (2008) BPM tem por princípio alcançar os objetivos estratégicos da organização por meio da melhoria, gestão e controle de processos de negócio essenciais. A melhoria tem o objetivo de tornar os processos de negócio mais eficientes e eficazes. A gestão refere-se à medição e gerenciamento do desempenho dos processos e das pessoas. E, o controle é obtido por meio da medição dos processos de negócio em um ciclo de melhoria, tal como o PDCA (DEMING, 1986).

A melhoria do processo de software é considerada parte da engenharia de processo de software (EL EMAM, 2004). Esta pode ser examinada em dois níveis: o primeiro refere-se às atividades técnicas e gerenciais dentro dos processos de ciclo de vida que são realizados durante a aquisição, desenvolvimento, manutenção e retirada do software; o segundo é um meta-nível, referente à definição, implementação, avaliação, medição, gerenciamento, mudanças e melhorias dos próprios processos de ciclo de vida.

Segundo Salviano (2006), "Melhoria de Processo de Software é uma abordagem para a melhoria de organizações intensivas em software, baseada em modelos de capacidade de processo de software, por meio do estabelecimento, avaliação e melhoria da capacidade de seus processos mais importantes, relacionados às atividades de aquisição, fornecimento, operação, desenvolvimento, manutenção, gerência, melhoria e/ou apoio de sistemas de software, com o objetivo de satisfazer de forma mais eficiente e eficaz os objetivos estratégicos da organização". 
Há na literatura várias abordagens para melhoria de processo, que podem ser utilizadas como guia, tais como: PDCA (DEMING, 1986), IDEAL (MCFEELEY, 1996), Ciclo de Melhoria da 15504 (INTERNATIONAL ORGANIZATION FOR STANDARDIZATION, 2003), Metodologia de Gestão de Mudanças (COSTA, 2006). Há, também, algumas abordagens elaboradas especificamente para o caso de MPEs, como PRO2PI-CYCLE (SALVIANO, 2006) e ASPE/MSC (WEBER et al., 2005b), por terem orientação detalhada das atividades a serem realizadas (como fazer). Essas abordagens são comentadas neste capítulo.

A melhoria de processo utiliza um ou mais modelos como referência para orientar as ações de melhoria. Dentre esses modelos de referência ${ }^{14}$ estão os modelos de capacidade de processo, tais como OPM3 (PROJECT MANAGEMENT INSTITUTE, 2003), os modelos de capacidade do CMMI (SOFTWARE ENGINEERING INSTITUTE, 2006) e da ISO/IEC 15504 (INTERNATIONAL ORGANIZATION FOR STANDARDIZATION, 2003), MR-MPS (WEBER et al., 2005a; SOFTEX, 2006) e outros modelos como PMBOK (PROJECT MANAGEMENT INSTITUTE, 2004), SWEBOK (ABRAN et al., 2004) e ISO 9000 (INTERNATIONAL ORGANIZATION FOR STANDARDIZATION, 2000). Alguns desses modelos de referência são comentados neste capítulo.

\subsection{Gestão de Processos de Negócio - Conceitos Básicos}

Processos de negócio são fatores chaves na integração de uma empresa (AGUILAR-SAVÉN \& OLHAGER, 2002). Segundo Rozenfeld et al. (2006), "processos de negócio compreendem um conjunto de atividades organizadas entre si visando produzir um bem ou serviço para um tipo específico de cliente (interno ou externo à

\footnotetext{
${ }^{14}$ Modelo de referência pode ser definido como um framework para entendimento de relacionamentos significativos entre as entidades de algum ambiente, e para o desenvolvimento de padrões ou especificações consistentes que apóiam o ambiente (Consultative Committee for Space Data Systems, Reference Model for an Open Archival Information System (OAIS), CCSDS 650.0-R-1.2, Red Book, June 2001) apud (SALVIANO, 2006).
} 
empresa)". Os processos de negócio podem representar operações repetitivas da empresa, que normalmente são estruturadas (exemplo: gestão financeira e gestão de produção). Outros processos de negócio não são tão estruturados, como é o caso do PDS (processo de desenvolvimento de software on-demand), uma vez que cada desenvolvimento de um software específico pode ser diferente.

Esses processos de negócio precisam ser gerenciados, de acordo com os objetivos estratégicos da organização para alcançar de modo eficiente esses objetivos. Por isso, é importante que estes processos estejam associados a uma abordagem de gestão - a Gestão de Processos de Negócio (BPM - Business Process Management). Essa abordagem pode ser visualizada tanto pela perspectiva de negócios quanto de tecnologia (SMITH \& FINGAR, 2003). Considerando a perspectiva de negócios, BPM é considerada uma das melhores práticas dentre os princípios de gestão para auxiliar as organizações a sustentarem sua vantagem competitiva (KILMANN, 1995).

As raízes da BPM podem sem encontradas voltando na década de $80 \mathrm{com}$ a filosofia de TQM (Total Quality Management - Gestão da Qualidade Total) e na década de 90 com a Reengenharia de Processo de Negócio (Business Process Reengineering - BPR). Os estudos de Davenport (1993) e Zairi \& Sinclair (1995) indicam que TQM é de natureza incremental, evolucionária e contínua. Em oposição, BPR é de natureza radical, revolucionária e ocorre de uma vez só. A partir de uma perspectiva holística, BPM integra as abordagens TQM e BPR as quais podem ser consideradas como apropriadas para a melhoria de desempenho de processos de negócio na maioria das circunstâncias (HUNG, 2006).

BPM tem o objetivo de entender e organizar a empresa como processos de negócio (SMITH \& FINGAR, 2003). Por outro lado, existem autores que enfatizam BPM como uma ferramenta tecnológica, vista como uma evolução de sistemas de gestão de workflow (AALST et al., 2003). Neste caso, o ciclo de vida de BPM tem quatro fases: projeto de processo, configuração de sistema, promulgação e diagnóstico. O foco de sistemas tradicionais de gestão de workflow é nas fases de 
projeto de processo e promulgação de processo do ciclo de vida de BPM. Esta definição de BPM estende a tradicional abordagem de gestão de workflow para suportar a fase de diagnóstico e permite por meio de novos caminhos apoiar o processo operacional (AALST et al., 2003; AALST, 2004).

No presente trabalho de pesquisa o escopo é considerar a melhoria do modelo de Processo de Venda e Desenvolvimento de Software (PV\&DS) on-demand em um contexto de BPM mais abrangente - o foco é sobre a visão de negócio de BPM. De qualquer modo, a implementação de tecnologia BPM é uma questão muito importante, tanto que é considerada em sistemas de Gestão de Ciclo de Vida de Produto (Product Lifecycle Management-PLM).

Para Zairi (1997) essa abordagem é dependente de elementos estratégicos, elementos operacionais, do uso de ferramentas e técnicas modernas, do envolvimento de pessoas e, o mais importante, tem um foco horizontal que possibilita o atendimento dos requisitos do cliente da melhor forma possível. Em BPM, o alinhamento das operações de negócio com as prioridades estratégicas e o envolvimento de pessoas são conceitos fundamentais na busca pela competitividade (ZAIRI, 1997; MCKAY \& RADNOR, 1998).

Hung (2006) entende BPM como uma filosofia de gestão integrada e um conjunto de práticas que incluem mudanças incrementais e radicais no processo de negócio, e enfatiza a melhoria contínua, satisfação do cliente e envolvimento dos funcionários. Nesse contexto, a gestão de mudanças se integra à abordagem BPM.

Zairi (1997) afirma que o BPM tem que ser governado por alguns princípios, dentre eles: (1) as principais atividades têm que ser devidamente mapeadas e documentadas; (2) BPM cria um foco nos clientes por meio de ligações horizontais entre as atividades; (3) BPM é dependente de sistemas e procedimentos documentados para assegurar disciplina, consistência e repetibilidade no desempenho da qualidade; (4) BPM é dependente de atividades de medição para avaliar o 
desempenho de cada processo individualmente; (5) BPM tem base em uma abordagem contínua de otimização e (6) BPM é uma abordagem de mudança cultural.

A fim de complementar a definição dos princípios da BPM, Hung (2001) ${ }^{15}$ apud Hung (2006) inclui: a visão holística, a autoridade estratégica, a TI (tecnologia da informação) que permite o gerenciamento dos processos de negócio, a transformação do negócio, o impacto por toda a organização e a ênfase inter-funcional da gestão do processo.

\subsection{Algumas Abordagens para Melhoria de Processo}

\subsubsection{PDCA}

A idéia original do PDCA (Plan, Do, Check, Action) foi desenvolvida na década de 1930 por Shewhart e popularizado por Deming (1986) como sendo um ciclo de controle estatístico do processo que pode ser repetido continuamente sobre qualquer processo ou problema. O início do ciclo PDCA se dá com o planejamento do que será feito e com a definição de metas e métodos para atingir essas metas. Este plano é implantado, coletando-se dados e é realizada a verificação dos resultados em relação às metas definidas. Posteriormente, são tomadas ações corretivas ou de melhoria, caso necessário.

\subsubsection{IDEAL}

O modelo IDEAL (Initiating, Diagnosing, Establishing, Acting, Learning) foi criado pelo SEI (Software Engineering Institute) para o aprimoramento contínuo do processo de desenvolvimento de software (MCFEELEY, 1996). Foi desenvolvido para ser uma ferramenta de apoio à implantação do CMM (Capability Maturity Model) para software.

\footnotetext{
${ }^{15}$ HUNG, R. Y. (2001). An empirical examination of the relationship between BPM and business performance: a study of Australia's top 1000 companies (unpublished PhD dissertation, The University of Sydney).
} 
Trata-se de um modelo de programa de melhoria de processo de software (SPI - Software Process Improvement) usado para guiar o desenvolvimento de um plano integrado para inicialização e gerenciamento de um programa de SPI. Esse modelo é composto por 5 fases que compõem o ciclo de melhoria. É importante ressaltar que o tempo para completar um ciclo por completo pode variar de organização para organização.

O ciclo de melhoria começa com a fase de Inicialização que foca o comprometimento dos recursos iniciais e o estabelecimento da infra-estrutura necessária para a melhoria. A segunda fase é o Diagnóstico que estabelece os níveis atuais de maturidade de processo, a descrição atual do processo e inicia o desenvolvimento de um plano de ação. A terceira fase é o Estabelecimento com o objetivo de estabelecer metas e prioridades e completar o plano de ação. A quarta fase é a Ação na qual realiza-se a pesquisa e são desenvolvidas soluções para os problemas do processo, expandindo as melhorias de processo com sucesso para toda a organização. Por fim, a fase Alavancagem tem o objetivo a preparação para 0 próximo ciclo, a partir da fase de Diagnóstico, e aplicação das lições aprendidas para refinar o processo de SPI.

\subsubsection{Ciclo de Melhoria da ISO/IEC 15504}

A parte 4 da norma ISO/IEC 15504 (INTERNATIONAL ORGANIZATION FOR STANDARDIZATION, 2003) descreve orientações para utilização de modelos para melhoria de processo ou determinação da capacidade de processo.

O guia de melhoria de processo é composto por 8 (oito) etapas. Na primeira etapa examinam-se os objetivos de negócio da organização e a motivação existente para melhorar. Na segunda etapa o programa de melhoria do processo é iniciado; ele deve ser implementado e gerenciado como um projeto com definição de responsáveis, orçamento, cronograma, milestones, entre outros. Na terceira etapa avalia-se a 
capacidade atual do processo, utilizando como referência as partes 2 (framework de avaliação) e 3 (guia de execução da avaliação) da ISO/EC 15504. Na quarta etapa, o resultado da avaliação é analisado e confrontado com os objetivos de negócios da organização para: identificar, analisar e listar as áreas de melhoria; definir os objetivos específicos da melhoria e derivar um plano de ação. Na quinta etapa, o plano de ação é implementado para melhorar os processos da organização. Essa implementação pode ser simples ou complexa, dependendo do conteúdo do plano de ação e das características da organização. Em geral, vários projetos de implementação podem ser iniciados, cada um concentrado em implementar uma ou mais ações definidas no plano de ação. Na sexta etapa, quando os projetos de implementação foram realizados, a organização deve: confirmar se os objetivos planejados foram alcançados e se os benefícios esperados se concretizaram; checar se os processos e práticas apropriados foram adotados; confirmar que a cultura organizacional foi modificada, conforme apropriado; re-avaliar os riscos associados ao programa de melhoria do projeto e re-avaliar os custos e benefícios. Na sétima etapa devem ser sustentadas as melhorias, mantendo a melhoria do nível de capacidade alcançado. Isso requer gerenciamento para monitorar a institucionalização dos processos melhorados. A última etapa tem como objetivo monitorar continuamente o desempenho dos processos da organização e iniciar melhorias em novos processos, como parte do programa de melhoria contínua.

\subsubsection{Metodologia de Gestão de Mudanças}

A Metodologia de Gestão de Mudanças foi concebida a partir da sistematização das atividades de métodos de gestão de mudança analisados por Costa (2006).

Na primeira fase da metodologia (Figura 3.1), "Definição da Mudança", avaliase a necessidade de mudança e seus objetivos juntamente à estratégia empresa. $\mathrm{Na}$ fase de "Diagnóstico" é realizada a análise da situação atual. Na fase seguinte, "Definir 
portfólio de projetos", as propostas de projetos de mudanças existentes são analisadas e suas implantações são priorizadas. É importante ressaltar que essa fase só ocorre quando existem vários projetos de mudança.

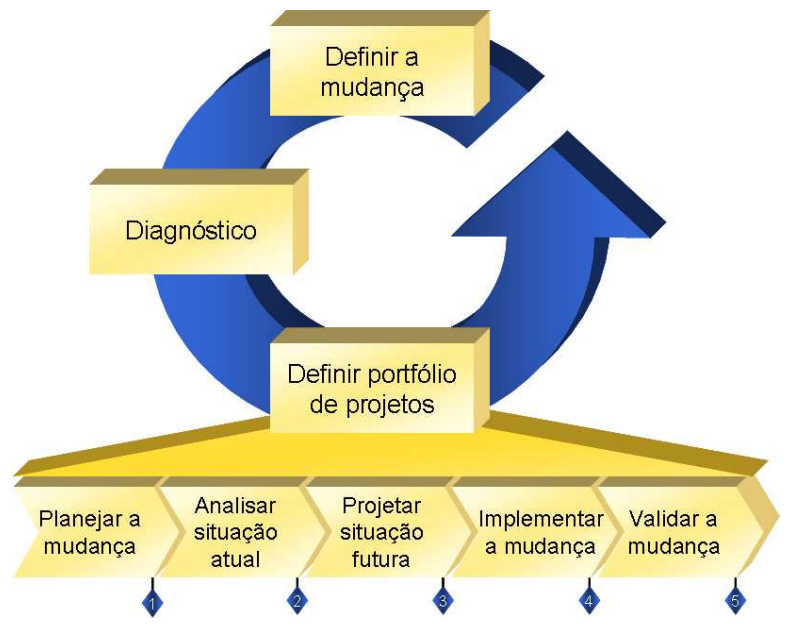

Figura 3.1 - Metodologia de Gestão de Mudanças. Fonte: (COSTA, 2006)

Para cada um dos projetos selecionados, é dado início à fase "Planejar a mudança", em que por meio do escopo do projeto, são definidos e refinados os objetivos da mudança e planejadas as ações necessárias para se alcançar esses objetivos. Nessa fase, também são elaborados a WBS (work breakdown structure) e o cronograma do projeto. Na fase "Analisar a situação atual", é feito um diagnóstico mais detalhado da situação corrente, levantados os requisitos da mudança e os dados quantitativos e qualitativos da situação em que o projeto de melhoria está intervindo.

$\mathrm{Na}$ fase seguinte, "Projetar a situação futura", é projetada a solução, considerando-se os objetivos iniciais do projeto de melhoria e a opinião dos interessados (stakeholders) no projeto de mudança, para que as possíveis resistências sejam minimizadas. Na fase "Implementar a mudança" são realizados os treinamentos e é implantada a mudança e comunicada a todos os envolvidos. Por fim, na fase "Validar a mudança", após um período de institucionalização da mudança, é verificado se houve algum desvio na implantação. É analisado se o problema inicial e a 
necessidade de mudança foram satisfeitos e, por fim, comunicado o encerramento do projeto em questão.

\subsubsection{PRO2PI-CYCLE}

Salviano (2006), em sua pesquisa, caracteriza as diferenças e similaridades entre as arquiteturas estagiada e contínua para modelos de capacidade de processo e faz reflexões sobre tais arquiteturas para subsidiar uma evolução da atual melhoria de processo para uma melhoria mais viável e mais adequada ao contexto e objetivos estratégicos da organização: uma Engenharia de Processo Dirigida por Perfil de Capacidade de Processo (Process Capability Profile Driven Process Engineering PDCE). A partir dessas reflexões, identifica três gerações de arquiteturas de modelos de capacidade de processo. São elas:

- Arquitetura estagiada fixa (1 ${ }^{a}$ geração): os modelos desta geração são compostos por uma seqüência de PCP (perfil de capacidade de processo), onde cada um é composto por uma combinação fixa de áreas de processo em um determinado nível de capacidade de processo. A utilização de um modelo deste tipo deve seguir exatamente o que ele propõe, podendo apenas ser interpretadas as orientações para o contexto da utilização. Exemplos: modelo na representação estagiada do CMMI, MR-MPS (Modelo de Referência) do MPS.BR.

- Arquitetura contínua fechada (2a geração): as áreas de processo e os níveis de capacidade de processo são fixos e as suas combinações são variáveis. A utilização de um modelo com este tipo de arquitetura passa pela escolha de um PCP, a partir dos níveis de capacidade de processo e áreas de processo, seguindo as regras de composição. Exemplos: ISO/IEC 15504-5 e modelo na representação contínua do CMMI.

- Arquitetura contínua aberta (3ª geração): apenas os níveis de capacidade são fixos. Com isto, podem ser definidos conjuntos de áreas de processo e, então, 
definidas combinações de áreas de processo e níveis de capacidade de processo em PCPs. A utilização de modelos com este tipo de arquitetura passa por uma etapa anterior às da utilização de modelos com arquitetura da $2^{a}$ geração, pois inclui a escolha ou definição de áreas de processo. Assim, aumenta-se a flexibilidade e as oportunidades de melhor alinhamento da melhoria com a organização. Entretanto, aumenta-se o risco de escolhas inadequadas, o que leva ao aumento da necessidade de metodologias para sua utilização.

A evolução da atual melhoria de processo - PDCE, proposta por Salviano (2006), é fundamentada na utilização da 3ª geração de arquitetura de modelos de capacidade - contínua aberta. Como representante dessa geração, Salviano (2006) propõe a extensão do ISO/IEC 15504. Ele defende que, em geral, a melhoria de processo pode ser baseada em PCPs dinâmicos e específicos, ou ainda, em níveis de maturidade dinâmicos e específicos. Assim, é diluída a separação rigorosa entre definição de modelos (hoje feita mais por institutos) e a utilização de modelos, uma vez que uma organização ao fazer a melhoria de processo, também define modelos por meio de PCPs.

O "estabelecimento de perfil de capacidade de processo" pode ser visto como uma área de processo, segundo o CMMI, ou como um processo do grupo de melhoria de processo - PIM (Process Improvement Process Group) da norma ISO/IEC 12207 e do modelo ISO/IEC 15504-5.

Para experimentar, validar e evoluir a Engenharia de Processo Dirigida por Perfil de Capacidade de Processo (PDCE), Salviano (2006) propõe a abordagem $\mathrm{PRO}_{2 \mathrm{PI}}{ }^{16}$ (Perfil de Capacidade de Processo para Melhoria de Processo).

PRO2PI-CYCLE é um processo para ciclo de melhoria com PRO2PI, composto por seis fases: 1. Inicia o ciclo de melhoria, 2. Avalia práticas correntes, 3. Planeja

\footnotetext{
${ }^{16}$ PRO2PI: é uma abstração, segundo o aspecto de capacidade de processo, de um processo, e pode ser utilizado como referência para a melhoria do processo atual para o estado estabelecido por ele, em uma organização.
} 
ações de melhoria, 4. Realiza ações de melhoria, 5. Prepara a institucionalização da melhoria e 6. Institucionaliza a melhoria.

Para tornar viável para MPEs intensivas em software, com processos de baixa capacidade (que buscam até o nível 3 de capacidade, segundo a 15504, por exemplo), iniciarem um ciclo de melhoria, estabelecendo um PRO2PI, Salviano (2006) definiu um método, denominado PRO2PI-WORK (PRO2PI Establishment Workshop Method). Esse método realiza de forma compactada as atividades das três primeiras etapas do ciclo de melhoria PRO2PI-CYCLE.

\subsubsection{ASPE/MSC}

ASPE/MSC (Approach for Software Process Establishment in Micro and Small Companies) tem o objetivo de estabelecer processos de software voltada para MPEs, de forma incremental, visando a melhoria contínua (WEBER et al., 2005b).

Para o estabelecimento de processos de software no contexto de MPEs é necessário que haja baixo investimento, fácil compreensão, orientação detalhada das atividades a serem executadas (como fazer), ser de domínio público, suporte de guias para sua implantação e adaptação, entre outros.

As fases dessa abordagem são: 1. Diagnóstico do Processo de Software Atual, obtido por meio de um método de avaliação específico para MPEs); 2. Análise Estratégica para definição e priorização das ações para o estabelecimento de processos na empresa; 3. Definição do Processo, de forma explícita e descritiva para que as pessoas se orientem na execução das atividades; 4. Implantação do Processo por meio da institucionalização e avaliação do processo que foi definido na organização. 


\subsection{Modelos de Referência utilizados para Melhoria de Processo}

Alguns modelos de referência existentes na literatura, tanto modelos de capacidade de processo quanto outros modelos que podem ser usados como referências para a melhoria de processo são apresentados, a seguir.

\subsubsection{Framework ISO/IEC 15504 e Modelo 15504-5}

A ISO/IEC 15504 (INTERNATIONAL ORGANIZATION FOR STANDARDIZATION, 2003) é um framework de avaliação de processo genérico para qualquer área de tecnologia, inclusive a engenharia de software, com dois contextos de uso: Melhoria do Processo e Determinação da Capacidade de Processo. No primeiro contexto, o resultado identifica a capacidade do processo que é utilizada para identificar mudanças de melhoria. Já no segundo contexto, a capacidade identificada é utilizada para descobrir riscos que o processo avaliado incorre e, também, pode ser utilizado como motivação para a melhoria do processo.

A norma ISO/IEC 15504 está descrita em cinco partes: a parte 1 refere-se aos conceitos, a parte 2 descreve o framework de avaliação, a parte 3 descreve orientações para uso do framework descrito na parte 2 e a parte 4 descreve orientações para utilização de modelos para melhoria ou determinação da capacidade. A parte 5 - 15504-5 (Information Technology - An exemplar Process Assessment Model) - refere-se a um modelo de avaliação exemplo que apóia a realização de uma avaliação por meio de indicadores que orientam na interpretação dos objetivos e resultados definidos nas emendas Amd 1 e Amd 2 da ISO/IEC 12207 e dos atributos de processo definidos na 15504-2. Esse modelo aborda a área de engenharia de software, embora a ISO/IEC 15504 possa ser utilizada em qualquer área tecnológica.

A arquitetura definida pela ISO/IEC 15504 é contínua, com duas dimensões: uma que define os processos (dimensão de processo) e outra que define os níveis de 
capacidade que cada um dos processos pode ter ao serem estabelecidos na organização (dimensão de capacidade).

A dimensão de processo usa as definições de processos das emendas Amd1 e $\begin{array}{lllllll}\text { Amd2 da } & \text { ISO/IEC } 12207 \text { (INTERNATIONAL ORGANIZATION FOR }\end{array}$ STANDARDIZATION, 2001) para identificar um Modelo de Referência de Processo. Os processos do Modelo de Referência são classificados em três categorias: fundamentais do ciclo de vida, de apoio ao ciclo de vida e organizacionais. Os processos fundamentais são essenciais durante o ciclo de vida do software e estão agrupados em: processos de aquisição, de fornecimento, de desenvolvimento e de operação. Os processos organizacionais são utilizados para estabelecer e implementar uma estrutura subjacente na organização, e também, para melhorar continuamente a estrutura e os processos. Esses processos estão agrupados em: processos de gerenciamento, de melhoria de processo, de infraestrutura e recursos, e de reuso. Já os processos de apoio ao ciclo de vida consistem de processos que dão suporte a outros processos como uma parte integrante, com um propósito distinto, e contribui para o sucesso e qualidade do projeto de software.

Cada processo no Modelo de Avaliação é descrito em termos da declaração de um propósito. A lista de resultados é associada a cada declaração do propósito do processo, como uma lista de resultados positivos esperados da realização, ou melhor, do desempenho do processo. A satisfação do propósito de um processo representa o primeiro passo em direção ao nível 1 de capacidade de processo onde os resultados esperados são observáveis.

O Modelo de Avaliação de Processo expande as definições de processo do Modelo de Referência de Processo incluindo um conjunto de indicadores de desempenho de processo: práticas base e produtos de trabalho. Uma prática base é uma atividade direcionada ao propósito de um processo que identifica "o quê" deve ser feito, sem especificar o "como". Para cada processo, de acordo com a dimensão processo, há um conjunto de práticas base definidas ao qual, uma vez realizado, 
proporciona o alcance dos resultados que refletem o propósito do processo; cada prática base é explicitamente associada a um resultado do processo. A realização de um processo produz produtos de trabalho que são identificáveis e utilizados para alcançar o propósito do processo; cada produto de trabalho de entrada e saída é relacionado a um ou mais resultados. As práticas base e produtos de trabalho são usados para medir o grau de alcance do atributo desempenho do processo avaliado, ou seja, dão suporte à avaliação de um processo em relação ao nível 1 de capacidade. Cada produto de trabalho tem um conjunto de características do produto que o identifica e pode ser usado como referência na revisão do produto de trabalho a fim de avaliar a realização/desempenho efetivo de um processo.

A dimensão de capacidade do Modelo de Avaliação de Processo utiliza as definições de níveis de capacidade e atributos de processo da 15504-2 e expande cada um dos nove atributos por meio da inclusão de um conjunto de indicadores de capacidade de processo (práticas genéricas, recursos genéricos e produtos de trabalho genéricos). Atributos de processo (PA - process attributes) são características de um processo que podem ser avaliadas de acordo com uma escala de desempenho, fornecendo uma medida da capacidade do processo. Cada atributo mede um aspecto particular da capacidade do processo necessário para apoiar a melhoria do processo e a determinação da capacidade. Um nível de capacidade é um conjunto de atributos de processo que trabalham juntos para fornecer uma alavancagem na capacidade de desempenho de um processo. Esses níveis constituem um caminho racional de progresso por meio da melhoria da capacidade de algum processo.

As práticas genéricas (GP) são atividades genéricas que fornecem um guia para a implementação dos atributos de processo; muitas delas são práticas gerenciais. Os recursos genéricos (GR) são pessoas, ferramentas, métodos e infraestrutura que podem ser usados na realização dos atributos de processo. E, os produtos de trabalho genéricos (GWP) são conjuntos de características evidenciadas nos produtos de 
trabalho como resultado da realização de um atributo. Os GWP são identificados de 01-00 à 21-00; para cada um deles há produtos de trabalho específicos (SWP) identificados pelos dois primeiros dígitos do identificador do GWP seguido de dois dígitos seqüenciais. Exemplo: 05-00 é o identificador do GWP "objetivos do negócio" e 05-01, 05-02, 05-03 são exemplos de identificadores de SWP desse GWP.

Há seis níveis de capacidade, incorporando nove atributos de processo. E, para cada um desses atributos existem práticas genéricas (GP), recursos genéricos e produtos de trabalho genéricos. Os níveis de capacidade são:

- Nível 0: Processo incompleto: o processo não é implementado, ou falha na tentativa de alcançar os propósitos do processo. Neste nível, há poucas ou nenhuma evidência de alguma realização sistemática do propósito do processo.

- Nível 1: Processo executado: o processo implementado atinge ao propósito do processo.

- Nível 2: Processo gerenciado: o processo realizado (nível 1) é agora implementado em um estilo gerenciado (planejado, monitorado e ajustado) e os produtos de trabalho são apropriadamente estabelecidos, controlados e mantidos.

- Nível 3: Processo estabelecido: o processo gerenciado (nível 2) é agora implementado usando um processo definido que é capaz de alcançar os resultados do processo.

- Nível 4: Processo previsível: o processo estabelecido (nível 3) opera dentro de limites definidos para alcançar os resultados do processo.

- Nível 5: Processo em otimização: o processo previsível (nível 4) é melhorado continuamente para atingir objetivos de negócio projetados e relevantes. 


\subsubsection{Framework SEI CMMI e Modelo CMMI-DEV}

O propósito do framework CMMI (Capability Maturity Model Integration) é fornecer orientação para melhorar o processo da organização e gerenciar o desenvolvimento, aquisição e manutenção de produtos e serviços (SOFTWARE ENGINEERING INSTITUTE, 2006).

A arquitetura do modelo CMMI foi melhorada para apoiar várias constelações e o compartilhamento das melhores práticas entre as constelações e os seus modelos.

Uma constelação CMMl é um conjunto de componentes que inclui um modelo, o seu material didático, e métodos de avaliação para apoiar uma área de interesse. Atualmente, existem três constelações: desenvolvimento (CMMI-DEV), serviços (CMMI-SVC) e aquisição (CMMI-ACQ). Os modelos do CMMI que já estavam disponíveis na comunidade antes de 2006 foram considerados parte da constelação do CMMI para o Desenvolvimento (CMMI-DEV).

CMMI-DEV é um modelo de referência que consiste de melhores práticas que abordam atividades de desenvolvimento e manutenção aplicadas a produtos e serviços. Ele contém práticas que cobrem gestão de projetos, gestão de processos, engenharia de sistemas, engenharia de hardware e outros processos de apoio usados no desenvolvimento e manutenção, substituindo os modelos CMMI-SE/SW da versão anterior.

A constelação CMMI-DEV consiste em dois modelos: CMMI for Development e CMMI for Development +IPPD (contém objetivos e práticas adicionais que cobrem o uso de equipes integradas nas atividades de desenvolvimento e manutenção).

Os componentes do modelo são agrupados em três categorias: requeridos, esperados e informativos (Figura 3.1). 
Os componentes requeridos descrevem o quê uma organização deve alcançar para satisfazer à área de processo ${ }^{17}$ (PA - process area). Os componentes esperados descrevem o quê uma organização pode implementar para alcançar um componente requerido. Os componentes informativos fornecem detalhes que auxiliam as organizações a pensarem em como abordar os componentes requeridos e esperados. As sub-práticas e os produtos de trabalho são exemplos de componentes informativos.

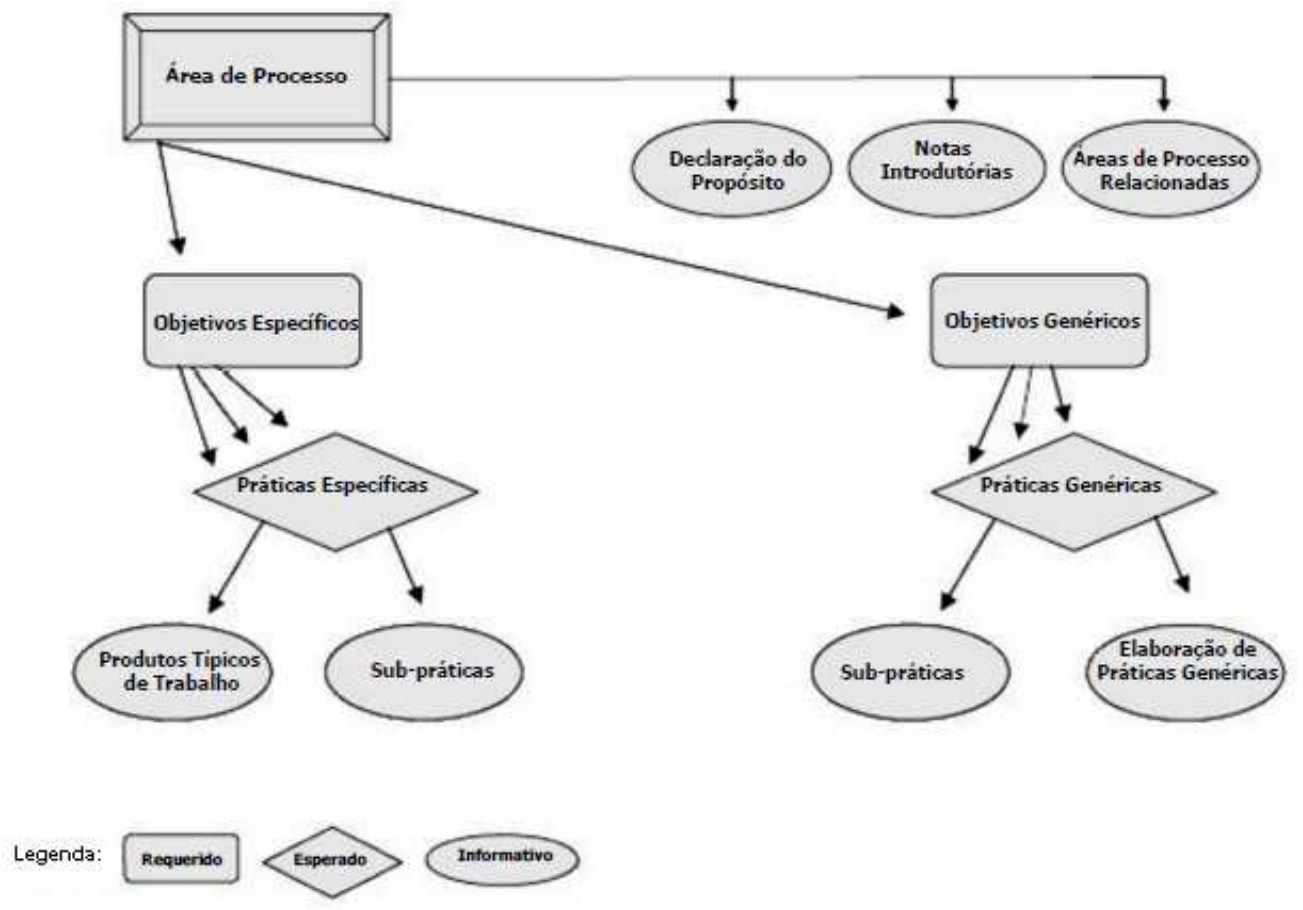

FIGURA 3.1 - COMPONENTES DOS MODELOS DO CMMI FonTE: TRADUZIDO dE (SOFTWARE ENGINEERING INSTITUTE, 2006)

A arquitetura dos modelos do CMMI é composta basicamente por áreas de processo, organizadas em duas representações: contínua e por estágios.

A arquitetura por estágios utiliza-se dos níveis de maturidade para representar a melhoria em um conjunto de áreas de processo e, por conseqüência, na organização. Já a arquitetura contínua utiliza-se dos níveis de capacidade para representar a melhoria em áreas de processo selecionadas. Por isso, os níveis de

\footnotetext{
${ }^{17}$ Uma área de processo é um grupo de práticas relacionadas em uma área que, quando implementadas coletivamente, satisfazem um conjunto de objetivos considerados importantes para realizar a melhoria nessa área.
} 
maturidade de 2 a 5 usam os mesmos termos que os níveis de capacidade de 2 a 5. Isso é intencional devido os conceitos de níveis de maturidade e capacidade serem complementares. Os níves de maturidade, de 1 a 5, são:

1. Inicial: no nível de maturidade 1, os processos são usualmente ad hoc e caóticos. A organização usualmente não fornece um ambiente estável para apoiar os processos. O sucesso nessas organizações depende da competência de pessoas da organização e não do uso de processos comprovados. Apesar desse caos, as organizações desse nível de maturidade freqüentemente produzem produtos e serviços que funcionam; de qualquer modo, elas freqüentemente excedem seus orçamentos e não atendem aos seus cronogramas. Além disso, são caracterizadas por abandonar seus processos em tempo de crise e pela não habilidade de repetir seus sucessos.

2. Gerenciado: no nível de maturidade 2, os projetos da organização tem assegurado que os processos são planejados e executados de acordo com uma política; os projetos empregam pessoas habilitadas que tem recursos adequados para produzir os resultados controlados; envolvem stakeholders relevantes; são monitorados, controlados e revisados; e são avaliados pela aderência às descrições de seus processos. Os estados dos produtos de trabalho e da entrega de serviços são visíveis para o gerenciamento nos pontos definidos (ex, em milestones). Os compromissos são estabelecidos entre os stakeholders relevantes e são revisados quando necessário.

Os produtos de trabalho são apropriadamente controlados e tanto os produtos de trabalho quanto os serviços satisfazem suas descrições de processo, padrões e procedimentos.

3. Definido: no nível de maturidade 3, os processos são bem caracterizados e compreendidos, e são descritos em padrões, procedimentos, ferramentas e métodos. O conjunto de processos padrão da organização, os quais são base para a maturidade no nível 3, é estabelecido e melhorado com o passar do 
tempo. Esses processos padrão são usados para estabelecer consistência através da organização. Os projetos estabelecem seus processos definidos a partir desse conjunto de processos padrão. Nesse nível, o objetivo genérico 3 e suas práticas genéricas (não endereçadas no nível de maturidade 2) são aplicados nas PAs do nível de maturidade 2 e 3, para alcançar o nível de maturidade 3.

4. Gerenciado Quantitativamente: no nível de maturidade 4, a organização e os projetos estabelecem os objetivos quantitativos para a qualidade e desempenho dos processos e usa-os como critérios para o gerenciamento dos processos. Os objetivos quantitativos são baseados nas necessidades do cliente, usuários finais, organização e implementadores de processo. A qualidade e o desempenho do processo são entendidos em termos estatísticos e é gerenciado ao longo da vida do processo.

Para sub-processos selecionados, as medidas detalhadas do desempenho do processo são coletadas e analisadas estatisticamente. Essas medidas são incorporadas em um repositório de medidas da organização para apoiar na tomada de decisão.

As causas especiais de variação de processo são identificadas e, quando apropriadas, as origens das causas especiais são corrigidas para a prevenção de ocorrências futuras. A diferença entre os níveis de maturidade 3 e 4 é a previsibilidade do desempenho do processo; no nível de maturidade 4, o desempenho dos processos é controlado usando técnicas estatísticas e outras técnicas quantitativas, e é previsível quantitativamente. No nível de maturidade 3 , os processos são tipicamente previsíveis somente qualitativamente.

5. Em otimização: no nível de maturidade 5, uma organização melhora continuamente seus processos com base no entendimento quantitativo das causas comuns de variação inerentes no processo. Esse nível de maturidade 
foca na melhoria contínua do desempenho de processo por meio de melhorias tecnológicas e de processo incrementais e inovadoras. Os objetivos de melhoria de processo quantitativo para uma organização são estabelecidos, continuamente revisados para refletir as mudanças dos objetivos do negócio, e usados como critérios para o gerenciamento da melhoria do processo. Os efeitos das melhorias de processo implantadas são medidos e avaliados em relação aos objetivos de melhoria quantitativa de processo. Tanto os processos definidos quanto o conjunto de processos padrão da organização são alvos de atividades de melhoria mensuráveis.

A diferença entre os níveis de maturidade 4 e 5 é o tipo de variação de processo endereçada. No nível de maturidade 4, a organização está preocupada em endereçar causas especiais de variação de processo e fornecer previsibilidade estatística dos resultados. Embora os processos possam produzir resultados previsíveis, os resultados podem ser insuficientes para alcançar os objetivos estabelecidos. No nível de maturidade 5, a organização está preocupada em endereçar causas comuns de variação do processo e mudar o processo a fim de melhorar o desempenho do processo e alcançar os objetivos quantitativos de melhoria do processo.

Os níveis de capacidade de 2 a 5 usam os mesmos termos que os objetivos genéricos de 2 a 5 . Isso é intencional devido a cada um dos objetivos e práticas genéricas refletirem o significado dos níveis de capacidade em termos de objetivos e práticas que podem ser implementadas. Os seis níveis de capacidade, de 0 a 5, são:

O. Incompleto: um processo incompleto é um processo que ou não é realizado ou é parcialmente realizado. Um ou mais objetivos específicos (SG) das PAs não são satisfeitos, e nenhum objetivo genérico existe para este nível, uma vez que não há razão para institucionalizar um processo realizado parcialmente.

1. Realizado: um processo realizado é aquele que satisfaz os SGs das PAs. Ele apóia e possibilita que o trabalho necessário para produzir os produtos de 
trabalho seja realizado. Embora o nível de capacidade 1 resulte em importantes melhorias, elas podem ser perdidas com o tempo se elas não forem institucionalizadas. A aplicação da institucionalização (as práticas genéricas dos níveis de capacidade 2 a 5) auxiliam a assegurar que aquelas melhorias sejam mantidas.

2. Gerenciado: um processo gerenciado é um processo realizado (nível de capacidade 1) que tem uma infraestrutura básica para apoiar o processo. Ele é planejado e executado de acordo com uma política; emprega pessoas habilitadas que tem recursos adequados para produzir resultados controlados; envolve stakeholders relevantes; é monitorado, controlado e revisado; e é avaliado pela aderência à sua descrição. A disciplina de processos com nível de capacidade 2 auxilia a assegurar que práticas existentes sejam conservadas durante períodos de estresse.

3. Definido: um processo definido é um processo gerenciado (nível de capacidade 2) que é obtido a partir de um conjunto de processos padrão de acordo com as diretrizes da organização. A distinção entre os níveis de capacidade 2 e 3 é que o escopo de padrões, descrições de processos e procedimentos podem ser diferentes para cada instância específica do processo (para um projeto, por ex).

No nível de capacidade 2, os padrões, descrições de processo e procedimentos são diferentes para cada instância específica do processo (para um projeto particular, por ex.). Já no nível de capacidade 3, os padrões, descrições de processo e procedimentos para um projeto são adequados a partir de um conjunto de processos padrão e, portanto, são mais consistentes. Além disso, no nível de capacidade 3, os processos são tipicamente descritos de modo mais rigorosos do que no nível de capacidade 2.

Um processo definido define claramente o propósito, entradas, critérios de entrada, atividades, papéis, medidas, passos de verificação, saídas e critérios 
de saída. No nível de capacidade 3, os processos são gerenciados mais proativamente usando um entendimento dos inter-relacionamentos entre as atividades do processo e medidas detalhadas do processo, seus produtos de trabalho e serviços.

4. Gerenciado Quantitativamente: um processo gerenciado quantativamente é um processo definido (nível de capacidade 3) que é controlado usando técnicas estatísticas e outras quantitativas. Objetivos quantitativos para a qualidade e desempenho do processo são estabelecidos e usados como critérios para gerenciar o processo. A qualidade e o desempenho do processo é entendido em termos estatísticos e é gerenciado durante toda a vida do processo.

5. Em otimização: um processo em otimização é um processo gerenciado quantitativamente (nível de capacidade 4) que é melhorado com base no entendimento das causas comuns de variação no processo. O foco de um processo em otimização é melhorar continuamente o espectro do desempenho por meio de melhorias incrementais e inovadoras.

As regras para se alcançar determinado nível de maturidade são:

- Para alcançar o nível de maturidade 2, todas as PAs alinhadas ao nível de maturidade 2 devem atingir ao nível de capacidade 2 ou mais alto.

- Para alcançar o nível de maturidade 3, todas as PAs alinhadas aos níveis de maturidade 2 e 3 devem atingir ao nível de capacidade 3 ou mais alto.

- Para alcançar o nível de maturidade 4, todas as PAs alinhadas aos níveis de maturidade 2, 3 e 4 devem atingir ao nível de capacidade 3 ou mais alto.

- Para alcançar o nível de maturidade 5, todas as PAs devem atingir ao nível de capacidade 3 ou mais alto.

O nível de capacidade 4 para PAs não pode ser pré-determinado porque as escolhas dependem da seleção feita pela organização em implementar as PAs do nível de maturidade 4. O mesmo acontece para o nível de maturidade 5. 
Todos os objetivos e práticas genéricas são usados na representação contínua. Na representação por estágios, somente os objetivos genéricos 2 e 3 são usados. Quando se tenta alcançar o nível 2, usa-se as PAs no nível de maturidade 2 e o objetivo genérico 2 com suas respectivas práticas. Os objetivos genéricos 4 e 5 e suas práticas genéricas associadas não são usados porque nem todos os processos serão elevados ao nível acima de um "processo definido". Somente os processos selecionados e sub-processos serão gerenciados quantitativamente e otimizados, e quais processos e sub-processos são selecionados é endereçado pelas PAs no nível de maturidade 4 e 5.

Quando se alcança os níveis de maturidade 3, 4 e 5, usa-se PAs nos níves de maturidade apropriados e todas as PAs dos níveis de maturidade mais baixos. Em adição, o objetivo genérico 3 e suas práticas genéricas associadas (as quais incluem as práticas genéricas associadas com o objetivo genérico 2) são aplicadas para todas as PAs. Isso significa que se já foi alcançado o nível de maturidade 2, para alcançar o nível de maturidade 3 deve-se retornar para as PAs do nível de maturidade 2 e aplicar o objetivo genérico 3 e suas respectivas práticas.

Segundo Chrissis et al. (2003), três categorias de fatores podem influenciar a decisão sobre a escolha da arquitetura contínua ou por estágios: fatores de negócio, culturais e legados.

Curtis (1998) defende que os modelos contínuos são aqueles que desejam liberdade para escolher o foco da melhoria (atuando na melhoria de cada processo em separado) e que os modelos por estágios são aqueles que desejam a mudança da cultura da organização.

Já para Kasse ${ }^{18}$ (2004) apud (SALVIANO, 2006), a arquitetura por estágios auxilia a organização a priorizar seus esforços de melhoria, especialmente quando a organização é principiante na área de melhoria de processo ou está em um nível baixo de maturidade e tem pouca experiência em estabelecimento de processo. E, a

\footnotetext{
${ }^{18}$ KASSE, T. (2004). Practical Insight into CMMI. Artech House Publishers.
} 
arquitetura contínua do CMMI auxilia a organização a construir um perfil alvo de áreas de processo que auxiliará a organização a resolver objetivos estratégicos conhecidos. Olson $^{19}$ (2003) apud (SALVIANO, 2006) diz que a questão não é qual representação, por estágios ou contínua, deve ser usada. Primeiramente, devem ser identificadas as metas de qualidade, objetivos e estratégia da organização para depois definir uma estratégia de melhoria: melhoria da qualidade, controle da qualidade ou planejamento da qualidade. Por exemplo: (1) se uma organização tem o orçamento limitado, precisa economizar recursos e ter um retorno de investimento rápido, então deve escolher uma estratégia de melhoria da qualidade, o que sugere a arquitetura contínua com a escolha de uma área de processo para orientar a melhoria; (2) se uma organização deseja ser a melhor dentre o seu nicho de mercado em um prazo longo, e deseja chegar nesta posição de forma ordenada, pode selecionar a estratégia de planejamento da qualidade, o que sugere a arquitetura por estágios.

Embora existam muitas razões para usar a representação contínua, os índices fornecidos pelos perfis de capacidade de processo $^{20}$ são limitados em sua habilidade de fornecer às organizações um caminho para compará-la, de modo geral, com outras organizações. Os perfis de capacidade podem ser usados, nesse caso, se cada organização seleciona as mesmas PAs; de qualquer maneira, os níves de maturidade tem sido usados para comparar as organizações ao longo dos anos e já fornece um conjunto pré-definido de PAs. Por isso, foi criada uma equivalência entre perfis de níveis de capacidade e níveis de maturidade. Assim, uma organização que usa a representação contínua para uma avaliação, pode converter o perfil de capacidade de processo a um nível de maturidade associado (SOFTWARE ENGINEERING INSTITUTE, 2006).

19 OLSON, T. G. (2003). Staged or Continuous: Which Model Should I Choose?, Slides from presentation at Third Annual CMMI Technology Conference and Users Group, USA, November 2003.

${ }^{20} \mathrm{Um}$ perfil de capacidade é uma lista de PAs e os níveis de capacidade correspondentes para cada. $O$ perfil possibilita que uma organização rastreei seu nível de capacidade em relação às PAs. O perfil é denominado perfil realizado quando representa o progresso atual de cada PA. Alternativamente, o perfil é um perfil almejado quando representa objetivos planejados de melhoria dos processos da organização. 


\subsubsection{MPS.BR e Modelo MR-MPS}

A Associação para Promoção da Excelência do Software Brasileiro (SOFTEX) iniciou um programa mobilizador denominado MPS.BR (Melhoria de Processos do Software Brasileiro) com o intuito de melhorar continuamente a qualidade de software no Brasil a um custo acessível. Isso devido à dificuldade e alto custo de implantação e avaliação do CMMI (SOFTWARE ENGINEERING INSTITUTE, 2002) e a necessidade de expandir o mercado de software brasileiro (WEBER et al., 2005b).

O Modelo MPS.BR teve como bases de construção as normas ISO/IEC 12207 (INTERNATIONAL ORGANIZATION FOR STANDARDIZATION, 2001) e ISO/IEC 15504 (INTERNATIONAL ORGANIZATION FOR STANDARDIZATION, 2003) e as melhores práticas da engenharia de software, e mantém compatibilidade com o CMMI.

A sua originalidade não está no conteúdo, mas sim na estratégia de implementação, criada para a realidade brasileira (SOFTEX, 2006). Esse modelo possui três componentes:

- Modelo de Referência (MR-MPS): é definido por meio de níveis de maturidade, seqüenciais e acumulativos. Cada nível de maturidade é uma junção entre processos e capacidade dos processos, ou seja, é composto por um conjunto de processos em um determinado nível de capacidade. O progresso e o atendimento do nível de maturidade se obtém quando são atendidos todos os resultados e propósito do processo; e os atributos de processo relacionados aquele nível.

- Método de Avaliação (MA-MPS): descreve o modo como a avaliação deve ser efetuada, quais os requisitos dos avaliadores e os requisitos para atender ao MR-MPS. O MA-MPS foi definido em conformidade com os requisitos para modelos de referência de processo e métodos de avaliação de processos estabelecidos na norma ISO/IEC 15504-2 e atende aos requisitos específicos do Programa MPS.BR. Assim, o método está em conformidade com a ISO/IEC 15504 e é compatível com o método SCAMPI 
para avaliação, segundo o modelo CMMI, também definido com base na ISO/IEC 15504.

- Modelo de Negócio (MN-MPS): compreende (i) um Modelo de Negócio Cooperado (MNC-MPS) - próprio para grupos de pequenas e médias empresas que necessitam melhorar radicalmente seus processos de software; (ii) um Modelo de Negócio Específico (MNE-MPS) - próprio para empresas de qualquer porte e natureza que não querem compartilhar com outras empresas a melhoria de seus processos de software.

\subsubsection{ISO 9000}

A série ISO 9000 foi elaborada através de um consenso internacional sobre as práticas que uma empresa pode tomar a fim de atender plenamente os requisitos de qualidade do cliente. A ISO 9000 não fixa metas a serem atingidas pelas empresas a serem certificadas, a própria empresa é quem estabelece as metas a serem atingidas.

As normas da família ISO 9000-2000 foram desenvolvidas para apoiar organizações, de todos os tipos e tamanhos, na implementação e operação de sistemas de gestão da qualidade eficazes.

ISO 9000 inclui as seguintes normas: ISO 9000:2000, ISO 9001:2000 e ISO 9004:2000. A ISO 9000 descreve os fundamentos de sistemas de gestão da qualidade e estabelece a terminologia para estes sistemas. A ISO 9001 (INTERNATIONAL ORGANIZATION FOR STANDARDIZATION, 2000) especifica requisitos para um sistema de gestão da qualidade, onde uma organização precisa demonstrar sua capacidade para fornecer produtos que atendam os requisitos do cliente e os requisitos regulamentares aplicáveis, e objetiva aumentar a satisfação do cliente. A ISO 9004 fornece diretrizes que consideram tanto a eficácia como a eficiência do sistema de gestão da qualidade. O objetivo desta norma é melhorar o desempenho da organização e a satisfação dos clientes e das outras partes interessadas. 


\subsubsection{PMBOK}

O Corpo de Conhecimento da Gestão de Projeto (PMBOK - Project Management Body of Knowledge) foi desenvolvido pelo Project Management Institute (PMI) para ser um guia que disponibiliza conhecimento relacionado à gestão de projetos.

Contém um conjunto de práticas já sedimentadas em gestão de projetos, coletadas por profissionais envolvidos em projetos de todo o mundo. E, passa por evoluções de 4 em 4 anos, baseadas em contribuições de seus membros. É aplicável em qualquer área inclusive em projetos de software.

De acordo com o PMBOK (PROJECT MANAGEMENT INSTITUTE, 2004), a gestão de projetos ocorrerá em áreas de conhecimento, por meio da aplicação e integração de processos. As áreas de conhecimento totalizam nove: escopo do projeto, tempo, custo, qualidade, recursos humanos, comunicações, riscos, aquisições e integração do projeto.

As fases da gestão de projeto que cobrem as áreas de conhecimento com maior ou menor ênfase são: Iniciação, onde é definido e autorizado o projeto ou fase do projeto; Planejamento, onde são definidos e refinados os objetivos, planejada a ação necessária para alcançar os objetivos e o escopo do projeto; Execução, onde há a integração das pessoas e outros recursos para a realização do plano de gestão do projeto; Monitoramento e Controle do progresso do projeto para identificar variações em relação ao plano de gestão do projeto, de forma que possam ser tomadas ações corretivas quando necessário para atender aos objetivos do projeto; Encerramento, onde é formalizado a aceitação do produto, serviço ou resultado, conduzindo ao final do projeto ou de fase do projeto. 


\subsubsection{SWEBOK}

O Corpo de Conhecimento de Engenharia de Software (SWEBOK - Software Engineering Body of Knowledge) é coordenado por um projeto da IEEE Computer Society e ACM (Association for Computing Machinery) em busca dos seguintes objetivos: promover uma visão consistente mundialmente da engenharia de software, caracterizar o conteúdo da engenharia de software, esclarecer o escopo e limites da engenharia de software em relação a outras disciplinas (como engenharia da computação, ciência da computação, matemática, gestão de projetos, gestão da qualidade, ergonomia de software e engenharia de sistemas) e prover uma fundação para o desenvolvimento de currículos e material para certificações individuais (ABRAN et al., 2004).

O primeiro dos objetivos anteriormente citados - promover uma visão consistente mundialmente da engenharia de software - foi suportado por um processo de desenvolvimento no qual estavam engajados, aproximadamente, 500 revisores de 42 países na elaboração da versão experimental (1998-2001) e, depois, mais 120 revisores de 21 países no ano de 2003 na elaboração da versão 2004.

\subsection{Considerações Finais}

Há na literatura vários modelos de melhoria de processo, como os apresentados neste capítulo, que podem ser utilizados como referência para compor o contexto de utilização de um modelo de processo de software.

Os frameworks para modelos de capacidade de processo $^{21}$ e métodos de avaliação de processo - CMMI e ISO/IEC 15504 - são os mais relevantes no setor de software (SALVIANO, 2006). O MPS.BR é compatível com o CMMI.

\footnotetext{
${ }^{21}$ Alguns modelos utilizam níveis de "maturidade", tais como: SW-CMM, CMMI-SE/SW e CMMI-DEV. Essa maturidade é definida em função da capacidade de processo, por isso, o termo "capacidade" é suficiente para caracterizar esses modelos, também.
} 


\section{METODOLOGIA DE PESQUISA}

\subsection{Considerações Iniciais}

A pesquisa é uma atividade voltada para a solução de problemas teóricos ou práticos com o emprego de processos científicos, ou seja, ela parte de uma dúvida ou problema, e com o uso do método científico, busca uma resposta ou solução (CERVO \& BERVIAN, 2002).

Método científico é o conjunto de processos ou operações mentais que se devem empregar na investigação. É a linha de raciocínio adotada no processo de pesquisa.

Para o estabelecimento do método científico é necessário definir o referencial teórico, isto é, a categoria de métodos de pesquisa mais amplos - aqueles diretamente relacionados com as correntes que estudam métodos de pesquisa dentro da área de epistemologia (PÁDUA, 1996). Os referenciais teóricos existentes são: dedutivo, indutivo, dialético, fenomenológico e hipotético-dedutivo (GIL,1999; MARCONI \& LAKATOS, 2000).

Na literatura, há diversas classificações de tipos de pesquisas, sendo que os critérios para essas classificações variam de acordo com o enfoque dado (BRYMAN, 1989; DANE, 1990; PÁDUA, 1996; GIL, 1999; CERVO \& BERVIAN, 2002; MARKONI \& LAKATOS, 2000). Há classificações do ponto de vista da natureza da pesquisa, dos objetivos de pesquisa e dos procedimentos técnicos da pesquisa.

Neste capítulo será apresentado o referencial teórico que embasou a pesquisa realizada neste trabalho e as classificações da pesquisa, de acordo com os vários critérios existentes. 


\subsection{Abordagens e métodos de pesquisa}

O referencial teórico adotado neste trabalho é o hipotético-dedutivo, que se inicia pela percepção de uma lacuna nos conhecimentos, acerca da qual se formula hipóteses e, pelo processo de inferência dedutiva, testa-se a predição da ocorrência de fenômenos abrangidos pela hipótese. Desse modo, a busca da solução do problema é feita quando teorias ou leis falham na solução de um problema (refutação) e, então, é proposta uma nova teoria ou lei (conjectura) que resolva o problema e incorpore a teoria ou lei anterior. Assim, cada vez que a teoria resistir a um teste para refutação será considerada mais robusta $\left(\mathrm{POPPER}^{22}, 1975\right.$ apud MARCONI \& LAKATOS, 2000).

Tal referencial teórico é adequado a este trabalho de pesquisa, uma vez que a análise do Modelo elaborado foi realizada por meio da tentativa de refutação de uma hipótese, durante a implantação das atividades do modelo em ambientes reais de MPEs e durante as análises críticas de profissionais da área.

O presente trabalho considerou a seguinte hipótese: "É possível criar um modelo que considere tanto um modelo de processo de software quanto modelos de capacidade de processo em um contexto de melhoria de processo, a fim de orientar a definição por parte de uma MPE de seu processo padrão de venda e desenvolvimento de software on-demand, de maneira mais detalhada do que a sugerida pelos modelos de capacidade de processo".

Do ponto de vista da natureza da pesquisa, ela pode ser classificada em pesquisa pura ou básica e pesquisa aplicada (CERVO \& BERVIAN, 2002). Nesse aspecto, este trabalho de pesquisa é classificado como uma pesquisa aplicada, uma vez que objetiva gerar conhecimentos para aplicação prática dirigida à solução de um problema específico: auxiliar as MPEs na definição e melhoria de seu processo de

\footnotetext{
${ }^{22}$ POPPER, K. S. (1975). A lógica da pesquisa científica. $2^{\underline{a}}$ ed. São Paulo: Cultrix.
} 
venda e desenvolvimento de software, em conformidade com os modelos de capacidade de processo CMMI e ISO/IEC 15504.

Do ponto de vista da forma de abordagem do problema, a classificação de pesquisa pode ser: quantitativa e qualitativa (BRYMAN, 1989). Considerando que este trabalho de pesquisa não buscou provar estatisticamente os benefícios e adequação da integração do modelo de processo de software aos modelos de capacidade de processo, pode ser caracterizado do ponto de vista da forma de abordagem do problema como uma abordagem qualitativa.

Do ponto de vista dos objetivos de pesquisa, ela pode ser classificada, segundo GIL (1999), como exploratória, descritiva e explicativa. Para Dane (1990), além dessas há a pesquisa preditiva e a pesquisa ação.

De acordo com o objetivo da pesquisa esse trabalho pode ser classificado como pesquisa-ação. Segundo Thiollent (2002), na pesquisa-ação os pesquisadores desempenham um papel ativo no equacionamento dos problemas encontrados, no acompanhamento e na avaliação das ações desencadeadas em função dos problemas. Sendo assim, neste tipo de pesquisa, além da exigência do envolvimento ativo do pesquisador e ação por parte das pessoas ou dos grupos envolvidos no problema, é necessário produzir conhecimentos, adquirir experiência, contribuir para a discussão da área estudada ou fazer avançar o debate acerca das questões abordadas.

Neste trabalho de pesquisa, o pesquisador agiu na busca de uma solução para orientar mais detalhadamente às MPEs durante a definição e melhoria de seu processo de venda e desenvolvimento de software on-demand. Isso foi realizado aplicando o modelo elaborado neste trabalho de pesquisa em duas MPEs, aprendendo com os resultados, obtendo críticas e sugestões de profissionais da área.

Do ponto de vista dos procedimentos técnicos, as principais classificações são (PÁDUA, 1996; CERVO \& BERVIAN, 1983): pesquisa bibliográfica, pesquisa documental, pesquisa experimental, levantamento, pesquisa de campo e estudo de 
caso. Nesse trabalho de pesquisa foram utilizadas: a pesquisa bibliográfica para 0 levantamento dos assuntos abordados no trabalho de pesquisas.

Dentre o conjunto de técnicas de coleta de dados existente na literatura (MARCONI \& LAKATOS, 1999), nesse trabalho de pesquisa foram utilizados: 1) um questionário (Apêndice 1) aplicado a 5 (cinco) MPE's que desenvolvem software e 9 (nove) CPDs (Centro de Processamento de Dados) de empresas diversas os quais desenvolvem software para uso interno, que confirmou a seleção das áreas de conhecimento definidas no Modelo ProcSoftVD e indicou a importância de outras áreas de conhecimento que serão consideradas em um trabalho futuro; 2) um questionário (Apêndice 7) entregue a profissionais que trabalham em MPEs ou já trabalharam em empresas e também profissionais com mestrado e doutorado na área, para levantarem os pontos fortes e fracos do modelo e para estabelecerem o nível de atendimento do modelo em relação às características de qualidade: funcionalidade, usabilidade, manutenibilidade, portabilidade e eficiência; 3) entrevistas com esses profissionais a fim de obter sugestões para melhorar o modelo.

\subsection{Etapas do trabalho}

Primeiramente, foi realizada a revisão bibliográfica para fundamentar a proposta elaborada nesse trabalho de pesquisa. Os assuntos pesquisados foram: modelos de processo de software, modelos de capacidade de processo e modelos/métodos/abordagens de melhoria de processo.

As outras atividades realizadas neste trabalho de pesquisa foram agrupadas em três etapas (Figura 4.1): 


\section{Revis ão B ibliog ráfica}

\section{E tapa 1 - 1a versão do Modelo ProcS oftVD}

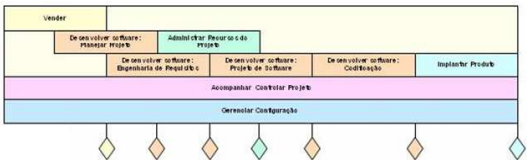

1.1 Mapeamento do C MMI e IS O/IE C 15504-5

1.2 P roposição da 1a versão do Modelo ProcS oftVD

1.3 Implantação do Modelo P rocS oftVD

\section{E tapa 2 - 2a versão do Modelo ProcS oftVD}

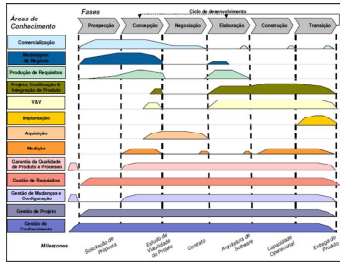

2.1 Análise dos pontos fracos da 1ạ versão do modelo

2.2 A tualização do mapeamento do CMMI e IS O/LE C 15504-5

2.3 P roposição da 2a versão do Modelo ProcS oftVD

\section{E tapa 3 - Modelo de Gestão de Processo (ProcSoftVD - Gestão)}

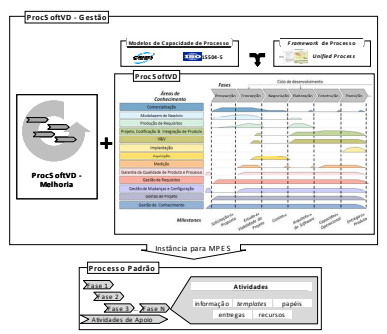

3.1 Avaliação de abordagens/metodologias/modelos relacionados à melhoria de processo

3.2 Proposição do Método de Melhoria de Processo de $S$ oftware (P rocS oftVD - Melhoria)

3.3 P roposição do P rocS oftVD - G estão

3.4 Implantação do ProcS oftVD - G estão

3.5 Avaliação do P rocS oftVD - G estão

Figura 4.1 - Etapas do Trabalho de Pesquisa

- Etapa 1: a principal entrega dessa etapa foi uma primeira versão do modelo ProcSoftVD (seção 5.2). Para isso, foram realizadas as seguintes atividades:

1.1 Mapeamento do CMMI e ISO/IEC 15504-5: foi mapeada a equivalência dos objetivos específicos do nível de maturidade 2 do CMMI em relação às práticas-base da parte 5 do relatório técnico da ISO/IEC 15504 para, posteriormente, associar cada uma das atividades do modelo de processo proposto (item 1.2) a esses objetivos específicos e práticasbase. Essa associação das atividades do modelo ProcSoftVD com o 
CMMI e ISO/IEC 15504-5 serve para mostrar ao usuário do modelo, caso seja necessário, que as atividades do modelo ProcSoftVD atendem às melhores práticas sugeridas pelo CMMI e ISO/IEC 15504-5; que o modelo ProcSoftVD está em consonância com modelos/normas internacionais de qualidade de processo.

1.2 Proposição da $1^{\underline{a}}$ versão do Modelo ProcSoftVD: essa versão do modelo foi elaborada com base na estrutura do modelo de processo cascata; uma estrutura seqüencial e linear que dificilmente retrata a maioria dos projetos de desenvolvimento de software on-demand. Foram definidas as atividades de cada uma das fases, suas tarefas, artefatos de entrada e saída, papéis dos responsáveis pela execução das atividades, recursos a serem utilizados e templates (formulários com uma estrutura definida para cada documento a ser criado pelas atividades do modelo). Foram elaborados: um pôster contendo a visão gráfica de todas as atividades de cada uma das fases do modelo (Figura 5.2); um pôster contendo a visão gráfica dos documentos a serem utilizados/criados nas/pelas atividades do modelo (Figuras $5.5 \mathrm{e}$ 5.6); um manual contendo o detalhamento de cada uma das atividades das fases do modelo (Figura 5.7) e um manual contendo a estrutura de cada um dos documentos a serem utilizados/criados nas/pelas atividades do modelo (Figura 5.8).

1.3 Implantação do Modelo ProcSoftVD: o modelo definido anteriormente foi instanciado para a Empresa 1 (Figura 5.3) e, a partir dessa instância, por meio da pesquisa-ação foram implantadas duas fases - fases Vender e Planejar Projeto. 
- Etapa 2: a principal entrega dessa etapa foi uma segunda versão do modelo ProcSoftVD (seção 5.2). Para isso, foram realizadas as seguintes atividades:

2.1 Análises dos pontos fracos da $1^{\underline{a}}$ versão do modelo: durante a pesquisaação realizada na Empresa 1, os funcionários da empresa junto ao pesquisador deste trabalho detectaram que a estrutura do modelo (seqüencial e linear) não era adequada para o projeto piloto o qual foi utilizado durante a implantação das fases Vender e Planejar Projeto. Percebeu-se, assim, a necessidade de alteração na estrutura do modelo ProcSoftVD para atender a maioria dos projetos de desenvolvimento de software on-demand. Também foram detectados alguns pontos fracos em algumas atividades do modelo que deveriam ser melhorados em uma próxima versão do modelo.

2.2 Atualização do mapeamento do CMMI e ISO/IEC 15504-5: foi publicada uma versão mais atual do CMMI - CMMI-DEV v1.2 e foi obtida a norma ISO/IEC 15504. Por isso, foi realizada a atualização do mapeamento.

2.3 Proposição da $2^{a}$ versão do Modelo ProcSoftVD: uma vez identificada a deficiência da estrutura do modelo (item 2.1), a estrutura do modelo foi modificada para aceitar projetos de desenvolvimento de software mais condizentes à realidade: feitos de forma incremental e evolutiva. Foram também definidos, em meio à pesquisa-ação, os requisitos (seção 5.2.1) a serem atendidos pelo modelo ProcSoftVD; foram re-elaborados os elementos do modelo: atividades, tarefas, artefatos de entrada e saída, papéis, recursos e templates para cada atividade do modelo ProcSoftVD e para facilitar o entendimento da associação dos elementos do modelo ProcSoftVD foi elaborado um meta-modelo (seção 5.2.2). 
- Etapa 3: a principal entrega dessa etapa foi o Modelo de Gestão do Processo de Venda e Desenvolvimento de Software On-demand para MPEs (ProcSoftVD - Gestão) - a integração do modelo ProcSoftVD com um método de melhoria de processo (capítulo 5). Para isso, foram realizadas as seguintes atividades:

3.1 Avaliação de abordagens, metodologias e modelos relacionados à melhoria de processo: para a implantação de algumas fases da $1^{\text {a }}$ versão do modelo ProcSoftVD na Empresa 1, foi utilizada a Metodologia de Gestão de Mudanças elaborada por Costa (2006). Questionou-se sobre a existência na literatura de outras metodologias/abordagens/métodos voltadas especificamente para melhoria de processo de software para MPEs. Foi realizado, então, um levantamento bibliográfico sobre abordagens de melhoria de processo existentes na literatura e, posteriormente, foi realizada uma seleção, entre as abordagens de melhoria de processo levantadas, das mais adequadas para serem utilizadas pelas MPE's de software.

3.2 Proposição do Método de Melhoria de Processo de Software (ProcSoftVD - Melhoria) (seção 5.3): a partir da avaliação das abordagens, metodologias e modelos relacionados à melhoria de processo (item 3.1) foi identificada a complementaridade entre algumas delas e, com base nessa complementaridade foi elaborado um método de melhoria de processo (ProcSoftVD - Melhoria).

3.3 Proposição do ProcSoftVD - Gestão (capítulo 5): considerando o contexto de gestão de processos de negócio, mais especificamente o de melhoria, foi elaborado o ProcSoftVD - Gestão (Figura 5.1), um Modelo de Gestão do Processo de Venda e Desenvolvimento de Software On-demand que tem o objetivo de orientar de maneira 
detalhada às MPEs a definirem o seu processo padrão de venda e desenvolvimento de software on-demand.

3.4 Implantação do ProcSoftVD - Gestão (seção 6.2): foi aplicado o Método de Melhoria de Processo (ProcSoftVD - Melhoria), elaborado anteriormente, em uma MPE (Empresa 2) (Apêndice 6). Nessa aplicação foram definidos ciclos de melhoria compostos por áreas de conhecimento a serem implantadas, de acordo com a prioridade da empresa. Assim, foi realizada a implantação das áreas de conhecimento "Modelagem de Negócios" e "Produção de Requisitos" do Modelo de Processo de Venda e Desenvolvimento de Software Ondemand para MPEs (ProcSoftVD).

3.5 Avaliação do ProcSoftVD - Gestão (seção 6.3): foram realizados questionários (Apêndice 7) e entrevistas com 6 (seis) profissionais da área de computação, sendo que 5 (cinco) deles tem experiência como analista de sistemas/programador e 4 (quatro) deles tem mestrado/doutorado na área de computação e atuantes como docente em universidades.

\subsection{Considerações Finais}

Neste capítulo foram apresentados o referencial teórico que embasou a pesquisa realizada neste trabalho, as classificações da pesquisa, de acordo com os vários critérios existentes e as etapas do trabalho de pesquisa.

No próximo capítulo será apresentado a principal entrega resultante deste trabalho de pesquisa - o Modelo ProcSoftVD - Gestão. 


\section{Modelo de Gestão do Processo de Venda e Desenvolvimento de Software On-demand para MPEs (ProcSoftVD - Gestão)}

\subsection{Considerações Iniciais}

Neste capítulo é apresentado o ProcSoftVD - Gestão (Figura 5.1) - um modelo de Gestão do Processo de Venda e Desenvolvimento de software on-demand para MPEs, elaborado a partir da integração do Modelo do Processo de Venda e Desenvolvimento de software on-demand para MPEs (ProcSoftVD) (seção 5.2) com o Método de Melhoria do Processo de Software (ProcSoftVD - Melhoria) (seção 5.3).

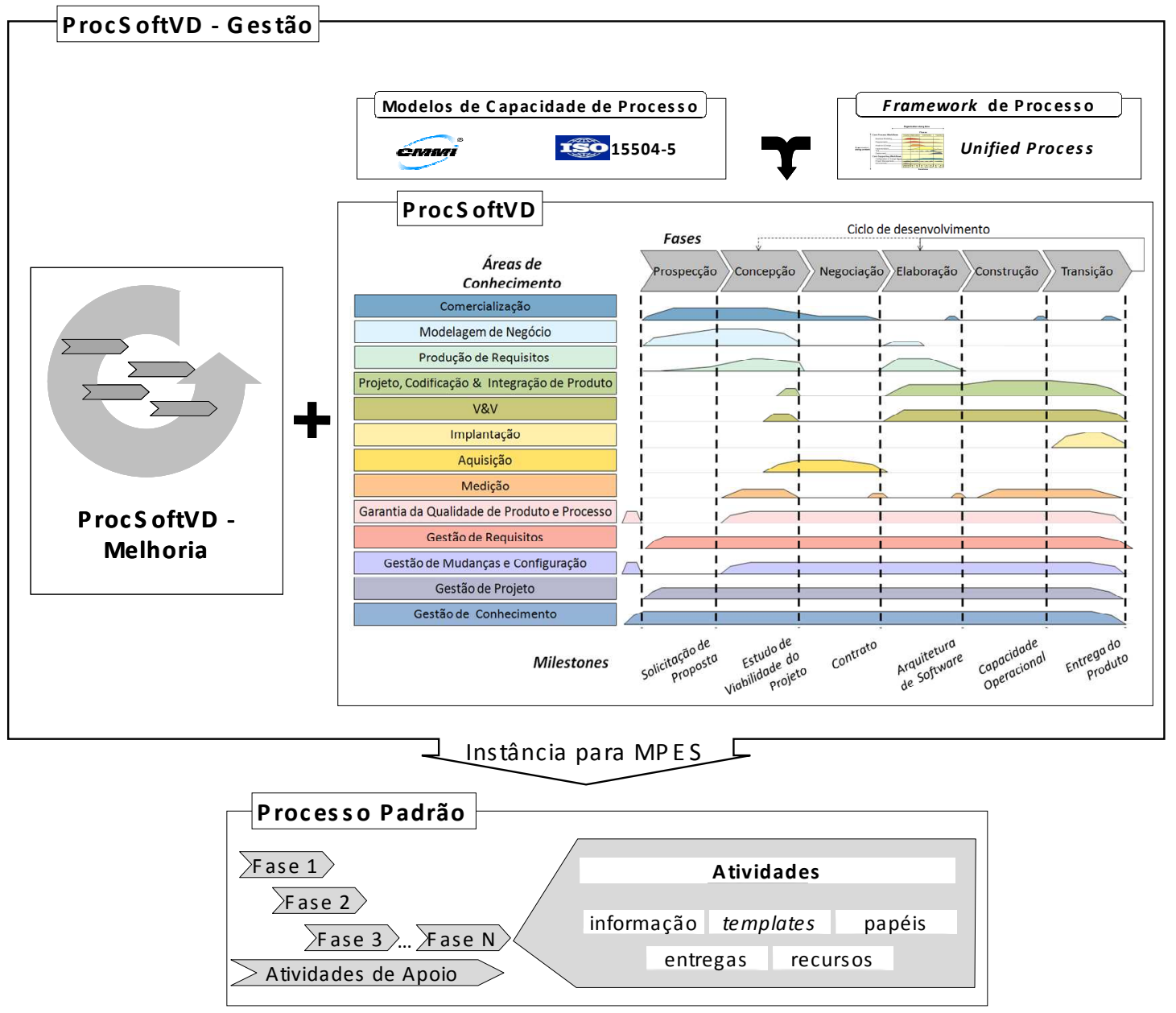

Figura 5.1 - Modelo de Gestão do Processo de Venda e Desenvolvimento de Software On-demand PARA MPES (PROCSOFTVD - GESTÃO) 
Além disso, na seção 5.4, é apresentada a publicação web do modelo ProcSoftVD - Gestão que pode ser acessada por qualquer interessado.

\subsection{Evolução do Modelo de Processo de Venda e Desenvolvimento de Software On-demand para MPEs (ProcSoftVD)}

Inicialmente, esse projeto de pesquisa tinha como objetivo principal melhorar o desempenho de empresas que pertenciam a um APL (arranjo produtivo local) (CASSIOLATO \& LASTRES, 2001); participavam do projeto duas empresas. Para isso, foram definidos alguns objetivos secundários, dentre eles o de modelar um Processo Genérico para Venda e Desenvolvimento de Software (PV\&DS) On-Demand Colaborativo. Um dos resultados parciais desse projeto foi uma versão inicial do Modelo Genérico do PV\&DS on-demand (Figura 5.2), elaborada a partir do mapeamento das práticas do nível de maturidade 2 do CMMI v1.1 com as práticas definidas no modelo ISO/IEC TR 15504-1998.

Entretanto, depois de um ano de andamento do projeto anteriormente referido, devido a mudanças estratégicas de uma das empresas do APL, apenas a Empresa 1 continuou no projeto. Trata-se de uma pequena empresa de base tecnológica, fundada em janeiro de 2000, cujo alvo é o desenvolvimento de software, mais especificamente o desenvolvimento de sistemas para Internet, e-learning e software sob encomenda. 

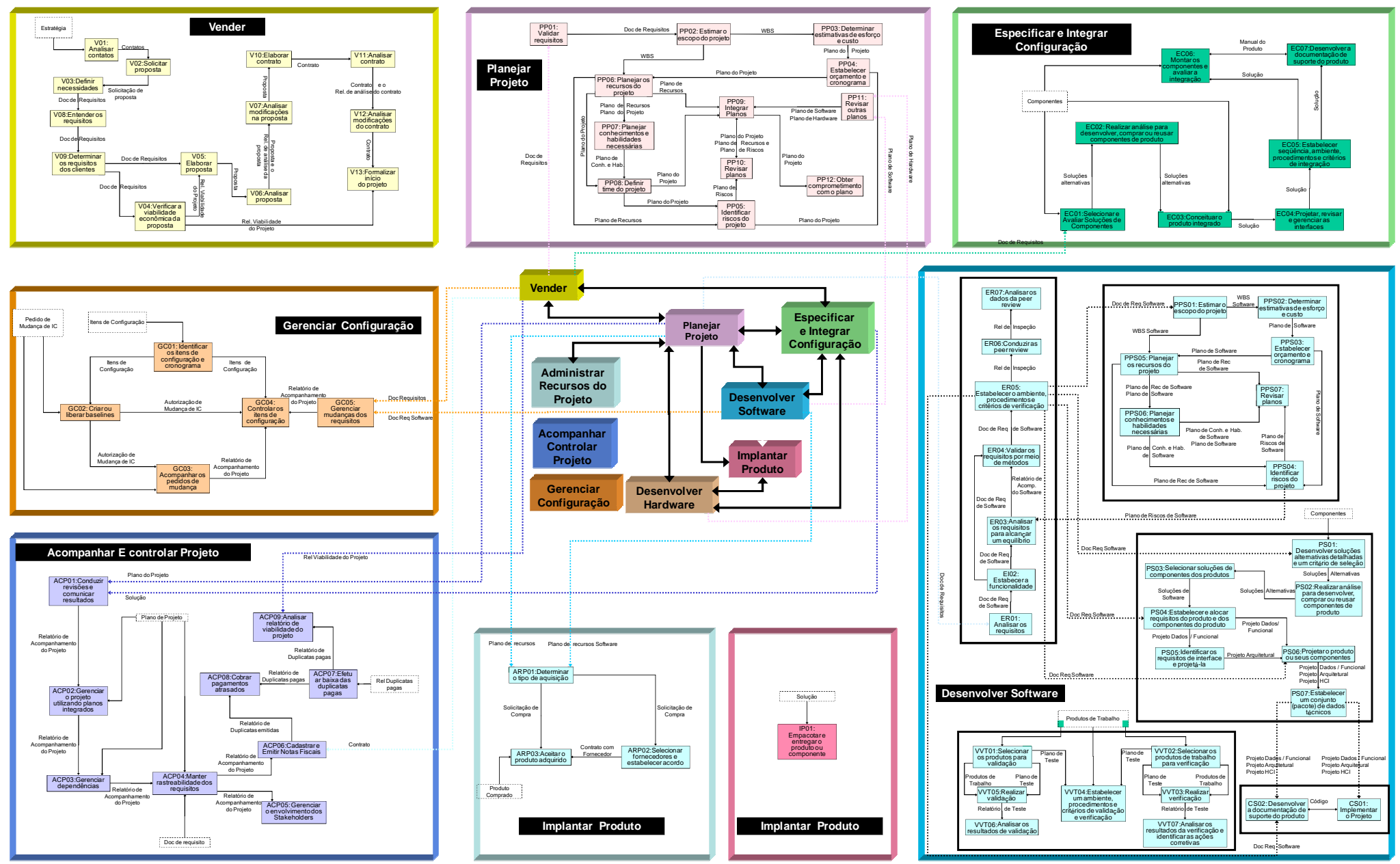

Figura 5.2 - Primeira Versão do Modelo Genérico Do PV\&DS On-demand 
Aplicando a Metodologia de Gestão de Mudanças proposta em COSTA (2006) na Empresa 1, foi revelado que não existiam padrões de documentos e nem uma visão sistemática de suas atividades, implicando no desenvolvimento de projetos de sistemas com base na experiência do gerente de projeto em conduzir esses projetos. Além disso, havia uma grande rotatividade de pessoal na empresa dificultando o desenvolvimento de sistemas a contento de ambas as partes envolvidas - cliente e empresa, no prazo estabelecido.

Foi, então, definido um portfólio de projetos de mudança para a Empresa 1, tendo como primeiro projeto de mudança a instanciação do Modelo Genérico do PV\&DS on-demand para a Empresa 1. As entregas dessa instanciação foram: um pôster com a visão geral das atividades do modelo proposto, agrupadas em fases, com seus respectivos fluxos de entradas e saídas (Figura 5.3; nessa figura estão destacadas em vermelho pontilhado as atividades da fase "Vender" que podem ser melhor visualizadas na Figura 5.4); um pôster do conteúdo dos documentos do modelo instanciado para facilitar o entendimento comum a todos (Figura 5.5; nessa figura está destacado em vermelho pontilhado o artefato "Documento de Requisitos" que pode ser melhor visualizado na Figura 5.6); um manual contendo o detalhamento de todas as atividades do modelo de processo proposto (Figura 5.7) e um manual com os templates (modelos de documentos) (Figura 5.8) para os artefatos utilizados/criados nas/por meio das atividades do modelo de processo proposto. 


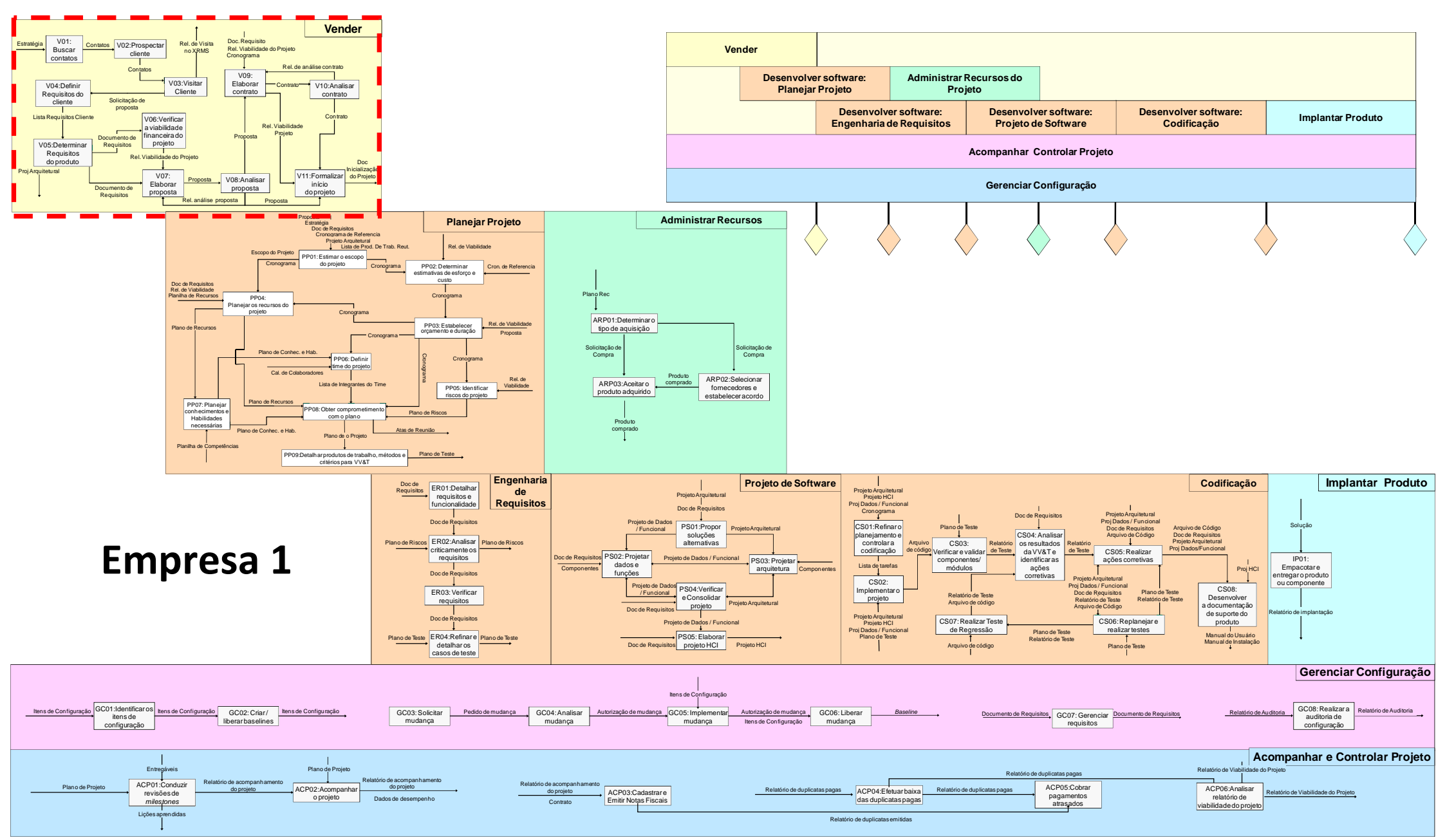

FiguRA 5.3 - INSTÂNCIA do MOdELO GENÉRICO Do PV\&DS ON-DEMAND PARA A EmPRESA 1 


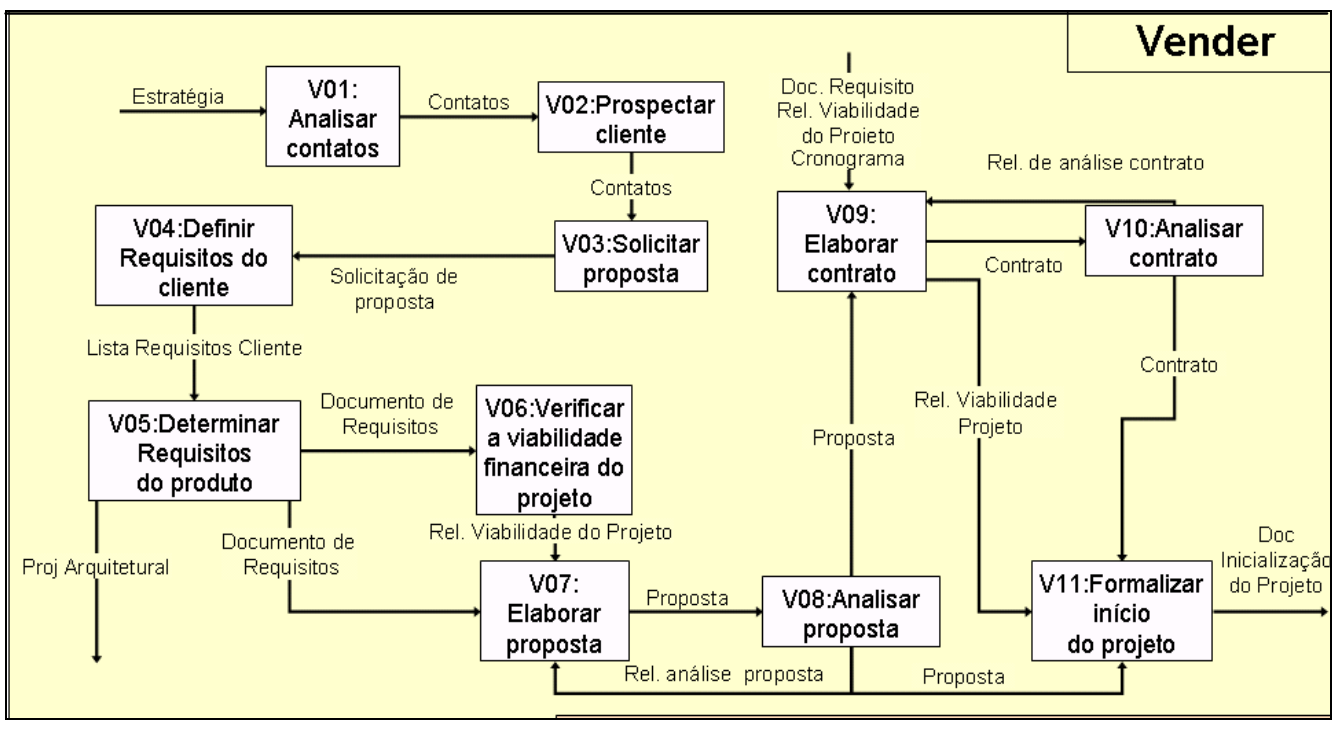

Figura 5.4 - Visão Gráfica Da Fase Vender 


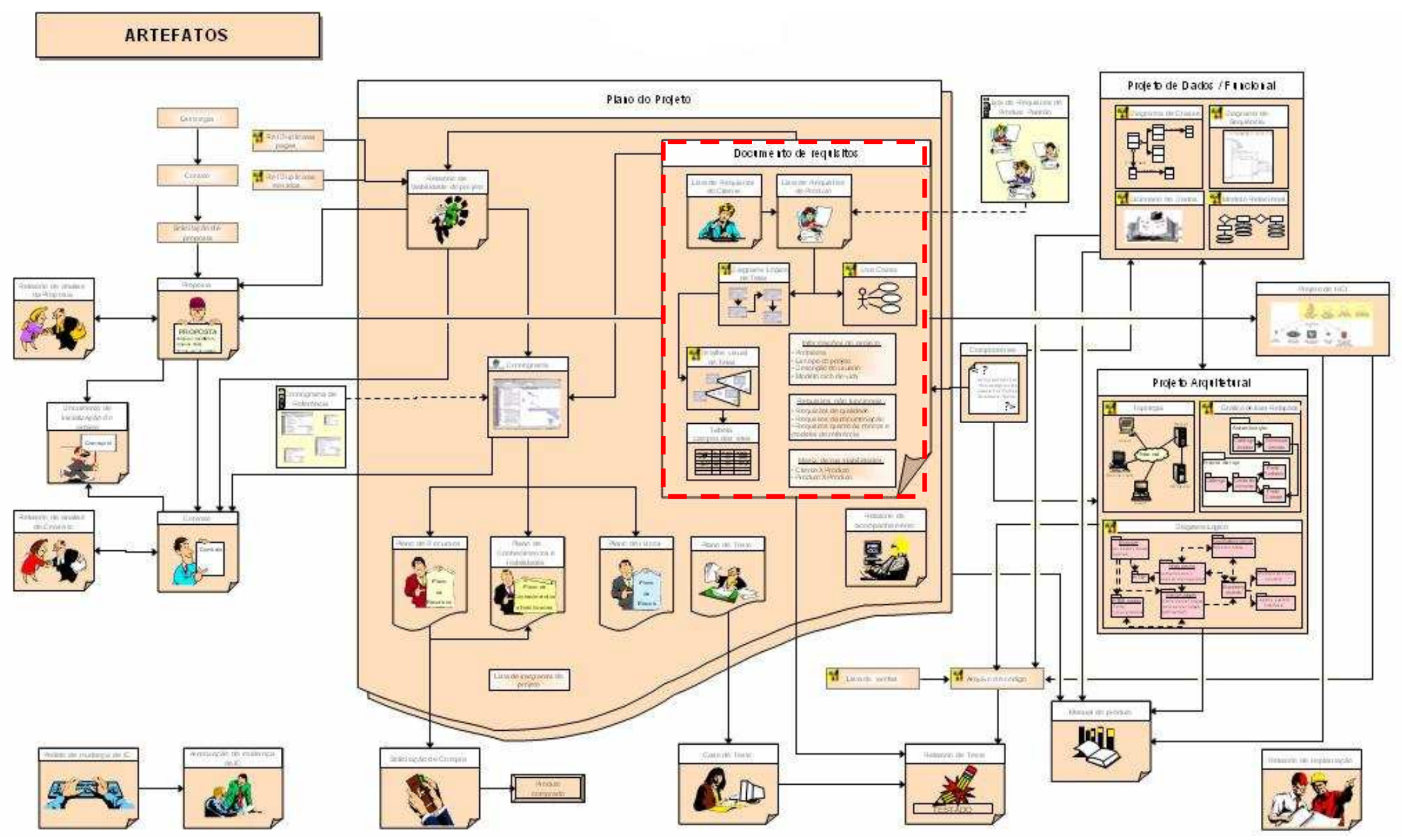

FIGURA 5.5- VISUALIZAÇÃo GRÁFICA DO CONTEÚDO DOS ARTEFATOS DO PROCESSO PROPOSTO 


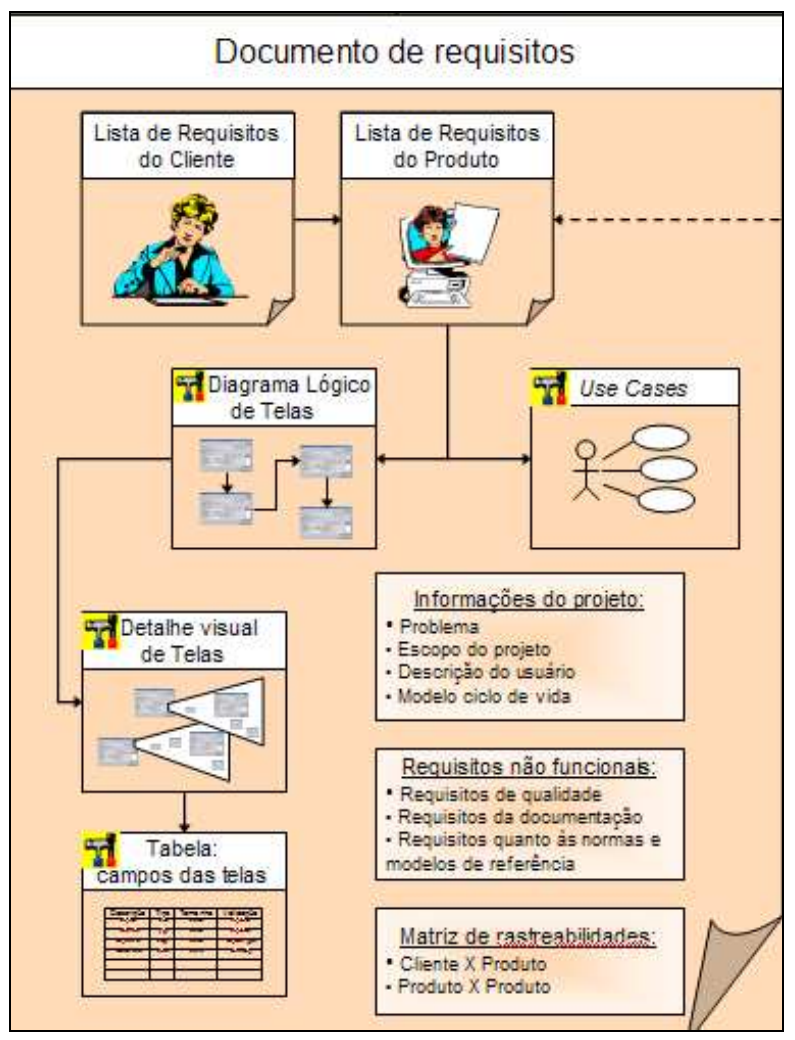

FiguRA 5.6 - VISUALIZAÇÃo GRÁFICA do CONTEÚdo do ARTEFATO “DOCUMENTO DE REQUISITOS" 


\begin{tabular}{|c|c|}
\hline Atividade & V05. Determinar requisitos do produto \\
\hline Objetivo & $\begin{array}{l}\text { Transformar os requisitos do cliente em requisitos do produto, uma vez que uma } \\
\text { necessidade do cliente pode ser traduzida em mais de um requisito do produto; a } \\
\text { descrição dos requisitos dependerá do nivel de detalhamento definido. Também, } \\
\text { quando necessário, já devem ser elaboradas as telas do produto }\end{array}$ \\
\hline Tarefas & $\begin{array}{l}\text { - Definir o ID do projeto } \\
\text { - Selecionar topologia do sistema } \\
\text { - Selecionar uma lista de requisitos do produto padrão } \\
\text { - } \text { - Mames, tipos, descrição e prioridade dos requisitos } \\
\text { - Marcar quais dos requisitos serão colocados na proposta } \\
\text { - Definir o nível de detalhamento do Documento de Requisitos e Projeto Arquitetura } \\
\text { - } \text { nesta fase } \\
\text { - Criar os requisitos definidos conforme o nível de detalhamento }\end{array}$ \\
\hline Papéis & $\begin{array}{l}\text { Gerente de Projeto } \\
\text { Equipe de Vendas }\end{array}$ \\
\hline Entradas & Lista de requisitos do cliente \\
\hline Saídas & $\begin{array}{l}\text { Documento de Requisitos }(T)^{*} \text { (inclui a Lista de Requisitos do Produto }(T) \text { ) } \\
\text { Projeto Arquitetural }(T)^{\star}\end{array}$ \\
\hline Recursos & \\
\hline
\end{tabular}

\begin{tabular}{|l|l|}
\hline Atividade & V06. Verificar a viabilidade financeira do projeto \\
\hline Objetivo & $\begin{array}{l}\text { Avaliar, com base no Documento de Requisitos e na base de dados histórica, se é } \\
\text { viável a execução do projeto em termos financeiros }\end{array}$ \\
\hline Tarefas & - Definir cost driver \\
& $\begin{array}{l}\text { - Definir valor da unidade do cost driver } \\
\text { - Definir o custo operacional geral produto } \\
\end{array}$ \\
& $\begin{array}{l}\text { - Defimar valores de possiveis aquisições } \\
\text { - Definir o valor factivel }\end{array}$ \\
& $\begin{array}{l}\text { - Definir o fluxo de caixa do projeto } \\
\text { - Definir o cronograma de recebimentos }\end{array}$ \\
\hline Papéis & $\begin{array}{l}\text { Gerente do Projeto } \\
\text { Equipe de Vendas }\end{array}$ \\
\hline Entradas & Documento de Requisitos $(\mathrm{T})$ \\
\hline Saídas & Relatório de Viabilidade do Projeto $(\mathrm{T})$ \\
\hline Recursos & \\
\hline
\end{tabular}

Figura 5.7 - Detalhamento de uma Atividade do Modelo de Processo Proposto 


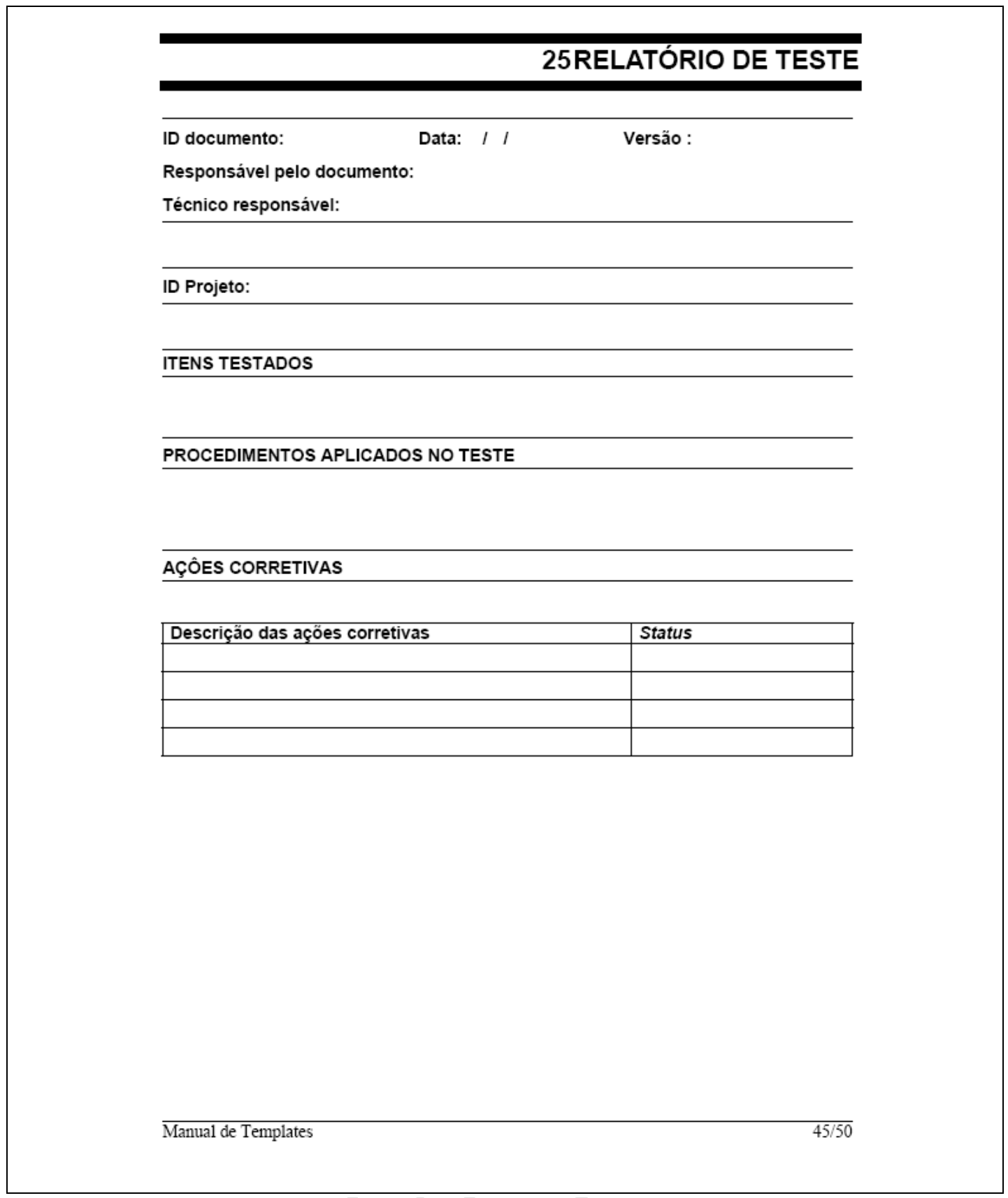

FIGURA 5.8 - EXEMPLO DE TEMPLATE

Após uma análise crítica em relação às entregas, citadas anteriormente, por parte dos colaboradores da Empresa 1, foi iniciado o projeto de implementação da fase de Vendas e Planejamento de Projeto do PV\&DS on-demand instanciado para a Empresa 1. Alguns resultados qualitativos do projeto de mudança "implementação da 
fase de Vendas" do Processo de V\&DS on-demand foram: um aumento nas vendas de projetos de sistemas, a redução no tempo de criação de propostas para o cliente (em média, de 10 dias para 2 dias, segundo os vendedores da empresa) e melhor comunicação entre os colaboradores da área de venda e da área técnica da empresa.

A descrição detalhada da aplicação da Metodologia de Gestão de Mudança encontra-se na dissertação de mestrado de Costa (COSTA, 2006).

Com o lançamento da versão 1.2 do CMMI, foi realizado um novo mapeamento dos objetivos específicos definidos para cada área de processo do CMMI-DEV em relação às práticas-base da norma ISO/IEC 15504-5.

Durante a implantação de duas fases do modelo na Empresa 1 percebeu-se a necessidade de alterar a estrutura do modelo (seqüencial e linear) para retratar mais fielmente os projetos normalmente existentes.

Foram estudados vários modelos de processo de software existentes na literatura (MILLS et al. 1987; BOEHM et al., 1998; JACOBSON et al., 1999; PRESSMAN, 2006; SOMMERVILLE, 2007; ECLIPSE PROCESS FRAMEWORK COMMUNITY, 2008) para ser definida a nova estrutura do modelo de descrição de processo, agora denominado ProcSoftVD.

Selecionou-se o framework UP (Unified Process), pois propicia o desenvolvimento incremental e evolutivo do software, o que se acredita ser o mais voltado à realidade. Além disso, sua estrutura bi-dimensional permite a visualização das disciplinas ou workflows (neste trabalho de pesquisa denominado "áreas de conhecimento") com maior ou menor ênfase em cada uma das fases que compõem o processo e permite, também, que possam ser selecionadas as áreas de conhecimento que a empresa acredita serem prioritárias em cada ciclo de melhoria. .

Para essa nova versão do Modelo ProcSoftVD foram definidos alguns requisitos, descritos na seção 5.2.1. Com o intuito de facilitar a visualização do relacionamento entre os elementos que compõem o modelo ProcSoftVD foi elaborado um meta-modelo, apresentado na seção 5.2.2. Na seção 5.2.3 são apresentadas as 
duas perspectivas dessa nova versão do Modelo ProcSoftVD: fases e áreas de conhecimento.

\subsubsection{Requisitos do ProcSoftVD}

Os requisitos definidos nesta seção foram identificados durante a pesquisaação realizada na Empresa 1. São eles:

- As atividades do processo devem ser agrupadas por fases e também por áreas de conhecimento para auxiliar na visualização, utilização e controle do processo;

- Cada atividade deve ter uma descrição geral e um detalhamento em forma de tarefas;

- Para cada atividade devem ser indicados os possíveis papéis desempenhados pelos responsáveis em executar a atividade;

- Para cada atividade devem ser indicados possíveis recursos (principalmente ferramentas computacionais) que poderiam auxiliar na realização da atividade;

- Para cada atividade devem ser indicados os artefatos de entrada e saída necessários;

- Para cada artefato do processo deve ser elaborado um template (formulário com a possível estrutura dos artefatos), a fim de facilitar para uma MPE saber o conteúdo que pode compor cada artefato;

- Deve-se permitir que o usuário tenha, além da visão textual das atividades do processo, uma visão gráfica. Essa visão gráfica permite a visualização dos relacionamentos das atividades (o que é difícil muitas vezes de ser identificado na visão textual);

- Deve-se permitir que o usuário tenha acesso às atividades de uma determinada fase do processo selecionada (tanto na visão gráfica quanto 
na textual) e, a partir do acesso de uma delas, deve-se ter acesso às respectivas atividades e seus artefatos de entrada e saída. A partir do acesso de uma atividade deve ser possível visualizar as tarefas, o(s) recurso(s) necessário(s) para realização da atividade e o(s) papel(is) desempenhado(s) pelo(s) responsável(is);

- Deve-se permitir que o usuário tenha acesso às atividades, de acordo com uma determinada área de conhecimento selecionada;

- Deve-se permitir que o usuário tenha acesso aos objetivos específicos do CMMI e às práticas-base da norma ISO/IEC 15504-5 que são atendidos por cada uma das atividades pertencentes ao ProcSoftVD.

\subsubsection{Meta-modelo do ProcSoftVD}

O meta-modelo, apresentado na Figura 5.9, foi elaborado para facilitar a visualização do relacionamento entre os elementos que compõem o modelo ProcSoftVD.

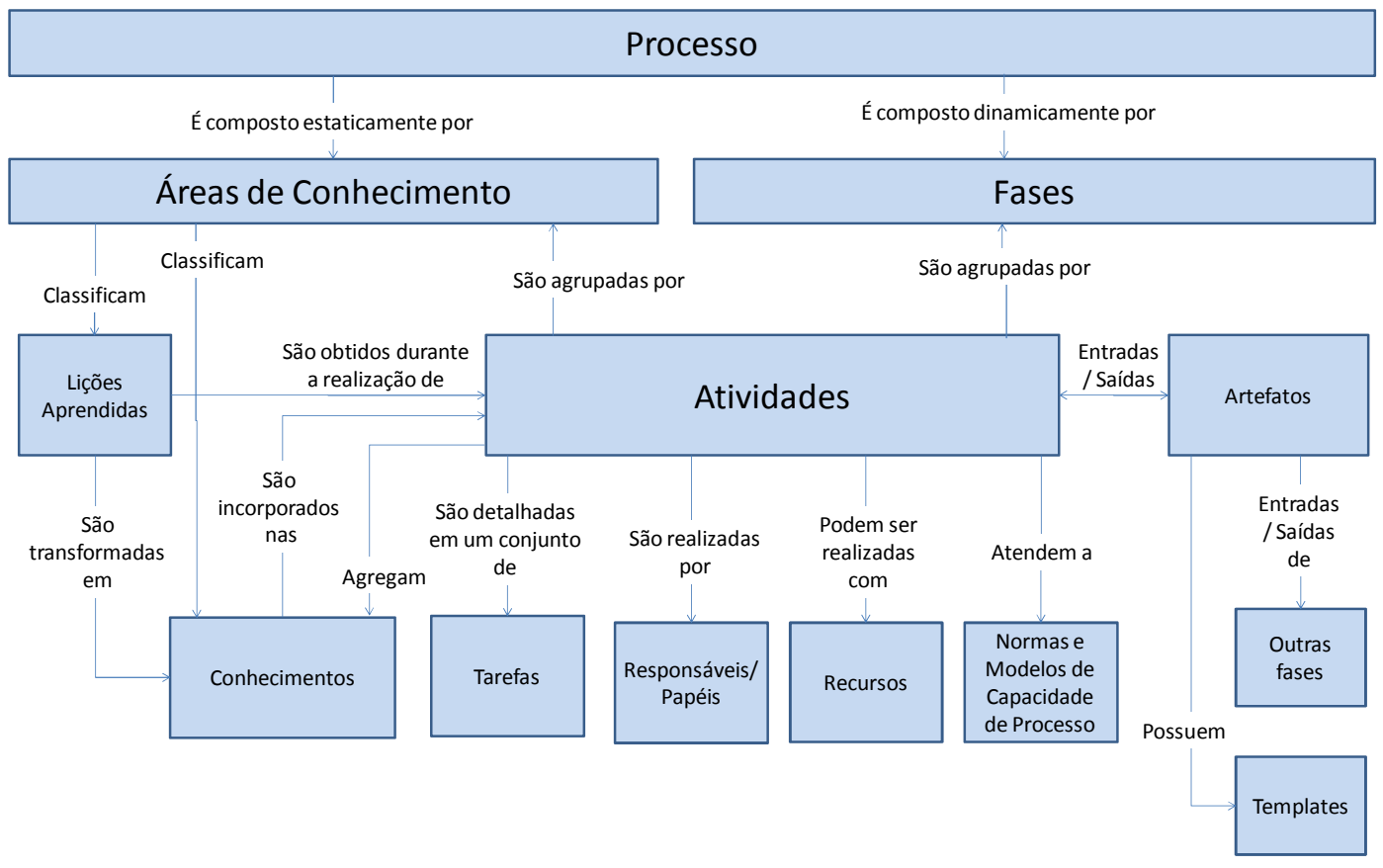

Figura 5.9 - Meta-modelo do ProcSoftVd 
O ProcSoftVD é composto estaticamente por áreas de conhecimento e dinamicamente por fases. Assim, o modelo permite que o usuário tenha acesso às atividades do processo, agrupadas por fase ou agrupadas por áreas de conhecimento.

As atividades são detalhadas em um conjunto de tarefas, são realizadas por responsáveis que desempenham papéis na organização e podem ser realizadas com recursos (como ferramentas).

Para a realização das atividades têm-se como entrada artefatos e após a realização das atividades são criados/modificados artefatos (saídas). Esses artefatos possuem templates (formulários que apresentam uma possível estrutura para os artefatos; além disso, como suporte para os usuários, no próprio template há uma breve revisão bibliográfica relacionada ao artefato e em alguns casos, há alguns exemplos).

As atividades do processo atendem às normas e modelos de capacidade de processo (no caso, CMMI-DEV e ISO/IEC 15504-5). Durante a realização de cada uma das atividades, os responsáveis podem registrar lições aprendidas que são classificadas por áreas de conhecimento e podem ser transformadas em conhecimento integrante da memória organizacional da empresa que é utilizada como subsídio nos ciclos de melhoria do processo da empresa. Dessa forma, o conhecimento obtido é incorporado nas atividades do processo. Esses conhecimentos são classificados por áreas de conhecimento.

\subsubsection{Perspectivas do ProcSoftVD}

Como citado anteriormente, o ProcSoftVD possui duas perspectivas: fases e áreas de conhecimento.

\section{a) Perspectiva - Fases}

No modelo ProcSoftVD (Figura 5.10) foram adicionadas duas fases, além das fases sugeridas pelo UP: a fase de prospecção é sugerida devido o modelo abranger 
não só o desenvolvimento, mas também a venda do software. E, a fase de negociação foi incluída no modelo, pois os modelos de processo existentes não abordam atividades relacionadas à negociação de um contrato com o cliente para o desenvolvimento do software. Essa fase de negociação é importante para se estabelecer o escopo do projeto e firmá-lo em um contrato.

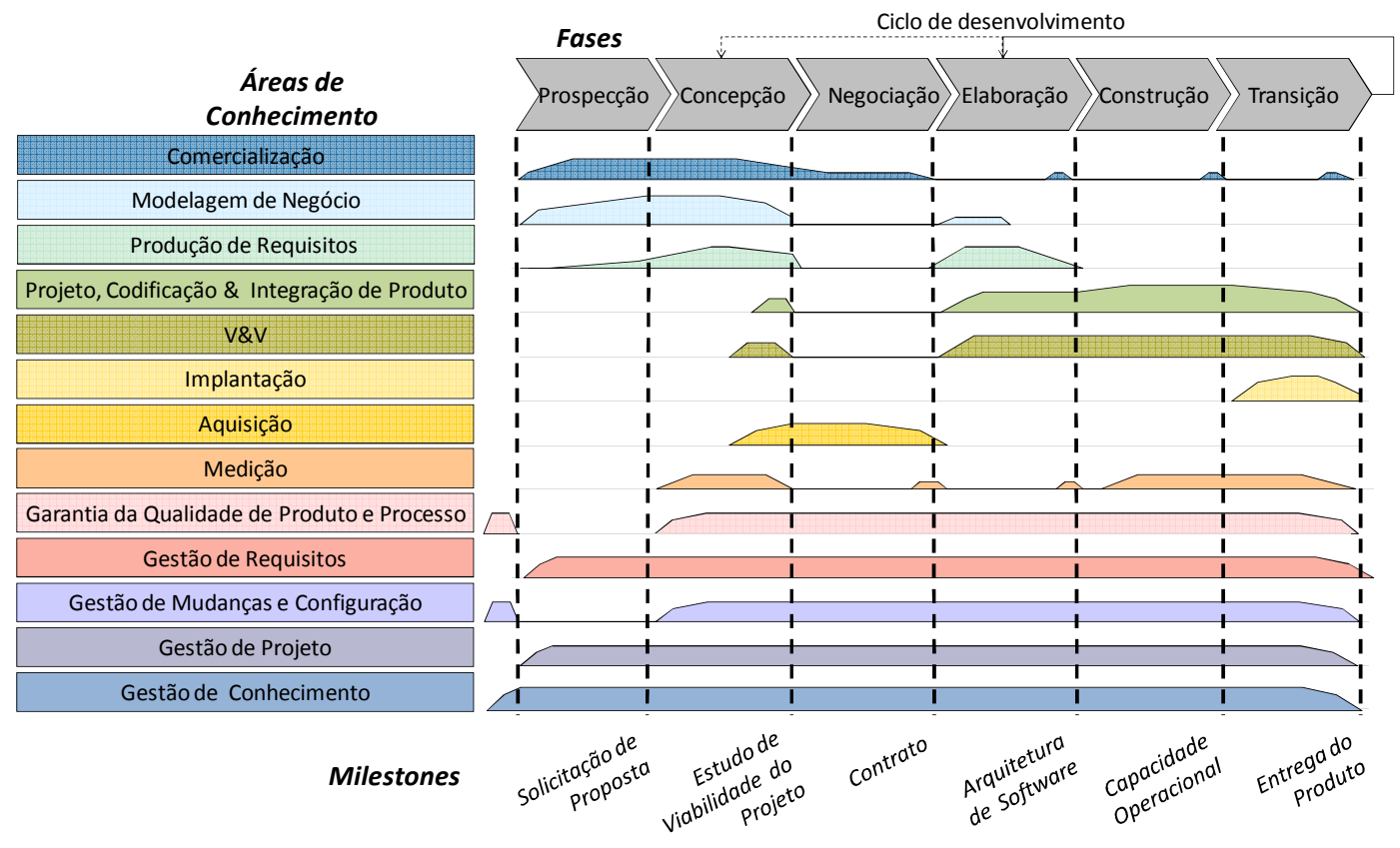

Figura 5.10 - MODELO PROCSOFTVD

Uma vez realizada a busca de potenciais clientes e algum deles tenha solicitado uma proposta (fase de prospecção), inicia-se a fase de concepção. A fase de prospecção é realizada, normalmente, em apenas uma iteração.

A partir da fase de concepção até a fase de transição, forma-se o ciclo de desenvolvimento que ocorre a cada release (versão entregue ao cliente) do produto elaborado, ou seja, o software é elaborado de forma incremental e evolutiva. Entretanto, normalmente, o ciclo de desenvolvimento ocorre entre as fases de elaboração a transição, pois se estenderá para a fase de concepção nos casos onde o cliente solicita mudanças que implicam em criação de um novo contrato com novos acordos relacionados ao escopo do projeto, prazo de entrega e preço. $\mathrm{Na}$ fase de 
concepção tem-se uma visão geral do produto e seu término é marcado pelo estudo de viabilidade do projeto. Nessa fase há tantas iterações quanto necessárias até que haja um acordo entre as partes envolvidas em relação ao contrato. Também, nessa fase é estimada a quantidade de ciclos de desenvolvimento necessária para o produto final ser concebido. Assim, para cada ciclo de desenvolvimento: na fase de elaboração os requisitos são detalhados e são planejados os testes; na fase de construção os requisitos são transformados em uma versão do produto e os testes planejados são executados; e na fase de transição é feito o teste de validação tanto pela empresa desenvolvedora, a partir dos critérios de validação estabelecidos pelo cliente, quanto pelo próprio cliente e é realizada a implantação da versão no cliente. São realizados os outros ciclos de desenvolvimento estimados para compor a versão final do produto. De acordo com os feedbacks (retornos) do cliente, as versões podem ter que passar por mais ciclos de desenvolvimento até estar de acordo com os requisitos estabelecidos pelo cliente.

Para cada fase realizada têm-se atividades com maior ênfase em determinadas áreas de conhecimento. Por exemplo, a área de conhecimento "Modelagem de Negócio" ocorre com maior ênfase nas fases de prospecção e concepção, mas se necessário podem ser executadas atividades dessa área na fase de elaboração, também. Em cada fase podem existir várias iterações (repetições) das atividades que a compõem, dependendo da necessidade.

A cada término de fase há um milestone (marco de referência) que indica o que se espera como produto final de cada fase, além de ser o marco onde são realizadas atividades relacionadas à garantia da qualidade do produto e do processo de software.

\section{b) Perspectiva - Áreas de Conhecimento}

As micro e pequenas empresas (MPEs) podem optar por iniciar a melhoria do processo de venda e desenvolvimento de software de sua empresa aos poucos, selecionando as áreas de conhecimento que acreditam ser de mais alta prioridade. 
Para isso, utiliza-se o Método para Melhoria do Processo de Software voltado para MPEs (seção 5.3). Nesse caso, ela deve utilizar o modelo ProcSoftVD pela perspectiva estática, ou seja, pelas áreas de conhecimento. Assim, acessando uma área de conhecimento, serão apresentadas todas as atividades de cada uma das fases do modelo relacionadas de alguma maneira a essa área de conhecimento. Cada uma das atividades é identificada por uma sigla seguida de um número seqüencial que é reiniciado em cada fase (por exemplo: P01. Buscar contatos, CP02. Definir escopo do projeto). Na fase de prospecção, as atividades são identificadas pela sigla "P", na fase de concepção por "CP", na fase de negociação por "N", na fase de elaboração por "E", na fase de construção por "CT" e na fase de transição por "T".

As áreas de conhecimento "GCf - Gestão de Mudanças e Configuração" e "GCo - Gestão de Conhecimento" permeiam todas as fases do modelo ProcSoftVD. Por isso, podem ser acessadas a qualquer momento em meio à realização das atividades.

Quanto às áreas de conhecimento consideradas nessa versão do ProcSoftVD, tem-se todas as áreas de processo do nível de maturidade 2 do CMMI-DEV e o restante das áreas de processo da categoria "Engenharia" do CMMI no nível de capacidade 2. Em alguns casos, o nome da área de conhecimento não é o mesmo do nome da área de processo do CMMI, pois o nome sugerido no modelo ProcSoftVD foi definido neste trabalho a partir da análise da descrição das áreas de processo do CMMI, dos processos utilizados na ISO/IEC 15504-5 e dos workflows definidos pelo Unified Process (UP). O Quadro 5.11 apresenta as áreas de conhecimento cobertas pelo ProcSoftVD e a associação com as áreas de processo do CMMI, com os processos da ISO/IEC 15504-5 e com os workflows do UP. 
Quadro 5.11- Associação das ÁReas de Conhecimento do ProcSoftVD com outros modelos

\begin{tabular}{|c|c|c|c|}
\hline Áreas de conhecimento do ProcSoftVD & CMMI-DEV & ISO/IEC 15504-5 & Unified Process \\
\hline Comercialização & & $\begin{array}{l}\text { - Prospecção do Fornecedor } \\
\text { - Acordado Contratual }\end{array}$ & \\
\hline Modelagem de Negócios & & & Modelagem de Negócios \\
\hline Produção de Requisitos & - Desenvolvimento de Requisitos & \begin{tabular}{|l|} 
- Elicitação de Requisitos \\
- Análise de Requisitos do Sistema \\
- Análise de Requisitos do Software
\end{tabular} & \\
\hline Projeto, Codificação \& Integração de Produto & $\begin{array}{l}\text { - Solução Técnica } \\
\text { - Integração de Produto }\end{array}$ & \begin{tabular}{|l} 
- Projeto do Software \\
- Integração do Software \\
- Integração do Sistema \\
\end{tabular} & - Implementação \\
\hline V\&V & $\begin{array}{l}\text { - Verificação } \\
\text { - Validação }\end{array}$ & \begin{tabular}{|l|} 
- Verificação \\
- Validação \\
- Teste de Software \\
- Teste de Sistema \\
\end{tabular} & - Teste \\
\hline Implantação & & - Entrega de Produto & - Implantação \\
\hline Aquisição & - Gestão de Acordo com o Fornecedor & - Aquisição & \\
\hline Medição & - Análise e Medição & - Medição & \\
\hline Garantia da Qualidade de Produto e Processo & $\begin{array}{l}\text { - Garantia da Qualidade de Produto e } \\
\text { Processo }\end{array}$ & $\begin{array}{l}\text { - Garantia da Qualidade de Produto e } \\
\text { Processo }\end{array}$ & \\
\hline Gestão de Requisitos & - Gestão de Requisitos & & \\
\hline Gestão de Mudanças e Configuração & - Gestão de Configuração & \begin{tabular}{|l|} 
- Gestão de Configuração \\
- Gestão de Solicitação de Mudanças
\end{tabular} & \begin{tabular}{|l|} 
- Gerenciamento de \\
Configuração e Mudança
\end{tabular} \\
\hline Gestão de Projeto & $\begin{array}{l}\text { - Planejamento de Projeto } \\
\text { - Monitoramento e Controle de } \\
\text { Projeto }\end{array}$ & - Gestão de Projeto & - Gerenciamento de Projetos \\
\hline Gestão de Conhecimento & & Gestão de Conhecimento & \\
\hline
\end{tabular}

Foi elaborado um questionário (Apêndice 1) aplicado a 5 (cinco) MPE's que desenvolvem software on-demand e 9 (nove) CPDs (Centro de Processamento de Dados) de empresas diversas os quais desenvolvem software on-demand para uso interno, que confirmou a importância de algumas áreas de conhecimento definidas no Modelo ProcSoftVD (Apêndice 2) e indicou a importância de outras áreas de conhecimento que serão melhor investigadas em um trabalho futuro.

Durante a análise desse questionário respondido pelas MPE's, notou-se que quase todas elas acreditam ser muito importante entender e modelar o negócio do cliente, entretanto, a maioria não o faz. Sendo assim, foi considerada também no ProcSoftVD a área de conhecimento "Modelagem de Negócio", indicada pelo modelo Unified Process. A área de conhecimento "Comercialização", apesar de não ser citada pelo CMMI-DEV, é bastante importante para as MPE's buscarem novos clientes, elaborarem/submeterem propostas ao cliente, negociarem um contrato claro e sem ambigüidades que especifique as expectativas, responsabilidades, entregas e compromissos de ambas as partes cliente e fornecedor, realizar a viabilidade financeira do projeto e controlar os pagamentos dos produtos/serviços vendidos pela empresa. 
As áreas de conhecimento abordadas no ProcSoftVD e uma breve descrição de cada uma delas é feita, a seguir.

Comercialização: essa área de conhecimento foi criada para abordar (1) atividades relacionadas à prospecção de potenciais clientes para a empresa (o que não é coberto pelo CMMI, nem pela ISO/IEC 15504-5); (2) atividades relacionadas à elaboração/submissão de propostas ao cliente e negociação e aprovação de contrato sem ambigüidades que especifique as expectativas, responsabilidades, entregas e compromissos de ambas as partes cliente e fornecedor; (3) atividades relacionadas à viabilidade financeira do projeto e relacionadas ao pagamento dos produtos/serviços vendidos pela empresa. As atividades do item (2) foram definidas com subsídio dos processos "Prospecção do Fornecedor" e "Acordado Contratual" da ISO/IEC 15504-5.

Modelagem de Negócio: o objetivo dessa área de conhecimento é documentar os processos de negócio usando casos de uso de negócio ${ }^{23}$, a fim de assegurar um entendimento comum entre todos os stakeholders (envolvidos) sobre as necessidades existentes no processo de negócio da organização cliente. Essa área de conhecimento teve sua origem no Unified Process.

Produção de Requisitos: tem o objetivo de produzir e analisar os requisitos do cliente, do produto e dos componentes de produto. Essa área de conhecimento teve sua origem relacionada à área de processo "Desenvolvimento de Requisitos" do CMMI-DEV e aos processos "Elicitação de Requisitos", "Análise de Requisitos do Sistema" e "Análise de Requisitos do Software" da ISO/IEC 15504-5.

Projeto, Codificação \& Integração de Produto: Engloba os processos "Projeto do Software", "Integração do Software" e "Integração do Sistema" da 15504-5, o workflow "Implementação" do UP e as áreas de processo "Solução Técnica" e "Integração de Produto" do CMMI-DEV. Segundo a 15504-5, o processo "Projeto de

\footnotetext{
${ }^{23}$ Ver RUP - Rational Unified Process. Modelo integrado à ferramenta CASE Rational Rose.
} 
Software" tem o objetivo de fornecer um design para o software que é implementado e pode ser verificado em confronto aos requisitos; o processo "Integração de Software" tem o objetivo de combinar as unidades de software, produzindo itens de software integrados, consistentes com o projeto de software, os quais demonstram que os requisitos funcionais e não-funcionais foram satisfeitos; e o processo "Integração do Sistema" tem como objetivo integrar os elementos do sistema (incluindo os itens de software, itens de hardware, operações manuais e outros sistemas, se necessário) para produzir um sistema completo que satisfaça ao projeto do sistema e às expectativas do cliente, expressadas em requisitos do sistema. Segundo o modelo CMMI-DEV, a área de processo "Solução Técnica" tem como objetivo projetar, desenvolver e implementar soluções para os requisitos, soluções essas que envolvem produtos, componentes de produtos e processos de ciclo de vida relacionados ao produto; e a área de processo "Integração do Produto" tem o objetivo de montar o produto, a partir dos componentes de produto, assegurar que o produto ao ser integrado funcione adequadamente, e entregar o produto.

V\&V: Engloba as áreas de processo (CMMI) e processos (15504-5) "Validação" e "Verificação" e os processos "Teste de Software" e "Teste de Sistema" da 15504-5. O objetivo da área de processo/processo "Validação" é demonstrar que o produto ou componente do produto atenda ao uso pretendido quando colocado no ambiente destinado. Já o objetivo da área de processo/processo "Verificação" é assegurar que produtos de trabalho (e serviços, no caso do $\mathrm{CMMI}$ ) selecionados alcancem seus requisitos especificados. Testes desempenham um papel extremamente importante em V\&V (Verificação e Validação). Segundo o modelo 15504-5, o processo "Teste" pode ser realizado tanto no software quanto no sistema. O processo "Teste de Software" tem como objetivo confirmar que o produto de software integrado atende aos requisitos definidos. E, o processo "Teste de Sistema" tem o objetivo de assegurar que a implementação de cada requisito de sistema seja testada quanto à sua conformidade e que o sistema esteja pronto para entrega. 
Implantação: o objetivo é entregar o produto produzido para os usuários finais, por meio das atividades de codificação, teste, empacotamento e instalação do software. Essa área de conhecimento teve sua origem no UP e também está relacionada ao processo "Entrega de Produto" da 15504-5.

Aquisição: essa área de conhecimento tem o objetivo de gerenciar a aquisição de produtos de fornecedores, sejam equipamentos ou até mesmo componentes de software do produto (no caso de terceirização do serviço). Exemplos de produtos e componentes de produtos que podem ser adquiridos pelo projeto: subsistemas (por exemplo, um sistema navegacional de uma aeronave), software, hardware, documentação (como manuais de instalação, de operação e do usuário). A origem dessa área de conhecimento está relacionada ao grupo de processo "Aquisição" da 15504-5 à área de processo denominada "Gestão de Acordo com Fornecedor" do CMMI-DEV.

Medição: essa área de conhecimento tem o objetivo de coletar e analisar dados relacionados aos produtos desenvolvidos e aos processos implementados dentro da organização por meio de projetos, a fim de dar um suporte efetivo à gestão dos processos e demonstrar objetivamente a qualidade dos produtos. Sua origem está relacionada à área de processo "Análise e Medição" do CMMI-DEV e do processo "Medição" da 15504-5.

Garantia da Qualidade de Produto e Processo: o objetivo dessa área de conhecimento é fornecer a garantia da qualidade dos processos e produtos de trabalho. Sua origem está relacionada tanto ao CMMI quanto à ISO/IEC 15504.

Gestão de Requisitos: o objetivo dessa área de conhecimento, que teve sua origem no CMMI-DEV, é gerenciar os requisitos dos produtos e componentes de produtos dos projetos e identificar inconsistências entre esses requisitos e os planos e produtos de trabalho dos projetos. Para isso, essa área trata do rastreamento dos requisitos em meio ao projeto e das mudanças desses requisitos. As mudanças 
relacionadas aos requisitos utilizam algumas das atividades definidas pela área de conhecimento "Gestão de Mudanças e Configuração".

Gestão de Mudanças e Configuração: essa área de conhecimento engloba a área de processo "Gestão de Configuração" do CMMI-DEV e os processos "Gestão de Configuração" e "Gestão de Solicitação de Mudanças" da 15504-5. O objetivo dessa área de conhecimento é estabelecer e manter a integridade de produtos de trabalho usando a identificação de configuração, controle de configuração, prestação de contas (explicação) do status da configuração e auditoria da configuração, além de assegurar que solicitações de mudanças no projeto sejam gerenciadas, rastreadas e controladas.

Gestão de Projetos: o objetivo dessa área de processo é identificar, estabelecer, coordenar e monitorar as atividades, tarefas e recursos necessários para um projeto produzir um produto e/ou serviço, no contexto dos requisitos e restrições de projetos. Engloba tanto o processo "Gestão de Projetos" da 15504-5 quanto as áreas de processo "Planejamento de Projeto" e "Monitoramento e Controle de Projeto" do CMMI.

Gestão de Conhecimento: tem como objetivo assegurar que o conhecimento, informação e habilidades individuais sejam coletadas, compartilhadas, reusadas e melhoradas por toda a organização. Sua origem está relacionada ao processo "Gestão de Conhecimento" da ISO/IEC 15504. A Figura 5.12 apresenta as atividades da área de conhecimento Gestão de Conhecimento, por meio da notação SADT adaptada, e o relacionamento dessas no contexto de melhoria de processo. Essa área de conhecimento permeia todo o processo de software, por isso, os responsáveis durante a realização de atividades podem ter alguma lição aprendida (conhecimento) a ser registrada. Essas lições aprendidas devem ser lapidadas por algum membro da empresa que desempenhe o papel de avaliador do conhecimento (mesmo que tenha subsídio da experiência de outros funcionários), integrando a memória organizacional da empresa. Uma vez que o conhecimento é lapidado, pode ser disseminado para todos os outros envolvidos no processo, por meio dos próximos ciclos de melhoria 
definidos durante a aplicação do Método de Melhoria do Processo de Software (ProcSoftVD - Melhoria).

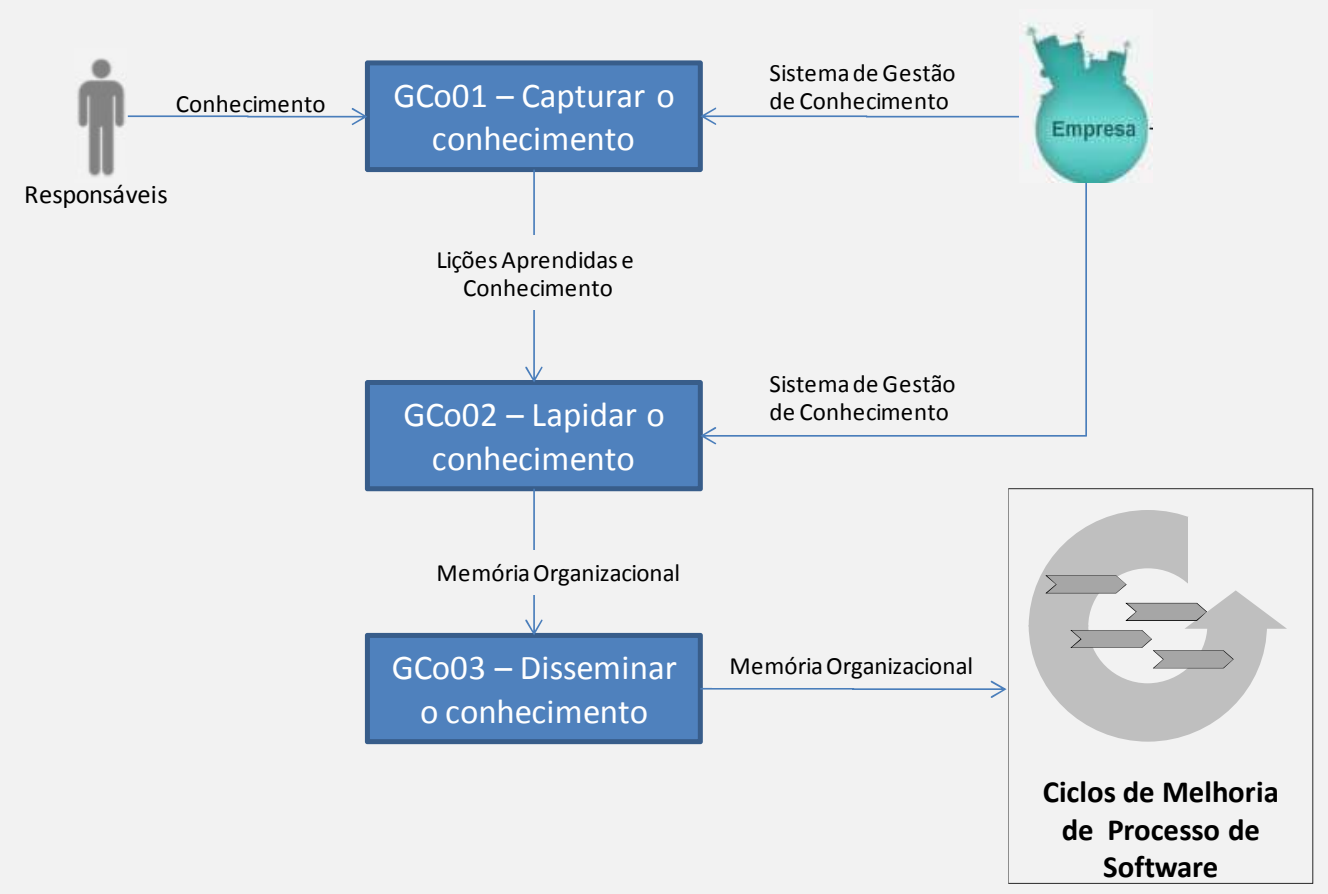

Figura 5.12- Atividades da Área de Gestão de Conhecimento do Modelo ProcSoftVD

O Modelo ProcSoftVD completo encontra-se nos Apêndices 3, 4 e 5 deste trabalho. O Apêndice 3 apresenta as atividades do modelo na visão textual, agrupadas por fases e por áreas de conhecimento, e na visão gráfica. Além disso, apresenta cada uma das atividades com sua respectiva descrição, responsáveis, artefatos de entrada e saída, recursos e tarefas. O Apêndice 4 apresenta todos os templates de artefatos criado/utilizado no modelo e o Apêndice 5 mostra o mapeamento das atividades do modelo ProcSoftVD com os objetivos específicos do CMMI-DEV e as práticas-base da ISO/IEC 15504-5. 


\subsection{Método de Melhoria do Processo de Venda e Desenvolvimento de Software On-demand para MPEs (ProcSoftVD - Melhoria)}

Quando a empresa decide realizar algum tipo de melhoria em seus processos, é importante que essa melhoria seja analisada e planejada, antes de ser executada. Existem vários métodos de melhoria disponíveis na literatura (DEMING, 1986; MCFEELEY, 1996; INTERNATIONAL ORGANIZATION FOR STANDARDIZATION, 2003; WEBER et al., 2005b; SALVIANO, 2006; COSTA, 2006). Para utilizar o ProcSoftVD em um contexto de gestão de processos poderia ser utilizado, inicialmente, qualquer um desses métodos. Entretanto, realizando uma análise desses métodos (Quadro 5.13) percebeu-se uma complementaridade entre alguns deles e, por isso, foi elaborado o Método de Melhoria de Processo (ProcSoftVD - Melhoria), descrito nessa seção, a partir da combinação de três abordagens: ASPE/MSC (WEBER et al., 2005b), PRO2PI-WORK (SALVIANO, 2006) e Metodologia de Gestão de Mudanças (COSTA, 2006).

Quadro 5.13 - Quadro Comparativo dos Métodos de Melhoria de Processo 


\begin{tabular}{|c|c|c|c|}
\hline ProcSoftVD - Melhoria & ASPE/MSC & PRO2PI-WORK & \begin{tabular}{|c|}
$\begin{array}{c}\text { Metodologia de Gestão de } \\
\text { Mudanças }\end{array}$ \\
\end{tabular} \\
\hline Fase 1 - Diagnóstico do Processo de Software Atual e Definição do Perfil-Alvo & $\begin{array}{l}\text { Diagnóstico do Processo de } \\
\text { Software Atual }\end{array}$ & Definição do Perfil-Alvo & \\
\hline 1.1 Descrever o processo de software atual & $\mathrm{X}$ & $\mathrm{X}$ & \\
\hline $\begin{array}{l}1.2 \text { Identificar com os diretores da empresa os objetivos estratégicos do negócio, } \\
\text { considerando metas de melhoria }\end{array}$ & $\mathrm{x}$ & & \\
\hline 1.3 Definir os perfis-alvo do processo & & $\mathrm{X}$ & \\
\hline Fase 2 - Análise Estratégica e Planejamento da Mudança & Análise Estratégica & & Planejamento da Mudança \\
\hline $\begin{array}{l}2.1 \text { Identificar, analisar e priorizar as áreas de conhecimento a serem melhoradas, com } \\
\text { base nos perfis-alvo definidos na fase } 1\end{array}$ & $\mathrm{x}$ & & \\
\hline 2.2 Definir um plano de ação & $\mathrm{X}$ (superficialmente) & & $\mathrm{X}$ (detalhadamente) \\
\hline Fase 3 - Definicão das atividades da(s) área(s) de conhecimento & $\bar{X}$ & & \\
\hline $\begin{array}{l}3.1 \text { Identificar as principais atividades que serão executadas durante a realização da } \\
\text { área de conhecimento }\end{array}$ & $x$ & & \\
\hline $\begin{array}{l}\text { 3.2 Identificar os papéis e as responsabilidades relacionadas a cada atividade } \\
\text { selecionada }\end{array}$ & $\mathrm{x}$ & & \\
\hline $\begin{array}{l}\text { 3.3 Identificar os artefatos que serão consumidos ou produzidos durante a execução de } \\
\text { cada atividade, e, caso existam, seus respectivos templates }\end{array}$ & $x$ & & \\
\hline $\begin{array}{l}3.4 \text { Identificar as medidas que devem ser coletadas durante a execução de uma } \\
\text { atividade }\end{array}$ & $x$ & & \\
\hline $\begin{array}{l}\text { 3.5 Identificar outras informações importantes, como critérios de entrada e de saída, } \\
\text { métodos e ferramentas }\end{array}$ & $x$ & & \\
\hline Fase 4 - Implantação da(s) área(s) de conhecimento & $\mathrm{X}$ & & \\
\hline 4.1 Planejar como será avaliada a área de conhecimento durante a sua execução & $x$ & & \\
\hline 4.2 Definir escopo de utilização da área de conhecimento & $\mathrm{X}$ & & \\
\hline 4.3 Treinar e motivar os participantes envolvidos & $\mathrm{X}$ & & \\
\hline 4.4 Iniciar o uso do guia & $\mathrm{X}$ & & \\
\hline 4.5 Analisar e interpretar os dados coletados durante a utilização do guia & $\mathrm{X}$ & & \\
\hline 4.6 Apresentar os resultados da análise para a diretoria & $X$ & & \\
\hline
\end{tabular}

A primeira refere-se a uma abordagem para estabelecimento de processo de software em MPEs, a segunda refere-se a um método para estabelecimento do perfil de capacidade de processo para melhoria de processo em MPEs e a terceira refere-se a uma metodologia de gestão de mudanças que incorpora melhores práticas de gestão de projeto ao tratar as mudanças a serem realizadas por meio de projetos de mudanças.

O ProcSoftVD - Melhoria é composto por quatro fases, descritas a seguir, sugeridas pela ASPE/MSC (WEBER et al., 2005b) e adaptadas neste trabalho de pesquisa, a atividade de definição do perfil de processo é realizada utilizando a estratégia definida no PRO2PI-WORK (SALVIANO, 2006) e a atividade relacionada à definição de um plano de ação é realizada com base nas melhores práticas de gestão de projetos sugeridas por Costa (2006) em sua Metodologia de Gestão de Mudanças. 


\section{Fase 1. Diagnóstico do Processo de Software Atual e Definição do Perfil-Alvo}

Nessa fase deve ser realizado o diagnóstico do processo de software atualmente utilizado na MPE. As atividades pertencentes a essa fase são:

1.1 Descrever o processo de software atual da empresa em alto nível. Para isso pode ser usada qualquer representação de modelagem de processo, tais como: SADT (Structured Analysis and Design Technique) (MCGOWAN \& MARCA, 1987), IDEF0 (Integration definition for function modeling) (AIR FORCE, 1980), EPC (Eventdriven process chain) (SCHEER, 1998), UML (Unified Modeling Language) e BPMN (Business Process Modeling Notation) (BUSINESS PROCESS MANAGEMENT INITIATIVE, 2008) ou até mesmo uma descrição textual.

1.2 Identificar com os diretores da empresa os objetivos estratégicos de negócio, considerando metas de melhoria.

1.3 Definir os perfis-alvo do processo, ou seja, quais são as áreas de conhecimento mais importantes para a empresa e qual o respectivo nível de capacidade que elas devem possuir para que os objetivos estratégicos e de melhoria sejam alcançados, considerando o escopo do modelo de referência utilizado (no caso, sugere-se o Modelo ProcSoftVD proposto neste trabalho de pesquisa). Isso pode ser realizado em uma reunião com pessoas representantes do nível gerencial e operacional da empresa. Para cada área de conhecimento devem ser realizadas as tarefas, a seguir, da forma mais rápida possível ${ }^{24}$ :

- apresenta-se a definição da área de conhecimento, conforme o modelo de referência utilizado; os principais sintomas típicos quando ela não é bem executada e os principais benefícios que justificam porque ela é importante.

- discute-se e identifica-se a correspondência da área de conhecimento na organização.

- identifica-se como a área de conhecimento é executada atualmente, ou seja, em qual nível de capacidade e justificativas.

\footnotetext{
${ }^{24}$ Em Salviano (2006) é sugerido não exceder 20 minutos.
} 
- define-se a importância da área de conhecimento para os objetivos estratégicos da organização, observando os benefícios típicos de sua execução, com pontuação baixa, média ou alta, descrevendo as razões da pontuação.

- define-se o risco em continuar executando a área de conhecimento da forma como é executada atualmente na empresa, definindo uma pontuação (baixa, média ou alta), e descreve-se as razões da pontuação.

- posiciona-se cada área de conhecimento no quadro de importância versus risco e atribui-se uma pontuação para as combinações, com preferência para a importância. A pontuação, apresentada na Tabela 5.14, é sugerida em Salviano (2006).

TABela 5.14 - Pontuação para As ÁReAs de Conhecimento (SALVIANO, 2006)

\begin{tabular}{|c|c|c|c|}
\hline $\begin{array}{c}\text { Risco } \\
\text { Importância }\end{array}$ & Baixo & Médio & Alto \\
\hline Alta & 6 & 9 & 10 \\
\hline Média & 4 & 7 & 8 \\
\hline Baixa & 2 & 3 & 5 \\
\hline
\end{tabular}

\section{Fase 2. Análise Estratégica e Planejamento da Mudança}

Esta fase tem por objetivo a definição e priorização das ações para o estabelecimento de áreas de conhecimento na empresa, baseado no diagnóstico e de acordo com os objetivos estratégicos e as metas de melhoria. Essas ações serão tratadas como um projeto de mudança. As atividades a serem realizadas nessa fase são:

2.1 Identificar, analisar e priorizar as áreas de conhecimento a serem melhoradas, com base nos perfis-alvo definidos na fase 1. As áreas de conhecimento a serem priorizadas são as com maior pontuação, atribuída durante a atividade 1.3. Dentre essas áreas de conhecimento selecionadas pode $(m)$ ser definida(s), ainda, a(s) 
mais prioritária(s) a ser(em) considerada(s) nos primeiros ciclos de melhoria. Para isso devem ser considerados benefícios, custos estimados, interdependência entre áreas de conhecimento, metas de negócio e melhoria, freqüência de uso da área de conhecimento, grau de divergência entre seus executores, número de atores envolvidos, etc. Poucas áreas de conhecimento devem ser selecionadas para serem estabelecidas em cada ciclo de melhoria.

2.2 Definir um plano de ação. Para isso, deve-se:

- Definir um patrocinador dentro da organização cujas responsabilidades englobam assegurar o comprometimento da alta gerência e assegurar verba para que os recursos necessários durante o processo de mudança sejam fornecidos.

- Definir o escopo do projeto de mudança: deve-se definir, em detalhes, as entregas do projeto de mudança e as ações necessárias para criar essas entregas. Devem ser documentados características e limites do projeto, além dos métodos de aceitação e controle do escopo. O escopo do projeto de mudança deve fornecer um entendimento comum a todos os stakeholders e descrever os principais objetivos do projeto.

- Criar a WBS (Work Breakdown Structure): o objetivo desta atividade é dividir as principais entregas do projeto e os pacotes de trabalho em componentes menores, ou seja, em atividades que se deseja controlar e monitorar durante o projeto.

- Elaborar o cronograma do projeto: deve-se estabelecer a programação do projeto, na qual estarão definidas as datas de início e término de cada atividade planejada, a precedência entre elas, as pessoas responsáveis por cada uma delas e os recursos necessários para a sua execução. Quando o cronograma estiver elaborado, deve-se nivelar o esforço das pessoas da equipe em relação à realização das atividades para evitar sobrecarga de algum colaborador, ou criar gargalos no desenvolvimento do projeto de 
mudança, decorrentes de excesso de atividades atribuídas à mesma pessoa.

- Avaliar os riscos: é importante identificar os principais riscos do projeto de mudança e administrar os riscos. Uma vez identificados, para administrá-los é preciso definir a probabilidade de ocorrência e o impacto de cada um deles. Para os riscos de maior importância e probabilidade de ocorrência, deve ser criado um plano de ação para sua mitigação e um plano de contingência.

- Garantir a infra-estrutura: deve-se garantir "como" a empresa vai dar suporte à mudança. Devem ser definidos os treinamentos para as equipes, como elas serão avaliadas, quais as ferramentas necessárias para a execução da mudança, e se a infra-estrutura existente é adequada.

\section{Fase 3. Definição das atividades da(s) área(s) de conhecimento}

Nessa fase deve ser realizada a definição/adaptação das atividades das áreas de conhecimento, selecionadas no projeto de mudança anteriormente planejado, de forma explícita e descritiva, para que as pessoas se orientem durante a execução dessas atividades. Para isso, poderiam ser utilizados normas e modelos de referência, tais como ISO/IEC 12207, CMMI, ISO/IEC 15504 e, até mesmo, processos proprietários como o RUP. Neste trabalho de pesquisa, sugere-se a utilização do Modelo ProcSoftVD.

As atividades que compõem essa fase são:

3.1 Identificar as principais atividades que serão executadas durante a realização da área de conhecimento. A seqüência de execução que elas acontecem e os desvios condicionais existentes podem ser visualizados por meio de um fluxograma ou de diagramas SADT.

3.2 Identificar os papéis e as responsabilidades relacionados a cada atividade selecionada. 
3.3 Identificar os artefatos que serão consumidos ou produzidos durante a execução de cada atividade, e, caso existam, seus respectivos templates.

3.4 Identificar as medidas que devem ser coletadas durante a execução de uma atividade, pois estabelecem quais dados quantitativos e qualitativos serão coletados para dar suporte à gerência de projetos, a melhoria e a garantia da qualidade.

3.5 Identificar outras informações importantes, como critérios de entrada e de saída, métodos e ferramentas.

\section{Fase 4. Implantação da(s) área(s) de conhecimento}

Nessa fase a área de conhecimento definida anteriormente deve ser institucionalizada e avaliada. Para isso, deve-se garantir que todos os envolvidos conheçam e utilizem a área de conhecimento e sejam coletados dados que dêem informações sobre os resultados obtidos. As atividades a serem realizadas são:

4.1 Planejar como será avaliada a área de conhecimento durante a sua execução. São definidas medidas que devem ser coletadas durante o uso da área de conhecimento, visando à análise das metas que foram definidas na fase de análise estratégica. Para isso, pode ser usado o método GQM (Goal-Question-Metric) (BASILI \& WEISS, 1984).

4.2 Definir o escopo de utilização da área de conhecimento, ou seja, decidir se o guia elaborado será utilizado inicialmente em todos os projetos da empresa ou apenas será executado um projeto piloto para avaliação.

4.3 Treinar e motivar os participantes envolvidos, dentro do escopo que foi definido, para que estejam aptos a desempenhar suas atividades. O objetivo desta atividade é mobilizar as pessoas integrantes da equipe do projeto de mudança, preparar e aplicar os treinamentos definidos como sendo requisitos para garantir a eficácia do projeto de mudança. 
4.4 Iniciar o uso do guia. Durante a utilização, as dúvidas que surgem são esclarecidas, sugestões e observações são anotadas e as medidas definidas durante o planejamento da avaliação são coletadas.

4.5 Analisar e interpretar os dados coletados durante a utilização do guia. Essa atividade deve ser realizada pelo engenheiro de processo junto a alguma outra pessoa da organização.

4.6 Apresentar os resultados da análise para a diretoria, para a tomada de decisão relacionada à iniciação de um novo ciclo de melhoria - projeto de mudança.

\subsection{Publicação web do Modelo de Gestão do Processo de Venda e Desenvolvimento On-demand para MPEs}

O ProcSoftVD - Gestão encontra-se disponível no endereço www.numa.org.br/GProcSoftVD. Na página principal (Figura 5.15) encontra-se uma breve introdução sobre o modelo. Há um menu do lado esquerdo com quatro links: "Visão Gráfica", "Visão Textual", "Mapeamento com CMMI e ISO/IEC 15504" e "ProcSoftVD - Melhoria". O primeiro link "Visão Gráfica" refere-se à apresentação do modelo em forma gráfica, onde as atividades serão representadas com a notação SADT (MCGOWAN \& MARCA, 1987) adaptada. 


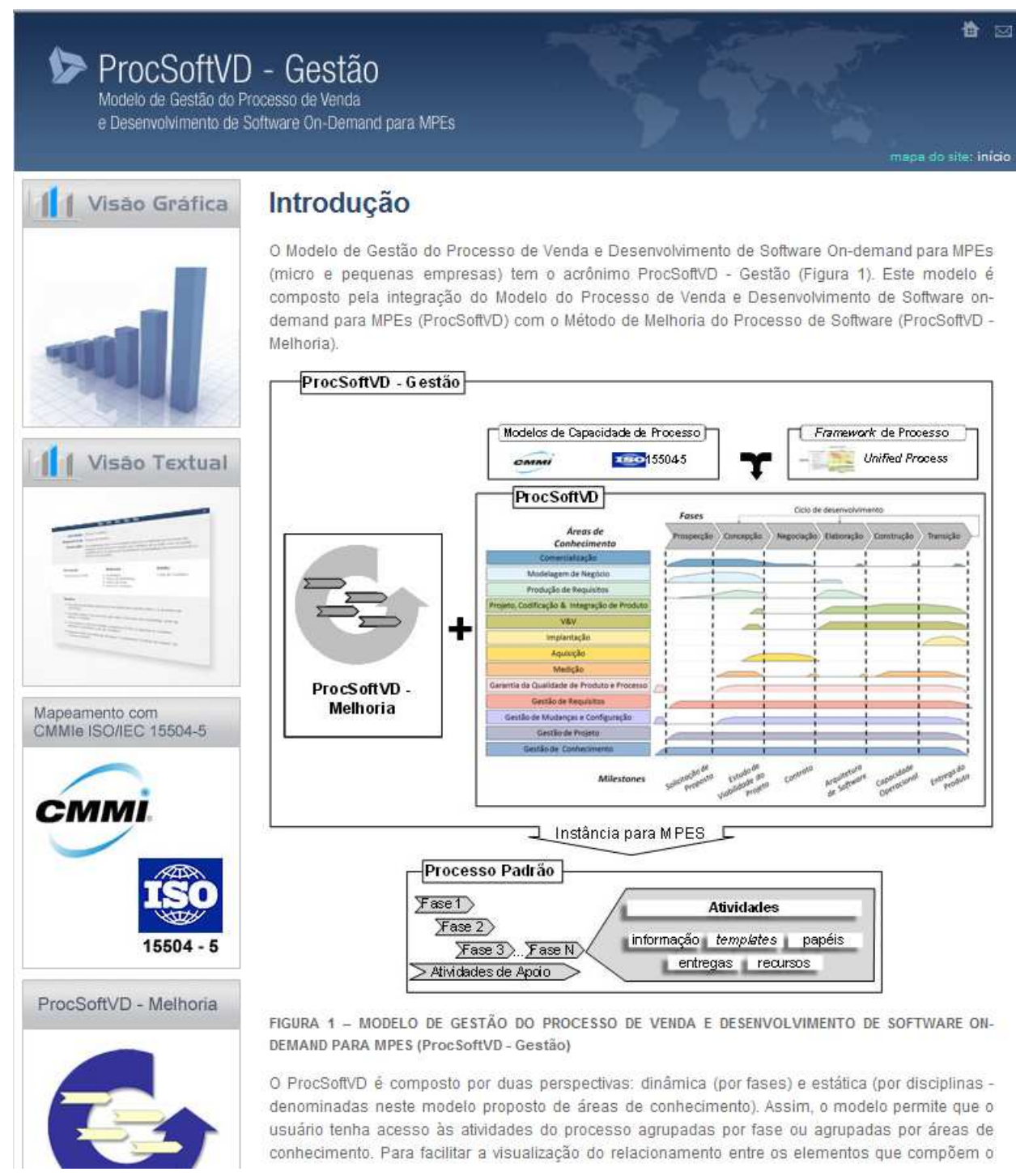

Figura 5.15 - PÁgina Principal do GProcSoftVD

Acessando o link "Visão Gráfica" é possível visualizar as atividades do modelo e a seqüência entre elas. A Figura 5.16 apresenta um exemplo de visão gráfica. 


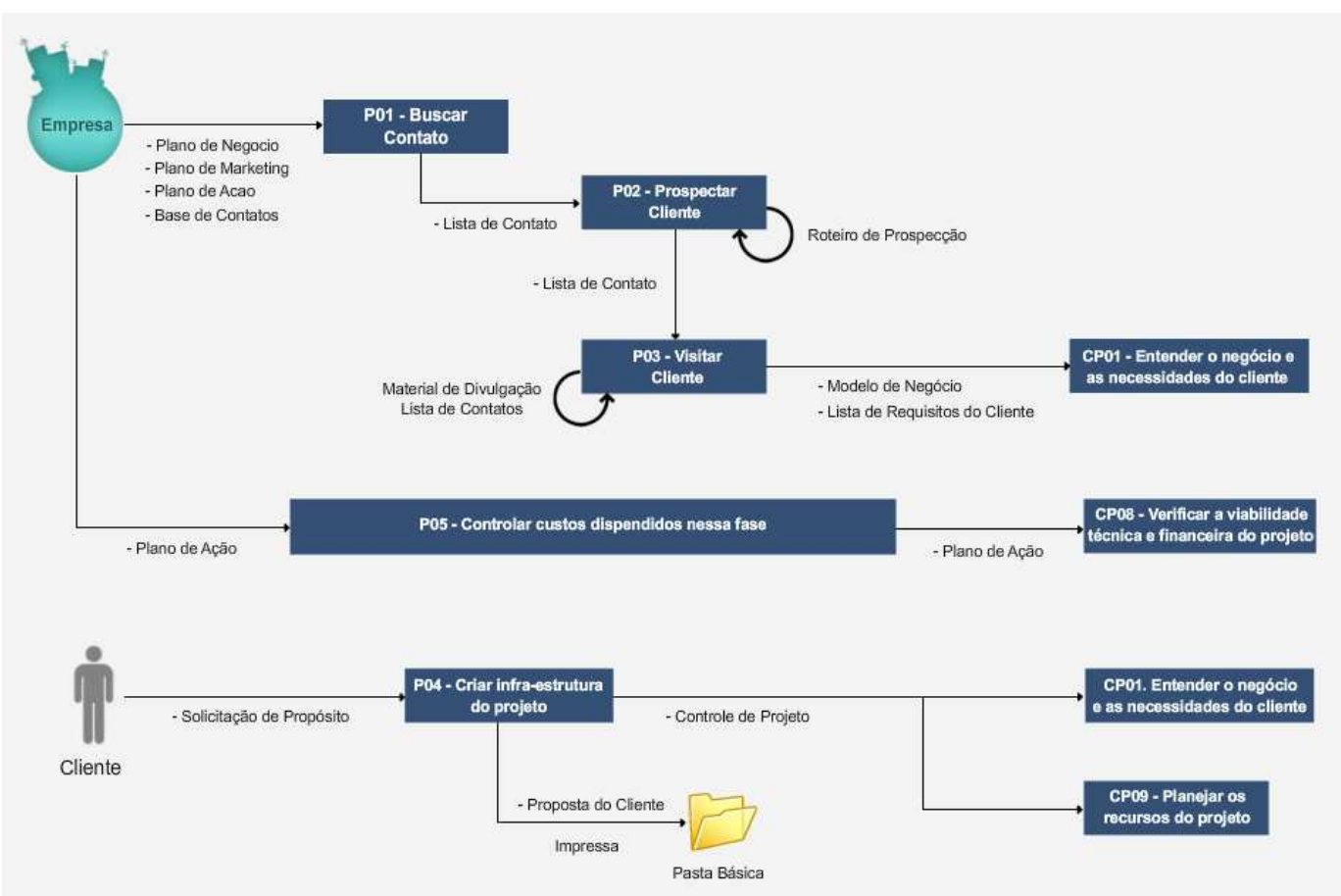

Figura 5.16 - EXEMPLO dE VISÃo GRÁFICA - FASE DE PROSPECÇÃo

Acessando o link "Visão Textual" é possível ter uma visão dinâmica (por fases) e estática (por áreas de conhecimento) do modelo (Figura 5.17). Clicando nas fases, tem-se acesso a uma página que mostra todas as atividades do modelo com suas respectivas entradas e saídas. Um exemplo é apresentado na Figura 5.18. Clicando nas atividades, tem-se acesso a uma página com todos os detalhes dessa atividade. Nessa página, as entradas e saídas que possuírem templates terão um link e os documentos com templates citados nas tarefas, serão representados com a marcação “( T )" (Figura 5.19). Os templates são formulários com uma possível estrutura para o artefato correspondente e, em alguns deles há exemplos e até mesmo uma breve revisão bibliográfica para explicar os conceitos pertinentes ao artefato. 


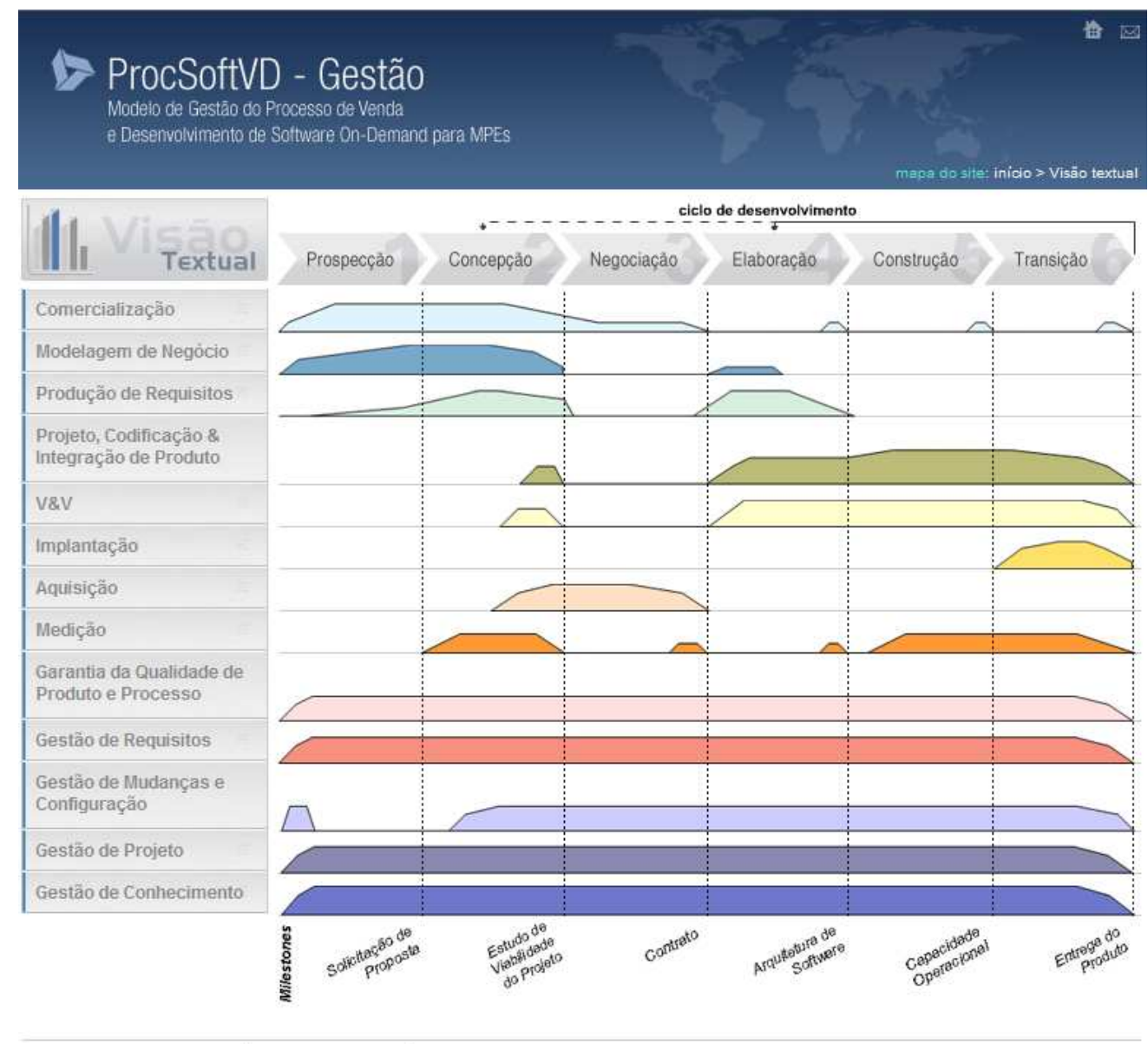

ProcSoftVD - Gestão - Modelo de Gestão do Processo de Venda e Desenvolvimento de Software On-Demand para MPEs

Figura 5.17 - Visão Textual: Perspectiva por Fases e por Áreas de Conhecimento 


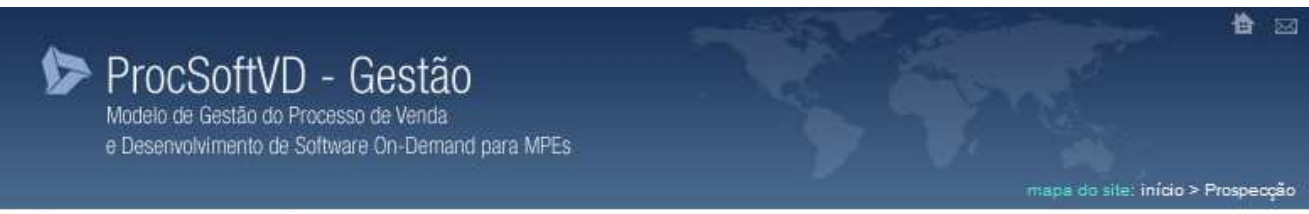

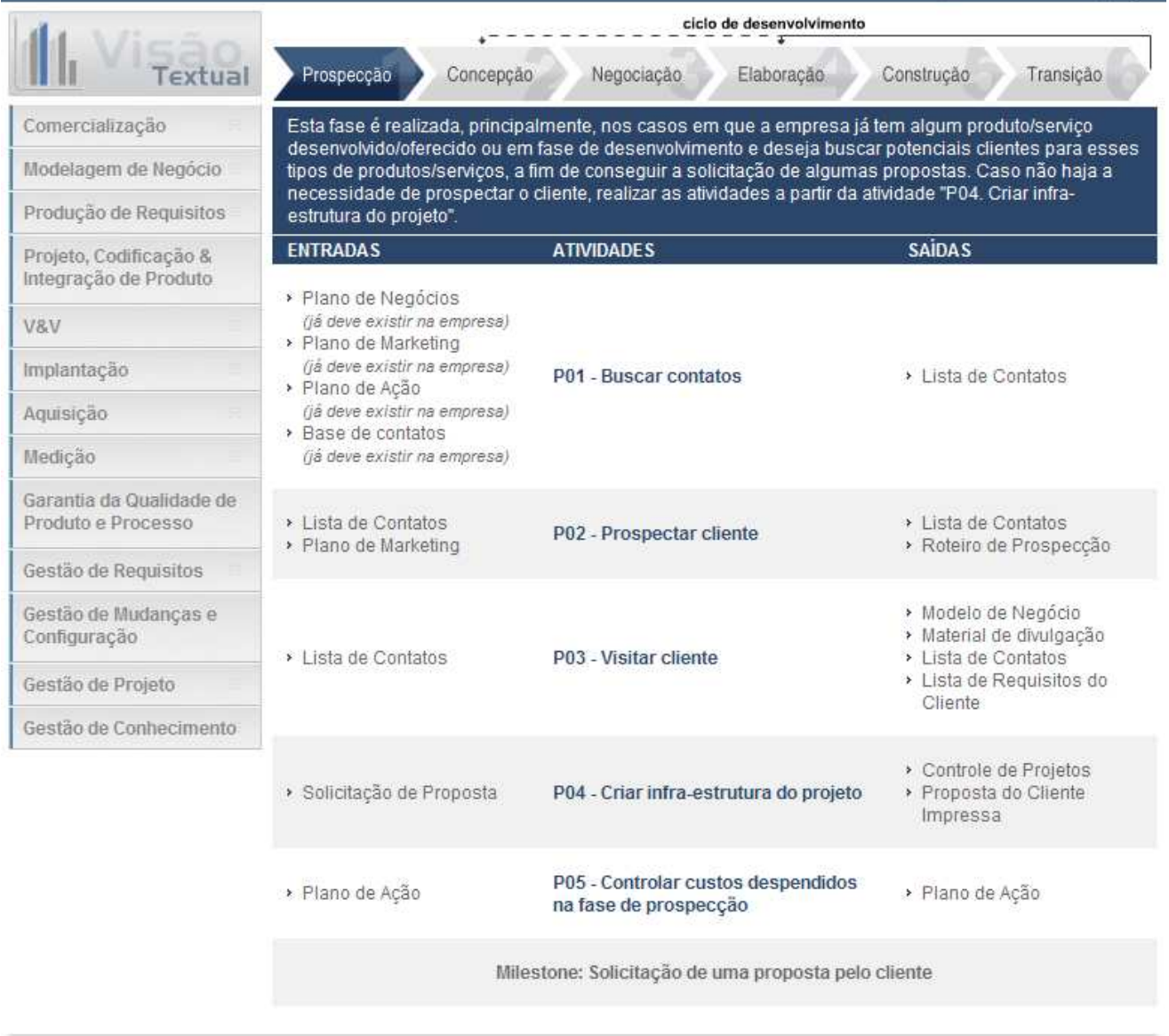

ProcSoftVD - Gestão - Modelo de Gestão do Processo de Venda e Desenvolvimento de Software On-Demand para MPES

\section{Figura 5.18 - EXEMPLo de UMA ATIVIDADE - FASE de PROSPECÇÃo}




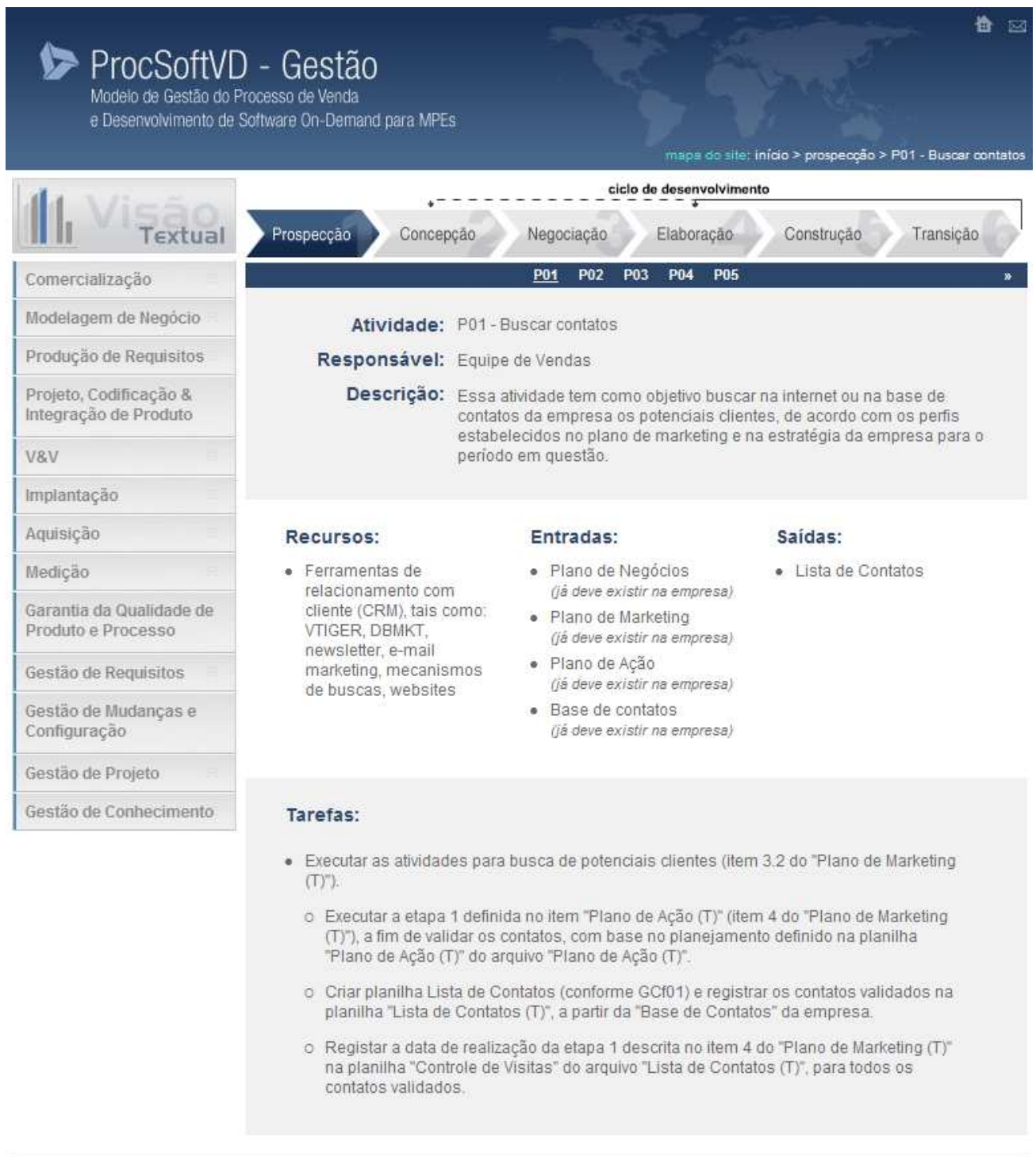

ProcSoftVD - Gestão - Modelo de Gestão do Processo de Venda e Desenvolvimento de Software On-Demand para MPES

Figura 5.19 - Exemplo de Detalhamento de Atividade

Acessando o link "Visão Textual" também é possível visualizar as áreas de conhecimento do modelo no menu à esquerda. Clicando nas áreas de conhecimento, tem-se acesso a uma página que mostra todas as atividades do modelo que possuem algo a ser realizado relativo àquela área de conhecimento (Figura 5.20). Clicando nas atividades, você tem acesso a uma página com todos os detalhes dessa atividade, como mostrado na Figura 5.19. Essa opção de visualizar as atividades por área de conhecimento é interessante para as MPEs que definiram um perfil de capacidade de processo a ser alcançado, ou seja, quais são as áreas de conhecimento de mais alta 
prioridade a serem melhoradas em sua empresa, por meio da aplicação do "Modelo para Melhoria do Processo de Software voltado para MPEs" (acessado por meio da página inicial do site, ao clicar no link "Melhoria do Processo de Software voltado para MPEs" no menu do lado esquerdo).

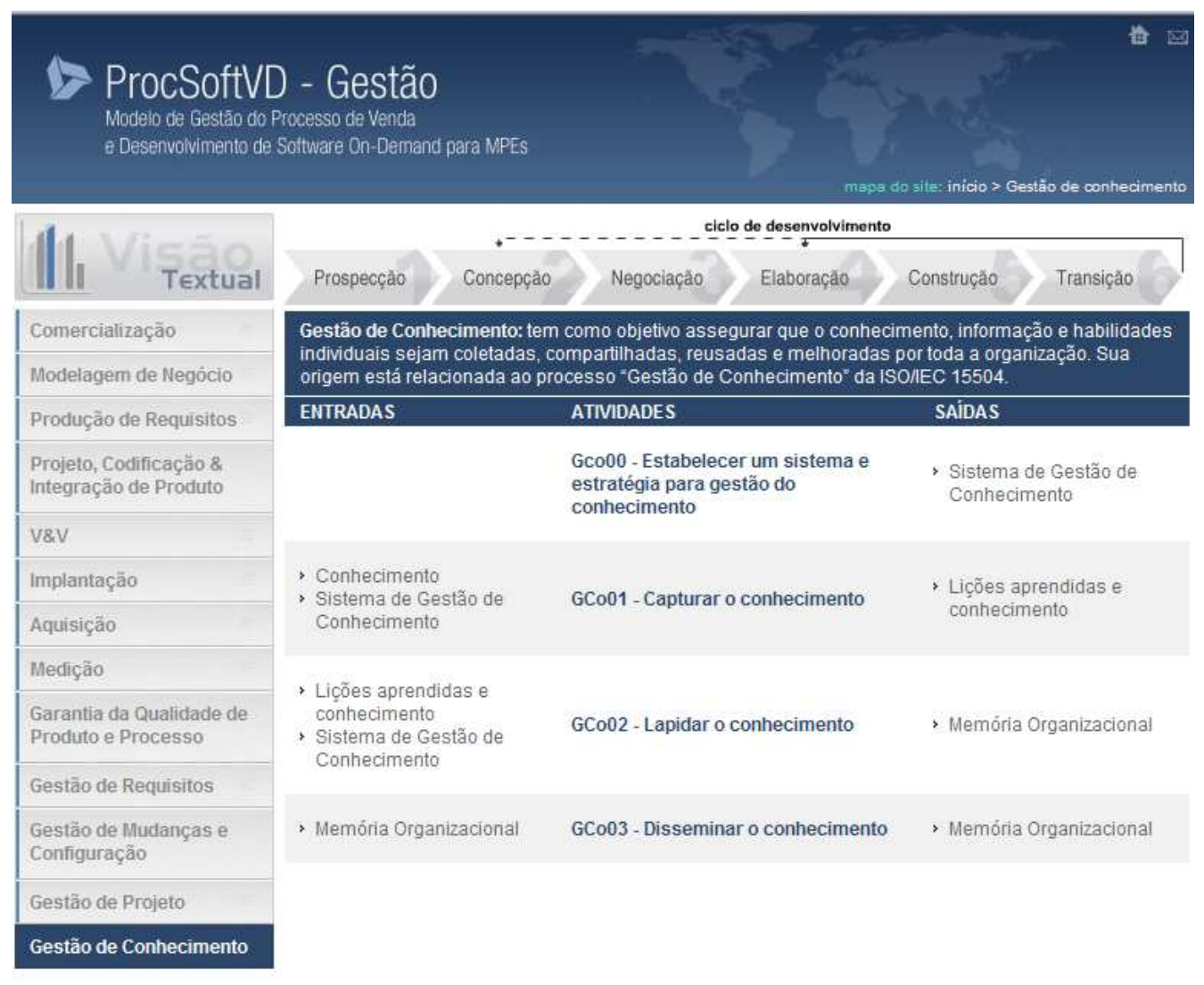

ProcSoftvD - Gestão - Modelo de Gestão do Processo de Venda e Desenvolvimento de Software On-Demand para MPES

Figura 5.20 - Atividades da Área de Conhecimento “Gestão de Conhecimento"

O mapeamento de todas as atividades do modelo ProcSoftVD com os objetivos específicos do CMMI-DEV e práticas-base da ISO/IEC 15504-5 está disponível por meio do acesso ao link "Mapeamento com CMMI e ISO/IEC 15504" no menu do lado esquerdo da página inicial do site (Figuras 5.21 e 5.22). 


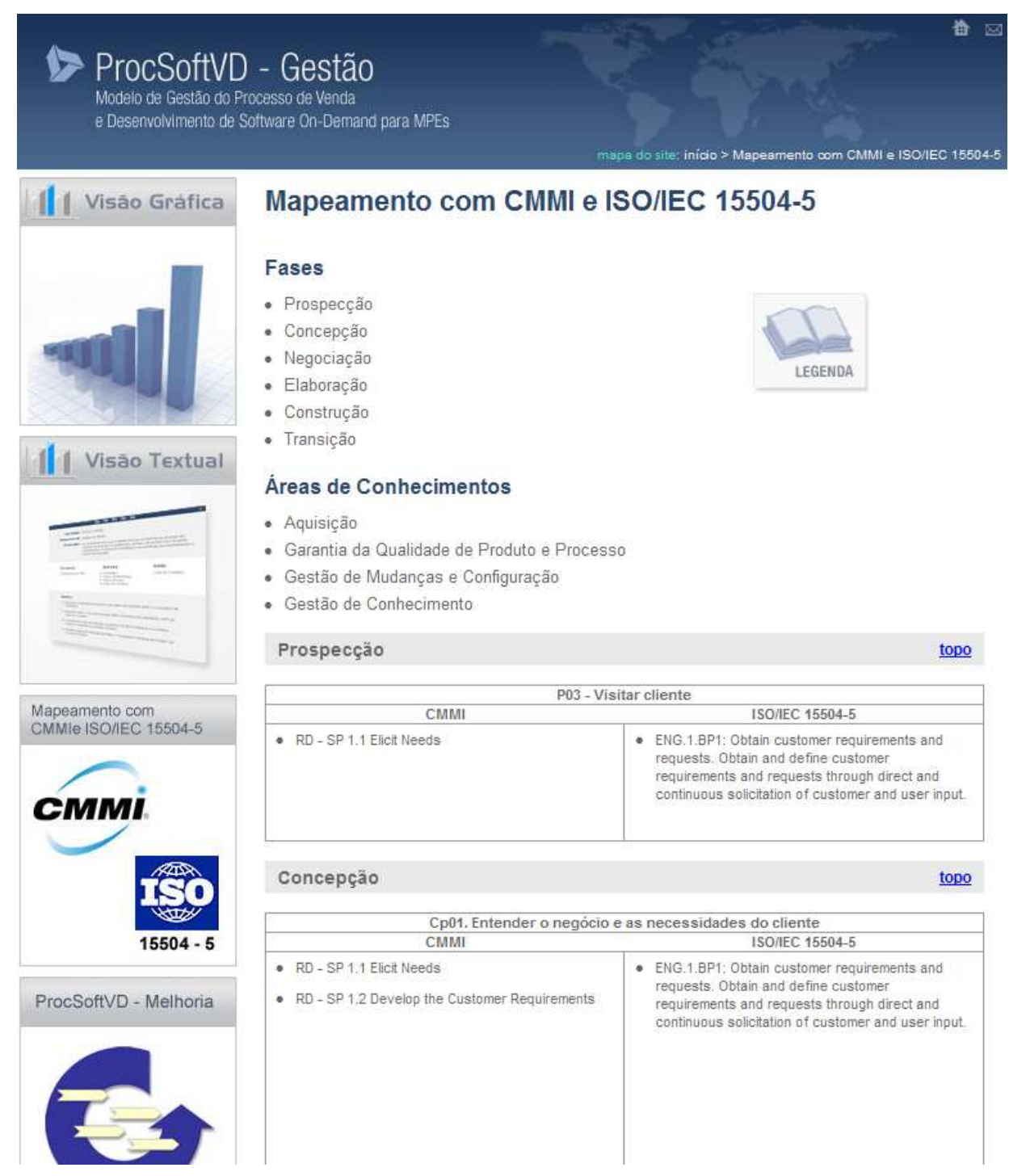

Figura 5.21 - MAPEAmento do ProcSoftVD com CMMI E ISO/IEC 15504-5 


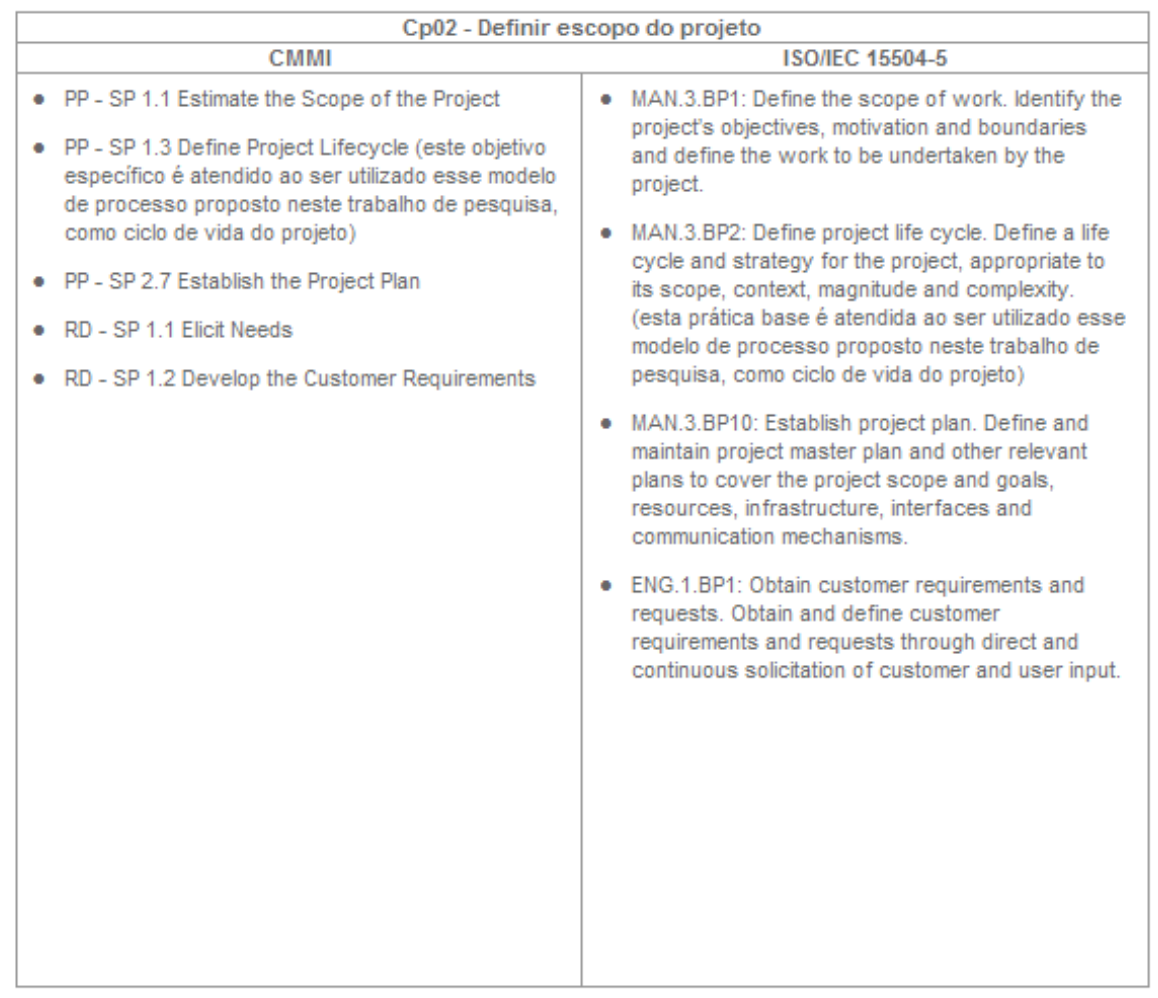

Figura 5.22 - Exemplo de Mapeamento da Atividade "Definir escopo do Projeto"

Os Apêndices 3, 4 e 5 apresentam o modelo ProcSoftVD por completo.

\subsection{Considerações Finais}

Este capítulo apresentou o processo de desenvolvimento da principal entrega deste trabalho de pesquisa: o Modelo de Gestão do Processo de Venda e Desenvolvimento de Software On-demand para MPEs (ProcSoftVD - Gestão).

No próximo capítulo são apresentadas as aplicações do Modelo ProcSoftVD Gestão e os resultados obtidos durante essas aplicações. 


\section{Aplicações e Resultados do Modelo ProcSoftVD - Gestão}

\subsection{Considerações Iniciais}

O ProcSoftVD - Gestão foi aplicado em uma MPE (seção 6.2) e o ProcSoftVD foi verificado em dois tipos de avaliação: análise dos pontos fortes e fracos do modelo por parte de profissionais da área (seção 6.3) e análise do modelo quanto às características de qualidade de produto (seção 6.4).

\subsection{Aplicação do ProcSoftVD - Gestão}

A aplicação foi realizada em uma MPE (Empresa 2) que possui uma carteira de 40 (quarenta) clientes, aproximadamente, e possui 3 (três) funcionários.

Após a aplicação do método de melhoria de processo ProcSoftVD - Melhoria, descrita no Apêndice 6, as áreas de conhecimento Modelagem de Negócios e Produção de Requisitos foram selecionadas como mais prioritárias e, por isso, foram implantadas no primeiro ciclo de melhoria nessa MPE.

Foi relatado pelo desenvolvedor que aplicando as atividades e templates sugeridos para essas áreas de conhecimento, pôde perceber o quão mais fácil é desenvolver um software quando se entende realmente o negócio do cliente e quando esse negócio é documentado de alguma forma que lhe dê subsídio para tirar eventuais dúvidas durante a definição dos requisitos do software a ser desenvolvido.

Anteriormente à aplicação dessas áreas de conhecimento, não se tinha nenhuma sistemática em relação a elas na empresa, além de não se ter templates para facilitar o registro das informações obtidas com o cliente. O desenvolvedor da empresa também relatou que o tempo investido para realizar as atividades de modelagem de negócios e produção de requisitos foi compensado por meio da 
minimização de erros encontrados no software ao realizar os testes de mesa, da forma como realizam na empresa.

\subsection{Análise dos Pontos Fortes e Fracos do Modelo ProcSoftVD}

Foi realizada uma análise do modelo ProcSoftVD por 6 (seis) profissionais da área de computação, a partir de um questionário (Apêndice 7).

Os critérios a serem atendidos para selecionar esses profissionais foram: ter experiência como analista de sistemas e desenvolvedor de programas e ter conhecimentos a respeito da área de engenharia de software. O perfil de cada um dos profissionais é descrito, a seguir.

- Um profissional (P1) com graduação na área de computação e mestrado na área de informática educacional que já trabalhou em empresas desempenhando as funções de analista de sistemas/programador e até mesmo de gerente de CPD. Atualmente, é docente em uma universidade e leciona disciplinas, tais como: Fundamentos de Sistemas de Informação, Gestão da Informação e de Sistemas de Informação, Inglês Técnico, Introdução à Ciência da Computação e Engenharia de Software.

- Um profissional (P2) com graduação e mestrado na área de computação que já trabalhou em um CPD de uma universidade desempenhando as funções de analista de sistemas/programador. Atualmente, é docente em uma universidade e leciona disciplinas, tais como: Algoritmos, Engenharia de Software, Banco de Dados, Linguagens de Programação (Delphi, JavaScript).

- Um profissional (P3) com graduação e mestrado na área de computação que atua como coordenador do Curso em Ciência da Computação em uma universidade e docente de disciplinas, tais como: Análise e Projeto de Sistemas Orientados a Objetos, Engenharia de Software, Banco de Dados, Algoritmos e Linguagens de Programação. 
- Um profissional (P4) com graduação, mestrado e doutorado na área de computação que já trabalhou desempenhando o papel de analista de sistemas/programador em uma empresa. Atualmente, é docente em uma universidade pública e leciona as disciplinas: Engenharia de Software, Linguagens de Programação (JAVA), Compiladores e Teoria da Computação. Já atuou como programador em empresas.

- Um profissional (P5) que está finalizando seu curso de graduação em Sistemas de Informação, entretanto, é proprietário de uma empresa de desenvolvimento de software que está no mercado há 8 anos e tem uma carteira de, aproximadamente, 40 clientes de um determinado produto da empresa - a MPE onde foram aplicadas as áreas de conhecimento "Modelagem de Negócios" e "Produção de Requisitos".

- Um profissional (P6) que está finalizando seu curso de graduação em Sistemas de Informação, tem uma empresa de desenvolvimento de software incubada na INTEPP (Incubadora Tecnológica de Presidente Prudente) e adotou o modelo de processo, elaborado nesse trabalho de pesquisa, como guia para orientar nas atividades de venda e desenvolvimento de software na sua empresa.

As respostas desses 6 (seis) profissionais da área de computação podem ser visualizadas no Apêndice 8 . Os resultados consolidados, a partir dessas respostas, são:

- Quanto à Área de Conhecimento Comercialização: o modelo cobre atividades relacionadas à comercialização as quais a organização desenvolvedora deve se preocupar. Essas atividades fornecem condições para o gerenciamento do contato com o cliente, transmitindo eficiência e credibilidade perante o cliente, além de abranger aspectos formais da comercialização sem exageros, por meio de uma linguagem de fácil entendimento. 
- Quanto à Área de Conhecimento Modelagem de Negócios: as tarefas que incluem a modelagem de negócio estão claramente definidas, com foco em aspectos fundamentais dessa área de conhecimento. Há clareza na exposição das atividades e riqueza de detalhes por meio dos templates que mostram exemplos e sugestões.

- Quanto à Área de Conhecimento Produção de Requisitos: "Tempo despendido em modelagem, análise e produção de requisitos é um excelente investimento, e não um gasto" - comentário realizado por um dos profissionais. O modelo apresenta as atividades e templates relacionados à produção de requisitos de modo completo, seguindo diretrizes do padrão de documentação de requisitos IEEE 830 e atendendo aos objetivos específicos do CMMI em relação à área de processo "Desenvolvimento de Requisitos". Entretanto, um dos profissionais relatou que o material para ser lido, analisado, documentado e empreendido, para autônomos e equipes pequenas, é bastante extenso.

- Quanto à Área de Conhecimento Projeto, Codificação \& Integração de Produto: um dos profissionais relatou que "um software deve ser bem projetado para ser desenvolvido de forma a permitir uma fácil manutenção e evolução dele, pois os custos de manutenção são muito superiores ao custo de desenvolvimento". O modelo apresenta um vasto material de apoio para a transformação dos requisitos em uma solução de projeto, fornecendo subsídios para o início da codificação por parte dos responsáveis pelo desenvolvimento do software.

- Quanto à Área de Conhecimento V\&V: as atividades de V\&V, especialmente os testes, têm grande importância durante o desenvolvimento do software. Essas atividades foram bem distribuídas nas fases do modelo ProcSoftVD, tendo uma presença marcante no modelo. 
- Quanto à Área de Conhecimento Implantação: o modelo apresenta atividades relacionadas à implantação dos releases do produto ao cliente de forma completa, facilitando o gerenciamento das entregas ao cliente.

- Quanto à Área de Conhecimento Aquisição: o modelo contribui com essa área de conhecimento, pois mostra com clareza o que pode ser realizado para realizar a cotação e análise dos melhores fornecedores para viabilizar o projeto de desenvolvimento para a empresa e para ter controle da qualidade dos produtos/serviços adquiridos.

- Quanto à Área de Conhecimento Medição: o modelo fornece subsídios para se obter dados relacionados aos projetos da empresa, dados como tempo estimado e concretizado, valor cobrado, entre outros, que serão utilizados para estimativas em projetos futuros. Além disso, deixa evidente a importância da definição de critérios de medição e coleta de medidas para o aprimoramento do processo e para a garantia da qualidade do produto.

- Quanto à Área de Conhecimento Garantia da Qualidade de Produto e Processo: a garantia da qualidade tanto do produto quanto do processo foi apontada no modelo em todas as etapas de desenvolvimento, o que representa uma potencialidade do modelo.

- Quanto à Área de Conhecimento Gestão de Requisitos: a gestão de requisitos é abordada no modelo de maneira bem articulada e completa. Durante o avanço nas fases do modelo, nas atividades onde podem ser realizadas modificações nos requisitos, o modelo apresenta atividades de rastreamento dos requisitos e direciona as modificações para serem tratadas pelas atividades de gestão de mudanças e configuração. Um ponto vulnerável detectado foi o caso de não estar explícito no modelo o gerenciamento dos requisitos relacionados aos possíveis componentes (de software, por exemplo) adquiridos de fornecedores. 
- Quanto à Área de Conhecimento Gestão de Projetos: é importante entender o escopo do projeto e fazer o planejamento preliminar desse escopo, a fim de ser ter uma visão macro em relação ao que se pretende atingir com o produto resultante do projeto, quanto custará, quanto tempo demorará para ser produzido e qual o retorno financeiro desse projeto. E, também, é importante fazer o monitoramento e controle desse projeto para que se possa tomar medidas reativas e até mesmo pró-ativas. O modelo ProcSoftVD atende a esses requisitos.

- Quanto à Área de Conhecimento Gestão de Mudanças e Configuração: o modelo mostra os cuidados que devem ser tomados e os controles necessários ao ser realizada alguma modificação no projeto em desenvolvimento. Entretanto, seria interessante que o modelo explicitasse alguma forma de help-desk para auxiliar no controle das solicitações de modificações, principalmente do cliente.

- Quanto à Área de Conhecimento Gestão de Conhecimento: o modelo mostra uma forma de gerenciar o conhecimento de todos os colaboradores da empresa, fazendo com que o conhecimento e experiência de um colaborador sejam disseminados para outros interessados.

Além de identificar pontos fracos e fortes do modelo em relação a cada área de conhecimento, os seis profissionais responderam a quatro questões. As respostas para essas questões encontram-se no Apêndice 9. Para os profissionais que não conheciam o CMMI e a ISO/IEC 15504, foi realizada uma apresentação, expondo os conceitos, estrutura e funcionamento de cada um deles.

Quanto à análise do mapeamento das atividades do modelo ProcSoftVD para com os objetivos específicos do CMMI e as práticas-base da ISO/IEC 15504-5, foram realizadas entrevistas desestruturadas com os profissionais (P1, P2, P3, P4, P5 e P6). De forma geral, esses profissionais acreditam que esse mapeamento possa ser 
bastante interessante para o caso de empresas que desejam futuramente iniciar um processo de certificação pelo CMMI ou MPS.BR, e até mesmo para que as empresas tenham consciência que as atividades sugeridas pelo modelo ProcSoftVD são condizentes com o que modelos de capacidade de processo existentes no mercado definem como sendo o ideal.

\subsection{Análise das características de qualidade do Modelo ProcSoftVD}

O modelo ProcSoftVD foi avaliado pelos profissionais (P1, P2, P3, P4, P5 e P6) quanto a cinco características de qualidade definidas pela ISO/IEC 9126-1 ${ }^{25}$, adaptadas para o produto "modelo de processo de software". As características avaliadas são: funcionalidade, usabilidade, manutenibilidade, portabilidade e eficiência.

Os profissionais selecionaram entre os níveis de atendimento "alto", "médio", "baixo" e "NA - não se aplica" do modelo ProcSoftVD para cada uma das subcaracterísticas da característica avaliada e, também, fizeram comentários justificando suas respostas. As opções selecionadas pelos profissionais quanto às subcaracterísticas foram organizadas no Quadro 6.1.

\footnotetext{
${ }^{25}$ ISO/IEC 9126-1: International Standard Organization (2001). Software Engineering - Product Quality.
} Part 1: Qualit Model. 
Quadro 6.1 - Características de qualidade do Modelo ProcSoftVd

\begin{tabular}{|c|c|c|c|c|c|c|c|}
\hline Características & Subcaracterísticas & P1 & P2 & P3 & $\mathbf{P 4}$ & P5 & P6 \\
\hline \multirow{4}{*}{$\begin{array}{l}\text { Funcionalidade: } \\
\text { Satisfaz as } \\
\text { necessidades? }\end{array}$} & Adequação: Propõe-se a fazer o que é apropriado? & Alto & Alto & Alto & Médio & Alto & Alto \\
\hline & Acurácia: Faz o que foi proposto de forma precisa? & Alto & Alto & Médio & Baixo & Médio & Alto \\
\hline & Interoperabilidade: Interage com modelos/normas especificados? & Alto & Alto & Médio & Médio & Médio & Alto \\
\hline & Segurança: Evita acesso não autorizado aos dados? & Baixo & NA & NA & NA & NA & Baixo \\
\hline \multirow{4}{*}{$\begin{array}{l}\text { Usabilidade: É fácil de } \\
\text { usar? }\end{array}$} & Inteligibilidade: É fácil entender sua aplicação e operação? & Alto & Alto & Médio & Baixo & Médio & Alto \\
\hline & Aprendizagem: É fácil de aprender a usar? & Alto & Médio & Médio & Baixo & Médio & Médio \\
\hline & Operacionalização: É fácil de operar e controlar? & Alto & Alto & Médio & Baixo & Médio & Médio \\
\hline & Atratividade: Pode ser atraente ao usuário? & Alto & Alto & Médio & Baixo & Médio & Alto \\
\hline \multirow{4}{*}{$\begin{array}{l}\text { Manutenibilidade: } \text { É } \\
\text { fácil de modificar? }\end{array}$} & Analisabilidade: É fácil de encontrar uma falha, quando ocorre? & Alto & Médio & Baixo & Baixo & Alto & Alto \\
\hline & Modificabilidade: É fácil modificar e adaptar? & Médio & Alto & Médio & Baixo & Alto & Alto \\
\hline & Estabilidade: Há grande risco quando se faz alterações? & Alto & Alto & Alto & Baixo & Médio & Médio \\
\hline & Testabilidade: É fácil testar quando se faz alterações? & Alto & Alto & Médio & Baixo & Médio & Médio \\
\hline \multirow{4}{*}{$\begin{array}{l}\text { Portabilidade: É fácil } \\
\text { de usar em outro } \\
\text { ambiente (no caso, em } \\
\text { outra MPE)? }\end{array}$} & $\begin{array}{l}\text { Adaptabilidade: É fácil adaptar a outros ambientes (no caso, outras } \\
\text { MPEs)? }\end{array}$ & Médio & Médio & Alto & NA & Médio & Alto \\
\hline & $\begin{array}{l}\text { Capacidade para ser instalado: É fácil instalar em diversos ambientes } \\
\text { (no caso, em diversas MPEs)? }\end{array}$ & Baixo & Alto & Alto & NA & Médio & Alto \\
\hline & $\begin{array}{l}\text { Capacidade para co-existir: É capaz de repartir os recursos com outro } \\
\text { modelo de processo de software? }\end{array}$ & Alto & Médio & Médio & NA & Médio & Alto \\
\hline & $\begin{array}{l}\text { Capacidade para substituir: Ele pode facilmente substituir outro modelo } \\
\text { de processo de software? }\end{array}$ & NA & Alto & Baixo & NA & NA & Alto \\
\hline \multirow{2}{*}{$\begin{array}{l}\text { Eficiência: É rápido e } \\
\text { "enxuto"? }\end{array}$} & $\begin{array}{l}\text { Tempo de resposta: Qual é o tempo de resposta, a velocidade de } \\
\text { execução? }\end{array}$ & Alto & Alto & Baixo & Baixo & Médio & Médio \\
\hline & Recursos empregados: Quanto recurso usa? Durante quanto tempo? & Baixo & Alto & Alto & Alto & Alto & Alto \\
\hline
\end{tabular}

Pode-se verificar divergência nas respostas dos profissionais P1, P2, P3, P4, P5 e P6 (Figura 6.2), uma vez que não houve consenso em relação a nenhuma característica analisada, evidenciando a influência dos conhecimentos prévios desses profissionais.

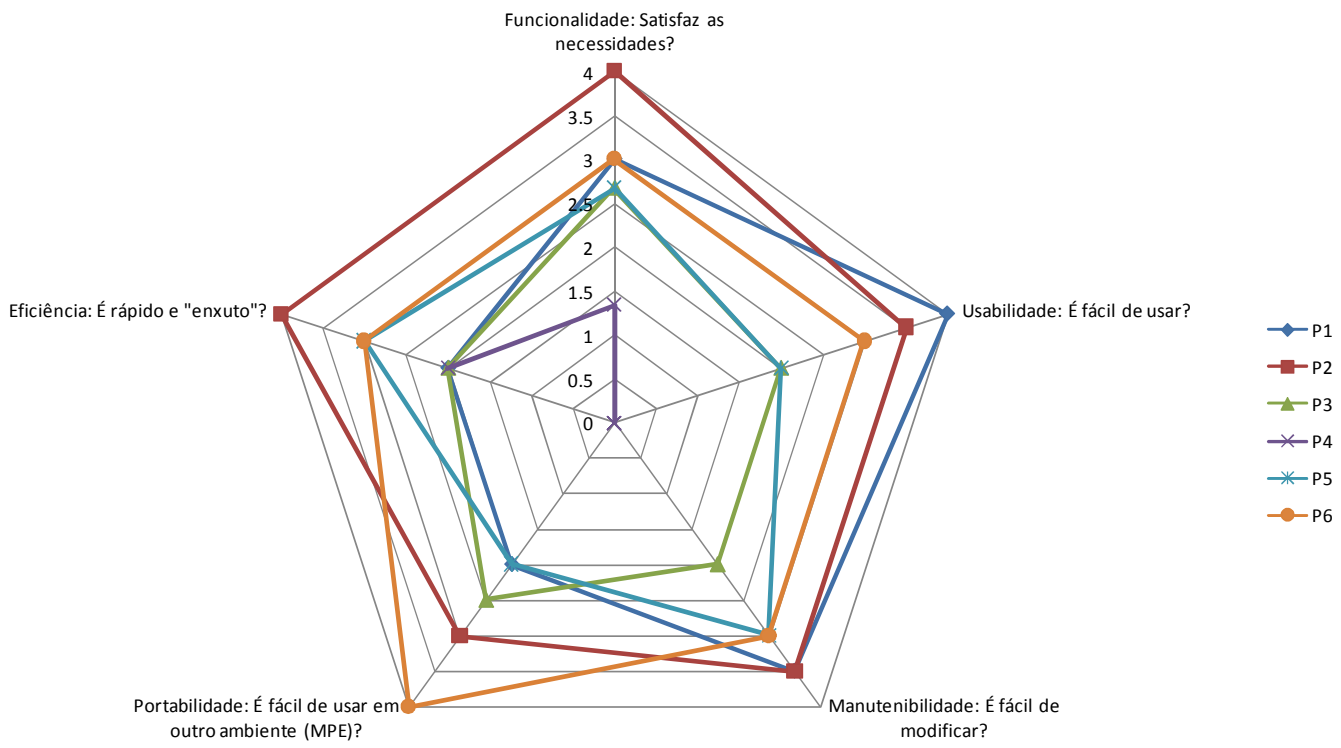

FIGURA 6.2 - GRÁFICO dE RELAÇÃo ENTRE AS RESPOSTAS DOS PROFISSIONAIS 
Entretanto, os comentários dos profissionais relacionado a cada uma das subcaracterísticas foram compilados e resultaram nas seguintes informações:

- Quanto à funcionalidade do modelo ProcSoftVD: o modelo propõe-se a realizar o que é apropriado, pois oferece um guia de melhoria do processo de software para MPEs com templates bem elaborados e sugestivos que conduzem o usuário. Entretanto, a estrutura organizacional da empresa (considerando o conhecimento dos colaboradores e infraestrutura da organização) é um fator determinante para o sucesso da aplicação do modelo.

- Quanto à usabilidade do modelo ProcSoftVD: o modelo apresenta as atividades com um nível de esclarecimento, explicações e orientações muito bom e, portanto, fácil de entender. Entretanto, o uso do modelo se torna mais fácil quando o usuário já tem conhecimentos relacionados aos processos de desenvolvimento. A apresentação do modelo em um site permite que o modelo seja consultado por qualquer usuário que navegue pela internet em busca de possíveis soluções para os problemas em sua empresa por falta de um processo bem definido.

- Quanto à manutenibilidade do modelo ProcSoftVD: como qualquer outro modelo, o ProcSoftVD apresenta relacionamentos entre as atividades das diversas áreas de conhecimento. Sendo assim, durante o processo de instanciação do modelo em uma MPE, é preciso ter atenção ao serem realizadas as adaptações pertinentes, pois uma modificação em uma atividade pode impactar várias outras atividades do modelo.

- Quanto à portabilidade do modelo ProcSoftVD: existe a possibilidade de instanciar todo o modelo para empresa ou instanciar apenas determinadas áreas de conhecimento para ser utilizada em uma MPE. Entretanto, sugerese que a instância do modelo para a empresa seja realizada por alguém 
que tenha conhecimento sobre atividades existentes em modelos de processo de software.

- Quanto à eficiência do modelo ProcSoftVD: considerando que a eficiência refere-se à rapidez de aplicação do modelo e também à questão de recursos necessários para essa aplicação, é preciso realizar a implantação do modelo em outras MPEs para se ter uma amostra mais significativa para se chegar a uma conclusão quanto a essa característica. De qualquer modo, é difícil quantificar os recursos a serem usados, pois uma mesma pessoa na empresa (principalmente em MPEs) pode realizar vários papéis. Além disso, instanciar um modelo não é uma tarefa rápida e trivial. Em princípio, acredita-se que enquanto os usuários não estiverem familiarizados com o processo esse tende a ser realizado de maneira lenta.

\subsection{Considerações Finais}

Neste capítulo foram apresentados os resultados da aplicação do modelo em uma MPE e as avaliações do modelo, segundo seus pontos fortes e fracos e segundo as características de qualidade, por 6 (seis) profissionais da área de computação.

O próximo capítulo discorrerá sobre as conclusões e trabalhos futuros. 


\section{Conclusões e Trabalhos Futuros}

\subsection{Considerações Iniciais}

O presente trabalho de pesquisa propõe um Modelo de Gestão do Processo de Venda e Desenvolvimento de Software On-demand para MPEs (ProcSoftVD - Gestão) que integra os modelos/normas de capacidade de processo CMMI-DEV e ISO/IEC 15504-5 com o framework Unified Process, no contexto de gestão de processos de negócio.

A avaliação do modelo foi realizada utilizando uma amostra de seis profissionais da área e duas MPEs, amostra essa considerada pequena dada a complexidade do assunto analisado. Isso evidencia uma restrição metodológica do trabalho, já que não foi possível considerar uma amostra representativa. Assim, as conclusões aqui expostas referem-se a uma visão parcial. Entretanto, essa visão permitiu identificar algumas evidências sobre pontos vulneráveis do modelo que serão expostos (juntamente aos pontos fortes do modelo) na próxima seção, e que deverão ser explorados com maior rigor em trabalhos futuros, descritos na seção 7.3.

\subsection{Conclusões}

Por meio da análise dos dados obtidos durante as avaliações do modelo, podese concluir que para as MPEs analisadas foi mais interessante utilizar como modelo de referência para criar o seu processo padrão o ProcSoftVD, ao invés de criar o seu processo padrão a partir de modelos de capacidade de processo, tais como o CMMI e a ISO/IEC 15504-5, devido ao nível de detalhamento das atividades por meio das tarefas e templates sugeridos.

O modelo ProcSoftVD aborda vários aspectos relevantes do processo de desenvolvimento de software para as MPEs. É viável, pois além de descrever cada fase do modelo proposto com um vocabulário de fácil entendimento, ainda 
indica/sugere formas para sua aplicação na empresa. Além disso, os artefatos criados pelas atividades possuem referências, fundamentação teórica e exemplos sobre cada assunto que pode não ser trivial ao seu público-alvo.

Mostrou-se útil para conscientizar uma MPE sobre a necessidade e vantagens de se ter um processo padrão, uma vez que atualmente várias empresas estão perdendo licitações por não atenderem aos modelos de capacidade de processo, como o CMMI. Uma certificação desse tipo é bastante cara e talvez uma MPE ainda não tenha recursos o suficiente para tal. Nesse contexto, o ProcSoftVD - Gestão pode ser acessado por qualquer MPE brasileira, pois seu acesso é livre e gratuito, o que minimiza os investimentos com consultoria externa.

Uma das características relevantes do modelo ProcSoftVD é a possibilidade de selecionar as áreas de conhecimento mais prioritárias a serem implantadas na empresa aos poucos, de acordo com os ciclos de melhoria definidos na aplicação do Método de Melhoria de Processo de Venda e Desenvolvimento de Software ondemand (ProcSoftVD - Melhoria) elaborado neste trabalho de pesquisa. Essa característica foi evidenciada durante a instanciação do modelo ProcSoftVD nas duas MPEs participantes do projeto de pesquisa.

Uma característica inédita identificada foi a abordagem de atividades da área de conhecimento "Comercialização" (além das sugeridas pela ISO/IEC 15504-5) e as fases de "Prospecção" e "Negociação" no processo de desenvolvimento de software on-demand, pois envolvem atividades de busca por potenciais clientes, atividades de entendimento das necessidades do cliente para que haja um acordo entre as partes envolvidas - o cliente e a empresa - em relação aos requisitos a serem atendidos, atividades relacionadas à viabilidade financeira do projeto e relacionadas ao pagamento dos produtos/serviços vendidos pela empresa.

Em relação à área de conhecimento "Gestão de Conhecimento", não foi possível no âmbito deste trabalho encontrar evidências a respeito de sua efetividade, pois nos ciclos de melhoria definidos pelas MPEs participantes do projeto essa área 
não foi considerada nos primeiros ciclos de melhoria. Acompanhar o ciclo completo de melhoria do processo na empresa requer mais tempo de implantação e análise.

\subsection{Trabalhos Futuros}

Alguns trabalhos futuros propostos, a partir da análise dos resultados e conclusões expostos são:

- Aplicação do modelo em outras MPEs para se ter uma amostra mais significativa;

- Definição de um ambiente (PSEE) que apóie a definição do modelo de processo de uma MPE, a partir do Modelo ProcSoftVD;

- Expansão do modelo para cobertura de outras áreas de conhecimento;

- Definição de perfis de capacidade de processo voltados a possíveis situações enfrentadas por MPE's;

- Análise da inclusão de práticas ágeis no Modelo ProcSoftVD;

- Mapeamento das atividades do Modelo ProcSoftVD com os resultados esperados do MPS.BR;

- Investigação de como utilizar o Modelo ProcSoftVD como material de treinamento para melhoria de processos em MPEs;

- Adaptação do modelo para o caso de incubadoras.

\subsection{Considerações Finais}

Este capítulo apresentou as conclusões sintetizadas a partir dos resultados desse trabalho de pesquisa, além dos trabalhos que podem ser desenvolvidos na linha de evolução do Modelo ProcSoftVD - Gestão. 


\section{Referências}

AALST, W. M. P. van der; HOFSTEDE, A. H. M. ter; WESKE, M. (2003). Business Process Management: A Survey. BPM Center Report BPM-03-02, BPMcenter.org, 2003. Disponível em: <http://is.tm.tue.nl/staff/wvdaalst/BPMcenter/reports/2003/BPM03-02.pdf>. Acesso em: 20 fev 2007.

AALST, W. M. P. van der (2004). Business Process Management Demystified: A Tutorial on Models, Systems and Standards for Workflow Management. In: Desel, J.; Reisig, W.; Rozenberg, G. (Eds): ACPN 2003, LNCS 3098, pp. 1-65, SpringerVerlag Berlin Heidelberg, 2004.

ABRAN, A.; MOORE, J. W.; BOURQUE, P.; DUPUIS, R.; TRIPP, L. L. (2004). Guide to the Software Engineering Body of Knowledge - SWEBOK, 2004 version, The Institute of Electrical and Electronics Engineers, Inc. - IEEE, 210 pages.

AGUILAR-SÁVEN, R. S. \& OLHAGER, J. (2002). Integration of product, process and functional orientations: Principals and a case study. In: International Conference on Advance Production Management Systems. The Netherland.

AIR FORCE (1980). IDEF0 CAM. Arlington, Texas: AIR FORCE, 1980.

AMBLER, S. W. (2005). A Manager's Introduction to The Rational Unified Process (RUP). Disponível em: <http://www.ambysoft.com/downloads/managersIntroToRUP.pdf>. Acessado em: 26 out 2006.

ARBAQUI, S.; DERNIAME, J. C.; OQUENDO, F.; VERJUS, H. (2002). A Comparative Review of Process-Centered Software Engineering Environments. In: Annals of Software Engineering 14, 311-340, Kluwer Academic Publishers.

BASILI, V. R.; WEISS, D. M. (1984). A Methodology for Collecting Valid Software Engineering Data. In: IEEE Transactions on Software Engineering, SE-10(6), 728738.

BOEHM, B.; EGYED, A.; PORT, D.; SHAH, A.; KWAN, J.; MADACHY, R. (1998). A stakeholder win-win approach to software engineering education. Annals of Software Engineering 6 (1998) 295-321.

BOGEN, J.; GRONAU, N.;SCHMID, S. (2005). Improvement of software engineering by modeling of knowledge intensive business processes, Technical Report, WI 12/2005. Disponível em: <http://wi.unipotsdam.de/hp.nsf/0/B0F253DF0812167CC12570180031E56F/\$FILE/WI-200512.pdf>. Acessado em: 10 nov 2006.

BORSSATTO, I. (2008). A implementação do MPS.BR nível F na Synos. Disponível em: <http://www.softex.br/mpsBr/ artigos/artigo.asp?id=1828>. Acesso em: 05 jun 2008.

BUSINESS PROCESS MANAGEMENT INITIATIVE (2008). BPMN - Business Process Modeling Notation. Disponível em: <http://www.bpmi.org >. Acesso em: 05 mai 2008.

BRYMAN, A. (1989). Research Methods and Organization Studies. Routledge. 
CASSIOLATO, J. E.; LASTRES, H. M. M. (2001). Arranjos e Sistemas Produtivos Locais na Indústria Brasileira. Revista de Economia Contemporânea. Rio de Janeiro: UFRJ. Disponível em:

$<$ http://www.desenvolvimento.gov.br/arquivo/sti/publicacoes/futAmaDilOportunidades/r ev20010424 04.pdf > . Acesso em: 30 set 2005.

CERVO, A. L. \& BERVIAN, P. A. (2002). Metodologia Científica. 5a ed. São Paulo: Pearson Prentice Hall.

CHRISSIS, M. B.; KONRAD, M.; SHRUM, S. (2003). CMMI: Guidelines for Process Integration and Product Improvement, Addison-Wesley Pub Co, 2003.

COSTA, J.M.H. (2006). Proposta de uma metodologia de gestão de mudanças: aplicação em uma empresa desenvolvedora de software. 208f. Dissertação (Mestrado) - Escola de Engenharia de São Carlos, Universidade de São Paulo, São Carlos, 2006.

CURTIS, B. (1998). Which Comes First, the Organization or its Processes. IEEE Software, pgs 10-13, November/December 1998.

DANE, F. C. (1990). Research Methods. Belmont, California, Brooks/Cole.

DAVENPORT, T. H. (1993). Need radical innovation and continuous improvement? Integrate process reengineering and TQM. Planning Review, 21 (3), p. 6-12.

DEMING, E. (1986). Out of the Crisis. Cambridge. MIT Center for Advanced Engineering Study, 1986.

DeSOUZA, K. C. (2003). Barries to Effective Use of Knowledge Management Systems in Software Engineering. Communications of the ACM, January, 2003, v. 46, n.1, p. 99-101.

ECLIPSE FOUNDATION (2008). Eclipse Process Framework. Disponível em: < http://www.eclipse.org/epf/>. Acesso em: 15 mai 2008.

ECLIPSE PROCESS FRAMEWORK COMMUNITY (2008). OpenUP. Disponível em: < http://epf.eclipse.org/wikis/openup/>. Acesso em: 15 mai 2008.

EL EMAM, K. (2004). Software Engineering Process. In: Chapter 9 of Guide to the SoftwareEngineering Body of Knowledge (SWEBOK), 2004 version, (Abran et al. 2004), pgs 9-1 to 9-14. Disponível em: <http://www.swebok.org/>. Acesso em: 15 mai 2008.

FALBO, R. A.; ARANTES, D. O.; NATALI, A. C. C. (2004). Integrating Knowledge Management and Groupware in a Software Development Environment. In: D. Karagiannis and U. Reimer (eds.): PAKM 2004, LNAAI 3336, pp. 94-105.

FIGUEIREDO, S.; SANTOS, G.; MONTONI, M.; ROCHA, A. R.; BARRETO, Andréa.; BARRETO, Ahilton; FERREIRA, A. (2006). Taba Workkstation: Supporting Technical Solution Through Knowledge Management of Design Rationale. In: REIMER, U. \& KARAGIANNIS, D. (Eds.): PAKM 2006, LNAI 4333, Springer-Verlag Berlin Heidelberg, p. 61-72.

GIL, A. C. (1999). Métodos e Técnicas da Pesquisa Social. 5ª ed. São Paulo: Atlas. 
HUNG, R. Y. (2006). Business process management as competitive advantage: a review and empirical study. Total quality management. 17(1), 21-40, jan, 2006.

IBM. (2006). Rational Method Composer. Disponível em: <http://www128.ibm.com/developerworks/downloads/r/rup/support.html?S TACT=105AGX28\&S CMP=DLMAIN >. Acesso em: 02 fev 2006.

INTERNATIONAL ORGANIZATION FOR STANDARDIZATION. (2000). ISO 9001:2000. Quality management systems. Requirements.

INTERNATIONAL ORGANIZATION FOR STANDARDIZATION. (2001). ISO/IEC 12207 AMD1 e AMD2: Information technology - Software life cycle processes.

INTERNATIONAL ORGANIZATION FOR STANDARDIZATION. (2003). ISO/IEC 15504: Information Technology - Process Assessment.

JACOBSON, I.; BOOCH, G.; RUMBAUGH, J. (1999). The Unified Software development Process. Addison Wesley.

JESTON, J.; NELIS, J. (2008). Business Process Management - Practical Guidelines to Successful Implementations. 2th edition. Butterworth-Heinemann.

KILMANN, R. (1995). A holistic program and critical success factors of corporate transformation. European Management Journal, 13 (2), p. 175-186.

KRUCHTEN, P. (2004). The Rational Unified Process: An Introduction. AddisonWesley.

LIMA, A.; FRANÇA, B.; SCHLEBBE, H.; REIS, R. Q.; REIS, C. L. (2006). WebAPSEE: Um Ambiente Livre e Flexível para Gerência de Processos de Software. VII Workshop de Software Livre. Porto Alegre, abr.

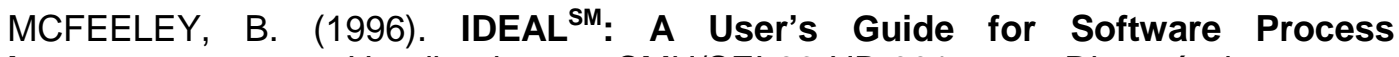
Improvement. Handbook CMU/SEI-96-HB-001. Disponível em: $<$ http://www.sei.cmu.edu/pub/documents/96.reports/pdf/hb001.96.pdf>. Acesso em: 15 mai 2008.

MCGOWAN, D. A.; MARCA, C. L. (1987). SADT: Structured Analysis and Design Technique. McGraw-Hill, New York.

McKAY, A. \& RADNOR, Z. (1998). A characterization of a business process. International Journal of Operational and Production Management, 18 (9/10), p. 924936.

MCT (2005). Qualidade e Produtividade no Setor Brasileiro. Pesquisa 2005. Disponível em: <http://www.mct.gov.br/index.php/content/view/3253.html>. Acesso em: 15 mai 2008.

MICROSOFT. (2006). Visual Studio Team System. Disponível em: $<$ https://ms.helifan.net/brasil/msdn/teamsystem/default.mspx>. Acesso em: $02 \mathrm{fev}$ 2006.

MONTEIRO, R. W.; MARTINS, C.; CABRAL, R.; ROCHA, A. R. (2008). A Empresa de Processamento de Dados do Estado do Pará Rumo ao Nível F do MR-MPS. 
Disponível em: <http://www.softex.br/mpsBr/ artigos/artigo.asp?id=1828>. Acesso em: 05 jun 2008.

MONTONI, M.; MIRANDA, R.; ROCHA, A. R.; TRAVASSOS, G. H. (2004a). Knowledge Acquisition and Communities of Practice: An Approach to Convert Individual Knowledge into Multi-organizational knowledge. In: G. Melnik and H. Holz (eds.): LSO 2004, LNCS 3096, pp. 110-121.

MONTONI, M.; SANTOS, G.; VILLELA, K.; MIRANDA, R.; ROCHA, A. R.; TRAVASSOS, G. H.; FIGUEIREDO, S.; MAFRA, S. (2004b). Knowledge Management in an Enterprise-Oriented Software Development Environment. In: D. Karagiannis and U. Reimer (eds.): PAKM 2004, LNAI 3336, pp. 117-128.

MONTONI, M.; SANTOS, G.; VILLELA, K.; ROCHA, A. R.; TRAVASSOS, G. H.;FIGUEIREDO, S.; MAFRA, S.; ALBUQUERQUE, A.; MIAN, P. (2005). EnterpriseOriented Software Development Environments to Support Software Products and Process Quality Improvement. In: BOMARIUS, F. \& SIRVIO, K. (Eds.): PROFES 2005, LNCS 3547, Springer-Verlag Berlin Heidelberg, p. 370-384.

MONTONI, M.; SANTOS, G.; ROCHA, A. R. WEBER, K. C.; ARAÚJO, E. E. R. (2007). MPS Model and TABA Workstation: Implementing Software Process Improvement Initiatives in Small Settings. In: Fifth International Workshop on Software Quality (WoSQ0'7), IEEE Computer Society.

OlIVEIRA, A. C. G.; GUIMARÃES, F. A.; FONSECA, I. A. (2008). Utilizando Metodologias Ágeis para Atingir MPS.BR Nível F na PowerLogic. Disponível em: <http://www.softex.br/mpsBr/ artigos/artigo.asp?id=1828>. Acesso em: 05 jun 2008.

PÁDUA, E. M. M. (1996). Metodologia da Pesquisa: Abordagem Teórico-Prática. Campinas-SP: Papirus.

PAULK, M. C.; WEBER, C. V.; CURTIS, B.; CHRISSIS, M. B. (1995). The Capability Maturity Model: Guidelines for Improving the Software Process. SEI Series in Software Enginnering, Addison-Wesley.

PINO, F. J.; GARCIA, F.; PIATTINI, M. (2008). Software Process Improvement in Small and Medium Software Enterprises: a Systematic Review. In: Software Quality Journal, 16:237-261.

PORTO, J.B.; LÓPEZ, P. A. P.; ALBERTUNI, I.; RICHTER, L. A.; CORRÊA NETO, J. A. (2008). A Experiência de Avaliação MPS.BR Nível F na Qualità. Disponível em: <http://www.softex.br/mpsBr/ artigos/artigo.asp?id=1828>. Acesso em: 05 jun 2008.

PRESSMAN, R. S. (2006). Engenharia de Software. 6ª ed. São Paulo: McGraw-Hill.

PROJECT MANAGEMENT INSTITUTE (2003). Organizational Project Management Maturity Model Handbook (OPM3), December 2003.

PROJECT MANAGEMENT INSTITUTE (2004). A Guide to the Project Management Body of Knowledge, PMBOK Guide, Third Edition, PMI.

ROCHA, A. R.; MONTONI, M.; SANTOS, G.; MAFRA, S.; FIGUEIREDO, S.; ALBUQUERQUE, A.; MIAN, P. (2005). Reference Model for Software Process Improvement: A Brazilian Experience. In: I. Richardson et al. (Eds.): EuroSPI 2005, Lecture Notes in Computer Science (LNCS) 3792, pp. 130-141. 
ROCHA, A.R.; MONTONI, M.; SANTOS, G.; OLIVEIRA, K.; NATALI, A. C.; MIAN, P.; CONTE, T.; MAFRA, S.; BARRETO, A.; ALBUQUERQUE, A.; FIGUEIREDO, S.; SOARES, A.; BIANCHI, F.; CABRAL, R.; NETO, A. D. (2006). Success Factors and Difficulties in Software Process Deployment Experiences based on CMMI and MR-MPS.BR, In: Proc. Of the $6^{\text {th }}$ International Workshop on Learning Software Organizations (LSO'2006), Rio de Janeiro, Brazil, september, 2006, pp. 77-87.

ROZENFELD, H.; FORCELLINI, F. A.; AMARAL, D. C.; TOLEDO, J. C. de; SILVA, S. L. da; ALLIPRANDINI, D. H.; SCALICE, R. K. (2006). Gestão de Desenvolvimento de Produtos - Uma referência para a melhoria do processo. São Paulo: Saraiva.

RUS, I. \& LINDVALL, M. (2002). Knowledge Management in Software Engineering. IEEE Software, May/Jun, 26-38.

SALVIANO, C. F. (2006). Uma proposta orientada a perfis de capacidade de processo para evolução da melhoria de processo de software. Tese de Doutorado sob orientação de Mário Jino. Departamento de Engenharia Elétrica. Universidade Estadual de Campinas, UNICAMP, Brasil.

SCHEER, A.W. (1998). Business Process Engineering: reference models for industrial enterprises, Heidelberg, Springer-Verlag.

SCHEID, M.; PESSOA, M. V.; GOMES, R. F.; RAIMUNDO, E. S.; OLIVEIRA, M. A. A. de; SANTOS, G.; FIGUEIREDO, S.; ROCHA, A. R. (2008). Implantação do MR-MPS Nível E no Centro de Computação da Aeronáutica de São José dos Campos. Disponível em: <http://www.softex.br/mpsBr/ artigos/artigo.asp?id=1828>. Acesso em: 05 jun 2008.

SEGRINI, B. M.; BERTOLLO, G.; FALBO, R. A. (2006). Evoluindo a Definição de Processos de Software em ODE. In: XIII Sessão de Ferramentas do SBES (Simpósio Brasileiro de Engenharia de Software). Florianópolis/SC, Brasil, p. 109-114.

SMITH, H.; FINGAR, P. (2003). Business Process Management: The third wave. Meghan-Kiffer Press, 2003.

SOFTEX (2007). MPS.BR- Melhoria de Processo do Software Brasileiro . Guia Geral. Disponível em:

$<$ http://www.softex.br/mpsbr/ guias/MPS.BR Guia Geral V1.2.pdf>. Acesso em: 15 mai 2008.

SOFTWARE ENGINEERING INSTITUTE (2002). Capability Maturity Model Integration - CMMI, version 1.1.

SOFTWARE ENGINEERING INSTITUTE (2006). CMMI for Development, version 1.2 - CMMI-DEV. Disponível em:

$<$ http://www.sei.cmu.edu/pub/documents/06.reports/pdf/06tr008.pdf>. Acesso em: 27 out 2008.

SOMMERVILLE, I. (2007). Engenharia de Software. 8 ${ }^{a}$ ed. São Paulo: Pearson Addison Wesley.

SPÍNOLA, R. O.; ÁVILA, A. L. (2008). Introdução à Engenharia de Requisitos. In: Engenharia de Software Magazine, Edição 01, pg 46-54, DevMedia, Disponível em: < http://www.devmedia.com.br/articles/viewcomp.asp?comp=8034\&hl>. Acesso em: 27 out 2008. 
SWEBOK (2004). SWEBOK - Software Engineering Body of Knowledge. Disponível em: <http://www.swebok.org/>. Acesso em: 08 out 2005.

THIOLLENT, M. (1995). Metodologia da Pesquisa-Ação. São Paulo: Cortez.

VARGAS, D.; NIGRI, M.; KRIEGER, M.; BARRETO, A.; MONTONI, M.; CABRAL, R.; ROCHA, A. R. (2008). Melhoria de Processos na Marlin. Disponível em:

$<$ http://www.softex.br/mpsBr/ artigos/artigo.asp?id=1828>. Acesso em: 05 jun 2008.

WEBER, K. C.; ARAÚJO, E. R.; ROCHA, A. R.; MACHADO, C. F.; SCALET, D.; SALVIANO, C. F. (2005a). Brazilian Software Process Reference Model and Assessment Method, In: P. Yolum et al. (Eds), Proceedings of ISCIS 2005 (20th Int. Symp. On Computer and Info. Sciences), LNCS 3733, pp. 402-411. Copyright Springer-Verlag, Berlin Heindelberg.

WEBER, S.; HAUCK, J. C. R.; VON WANGENHEIM, C. (2005b). Estabelecendo Processos de Software em Micro e Pequenas Empresas. SBQS - Simpósio Brasileiro de Qualidade de Software, Porto Alegre, Brasil.

WEBER, K. C.; ARAUJO, E. (2006). Avaliação do Modelo MPS em Empresas em 2005 e 2006. Disponível em:

$<$ http://golden.softex.br/portal/softexweb/uploadDocuments/ mpsbr/PBQP\%202006\%2 0Artigo\%20Projeto\%204.pdf >. Acesso em: 15 mai 2008.

WEBER, K. C.; NASCIMENTO, C. J. do; MARINHO, D. S. (2006). Programa Brasileiro da Qualidade e Produtividade em Software: Treze anos acompanhando e disseminando a cultura da qualidade. Disponível em: <http://www.mct.gov.br/upd blob/0006/6446.pdf>. Acesso em: 15 mai 2008.

WELLS, D. (2006). Extreme Programming: A gentle introduction. Disponível em: $<$ http://www.extremeprogramming.org >. Acesso em: 15 mai 2008.

ZAIRI, M. \& SINCLAIR, D. (1995). BPR and process management: a survey of current practice and future trends in integrated management. Business Process Reengineering and Management Journal, 1 (1), p. 8-29.

ZAIRI, M. (1997). Business process management: a boundaryless approach to modern competitiveness. Business Process Management Journal, 3 (1), p. 64-80. 


\section{Apêndice 1 - Questionário para Levantamento de Áreas de Conhecimento relevantes para algumas MPEs}

\section{QUESTIONÁRIO}

\section{Identificação}

1.1 Seu nome (opcional):

1.2 E-mail pessoal para contato:

1.3 Qual é a sua formação acadêmica?

R.

1.4 Qual o nome da faculdade onde se formou? E, em que ano?

R.

1.5 Função que você exerce na empresa:
a. ( ) Gerente/Supervisor
b. ( ) Gerente de Projetos
c. ( ) Analista de Sistemas
d. ( ) Programador
e. ( ) Outra. Qual ?

1.6 Você tem autoridade para fazer alguma modificação na forma de conduzir as atividades de desenvolvimento de software dentro da empresa?
( ) Sim.
( ) Não.

\section{Caracterização da Empresa de Desenvolvimento de Software ou CPD}

2.1 Nome da Empresa/local onde trabalha (opcional):

2.2 Quantidade de funcionários:

( ) Na empresa

( ) No CPD da empresa (se for o caso)

2.3 Quanto às atividades de desenvolvimento de software na empresa ou no CPD da empresa (se for o caso), tem-se:

a. ( ) Desenvolvimento de software de prateleira (pacote de software). Ex: software pronto vendido em supermercados.

b. ( ) Desenvolvimento de software sob encomenda (solicitado por um determinado cliente).

c. ( ) Desenvolvimento de software embarcado (que controla outros equipamentos). 
d. ( ) Desenvolvimento de software para internet.

e. ( ) Desenvolvimento de software para uso próprio.

f. ( ) Desenvolvimento e distribuição de um único software.

g. ( ) Outra. Qual?

2.4 Qual(is) o(s) tipo(s) de software(s) desenvolvido(s)?

( ) Administração Comercial

( ) Administração Escolar

( ) Administração Pública

( ) Administração de Recursos Humanos

( ) Agropecuário

( ) Automação Bancária

( ) Automação de Escritórios

( ) Comércio Eletrônico

( ) Contabilidade

( ) Educacional

( ) Entretenimento

( ) Ferramentas de desenvolvimento de sistemas

( ) Financeiro

( ) Processador de imagens

( ) Outro(s). Qual(is)?

2.5 As pessoas que trabalham na equipe de desenvolvimento de software são resistentes às mudanças?

( ) Sim.

( ) Não.

Comentários:

\section{Comercialização do Produto Software}

Para quem não assinalou a opcão (e.) da questão 2.3, por gentileza, responda às questões de 3.1 a 3.4 . 3.1 Quanto à venda do produto, considerando o total de produtos já desenvolvidos em sua empresa:

a. ( ) Quantos produtos foram vendidos junto ao código-fonte, documentação do produto e manual do usuário?

b. ( ) Quantos foram vendidos apenas com o código-fonte?

c. ( ) Quantos foram vendidos apenas com o executável?

d. ( ) Quantos produtos foram vendidos por licenças?

e. ( ) Outra situação. Qual? 
3.2 O desenvolvimento do sistema é feito por módulos (partes)?

( ) Sim.

Nesse caso, a cobrança ao cliente é feita a cada término do módulo entregue?

( ) Sim.

( ) Não. Como é realizada?

( ) Não. Como é realizada a cobrança?

3.3 É utilizada alguma ferramenta para auxiliar no controle de cobranças?

( ) Sim. Qual(is)?

( ) Não.

3.4 Você acha que seria útil definir algumas atividades e formulários para auxiliar a fase de comercialização do produto de software desenvolvido?

( ) Sim.

( ) Não.

Independente da resposta, por quê?

\section{Definição e Construção do Software}

4.1 Na empresa onde trabalha, há alguma descrição (seja em documentos ou site ou em uma ferramenta/aplicativo utilizado) referente às atividades que devem ser realizadas para a definicão do produto a ser desenvolvido?

( ) Sim.

( ) Não.

4.2 Você acha importante entender o negócio do cliente antes de construir um software para que esse atenda aos objetivos do negócio?

( ) Sim.

( ) Não.

4.3 Na empresa onde trabalha, é elaborada alguma modelagem do negócio do cliente para facilitar o entendimento a todos os envolvidos no projeto de desenvolvimento do software?

( ) Sim.

( ) Não.

4.4 Você acha importante que haja algum tipo de modelagem do negócio do cliente para facilitar o entendimento a todos os envolvidos no projeto de desenvolvimento do software?

( ) Sim.

( ) Não.

Independente da resposta, por quê? 
4.5 Após realizar o entendimento das necessidades do cliente, vocês realizam alguma atividade anterior à codificação do software, tal como a elaboração de um documento de requisitos e/ou de um modelo de dados?

( ) Sim. Quais são as atividades?

( ) Não.

4.6 Quais as ferramentas/aplicativos que vocês usam durante o processo de desenvolvimento de software, considerando desde a atividade de obtenção dos requisitos do cliente até a entrega e/ou implantação do software no cliente e até mesmo o suporte ao cliente?

$\mathrm{R}$ :

\section{Relevância dos Processos relacionados ao Ciclo de Vida do Software}

5.1 Junto ao questionário foi enviada uma planilha denominada "RELEVANCIA_PROCESSOS" onde devem ser selecionadas uma das alternativas disponibilizadas para cada questão.

Nessa planilha estão definidos alguns processos que podem ser utilizados durante 0 ciclo de vida do software. Na coluna A encontra-se o nome do processo e na coluna $F$ encontra-se uma breve descrição do respectivo processo (para acessar, basta clicar em cima da célula desejada e a descrição aparecerá na barra de fórmulas, como apresentado na Figura A1.1).

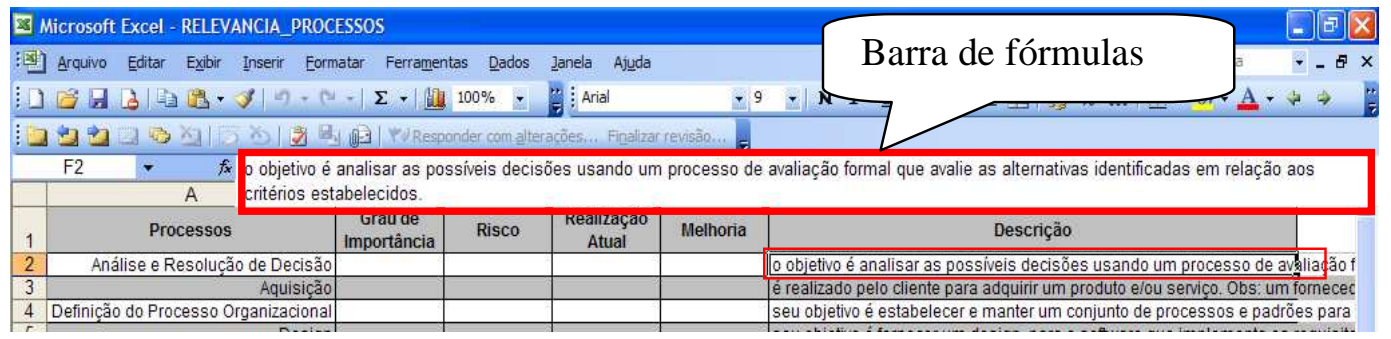

Figura A1.1 - Planilha de Relevância (Descrição do Processo)

Independente se a sua empresa tem ou não atividades formalizadas em relação ao desenvolvimento do software, defina:

- o grau de importância de cada um dos processos na sua empresa;

- o risco em continuar executando o processo em questão da forma como é executado atualmente.

- se o processo é executado ou não na empresa, atualmente.

- quais processos você escolheria para serem melhorados em sua empresa.

Uma explicação para cada um dos itens anteriores é fornecida como comentário. Para acessar, basta posicionar o mouse em cima da coluna desejada, como mostrado na Figura A1.2. 


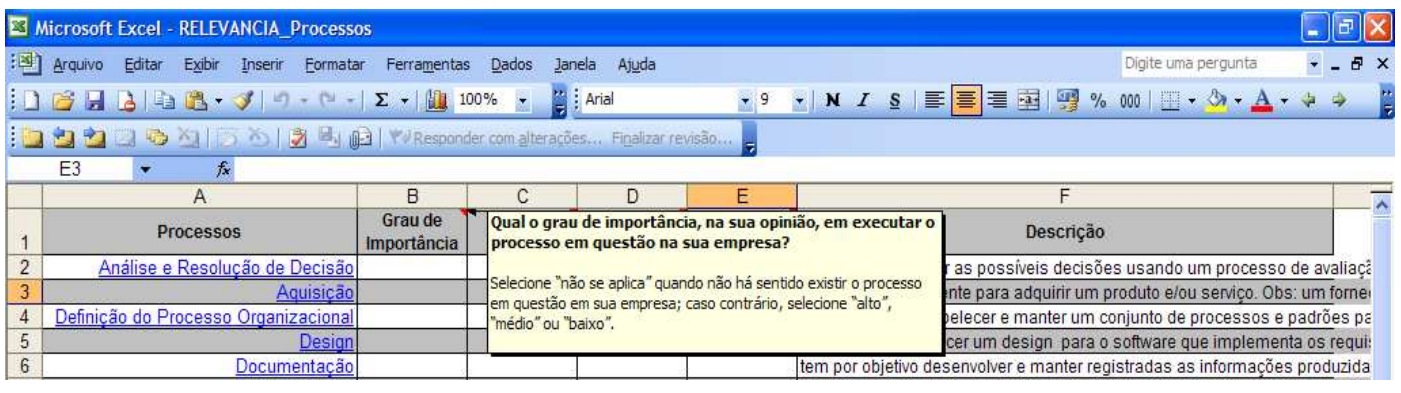

Figura A1.2 - Planilha de Relevância (Comentário Referente À cada QUestão)

Para selecionar uma resposta para cada questão, clique na célula correspondente à linha do processo analisado. Aparecerá o ícone ઇ $\sqcup$, como mostrado na Figura A1.3; Clique nesse ícone para selecionar a opção desejada.

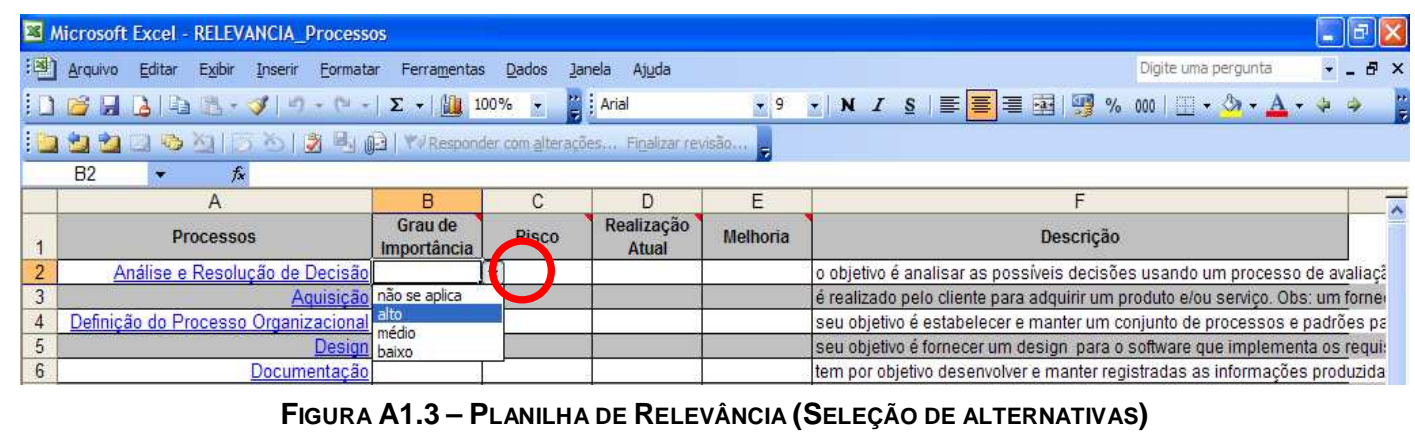

5.2 Você acredita que um modelo de processo de desenvolvimento de software auxiliaria as pessoas envolvidas no desenvolvimento do software, servindo como um guia comum para todos?

( ) Sim.

( ) Não. Por quê?

5.3 Você tem interesse nos resultados dessa pesquisa, depois de finalizada?
( ) Sim.
( ) Não.

5.4 Você tem interesse em conhecer o modelo de processo de desenvolvimento de software que será criado nesse trabalho de doutorado?

( ) Sim. 


\section{Apêndice 2 - Resultado da Análise do Questionário definido no Apêndice 1}

A partir dos questionários respondidos pelas 5 (cinco) MPE's que desenvolvem software e 9 (nove) CPDs (Centro de Processamento de Dados) de empresas diversas os quais desenvolvem software para uso interno, foram confirmadas as áreas de conhecimento definidas no Modelo ProcSoftVD e foi indicada a importância de outras áreas de conhecimento que serão consideradas em um trabalho futuro. A Figura A2.1 apresenta a tabulação das áreas de conhecimento investigadas quanto ao grau de importância de cada uma delas para a empresa e quanto ao grau de risco para a empresa caso não sejam realizadas atividades das respectivas áreas de conhecimento.

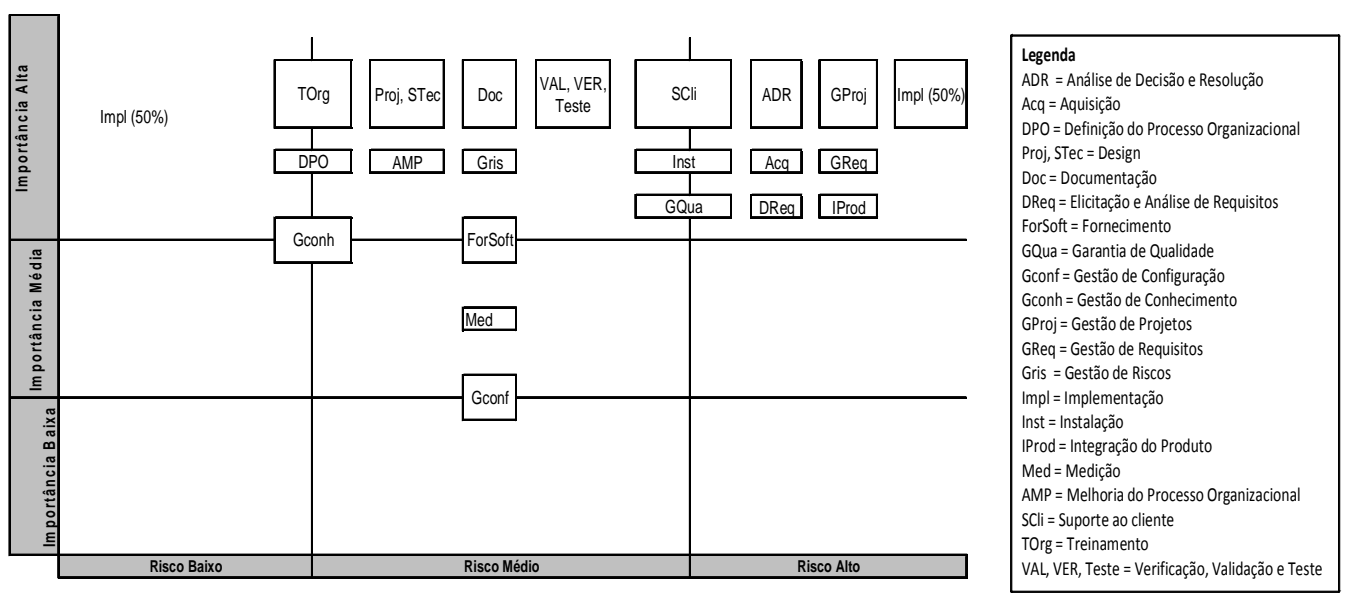

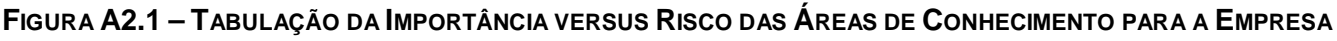

Percebe-se que para as empresas investigadas as áreas de conhecimento com mais alta prioridade são as que têm alta importância e alto risco caso continue sendo realizada pela empresa da forma que está atualmente. São elas: Gestão de Projetos, Aquisição, Gestão de Requisitos, Elicitação e Análise de Requisitos, Integração do Produto, Análise de Decisão e Resolução. Como segunda prioridade, foram estabelecidas as áreas de conhecimento: Garantia da Qualidade, Instalação e Suporte ao Cliente. Projeto (design), Verificação, Validação e Testes foram considerados de 
alta importância, porém de risco mediano caso não sejam definidas atividades formalizadas para a empresa. 


\section{Apêndice 3 - Modelo ProcSoftVD (Atividades)}

Este apêndice apresenta as atividades do modelo ProcSoftVD, agrupadas por fases (Quadros A3.1 a A3.6) e agrupadas por áreas de conhecimento (Quadros A3.7 a A3.19). Além disso, apresenta a visão gráfica do modelo (Figuras A3.20 a A3.26) e o detalhamento de cada uma das atividades (Quadros A3.27 a A3.77).

Quadro A3.1 - Entradas, Atividades e Saídas da fase Prospecção

PROSPECÇÃO: Esta fase é realizada, principalmente, nos casos em que a empresa já tem algum produto/serviço desenvolvido/oferecido ou em fase de desenvolvimento e deseja buscar potenciais clientes para esses tipos de produtos/serviços, a fim de conseguir a solicitação de algumas propostas. Caso não haja a necessidade de prospectar o cliente, realizar as atividades a partir da atividade "P04. Criar infra-estrutura do projeto". ENTRADAS

- Plano de Negócios

(já deve existir na empresa)

- Plano de Marketing (já deve existir na empresa)

- Plano de Ação (já deve existir na

P01 - Buscar contatos

- Lista de Contatos empresa)

- Base de contatos (já deve existir na empresa)

- Lista de Contatos

- Plano de Marketing
P02 - Prospectar cliente
- Lista de Contatos

- Roteiro de Prospecção
- $\quad$ Lista de Contatos

P03 - Visitar cliente
- Modelo de Negócio

- Material de divulgação

- Lista de Contatos

- Lista de Requisitos do Cliente
- Solicitação de Proposta

P04 - Criar infra-estrutura do projeto
- Controle de Projetos

- Proposta do Cliente Impressa

- Plano de Ação

P05 - Controlar custos despendidos na fase de prospecção

- Plano de Ação 


\section{Quadro A3.2 - Entradas, Atividades e Saídas da fase Concepção}

CONCEPÇÃO: Esta fase tem como objetivo entender o negócio do cliente, verificar a viabilidade técnica e financeira do projeto para a empresa desenvolvedora, bem como os riscos, ter a visão geral do sistema e sintetizar uma arquitetura candidata para o software. Assim, têm-se subsídios para negociar o contrato com o cliente.
ENTRADAS
ATIVIDADES
SAÍDAS

- Controle de Projetos

- Modelo de Negócio

- Lista de Requisitos do Cliente

- Relatório de Análise dos Requisitos
CP01 - Entender o negócio e as necessidades do cliente

- Documento de Requisitos
CP02 - Definir escopo do projeto
- Modelo de Negócio

- Lista de Requisitos do Cliente

- Infra-Estrutura do Cliente

- Relatório de Análise dos Requisitos

- Modelo de Negócio

- Documento de Requisitos

- Lista de Requisitos Padrão do Produto (já existente na empresa)

CP03 - Determinar requisitos do produto

- Documento de Requisitos

- Projeto IHM

- Documento de Requisitos

- Checklist de Requisitos

- Modelo de Negócio

- Projeto IHM

CP04 - Verificar e Validar os requisitos

- Plano de Projeto

- Relatório de Análise dos Requisitos

Documento de Requisitos
CP05 - Estudar soluções alternativas de arquitetura do software
- Arquitetura do Software

- Documento de Requisitos
- Documento de Requisitos

- Cronograma

- Plano de Projeto
CP06 - Definir/Redefinir cronograma do projeto
- Cronograma

- Plano de Projeto

- Documento de Requisitos

- Base de Dados Histórica da empresa

- Cronograma

CP07 - Determinar estimativas de esforço e tempo
- Cronograma

- Plano de Projeto 


\section{Quadro A3.2 - Entradas, Atividades e Saídas da fase Concepção (Cont.)}

\begin{tabular}{l|l|l} 
ENTRADAS ATIVIDADES SAIDAS
\end{tabular}

- Documento de Requisitos

- Plano de Projeto

- Plano de Projeto

- Arquitetura do

CP08 - Verificar a viabilidade técnica

- Plano de Ação financeira do projeto

- Relatório de Viabilidade do Projeto

- Infra-Estrutura do Cliente
- Fluxo de Caixa

- Plano de Projeto

- Controle de Projetos

- Pedido de Compra

- Controle de Projetos

- Plano de Projeto habilidades necessárias

CP09 - Planejar os recursos do projeto

Controle de Projetos

- Plano de Projeto
- Controle de Projetos

- Plano de Projeto

CP11 - Identificar riscos inerentes ao projeto

- Plano de Projeto

- Cronograma

- Relatório de Viabilidade do Projeto

- Fluxo de Caixa

- Plano de Projeto
- Controle de Projetos

- Plano de Projeto
CP12 - Acompanhar o andamento do projeto
- Controle de Projetos

- Relatório de Acompanhamento do Projeto

- Plano de Ação

CP13 - Controlar custos despendidos na fase de concepção

- Plano de Ação

Milestone: Estudo de Viabilidade do Projeto

- Plano de Garantia da Qualidade (já existente na empresa)

- Produto de Trabalho: Relatório de Viabilidade do Projeto
CP14 - Conduzir revisão do milestone: Estudo de Viabilidade do Projeto
- Relatório sobre

Garantia da Qualidade 


\section{Quadro A3.3 - Entradas, Atividades e Saídas da fase Negociação}

NEGOCIAÇÃO: Esta fase tem por objetivo fechar um contrato com o cliente. Para isso, será elaborada, primeiramente, uma proposta pautada no estudo de viabilidade do projeto e no planejamento inicial sob a qual será feita a negociação.

\section{ENTRADAS}

- Documento de Requisitos

- Relatório de Viabilidade do Projeto

- Relatório de Análise da Proposta

- Cronograma

- Proposta Comercial

- Proposta Técnica

\section{ATIVIDADES}

SAÍDAS

- Proposta Técnica

- Proposta Comercial

- Relatório de Viabilidade do Projeto

- Cronograma

- Documento de Requisitos
- Proposta

- Relatório de Análise do Contrato
N03 - Elaborar contrato

- Contrato

N04 - Analisar contrato
- Relatório de Análise da Proposta
- Cronograma

- Plano de Projeto

- Controle de Projetos

- Contrato assinado
N05 - Definir time do projeto
- Contrato

- Relatório de Análise do Contrato
- Contrato

- Proposta Técnica

- Pedido de Compra

- Controle de Projetos

- Plano de Projeto
- Plano de Projeto

- Cronograma

- Controle de Projetos
- Controle de Projetos

- Plano de Projeto

- Relatório de Acompanhamento do Projeto

- Plano de Ação
N07 - Acompanhar o andamento do projeto
- Documento de formalização do projeto

- Pedido de Compra

- Controle de Projetos 


\section{Quadro A3.3 - Entradas, Atividades e Saídas da fase Negociação (Cont.)}

\begin{tabular}{l|l|l} 
ENTRADAS ATIVIDADES & SAIDAS
\end{tabular}

- Plano de Garantia da

Qualidade

- Produto de Trabalho:

Contrato

N09 - Conduzir revisão do milestone:

- Relatório sobre Garantia

- Relatório sobre

Contrato

da Qualidade

Garantia da Qualidade

\section{Quadro A3.4 - Entradas, ATividades e Saídas da fase Elaboração}

ELABORAÇ̃̃: Esta fase tem o objetivo de definir uma baseline da arquitetura do software para fornecer uma base estável para o esforço de implementação na fase de construção e, também, detalhar os requisitos, refinar o cronograma e planejar os testes a serem realizados em cada ciclo de desenvolvimento estimado na fase de concepção.
ENTRADAS
ATIVIDADES
SAÍDAS

- Documento de Requisitos

- $\quad$ Projeto IHM

- Cronograma

E01 - Detalhar requisitos

- Documento de

Requisitos

- Modelo de Negócio

- Projeto IHM

- Modelo de Negócio

- Documento de Requisitos

- Checklist de Requisitos

- Modelo de Negócio

- Projeto IHM

E02 - Verificar e Validar os requisitos

- Relatório de Análise dos Requisitos

- Relatório de Análise dos Requisitos

- Arquitetura do Software

- Documento de Requisitos

- Cronograma

E03- Definir solução de projeto

E04 - Detalhar o cronograma
- Cronograma
- $\quad$ Arquitetura do Software

- Documento de

Requisitos

- Modelo de Design
- Controle de Tarefas
- Plano de Projeto

- Cronograma

- Biblioteca de Casos de Teste Padrão

- Documento de Requisitos

- Modelo de Design

- Arquitetura do Software
- Planilha de Teste

- Plano de Projeto

- Cronograma
E05 - Definir técnicas e critérios para V\&V 
Quadro A3.4 - Entradas, Atividades e Saídas da fase Elaboração (CONT.)

ENTRADAS ATIVIDADES SAIDAS

- Plano de Projeto

- Relatório de Acompanhamento de Projeto

- Controle de Projetos

- Cronograma
- Relatório de Acompanhamento de Projeto

E06 - Monitorar e controlar o projeto

- Controle de Projetos

- Cronograma
- Controle de Projetos

- Relatório de Viabilidade do Projeto

- Fluxo de caixa
E07 - Monitorar e Controlar questões financeiras
- Controle de Projetos

- Cobrança

- Fluxo de Caixa

Milestone: Arquitetura do Software

- Plano de Garantia da Qualidade

- Produto de trabalho: Arquitetura do Software

- Relatório sobre Garantia de Qualidade
E08 - Conduzir revisão do milestone: Arquitetura do Software
- Relatório sobre Garantia de Qualidade

\section{Quadro A3.5 - Entradas, Atividades e Saídas da fase Construção}

CONSTRUÇÃO: Essa fase tem por objetivo elaborar versões utilizáveis (alpha, beta, e outras entregas testadas) e completar a análise, projeto, desenvolvimento e teste de todas as funcionalidades requeridas. ENTRADAS ATIVIDADES

- Arquitetura do Software

- Modelo de Design

- Projeto IHM

- Controle de Tarefas

СT01 - Codificar componentes

- $\quad$ Arquivo de Código

- Arquivo de Código

- Planilha de Teste

- Plano de Projeto

- Planilha de Teste

- Arquivo de Código
CT02 - Realizar teste de unidade

СT03 - Analisar os resultados de teste

- Arquivo de Código

- Planilha de Teste

- Arquivo de Código

- Plano de Projeto

- Planilha de Teste
CT04 - Integrar e testar integração entre componentes
- Planilha de Teste

- Arquivo de Código
- Controle de Tarefas 
Quadro A3.5 - Entradas, Atividades e Saídas da fase Construção (Cont.)

ENTRADAS ATIVIDADES SAÍDAS

- Plano de Projeto

- Relatório de Acompanhamento de Projeto

- Controle de Projetos

- Cronograma
CT05 - Monitorar e controlar o projeto

- Controle de Projetos

- Relatório de Viabilidade do Projeto

- Fluxo de caixa
CT06 - Monitorar e Controlar questões financeiras
- Relatório de Acompanhamento de Projeto

- Controle de Projetos

- Cronograma

Milestone: Capacidade Operacional

- Plano de Garantia da Qualidade

- Produto de Trabalho: Arquivo de Código (Capacidade

Operacional do

CT07 - Conduzir revisão do milestone:

Produto)

- Relatório sobre

Garantia da Qualidade

Capacidade Operacional
- Relatório sobre

Garantia da Qualidade

\section{Quadro A3.6 - EnTradas, ATIVIDAdes e Saídas da fase Transição}

TRANSIÇÃO: Essa fase tem por objetivo assegurar que o software esteja disponível para os usuários finais. Essa fase pode atravessar muitas iterações, e inclui testes do produto em preparação para a entrega, e faz os ajustes baseado no feedback do usuário. Esses feedbacks devem focar principalmente o ajuste do produto, a configuração, instalação e questões de usabilidade.

\section{ENTRADAS}

- Arquivo de Código

- Plano de Projeto

- Documento de Requisitos

- Planilha de Teste

- Arquivo de Código

- Planilha de Teste
T02 - Analisar e Ajustar a versão do produto
- Arquivo de Código

- Planilha de Teste

- Plano de Projeto

- Planilha de Teste

- Arquivo de Código 
Quadro A3.6 - Entradas, Atividades e SaídAs da fase Transição (Cont.)

\begin{tabular}{|c|c|c|}
\hline ENTRADAS & ATIVIDADES & SAÍDAS \\
\hline $\begin{array}{l}\text { - } \quad \text { Arquivo de Código } \\
\text { - } \quad \text { Manual do Usuário }\end{array}$ & T04 - Entregar/Instalar a versão do produto & $\begin{array}{l}\text { - } \quad \text { Versão do Produto } \\
\text { - } \quad \text { Macumento de Aceite } \\
\text { - } \\
\text { Arquivo para } \\
\text { Instalação }\end{array}$ \\
\hline $\begin{array}{l}\text { - Plano de Projeto } \\
\text { - Relatório de } \\
\text { Acompanhamento de } \\
\text { Projeto } \\
\text { - Controle de Projetos } \\
\text { - Cronograma }\end{array}$ & T05 - Monitorar e controlar o projeto & $\begin{array}{ll}\text { - } & \text { Relatório de } \\
& \text { Acompanhamento de } \\
\text { Projeto } \\
\text { - Controle de Projetos } \\
\text { - Cronograma }\end{array}$ \\
\hline $\begin{array}{ll}\text { - } & \text { Controle de Projetos } \\
\text { - } & \text { Relatório de } \\
\text { - } & \text { Viabilidade do Projeto } \\
\text { - Fluxo de caixa }\end{array}$ & $\begin{array}{l}\text { T06 - Monitorar e Controlar questões } \\
\text { financeiras }\end{array}$ & $\begin{array}{l}\text { - Controle de Projetos } \\
\text { - } \quad \text { Cobrança } \\
\text { - Fluxo de caixa }\end{array}$ \\
\hline & Milestone: Entrega do Produto & \\
\hline $\begin{array}{l}\text { Plano de Garantia da } \\
\text { Qualidade } \\
\text { - } \quad \text { Produto de Trabalho: } \\
\text { Entrega do Produto } \\
\text { - } \quad \text { Relatório sobre } \\
\text { Garantia da Qualidade }\end{array}$ & $\begin{array}{l}\text { T07 - conduzir revisão do milestone: entrega } \\
\text { do produto }\end{array}$ & $\begin{array}{l}\text { Relatório sobre } \\
\text { Garantia da Qualidade }\end{array}$ \\
\hline
\end{tabular}

A seguir, os quadros A3.7 a A3.19 apresentam as atividades do modelo ProcSoftVD, com suas respectivas entradas e saídas, agrupadas pelas áreas de conhecimento que compõem o modelo: Comercialização, Modelagem de Negócio, Produção de Requisitos, Projeto, Codificação \& Integração de Produto, V\&V, Implantação, Aquisição, Medição, Garantia da Qualidade de Produto e Processo, Gestão de Requisitos, Gestão de Mudanças e Configuração, Gestão de Projeto e Gestão do Conhecimento. 


\section{Quadro A3.7 - Entradas, Atividades e Saídas da Área de Conhecimento Comercialização}

COMERCIALIZAÇ̃̃O: essa área de conhecimento foi criada para abordar (1) atividades relacionadas à prospecção de potenciais clientes para a empresa (o que não é coberto pelo CMMI, nem pela ISO/IEC 15504-5); (2) atividades relacionadas à elaboração/submissão de propostas ao cliente e negociação e aprovação de contrato sem ambigüidades que especifique as expectativas, responsabilidades, entregas e compromissos de ambas as partes cliente e fornecedor; (3) atividades relacionadas à viabilidade financeira do projeto e relacionadas ao pagamento dos produtos/serviços vendidos pela empresa. As atividades do item (2) foram definidas com subsídio dos processos "Prospecção do Fornecedor" e "Acordado Contratual" da ISO/IEC 15504-5.

- Plano de Negócios (já deve existir na empresa)

- Plano de Marketing (já deve existir na empresa)

- Plano de Ação (já deve existir na empresa)

P01 - Buscar contatos

- Lista de Contatos

- Base de contatos (já deve existir na empresa)

- Lista de Contatos

- Plano de Marketing
- Lista de Contatos

- Roteiro de Prospecção
- Lista de Contatos

P03 - Visitar cliente
- Modelo de Negócio

- Material de divulgação

- Lista de Contatos

- Documento de Requisitos

- Plano de Projeto

- Arquitetura do Software

- Fluxo de Caixa

- Plano de Ação

- Relatório de Viabilidade do Projeto

- Infra-Estrutura do Cliente
CP08 - Verificar a viabilidade técnica e

financeira do projeto

- Plano de Projeto

- Relatório de Viabilidade

- Fluxo de Caixa
- Documento de

Requisitos

- Relatório de Viabilidade do Projeto

- Relatório de Análise da Proposta

N01 - Elaborar a proposta

- Proposta Técnica

- Proposta Comercial

- Cronograma
- Proposta Técnica

- Proposta Comercial

- Relatório de Viabilidade do Projeto

- Cronograma

- Documento de Requisitos 


\section{Quadro A3.7 - Entradas, Atividades e Saídas da Área de Conhecimento Comercialização (Cont.)}

ENTRADAS

- Proposta Comercial

- Proposta Técnica

N02 - Analisar proposta
SAÍDAS

- Proposta Comercial

- Proposta Técnica

- Relatório de Análise da Proposta

- Proposta

- Relatório de Viabilidade do Projeto

- Relatório de Análise do Contrato

N03 - Elaborar contrato

- $\quad$ Contrato

- Cronograma

- Contrato

- Contrato

- Proposta Técnica

- Pedido de Compra

- Controle de Projetos

- Plano de Projeto

- Contrato

- Controle de Projetos

- Relatório de Viabilidade do Projeto

E07 - Monitorar e Controlar questões financeiras
- Relatório de Análise do Contrato

- Contrato
- Arquivo de Código

- Manual do Usuário
N06 - Formalizar início do projeto

- Documento de formalização do projeto

- Pedido de Compra

- Controle de Projetos
- Controle de Projetos

- Relatório de Viabilidade do Projeto

- Cobrança

- Fluxo de Caixa
- Versão do Produto

- Documento de Aceite

- Manual do Usuário

- Arquivo para Instalação 


\section{Quadro A3.8 - Entradas, Atividades e Saídas da Área de Conhecimento Modelagem de Negócio}

MODELAGEM DE NEGÓcIO: o objetivo dessa área de conhecimento é documentar os processos de negócio usando casos de uso de negócio, a fim de assegurar um entendimento comum entre todos os stakeholders (envolvidos) sobre as necessidades existentes no processo de negócio da organização cliente. Essa área de conhecimento teve sua origem no Unified Process.

\section{ENTRADAS}

- Lista de Contatos

- Controle de Projetos

- Modelo de Negócio

- Lista de Requisitos do Cliente

\section{ATIVIDADES}

SAÍDAS

- Modelo de Negócio

- Material de divulgação

- Lista de Contatos

- Modelo de Negócio

- Documento de Requisitos

CP01 - Entender o negócio e as necessidades do cliente
- Infra-Estrutura do Cliente
- Documento de Requisitos

- Projeto IHM

- Cronograma

- Modelo de Negócio
E01 - Detalhar requisitos
- Documento de Requisitos

- $\quad$ Projeto IHM

- Modelo de Negócio

\section{Quadro A3.9 - Entradas, Atividades e Saídas da Área de Conhecimento Produção de Requisitos}

PRODUÇÃO DE REQUISITOS: tem o objetivo de produzir e analisar os requisitos do cliente, do produto e dos componentes de produto. Essa área de conhecimento teve sua origem relacionada à área de processo "Desenvolvimento de Requisitos" do CMMI-DEV e aos processos "Elicitação de Requisitos", "Análise de Requisitos do Sistema" e "Análise de Requisitos do Software" da ISO/IEC 15504-5.

\section{ENTRADAS}

- Lista de Contatos

P03 - Visitar cliente

- Controle de Projetos

- Modelo de Negócio

- Lista de Requisitos do Cliente

\section{ATIVIDADES}

\section{SAÍDAS}

- Modelo de Negócio

- Material de divulgação

- Lista de Contatos
- Documento de Requisitos
CP01 - Entender o negócio e as necessidades do cliente
- Modelo de Negócio

- Documento de Requisitos

- Infra-Estrutura do Cliente

- Modelo de Negócio

- Documento de Requisitos

- $\quad$ Lista de Requisitos Padrão do Produto (já

CP03 - Determinar requisitos do produto

- Documento de Requisitos

- Projeto IHM 
Quadro A3.9 - Entradas, Atividades e Saídas da Área de Conhecimento Produção de Requisitos (CONT.)

\begin{tabular}{l|l} 
ENTRADAS & ATIVIDADES \\
\hline
\end{tabular}

- Documento de

Requisitos

- Checklist de

Requisitos

- Modelo de Negócio

- Documento de Requisitos

CP05 - Estudar soluções alternativas de arquitetura do software
- Documento de

Requisitos

- Relatório de Análise

dos Requisitos

- Modelo de Negócio

- Arquitetura do Software

- Documento de Requisitos

- Cronograma

- Relatório de Viabilidade do Projeto

- Fluxo de Caixa

CP11 - Identificar riscos inerentes ao projeto

- Plano de Projeto

- Plano de Projeto

- Documento de Requisitos

- Projeto IHM

- Cronograma

E01 - Detalhar requisitos

- Documento de Requisitos

- Projeto IHM

- Modelo de Negócio

- Modelo de Negócio

- Documento de Requisitos

- Checklist de Requisitos

E02 - Verificar e Validar os requisitos

- Modelo de Negócio

- Documento de Requisitos

- Relatório de Análise dos Requisitos

- Modelo de Negócio 


\section{Quadro A3.10 - Entradas, Atividades e Saídas da Área de Conhecimento Projeto, Codificação \& INTEgRAÇÃo de Produto}

PROJETO, CODIFICAÇÃO \& INTEGRACÃO DE PRODUTO: Engloba os processos "Projeto do Software", "Integração do Software" e "Integração do Sistema" da 15504-5, o workflow "Implementação" do UP e as áreas de processo "Solução Técnica" e "Integração de Produto" do CMMI-DEV. Segundo a 15504-5, o processo "Projeto de Software" tem o objetivo de fornecer um design para o software que é implementado e pode ser verificado em confronto aos requisitos; o processo "Integração de Software" tem o objetivo de combinar as unidades de software, produzindo itens de software integrados, consistentes com o projeto de software, os quais demonstram que os requisitos funcionais e não-funcionais foram satisfeitos; e o processo "Integração do Sistema" tem como objetivo integrar os elementos do sistema (incluindo os itens de software, itens de hardware, operações manuais e outros sistemas, se necessário) para produzir um sistema completo que satisfaça ao projeto do sistema e às expectativas do cliente, expressadas em requisitos do sistema. Segundo o modelo CMMI-DEV, a área de processo "Solução Técnica" tem como objetivo projetar, desenvolver e implementar soluções para os requisitos, soluções essas que envolvem produtos, componentes de produtos e processos de ciclo de vida relacionados ao produto; e a área de processo "Integração do Produto" tem o objetivo de montar o produto, a partir dos componentes de produto, assegurar que o produto ao ser integrado funcione adequadamente, e entregar o produto.

ENTRADAS
- Documento de

Requisitos
CP05 - Estudar soluções alternativas de arquitetura do software
SAIDAS

- Arquitetura do Software

- Documento de Requisitos
- Arquitetura do Software

- Documento de Requisitos

- Modelo de Design

- Cronograma
E03- Definir solução de projeto

- Documento de Requisitos

- Modelo de Design
- Plano de Projeto

- Cronograma

- Biblioteca de Casos de Teste Padrão
- Documento de Requisitos

E05 - Definir técnicas e critérios para V\&V

Modelo de Design

- Arquitetura do Software
- Planilha de Teste

- Plano de Projeto

- Cronograma
- Arquitetura do Software

- Modelo de Design

- Projeto IHM

- Controle de Tarefas

СТ01 - Codificar componentes

- Arquivo de Código

- Arquivo de Código
- Controle de Tarefas
- Arquivo de Código

- Planilha de Teste
T02 - Ajustar a versão do produto 


\section{Quadro A3.11 - Entradas, Atividades e Saídas da Área de Conhecimento Verificação \& Validação}

V\&V: Engloba as áreas de processo (CMMI) e processos (15504-5) "Validação" e "Verificação" e os processos "Teste de Software" e "Teste de Sistema" da 15504-5. O objetivo da área de processo/processo "Validação" é demonstrar que o produto ou componente do produto atenda ao uso pretendido quando colocado no ambiente destinado. Já o objetivo da área de processo/processo "Verificação" é assegurar que produtos de trabalho (e serviços, no caso do CMMI) selecionados alcancem seus requisitos especificados. Testes desempenham um papel extremamente importante em V\&V (Verificação e Validação). Segundo o modelo 15504-5, o processo "Teste" pode ser realizado tanto no software quanto no sistema. O processo "Teste de Software" tem como objetivo confirmar que o produto de software integrado atende aos requisitos definidos. E, o processo "Teste de Sistema" tem o objetivo de assegurar que a implementação de cada requisito de sistema seja testada quanto à sua conformidade e que o sistema esteja pronto para entrega. ENTRADAS ATIVIDADES
- Documento de Requisitos

- Checklist de Requisitos

- Modelo de Negócio
CP04 - Verificar e Validar os requisitos

- Documento de Requisitos

- Checklist de Requisitos

- Modelo de Negócio Requisitos

- Relatório de Análise dos Requisitos

- Modelo de Negócio
- Documento de

- Plano de Projeto

- Cronograma

- Biblioteca de Casos de Teste Padrão

- Documento de Requisitos

E05 - Definir técnicas e critérios para V\&V

- Planilha de Teste

- Plano de Projeto

- Cronograma
- Documento de Requisitos

- Relatório de Análise dos Requisitos

- Modelo de Negócio

- Modelo de Design

- Arquitetura do Software

- Plano de Projeto

- Planilha de Teste

- Arquivo de Código
CT02 - Realizar teste de unidade

- Planilha de Teste
- Arquivo de Código

- Planilha de Teste
СT03 - Analisar os resultados de teste
- $\quad$ Arquivo de Código

- Plano de Projeto

- Planilha de Teste
CT04 - Integrar e testar integração entre componentes
- Planilha de Teste

- Arquivo de Código

- Arquivo de Código

- Plano de Teste

- Documento de Requisitos

- $\quad$ Planilha de Teste 


\section{Quadro A3.11 - Entradas, Atividades e Saídas da Área de Conhecimento Verificação \& Validação}

(CONT.)

\begin{tabular}{|c|c|c|c|}
\hline & ENTRADAS & ATIVIDADES & SAIDAS \\
\hline - & $\begin{array}{l}\text { Arquivo de Código } \\
\text { Planilha de Teste }\end{array}$ & T02 - Ajustar a versão do produto & Arquivo de Códig \\
\hline - & $\begin{array}{l}\text { Plano de Projeto } \\
\text { Planilha de Teste } \\
\text { Arquivo de Código }\end{array}$ & T03 - Realizar testes de regressão & $\begin{array}{l}\text { Planilha de Teste } \\
\text { Arquivo de Código }\end{array}$ \\
\hline
\end{tabular}

\section{Quadro A3.12 - Entradas, Atividades e Saídas da Área de Conhecimento Implantação}

IMPLANTAÇÃO: o objetivo é entregar o produto produzido para os usuários finais, por meio das atividades de codificação, teste, empacotamento e instalação do software. Essa área de conhecimento teve sua origem no UP e também está relacionada ao processo "Entrega de Produto" da 15504-5.

\section{ENTRADAS}

- $\quad$ Arquivo de Código

- Manual do Usuário

\section{ATIVIDADES}

SAÍDAS

- Versão do Produto

- Documento de Aceite

- Manual do Usuário

- $\quad$ Arquivo para Instalação

\section{Quadro A3.13 - Entradas, Atividades e Saídas da Área de Conhecimento Aquisição}

AQUISIÇÃO: essa área de conhecimento tem o objetivo de gerenciar a aquisição de produtos de fornecedores, sejam equipamentos ou até mesmo componentes de software do produto (no caso de terceirização do serviço). Exemplos de produtos e componentes de produtos que podem ser adquiridos pelo projeto: subsistemas (por exemplo, um sistema navegacional de uma aeronave), software, hardware, documentação (como manuais de instalação, de operação e do usuário). A origem dessa área de conhecimento está relacionada ao grupo de processo "Aquisição" da 15504-5 à área de processo denominada "Gestão de Acordo com Fornecedor" do CMMI-DEV.

\section{ENTRADAS}

- Cronograma

- Controle de Projetos

- Plano de Projeto

CP09 - Planejar os recursos do projeto

- Pedido de Compras

ACQ01 - Selecionar fornecedores e estabelecer acordo

- Pedido de Compras

- Produto comprado

\section{ATIVIDADES}

SAIDAS

- Plano de Projeto

- Controle de Projetos

- Pedido de Compra
- Produto comprado

- $\quad$ Produto comprado aceito 


\section{Quadro A3.14 - Entradas, Atividades e Saídas da Área de Conhecimento Medição}

MEDIÇÃO: essa área de conhecimento tem o objetivo de coletar e analisar dados relacionados aos produtos desenvolvidos e aos processos implementados dentro da organização por meio de projetos, a fim de dar um suporte efetivo à gestão dos processos e demonstrar objetivamente a qualidade dos produtos. Sua origem está relacionada à área de processo "Análise e Medição" do CMMI-DEV e do processo "Medição" da 15504-5.

\section{ENTRADAS}

\section{ATIVIDADES}

\section{SAIDAS}

- Documento de Requisitos

- Base de Dados Histórica da empresa

- Cronograma

- Plano de Projeto
CP07 - Determinar estimativas de esforço e tempo

- Cronograma

- Documento de Requisitos

- Plano de Projeto

- Documento de Requisitos

- Plano de Projeto

- Arquitetura do Software

- Fluxo de Caixa

- Plano de Ação

CP08 - Verificar a viabilidade técnica financeira do projeto
- Plano de Projeto

- Relatório de Viabilidade do Projeto

- Fluxo de Caixa

- Relatório de Viabilidade do Projeto

- Infra-Estrutura do Cliente

- Cronograma

- Relatório de Viabilidade do Projeto

- Fluxo de Caixa

- Plano de Projeto
CP11 - Identificar riscos inerentes ao projeto

CP14 - Conduzir revisão do milestone:

Estudo de Viabilidade do Projeto
- Plano de Projeto
- Plano de Projeto

- Plano de Garantia da Qualidade (já existente na empresa)

- $\quad$ Estudo de Viabilidade do Projeto
- Plano de Projeto

- Plano de Garantia da Qualidade

- Contrato
N09 - Conduzir revisão do milestone: Contrato
- Relatório sobre Garantia de Qualidade

- Contrato 


\section{Quadro A3.14 - Entradas, Atividades e Saídas da Área de Conhecimento Medição (Cont.)}

\section{ENTRADAS}

- Plano de Projeto

- Plano de Garantia da Qualidade

- Arquitetura do Software
E08 - Conduzir revisão do milestone: Arquitetura do Software
SAÍDAS

- Relatório sobre

Garantia de Qualidade

- Planilha de Teste

СT02 - Realizar teste de unidade

- Planilha de Teste

- $\quad$ Arquivo de Código

- Arquivo de Código

- Planilha de Teste

СТ03 - Analisar os resultados de teste
- $\quad$ Planilha de Teste
- Arquivo de Código

- Plano de Projeto

- Planilha de Teste
СТ04 - Integrar e testar integração entre componentes
- Planilha de Teste

- Arquivo de Código
- $\quad$ Plano de Garantia da Qualidade

- Produto de Trabalho: Arquivo de Código (Capacidade Operacional do Produto)

- Relatório sobre Garantia da Qualidade
CT07 - Conduzir revisão do milestone: Capacidade Operacional

- Arquivo de Código

- Plano de Teste

- Documento de

T01 - Validar a versão do produto

- $\quad$ Planilha de Teste Requisitos

- Arquivo de Código

- Planilha de Teste

T02 - Analisar e Ajustar a versão do produto

- $\quad$ Arquivo de Código

- Planilha de Teste

- Plano de Projeto

- Planilha de Teste

- Arquivo de Código

T03 - Realizar testes de regressão

- Planilha de Teste

- Arquivo de Código 
Quadro A3.14 - Entradas, Atividades e Saídas da Área de Conhecimento Medição (Cont.)

\begin{tabular}{|l|l|l|} 
ENTRADAS & ATIVIDADES & SAÍDAS \\
\hline
\end{tabular}

- Plano de Garantia da

Qualidade

- Produto de Trabalho:

Entrega do Produto

T07 - conduzir revisão do milestone: entrega

- Relatório sobre

- Relatório sobre

do produto

Garantia da Qualidade

Garantia da Qualidade

- $\quad$ Critérios estabelecidos
Gqpp00 - Desenvolver um Plano de Garantia da Qualidade
- Plano de Garantia de Qualidade
- Plano de Garantia de Qualidade
GqPP01 - Avaliar o processo e assegurar resolução de não conformidades
- Relatório sobre

Garantia da Qualidade
- Plano de Garantia de Qualidade
GqPP02 - Avaliar os produtos de trabalho e assegurar resolução de não conformidades
- Relatório sobre Garantia da Qualidade

\section{Quadro A3.15 - Entradas, Atividades e Saídas da Área de Conhecimento Garantia da Qualidade de Produto e Processo}

GARANTIA DA QUALIDADE DE PRODUTO E PROCESSO: o objetivo dessa área de conhecimento é fornecer a garantia de que processos e produtos de trabalho estejam em conformidade com planos e provisões pré-definidos. Sua origem está relacionada tanto ao CMMI quanto à ISO/IEC 15504.

\section{ENTRADAS}

\section{ATIVIDADES}

\section{SAIDAS}

- Plano de Projeto

- Plano de Garantia da Qualidade (já existente na empresa)

- Estudo de Viabilidade do Projeto
CP14 - Conduzir revisão do milestone: Estudo de Viabilidade do Projeto
- Relatório sobre Garantia de Qualidade

- Plano de Projeto

- Plano de Garantia da Qualidade

N09 - Conduzir revisão do milestone: Contrato

- Relatório sobre Garantia de Qualidade

- Contrato

E08 - Conduzir revisão do milestone: Arquitetura do Software
- Relatório sobre Garantia de Qualidade

- $\quad$ Arquitetura do Software 
Quadro A3.15 - Entradas, Atividades e Saídas da Área de Conhecimento Garantia da Qualidade de Produto e Processo (Cont.)

\begin{tabular}{l|l|l|l} 
ENTRADAS & ATIVIDADES & SAÍDAS
\end{tabular}

- Plano de Garantia da

Qualidade

- Produto de Trabalho: Arquivo de Código (Capacidade Operacional do Produto)

CT07 - Conduzir revisão do milestone: Capacidade Operacional
- Relatório sobre

Garantia da Qualidade

- Relatório sobre

Garantia da Qualidade

- Plano de Garantia da Qualidade

- Produto de Trabalho: Entrega do Produto

- Relatório sobre

T07 - conduzir revisão do milestone: entrega do produto

- Relatório sobre Garantia da Qualidade Garantia da Qualidade

- Plano de Garantia de Qualidade

- Plano de Garantia de Qualidade
GqPP01 - Avaliar o processo e assegurar resolução de não conformidades
- Relatório sobre Garantia da Qualidade

- Relatório sobre Garantia da Qualidade
GqPP02 - Avaliar os produtos de trabalho e assegurar resolução de não conformidades 


\section{Quadro A3.16 - Entradas, Atividades e Saídas da Área de Conhecimento Gestão de Requisitos}

GESTÃO DE REQUISITOS: o objetivo dessa área de conhecimento, que teve sua origem no CMMI-DEV, é gerenciar os requisitos dos produtos e componentes de produtos dos projetos e identificar inconsistências entre esses requisitos e os planos e produtos de trabalho dos projetos. Para isso, essa área trata do rastreamento dos requisitos em meio ao projeto e das mudanças desses requisitos. As mudanças relacionadas aos requisitos utilizam algumas das atividades definidas pela área de conhecimento "Gestão de Mudanças e Configuração".

\section{ENTRADAS}

- Documento de Requisitos

- Projeto IHM

- Cronograma

- Modelo de Negócio

\section{ATIVIDADES}

\section{SAÍDAS}

- Documento de

Requisitos

- Projeto IHM

- Modelo de Negócio

- Mudança interna ou externa

- Plano de Gestão de

GCf03 - Solicitar mudança(s)

- Banco de Dados de Configuração

E01 - Detalhar requisitos
Configuração
- Banco de Dados de Configuração
GCf04. Analisar/Autorizar e Planejar mudança(s)
- Banco de Dados de Configuração
- Plano de Gestão de Configuração

- Banco de Dados de Configuração

- Itens de configuração afetados
GCf05 - Implementar mudança(s)
- Banco de Dados de Configuração

- Itens de configuração afetados

\section{Quadro A3.17 - Entradas, Atividades e Saídas da Área de Conhecimento Gestão de MudançAS e} Configuração

GESTÃO DE MUDANÇAS E CONFIGURAÇÃO: essa área de conhecimento engloba a área de processo "Gestão de Configuração" do CMMI-DEV e os processos "Gestão de Configuração" e "Gestão de Solicitação de Mudanças" da 15504-5. O objetivo dessa área de conhecimento é estabelecer e manter a integridade de produtos de trabalho usando a identificação de configuração, controle de configuração, prestação de contas (explicação) do status da configuração e auditoria da configuração, além de assegurar que solicitações de mudanças no projeto sejam gerenciadas, rastreadas e controladas.

\section{ENTRADAS}

- Critérios

estabelecidos

\section{ATIVIDADES}

SAIDAS

Gqpp00 - Desenvolver um Plano de Gestão de Configuração

GCf01 - Criar e identificar os itens de configuração
- Plano de Gestão de Configuração
- Templates das atividades correspondentes

- Plano de Gestão de Configuração
- Itens de configuração identificados

- Banco de Dados de Configuração 


\section{Quadro A3.17 - Entradas, Atividades e Saídas da Área de Conhecimento Gestão de Mudanças e}

\section{ConfiguraçÃo (CONT.)}

\begin{tabular}{l|l|l|l} 
ENTRADAS & ATIVIDADES & SAÍDAS
\end{tabular}

- Itens de configuração identificados

- Banco de Dados de Configuração
GCf02 - Criar e liberar as baselines
- Baseline

- Banco de Dados de Configuração
- Mudança interna ou externa

- Plano de Gestão de Configuração
GCf03 - Solicitar mudança(s)

- Banco de Dados de Configuração
- Banco de Dados de Configuração
GCf04. Analisar/Autorizar e Planejar mudança(s)
- Banco de Dados de Configuração
- Plano de Gestão de Configuração

- Banco de Dados de Configuração

- Itens de configuração afetados
GCf05 - Implementar mudança(s)
Banco de Dados de Configuração

- Itens de configuração afetados
- Banco de Dados de Configuração

- Itens de configuração afetados
GCf06 - Verificar/Validar e Liberar mudança(s)
- Banco de Dados de Configuração

- Itens de configuração afetados

\section{Quadro A3.18 - Entradas, Atividades e Saídas da Área de Conhecimento Gestão de Projetos}

GESTÃO DE PROJETOS: o objetivo dessa área de processo é identificar, estabelecer, coordenar e monitorar as atividades, tarefas e recursos necessários para um projeto produzir um produto e/ou serviço, no contexto dos requisitos e restrições de projetos. Engloba tanto o processo "Gestão de Projetos" da 15504-5 quanto às áreas de processo "Planejamento de Projeto" e "Monitoramento e Controle de Projeto" do CMMI.
ENTRADAS

- Critérios

estabelecidos

- Critérios estabelecidos
Gcf00 - Desenvolver um Plano de Gestão de Configuração
- Plano de Gestão de Configuração

- Plano de Garantia de Qualidade 
Quadro A3.18 - Entradas, Atividades e Saídas da Área de Conhecimento Gestão de Projetos (Cont.) \begin{tabular}{l|l|l|} 
ENTRADAS & ATIVIDADES & SAÍDAS \\
\hline
\end{tabular}

Gco00 - Estabelecer um sistema e estratégia para gestão do conhecimento
- Sistema de Gestão de Conhecimento
- Solicitação de Proposta
P04 - Criar infra-estrutura do projeto
- Controle de Projetos

- Plano de Projeto

Controle de Projetos
- Documento de Requisitos
CP02 - Definir escopo do projeto
- Documento de Requisitos

- Cronograma
CP06 - Definir/Redefinir cronograma do projeto
- Cronograma
- Documento de Requisitos

- Base de Dados Histórica da empresa

- Cronograma

- Plano de Projeto
CP07 - Determinar estimativas de esforço e tempo
- Cronograma

- Documento de Requisitos

- Plano de Projeto

- Documento de Requisitos

- Plano de Projeto

- Arquitetura do Software

- Fluxo de Caixa

- Plano de Ação

- Relatório de Viabilidade do Projeto

- Infra-Estrutura do Cliente

- Plano de Projeto

- Relatório de Viabilidade do Projeto

- $\quad$ Fluxo de Caixa
- Cronograma

- Controle de Projetos

- Plano de Projeto
CP09 - Planejar os recursos do projeto
- Plano de Projeto

- Controle de Projetos

- Pedido de Compra
- Controle de Projetos

- Plano de Projeto
CP10 - Planejar conhecimentos e habilidades necessárias
- Controle de Projetos

- Plano de Projeto 


\section{Quadro A3.18 - Entradas, Atividades e Saídas da Área de Conhecimento Gestão de Projetos (Cont.)}

\section{ENTRADAS}

- Cronograma

- Relatório de Viabilidade do Projeto

- Fluxo de Caixa

- Plano de Projeto

- Controle de Projetos

- Plano de Projeto

- Relatório de Acompanhamento do Projeto
CP11 - Identificar riscos inerentes ao projeto ATIVIDADES

SAÍDAS

CP12 - Acompanhar o andamento do projeto

- Controle de Projetos

- Relatório de Acompanhamento do Projeto
- Plano de Ação

- Plano de Projeto

- Plano de Garantia da Qualidade (já existente na empresa

- Estudo de Viabilidade do Projeto
CP14 - Conduzir revisão do milestone:

Estudo de Viabilidade do Projeto
CP13 - Controlar custos dispendidos nessa fase
- Plano de Ação

- Relatório sobre Garantia de Qualidade

- Documento de Requisitos

- Relatório de Viabilidade do Projeto

- Relatório de Análise da Proposta

N01 - Elaborar a proposta

- Proposta Técnica

- Proposta Comercial

- Cronograma

- Cronograma

- Plano de Projeto

- Controle de Projetos
N05 - Definir time do projeto

- Plano de Projeto

- Cronograma
- Contrato

- Proposta Técnica

- Pedido de Compra

- Controle de Projetos

- Plano de Projeto
- Proposta Técnica

- Proposta Comercial

- Relatório de Viabilidade do Projeto

- Cronograma

- Documento de Requisitos
N06 - Formalizar início do projeto

- Documento de formalização do projeto

- Pedido de Compra

- Controle de Projetos 
Quadro A3.18 - Entradas, Atividades e Saídas da Área de Conhecimento Gestão de Projetos (Cont.) ENTRADAS ATIVIDADES

SAÍDAS

- Controle de Projetos

- Plano de Projeto

- Relatório de Acompanhamento do Projeto

N07 - Acompanhar o andamento do projeto

- Controle de Projetos

- Relatório de Acompanhamento do Projeto
- $\quad$ Plano de Ação

- Plano de Projeto

- Plano de Garantia da Qualidade

- Contrato
N09 - Conduzir revisão do milestone: Contrato
N08 - Controlar custos dispendidos nessa fase

- Cronograma

- Controle de Tarefas
E04 - Detalhar o cronograma
- Controle de Tarefas

- Plano de Projeto

- Cronograma

- Biblioteca de Casos de Teste Padrão

- Documento de Requisitos

E05 - Definir técnicas e critérios para V\&V

- Planilha de Teste

- Plano de Projeto

- Cronograma

- Modelo de Design

- Arquitetura do Software

- Plano de Projeto

- Relatório de Acompanhamento de Projeto

- Controle de Projetos

- Cronograma
E06 - Monitorar e controlar o projeto

- Contrato

- Controle de Projetos

- Relatório de Viabilidade do Projeto

\section{E07 - Monitorar e Controlar questões financeiras}

- Relatório de Acompanhamento de Projeto

- Controle de Projetos

- Cronograma
- Controle de Projetos

- Relatório de Viabilidade do Projeto

- Cobrança

- Fluxo de Caixa 


\section{Quadro A3.18 - Entradas, Atividades e Saídas da Área de Conhecimento Gestão de Projetos (Cont.)} ENTRADAS

- Plano de Projeto

- Plano de Garantia da Qualidade

- $\quad$ Arquitetura do Software
E08 - Conduzir revisão do milestone: Arquitetura do Software
- Relatório sobre

Garantia de Qualidade
- Plano de Projeto

- Relatório de Acompanhamento de Projeto

- Controle de Projetos

- Cronograma
CT05 - Monitorar e controlar o projeto

СT06 - Monitorar e Controlar questões financeiras
- Controle de Projetos

- Cobrança

- Fluxo de caixa
- Plano de Garantia da Qualidade

- Produto de Trabalho: Arquivo de Código (Capacidade Operacional do Produto)

- Relatório sobre Garantia da Qualidade
CT07 - Conduzir revisão do milestone: Capacidade Operacional
- Relatório de

Acompanhamento de Projeto

- Controle de Projetos

- Cronograma
- Plano de Projeto

- Relatório de Acompanhamento de Projeto

- Controle de Projetos

- Cronograma
T05 - Monitorar e controlar o projeto

- Controle de Projetos

- Relatório de Viabilidade do Projeto

- Fluxo de caixa
T06 - Monitorar e Controlar questões financeiras
- Relatório de Acompanhamento de Projeto

- Controle de Projetos

- Cronograma
Relatório sobre Garantia da Qualidade 
Quadro A3.18 - Entradas, Atividades e Saídas da Área de Conhecimento Gestão de Projetos (Cont.) ENTRADAS

- Plano de Garantia da Qualidade

- $\quad$ Produto de Trabalho: Entrega do Produto

- Relatório sobre

T07 - conduzir revisão do milestone: entrega do produto

- Relatório sobre

Garantia da Qualidade

\section{Quadro A3.19 - Entradas, Atividades e Saídas da Área de Conhecimento Gestão de Conhecimento}

GESTÃO DE CONHECIMENTO: tem como objetivo assegurar que o conhecimento, informação e habilidades individuais sejam coletadas, compartilhadas, reusadas e melhoradas por toda a organização. Sua origem está relacionada ao processo "Gestão de Conhecimento" da ISO/IEC 15504.
ENTRADAS

Gco00 - Estabelecer um sistema e estratégia para gestão do conhecimento

- Sistema de Gestão de Conhecimento
- Conhecimento

- Sistema de Gestão de Conhecimento
GCo01 - Capturar o conhecimento

- Lições aprendidas e conhecimento
- Lições aprendidas e conhecimento

- Sistema de Gestão de GCo02 - Lapidar o conhecimento Conhecimento

- Memória

Organizacional
GCo03 - Disseminar o conhecimento
- Memória

Organizacional

As Figuras $\mathrm{A} 3.20$ a $\mathrm{A} 3.25$, a seguir, apresentam a visão gráfica das atividades em fases. Os Quadros A3.20.1 a A3.20.5 apresentam o detalhamento de cada uma das atividades (responsável, descrição, recursos, entradas, saídas e tarefas) da fase de prospecção. Os Quadros A3.21.1 a A3.21.14 o detalhamento das atividades da fase de concepção, os Quadros A3.22.1 a A.3.22.9 da fase de negociação, os Quadros A3.23.1 a A3.23.8 da fase de elaboração, os Quadros A3.24.1 a A3.24.7 da fase de construção e os Quadros A3.25.1 a A3.25.7 da fase de transição. 


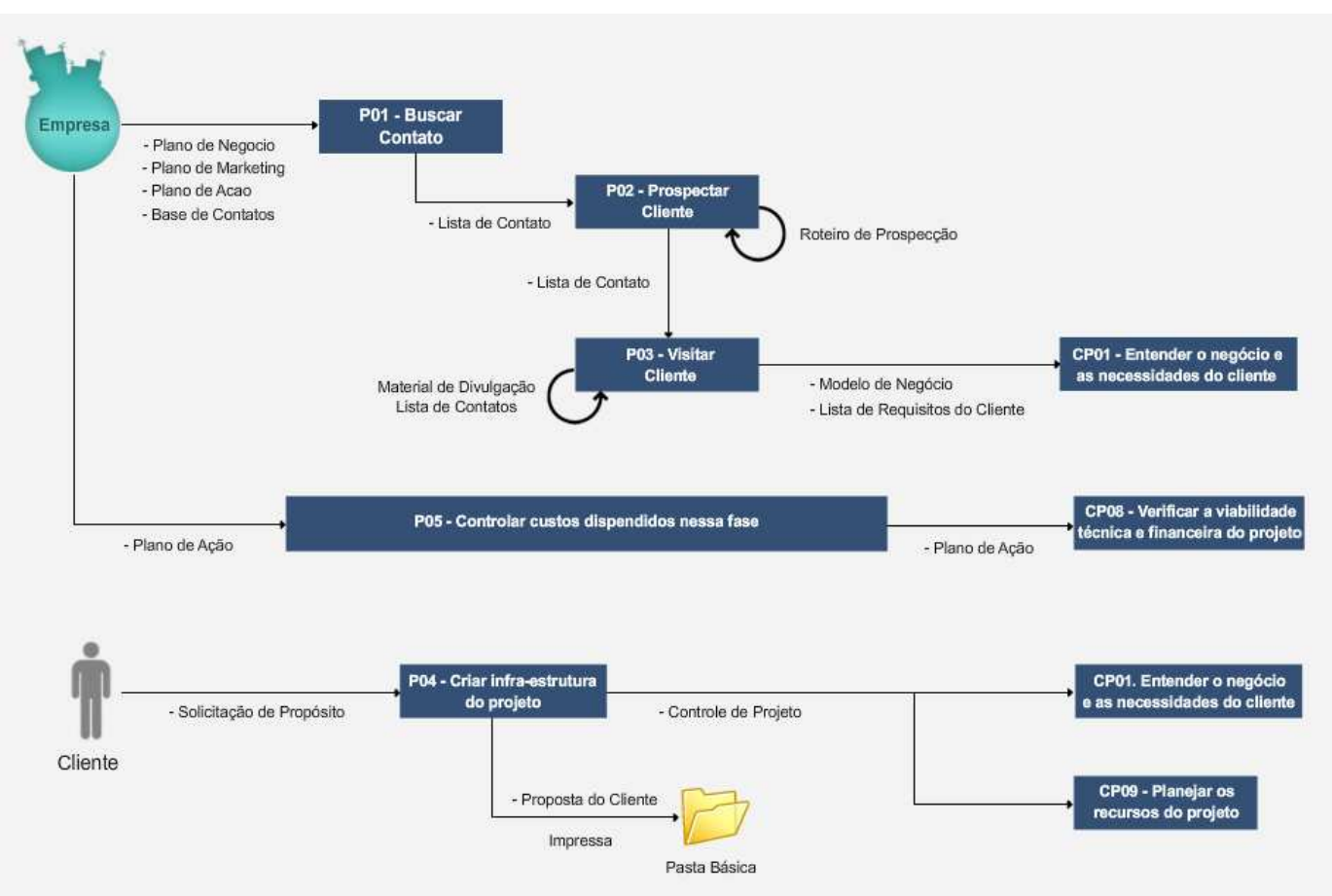

Figura A3.20 - Visão Gráfica - Fase: Prospecção

Quadro A3.20.1 - Detalhamento da Atividade P01

\begin{tabular}{|l|l|}
\hline Atividade & P01. Buscar contatos \\
\hline Responsáveis & Equipe de Vendas \\
\hline Descrição & $\begin{array}{l}\text { Essa atividade tem como objetivo buscar na internet ou na base de contatos } \\
\text { da empresa os potenciais clientes, de acordo com os perfis estabelecidos no } \\
\text { plano de marketing e na estratégia da empresa para o período em questão. }\end{array}$ \\
\hline Recursos & $\begin{array}{l}\text { - Ferramentas de relacionamento com cliente (CRM), tais como: VTIGER, } \\
\text { DBMKT, newsletter, e-mail marketing, mecanismos de buscas, websites }\end{array}$ \\
\hline Entradas & $\begin{array}{l}\text { e1) Plano de Negócios (já deve existir na empresa) } \\
\text { e2) Plano de Marketing (já deve existir na empresa) } \\
\text { e3) Plano de Ação (já deve existir na empresa) } \\
\text { e4) Base de contatos (já deve existir na empresa) }\end{array}$ \\
\hline Saídas & $\begin{array}{l}\text { s1) Lista de Contatos } \\
\text { - Executar as atividades para busca de potenciais clientes (item 3.2 do } \\
\text { "Plano de Marketing"). } \\
\text { * Executar a etapa 1 definida no item "Plano de Ação" (item } 4 \text { do "Plano } \\
\text { definido na planilha "Plano de Ação" do arquivo "Plano de Ação". } \\
\text { * Criar planilha Lista de Contatos (conforme GCf01) e registrar os } \\
\text { contatos validados na planilha "Lista de Contatos", a partir da "Base de } \\
\text { Contatos" da empresa. } \\
\text { * Registrar a data de realização da etapa 1 descrita no item } 4 \text { do "Plano } \\
\text { de Marketing" na planilha "Controle de Visitas" do arquivo "Lista de } \\
\text { Contatos", para todos os contatos validados. }\end{array}$ \\
\hline
\end{tabular}


Quadro A3.20.2 - Detalhamento da Atividade P02

\begin{tabular}{|l|l|}
\hline Atividade & P02. Prospectar cliente \\
\hline Responsáveis & Equipe de Vendas \\
\hline Descrição & $\begin{array}{l}\text { Essa atividade tem como objetivo fazer com que a empresa desenvolvedora } \\
\text { entre em contato com o cliente para averiguar a possibilidade de um projeto. }\end{array}$ \\
\hline Recursos & $\begin{array}{l}\text { - Ferramentas de relacionamento com cliente (CRM), tais como: VTIGER, } \\
\text { DBMKT, newsletter, e-mail marketing, mecanismos de buscas, websites }\end{array}$ \\
\hline Entradas & $\begin{array}{l}\text { e1) Lista de Contatos } \\
\text { e2) Plano de Marketing }\end{array}$ \\
\hline Saídas & $\begin{array}{l}\text { s1) Lista de Contatos } \\
\text { s2) Roteiro de Prospecção }\end{array}$ \\
\hline Tarefas & $\begin{array}{l}\text { - Selecionar abordagem do cliente, priorizando contatos que demonstraram } \\
\text { interesse depois de executada a etapa 1 do item 4 do "Plano de Marketing". } \\
\text { Exemplo de abordagem selecionada: etapa } 2 \text { do plano de ação - Contato } \\
\text { telefônico } \\
\text { - Identificar contato chave para processo de prospecção e registrar na } \\
\text { planilha "Lista de Contatos" do arquivo "Lista de Contatos". Exemplo: } \\
\text { Contato que tem poder de decisão } \\
\text { - Levantar informações sobre o cliente e registrar na planilha "Lista de } \\
\text { Contatos" do arquivo "Lista de Contatos". Exemplo: Verificação de gargalos } \\
\text { e necessidades, nível de satisfação com o atual prestador de serviços, etc } \\
\text { - Criar "Roteiro de Prospecção" (conforme GCf01), de acordo com o item 4 } \\
\text { (plano de ação) do "Plano de Marketing" } \\
\text { - Entrar em contato com o cliente utilizando o roteiro de prospecção } \\
\text { - Registrar a data de comunicação com o cliente na coluna "Etapa 2" na } \\
\text { "Lista de Contatos" } \\
\text { - Verificar o interesse do cliente por uma proposta e registrar na coluna } \\
\text { "Interesse por proposta" }\end{array}$ \\
\hline
\end{tabular}


Quadro A3.20.3 - Detalhamento da Atividade P03

\begin{tabular}{|c|c|}
\hline Atividade & P03. Visitar cliente \\
\hline Responsáveis & $\begin{array}{l}\text { Equipe de Vendas } \\
\text { Cliente }\end{array}$ \\
\hline Descrição & $\begin{array}{l}\text { Essa atividade tem como objetivo iniciar um relacionamento personalizado } \\
\text { com o cliente, a fim de averiguar o interesse do cliente na solicitação de } \\
\text { uma proposta de solução para as demandas colocadas. }\end{array}$ \\
\hline Recursos & $\begin{array}{l}\text { - Meios de deslocamento } \\
\text { - Laptop } \\
\text { - Ferramenta de modelagem de negócio (ex: Rational Rose, ARPO) }\end{array}$ \\
\hline Entradas & e1) Lista de Contatos \\
\hline Saídas & $\begin{array}{l}\text { s1) Modelo de Negócio } \\
\text { s2) Material de divulgação } \\
\text { s3) Lista de Contatos } \\
\text { s4) Lista de Requisitos do Cliente }\end{array}$ \\
\hline Tarefas & $\begin{array}{l}\text { - Pesquisar informações sobre a atividade do cliente e de soluções } \\
\text { utilizadas pelo mesmo e registrar na planilha "Lista de Contatos" do arquivo } \\
\text { "Lista de Contatos" } \\
\text { - Preparar material de divulgação, no caso de existir na empresa algum } \\
\text { produto que se encaixe na necessidade do cliente } \\
\text { * Levantar situações onde a empresa desenvolvedora teve sucesso no } \\
\text { atendimento de clientes com problemas análogos } \\
\text { * Preparar demonstrações (.ppt, flash) sobre as situações análogas } \\
\text { levantadas } \\
\text { - Na reunião com o cliente, levantar possíveis demandas, necessidades e } \\
\text { informações do cliente, inclusive os casos de uso de negócio do cliente, } \\
\text { caso necessário. } \\
\text { * Criar arquivo "Lista de Requisitos do Cliente" (conforme GCf01) para } \\
\text { armazenar as demandas e necessidades do cliente } \\
\text { * Solicitar ao cliente que a empresa seja procurada quando surgirem } \\
\text { demandas futuras. } \\
\text { * Cadastrar a data da visita na planilha "Controle de Visitas" do arquivo } \\
\text { "Lista de Contatos" } \\
\text { * Criar o arquivo "Modelo de Negócio" (conforme GCf01) e registrar as } \\
\text { informações obtidas relacionadas ao vocabulário do negócio (item 1), aos } \\
\text { casos de uso de negócio (item 2) e às regras de negócio (item 3) }\end{array}$ \\
\hline
\end{tabular}


Quadro A3.20.4 - Detalhamento da Atividade P04

\begin{tabular}{|c|c|}
\hline Atividade & P04. Criar infra-estrutura do projeto \\
\hline Responsáveis & Gerente de Projeto \\
\hline Descrição & $\begin{array}{l}\text { A qualquer momento, um cliente pode solicitar uma proposta e, nesse caso, } \\
\text { deve-se criar a infra-estrutura necessária para dar início ao projeto. }\end{array}$ \\
\hline Recursos & Ferramenta de gestão de projetos (ex: dotProject, MS-Project, Primavera) \\
\hline Entradas & e1) Solicitação de Proposta \\
\hline Saídas & $\begin{array}{l}\text { s1) Controle de Projetos } \\
\text { s2) Proposta do Cliente Impressa }\end{array}$ \\
\hline Tarefas & $\begin{array}{l}\text { - Caso o arquivo "Controle de Projetos" ainda não tenha sido criado, criá-lo } \\
\text { (conforme GCf01) } \\
\text { - Definir o ID do projeto (há uma sugestão no item } 4 \text { "Estratégia de } \\
\text { identificação dos itens de configuração" do "Plano de Gestão de } \\
\text { Configuração") } \\
\text { - Criar projeto na planilha "Identificação de Projetos" do arquivo "Controle } \\
\text { de Projetos" da empresa e preencher os campos: id_projeto e descrição } \\
\text { - Criar pasta física e pasta lógica e marcar "sim" nas respectivas colunas da } \\
\text { planilha "Identificação de Projetos" do arquivo "Controle de Projetos" } \\
\text { * Quanto à proposta solicitada pelo cliente, se for o caso: } \\
\text { - Registrar data de solicitação da proposta pelo cliente, caso ocorra, na } \\
\text { planilha "Controle de Visitas" do arquivo "Lista de Contatos" } \\
\text { - Digitalizar a proposta solicitada pelo cliente } \\
\text { - Anexar a proposta na pasta lógica } \\
\text { - Imprimir a proposta e solicitar que o cliente a assine para que seja } \\
\text { armazenada na pasta física. } \\
\text { - Selecionar projeto na planilha "Acompanhamento" do arquivo "Controle de } \\
\text { Projetos" da empresa e preencher os campos: situação (selecionar a opção } \\
\text { "inicializado" do combo-box), data de inicialização do projeto, marcar a fase } \\
\text { de concepção, ciclo de desenvolvimento e data de início da fase de } \\
\text { concepção }\end{array}$ \\
\hline
\end{tabular}


Quadro A3.20.5 - Detalhamento da Atividade P05

\begin{tabular}{|c|c|}
\hline Atividade & P05. Controlar custos despendidos na fase de prospecção \\
\hline Responsáveis & Equipe de Vendas \\
\hline Descrição & $\begin{array}{l}\text { Essa atividade tem como objetivo registrar todos os custos referentes à } \\
\text { execução das atividades dessa fase. }\end{array}$ \\
\hline Recursos & \\
\hline Entradas & e1) Plano de Ação \\
\hline Saídas & s1) Plano de Ação \\
\hline Tarefas & $\begin{array}{l}\text { - Atualizar na planilha "Acompanhamento" (item "Atividades") do arquivo } \\
\text { "Plano de Ação" a quantidade de atividades realizadas de fato } \\
\text { - Atualizar na planilha "Acompanhamento" (item "Custos") os custos reais } \\
\text { referentes à execução de todas as atividades dessa fase }\end{array}$ \\
\hline
\end{tabular}




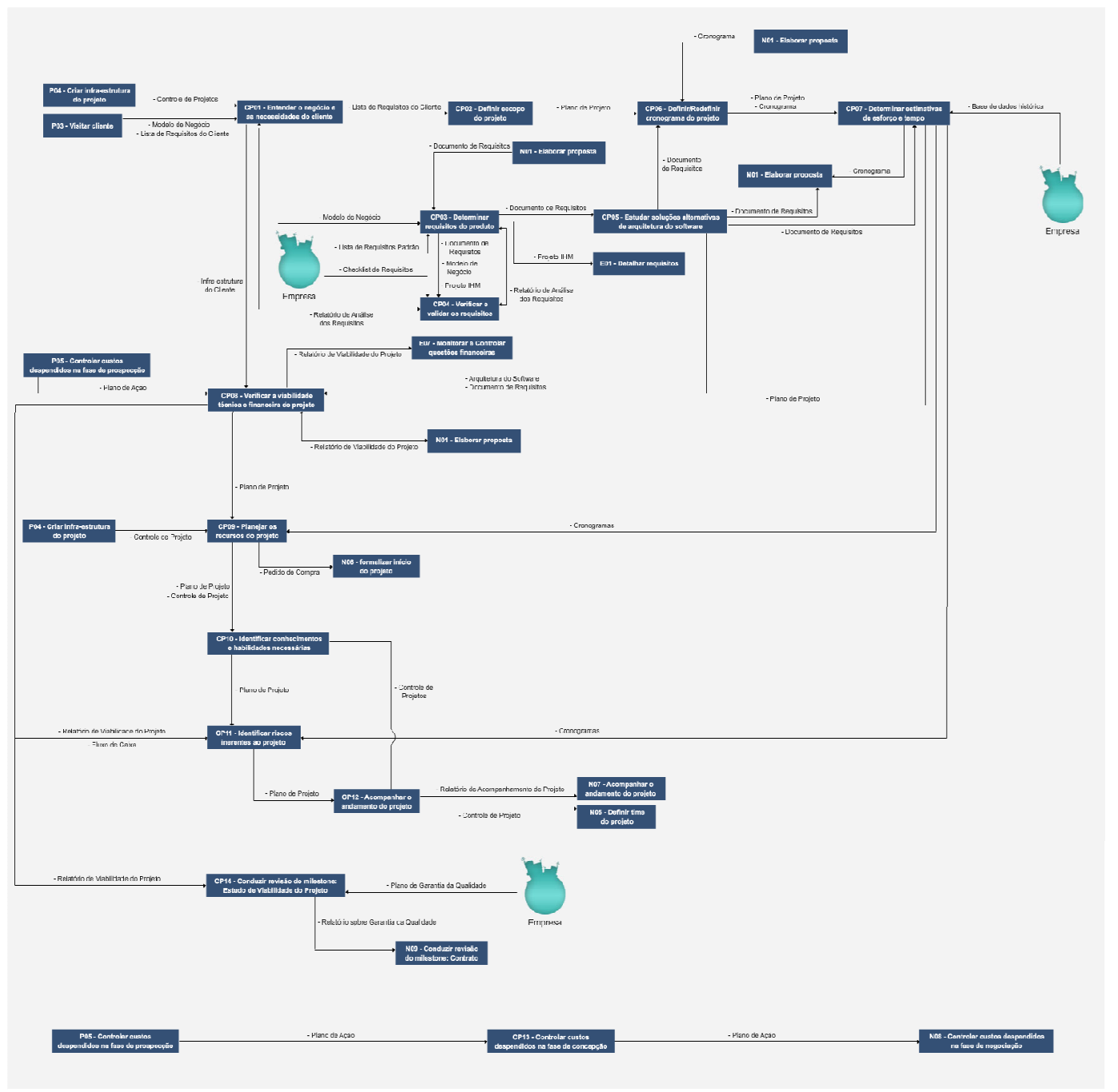

Figura A3.21 - Visão GráficA - FASE: ConcePCÇÃo 


\section{Quadro A3.21.1 - Detalhamento da Atividade Cp01}

\begin{tabular}{|l|l|}
\hline Atividade & Cp01. Entender o negócio e as necessidades do cliente \\
\hline Responsáveis & $\begin{array}{l}\text { Gerente de Projeto } \\
\text { Engenheiro de Requisitos } \\
\text { Cliente }\end{array}$ \\
\hline Descrição & $\begin{array}{l}\text { Essa atividade tem por objetivo entender o negócio do cliente, as } \\
\text { necessidades do cliente e as regras de seu negócio, por meio de técnicas } \\
\text { de levantamentos de requisitos, a fim de definir com clareza os requisitos do } \\
\text { sistema. }\end{array}$ \\
\hline Recursos & $\begin{array}{l}\text { - Ferramenta de modelagem de negócio (ex: Rational Rose, ARPO) } \\
\text { - Técnica JAD } \\
\text { - Ferramenta de Prototipação }\end{array}$ \\
\hline Entradas & $\begin{array}{l}\text { e1) Controle de Projetos } \\
\text { e2) Modelo de Negócio } \\
\text { e3) Lista de Requisitos do Cliente } \\
\text { e4) Relatório de Análise dos Requisitos }\end{array}$ \\
\hline Saídas & $\begin{array}{l}\text { s1) Modelo de Negócio } \\
\text { s2) Lista de Requisitos do Cliente } \\
\text { s3) Infra-Estrutura do Cliente } \\
\text { s4) Relatório de Análise dos Requisitos }\end{array}$ \\
\hline
\end{tabular}




\section{Quadro A3.21.1 - Detalhamento da Atividade Cp01 (Cont.)}

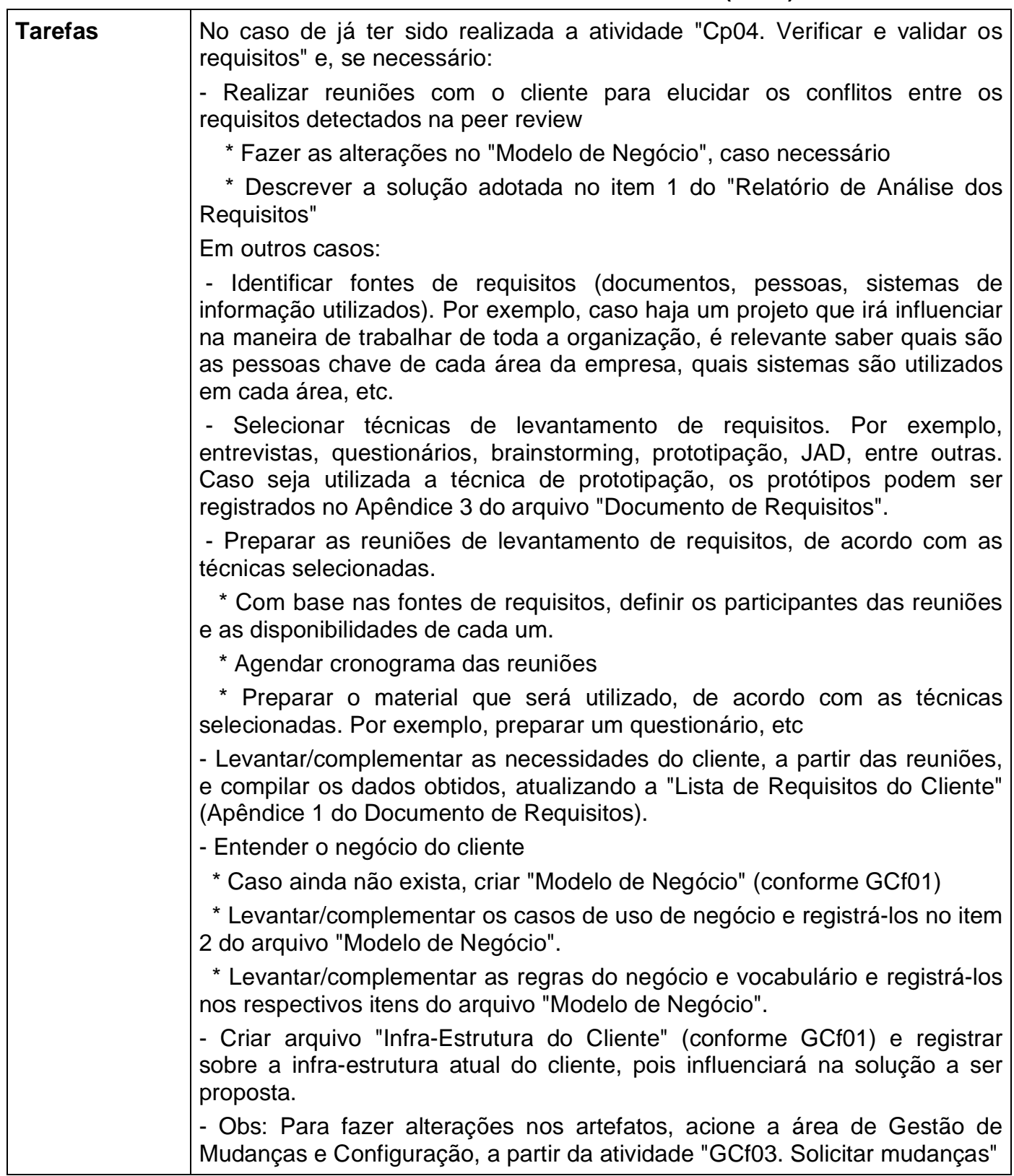


Quadro A3.21.2 - Detalhamento da Atividade Cp02

\begin{tabular}{|c|c|}
\hline Atividade & Cp02. Definir escopo do projeto \\
\hline Responsáveis & $\begin{array}{l}\text { Gerente de Projeto } \\
\text { Engenheiro de Requisitos }\end{array}$ \\
\hline Descrição & $\begin{array}{l}\text { Essa atividade deverá ser realizada para dar início ao planejamento do } \\
\text { projeto e para dar suporte à realização da proposta que deverá ser enviada } \\
\text { ao cliente. }\end{array}$ \\
\hline Recursos & \\
\hline Entradas & e1) Lista de Requisitos do Cliente \\
\hline Saídas & s1) Plano de Projeto \\
\hline Tarefas & $\begin{array}{l}\text { - Criar Plano do Projeto (conforme GCf01) } \\
\text { - A partir do levantamento de requisitos, descrever o escopo do projeto do } \\
\text { arquivo "Plano de Projeto". } \\
\text { * Descrever o cenário (item 1.1): } \\
\text { - identificar as necessidades que motivaram o cliente a solicitar o } \\
\text { projeto, a partir da "Lista de Requisitos do Cliente" } \\
\text { - definir os stakeholders (interessados) e usuários do sistema (quem } \\
\text { são e quais as necessidades de cada um) e } \\
\text { - descrever as expectativas que o projeto visa atender } \\
\text { * Definir premissas, limitações e restrições do projeto (item 1.3) } \\
\text { - Definir os critérios de aceitação do cliente e registrá-los no item } 1.4 \text { do } \\
\text { "Plano de Projeto" } \\
\text { * Descrever como o projeto atenderá às expectativas do cliente } \\
\text { * Descrever itens de sucesso para o cliente, como antecipação de } \\
\text { prazos }\end{array}$ \\
\hline
\end{tabular}


Quadro A3.21.3 - Detalhamento da Atividade Cp03

\begin{tabular}{|c|c|}
\hline Atividade & Cp03. Determinar requisitos do produto \\
\hline Responsáveis & Engenheiro de Requisitos \\
\hline Descrição & $\begin{array}{l}\text { Transformar os requisitos do cliente em requisitos do produto, uma vez que } \\
\text { uma necessidade do cliente pode ser traduzida em mais de um requisito do } \\
\text { produto; a descrição dos requisitos dependerá do nível de detalhamento } \\
\text { definido. Também, quando necessário, devem ser utilizados protótipos para } \\
\text { auxiliar na melhor definição dos requisitos. }\end{array}$ \\
\hline Recursos & \\
\hline Entradas & $\begin{array}{l}\text { e1) Modelo de Negócio } \\
\text { e2) Documento de Requisitos } \\
\text { e3) Lista de Requisitos Padrão do Produto (já existente na empresa) } \\
\text { e4) Relatório de Análise dos Requisitos }\end{array}$ \\
\hline Saídas & $\begin{array}{l}\text { s1) Documento de Requisitos } \\
\text { s2) Projeto IHM } \\
\text { s3) Relatório de Análise dos Requisitos }\end{array}$ \\
\hline Tarefas & $\begin{array}{l}\text { No caso de já ter sido realizada a atividade "Cp04. Verificar e validar os } \\
\text { requisitos" e, se necessário: } \\
\text { - Realizar reuniões com o cliente para elucidar os conflitos entre os } \\
\text { requisitos detectados na peer review } \\
\text { * Fazer as alterações no "Documento de Requisitos", caso necessário } \\
\text { * Descrever a solução adotada no item } 2 \text { do "Relatório de Análise dos } \\
\text { Requisitos" } \\
\text { Em outros casos: } \\
\text { - Descrever/Atualizar o escopo do produto; as siglas, abreviações e } \\
\text { definições utilizadas e as referências adquiridas e registrá-los no arquivo } \\
\text { "Documento de Requisitos". } \\
\text { * Criar/Atualizar o arquivo "Documento de Requisitos" (conforme GCf01) } \\
\text { - Definir/Atualizar e registrar no capítulo } 2 \text { do "Documento de Requisitos", a } \\
\text { partir da Lista de Requisitos do Cliente (apêndice do arquivo "Documento de } \\
\text { Requisitos") e do "Modelo de Negócio": a Perspectiva do Produto, as } \\
\text { principais Funções do Produto, as Características dos Usuários, os Limites, } \\
\text { Suposições e Dependências } \\
\text { * Caso se trate de algum produto já desenvolvido pela empresa, deve-se } \\
\text { selecionar a partir da "Lista de Requisitos do Padrão Produto", aqueles } \\
\text { requisitos que serão colocados na proposta ao cliente. } \\
\text { - Definir/Atualizar volatilidade dos requisitos, isto é, probabilidade de } \\
\text { mudança dos requisitos elicitados } \\
\text { - Caso o sistema tenha que atender diferentes tipos de perfis de usuários: } \\
\text { * Criar/Atualizar Projeto IHM (conforme GCfo1) } \\
\text { * Definir perfis de usuários e registrar no item } 1 \text { do "Projeto IHM" (Projeto } \\
\text { de Interface Homem Máquina) } \\
\text { - Obs: Para fazer alterações nos artefatos, acione a área de Gestão de } \\
\text { Mudanças e Configuração, a partir da atividade "GCf03. Solicitar mudanças" }\end{array}$ \\
\hline
\end{tabular}


Quadro A3.21.4 - Detalhamento da Atividade Cp04

\begin{tabular}{|c|c|}
\hline Atividade & Cp04. Verificar e Validar os requisitos \\
\hline Responsáveis & $\begin{array}{l}\text { Equipe de Teste } \\
\text { Cliente } \\
\text { Engenheiro de Requisitos }\end{array}$ \\
\hline Descrição & $\begin{array}{l}\text { Essa atividade tem por objetivo a realização da verificação dos requisitos e, } \\
\text { posteriormente, da validação dos mesmos junto ao cliente. }\end{array}$ \\
\hline Recursos & \\
\hline Entradas & $\begin{array}{l}\text { e1) Documento de Requisitos } \\
\text { e2) Checklist de Requisitos } \\
\text { e3) Modelo de Negócio } \\
\text { e4) Projeto IHM } \\
\text { e5) Relatório de Análise dos Requisitos }\end{array}$ \\
\hline Saídas & s2) Relatório de Análise dos Requisitos \\
\hline Tarefas & $\begin{array}{l}\text { - Realizar peer review (uma das pessoas não deve ter participado do } \\
\text { desenvolvimento do Documento de requisitos) } \\
\text { * Analisar os requisitos a partir do "Documento de Requisitos", "Modelo de } \\
\text { Negócio" e "Projeto IHM" e, se for o caso, do "Relatório de Análise dos } \\
\text { Requisitos" para ver se há conflitos entre as solicitações dos stakeholders, } \\
\text { documentando tais conflitos no "Relatório de Análise dos Requisitos" } \\
\text { (criar/atualizar "Relatório de Análise dos Requisitos", conforme GCf01) } \\
\text { * Para dar subsídio ao peer review, pode ser utilizado um checklist (vide } \\
\text { "Checklist de Requisitos") } \\
\text { - Realizar reuniões com o cliente para validar os requisitos (averiguar se o } \\
\text { que está descrito está de acordo com as necessidades do cliente) } \\
\text { * Registrar eventuais conflitos no "Relatório de Análise dos Requisitos" }\end{array}$ \\
\hline
\end{tabular}


Quadro A3.21.5 - Detalhamento da Atividade Cp05

\begin{tabular}{|c|c|}
\hline Atividade & Cp05. Estudar soluções alternativas de arquitetura do software \\
\hline Responsáveis & $\begin{array}{l}\text { Equipe de Desenvolvimento } \\
\text { Engenheiro de Requisitos }\end{array}$ \\
\hline Descrição & $\begin{array}{l}\text { Essa atividade é realizada com base nos requisitos mais críticos para ser } \\
\text { sugerida a arquitetura do software. }\end{array}$ \\
\hline Recursos & $\begin{array}{l}\text { Ferramenta de Modelagem de Software (ex: ArgoUML, Rational Rose, } \\
\text { Eclipse, JUDE) }\end{array}$ \\
\hline Entradas & e1) Documento de Requisitos \\
\hline Saídas & $\begin{array}{l}\text { s1) Arquitetura do Software } \\
\text { s2) Documento de Requisitos }\end{array}$ \\
\hline Tarefas & $\begin{array}{l}\text { - Criar/Atualizar o arquivo "Arquitetura do Software" (conforme GCf01) } \\
\text { - Definir os Fatores Arquiteturais, ou seja, os requisitos não funcionais que } \\
\text { influenciarão na escolha da arquitetura, e registrá-los no item } 1 \text { do } \\
\text { documento "Arquitetura do Software". } \\
\text { - Definir/Atualizar a arquitetura lógica do sistema, ou seja, a organização } \\
\text { em larga escala das classes de software em pacotes, subsistemas, e } \\
\text { dependendo do caso em camadas, e registrá-la no item } 2 \text { do documento } \\
\text { "Arquitetura do Software". } \\
\text { - Definir/Atualizar a topologia do sistema, ou seja, como os elementos } \\
\text { físicos do sistema estarão dispostos e registrar no item } 3 \text { do documento } \\
\text { "Arquitetura do Software". } \\
\text { - Descrever as decisões arquiteturais e registrar no item } 4 \text { do documento } \\
\text { "Arquitetura do Software". } \\
\text { - Averiguar quais componentes podem ser adquiridos sem custos, quais já } \\
\text { estão prontos e quais compensam ser comprados/terceirizados, e registrar } \\
\text { no Apêndice } 2 \text { do "Documento de Requisitos". } \\
\text { - Complementar o item "Perspectiva do Produto" do "Documento de } \\
\text { Requisitos", dependendo do que foi definido como sendo a arquitetura do } \\
\text { software. } \\
\text { - Obs: Para fazer alterações nos artefatos, acione a área de Gestão de } \\
\text { Mudanças e Configuração, a partir da atividade "GCf03. Solicitar mudanças" }\end{array}$ \\
\hline
\end{tabular}


Quadro A3.21.6 - Detalhamento da Atividade Cp06

\begin{tabular}{|c|c|}
\hline Atividade & Cp06. Definir/Redefinir cronograma do projeto \\
\hline Responsáveis & Gerente de Projeto \\
\hline Descrição & $\begin{array}{l}\text { Essa atividade tem como objetivo definir/redefinir o cronograma do projeto, a } \\
\text { partir da WBS elaborada. }\end{array}$ \\
\hline Recursos & $\begin{array}{l}\text { Ferramenta de gerenciamento de projeto (ex: dot Project, MS-Project, } \\
\text { Primavera) }\end{array}$ \\
\hline Entradas & $\begin{array}{l}\text { e1) Documento de Requisitos } \\
\text { e2) Cronograma } \\
\text { e3) Plano de Projeto }\end{array}$ \\
\hline Saídas & $\begin{array}{l}\text { s1) Cronograma } \\
\text { s2) Plano de Projeto }\end{array}$ \\
\hline Tarefas & $\begin{array}{l}\text { - Elaborar/Atualizar WBS (Work Breakdown Structure) no arquivo } \\
\text { "Cronograma" } \\
\text { * Pode ser usada uma ferramenta de gerenciamento de projeto, como dot } \\
\text { Project } \\
\text { * Definir/Redefinir quantos ciclos de desenvolvimento o projeto terá (cada } \\
\text { ciclo de desenvolvimento passa, normalmente, pelas fases elaboração, } \\
\text { construção e transição, com menor ou maior ênfase em algumas delas. } \\
\text { Entretanto, pode existir a ocasião em que seja necessário voltar à fase de } \\
\text { concepção para renegociar mudanças relevantes no projeto e, por } \\
\text { conseqüência, no contrato). Cada ciclo de desenvolvimento produz um } \\
\text { release do software. } \\
\text { * Definir/Redefinir as fases do projeto, se achar pertinente } \\
\text { * Definir/Redefinir as entregas do projeto, que são desdobramentos do } \\
\text { produto do projeto em resultados tangíveis, a partir do "Documento de } \\
\text { Requisitos". A característica fundamental das entregas é a capacidade de } \\
\text { serem medidas e avaliadas. Por ex: manual do usuário, manual do sistema, } \\
\text { versão do sistema. } \\
\text { * Criar/Atualizar arquivo "Plano de Projeto" (conforme GCf01) e registrar } \\
\text { quem são as entregas no escopo do projeto desse arquivo } \\
\text { * Definir/Redefinir pacotes de trabalho os quais representam um conjunto } \\
\text { de atividades que precisam ser feitas para obtenção de uma entrega ou de } \\
\text { um produto de projeto. } \\
\text { - Definir/Redefinir a inter-dependência e seqüência das atividades } \\
\text { * Baseado nos pacotes de trabalho, definidos anteriormente, relacionar } \\
\text { entradas e saídas de cada atividade } \\
\text { * Definir/Redefinir quais as entradas e saídas são mutuamente } \\
\text { dependentes } \\
\text { - Obs: Para fazer alterações nos artefatos, acione a área de Gestão de } \\
\text { Mudanças e Configuração, a partir da atividade "GCfo3. Solicitar mudanças" }\end{array}$ \\
\hline
\end{tabular}


Quadro A3.21.7 - Detalhamento da Atividade Cp07

\begin{tabular}{|c|c|}
\hline Atividade & Cp07. Determinar estimativas de esforço e tempo \\
\hline Responsáveis & $\begin{array}{l}\text { Gerente de Projeto } \\
\text { Equipe de Desenvolvimento } \\
\text { Engenheiro de Requisitos }\end{array}$ \\
\hline Descrição & $\begin{array}{l}\text { Essa atividade deverá ser realizada para estimar o esforço e duração das } \\
\text { atividades do projeto com base em cronogramas de referência, base de } \\
\text { dados histórica da empresa ou em experiências adquiridas, para que o } \\
\text { projeto possa ser medido e controlado. }\end{array}$ \\
\hline Recursos & $\begin{array}{l}\text { Ferramenta de gerenciamento de projeto (ex: dot Project, MS-Project, } \\
\text { Primavera) }\end{array}$ \\
\hline Entradas & $\begin{array}{l}\text { e1) Documento de Requisitos } \\
\text { e2) Base de Dados Histórica da empresa } \\
\text { e3) Cronograma } \\
\text { e4) Plano de Projeto }\end{array}$ \\
\hline Saídas & $\begin{array}{l}\text { s1) Cronograma } \\
\text { s2) Plano de Projeto }\end{array}$ \\
\hline Tarefas & $\begin{array}{l}\text { - Definir/Redefinir a dimensão (tamanho) do sistema a ser desenvolvido. } \\
\text { * Podem ser usadas as métricas pontos por função, quantidade de casos } \\
\text { de uso ou qualquer outra métrica que achar pertinente } \\
\text { - Procurar algum projeto similar na Base de Dados Histórica da empresa } \\
\text { (criada com o decorrer dos projetos da empresa), de acordo com alguns } \\
\text { parâmetros, tais como: domínio de negócio do sistema, tamanho do } \\
\text { sistema, funcionalidades do sistema, plataforma utilizada, nível de } \\
\text { conhecimento dos colaboradores. } \\
\text { - Calcular estimativas de esforço e duração em horas das atividades da } \\
\text { WBS. } \\
\text { * Criar/Atualizar arquivo "Cronograma" (conforme GCf01) } \\
\text { * Os cálculos devem ser registrados no "Cronograma" } \\
\text { * Utilizar a Base de Dados Histórica da empresa ou experiência de } \\
\text { especialistas, além do "Documento de Requisitos" do projeto em andamento } \\
\text { para embasar as estimativas de esforço e duração das atividades a serem } \\
\text { realizadas. } \\
\text { - Definir/Redefinir os papéis que devem executar cada uma das atividades e } \\
\text { registrar no "Cronograma". Por exemplo, a atividade elaborar cronograma } \\
\text { deve ser executada por um gerente de projeto e não por um colaborador da } \\
\text { equipe de teste } \\
\text { - Colocar no cronograma o valor da hora do papel que deve executar cada } \\
\text { atividade, a fim de calcular o custo de cada atividade, e do projeto como um } \\
\text { todo } \\
\text { - Estabelecer/Restabelecer prazos máximos no escopo do projeto do "Plano } \\
\text { de Projeto", a partir do cronograma elaborado. } \\
\text { - Obs: Para fazer alterações nos artefatos, acione a área de Gestão de } \\
\text { Mudanças e Configuração, a partir da atividade "GCf03. Solicitar mudanças" }\end{array}$ \\
\hline
\end{tabular}


Quadro A3.21.8 - Detalhamento da Atividade Cp08

\begin{tabular}{|c|c|}
\hline Atividade & Cp08. Verificar a viabilidade técnica e financeira do projeto \\
\hline Responsáveis & $\begin{array}{l}\text { Gerente de Projeto } \\
\text { Equipe de Vendas }\end{array}$ \\
\hline Descrição & $\begin{array}{l}\text { Essa atividade tem como objetivo avaliar se é viável a execução do projeto } \\
\text { em termos técnicos e financeiros. }\end{array}$ \\
\hline Recursos & $\begin{array}{l}\text { Ferramenta de gerenciamento de projeto (ex: dot Project, MS-Project, } \\
\text { Primavera) }\end{array}$ \\
\hline Entradas & $\begin{array}{l}\text { e1) Documento de Requisitos } \\
\text { e2) Plano de Projeto } \\
\text { e3) Arquitetura do Software } \\
\text { e4) Plano de Ação } \\
\text { e5) Infra-Estrutura do Cliente }\end{array}$ \\
\hline Saídas & $\begin{array}{l}\text { s1) Plano de Projeto } \\
\text { s2) Relatório de Viabilidade do Projeto } \\
\text { s3) Fluxo de Caixa }\end{array}$ \\
\hline Tarefas & $\begin{array}{l}\text { - Definir/Redefinir o custo operacional geral do produto para a empresa } \\
\text { desenvolvedora } \\
\text { * Criar/Atualizar arquivo "Relatório de Viabilidade" (conforme GCf01) } \\
\text { * Descrever os itens da configuração técnica para a solução a ser } \\
\text { concebida, a partir do documento "Arquitetura do Software" e registrar na } \\
\text { "Tabela de Custos" do "Relatório de Viabilidade". } \\
\text { * Descrever os outros direcionadores de custo (cost driver), tal como valor } \\
\text { da mão-de-obra } \\
\text { " Definir/Redefinir valor da unidade dos cost drivers } \\
\text { " Estimar valores de possíveis aquisições } \\
\text { * Considerar as restrições do projeto descritas no escopo do projeto no } \\
\text { arquivo "Plano de Projeto" } \\
\text { - Descrever relação custo x benefício para o cliente da solução proposta e } \\
\text { registrar no "Relatório de Viabilidade", considerando as informações } \\
\text { contidas na "Infra-Estrutura do Cliente" } \\
\text { - Fazer/Refazer o fluxo de caixa do projeto } \\
\text { * Criar/Atualizar arquivo "Fluxo de Caixa" (conforme GCf01) } \\
\text { * Utilizar dados relacionados aos custos até o fechamento do contrato, } \\
\text { advindos do "Plano de Ação" } \\
\text { - Definir/Redefinir o cronograma de recebimentos e registrar no "Relatório de } \\
\text { Viabilidade" } \\
\text { - Definir/Redefinir o preço do produto final do projeto e registrar no "Relatório } \\
\text { de Viabilidade" } \\
\text { - Registrar custo operacional geral e preço-meta do produto do projeto no } \\
\text { escopo do projeto do "Plano de Projeto" } \\
\text { - Verificar no Fluxo de Caixa, o valor que poderá ser investido no projeto por } \\
\text { mês, para que possam ser alocados colaboradores e recursos de forma } \\
\text { otimizada e que não inviabilize a questão financeira do projeto para a } \\
\text { empresa desenvolvedora } \\
\text { - Obs: Para fazer alterações nos artefatos, acione a área de Gestão de } \\
\text { Mudanças e Configuração, a partir da atividade "GCf03. Solicitar mudanças" }\end{array}$ \\
\hline
\end{tabular}


Quadro A3.21.9 - Detalhamento da Atividade Cp09

\begin{tabular}{|l|l|}
\hline Atividade & Cp09. Planejar os recursos do projeto \\
\hline Responsáveis & $\begin{array}{l}\text { Gerente de Projeto } \\
\text { Equipe de Compras }\end{array}$ \\
\hline Descrição & $\begin{array}{l}\text { Essa atividade tem como objetivo levantar quais são os recursos } \\
\text { necessários para o desenvolvimento do projeto. Entende-se por recursos } \\
\text { todos os equipamentos, ferramentas e materiais. }\end{array}$ \\
\hline Recursos & $\begin{array}{l}\text { Ferramenta de gerenciamento de projeto (ex: dot Project, MS-Project, } \\
\text { Primavera) }\end{array}$ \\
\hline Entradas & $\begin{array}{l}\text { e1) Cronograma } \\
\text { e2) Controle de Projetos } \\
\text { e3) Plano de Projeto }\end{array}$ \\
\hline Saídas & $\begin{array}{l}\text { s1) Plano de Projeto } \\
\text { s2) Controle de Projetos } \\
\text { s3) Pedido de Compra }\end{array}$ \\
\hline Tarefas & $\begin{array}{l}\text { - Verificar no "Cronograma" quais atividades ou entregas necessitam de } \\
\text { recursos e preencher no item "Plano de Recursos" do "Plano de Projeto" } \\
\text { - Verificar na planilha "Identificação de Recursos" do arquivo "Controle de } \\
\text { Projetos" se os recursos necessários existem e estão disponíveis ou se } \\
\text { precisam ser adquiridos. } \\
\text { * Se existirem e estiverem disponíveis, o gerente de projetos deve } \\
\text { assinalar na planilha "Alocação de Recursos" do "Controle de Projetos" a } \\
\text { data de alocação e a previsão de uso desse recurso em qual projeto. } \\
\text { * Se não existirem, criar o arquivo "Pedido de Compra" (conforme CGf01) } \\
\text { e preenchê-lo. Inserir no "Pedido de Compra" o status "congelado", que será } \\
\text { alterado para "liberado" caso o cliente feche o contrato. }\end{array}$ \\
\hline
\end{tabular}


Quadro A3.21.10 - Detalhamento da Atividade Cp10

\begin{tabular}{|l|l|}
\hline Atividade & Cp10. Identificar conhecimentos e habilidades necessárias \\
\hline Responsáveis & Gerente de Projeto \\
\hline Descrição & $\begin{array}{l}\text { Essa atividade tem como objetivo levantar quais são os conhecimentos e } \\
\text { habilidades necessárias para o desenvolvimento do projeto. }\end{array}$ \\
\hline Recursos & $\begin{array}{l}\text { Ferramenta de gerenciamento de projeto (ex: dot Project, MS-Project, } \\
\text { Primavera) }\end{array}$ \\
\hline Entradas & $\begin{array}{l}\text { e1) Controle de Projetos } \\
\text { e2) Plano de Projeto }\end{array}$ \\
\hline Saídas & $\begin{array}{l}\text { s1) Controle de Projetos } \\
\text { s2) Plano de Projeto }\end{array}$ \\
\hline Tarefas & $\begin{array}{l}\text { - Identificar quais habilidades/conhecimentos serão necessários para o } \\
\text { desenvolvimento do projeto e registrar no item "Plano de Habilidades e } \\
\text { Conhecimento" do "Plano de Projeto" } \\
\text { - Verificar no item "Plano de Recursos" do "Plano de Projeto", quais } \\
\text { ferramentas serão utilizadas no projeto para confrontar na planilha } \\
\text { "identificação de colaboradores" do arquivo "Controle de Projetos" quais são } \\
\text { os mais indicados para fazer parte do time } \\
\text { - Sugerir o time, baseado na análise realizada anteriormente, e registrá-lo } \\
\text { junto ao "Plano de Habilidades e Conhecimento" do "Plano de Projeto" } \\
\text { - Registrar na planilha "Alocação de Colaboradores", os colaboradores do } \\
\text { projeto que foram sugeridos para compor o time, a possível data de } \\
\text { alocação, previsão do término da alocação } \\
\text { - Definir status dos colaboradores pertencentes ao time como "reservado" } \\
\text { na planilha "Alocação de Colaboradores" do "Controle de Projetos" } \\
\text { - Obs: Para fazer alterações nos artefatos, acione a área de Gestão de } \\
\text { Mudanças e Configuração, a partir da atividade "GCf03. Solicitar mudanças" }\end{array}$ \\
\hline
\end{tabular}


Quadro A3.21.11 - Detalhamento da Atividade Cp11

\begin{tabular}{|c|c|}
\hline Atividade & Cp11. Identificar riscos inerentes ao projeto \\
\hline Responsáveis & $\begin{array}{l}\text { Gerente de Projeto } \\
\text { Analista de Riscos }\end{array}$ \\
\hline Descrição & $\begin{array}{l}\text { Essa atividade tem como objetivo identificar os riscos inerentes ao projeto e } \\
\text { estabelecer um plano de contingência. }\end{array}$ \\
\hline Recursos & \\
\hline Entradas & $\begin{array}{l}\text { e1) Cronograma } \\
\text { e2) Relatório de Viabilidade do Projeto } \\
\text { e3) Fluxo de Caixa } \\
\text { e4) Plano de Projeto }\end{array}$ \\
\hline Saídas & s1) Plano de Projeto \\
\hline Tarefas & $\begin{array}{l}\text { - Identificar os riscos orçamentários analisando o relatório de viabilidade } \\
\text { - Identificar os riscos de prazo verificando o caminho crítico (PERT/CPM) no } \\
\text { cronograma } \\
\text { - Identificar os riscos de rotatividade de pessoal baseado no histórico da } \\
\text { empresa } \\
\text { - Identificar riscos técnicos, riscos de projeto e de negócio } \\
\text { - Definir a escala dos riscos: booleana, qualitativa ou quantitativa. Por ex: } \\
\text { booleana: sim ou não; qualitativa: altamente, pouco, moderado, etc; } \\
\text { quantitativo: em termos numéricos como \% } \\
\text { - Elaborar/Atualizar checklists (conjuntos de questões) para classificar os } \\
\text { riscos ou utilizar checklists existentes, baseado na escala definida } \\
\text { anteriormente } \\
\text { - Definir/Redefinir a probabilidade de ocorrência dos riscos baseado na } \\
\text { classificação anterior } \\
\text { - Definir/Redefinir os impactos dos riscos, ou seja, quais as conseqüências } \\
\text { caso os riscos ocorram } \\
\text { - Definir/Redefinir prioridade dos riscos a serem "atacados", uma vez que se } \\
\text { conhece os impactos dos mesmos } \\
\text { - Definir/Redefinir ações pró-ativas para não deixar que os riscos negativos } \\
\text { priorizados se concretizem e para garantir que os riscos positivos } \\
\text { priorizados se concretizem } \\
\text { - Elaborar/Atualizar o plano de contingência que será utilizado caso algum } \\
\text { risco venha a se concretizar e registrá-lo no apêndice "Plano de } \\
\text { Contingência" do "Plano de Projeto" } \\
\text { - Obs: Para fazer alterações nos artefatos, acione a área de Gestão de } \\
\text { Mudanças e Configuração, a partir da atividade "GCf03. Solicitar mudanças" }\end{array}$ \\
\hline
\end{tabular}


Quadro A3.21.12 - Detalhamento da Atividade Cp12

\begin{tabular}{|l|l|}
\hline Atividade & Cp12. Acompanhar o andamento do projeto \\
\hline Responsáveis & Gerente de Projeto \\
\hline Descrição & Essa atividade tem como objetivo o acompanhamento do projeto. \\
\hline Recursos & $\begin{array}{l}\text { e1) Controle de Projetos } \\
\text { e2) Plano de Projeto }\end{array}$ \\
\hline Entradas & $\begin{array}{l}\text { s1) Controle de Projetos } \\
\text { s2) Relatório de Acompanhamento do Projeto }\end{array}$ \\
\hline Tarefas & $\begin{array}{l}\text { - Inserir a data de término da fase do projeto na planilha "Acompanhamento } \\
\text { de Projetos" do arquivo "Controle de Projetos", replicar a linha do projeto e } \\
\text { inserir a nova fase com sua data de início } \\
\text { - Inserir na planilha "Acompanhamento de Projetos" do arquivo "Controle de } \\
\text { Projetos" a quantidade de horas trabalhadas de cada um dos colaboradores } \\
\text { nessa fase. } \\
\text { - Revisar a documentação quanto aos riscos no arquivo "Plano de Projeto" } \\
\text { no contexto atual do projeto } \\
\text { * Em casos de problemas, acionar o "Plano de Contingência" (Apêndice 1 } \\
\text { do "Plano de Projeto") } \\
\text { * Criar arquivo "Relatório de Acompanhamento do Projeto" (conforme } \\
\text { GCf01) } \\
\text { * Registrar informações no arquivo "Relatório de Acompanhamento do } \\
\text { Projeto" referentes ao acionamento do "Plano de Contingência" }\end{array}$ \\
\hline
\end{tabular}

Quadro A3.21.13 - Detalhamento da Atividade Cp13

\begin{tabular}{|c|c|}
\hline Atividade & Cp13. Controlar custos despendidos na fase de concepção \\
\hline Responsáveis & $\begin{array}{l}\text { Equipe de Vendas } \\
\text { Gerente de Projeto }\end{array}$ \\
\hline Descrição & $\begin{array}{l}\text { Essa atividade tem como objetivo registrar todos os custos referentes à } \\
\text { execução das atividades dessa fase. }\end{array}$ \\
\hline Recursos & \\
\hline Entradas & e1) Plano de Ação \\
\hline Saídas & s1) Plano de Ação \\
\hline Tarefas & $\begin{array}{l}\text { - Atualizar na planilha "Acompanhamento" (item "Atividades") do arquivo } \\
\text { "Plano de Ação" a quantidade de atividades realizadas de fato. } \\
\text { - Atualizar na planilha "Acompanhamento" (item "Custos") os custos reais } \\
\text { referentes à execução de todas as atividades dessa fase. }\end{array}$ \\
\hline
\end{tabular}


Quadro A3.21.14 - Detalhamento da Atividade Cp14

\begin{tabular}{|c|c|}
\hline Atividade & Cp14. Conduzir revisão do milestone: Estudo de Viabilidade do Projeto \\
\hline Responsáveis & $\begin{array}{l}\text { Equipe de Qualidade } \\
\text { Gerente de Projeto }\end{array}$ \\
\hline Descrição & $\begin{array}{l}\text { Essa atividade tem o objetivo de revisar o milestone que marca o final dessa } \\
\text { fase. }\end{array}$ \\
\hline Recursos & \\
\hline Entradas & $\begin{array}{l}\text { e1) Plano de Garantia da Qualidade (já existente na empresa) } \\
\text { e2) Produto de Trabalho: Relatório de Viabilidade do Projeto }\end{array}$ \\
\hline Saídas & s1) Relatório sobre Garantia da Qualidade \\
\hline Tarefas & $\begin{array}{l}\text { - Realizar a atividade "GqPP01. Avaliar o processo e assegurar resolução } \\
\text { de não conformidades" } \\
\text { - Realizar a atividade "GqPP02. Avaliar os produtos de trabalho e assegurar } \\
\text { resolução de não conformidades" } \\
\text { - Obs: Para fazer alterações nos artefatos, acione a área de Gestão de } \\
\text { Mudanças e Configuração, a partir da atividade "GCf03. Solicitar mudanças" }\end{array}$ \\
\hline
\end{tabular}




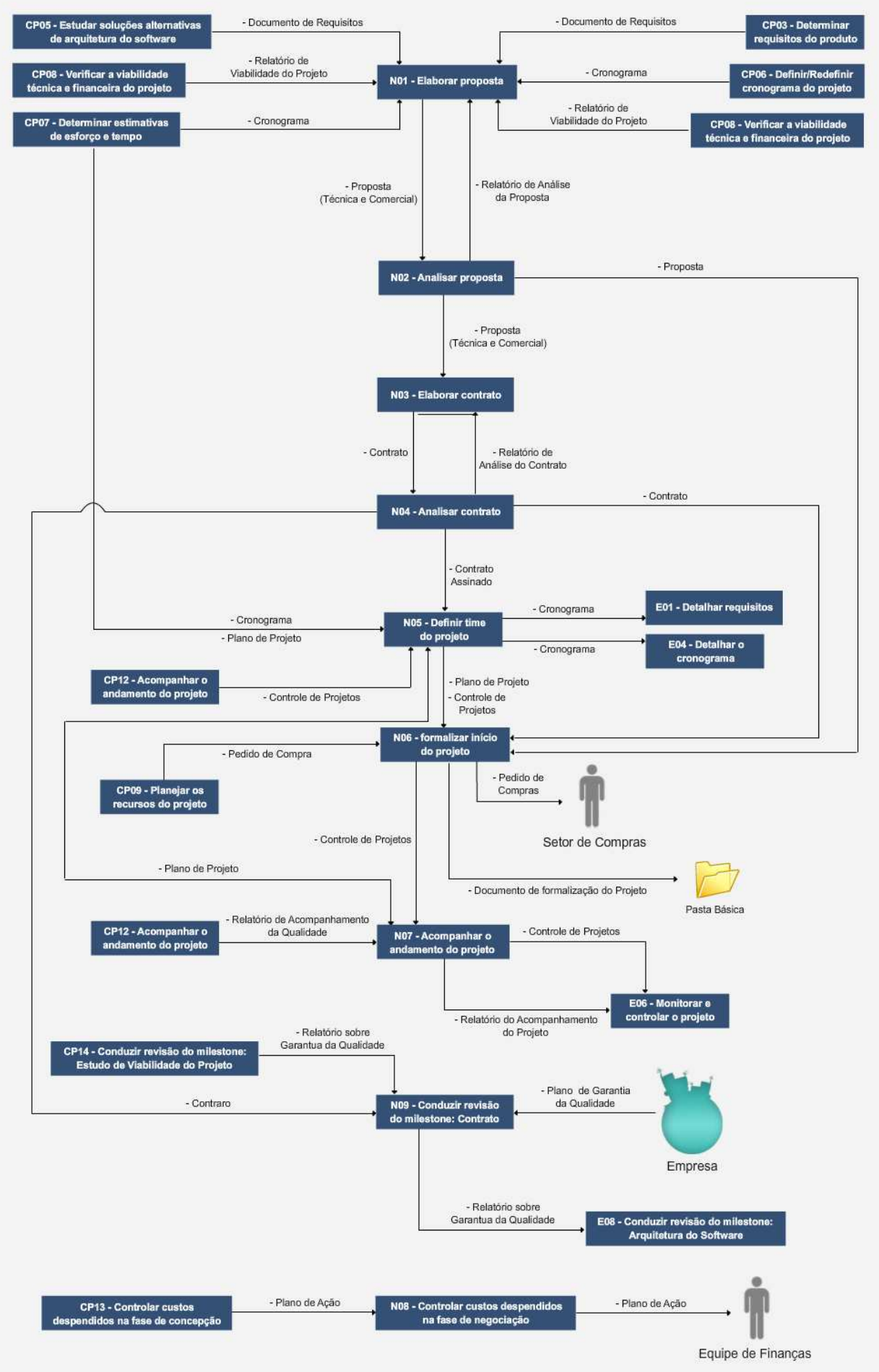

FIgura A3.22 - VISÃo GráfICA - FASE: Negociação 
Quadro A3.22.1 - Detalhamento da Atividade N01

\begin{tabular}{|c|c|}
\hline Atividade & N01. Elaborar proposta \\
\hline Responsáveis & $\begin{array}{l}\text { Gerente do Projeto } \\
\text { Equipe de Vendas } \\
\text { Engenheiro de Requisitos }\end{array}$ \\
\hline Descrição & $\begin{array}{l}\text { Elaborar a proposta do projeto baseado no Documento de Requisitos e no } \\
\text { cronograma de recebimentos estipulado no Relatório de Viabilidade do } \\
\text { Projeto, além de considerar o feedback do cliente encontrado no Relatório } \\
\text { de Análise da Proposta. }\end{array}$ \\
\hline Recursos & \\
\hline Entradas & $\begin{array}{l}\text { e1) Documento de Requisitos } \\
\text { e2) Relatório de Viabilidade do Projeto } \\
\text { e3) Relatório de Análise da Proposta } \\
\text { e4) Cronograma }\end{array}$ \\
\hline Saídas & $\begin{array}{l}\text { s1) Proposta Técnica } \\
\text { s2) Proposta Comercial } \\
\text { s3) Relatório de Viabilidade do Projeto } \\
\text { s4) Cronograma } \\
\text { s5) Documento de Requisitos }\end{array}$ \\
\hline Tarefas & $\begin{array}{l}\text { - Criar/Atualizar arquivo "Proposta Comercial" (conforme GCf01) e } \\
\text { preencher: } \\
\text { * os dados completos do cliente (Razão Social, CNPJ, Endereço, } \\
\text { Telefones, Contato) } \\
\text { * a relação custo x benefício da solução proposta para o cliente, advinda } \\
\text { do "Relatório de Viabilidade do Projeto" } \\
\text { * o cronograma estimado de entregas baseado no Cronograma (WBS) } \\
\text { * o preço baseado no "Relatório de Viabilidade do Projeto" } \\
\text { * o cronograma de pagamentos do cliente baseado no cronograma de } \\
\text { recebimentos do "Relatório de Viabilidade do Projeto" } \\
\text { - Determinar a validade da "Proposta Comercial" } \\
\text { - Criar/Atualizar arquivo "Proposta Técnica" (conforme GCf01) e: } \\
\text { * registrar os dados da empresa de desenvolvimento } \\
\text { * inserir, como apêndice, na "Proposta Técnica" os requisitos descritos no } \\
\text { item "2.2 Funções do Produto" do arquivo "Documento de Requisitos" } \\
\text { - Registrar o ID da "Proposta Técnica" na "Proposta Comercial" } \\
\text { - Analisar o "Relatório de Análise da Proposta" vindo do cliente com o } \\
\text { "Relatório de Viabilidade do Projeto" } \\
\text { - Realizar as possíveis modificações na proposta e, se necessário: } \\
\text { * acessar a atividade "Cp03. Determinar requisitos do produto" para } \\
\text { modificar o "Documento de Requisitos" } \\
\text { * acessar a atividade "Cp06. Definir/Redefinir cronograma do projeto" para } \\
\text { modificar o cronograma estimado de entregas do "Cronograma" (WBS) } \\
\text { * acessar a atividade "Cp08. Verificar a viabilidade técnica e financeira do } \\
\text { projeto" para modificar o cronograma de recebimentos do "Relatório de } \\
\text { Viabilidade do Projeto" } \\
\text { - Obs: Para fazer alterações nos artefatos, acione a área de Gestão de } \\
\text { Mudanças e Configuração, a partir da atividade "GCf03. Solicitar mudanças" }\end{array}$ \\
\hline
\end{tabular}


Quadro A3.22.2 - Detalhamento da Atividade N02

\begin{tabular}{|c|c|}
\hline Atividade & N02. Analisar proposta \\
\hline Responsáveis & Cliente \\
\hline Descrição & $\begin{array}{l}\text { O cliente deve analisar a proposta; no caso de estar de acordo deve } \\
\text { devolvê-la assinada, caso contrário, deve enviar as alterações necessárias } \\
\text { que serão registradas como um Relatório de Análise da Proposta. }\end{array}$ \\
\hline \multicolumn{2}{|l|}{ Recursos } \\
\hline Entradas & e1) Proposta (Comercial e Técnica) \\
\hline Saídas & s2) Relatório de Análise da Proposta \\
\hline Tarefas & $\begin{array}{l}\text { - Obter o feedback do cliente a respeito da proposta enviada. } \\
{ }^{*} \text { Caso o cliente esteja de acordo, deve assinar a proposta }\end{array}$ \\
\hline
\end{tabular}

Quadro A3.22.3 - Detalhamento da Atividade N03

\begin{tabular}{|c|c|}
\hline Atividade & N03. Elaborar contrato \\
\hline Responsáveis & $\begin{array}{l}\text { Equipe de Vendas } \\
\text { Gerente de projetos } \\
\text { Assessor Jurídico }\end{array}$ \\
\hline Descrição & $\begin{array}{l}\text { Elaborar o contrato do projeto baseado na Proposta assinada pelo cliente, } \\
\text { além de considerar o feedback dado pelo cliente encontrado no Relatório de } \\
\text { Análise do Contrato. }\end{array}$ \\
\hline Recursos & \\
\hline Entradas & $\begin{array}{l}\text { e1) Proposta } \\
\text { e2) Relatório de Análise do Contrato }\end{array}$ \\
\hline Saídas & s1) Contrato \\
\hline Tarefas & $\begin{array}{l}\text { - Criar/Atualizar arquivo "Contrato" (conforme GCf01) e preencher: } \\
\text { * os dados do cliente (obtidos da proposta comercial) } \\
\text { * os dados da empresa de desenvolvimento (obtidos da proposta técnica) } \\
\text { * o objeto de contrato } \\
\text { * os aspectos técnicos: prazo de desenvolvimento e data das entregas, } \\
\text { especificação quanto ao suporte, especificação quanto às condições de } \\
\text { instalação e uso do sistema } \\
\text { * os aspectos financeiros: preço, cronograma de pagamentos e } \\
\text { penalidades } \\
\text { * os aspectos legais: estabelecimento de garantias, definições de prazo do } \\
\text { contrato e de licenças de uso, definição das responsabilidades das partes } \\
\text { * o controle de alterações: procedimentos de mudanças e limitação para } \\
\text { alteração de requisitos } \\
\text { - Obs: Para fazer alterações nos artefatos, acione a área de Gestão de } \\
\text { Mudanças e Configuração, a partir da atividade "GCf03. Solicitar mudanças" }\end{array}$ \\
\hline
\end{tabular}


Quadro A3.22.4 - Detalhamento da Atividade N04

\begin{tabular}{|c|c|}
\hline Atividade & N04. Analisar contrato \\
\hline Responsáveis & Cliente \\
\hline Descrição & $\begin{array}{l}\text { O cliente deve analisar o contrato; no caso de estar de acordo deve devolvê- } \\
\text { lo assinado, caso contrário, deve enviar as alterações necessárias que } \\
\text { serão registradas como um Relatório de Análise do Contrato. }\end{array}$ \\
\hline \multicolumn{2}{|l|}{ Recursos } \\
\hline Entradas & e1) Contrato \\
\hline Saídas & s1) Relatório de Análise do Contrato \\
\hline Tarefas & $\begin{array}{l}\text { - Obter o feedback do cliente a respeito do contrato enviado, referente às } \\
\text { questões não tratadas na proposta, como questões legais e controle de } \\
\text { alterações } \\
\quad \text { * Caso o cliente esteja de acordo, deve assinar o contrato }\end{array}$ \\
\hline
\end{tabular}

Quadro A3.22.5 - Detalhamento da ATividade N05

\begin{tabular}{|c|c|}
\hline Atividade & N05. Definir time do projeto \\
\hline Responsáveis & Gerente de Projeto \\
\hline Descrição & $\begin{array}{l}\text { Definir quem serão as pessoas integrantes do time do projeto com base no } \\
\text { Plano de Habilidades e Conhecimento (do Plano de Projeto), no } \\
\text { Cronograma estabelecido e no calendário de colaboradores (obtido pela } \\
\text { análise da planilha "alocação de colaboradores" do Controle de Projetos). }\end{array}$ \\
\hline Recursos & $\begin{array}{l}\text { Ferramenta de gerenciamento de projeto (ex: dot Project, MS-Project, } \\
\text { Primavera) }\end{array}$ \\
\hline Entradas & $\begin{array}{l}\text { e1) Cronograma } \\
\text { e2) Plano de Projeto } \\
\text { e3) Controle de Projetos } \\
\text { e4) Contrato assinado }\end{array}$ \\
\hline Saídas & $\begin{array}{l}\text { s1) Plano de Projeto } \\
\text { s2) Cronograma } \\
\text { s3) Controle de Projetos }\end{array}$ \\
\hline Tarefas & $\begin{array}{l}\text { - Verificar no Calendário de Alocação de Colaboradores (obtido pela análise } \\
\text { da planilha "alocação de colaboradores" do Controle de Projetos) a } \\
\text { disponibilidade dos colaboradores, confrontando com o time sugerido no } \\
\text { Plano de Habilidades e Conhecimento do "Plano de Projeto" } \\
\text { * Reajustar o seqüenciamento das atividades ou alocar algumas das } \\
\text { atividades para outro colaborador, caso haja acúmulo de atividades para um } \\
\text { colaborador } \\
\text { * Definir o time do projeto e atualizar no Plano de Habilidades e } \\
\text { Conhecimento do "Plano de Projeto" e na planilha de alocação de } \\
\text { colaboradores do "Controle de Projetos", inserindo o status "formalizado" } \\
\text { para os colaboradores escolhidos } \\
\text { - Atualizar o Cronograma substituindo os papéis pelos colaboradores do } \\
\text { time de projeto } \\
\text { - Definir a estratégia utilizada durante o desenvolvimento do projeto, tal } \\
\text { como reuniões semanais com o cliente, e registrar no escopo do projeto do } \\
\text { "Plano de Projeto" }\end{array}$ \\
\hline
\end{tabular}


Quadro A3.22.6 - Detalhamento da ATIVIDADE N06

\begin{tabular}{|c|c|}
\hline Atividade & N06. Formalizar início do projeto \\
\hline Responsáveis & $\begin{array}{l}\text { Gerente de Projeto } \\
\text { Equipe de Vendas } \\
\text { Equipe de Qualidade } \\
\text { Equipe de Finanças } \\
\text { Equipe de Compras }\end{array}$ \\
\hline Descrição & $\begin{array}{l}\text { Comunicar a todos os interessados, interna e externamente ao projeto, a } \\
\text { inicialização do mesmo. }\end{array}$ \\
\hline Recursos & \\
\hline Entradas & $\begin{array}{l}\text { e1) Contrato } \\
\text { e2) Proposta Técnica } \\
\text { e3) Pedido de Compra } \\
\text { e4) Controle de Projetos } \\
\text { e5) Plano de Projeto }\end{array}$ \\
\hline Saídas & $\begin{array}{l}\text { s1) Documento de formalização do projeto } \\
\text { s2) Pedido de Compra } \\
\text { s3) Controle de Projetos }\end{array}$ \\
\hline Tarefas & $\begin{array}{l}\text { - Comunicar internamente a formalização do projeto, uma vez que foi } \\
\text { iniciado na fase de Prospecção, disponibilizando aos colaboradores a } \\
\text { Proposta Técnica } \\
\text { - Alterar o status do projeto (na planilha "Acompanhamento de Projetos" do } \\
\text { arquivo "Controle de Projetos") para "formalizado" e preencher a data de } \\
\text { formalização } \\
\text { - Emitir a Nota Fiscal e registrar a emissão na aba "Notas Fiscais" do } \\
\text { arquivo "Controle de Projetos" } \\
\text { - Lançar as duplicatas e registrar o lançamento na aba "Notas Fiscais" do } \\
\text { arquivo "Controle de Projetos" } \\
\text { - Comunicar ao setor de faturamento os registros do contrato } \\
\text { - Alterar o status do "Pedido de Compra" para "liberado" com a data de } \\
\text { liberação, se for o caso, e acessar as atividades "Acq01. Selecionar } \\
\text { fornecedores e estabelecer acordo" e "Acq02. Aceitar o produto adquirido" } \\
\text { - Obter comprometimento com o plano } \\
\text { * Criar arquivo "Documento de Formalização do Projeto" (conforme GCf01) } \\
\text { * Assegurar comprometimento dos colaboradores com o "Plano de Projeto" } \\
\text { por meio de uma reunião que deve ser documentada em forma de ata no } \\
\text { "Documento de Formalização do Projeto", assinado por todos os } \\
\text { colaboradores e anexado na pasta física do projeto. }\end{array}$ \\
\hline
\end{tabular}


Quadro A3.22.7 - Detalhamento da Atividade N07

\begin{tabular}{|c|c|}
\hline Atividade & N07. Acompanhar o andamento do projeto \\
\hline Responsáveis & Gerente de Projeto \\
\hline Descrição & Essa atividade tem como objetivo o acompanhamento do projeto. \\
\hline Recursos & \\
\hline Entradas & $\begin{array}{l}\text { e1) Controle de Projetos } \\
\text { e2) Plano de Projeto } \\
\text { e3) Relatório de Acompanhamento do Projeto }\end{array}$ \\
\hline Saídas & $\begin{array}{l}\text { s1) Controle de Projetos } \\
\text { s2) Relatório de Acompanhamento do Projeto }\end{array}$ \\
\hline Tarefas & $\begin{array}{l}\text { - Inserir a data de término da fase do projeto na planilha "Acompanhamento } \\
\text { de Projetos" do arquivo "Controle de Projetos", replicar a linha do projeto e } \\
\text { inserir a nova fase com sua data de início } \\
\text { - Inserir na planilha "Acompanhamento de Projetos" do arquivo "Controle de } \\
\text { Projetos" a quantidade de horas trabalhadas de cada um dos colaboradores } \\
\text { nessa fase. } \\
\text { - Revisar a documentação quanto aos riscos no arquivo "Plano de Projeto" } \\
\text { no contexto atual do projeto } \\
\text { * Em casos de problemas, acionar o "Plano de Contingência" (Apêndice } 1 \\
\text { do "Plano de Projeto") } \\
\text { * Criar/Atualizar arquivo "Relatório de Acompanhamento do Projeto" } \\
\text { (conforme GCf01) } \\
\text { * Registrar informações no arquivo "Relatório de Acompanhamento do } \\
\text { Projeto" referentes ao acionamento do "Plano de Contingência" } \\
\text { - Obs: Para fazer alterações nos artefatos, acione a área de Gestão de } \\
\text { Mudanças e Configuração, a partir da atividade "GCf03. Solicitar mudanças" }\end{array}$ \\
\hline
\end{tabular}

Quadro A3.22.8 - Detalhamento da Atividade N08

\begin{tabular}{|l|l|}
\hline Atividade & N08. Controlar custos despendidos na fase de negociação \\
\hline Responsáveis & $\begin{array}{l}\text { Equipe de Vendas } \\
\text { Gerente de Projeto }\end{array}$ \\
\hline Descrição & $\begin{array}{l}\text { Essa atividade tem como objetivo registrar todos os custos referentes à } \\
\text { execução das atividades dessa fase. }\end{array}$ \\
\hline Recursos & \begin{tabular}{l} 
e1) Plano de Ação \\
\hline Entradas
\end{tabular} \\
\hline Saídas & $\begin{array}{l}\text { - Atualizar na plano de Ação } \\
\text { "Plano de Ação" a quantidade de atividades realizadas de fato. } \\
\text { - Atualizar na planilha "Acompanhamento" (item "Custos") os custos reais } \\
\text { referentes à execução de todas as atividades dessa fase. }\end{array}$ \\
\hline Tarefas &
\end{tabular}


Quadro A3.22.9 - Detalhamento da Atividade N09

\begin{tabular}{|l|l|}
\hline Atividade & N09. Conduzir revisão do milestone: Contrato \\
\hline Responsáveis & $\begin{array}{l}\text { Equipe de Qualidade } \\
\text { Gerente de Projeto }\end{array}$ \\
\hline Descrição & $\begin{array}{l}\text { Essa atividade tem o objetivo de revisar o milestone que marca o final dessa } \\
\text { fase. }\end{array}$ \\
\hline Recursos & $\begin{array}{l}\text { e1) Plano de Garantia da Qualidade } \\
\text { e2) Produto de Trabalho: Contrato } \\
\text { e3) Relatório sobre Garantia da Qualidade }\end{array}$ \\
\hline Entradas & \begin{tabular}{l} 
s1) Relatório sobre Garantia da Qualidade \\
\hline Saídas
\end{tabular} \\
\hline Tarefas & $\begin{array}{l}\text { - Realizar a atividade "GqPP01. Avaliar o processo e assegurar resolução } \\
\text { - Realizar a atividade "GqPP02. Avaliar os produtos de trabalho e assegurar } \\
\text { resolução de não conformidades" } \\
\text { - Obs: Para fazer alterações nos artefatos, acione a área de Gestão de } \\
\text { Mudanças e Configuraçäo, a partir da atividade "GCf03. Solicitar mudanças" }\end{array}$ \\
\hline
\end{tabular}




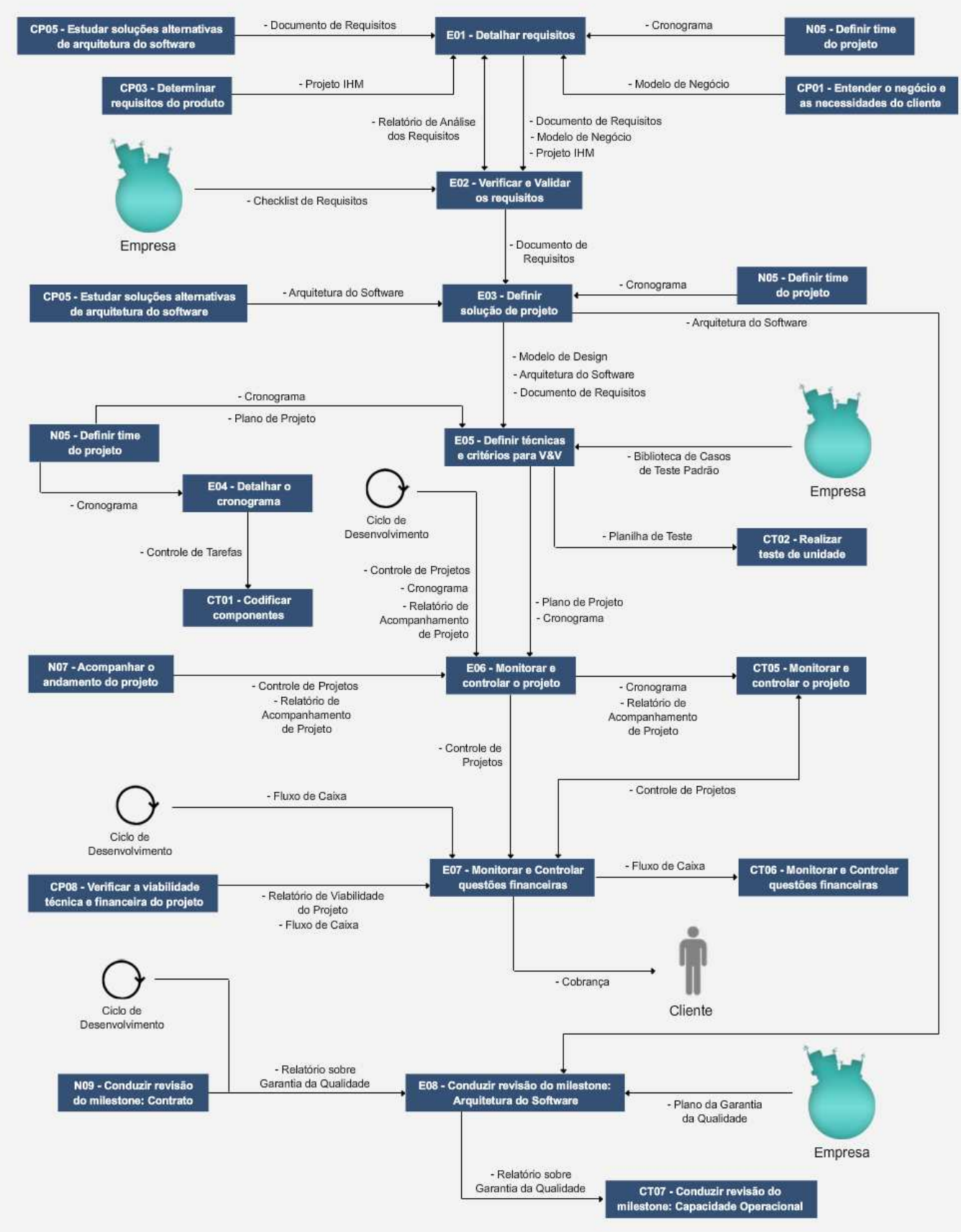

Figura A3.23 - VISÃo Gráfica - FaSE: ElaboraÇão 
Quadro A3.23.1 - Detalhamento da Atividade E01

\begin{tabular}{|c|c|}
\hline Atividade & E01. Detalhar requisitos \\
\hline Responsáveis & $\begin{array}{l}\text { Engenheiro de Requisitos } \\
\text { Equipe de Desenvolvimento }\end{array}$ \\
\hline Descrição & $\begin{array}{l}\text { Essa atividade tem o objetivo de detalhar os requisitos já obtidos, ao ponto } \\
\text { de ser mais útil aos programadores. }\end{array}$ \\
\hline Recursos & $\begin{array}{l}\text { - Ferramenta de Modelagem de Dados (ex: Dia, ArgoUML, ERWIN, Rational } \\
\text { Rose) } \\
\text { - Ferramenta de prototipação }\end{array}$ \\
\hline Entradas & $\begin{array}{l}\text { e1) Documento de Requisitos } \\
\text { e2) Projeto IHM } \\
\text { e3) Cronograma } \\
\text { e4) Modelo de Negócio }\end{array}$ \\
\hline Saídas & $\begin{array}{l}\text { s1) Documento de Requisitos } \\
\text { s2) Projeto IHM } \\
\text { s3) Modelo de Negócio }\end{array}$ \\
\hline Tarefas & $\begin{array}{l}\text { No caso de já ter sido realizada a atividade "E02. Verificar e validar os } \\
\text { requisitos" e, se necessário: } \\
\text { - Realizar reuniões com o cliente para elucidar os conflitos entre os } \\
\text { requisitos detectados na peer review } \\
\text { * Fazer as alterações no "Documento de Requisitos", caso necessário } \\
\text { * Fazer as alterações no "Modelo de Negócio", caso necessário } \\
\text { * Fazer as alterações no "Projeto IHM", caso necessário } \\
\text { * Descrever a solução adotada no item } 2 \text { do "Relatório de Análise dos Requisitos" } \\
\text { Em outros casos: } \\
\text { - Para cada incremento a ser criado no ciclo de desenvolvimento, definido } \\
\text { no "Cronograma: } \\
\text { * Se necessário, detalhar/atualizar o "Modelo de Negócio" } \\
\text { * Detalhar/Atualizar os requisitos funcionais do item } 2.2 \text { do "Documento de } \\
\text { Requisitos" e registrar no item } 3.4 \text { deste documento } \\
\text { * Elaborar/Atualizar o Modelo Conceitual e registrá-lo no item } 3.4 \text { do "Documento } \\
\text { de Requisitos" } \\
\text { * Detalhar/Atualizar os requisitos de interface externa e outros requisitos não } \\
\text { funcionais (tais como requisitos de documentação, de manutenção) do capítulo } 2 \text { do } \\
\text { Documento de Requisitos e registrar no capítulo } 3 \text { deste documento } \\
\text { * Elaborar/Atualizar o Projeto IHM } \\
\text { - Caso o perfil dos usuários não tenha sido definido na fase de concepção, criar } \\
\text { Projeto IHM (conforme GCf01), obter perfil dos usuários e registrar no "Projeto IHM" } \\
\text { - A partir do perfil dos usuários, definir os princípios gerais do projeto (com base } \\
\text { em critérios ergonômicos) } \\
\text { - Definir/Atualizar o padrão de telas no arquivo "Projeto IHM" } \\
\text { - Definir/Atualizar o mapa de navegação no arquivo "Projeto IHM" } \\
\text { - Criar/Atualizar a matriz de rastreabilidade entre requisitos do cliente e do } \\
\text { produto no Documento de Requisitos } \\
\text { - Criar/Atualizar a matriz de rastreabilidade entre requisitos funcionais e não } \\
\text { funcionais do produto no Documento de Requisitos } \\
\text { - Obs: Para fazer alterações nos artefatos, acione a área de Gestão de } \\
\text { Mudanças e Configuração, a partir da atividade "GCf03. Solicitar mudanças" }\end{array}$ \\
\hline
\end{tabular}


Quadro A3.23.2 - Detalhamento da Atividade E02

\begin{tabular}{|c|c|}
\hline Atividade & E02. Verificar e Validar os requisitos \\
\hline Responsáveis & $\begin{array}{l}\text { Equipe de Teste } \\
\text { Cliente } \\
\text { Engenheiro de Requisitos }\end{array}$ \\
\hline Descrição & $\begin{array}{l}\text { Essa atividade tem por objetivo a realização da verificação dos requisitos e, } \\
\text { posteriormente, da validação dos mesmos junto ao cliente. }\end{array}$ \\
\hline Recursos & \\
\hline Entradas & $\begin{array}{l}\text { e1) Documento de Requisitos } \\
\text { e2) Checklist de Requisitos } \\
\text { e3) Modelo de Negócio } \\
\text { e4) Projeto IHM } \\
\text { e5) Relatório de Análise dos Requisitos }\end{array}$ \\
\hline Saídas & s1) Relatório de Análise dos Requisitos \\
\hline Tarefas & $\begin{array}{l}\text { - Realizar peer review (uma das pessoas não deve ter participado do } \\
\text { desenvolvimento do Documento de requisitos) } \\
\text { * Analisar os requisitos a partir do "Documento de Requisitos", "Modelo de } \\
\text { Negócio" e "Projeto IHM" e, se for o caso, do "Relatório de Análise dos } \\
\text { Requisitos" para ver se há conflitos entre as solicitações dos stakeholders, } \\
\text { documentando tais conflitos no "Relatório de Análise dos Requisitos" } \\
\text { (criar/atualizar "Relatório de Análise dos Requisitos", conforme GCf01) } \\
\text { * Para dar subsídio ao peer review, pode ser utilizado um checklist (vide } \\
\text { "Checklist de Requisitos") } \\
\text { - Realizar reuniões com o cliente para validar os requisitos (averiguar se o } \\
\text { que está descrito está de acordo com as necessidades do cliente) } \\
\text { * Registrar eventuais conflitos no "Relatório de Análise dos Requisitos" }\end{array}$ \\
\hline
\end{tabular}


Quadro A3.23.3 - Detalhamento da ATIVIDADE E03

\begin{tabular}{|c|c|}
\hline Atividade & E03. Definir solução de projeto \\
\hline Responsáveis & $\begin{array}{l}\text { Equipe de Desenvolvimento } \\
\text { Engenheiro de Requisitos }\end{array}$ \\
\hline Descrição & $\begin{array}{l}\text { Essa atividade tem o objetivo de elaborar uma solução de projeto com base } \\
\text { na arquitetura de software estabelecida. }\end{array}$ \\
\hline Recursos & $\begin{array}{l}\text { - Ferramenta de Modelagem de Software (ex: ArgoUML, Dia, Rational Rose, } \\
\text { JUDE) } \\
\text { - Ferramenta de Modelagem de Dados (ex: ERWIN) }\end{array}$ \\
\hline Entradas & $\begin{array}{l}\text { e1) Arquitetura do Software } \\
\text { e2) Documento de Requisitos } \\
\text { e3) Cronograma }\end{array}$ \\
\hline Saídas & $\begin{array}{l}\text { s1) Arquitetura do Software } \\
\text { s2) Documento de Requisitos } \\
\text { s3) Modelo de Design }\end{array}$ \\
\hline Tarefas & $\begin{array}{l}\text { - Confirmar a arquitetura do software projetada na fase de concepção } \\
\text { * Caso seja necessário, podem ser realizadas modificações na } \\
\text { "Arquitetura do Software" } \\
\text { - Para cada incremento a ser criado no ciclo de desenvolvimento, definido } \\
\text { no "Cronograma" } \\
\text { * Criar/Atualizar "Modelo de Design" (conforme GCf01) } \\
\text { - Elaborar o Modelo Lógico do Sistema com base no Documento de } \\
\text { Requisitos (T) } \\
\text { - Criar o modelo físico de dados correspondente ao Modelo de Dados } \\
\text { (parte do modelo lógico do sistema) } \\
\text { - Criar/Atualizar a matriz de rastreabilidade entre requisitos do produto } \\
\text { do Documento de Requisitos e componentes do Modelo de Design e } \\
\text { registrar no "Documento de Requisitos" } \\
\text { - Obs: Para fazer alterações nos artefatos, acione a área de Gestão de } \\
\text { Mudanças e Configuração, a partir da atividade "GCf03. Solicitar mudanças" }\end{array}$ \\
\hline
\end{tabular}


Quadro A3.23.4 - Detalhamento da Atividade E04

\begin{tabular}{|c|c|}
\hline Atividade & E04. Detalhar o cronograma \\
\hline Responsáveis & $\begin{array}{l}\text { Equipe de Desenvolvimento } \\
\text { Gerente de Projeto }\end{array}$ \\
\hline Descrição & $\begin{array}{l}\text { Essa atividade tem como objetivo o detalhamento do cronograma, por parte } \\
\text { dos programadores. Assim, cada um deles será responsável por gerenciar } \\
\text { suas tarefas, respeitando o prazo a ele estabelecido no cronograma. }\end{array}$ \\
\hline Recursos & \\
\hline Entradas & e1) Cronograma \\
\hline Saídas & s1) Controle de tarefas \\
\hline Tarefas & $\begin{array}{l}\text { - Para cada incremento a ser criado no ciclo de desenvolvimento, definido } \\
\text { no "Cronograma" } \\
\text { * Definir/Atualizar as tarefas a serem realizadas para atender à(s) } \\
\text { atividade(s) estabelecida(s) no "Cronograma" } \\
\text { * Cada programador deve criar/atualizar o arquivo "Controle de Tarefas" } \\
\text { (conforme GCf01), registrar suas tarefas em uma "Lista de Tarefas" e será } \\
\text { responsável por controlar suas tarefas diariamente } \\
\text { - Obs: Para fazer alterações nos artefatos, acione a área de Gestão de } \\
\text { Mudanças e Configuração, a partir da atividade "GCf03. Solicitar mudanças" }\end{array}$ \\
\hline
\end{tabular}

Quadro A3.23.5 - Detalhamento da ATIVIDAde E05

\begin{tabular}{|l|l|}
\hline Atividade & E05. Definir técnicas e critérios para V\&V \\
\hline Responsáveis & $\begin{array}{l}\text { Equipe de Desenvolvimento } \\
\text { Equipe de Teste } \\
\text { Gerente de Projeto }\end{array}$ \\
\hline Descrição & $\begin{array}{l}\text { Essa atividade tem o objetivo de definir quais as técnicas e critérios de } \\
\text { verificação e validação serão utilizados para avaliar os componentes a } \\
\text { serem construídos. }\end{array}$ \\
\hline Recursos & $\begin{array}{l}\text { e1) Plano de Projeto } \\
\text { e2) Cronograma } \\
\text { e3) Biblioteca de Casos de Teste Padrão } \\
\text { e4) Documento de Requisitos } \\
\text { e5) Modelo de Design } \\
\text { e6) Arquitetura do Software }\end{array}$ \\
\hline Saídas & $\begin{array}{l}\text { s1) Planilha de Teste } \\
\text { s2) Plano de Projeto } \\
\text { s3) Cronograma }\end{array}$ \\
\hline
\end{tabular}


Quadro A3.23.5 - Detalhamento da Atividade E05 (Cont.)

\begin{tabular}{|c|c|}
\hline Tarefas & $\begin{array}{l}\text { - Considerar o tempo estimado no Cronograma (WBS) para elaborar os } \\
\text { casos de teste } \\
\text { - Planejar/Atualizar Teste de Unidade } \\
\text { * Definir os critérios de teste correspondentes às técnicas de teste a serem } \\
\text { utilizados e registrar no item "Plano de Teste" do "Plano de Projeto". Por } \\
\text { exemplo: critérios particionamento de classes em equivalência e análise do } \\
\text { valor limite da categoria de técnicas funcionais; critérios Todos-Arcos da } \\
\text { técnica estrutural; critério Análise de Mutantes da categoria de técnicas } \\
\text { baseadas em erros. } \\
\text { * Estabelecer os casos de teste a serem executados considerando cada } \\
\text { um dos critérios definidos, com base na Arquitetura do Software, Modelo de } \\
\text { Design e Documento de Requisitos. Para auxiliar nessa tarefa, pode-se } \\
\text { recorrer à biblioteca de casos de teste padrão da empresa (caso exista). } \\
\text { Criar/Atualizar arquivo "Planilha de Teste" (conforme GCf01) e registrar os } \\
\text { casos de teste a serem executados na planilha "Casos de Teste de } \\
\text { Unidade". } \\
\text { - Planejar/Atualizar Teste de Integração } \\
\text { * Definir o ambiente para a integração e teste. Esse ambiente pode incluir } \\
\text { o reuso de recursos organizacionais existentes, mas pode ser necessária a } \\
\text { aquisição de equipamentos (nesse caso, redirecionar para as atividades do } \\
\text { processo de apoio "Aquisição") } \\
\text { * Definir a estratégia de integração (pode ser: top-down ou botton-up), } \\
\text { definir os critérios de teste a serem utilizados e e registrá-los no item "Plano } \\
\text { de Teste" do "Plano de Projeto" } \\
\text { * Estabelecer os casos de teste, de acordo com a Arquitetura do Software, } \\
\text { Modelo de Design e Documento de Requisitos. Para auxiliar essa tarefa } \\
\text { pode-se recorrer à biblioteca de casos de teste padrão da empresa (caso } \\
\text { do cliente, com base nos critérios de avaliação definidos no "Documento de } \\
\text { Requisitos". Preencher na planilha "Casos de teste de validação" no arquivo } \\
\text { "Planilha de Teste" a lista de casos de teste a serem executados. } \\
\text { - Obs: Panilha de Teste" a lista de casos de teste a serem executados. } \\
\text { Mudanças e Configuração, a partir da atividade "GCfO3. Solicitar mudanças" } \\
\text { - Detalhar o "Cronograma" estabelecendo o tempo de execução dos casos } \\
\text { de testes } \\
\text { - Planejar/Atualizar Teste de Validação }\end{array}$ \\
\hline
\end{tabular}


Quadro A3.23.6 - Detalhamento da Atividade E06

\begin{tabular}{|c|c|}
\hline Atividade & E06. Monitorar e controlar o projeto \\
\hline Responsáveis & Gerente de Projeto \\
\hline Descrição & Essa atividade tem como objetivo o monitoramento e controle do projeto. \\
\hline Recursos & $\begin{array}{l}\text { Ferramenta de gerenciamento de projeto (ex: dot Project, MS-Project, } \\
\text { Primavera) }\end{array}$ \\
\hline Entradas & $\begin{array}{l}\text { e1) Plano de Projeto } \\
\text { e2) Relatório de Acompanhamento de Projeto } \\
\text { e3) Controle de Projetos } \\
\text { e4) Cronograma }\end{array}$ \\
\hline Saídas & $\begin{array}{l}\text { s1) Relatório de Acompanhamento de Projeto } \\
\text { s2) Controle de Projetos } \\
\text { s3) Cronograma }\end{array}$ \\
\hline Tarefas & $\begin{array}{l}\text { - Em qualquer iteração e ciclo de desenvolvimento: } \\
\text { * Inserir a data de término da fase do projeto na planilha } \\
\text { "Acompanhamento de Projetos" do arquivo "Controle de Projetos", replicar a } \\
\text { linha do projeto e inserir a nova fase com sua data de início } \\
\text { * Inserir na planilha "Acompanhamento de Projetos" do arquivo "Controle } \\
\text { de Projetos" a quantidade de horas trabalhadas de cada um dos } \\
\text { colaboradores nessa fase. } \\
\text { * Inserir no "Cronograma" a quantidade de horas trabalhadas de cada um } \\
\text { dos colaboradores nessa fase. } \\
\text { * Verificar no "Cronograma" o andamento das atividades executadas em } \\
\text { relação às atividades planejadas } \\
\text { - Identificar e gerenciar dependências em relação às datas planejadas } \\
\text { - Identificar compromissos que não foram satisfeitos } \\
\text { - Identificar a ocorrência de algum risco levantado no "Plano de } \\
\text { Projeto" e, nesse caso, executar o "Plano de Contingência" documentado no } \\
\text { "Plano de Projeto" } \\
\text { - Criar/Atualizar o arquivo "Relatório de Acompanhamento de Projeto" } \\
\text { (conforme GCf01) e registrar a revisão de andamento do projeto nesse } \\
\text { relatório } \\
\text { * Planejar e executar ações corretivas, caso necessário, e registrá-las no } \\
\text { "Relatório de Acompanhamento de Projeto" } \\
\text { - Obs: Para fazer alterações nos artefatos, acione a área de Gestão de } \\
\text { Mudanças e Configuração, a partir da atividade "GCf03. Solicitar mudanças" }\end{array}$ \\
\hline
\end{tabular}


Quadro A3.23.7 - Detalhamento da ATividade E07

\begin{tabular}{|c|c|}
\hline Atividade & E07. Monitorar e Controlar questões financeiras \\
\hline Responsáveis & $\begin{array}{l}\text { Gerente de Projeto } \\
\text { Equipe de Finanças }\end{array}$ \\
\hline Descrição & $\begin{array}{l}\text { Essa atividade tem como objetivo o monitoramento e controle de todas as } \\
\text { questões financeiras referentes ao projeto. }\end{array}$ \\
\hline Recursos & \\
\hline Entradas & $\begin{array}{l}\text { e1) Controle de Projetos } \\
\text { e2) Relatório de Viabilidade do Projeto } \\
\text { e3) Fluxo de caixa }\end{array}$ \\
\hline Saídas & $\begin{array}{l}\text { s1) Controle de Projetos } \\
\text { s2) Cobrança } \\
\text { s3) Fluxo de Caixa }\end{array}$ \\
\hline Tarefas & $\begin{array}{l}\text { - Dar baixa nas duplicatas pagas, na aba "Duplicatas" do arquivo "Controle } \\
\text { de Projetos" } \\
\text { - Confrontar relatório de duplicatas pagas com emitidas e cobrar os clientes } \\
\text { que estão com suas duplicatas vencidas } \\
\text { - Relatar à equipe de finanças a respeito do cliente inadimplente } \\
\text { - Analisar "Relatório de Viabilidade do Projeto" } \\
\text { * Inserir no "Fluxo de caixa" mensal os recebimentos } \\
\text { * Confrontar o "Relatório de viabilidade do Projeto" com o "Fluxo de caixa" } \\
\text { mensal } \\
\text { * Tomar as decisões cabíveis } \\
\text { * Atualizar "Fluxo de caixa" }\end{array}$ \\
\hline
\end{tabular}

Quadro A3.23.8 - Detalhamento da ATividade E08

\begin{tabular}{|l|l|}
\hline Atividade & E08. Conduzir revisão do milestone: Arquitetura do Software \\
\hline Responsáveis & $\begin{array}{l}\text { Equipe de Qualidade } \\
\text { Gerente de Projeto }\end{array}$ \\
\hline Descrição & $\begin{array}{l}\text { Essa atividade tem o objetivo de revisar o milestone que marca o final dessa } \\
\text { fase. }\end{array}$ \\
\hline Recursos & $\begin{array}{l}\text { e1) Plano de Garantia da Qualidade } \\
\text { e2) Produto de Trabalho: Arquitetura do Software } \\
\text { e3) Relatório sobre Garantia de Qualidade }\end{array}$ \\
\hline Entradas & $\begin{array}{l}\text { s1) Relatório sobre Garantia de Qualidade } \\
\text { Saídas }\end{array}$ \\
\hline Tarefas & $\begin{array}{l}\text { - Realizar a atividade "GqPP01. Avaliar o processo e assegurar resolução } \\
\text { - Realizar a atividade "GqPP02. Avaliar os produtos de trabalho e assegurar } \\
\text { resolução de não conformidades" } \\
\text { - Obs: Para fazer alterações nos artefatos, acione a área de Gestão de } \\
\text { Mudanças e Configuração, a partir da atividade "GCf03. Solicitar mudanças" }\end{array}$ \\
\hline
\end{tabular}




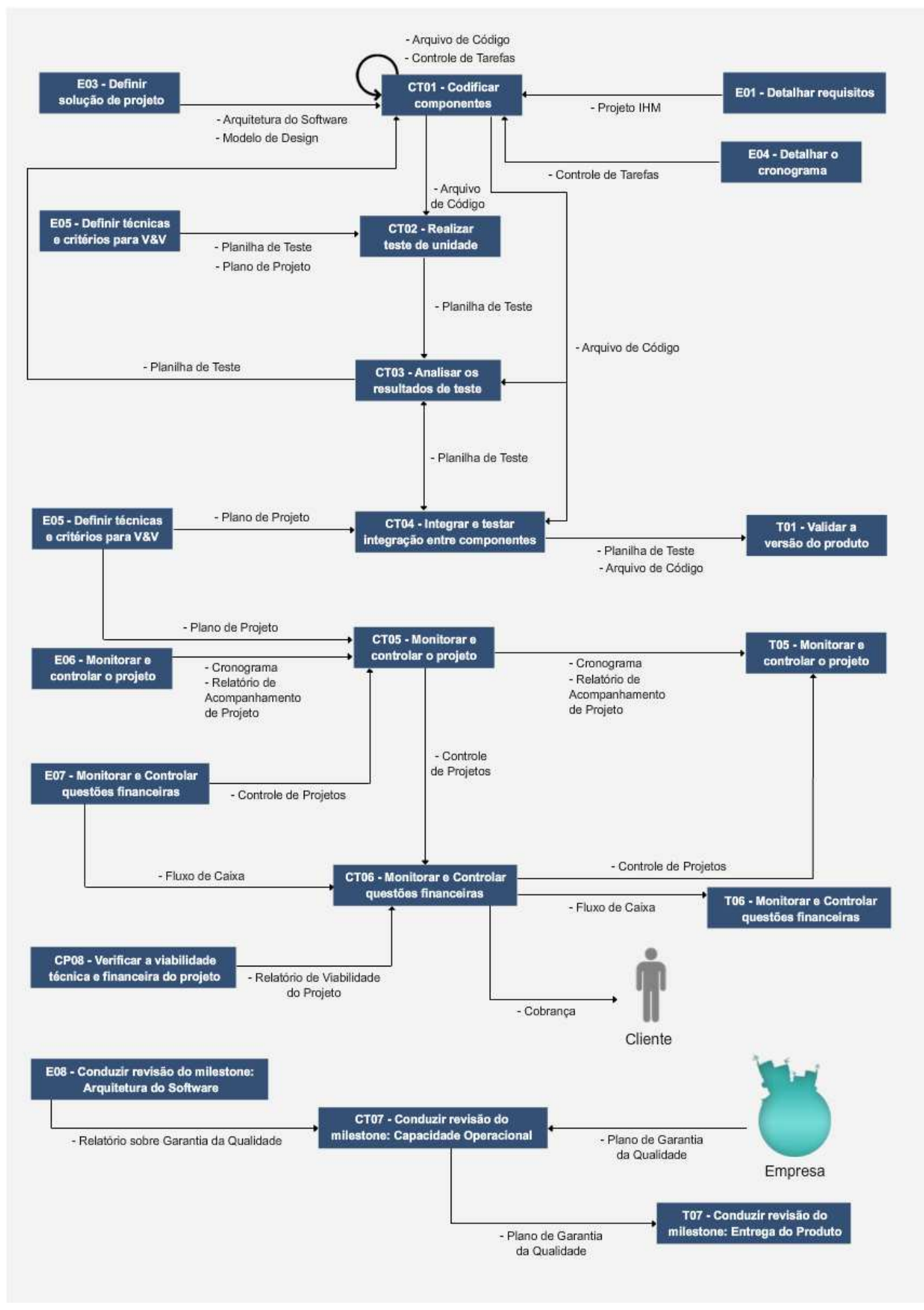

FIGURA A3.24 - VISÃo GrÁFICA - FASE: ConStruÇÃo 
Quadro A3.24.1 - Detalhamento da Atividade CT01

\begin{tabular}{|c|c|}
\hline Atividade & Ct01. Codificar componentes \\
\hline Responsáveis & Equipe de Desenvolvimento \\
\hline Descrição & $\begin{array}{l}\text { Essa atividade tem por objetivo a codificação das partes que compõem o } \\
\text { projeto em uma determinada linguagem de programação. }\end{array}$ \\
\hline Recursos & Linguagem e Ambiente de Programação \\
\hline Entradas & $\begin{array}{l}\text { e1) Arquitetura do Software } \\
\text { e2) Modelo de Design } \\
\text { e3) Projeto IHM } \\
\text { e4) Controle de Tarefas } \\
\text { e5) Arquivo de Código } \\
\text { e6) Planilha de Teste }\end{array}$ \\
\hline Saídas & $\begin{array}{l}\text { s1) Arquivo de Código } \\
\text { s2) Controle de Tarefas }\end{array}$ \\
\hline Tarefas & $\begin{array}{l}\text { - Para cada versão planejada no ciclo de desenvolvimento: } \\
\text { * Criar/Atualizar "Arquivo de Código" (conforme GCf01), com base nos } \\
\text { artefatos: "Arquitetura do Software", "Modelo de Design", "Projeto IHM" e, se } \\
\text { for o caso de ajustar o código, usar como subsídio os casos de teste } \\
\text { marcados na "Planilha de Teste" } \\
\text { * Realizar as tarefas de codificação, seguindo regras de padronização de } \\
\text { codificação da empresa para que o código fique auto-documentado. } \\
\text { * Registrar trabalho realizado e quantidade de tempo gasto no arquivo } \\
\text { "Controle de Tarefas" para informações sobre o andamento de suas tarefas } \\
\text { a serem comunicadas ao gerente de projeto, quando solicitado. } \\
\text { - Obs: Para fazer alterações nos artefatos, acione a área de Gestão de } \\
\text { Mudanças e Configuração, a partir da atividade "GCf03. Solicitar mudanças" }\end{array}$ \\
\hline
\end{tabular}

\section{Quadro A3.24.2 - Detalhamento da Atividade Ct02}

\begin{tabular}{|l|l|}
\hline Atividade & Ct02. Realizar teste de unidade \\
\hline Responsáveis & $\begin{array}{l}\text { Equipe de Desenvolvimento } \\
\text { Equipe de Teste }\end{array}$ \\
\hline Descrição & $\begin{array}{l}\text { Essa atividade tem por objetivo executar os casos de teste de unidade } \\
\text { definidos no plano de teste. }\end{array}$ \\
\hline Recursos & $\begin{array}{l}\text { - Ferramentas de Teste (ex: TestLink, Testitool, PHP Coverage, FunkLoad) } \\
\text { - Linguagem e Ambiente de Programação }\end{array}$ \\
\hline Entradas & $\begin{array}{l}\text { e1) Plano de Projeto } \\
\text { e2) Planilha de Teste } \\
\text { e3) Arquivo de Código }\end{array}$ \\
\hline Saídas & $\begin{array}{l}\text { s1) Planilha de Teste } \\
\text { s2) Arquivo de Código }\end{array}$ \\
\hline
\end{tabular}




\section{Quadro A3.24.2 - Detalhamento da Atividade Ct02 (Cont.)}

\begin{tabular}{|l|l|}
\hline Tarefas & - Realizar o Teste de Unidade planejado e registrado no "Plano de Projeto" \\
das unidades codificadas \\
* Executar os casos de teste de unidade definidos na planilha "Casos de \\
Teste de Unidade" do arquivo "Planilha de Teste" \\
* Registrar resultados obtidos na na planilha "Casos de Teste de \\
Unidade" do arquivo "Planilha de Teste" \\
* Quando necessário, realizar novamente os casos de teste (teste de \\
regressão), ou ainda, definir novos casos de teste e registrar na planilha \\
"Casos de Teste de Unidade" do arquivo "Planilha de Teste" para testar as \\
alterações realizadas no "Arquivo de Código" \\
- Obs: Para fazer alterações nos artefatos, acione a área de Gestão de \\
Mudanças e Configuração, a partir da atividade "GCf03. Solicitar mudanças"
\end{tabular}

\section{Quadro A3.24.3 - Detalhamento da Atividade Ct03}

\begin{tabular}{|c|c|}
\hline Atividade & Ct03. Analisar os resultados de teste \\
\hline Responsáveis & $\begin{array}{l}\text { Equipe de Desenvolvimento } \\
\text { Equipe de Teste }\end{array}$ \\
\hline Descrição & Essa atividade tem por objetivo analisar os resultados de teste. \\
\hline Recursos & \\
\hline Entradas & $\begin{array}{l}\text { e1) Arquivo de Código } \\
\text { e2) Planilha de Teste }\end{array}$ \\
\hline Saídas & s1) Planilha de Teste \\
\hline Tarefas & $\begin{array}{l}\text { - Confrontar os resultados obtidos com os resultados esperados que se } \\
\text { encontram na "Planilha de Teste" e marcar na planilha quais casos de teste } \\
\text { detectaram problemas } \\
\text { - Fazer os ajustes necessários no "Arquivo de Código", acessando a } \\
\text { atividade "Ct01. Codificar componentes" } \\
\text { - Obs: Para fazer alterações nos artefatos, acione a área de Gestão de } \\
\text { Mudanças e Configuração, a partir da atividade "GCf03. Solicitar mudanças" }\end{array}$ \\
\hline
\end{tabular}


Quadro A3.24.4 - Detalhamento da Atividade Ct04

\begin{tabular}{|l|l|}
\hline Atividade & Ct04. Integrar e testar integração entre componentes \\
\hline Responsáveis & $\begin{array}{l}\text { Equipe de Desenvolvimento } \\
\text { Equipe de Teste }\end{array}$ \\
\hline Descrição & $\begin{array}{l}\text { Essa atividade tem por objetivo integrar os componentes e executar os } \\
\text { casos de teste de integração definidos no plano de teste. }\end{array}$ \\
\hline Recursos & $\begin{array}{l}\text { - Ferramentas de Teste (ex: TestLink, Testitool, PHP Coverage, FunkLoad) } \\
\text { - Linguagem e Ambiente de Programação }\end{array}$ \\
\hline Entradas & $\begin{array}{l}\text { e1) Arquivo de Código } \\
\text { e2) Plano de Projeto } \\
\text { e3) Planilha de Teste }\end{array}$ \\
\hline Saídas & $\begin{array}{l}\text { s1) Planilha de Teste } \\
\text { s2) Arquivo de Código }\end{array}$ \\
\hline Tarefas & $\begin{array}{l}\text { - Realizar integração dos componentes, de acordo com a estratégia definida } \\
\text { no "Plano de Projeto" } \\
\text { * Averiguar se os componentes estão prontos para serem integrados } \\
\text { (considerando não só os componentes de software, mas também de } \\
\text { hardware se for o caso) } \\
\text { - Realizar o Teste de Integração, conforme os componentes/módulos são } \\
\text { integrados } \\
\text { * Executar os casos de teste de integração definidos na planilha "Casos de } \\
\text { Teste de Integração" do arquivo "Planilha de Teste", verificando a } \\
\text { corretitude das interfaces que conectam os componentes } \\
\text { * Registrar resultados obtidos na planilha "Casos de Teste de Integração" } \\
\text { do arquivo "Planilha de Teste" } \\
- \text { Obs: Para fazer alterações nos artefatos, acione a área de Gestão de } \\
\text { Mudanças e Configuração, a partir da atividade "GCf03. Solicitar mudanças" }\end{array}$ \\
\hline
\end{tabular}

Quadro A3.24.5 - Detalhamento da Atividade Ct05

\begin{tabular}{|l|l|}
\hline Atividade & Ct05. Monitorar e controlar o projeto \\
\hline Responsáveis & Gerente de Projeto \\
\hline Descrição & Essa atividade tem como objetivo o monitoramento e controle do projeto. \\
\hline Recursos & $\begin{array}{l}\text { Ferramenta de gerenciamento de projeto (ex: dot Project, MS-Project, } \\
\text { Primavera) }\end{array}$ \\
\hline Entradas & $\begin{array}{l}\text { e1) Plano de Projeto } \\
\text { e2) Relatório de Acompanhamento de Projeto } \\
\text { e3) Controle de Projetos } \\
\text { e4) Cronograma }\end{array}$ \\
\hline Saídas & $\begin{array}{l}\text { s1) Relatório de Acompanhamento de Projeto } \\
\text { s2) Controle de Projetos } \\
\text { s3) Cronograma }\end{array}$ \\
\hline
\end{tabular}




\section{Quadro A3.24.5 - Detalhamento da Atividade Ct05 (Cont.)}

\begin{tabular}{|c|c|}
\hline Tarefas & $\begin{array}{l}\text { - Em qualquer iteração e ciclo de desenvolvimento: } \\
\text { * Inserir a data de término da fase do projeto na planilha } \\
\text { "Acompanhamento de Projetos" do arquivo "Controle de Projetos", replicar a } \\
\text { linha do projeto e inserir a nova fase com sua data de início } \\
\text { * Inserir na planilha "Acompanhamento de Projetos" do arquivo "Controle } \\
\text { de Projetos" a quantidade de horas trabalhadas de cada um dos } \\
\text { colaboradores nessa fase. } \\
\text { * Inserir no "Cronograma" a quantidade de horas trabalhadas de cada um } \\
\text { dos colaboradores nessa fase. } \\
\text { * Verificar no "Cronograma" o andamento das atividades executadas em } \\
\text { relação às atividades planejadas } \\
\text { - Identificar e gerenciar dependências em relação às datas planejadas } \\
\text { - Identificar compromissos que não foram satisfeitos } \\
\text { - Identificar a ocorrência de algum risco levantado no "Plano de Projeto" e, } \\
\text { nesse caso, executar o "Plano de Contingência" documentado no "Plano de Projeto" } \\
\text { - Criar/Atualizar o arquivo "Relatório de Acompanhamento de Projeto" } \\
\text { (conforme GCf01) e registrar a revisão de andamento do projeto nesse relatório } \\
\text { * Planejar e executar ações corretivas, caso necessário, e registrá-las no } \\
\text { "Relatório de Acompanhamento de Projeto" } \\
\text { - Obs: Para fazer alterações nos artefatos, acione a área de Gestão de } \\
\text { Mudanças e Configuração, a partir da atividade "GCf03. Solicitar mudanças" }\end{array}$ \\
\hline
\end{tabular}

Quadro A3.24.6 - Detalhamento da Atividade CT06

\begin{tabular}{|l|l|}
\hline Atividade & Ct06. Monitorar e Controlar questões financeiras \\
\hline Responsáveis & $\begin{array}{l}\text { Gerente de Projeto } \\
\text { Equipe de Finanças }\end{array}$ \\
\hline Descrição & $\begin{array}{l}\text { Essa atividade tem como objetivo o monitoramento e controle de todas as } \\
\text { questões financeiras referentes ao projeto. }\end{array}$ \\
\hline Recursos & $\begin{array}{l}\text { e1) Controle de Projetos } \\
\text { e2) Relatório de Viabilidade do Projeto } \\
\text { e3) Fluxo de caixa }\end{array}$ \\
\hline Saídas & $\begin{array}{l}\text { s1) Controle de Projetos } \\
\text { s2) Cobrança } \\
\text { s3) Fluxo de Caixa }\end{array}$ \\
\hline Tarefas & $\begin{array}{l}\text { - Dar baixa nas duplicatas pagas, na aba "Duplicatas" do arquivo "Controle } \\
\text { de Projetos" } \\
\text { - Confrontar relatório de duplicatas pagas com emitidas e cobrar os clientes } \\
\text { que estão com suas duplicatas vencidas } \\
- \text { Relatar à equipe de finanças a respeito do cliente inadimplente } \\
\text { - Analisar "Relatório de Viabilidade do Projeto" } \\
\text { * Inserir no "Fluxo de caixa" mensal os recebimentos } \\
\text { * Confrontar o "Relatório de viabilidade do Projeto" com o "Fluxo de caixa" } \\
\text { mensal } \\
\text { * Tomar as decisões cabíveis } \\
\text { * Atualizar "Fluxo de caixa" }\end{array}$ \\
\hline
\end{tabular}


Quadro A3.24.7 - Detalhamento da Atividade Ct07

\begin{tabular}{|c|c|}
\hline Atividade & Ct07. Conduzir revisão do milestone: Capacidade Operacional \\
\hline Responsáveis & Equipe de Qualidade \\
\hline Descrição & $\begin{array}{l}\text { Essa atividade tem o objetivo de revisar o milestone que marca o final dessa } \\
\text { fase. É determinado se o produto está pronto para ser distribuído em um } \\
\text { ambiente de teste beta. }\end{array}$ \\
\hline Recursos & \\
\hline Entradas & $\begin{array}{l}\text { e1) Plano de Garantia da Qualidade } \\
\text { e2) Produto de Trabalho: Arquivo de Código (Capacidade Operacional do } \\
\text { Produto) } \\
\text { e3) Relatório sobre Garantia da Qualidade }\end{array}$ \\
\hline Saídas & s1) Relatório sobre Garantia da Qualidade \\
\hline Tarefas & $\begin{array}{l}\text { - Realizar a atividade "GqPP01. Avaliar o processo e assegurar resolução } \\
\text { de não conformidades" } \\
\text { - Realizar a atividade "GqPP02. Avaliar os produtos de trabalho e assegurar } \\
\text { resolução de não conformidades" } \\
\text { - Obs: Para fazer alterações nos artefatos, acione a área de Gestão de } \\
\text { Mudanças e Configuração, a partir da atividade "GCf03. Solicitar mudanças" }\end{array}$ \\
\hline
\end{tabular}




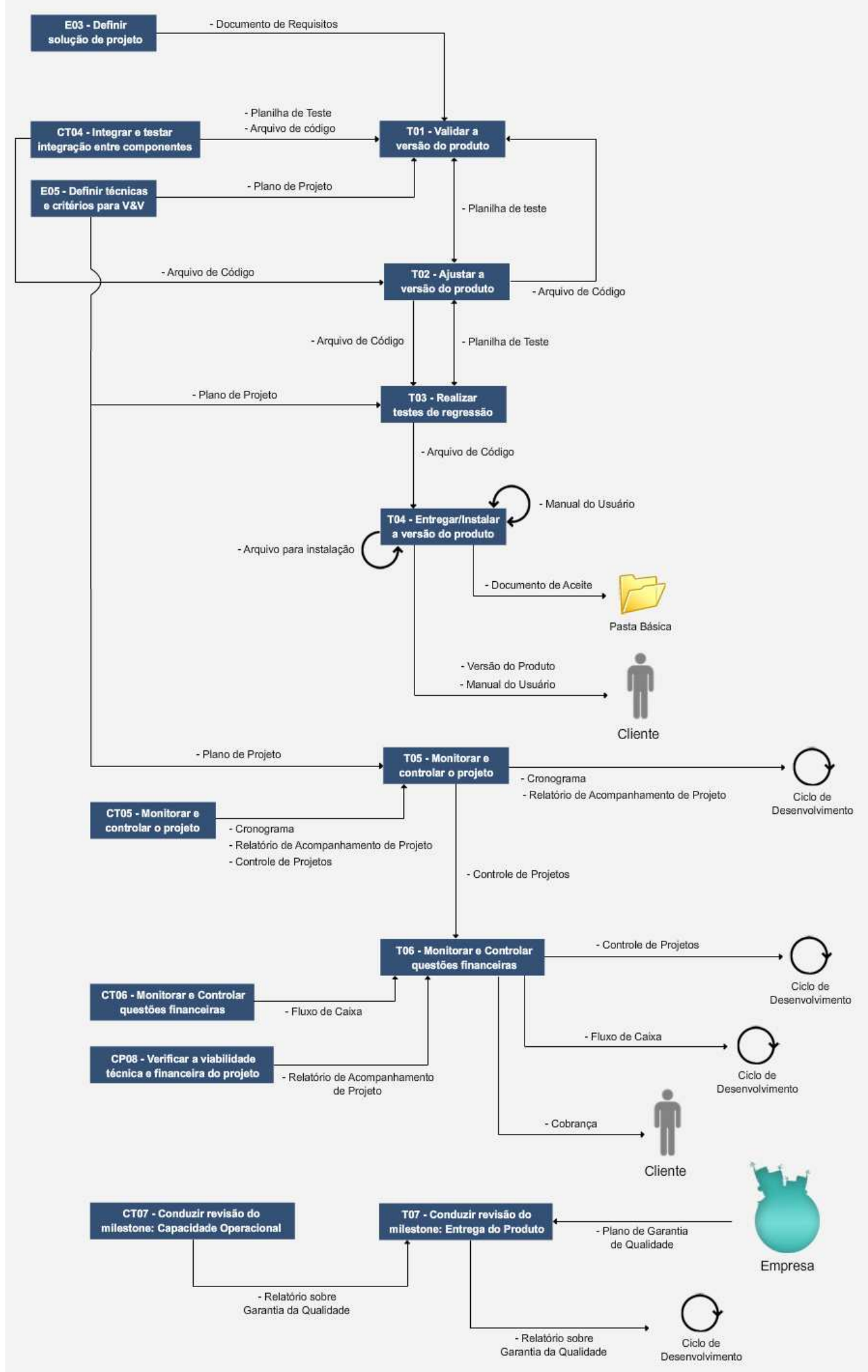

Figura A3.25 - Visão GráficA - FASE: Transição 
Quadro A3.25.1 - Detalhamento da ATIVIDADE T01

\begin{tabular}{|c|c|}
\hline Atividade & T01. Validar a versão do produto \\
\hline Responsáveis & $\begin{array}{l}\text { Equipe de Desenvolvimento } \\
\text { Equipe de Teste }\end{array}$ \\
\hline Descrição & $\begin{array}{l}\text { Essa atividade tem por objetivo executar os casos de teste de validação } \\
\text { definidos no plano de teste na versão do produto. }\end{array}$ \\
\hline Recursos & \\
\hline Entradas & $\begin{array}{l}\text { e1) Arquivo de Código } \\
\text { e2) Plano de Projeto } \\
\text { e3) Documento de Requisitos } \\
\text { e4) Planilha de Teste }\end{array}$ \\
\hline Saídas & s1) Planilha de Teste \\
\hline Tarefas & $\begin{array}{l}\text { - Realizar o Teste de Validação da versão do produto, simulando o ambiente } \\
\text { do cliente } \\
\text { * Executar os casos de teste de validação definidos na planilha "Casos de } \\
\text { Teste de Validação" do arquivo "Planilha de Teste" } \\
\text { * Registrar resultados obtidos na planilha "Casos de Teste de Validação" } \\
\text { do arquivo "Planilha de Teste" }\end{array}$ \\
\hline
\end{tabular}

Quadro A3.25.2 - Detalhamento da Ativid ade T02

\begin{tabular}{|c|c|}
\hline Atividade & T02. Analisar e Ajustar a versão do produto \\
\hline Responsáveis & $\begin{array}{l}\text { Equipe de Desenvolvimento } \\
\text { Equipe de Teste }\end{array}$ \\
\hline Descrição & $\begin{array}{l}\text { Essa atividade tem por objetivo analisar os resultados de teste realizar as } \\
\text { modificações necessárias na versão do produto validado. }\end{array}$ \\
\hline Recursos & Linguagem e Ambiente de Programação \\
\hline Entradas & $\begin{array}{l}\text { e1) Arquivo de Código } \\
\text { e2) Planilha de Teste }\end{array}$ \\
\hline Saídas & $\begin{array}{l}\text { s1) Arquivo de Código } \\
\text { s2) Planilha de Teste }\end{array}$ \\
\hline Tarefas & $\begin{array}{l}\text { - Confrontar os resultados obtidos com os resultados esperados que se } \\
\text { encontram na "Planilha de Teste" } \\
\text { - Confrontar os resultados obtidos em relação aos critérios de validação } \\
\text { definidos "Documento de Requisitos" } \\
\text { - Marcar na "Planilha de Teste" os critérios de validação que não foram } \\
\text { atendidos } \\
\text { - Fazer os ajustes necessários no "Arquivo de Código" } \\
\text { - Validar o "Arquivo de Código" modificado, acessando a atividade "T01. } \\
\text { Validar a versão do produto" } \\
\text { - Obs: Para fazer alterações nos artefatos, acione a área de Gestão de } \\
\text { Mudanças e Configuração, a partir da atividade "GCf03. Solicitar mudanças" }\end{array}$ \\
\hline
\end{tabular}


Quadro A3.25.3 - Detalhamento da Atividade T03

\begin{tabular}{|c|c|}
\hline Atividade & T03. Realizar testes de regressão \\
\hline Responsáveis & $\begin{array}{l}\text { Equipe de Desenvolvimento } \\
\text { Equipe de Teste }\end{array}$ \\
\hline Descrição & $\begin{array}{l}\text { Essa atividade tem por objetivo executar novamente os casos de teste de } \\
\text { unidade e de integração na versão ajustada do produto. }\end{array}$ \\
\hline Recursos & $\begin{array}{l}\text { - Ferramentas de Teste (ex: TestLink, Testitool, PHP Coverage, FunkLoad) } \\
\text { - Linguagem e Ambiente de Programação }\end{array}$ \\
\hline Entradas & $\begin{array}{l}\text { e1) Plano de Projeto } \\
\text { e2) Planilha de Teste } \\
\text { e3) Arquivo de Código }\end{array}$ \\
\hline Saídas & s1) Planilha de Teste \\
\hline Tarefas & $\begin{array}{l}\text { - Realizar, novamente, o Teste de Unidade, o Teste de Integração e o Teste } \\
\text { de Validação planejados e registrados no "Plano de Projeto" das unidades } \\
\text { codificadas anteriormente } \\
\text { *Executar os casos de teste de unidade e os casos de teste de integração } \\
\text { definidos nas planilhas "Casos de Teste de Unidade", "Casos de Teste de } \\
\text { Integração" e "Casos de Teste de Validação" do arquivo "Planilha de Teste" } \\
\text { * Registrar resultados obtidos nas respectivas planilhas } \\
\text { - Realizar os ajustes necessários na versão do produto, se for o caso, } \\
\text { acessando a atividade "T02. Ajustar a versão do produto" }\end{array}$ \\
\hline
\end{tabular}


Quadro A3.25.4 - Detalhamento da Atividade T04

\begin{tabular}{|l|l|}
\hline Atividade & T04. Entregar/Instalar a versão do produto \\
\hline Responsáveis & $\begin{array}{l}\text { Equipe de Desenvolvimento } \\
\text { Equipe de Suporte } \\
\text { Equipe de Vendas }\end{array}$ \\
\hline Descrição & $\begin{array}{l}\text { Essa atividade tem por objetivo a entrega e instalação (se for o caso) da } \\
\text { versão do produto para uso no ambiente do cliente. }\end{array}$ \\
\hline Recursos & $\begin{array}{l}\text { e1) Arquivo de Código } \\
\text { e2) Manual do Usuário }\end{array}$ \\
\hline Entradas & $\begin{array}{l}\text { s1) Versão do Produto } \\
\text { s2) Documento de Aceite } \\
\text { s3) Manual do Usuário } \\
\text { s4) Arquivo para Instalação }\end{array}$ \\
\hline $\begin{array}{l}\text { - Para documentar um release, deve-se: } \\
\text { * registrar as versões específicas dos componentes de código-fonte } \\
\text { usados para criar o código executável } \\
\text { * manter cópias dos códigos-fonte, do código-executável, de todos os } \\
\text { arquivos de dados e de configuração } \\
\text { * registrar as versões do sistema operacional, as bibliotecas, os } \\
\text { compiladores e outras ferramentas usadas para construir o software } \\
\text { - Gerar a versão executável do produto, a partir do "Arquivo de Código" } \\
\text { - Programar a implantação } \\
\text { - Criar/atualizar o "Arquivo para Instalação" (conforme GCf01) } \\
\text { - Realizar programação de implantação } \\
\text { - Treinar o cliente } \\
\text { - Criar/Atualizar o "Manual do Usuário" (conforme GCf01) } \\
\text { - Criar/Atualizar arquivo "Documento de Aceite" (conforme GCf01) e coletar } \\
\text { assinatura para confirmar que a versão foi entregue ao cliente. Anexar à } \\
\text { pasta física. } \\
\text { * Quando se tratar da versão final do sistema, o Manual do Usuário será } \\
\text { entregue. } \\
\text { - Obs: Para fazer alterações nos artefatos, acione a área de Gestão de } \\
\text { Mudanças e Configuração, a partir da atividade "GCf03. Solicitar mudanças" }\end{array}$ \\
\hline Tareas
\end{tabular}


Quadro A3.25.5 - Detalhamento da ATividade T05

\begin{tabular}{|c|c|}
\hline Atividade & T05. Monitorar e controlar o projeto \\
\hline Responsáveis & Gerente de Projeto \\
\hline Descrição & Essa atividade tem como objetivo o monitoramento e controle do projeto. \\
\hline Recursos & $\begin{array}{l}\text { Ferramenta de gerenciamento de projeto (ex: dot Project, MS-Project, } \\
\text { Primavera) }\end{array}$ \\
\hline Entradas & $\begin{array}{l}\text { e1) Plano de Projeto } \\
\text { e2) Relatório de Acompanhamento de Projeto } \\
\text { e3) Controle de Projetos } \\
\text { e4) Cronograma }\end{array}$ \\
\hline Saídas & $\begin{array}{l}\text { s1) Relatório de Acompanhamento de Projeto } \\
\text { s2) Controle de Projetos } \\
\text { s3) Cronograma }\end{array}$ \\
\hline Tarefas & $\begin{array}{l}\text { - Em qualquer iteração e ciclo de desenvolvimento: } \\
\text { * Inserir a data de término da fase do projeto na planilha } \\
\text { "Acompanhamento de Projetos" do arquivo "Controle de Projetos", replicar a } \\
\text { linha do projeto e inserir a nova fase com sua data de início } \\
\text { * Inserir na planilha "Acompanhamento de Projetos" do arquivo "Controle } \\
\text { de Projetos" a quantidade de horas trabalhadas de cada um dos } \\
\text { colaboradores nessa fase. } \\
\text { * Inserir no "Cronograma" a quantidade de horas trabalhadas de cada um } \\
\text { dos colaboradores nessa fase. } \\
\text { * Verificar no "Cronograma" o andamento das atividades executadas em } \\
\text { relação às atividades planejadas } \\
\text { - Identificar e gerenciar dependências em relação às datas planejadas } \\
\text { - Identificar compromissos que não foram satisfeitos } \\
\text { - Identificar a ocorrência de algum risco levantado no "Plano de } \\
\text { Projeto" e, nesse caso, executar o "Plano de Contingência" documentado no } \\
\text { "Plano de Projeto" } \\
\text { - Criar/Atualizar o arquivo "Relatório de Acompanhamento de Projeto" } \\
\text { (conforme GCf01) e registrar a revisão de andamento do projeto nesse } \\
\text { relatório } \\
\text { * Planejar e executar ações corretivas, caso necessário, e registrá-las no } \\
\text { "Relatório de Acompanhamento de Projeto" } \\
\text { - Obs: Para fazer alterações nos artefatos, acione a área de Gestão de } \\
\text { Mudanças e Configuração, a partir da atividade "GCf03. Solicitar mudanças" }\end{array}$ \\
\hline
\end{tabular}


Quadro A3.25.6 - Detalhamento da Atividade T06

\begin{tabular}{|c|c|}
\hline Atividade & T06. Monitorar e Controlar questões financeiras \\
\hline Responsáveis & $\begin{array}{l}\text { Gerente de Projeto } \\
\text { Equipe de Finanças }\end{array}$ \\
\hline Descrição & $\begin{array}{l}\text { Essa atividade tem como objetivo o monitoramento e controle de todas as } \\
\text { questões financeiras referentes ao projeto. }\end{array}$ \\
\hline Recursos & \\
\hline Entradas & $\begin{array}{l}\text { e1) Controle de Projetos } \\
\text { e2) Relatório de Viabilidade do Projeto } \\
\text { e3) Fluxo de caixa }\end{array}$ \\
\hline Saídas & $\begin{array}{l}\text { s1) Controle de Projetos } \\
\text { s2) Cobrança } \\
\text { s3) Fluxo de Caixa }\end{array}$ \\
\hline Tarefas & $\begin{array}{l}\text { - Dar baixa nas duplicatas pagas, na aba "Duplicatas" do arquivo "Controle } \\
\text { de Projetos" } \\
\text { - Confrontar relatório de duplicatas pagas com emitidas e cobrar os clientes } \\
\text { que estão com suas duplicatas vencidas } \\
\text { - Relatar à equipe de finanças a respeito do cliente inadimplente } \\
\text { - Analisar "Relatório de Viabilidade do Projeto" } \\
\text { * Inserir no "Fluxo de caixa" mensal os recebimentos } \\
\text { * Confrontar o "Relatório de viabilidade do Projeto" com o "Fluxo de caixa" } \\
\text { mensal } \\
\text { * Tomar as decisões cabíveis } \\
\text { * Atualizar "Fluxo de caixa" }\end{array}$ \\
\hline
\end{tabular}


Quadro A3.25.7 - Detalhamento da ATIVIDADE T07

\begin{tabular}{|c|c|}
\hline Atividade & T07. Conduzir revisão do milestone: Entrega do Produto \\
\hline Responsáveis & $\begin{array}{l}\text { Equipe de Qualidade } \\
\text { Gerente de Projeto }\end{array}$ \\
\hline Descrição & $\begin{array}{l}\text { Essa atividade tem o objetivo de revisar o milestone que marca o final dessa } \\
\text { fase. É decidido se os objetivos do projeto foram alcançados, e se deve ser } \\
\text { iniciado um outro ciclo de desenvolvimento (passagem pelas } 4 \text { fases; cada } \\
\text { passagem produz uma versão do software; tipicamente, os ciclos tem as } \\
\text { fases de concepção e elaboração mais curtas, uma vez que a definição e } \\
\text { arquitetura do produto são determinados nos ciclos anteriores; exceções } \\
\text { ocorrem qdo é necessária a redefinição do produto ou arquitetura). }\end{array}$ \\
\hline Recursos & \\
\hline Entradas & $\begin{array}{l}\text { e1) Plano de Garantia da Qualidade } \\
\text { e2) Produto de Trabalho: Entrega do Produto } \\
\text { e3) Relatório sobre Garantia da Qualidade }\end{array}$ \\
\hline Saídas & s1) Relatório sobre Garantia da Qualidade \\
\hline Tarefas & $\begin{array}{l}\text { - Realizar a atividade "GqPP01. Avaliar o processo e assegurar resolução } \\
\text { de não conformidades" } \\
\text { - Realizar a atividade "GqPP02. Avaliar os produtos de trabalho e assegurar } \\
\text { resolução de não conformidades" } \\
\text { - Obs: Para fazer alterações nos artefatos, acione a área de Gestão de } \\
\text { Mudanças e Configuração, a partir da atividade "GCf03. Solicitar mudanças" }\end{array}$ \\
\hline
\end{tabular}




\section{Apêndice 4 - Modelo ProcSoftVD (Templates)}

Os documentos A4.1 a A4.34, apresentados a seguir, são referentes aos templates dos artefatos de entrada e saída utilizados/criados nas/pelas atividades do modelo ProcSoftVD.

\section{A4.1 - CHECKLIST}

(Material elaborado pela Profa. Sandra Fabbri - UFSCAR (Universidade Federal de São Carlos.

Obtido por meio da URL: http://www2.dc.ufscar.br/ junia/Checklist.pdf em 30/09/2008)

Checklist é uma técnica usada durante revisões técnicas formais (FTR), atividade que garante a qualidade do software. Seus objetivos são:

- Descobrir erros de função, de lógica ou de implementação para qualquer representação do software.

- Verificar que o software em questão atende aos requisitos especificados.

- Garantir que o software foi representado de acordo com padrões pré-definidos.

- Garantir que o software seja desenvolvido de maneira uniforme.

- Desenvolver projetos mais gerenciáveis.

O checklist ajuda o gerente a coordenar a reunião de FTR e ajuda cada revisor a focar nas características importantes. Os checklists devem ser aplicados a documentos de analise, projeto, codificação, e teste, focando os aspectos e defeitos comuns da fase correspondente. Por exemplo, as questões no checklist para a fase de requisitos devem apontar os problemas e defeitos que podem aparecer nos documentos de especificação de requisitos e correlatos.

Entrada: um conjunto de requisitos do novo sistema Saída: uma lista de defeitos que devem ser corrigidos no novo sistema

Para o documento de requisitos, devem ser aplicadas as seguintes categorias de perguntas:

\section{Questões Gerais:}

1. Os objetivos do sistema foram definidos?

2. Os requisitos estão claros e sem ambigüidades?

3. É fornecida uma visão geral do sistema?

4. É fornecida uma visão geral das formas de operação do sistema?

5. O software e hardware necessários são especificados?

6. Se existem suposições que afetam a implementação, elas são especificadas?

7. Para cada função, os requisitos foram especificados em termos de entrada, processamento e saída?

8. Todas as funções, os dispositivos e as restrições são mapeados nos requisitos e vice-versa? 


\section{Omissão (0):}

1. Funcionalidades:

1.1. As funções descritas são suficientes para atender os objetivos do sistema?

1.2. As entradas declaradas para cada função são suficientes para executar essa função?

1.3. Os eventos indesejados foram considerados e as respostas necessárias a eles são especificadas?

1.4. O estado inicial e estados especiais foram considerados? (por exemplo, inicialização do sistema, término finalização anormal, etc)

2. Desempenho:

2.1. O sistema pode ser testado, demonstrado, analisado ou inspecionado para mostrar que satisfaz os requisitos?

2.2. Os tipos de dados, unidades, limites e resolução foram especificados?

2.3. A freqüência e volume de entrada e saída foram especificados para cada função foram especificadas?

3. Interface:

3.1. As entradas e saídas para todas as interfaces são suficientes?

3.2. Foram especificados os requisitos de interface entre hardware, software pessoas e procedimentos?

4. Ambiente:

4.1. Foram especificadas de forma apropriada as funcionalidades de interação entre hardware, software com o sistema?

\section{Fato incorreto (FI):}

2.1. Todas as funções descritas são necessárias para atingir os objetivos do sistema? 2.2. Todas as entradas da função, para cada função, são necessárias para executar a função?

2.3. As entradas e saídas para todas as interfaces são necessárias?

2.4. As saídas produzidas por uma função, para cada função, são usadas por outra função ou transferidas para a interface externa?

\section{Inconsistência (I):}

3.1. Os requisitos são consistentes entre si?

3.2. Os requisitos funcionais são consistentes com o sistema operacional?

\section{Ambigüidade (A):}

4.1. Cada requisito é definido de tal forma que seja discreto, sem ambigüidade, e testável?

4.2. Todas as transições de modo são especificadas de forma determinística?

\section{Informações estranhas (IE):}

5.1. As funções especificadas são coerentes com o sistema e com os objetivos a serem alcançados? 


\section{Miscelânea (M)}

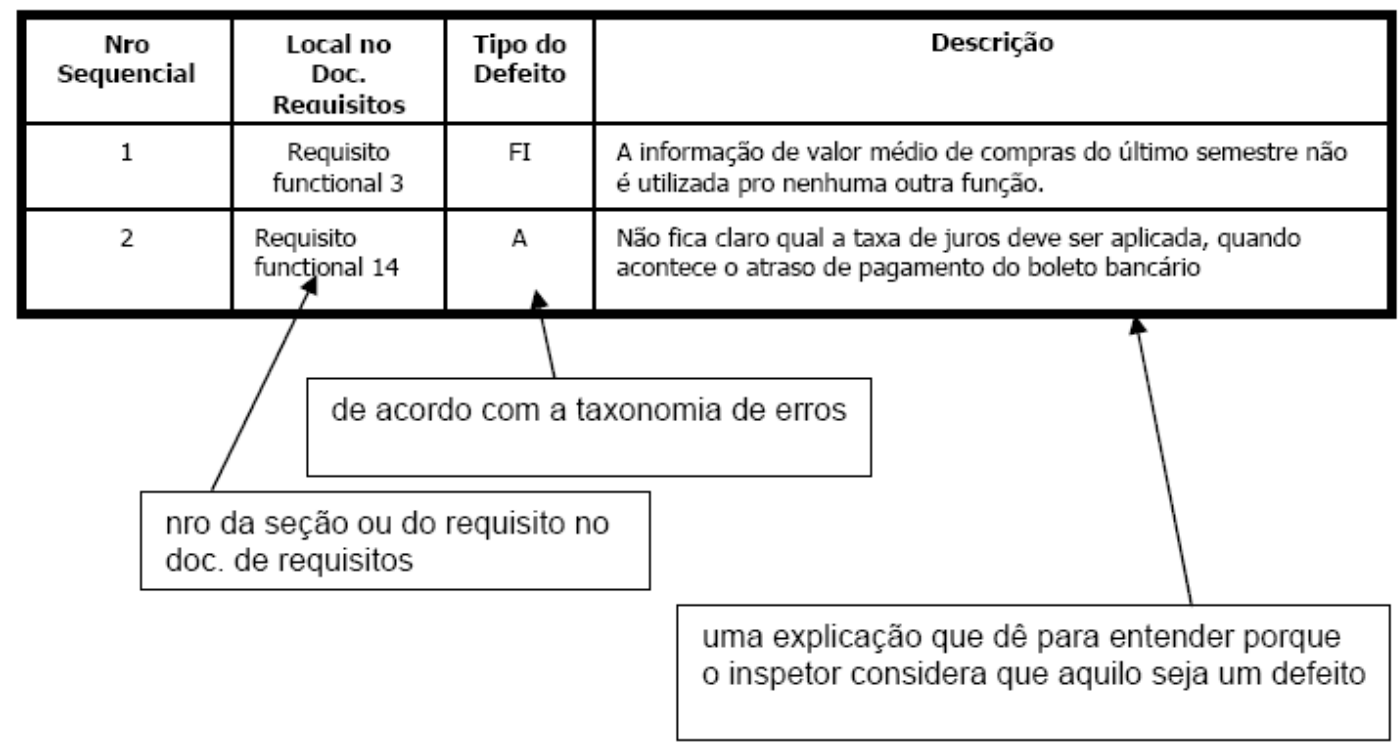




\section{A4.2 - ARQUITETURA DO SOFTWARE}

ID documento:

Data: / /

Versão :

Responsável pelo documento:

ID Projeto:

\section{HISTÓRICO DE REVISÕES}

\begin{tabular}{|l|l|l|l|l|}
\hline $\begin{array}{c}\text { Data de } \\
\text { criação/ } \\
\text { atualização }\end{array}$ & $\begin{array}{c}\text { Descrição da(s) Mudança(s) } \\
\text { Ocorrida(s) }\end{array}$ & Autor & $\begin{array}{c}\text { Versão do } \\
\text { Documento }\end{array}$ & $\begin{array}{c}\text { ID. } \\
\text { Solicitação } \\
\text { de } \\
\text { Mudança }\end{array}$ \\
\hline & & & & \\
\hline & & & & \\
\hline & & & & \\
\hline & & & & \\
\hline & & & & \\
\hline
\end{tabular}

\section{Fatores Arquiteturais}

$<$ Aqui são colocadas as referências relacionadas principalmente aos requisitos não funcionais que influenciarão na escolha da arquitetura.>

\section{Arquitetura Lógica}

< A arquitetura lógica é a organização em larga escala das classes de software em pacotes, subsistemas e, dependendo do estilo arquitetural, em camadas. É denominada arquitetura lógica porque não há decisão sobre como esses elementos são implantados pelos diferentes processos do sistema operacional ou pelos computadores físicos em uma rede (decisões essas posteriores, parte da arquitetura de implantação).

Uma camada é um agrupamento de granularidade muito grossa de classes, pacotes ou subsistemas que tem responsabilidade coesiva sobre um tópico importante do sistema. 


\section{Exemplo:}

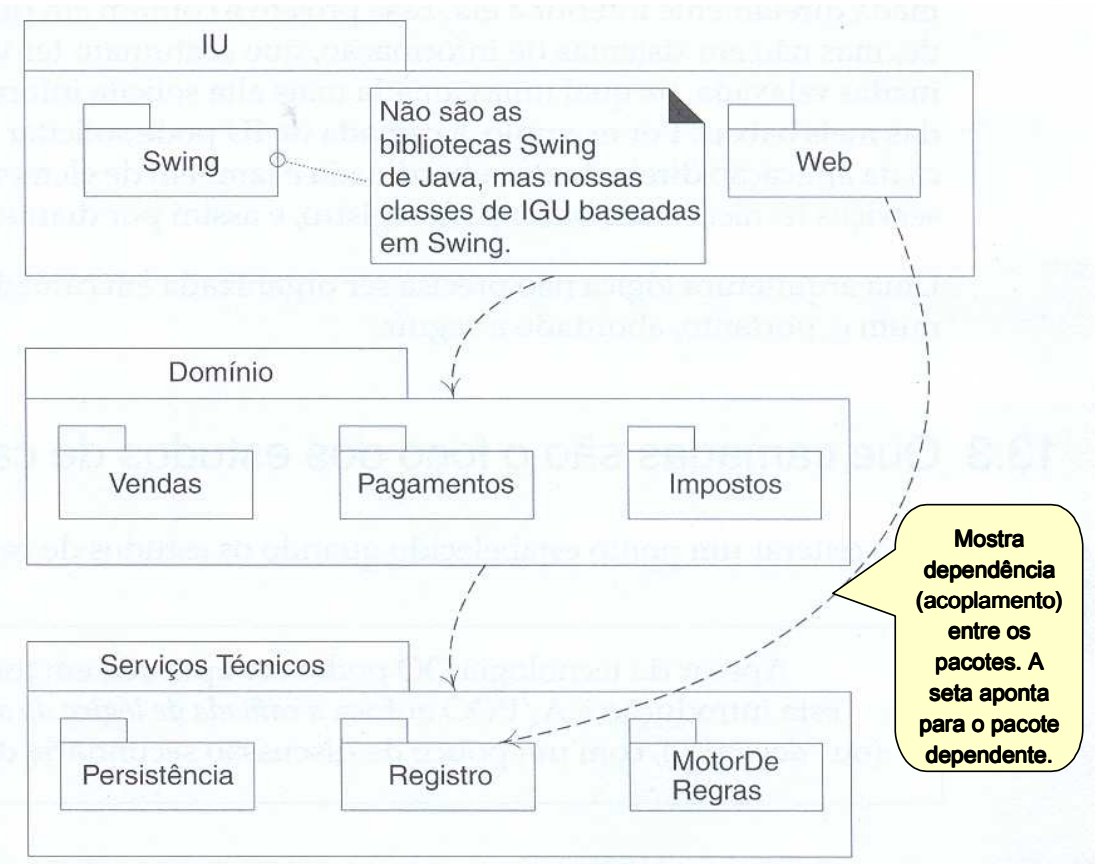

Fonte: LARMAN, C. Utilizando UML e Padrões: Uma introdução à análise e ao projeto orientados a objetos e ao desenvolvimento iterativo. Porto Alegre: Bookman, 2007.

$$
>
$$

\section{Topologia do Sistema}

< A topologia do sistema mostra a implantação de elementos de software à arquitetura do software e a comunicação (geralmente em uma rede) entre elementos físicos.

A topologia do sistema pode ser representada por um diagrama de implantação da $U M L$.

O Modelo de Implantação é opcional para sistemas de um único processador ou sistemas simples com pouca ou nenhuma distribuição de processamento. É obrigatório para sistemas com configurações complexas de rede ou de processador. Um diagrama de implantação mostra a atribuição de artefatos concretos de software (como arquivos executáveis) a nós computacionais (algo com serviços de processamento).

Exemplo: 


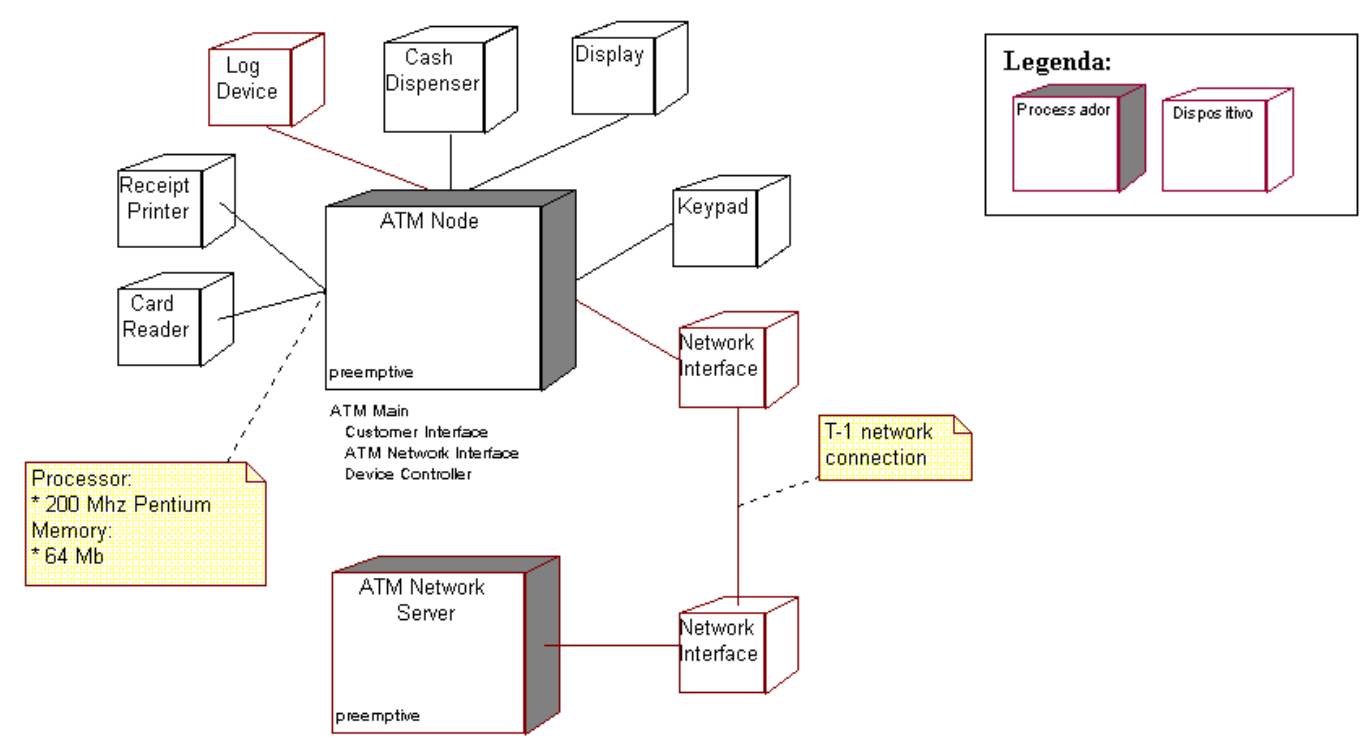

Fonte: RUP - Modelo pertencente à ferramenta CASE Rational Rose

Outro exemplo:

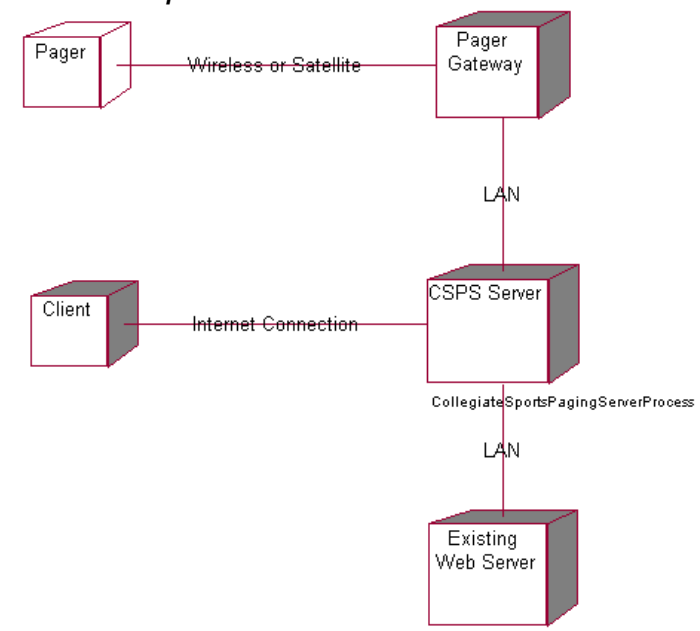

Fonte: Modelagem disponível (csps_design_v1_0.mdl) na ferramenta Rational Rose

$>$

\section{Decisões Arquiteturais}

$<$ Descreve as decisões quanto à arquitetura e as razões técnicas que motivaram a tomada dessas decisões.>

$<$

Referência Bibliográfica: CLEMENTS, P.; BACHMANN, F.; BASS, L.; GARLAN, D.; IVERS, J.; LITTLE, R.; NORD, R.; STAFFORD, J. Documenting Software Architectures. Views and Beyond. SEI Series in Software Engineering. Addison Wesley, 2003.

A arquitetura de software é um conjunto de decisões significativas sobre a organização de um sistema, a seleção dos elementos estruturais e suas interfaces que compõem o sistema, junto ao seu comportamento especificado nas colaborações entre esses elementos, a composição desses elementos estruturais e 
comportamentais em subsistemas mais abrangentes, e o estilo arquitetural que guia essa organização - esses elementos e suas interfaces, suas colaborações e sua composição (Booch et al., 1999).

Um tipo de visão define os tipos de elementos e os tipos de relacionamentos usados para descrever a arquitetura do sistema, a partir de determinada perspectiva. sistema:

Ao projetar um sistema, o arquiteto deve considerar três perspectivas do

1. Como o sistema é estruturado como um conjunto de unidades de implementação (tipo de visão módulo);

2. Como o sistema é estruturado como um conjunto de elementos que tem comportamento e interações em tempo de execução (tipo de visão componente-e-conector);

3. Como o sistema é relacionado às outras estruturas, exceto software, no seu ambiente (tipo de visão alocação).

Cada tipo de visão tem formas de ocorrer, denominadas estilos arquiteturais. Um estilo arquitetural é uma especialização de tipos de elementos e relação, com um conjunto de restrições sobre como eles podem ser usados. Dessa forma, esses estilos refletem padrões de interação, independente do sistema em questão.

Nem todo sistema é construído exclusivamente a partir de um único estilo. Normalmente, um sistema pode atender a vários estilos combinados.

Um módulo é uma unidade de código que implementa um conjunto de responsabilidades. Um módulo pode ser uma classe, uma coleção de classes, uma camada ou alguma decomposição da unidade de código. Todo módulo tem uma coleção de propriedades atribuídas a ele. Essas propriedades expressam informações importantes e restrições associadas ao módulo. Exemplos de propriedades: responsabilidades, visibilidade de informação e autor. Exemplos de relações entre os módulos: é parte de (is part of) ou herda de (inherits from).

Estilos arquiteturais do tipo de visão módulo:

- Decomposição: representa a decomposição do código em sistemas, subsistemas e assim por diante. Este estilo representa uma visão top-down do sistema.

- Uso: indica relacionamentos de dependência funcional entre os módulos. Esse estilo depende da relação uses, que é uma forma especial da relação depends-on. Esse estilo mostra aos desenvolvedores quais outros módulos devem existir para uma determinada parte do sistema executar de forma correta.

- Generalização: indica relacionamentos de especialização entre os módulos, como em uma hierarquia de classes. Esse estilo é normalmente utilizado para expressar design orientado a objetos.

- Em camadas: organiza o código em camadas disjuntas, de acordo com regras predefinidas. Por exemplo, regras podem estipular que somente 0 código da próxima camada mais abaixo pode ser usado. Indica a relação permissão-para-uso em uma parte restrita entre os módulos.

Estilos Arquiteturais do tipo de visão componente-e-conector (C\&C) expressam comportamento em tempo real. Eles são descritos em termos de componentes e conectores. Um componente é uma das principais unidades de processamento da execução do sistema; um conector é um mecanismo de interação para os componentes. Objetos, processos ou coleções de objetos podem ser componentes. Conectores incluem pipes, repositórios e sockets. Middleware pode ser visualizado como um conector entre os componentes que usam o middleware. Componentes e conectores podem ser decompostos em outros componentes e conectores. Mais genericamente, visões arquiteturais em tempo de execução de 
sistemas de objetos, tais como mostrado em diagramas de colaboração, são exemplos desse estilo de C\&C. Alguns estilos de componentes-e-conectores são:

- Pipe-and-filter: é aquele no qual o padrão de interação é caracterizado pelas transformações sucessivas de dados. Dados chegam em um filtro, são transformados e passados pelo pipe (canal) para o próximo filtro no pipeline (canalização). Exemplos de sistemas desse tipo são sistemas de processamento de sinal e pipes UNIX.

- Shared-data: centraliza na retenção de dados persistentes. Vários elementos acessam os dados persistentes, os quais são retidos em pelo menos um repositório. Sistemas de base de dados e baseados em conhecimento são exemplos de estilos de dados compartilhados.

- Publish-subscribe: é caracterizado pelos componentes que interagem por eventos anunciados. Componentes podem subscrever para um conjunto de eventos. Esse estilo é comumente usado para dissociar produtores e consumidores de mensagens.

- Client-server: mostra componentes interagindo por meio de serviços solicitados de outros componentes. A essência desse estilo é que a comunicação é tipicamente emparelhada. Uma solicitação de serviço de um cliente é emparelhada com a provisão daquele serviço. Servidores fornecem um conjunto de serviços por meio de uma ou mais interfaces, e clientes usam zero ou mais serviços fornecidos pelos servidores no sistema. Pode haver um servidor central ou vários distribuídos.

- Peer-to-peer: é caracterizado pela interação de pares de componentes trocando serviços. É uma espécie de interação solicita/responde sem a assimetria encontrada no estilo cliente-servidor. Exemplos de sistemas peer-to-peer incluem arquiteturas que são baseadas em infra-estrutura de objetos distribuídos, tais como CORBA, COM+, Java RMI (remote method invocation).

- Communicating-processes: é caracterizado pela interação de componentes executados concorrentemente através de vários mecanismos de conexão. Exemplos desses mecanismos de conexão são: sincronização, passagem de mensagens, troca de dados, etc. Os processos de comunicação são comuns na maioria dos grandes sistemas e necessário em todos os sistemas distribuídos.

Os estilos do tipo de visão alocação descrevem o mapeamento das unidades de software com os elementos do ambiente (o hardware, sistema de arquivos ou equipe de desenvolvimento). São eles:

- Implantação: mapeia os processos para os elementos de hardware: nós de processamento, canais de comunicação, repositórios de memória e de dados. Esse estilo, usado para descrever como os processos são alocados para o hardware e o tráfico de mensagens resultante, é usado para análise de desempenho, segurança e confiabilidade e fornece uma base para estimar o custo de implantação de um único nó.

- Implementação: mapeia módulos de um tipo de visão módulos para uma infra-estrutura de desenvolvimento. Elementos do estilo de implementação são módulos e entidades de configuração. Esse estilo é usado para descrever como módulos são mapeados para entidades dentro do sistema de gestão de configuração, tanto quanto gerenciar versões e coordenar o desenvolvimento multi-equipes.

- Designação de trabalho: mapeia módulos de um tipo de visão módulos para equipes de desenvolvimento. Elementos desse estilo são módulos e equipes de desenvolvimento. O estilo é usado para descrever quais 
equipes são responsáveis por quais elementos da WBS, tanto quanto para informar cronograma e estimativas de orçamento.

$>$

$<$

Referência Bibliográfica: SOMERVILLE, I. Engenharia de Software. 8 ${ }^{a}$ edição. São Paulo: Addison Wesley, 2003.

A arquitetura afeta o desempenho, proteção, disponibilidade e facilidade de manutenção de um sistema. O estilo e a estrutura escolhidos para uma aplicação podem, portanto, depender dos requisitos não funcionais do sistema. Por exemplo:

- Quanto ao desempenho: se o desempenho for um requisito crítico, a arquitetura deve ser projetada para localizar operações críticas dentro de alguns subsistemas, com tão pouca comunicação quanto possível entre eles. Isso pode significar o uso de componentes de alta granularidade em detrimento dos de baixa granularidade para reduzir as comunicações entre os componentes.

- Quanto à proteção: se a proteção for um requisito crítico, uma estrutura em camadas para a arquitetura deve ser usada, com os itens mais críticos protegidos por camadas mais internas e com alto nível de validação de proteção aplicado a essas camadas.

- Quanto à segurança: se a segurança for um requisito crítico, a arquitetura deve ser projetada de modo que as operações relacionadas à segurança estejam todas localizadas em um único subsistema ou em um pequeno número de subsistemas. Isso reduz os custos e os problemas de validação de segurança e torna possível fornecer esse serviço a sistemas de proteção relacionados.

- Quanto à disponibilidade: se a disponibilidade for um requisito crítico, a arquitetura deve ser projetada para incluir componentes redundantes e, assim que possível, substituir e atualizar componentes sem parar o sistema.

- Quanto à facilidade de manutenção: se a facilidade de manutenção for um requisito crítico, a arquitetura de sistema deve ser projetada usando componentes de baixa granularidade e autocontidos que possam ser prontamente mudados. Os criadores de dados devem ser separados dos clientes, e estruturas de dados compartilhadas devem ser evitadas.

A arquitetura de um sistema pode ser baseada em um modelo ou estilo de arquitetura específico. Entretanto, a arquitetura da maioria dos grandes sistemas não está de acordo com um único estilo. Partes diferentes do sistema podem ser projetadas usando estilos diferentes de arquitetura. Por exemplo, um sistema pode ser organizado com base em um repositório de dados compartilhados, mas pode criar camadas com base nisso para apresentar uma visão mais abstrata dos dados.

$$
>
$$




\section{A4.3 - CONTRATO}

$<$ Este contrato pode ser utilizado em casos de licença de software, incluindo 0 desenvolvimento, implantação e treinamento do sistema em questão e a entrega da documentação e programas fonte do sistema ao CONTRATANTE. Este template de contrato é uma adaptação de dois outros contratos: um cedido por Rogério Marcus Alessi (Secretário Municipal de Tecnologia da Informação da Prefeitura Municipal de Presidente Prudente, de 2004 a 2008) e outro disponibilizado na URL:

< http://www.ramosdainformatica.com.br/files/Clientes/modelo contrato desenvolvimento.pdf>

\section{CONTRATO DE LICENÇA DE SOFTWARE}

Pelo presente instrumento, de um lado <empresa>, inscrita no CNPJ sob número $x x x x x x x$, sito à <endereço, $\mathrm{nr}>$, cidade de $x x x x x x x$, Estado de $x x x x x$, neste ato representada pelo(a) $\operatorname{Sr}(a)$. Xxxx, CPF $x x x x x x x x x$, doravante denominada CONTRATANTE, e de outro $\operatorname{Sr}(a)$. $x x x x x x x$, sito à <endereço, $n r>$, cidade de $x x x x x x x$, Estado de $x x x x x$, CPF $x x x x x x x$, denominado CONTRATADO, têm entre si justo e contratado o que segue:

\section{Objeto}

1.10 presente contrato tem como objeto o desenvolvimento, implantação e treinamento do <nome do sistema>, doravante denominado simplesmente "Sistema", por parte da CONTRATADA, para uso específico da CONTRATANTE, conforme proposta técnica no Anexo 1, parte integrante deste instrumento.

\section{Aspectos Técnicos}

2.1 O prazo para desenvolvimento do sistema obedecerá ao cronograma no Apêndice 1, parte integrante deste instrumento.

2.2 O desenvolvimento e acompanhamento do sistema dar-se-á conforme estabelecido no cronograma citado no item 2.1, abrangendo reuniões e avaliações dos usuários da CONTRATANTE para desenvolvimento do Sistema.

2.3 <deixar claro sobre o suporte ao sistema, se está incluso no contrato ou não>

2.4 <deixar claro sobre as condições para instalação e uso do sistema>

\section{Aspectos Financeiros}

3.1 Pelo objeto proposto, obriga a CONTRATANTE a pagar à CONTRATADA a

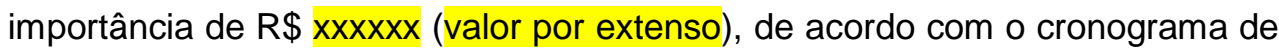
pagamentos no Apêndice 2, parte integrante deste instrumento.

3.2 Os custos adicionais com visitas, transporte e estadia, desde que previamente autorizados, serão reembolsados da seguinte forma: XXXXXXXXXXX. 
3.3 Não será cobrado da CONTRATANTE qualquer custo adicional referente a correções e ajustes efetuados no Sistema, salvo se decorrentes de implementações adicionais específicas e devidamente aprovadas por escrito pela CONTRATANTE, como: acréscimos de relatórios, módulos ou configurações solicitadas pela CONTRATANTE à CONTRATADA.

3.4 Qualquer uma das partes poderá rescindir o presente instrumento, mediante prévia comunicação à outra parte, por escrito, com antecedência mínima de xx dias, nas seguintes condições: <especificar multa e condições de pagamento dos serviços até então executados e outras condições, como por exemplo, se a CONTRATADA poderá ficar ou não com o Sistema>.

\section{Aspectos Legais}

4.1 O Sistema possui garantia vitalícia de funcionamento nas versões e condições (ambiente hardware/software) originalmente implantadas.

4.2 A responsabilidade da CONTRATADA restringir-se-á ao Sistema, não respondendo por problemas relacionados ao ambiente, como redes, sistemas operacionais e hardware.

4.3 A CONTRATADA não se responsabiliza por danos decorrentes do mau uso do sistema, alimentação errônea e/ou falta de conferência de dados gerados, bem como a inexistência de cópias de segurança dos dados atualizados.

4.4 O presente instrumento não dará azo à constituição de qualquer vínculo empregatício ou responsabilidade por parte da CONTRATANTE com relação aos empregados da CONTRATADA a seu serviço, responsabilizando-se esta última pelos direitos e deveres sociais e trabalhistas de seus empregados.

4.5 Pelo presente instrumento o CONTRATANTE receberá os programas fontes após sua regular quitação, responsabilizando-se pelo uso e guarda, nos termos da Lei 9.609/98.

\section{Controle de Alterações}

5.1 <descrever os procedimentos de mudanças e a limitação para alteração dos requisitos.>

E por estarem assim justas e contratadas, as partes assinam o presente contrato em $\mathrm{xx}$ ( $\mathrm{nr}$ de vias por extenso) vias de igual teor e forma na presença das testemunhas, a seguir.

Cidade, dia de mês por extenso de ano. 
CONTRATANTE

CONTRATADA

Testemunhas:

1) Ass.

Nome:

RG:

$2^{\mathrm{a})}$ Ass.

Nome:

$R G$ :

ANEXO 1 - PROPOSTA TÉCNICA: XXXXXXXXX

APÊNDICE 1 - CRONOGRAMA

<inserir aqui o cronograma, a partir da WBS>

APÊNDICE 2 - CRONOGRAMA DE PAGAMENTOS 


\section{A4.4 - DOCUMENTO DE REQUISITOS}

ID documento: Data: / / Versão :

Responsável pelo documento:

ID Projeto:

HISTÓRICO DE REVISÕES

\begin{tabular}{|l|l|l|l|c|}
\hline $\begin{array}{c}\text { Data de } \\
\text { criação/ } \\
\text { atualização }\end{array}$ & $\begin{array}{c}\text { Descrição da(s) Mudança(s) } \\
\text { Ocorrida(s) }\end{array}$ & Autor & $\begin{array}{c}\text { Versão do } \\
\text { Documento }\end{array}$ & $\begin{array}{c}\text { ID. } \\
\text { Solicitação } \\
\text { de Mudança }\end{array}$ \\
\hline & & & & \\
\hline & & & & \\
\hline & & & & \\
\hline & & & & \\
\hline & & & & \\
\hline
\end{tabular}

\section{1 - INTRODUÇÃO}

\subsection{Objetivo}

Este documento tem por objetivo apresentar os requisitos que o sistema deve atender em diferentes níveis de detalhamento. Dessa forma, serve como acordo entre as partes envolvidas - cliente e analista/desenvolvedor.

\subsection{Escopo}

- Identificar o(s) produto(s) de software a ser(em) produzido(s) pelo nome.

- Explicar o quê o(s) produto(s) de software fará(ão) e, se necessário, o quê não fará(ão).

- Descrever a aplicação do software a ser especificado, incluindo benefícios relevantes, objetivos e metas.

- Ser consistente com as especificações de mais alto nível (tal como a especificação de requisitos do sistema), se existirem.>

\subsection{Definições, Siglas e Abreviações}

<Fornecer as definições de todos os termos, acrônimos e abreviações necessárias para interpretar de modo apropriado a ERS. >

\subsection{Referências}

$<$

- Fornecer uma lista completa de todos os documentos referenciados na ERS.

- Identificar cada documento pelo título, número do relatório (se aplicável), data e organização que publicou.

- Especificar a(s) origem(s) das referências, ou seja, onde elou com quem podem ser obtidas.> 


\subsection{Visão Geral}

O Capítulo 2 fornece uma descrição geral do produto, tendo como público-alvo os clientes. Dessa forma, esse capítulo é uma síntese dos requisitos que o sistema deverá atender para auxiliar ao negócio do cliente. São descritos: a perspectiva e funções do produto, as características dos usuários e os limites, suposições e dependências que influenciem a eficácia e eficiência do sistema.

No Capítulo 3, os requisitos descritos no capítulo 2 são detalhados ao ponto de serem úteis para os analistas e programadores do sistema.

\section{2 - DESCRIÇÃO GERAL DO PRODUTO}

$<$ Tem por objetivo descrever fatores gerais do produto e seus requisitos, fornecendo um contexto para esses requisitos os quais são definidos em detalhes no capítulo 3 da ERS.>

\subsection{Perspectiva do Produto}

$<$ Deve ser descrito de maneira resumida, de forma textual, sem detalhamento (1/2 página, no máximo, pois trata-se de uma descrição geral), pois as interfaces mencionadas nessa seção serão detalhadas na seção 3.1 (Requisitos de Interface Externa). Segundo o padrão IEEE, se o produto a ser desenvolvido for parte de um sistema maior a ERS deverá identificar quais as interfaces existentes entre esse sistema e o produto a ser desenvolvido.

Exemplo 1:

O sistema funcionará em um PC AT atualmente disponível na Locadora Fulano de Tal. O sistema terá interface com leitores de códigos de barras para simplificar o processo de alugar e devolver uma fita, e com impressoras do tipo tal para emitir os recibos para os clientes e para a própria locadora. Todas as informações relativas aos clientes, tais como: $x, y, z$; e informações históricas das locações serão armazenadas.

O texto pode incluir (não obrigatoriamente, pois depende do caso) informações sobre:

-Interfaces do Sistema: Normalmente um software faz parte de um sistema (sistema administrativo) maior existente dentro de uma empresa. A ERS deve listar as interfaces do sistema para com o produto, identificando as funcionalidades do software que irão realizar essas interfaces.

-Interfaces do Usuário: Características lógicas das interfaces entre o produto e seus usuários, como por exemplos: formatos de telas, aspectos de otimização da interface com o usuário do sistema (por ex, mensagens curtas ou longas, definir que um usuário pode utilizar o sistema após $x$ horas de treinamento), padrão de relatórios ou menus de consulta, acesso por níveis de usuários, mensagens, dentre outros.

-Interfaces de Hardware: se o produto interage com dispositivos de hardware, estes devem ser especificados (por exemplo, impressoras, scanners, relógios de ponto, catracas eletrônicas ou outros dispositivos eletrônicos com o qual o produto irá comunicar-se).

-Interfaces de Software: especificar o uso de outros softwares necessários (banco de dados, sistemas operacionais, software para capturar imagem, ou outros softwares aplicativos de mesma natureza).

-Interfaces de Comunicação: especificar tipos de comunicação necessários para o funcionamento do produto. Por exemplo, o software que é responsável pelo gerenciamento da catraca precisa comunicar-se com as mesmas por meio de um par-trançado. Como, então, deverá ser implementada essa comunicação? Isso deve ser descrito aqui sem detalhes.

-Limites de Memória: especificar os limites mínimos de memória primária e secundária.

-Operações: rotinas de inicialização (definir níveis de acesso; processamento; backup e restauração do sistema). 
-Requisitos para adaptação de situação: especificar situações em que o software deve ser adaptado antes da instalação. Por exemplo: em um sistema que necessite a conexão com a internet. Se no momento da instalação o computador não estiver conectado, o sistema identifica e grava os dados em um arquivo temporário e, quando restabelecer a conexão, os dados são recuperados deste arquivo temporário e a instalação pode concluída. Outro exemplo refere-se às adaptações necessárias para a instalação do software em outra versão do S.O. $>$

\subsection{Funções do Produto}

< Nessa seção deve ser fornecido um resumo das principais funções que o software deve realizar. Além disso, pode ser inserido algum diagrama, tal como Diagrama de Casos de Uso, para mostrar a fronteira do sistema e para fornecer uma visão geral do comportamento do sistema (para que ele é usado e por quem).

Por exemplo:

O Sistema de Locadora de Vídeo deve manter os dados dos clientes, dos DVD's comprados de fornecedores registrados e das locações e devoluções realizadas por cada um dos clientes. Deve, também, permitir que o cliente faça a reserva de filmes, deve manter dados das contas a pagar e a receber e permitir a emissão do cupom fiscal.

Diagrama de Casos de Uso

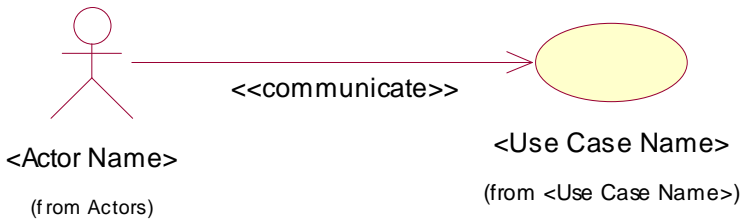

\subsection{Características do Usuário \\ $<$}

Descrever o nível educacional dos usuários do sistema, bem como a sua experiência e o conhecimento sobre informática para que seja diagnosticada a necessidade de treinamento específico. Deve fornecer as razões pelas quais certos requisitos são especificados.>

\subsection{Limites, Suposições e Dependências}

$<$

Descrever itens que limitem as opções do desenvolvedor, tais como: Normas regulamentadoras, Limitações do hardware, considerações de segurança, requisitos de confiabilidade, Linguagem de programação.

Com relação às suposições e dependências, descrever qualquer fator que afeta os requisitos expressos na ERS. Por exemplo: A não aquisição do ponto eletrônico fará com que o sistema não tenha o seu total desempenho, pois a entrada de dados será feita manualmente, inserindo somente as exceções do ponto diário, ou seja, a falta dos funcionários.>

\subsection{Requisitos Adiados}

$<$

Identificar os requisitos, que foram levantados, mas que por alguma razão serão adiados para versões futuras do sistema.>

\section{3 - REQUISITOS ESPECÍFICOS}

<Essa seção deve conter todos os requisitos do software com um nível de detalhamento suficiente para possibilitar aos projetistas/desenvolvedores projetarem um sistema que atenda a esses requisitos.>

\subsection{Requisitos de Interface Externa}

<Detalhar o que foi descrito de forma sucinta na seção 2.3 (perspectiva do produto) com relação às interfaces externas, sem repetir informação. Esses requisitos referem-se aos requisitos não funcionais > 


\subsubsection{Interfaces do Sistema}

<caso o software em questão tenha que ser integrado com algum já existente>

\subsubsection{Interfaces do Usuário}

$<$ Deve ser descrito como o usuário vai interagir com o sistema, sem mostrar graficamente as telas, pois existe uma seção específica para isso. Descrever como será o formato padrão das telas e relatórios, quais os procedimentos a serem adotados em caso de erros, para que servem e como serão apresentadas as mensagens do sistema para o usuário (por exemplo, não serão exibidas mensagens em caixas de diálogo, mas através de um label em um determinado local da tela. As mensagens exibidas em caixas de diálogos serão somente para erros do sistema que só podem ser resolvidas pelo desenvolvedor).>

\subsubsection{Interfaces de Software}

<descrever os detalhes dos softwares necessários para o desenvolvimento e execução do software em questão. Isso inclui nome, mnemônico, especificação numérica, versão e fonte>

\subsubsection{Interfaces de Hardware}

<Com relação à interface de hardware, por exemplo, a ERS deverá detalhar como será realizada a interface em questão. Se for um relógio de ponto, por exemplo, como será o layout do arquivo que será emitido pelo equipamento ao sistema. Por exemplo: O equipamento para a leitura do ponto dos funcionários será da marca $X X X X$, modelo $Y Y Y Y$, etc. O relógio ponto gera um arquivo com a extensão txt, o qual possui a seguinte estrutura em cada uma das linhas: CÓDIGO_FUNCIONÁRIO: 4 caracteres, DATA: 10 caracteres, HORÁRIO: 5 caracteres EX.:

\begin{tabular}{|l|l|l|}
\hline CODFUN & DATA & HORÁRIO \\
\hline 43219 & $05 / 09 / 2003$ & $7: 30$ \\
\hline 43219 & $05 / 09 / 2003$ & $11: 30$ \\
\hline & $\ldots$ & \\
\hline
\end{tabular}

$>$

\subsubsection{Interfaces de Comunicação}

<Especificar os tipos de comunicação utilizados para integração com outros periféricos e tecnologias. Ex: par-trançado, protocolos de comunicação, etc>

\subsection{Requisitos de Desempenho}

<Especificar os requisitos numéricos estáticos e dinâmicos sobre o software ou uma interação humana com o software. Os requisitos numéricos estáticos podem incluir: o número de terminais suportado, o número de usuários simultâneos suportado, a quantidade e o tipo de informação a ser manipulado. Os requisitos numéricos dinâmicos podem incluir, por exemplo, o número de transações e tarefas e a quantidade de dados a ser processado dentro de determinado período de tempo e condições de pico de sobrecarga. Todos esses requisitos devem ser declarados em termos mensuráveis. Por ex: "95 \% das transações devem ser processadas em menos de 1 segundo".>

\subsection{Outros Requisitos}

$<$ Descrever aqui restrições do projeto que podem ser impostas por conformidade a padrões, limitações de hardware, e por outros requisitos não funcionais: manutenibilidade, portabilidade, confiabilidade, requisitos éticos, requisitos de entrega, etc.

$>$

\subsection{Funções}

Serão descritas todas as funções do produto. Esses requisitos funcionais podem ser representados por meio de texto estruturado em linguagem natural, mas também podem ser representados por meio de casos de uso, dentre outras maneiras.

A seguir, serão apresentadas duas alternativas para documentar os requisitos.

Alternativa 1) As funções são descritas por meio de um texto estruturado em linguagem natural e para cada função são descritos os itens de entrada necessários (dados/informação) e os itens de saída gerados, além das regras de negócio que irão influenciar as funções.

Essas funções podem ser classificadas em: 
- Funções Básicas: referem-se às operações CRUD (create, read, update, delete) necessárias para a execução das funções fundamentais. Esse conjunto de operações pode ser denominado "Gerenciar dados de ....".

- Funções Fundamentais: referem-se às transações de negócio (movimentações), que realmente agregam valor ao negócio;

- Funções de Saída: referem-se às funções que geram informações de saída relevantes para atender às necessidades do cliente (por exemplo, relatórios com cruzamento de informações). Nesse caso, devem ser descritos não só os itens de entrada (filtros), mas também os itens de saída (informações) pertinentes.

\section{Observações:}

1) é importante que cada função tenha um identificador, a fim de facilitar a rastreabilidade desse requisito. Sugere-se que seja utilizado RF (requisito funcional) seguido de um underline, uma letra indicando se é função básica, fundamental ou saída externa $(B, F$, S) e um número sequencial. Ex: RF_B1. e RF_B2. para funções básicas, RF_F1., RF_F2. para funções fundamentais e RF_S1., RF_-S2. para funções de saída externa).

2) não devem ser citados aqui os campos das possíveis tabelas do sistema, tais como, códigos sequenciais criados para facilitar na implementação. Aqui deverão ser citados apenas os itens de informação relacionados às funções do sistema.

3) As funções de gerenciamento do usuário, backup e restauração do sistema não serão citadas aqui, uma vez que já foram descritas no item 2.3 - Perspectiva do Produto.

EXEMPLO: Em um sistema de locadora de vídeo:

FUNÇÕES BÁSICAS

RF_B1. Gerenciar cliente: o usuário pode inserir, consultar, alterar e deletar os dados pessoais do cliente (nome, endereço, cep, cidade, estado, CPF, data de nascimento, e-mail e fone para contato).

RF_B2. Gerenciar vídeo: o usuário pode inserir, consultar, alterar e deletar os dados relacionados aos vídeos (código do vídeo, título, gênero, quantidade, preço de locação ).

FUNÇÕES FUNDAMENTAIS

RF_F1. Efetuar Reserva: o cliente pode fazer a reserva de determinado vídeo. Para isso são necessários os seguintes itens de informação: dados pessoais do cliente, dados do vídeo, data e hora da reserva. Caso o cliente ainda não esteja cadastrado no sistema, é necessário realizar um cadastro mesmo que somente com os itens obrigatórios: nome, CPF e fone.

RF_F2. Efetuar Locação: o cliente pode locar um vídeo, caso este não esteja reservado. São necessários os itens de informação: dados pessoais do cliente, dados do vídeo, preço da locação, data da locação e data para devolução (o cliente pode devolver o vídeo sem adicionais ao preço da locação em até 3 dias, após a data da locação). O registro da locação deve ser vinculado à uma conta a receber.

RF_F3. Efetuar Devolução: no ato da devolução são necessários os itens de informação: dados do cliente, dados do vídeo e data de devolução. Caso a data de devolução tenha ultrapassado os 3 dias após a locação, deve ser calculada uma multa de $10 \%$ sobre o valor da locação por dia de atraso.

RF_F4. Dar Baixa das contas a receber: o cliente pode optar por efetuar o pagamento no ato da locação ou da devolução. Sendo assim, deve ser registrada a data do pagamento e o valor pago, e deve ser gerado um cupom fiscal contendo as informações pertinentes à locação e ao pagamento.

RF_F5. Comprar vídeos por parte da locadora (incluindo contas a pagar): ....

RF_F6. Dar Baixa das contas a pagar: ....

FUNÇÕES DE SAÍDA

RF_S1. Listagem dos Clientes que mais locaram em determinado período: o usuário entra com o período e como saída tem-se uma lista contendo o nome, telefone de contato e e-mail de todos os clientes que mais locaram.

RF_S2. Balancete do mês:...

RF_S3. Fila de espera referente à reserva: ... 


\section{RF_S4. Listagem de Clientes inadimplentes: ...}

Para complementar o entendimento dos requisitos, sugere-se elaborar o Modelo Conceitual, ou também denominado Modelo de Domínio, um modelo que pode ser utilizado como preliminar para a elaboração futura do modelo de dados do sistema. Esse tem por objetivo a visualização dos conceitos do domínio. Para a elaboração do modelo conceitual utiliza-se da representação do diagrama de classes da UML, entretanto, são colocados somente o nome do conceito, os seus atributos mais relevantes e as multiplicidades. É importante ressaltar que um conceito, não necessariamente, será uma classe de implementação.

Alternativa 2) Elaborar uma Lista de Funcionalidades na qual serão descritas todas as funções do sistema (requisitos funcionais), detalhadamente, inclusive as operações CRUD (que não serão consideradas $C D U$ ).

$\mathrm{Na}$ coluna Referência deve ser colocado um identificador corresponde ao requisito funcional. Exemplo: RF_1, RF_2. A coluna Categoria deve ser preenchida com Evidente (a função deve ser executada, e o usuário deve estar ciente da execução. Ex.: Registrar Venda, Processar Pagamento) ou Oculta (deve ser executada, mas de modo transparente para o usuário. Ex.: Dar baixa na qtde de um produto no estoque)

Exemplo:

\begin{tabular}{|l|l|l|}
\hline Referência & Funções & Categoria \\
\hline$R F_{-} B 1$ & Gerenciar cliente & Evidente \\
\hline$R F_{-} F 1$ & Efetuar Reserva & Evidente \\
\hline$R F_{-} F 1.1$ & Verificar cadastro do cliente & Oculta \\
\hline$R F_{-} F 1.2$ & Registrar reserva & Oculta \\
\hline
\end{tabular}

A seguir, realizar as Especificações dos Casos de Uso Essenciais (sem definir considerações tecnológicas). Cada caso de uso (CDU) pode ser especificado usando um template (tal como o definido no RUP e mostrado, a seguir).

\begin{tabular}{|l|l|}
\hline Seção do CDU & Comentário \\
\hline Nome do Caso de Uso & Começar com um verbo. \\
\hline Breve Descrição & Descrição em alto nível do CDU. \\
\hline Fluxo Básico & $\begin{array}{l}\text { Um caminho típico, incondicional e otimista do cenário de } \\
\text { sucesso. }\end{array}$ \\
\hline Fluxos Alternativos & Cenários Alternativos de sucesso ou fracasso. \\
\hline Requisitos Especiais & Requisitos não funcionais relacionados. \\
\hline Pré-Condições & O que precisa ser verdade antes da realização do CDU. \\
\hline Pós-Condições & $\begin{array}{l}\text { O que precisa ser verdade quando da finalização bem } \\
\text { sucedida. }\end{array}$ \\
\hline Relacionamentos & $\begin{array}{l}\text { Os relacionamentos que envolvem os CDUs, tais como include } \\
\text { e extend. }\end{array}$ \\
\hline
\end{tabular}

Ainda, para os CDUs que possuem atividades concorrentes, pode-se elaborar um Diagrama de Atividades.

Para complementar o entendimento dos requisitos, sugere-se elaborar o Modelo Conceitual, ou também denominado Modelo de Domínio, um modelo que pode ser utilizado como preliminar para a elaboração futura do modelo de dados do sistema. Esse tem por objetivo a visualização dos conceitos do domínio. Para a elaboração do modelo conceitual utiliza-se da representação do diagrama de classes da UML, entretanto, são colocados somente o nome do conceito, os seus atributos mais relevantes e as multiplicidades. É importante ressaltar que um conceito, não necessariamente, será uma classe de implementação.

$>$ 
VOLATILIDADE DOS REQUISITOS

\begin{tabular}{|c|c|c|c|}
\hline RQ & Alta & Média & Baixa \\
\hline & $\square$ & $\square$ & $\square$ \\
\hline & $\square$ & $\square$ & $\square$ \\
\hline & $\square$ & $\square$ & $\square$ \\
\hline & $\square$ & $\square$ & $\square$ \\
\hline
\end{tabular}

MATRIZ DE RASTREABILIDADE - REQUISITOS CLIENTE X PRODUTO

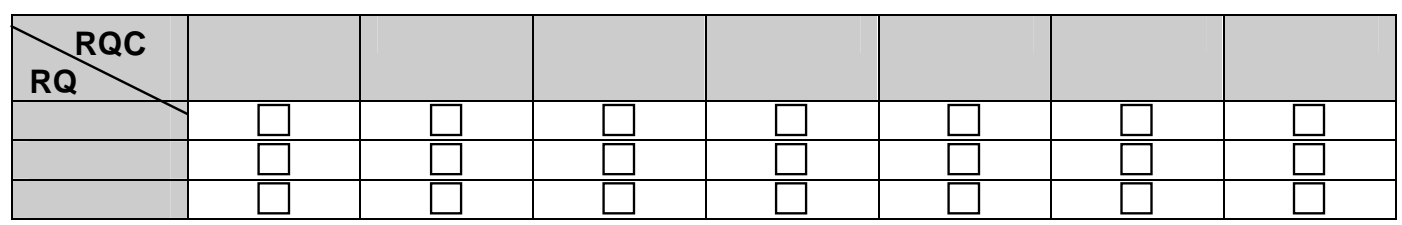

MATRIZ DE RASTREABILIDADE - REQUISITOS FUNCIONAIS E NÃO FUNCIONAIS DO PRODUTO

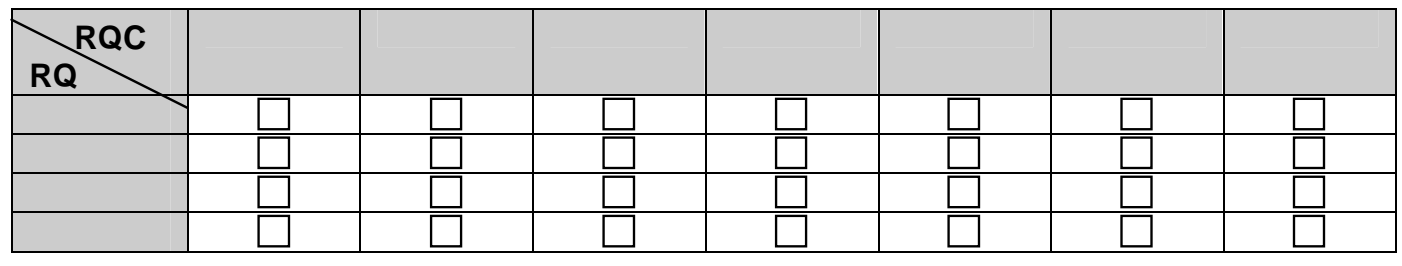

MATRIZ DE RASTREABILIDADE - REQUISITOS DO PRODUTO X COMPONENTES

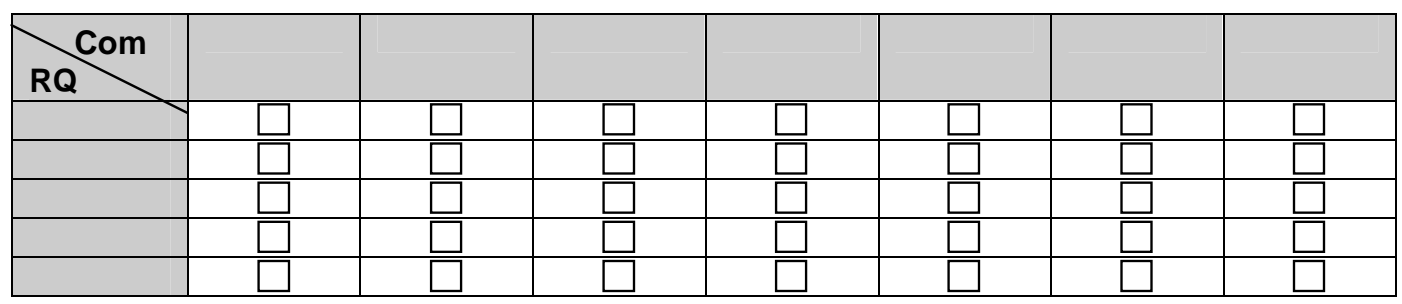

APÊNDICE 1 - LISTA DE REQUISITOS DO CLIENTE

$<$ Aqui são descritos os requisitos do cliente, da forma como eles os expõe. Muitas vezes, um requisito de cliente transforma-se em $\mathrm{N}$ requisitos do sistema.

1. <requisito 1 do cliente>

2. <requisito 2 do cliente $>$

3. <requisito 3 do cliente>

4. ...

$>$

\section{APÊNDICE 2 - COMPONENTES EMPREGADOS}

$<$ Aqui são identificados os componentes utilizados no projeto, inclusive os já existentes em uma Biblioteca.

1. <componente 1>

2. <componente 2>

3. <componente 3>

4. ...

$>$

APÊNDICE 3 - PROTÓTIPOS

$<$ Aqui são inseridos os protótipos, caso tenham sido construídos para auxiliar no levantamento e análise dos requisitos> 


\section{A4.5 - DOCUMENTO DE ACEITE}
ID documento:
Data: / /
Versão :

Responsável pelo documento:

ID Projeto:

\begin{tabular}{|c|c|c|c|c|c|c|c|}
\hline Nome & $\begin{array}{c}\text { Cargo / } \\
\text { Papel }\end{array}$ & Instituição & Aprovação & Observações & Data & $\begin{array}{c}\text { Versão } \\
\text { Avaliada } \\
\end{array}$ & ID Comprovante assinado \\
\hline & & & $\begin{array}{l}\text { Aprovado [ ] } \\
\text { Reprovado [ ] } \\
\text { Aprovado com } \\
\text { ressalvas [ ]. } \\
\text { Nesse caso, data } \\
\text { limite: } \\
\mathrm{dd} / \mathrm{mm} / \text { aaaa }\end{array}$ & & $\mathrm{dd} / \mathrm{mm} /$ aaaa & & \\
\hline
\end{tabular}




\section{A4.6 - MANUAL DO USUÁRIO}

ID documento:

Data: / /

Versão :

Responsável pelo documento:

\section{HISTÓRICO DE REVISÕES}

\begin{tabular}{|l|l|l|l|c|}
\hline $\begin{array}{c}\text { Data de } \\
\text { criação/ } \\
\text { atualização }\end{array}$ & $\begin{array}{c}\text { Descrição da(s) Mudança(s) } \\
\text { Ocorrida(s) }\end{array}$ & Autor & $\begin{array}{c}\text { Versão do } \\
\text { Documento }\end{array}$ & $\begin{array}{c}\text { ID. } \\
\text { Solicitação } \\
\text { de } \\
\text { Mudança }\end{array}$ \\
\hline & & & & \\
\hline & & & & \\
\hline & & & & \\
\hline & & & & \\
\hline & & & & \\
\hline
\end{tabular}

<Essa estrutura de Manual de Usuário segue a sugestão utilizada na FIPP Faculdade de Informática de Presidente Prudente/UNOESTE pelos alunos que desenvolvem sistemas durante o estágio supervisionado.>

\section{Introdução}

<descrever o objetivo do manual do usuário>

\section{Descrição do Produto}

<aqui devem ser inseridas as funções e perspectivas do produto: itens 2.1 e 2.2 do Documento de Requisitos>

\section{Perspectiva do Produto}

\section{Funções do Produto}

\section{Procedimentos}

$<$ Sugere-se que sejam inseridas as figuras mostrando os passos de cada um dos procedimentos, a seguir.>

Instalação do Produto

Configuração do Produto

Inicialização do Produto

Encerramento do Produto 


\section{Como preencher campos das telas do produto}

< Sugere-se que sejam inseridas as figuras mostrando as telas que são acionadas por cada opção selecionada do sistema junto à descrição de cada um dos campos da tela que necessitam de uma explicação para ser melhor compreendido.>

\section{Rotinas de Backup e Restauração}

6. Mensagens de Advertência e Erro < Para cada mensagem mostre o significado e a solução, caso seja uma mensagem de erro>

Mensagem:

Significado:

Solução:

Mensagem:

Significado:

Solução: 


\section{A4.7 - MODELO DE NEGÓCIO}

ID do documento:

Data documento: / /

Responsável pelo documento:

\section{ID Projeto:}

\section{HISTÓRICO DE REVISÕES}

\begin{tabular}{|c|c|c|c|c|}
\hline $\begin{array}{c}\text { Data de } \\
\text { criação/ } \\
\text { atualização }\end{array}$ & $\begin{array}{c}\text { Descrição da(s) Mudança(s) } \\
\text { Ocorrida(s) }\end{array}$ & Autor & $\begin{array}{c}\text { Versão do } \\
\text { Documento }\end{array}$ & $\begin{array}{c}\text { ID. } \\
\text { Solicitação } \\
\text { de } \\
\text { Mudança }\end{array}$ \\
\hline & & & & \\
\hline & & & & \\
\hline & & & & \\
\hline
\end{tabular}

\section{Vocabulário do Negócio}

< Nessa seção devem ser descritos os principais termos pertinentes ao negócio, a fim de esclarecer a terminologia utilizada pelo cliente.>

\begin{tabular}{|l|l|l|}
\hline Termo & Descrição & Sinônimo \\
\hline & & \\
\hline & & \\
\hline & & \\
\hline & & \\
\hline
\end{tabular}

\section{Casos de Uso de Negócio}

< Um caso de uso de negócio é uma seqüência de ações realizada em um negócio que produz um resultado de valor observável para um ator do contexto do negócio.

Os processos de um negócio são definidos como vários casos de uso de negócio diferentes, cada um representa um fluxo de trabalho específico no negócio. Uma coleção de casos de uso de negócio fornece uma visão geral do negócio muito útil para informar aos funcionários sobre as diferentes partes do negócio que estão sendo realizadas e os resultados esperados. Um processo de negócio gera valor para o negócio ou minimiza os custos para o negócio. A figura 1 mostra um exemplo de caso de uso de negócio.

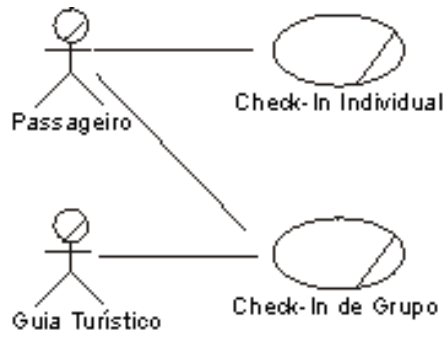

Figura 1 - Caso de uso de negócio relacionado ao Check-In no Aeroporto Fonte: <http://www.wthreex.com/rup/> 
Em uma modelagem de negócios controlada por caso de uso são desenvolvidas duas visões do negócio:

- visão externa do negócio: o caso de uso de negócio define "o quê" é essencial realizar para que o negócio forneça os resultados desejados ao ator. Define, também, qual interação o negócio deve ter com os atores quando é executado.

- visão interna do negócio: a realização de casos de uso de negócio define como o trabalho deve ser organizado e realizado para alcançar os resultados desejados. Uma realização abrange os trabalhadores de negócios, as entidades de negócios envolvidas na execução de um caso de uso de negócio e os relacionamentos entre eles.

Diagramas de atividades da UML e diagramas de workflow podem ser utilizados para visualizar a descrição do processo de negócios, ou seja, as atividades do negócio, o fluxo de informação entre elas e a origem e o destino das informações.

Um diagrama de atividades, por exemplo, pode ser usado para ilustrar o fluxo de trabalho de um caso de uso de negócio. Esse diagrama explora a ordem das atividades que são realizadas para alcançar as metas do negócio. Dentre essas atividades pode-se ter atividades manuais e/ou automatizadas. A figura 2 apresenta um diagrama de atividades relacionado ao caso de uso de negócio "Check-In Individual" do modelo de casos de uso de negócio Check-In no Aeroporto (figura 1).

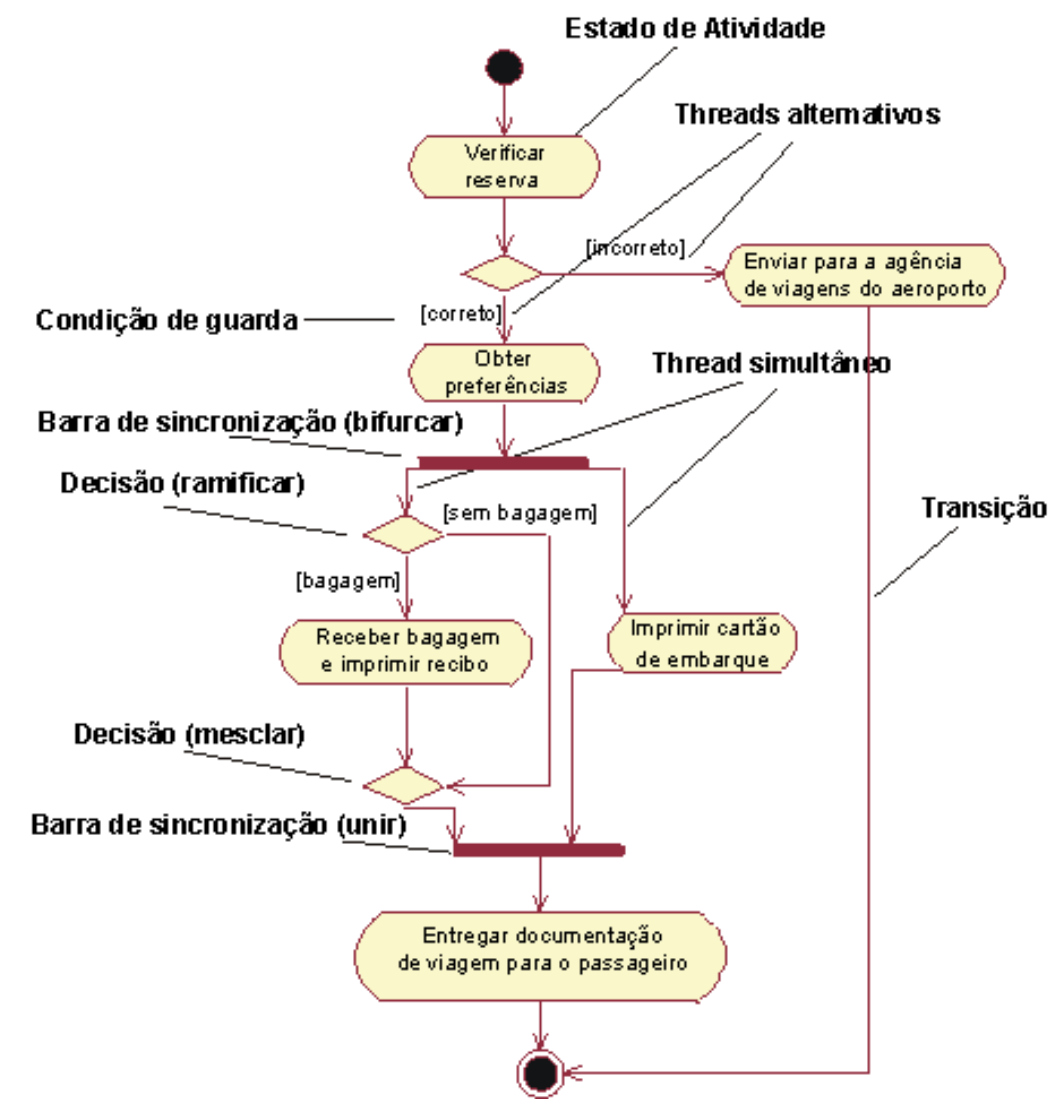

Figura 2 - Diagrama de atividades do caso de uso de negócio "Check-In Individual” Fonte: <http://www.wthreex.com/rup/> 
A figura 3 ilustra o fluxo de trabalho de um caso de uso de negócio que representa um processo de vendas geral. Nesse exemplo, as raias representam departamentos na organização.

Referência: RUP - Rational Unified Process. Modelo integrado à ferramenta CASE Rational Software.

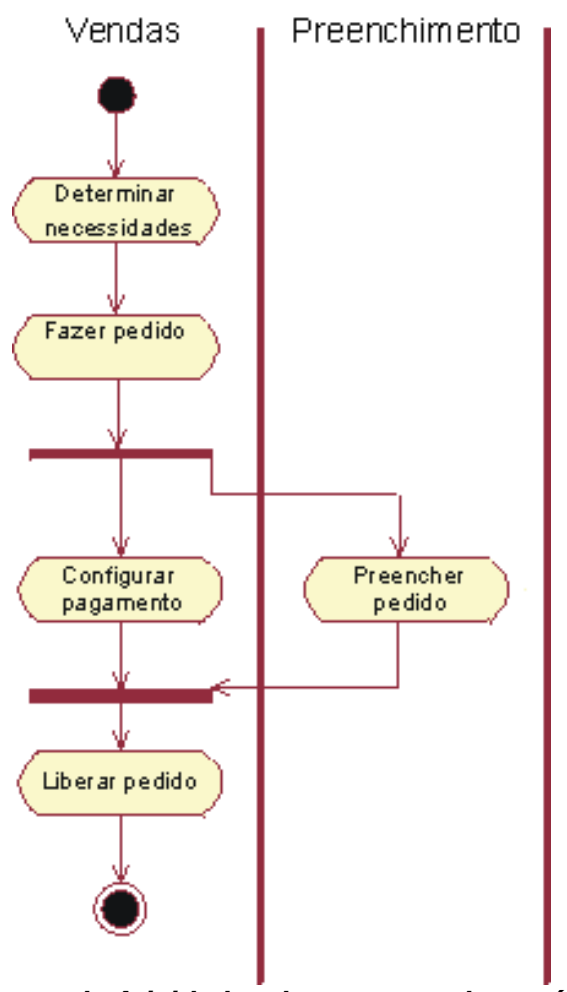

Figura 3 - Digrama de Atividades do processo de negócio de vendas.

Fonte: <http://www.wthreex.com/rup/>

$>$

\section{Regras do Negócio}

< Regras de negócio (também chamadas de regras de domínio) descrevem tipicamente requisitos ou políticas que transcendem um projeto de software - elas são necessárias no domínio ou no negócio e muitas aplicações podem precisar respeitálas. Um exemplo são as leis sobre impostos governamentais. Os detalhes das regras de domínio podem ser registrados na especificação dos requisitos, mas como elas são usualmente mais duradouras e aplicáveis do que para um projeto de software, colocálas em um artefato central de regras de negócio (compartilhado por todos analistas da empresa) leva ao melhor reúso do esforço de análise.

Exemplo:

\begin{tabular}{|l|l|l|l|}
\hline Id Regra & Regra & Mutabilidade & Fonte \\
\hline Regra 1 & $\begin{array}{l}\text { Regras de desconto para compradores. } \\
\text { Empregado: } 20 \% \\
\text { Cliente Preferencial: } 10 \% \\
\text { Idoso: } 15 \% \text { de }\end{array}$ & $\begin{array}{l}\text { Alta. Cada varejista } \\
\text { usa regras diferentes. }\end{array}$ & $\begin{array}{l}\text { Política de } \\
\text { Varejo. }\end{array}$ \\
\hline Regra 2 & $\begin{array}{l}\text { Restituições de pagamento a crédito } \\
\text { podem somente ser pagas como crédito à } \\
\text { conta de crédito do comprador, não em } \\
\text { dinheiro. }\end{array}$ & $\begin{array}{l}\text { Bolítica da } \\
\text { companhia de } \\
\text { autorização } \\
\text { de crédito. }\end{array}$ \\
\hline
\end{tabular}


Referência: LARMAN, C. Utilizando UML e Padrões: Uma introdução à análise e ao projeto orientados a objetos e ao desenvolvimento iterativo. Porto Alegre: Bookman, 2007.

Para marcar quais das regras de negócio devem ser atendidas pelo software a ser desenvolvido, sugere-se uma coluna na tabela anterior que define o(s) ID(s) do(s) projeto(s) os quais as regras de negócio são utilizadas.

No exemplo, a seguir, a regra 1 é utilizada tanto no projeto "AAA" quanto no projeto "BBB" daquele cliente.

\begin{tabular}{|l|lr|l|l|l|}
\hline Id & Regra & Mutabilidade & Fonte & ID Projeto \\
\hline Regra 1 & $\begin{array}{l}\text { Regras de desconto para } \\
\text { compradores. }\end{array}$ & $\begin{array}{l}\text { Alta. Cada } \\
\text { varejista usa } \\
\text { Empregado: } 20 \% \\
\text { Cliente Preferencial: } 10 \% \\
\text { ldoso: } 15 \%\end{array}$ & $\begin{array}{l}\text { Política de } \\
\text { Varejo. } \\
\text { diferentes. }\end{array}$ & & AAA \\
BBB & & \\
& & & \\
\hline
\end{tabular}

Uma regra de negócio define ou restringe um aspecto do negócio, a fim de afirmar a estrutura do negócio ou influenciar o comportamento do negócio.

As regras de negócio definem como o negócio funciona, podem abranger suas políticas, interesses, objetivos, compromissos éticos e sociais, obrigações contratuais, decisões estratégicas, leis e regulamentações, entre outros.

Regras de negócio, freqüentemente, focam questões de controle de acesso, podem, também, fazer parte dos cálculos nos negócios e focam as políticas da organização. Por exemplo:

- professores têm permissão de acessar e modificar as notas dos estudantes das disciplinas as quais ele é responsável somente;

- conversão de uma nota de percentual (como 91\%) para uma letra significativa no contexto (como "A");

- a política da universidade é reprovar no termo cursado caso o aluno reprove em mais de duas disciplinas no mesmo semestre.

- Professores assistentes só podem administrar grades de estudantes se autorizados pelos professores efetivos. 


\section{A4.8 - MODELO DE DESIGN}

ID documento:

Data: / /

Versão :

Responsável pelo documento:

\section{ID Projeto:}

ID do Documento de Requisitos:

ID da Arquitetura do Software:

\section{HISTÓRICO DE REVISÕES}

\begin{tabular}{|l|l|l|l|l|}
\hline $\begin{array}{c}\text { Data de } \\
\text { criação/ } \\
\text { atualização }\end{array}$ & $\begin{array}{c}\text { Descrição da(s) Mudança(s) } \\
\text { Ocorrida(s) }\end{array}$ & Autor & $\begin{array}{c}\text { Versão do } \\
\text { Documento }\end{array}$ & $\begin{array}{c}\text { ID. } \\
\text { Solicitação } \\
\text { de } \\
\text { Mudança }\end{array}$ \\
\hline & & & & \\
\hline & & & & \\
\hline & & & & \\
\hline
\end{tabular}

\section{Modelo Lógico do Sistema}

< Esse modelo tem como objetivo mostrar os elementos que irão compor o software e os relacionamentos entre eles. Pode ser representado por:

\section{Alternativa 1:}

- Diagrama de Classes: contém as classes do sistema que podem estar organizadas em pacotes e subsistemas. Um pacote deve ser usado em casos onde um conjunto de classes e/ou outros pacotes necessitam ser agrupados para modelar os objetivos da organização. O conteúdo do pacote pode ter visibilidade pública. Um subsistema deve ser usado em casos onde um conjunto de classes e/ou outros pacotes necessitam ser encapsulados dentro de um container e escondidos por meio de um conjunto de interfaces bem definido. Por convenção, nenhum conteúdo dos subsistemas é visível, exceto as interfaces. Isso permite facilidade na substituição e oferece maior grau de encapsulamento em comparação aos pacotes.

- Diagrama de Interação para cada caso de uso, a fim de definir quem são os métodos das classes.

- Mapeamento OO-Relacional: como normalmente são usados bancos de dados relacionais, é necessário o mapeamento das classes para tabelas.

\section{Alternativa 2:}

- Diagrama Entidade-Relacionamento

- Diagrama de Estrutura Modular

$>$

\section{Modelo Físico de Dados}

< Representa todas as tabelas do banco de dados a serem criadas com a definição de seus respectivos campos.> 


\section{A4.9 - PEDIDO DE COMPRA}

ID documento:

Data: / /

Versão :

Responsável pelo documento:

ID Projeto:

Status do Pedido de Compra

( ) Congelado - Data: / /

( ) Liberado - Data: / /

\section{HISTÓRICO DE REVISÕES}

\begin{tabular}{|c|c|c|c|c|}
\hline $\begin{array}{c}\text { Data de } \\
\text { criação/ } \\
\text { atualização }\end{array}$ & $\begin{array}{c}\text { Descrição da(s) Mudança(s) } \\
\text { Ocorrida(s) }\end{array}$ & Autor & $\begin{array}{c}\text { Versão do } \\
\text { Documento }\end{array}$ & $\begin{array}{c}\text { ID. } \\
\text { Solicitação } \\
\text { de } \\
\text { Mudança }\end{array}$ \\
\hline & & & & \\
\hline & & & & \\
\hline
\end{tabular}

\section{DESCRIÇÃO DOS REQUISITOS}

$<$ Aqui são descritos os requisitos validados esperados do(s) produto(s) a ser(em) adquirido(s).>

\section{DADOS DA SOLICITAÇÃO DE COMPRAS}

\begin{tabular}{|l|l|l|l|}
\hline Descrição & Quantidade & $\begin{array}{l}\text { Data limite } \\
\text { de entrega }\end{array}$ & Justificativa \\
\hline & & & \\
\hline & & & \\
\hline & & & \\
\hline & & & \\
\hline
\end{tabular}




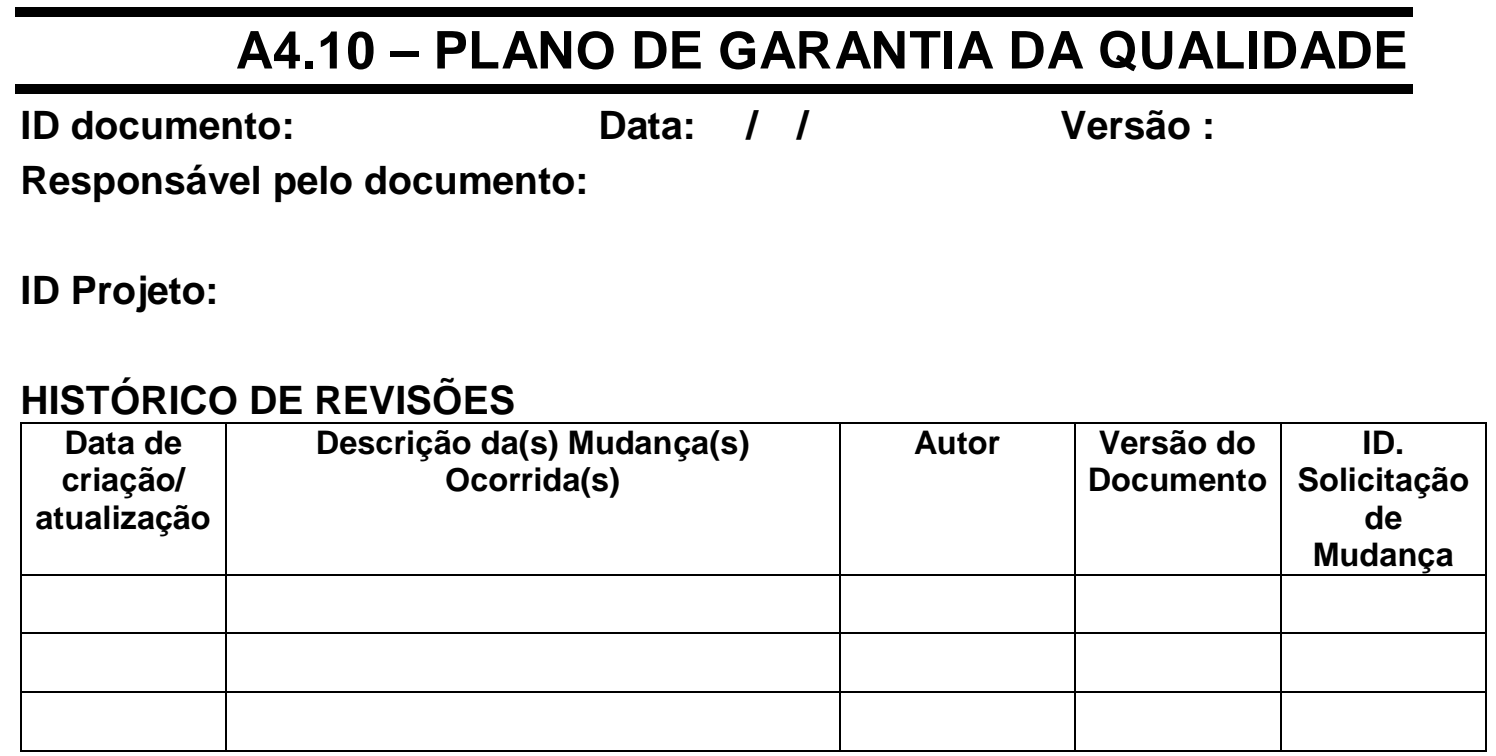

\section{Critérios de qualidade do projeto}

< Aqui são definidos os critérios de qualidade esperados do projeto desenvolvido. Esses critérios podem incluir, além dos critérios estabelecidos pela empresa desenvolvedora (tais como: prazo de entrega, conformidade com os templates definidos no processo), os critérios de aceitação do produto determinados pelo cliente durante a definição do escopo do projeto. Alguns exemplos de critérios: usabilidade, confiabilidade, manutenibilidade, portabilidade, eficiência>

\section{Métodos de garantia da qualidade do processo}

< Aqui são definidos os métodos que podem ser utilizados para garantia a qualidade do processo definido. No modelo de processo genérico, elaborado nesse trabalho de pesquisa de doutorado foi adotada a utilização da análise de conferência do processo definido durante a realização de um projeto (averiguar se o processo está realmente sendo seguido). Essa análise de conferência é realizada a cada término de fase, junto à revisão do milestone.>

\section{Medidas/Métricas}

\section{Objetivos de medição}

\section{Métricas de produto}

< Um exemplo de métrica de produto é: a atratividade da interface do software, ou seja, quão atrativa é a interface para o usuário? Pode ser utilizado um questionário para a obtenção dessa medida.>

\section{Métricas de processo}

< Um exemplo de métrica de processo é: a estabilidade da especificação funcional, ou seja, qual estável foi a especificação funcional durante o ciclo de desenvolvimento de software? Para obter essa medida é preciso contar o número de funções alteradas (adicionadas, modificados ou excluídas) durante o ciclo de desenvolvimento $(A)$ e então comparar com o número de funções descritas no Documento de Requisitos (B).

Medida $=1-A / B=>$ quanto mais próximo o resultado de 1 , mais estável a especificação é.> 


\section{Estratégia de coleta, armazenamento e análise das medidas}

<No caso do Modelo de Processo Genérico, por exemplo, a medida tamanho do software é coletada para estimar o esforço e custo que pode ser despendido no projeto. A estratégia adotada para coletar essa medida é utilizando inicialmente a experiência dos especialistas que trabalham na empresa e, com o passar do tempo, por meio de uma base de dados histórica onde serão registradas medidas como tamanho do software, tempo utilizado para desenvolvimento, recursos utilizados, capacidade do pessoal, entre outras medidas, para conseguir estimar o esforço e custo de um novo projeto, a partir de projetos similares já desenvolvidos pela empresa.>

\section{Referência Bibliográfica:}

SOMMERVILLE, I. Engenharia de Software. 8 ${ }^{\mathbf{a}}$ ed. São Paulo: Pearson Addison Wesley, 2007.

Segundo Sommerville (2007), Garantia de Qualidade é o processo de definição de como a qualidade de software pode ser atingida e como a organização de desenvolvimento sabe que o software possui o nível de qualidade necessário. $O$ processo de garantia de qualidade está, principalmente, relacionado à definição e seleção de padrões que devem ser aplicados ao processo de desenvolvimento de software ou ao produto de software.

Garantia da Qualidade de Software tem o objetivo de fornecer a garantia de que processos e produtos de trabalho estejam em conformidade com planos e provisões pré-definidos.

Humphrey (1989) sugere uma estrutura geral para um plano de qualidade. Essa estrutura inclui:

- Apresentação do produto. Descrição do produto, o mercado pretendido e as expectativas de qualidade para o produto.

- Plano de produto. As datas críticas de liberação e as responsabilidades para o produto junto com planos para serviço de distribuição e de produto.

- Descrições de processo. Os processos de desenvolvimento e de serviços devem ser usados para o desenvolvimento e gerenciamento de produto.

- Metas de qualidade. As metas e os planos de qualidade para o produto incluindo identificação e justificativa de atributos críticos de qualidade de produto.

- Riscos e gerenciamento de riscos. Os riscos principais que poderiam afetar a qualidade de produto e as ações para tratar esses riscos.

Em um plano de qualidade deve-se definir os atributos de qualidade mais importantes para o software em desenvolvimento. Exemplos: segurança, confiabilidade, adaptabilidade, portabilidade, facilidade de uso, facilidade de reuso, eficiência.

As revisões são métodos de validação de qualidade de um processo ou produto amplamente usados. Alguns tipos de revisão são apresentados, a seguir:

- Inspeções de programa: tem o objetivo de detectar erros detalhados nos requisitos, projeto ou código. Uma lista de verificação de possíveis erros deve guiar a revisão.

- Revisões de progresso: o objetivo é fornecer informações para a gerência sobre o progresso geral do projeto. Esta é uma revisão de processo e de produto e concentra-se em custos, planejamentos e prazos.

- Revisões de qualidade: o objetivo é conduzir uma análise técnica dos componentes de produto ou documentação para encontrar inconsistências 
entre especificação e projeto, código ou documentação de componente e assegurar que padrões de qualidade definidos foram seguidos.

A medição de software se dedica a derivar um valor numérico para algum atributo de um produto de software ou de um processo de software. Alguns exemplos de medidas de produto: tamanho do software, número de defeitos. Alguns exemplos de métricas de processo: o esforço médio e o tempo necessário para reparar os defeitos reportados, o esforço total em termos de pessoas-dia, custos de viagem e recursos computacionais para um processo específico. Comparando-se esses valores uns com os outros e aos padrões que se aplicam em uma organização, você pode ser capaz de tirar conclusões sobre a qualidade de software ou dos processos de software (SOMMERVILLE, 2007). Por ex: uma organização planeja introduzir uma nova ferramenta de teste de software. Antes de introduzir a ferramenta, pode-se registrar o número de defeitos do software descobertos em um dado tempo; depois da introdução da ferramenta, pode-se concluir que ela fornece apoio útil ao processo de validação de software.

Existem duas maneiras nas quais as medições de software podem ser usadas:

- Para fazer previsões gerais sobre um sistema. Ao medir as características dos componentes de sistema e, em seguida, agregar essas medições, pode-se derivar uma estimativa geral de algum atributo de sistema, como o número de defeitos no sistema.

- Para identificar componentes anômolos. As medições podem identificar componentes individuais cujas características desviem de alguma regra. Por ex: é possível medir os componentes para descobrir os com maior complexidade e, supondo que esses são provavelmente os que terão mais erros, concentra-se sobre esses componentes durante o processo de revisão.

Para escolher as medições a serem realizadas, pode-se utilizar a abordagem GQM (Goal-Question-Metric) de Basili (BASILI \& ROMBACH, 1988). Essa abordagem conta com a identificação de:

1. Objetivos: definem o que a organização está tentando obter. Exemplos: o aumento da produtividade de programadores, redução do tempo de desenvolvimento de produto, incremento da confiabilidade do produto.

2. Questões: São refinamentos dos objetivos. Normalmente, um objetivo terá um número de questões associadas que necessitam ser respondidas. Exemplo: Como o tempo necessário para finalizar os requisitos de produto pode ser reduzido?

3. Métricas: são as medições que necessitam ser coletadas para auxiliar a responder às questões e confirmar se os aprimoramentos de processos alcançaram o objetivo desejado. Exemplo de medição da questão anterior: o número de comunicações formais entre o cliente e o contratado para cada mudança de requisitos.

Segundo a ISO/IEC 9126 (Software Engineering - Product Quality) há três tipos de métricas:

- Métricas internas: podem ser aplicadas em um produto de software nãoexecutável durante os estágios de desenvolvimento, tais como: solicitação de proposta, definição de requisitos, especificação de design ou códigofonte. Essas métricas fornecem ao usuário a habilidade de medir a qualidade das entregas intermediárias e, portanto, prediz a qualidade do produto final. Assim, é possível identificar questões de qualidade e iniciar ações corretivas tão logo quanto possível no ciclo de desenvolvimento de software. 
- Métricas externas: podem ser usadas para medir a qualidade do produto de software por meio da medição do comportamento do sistema do qual faz parte. As métricas externas podem ser usadas durante os estágios de teste do processo de ciclo de vida e durante alguns estágios de operação. A medição é realizada quando o software está sendo executado no ambiente do sistema no qual se pretende operar.

- Métricas de qualidade em uso: medem se um produto atende às necessidades dos usuários para alcançar objetivos específicos com efetividade, produtividade, segurança e satisfação no contexto de uso especificado. Isso pode ser alcançado no ambiente real onde o sistema operará. 


\section{A4.11 - PLANO DE GESTÃO DE CONFIGURAÇÃO}

\section{Introdução}

\subsection{Objetivo}

Este documento define um plano de gerenciamento de configuração padrão da empresa. Este plano descreve os padrões e procedimentos que devem ser usados para o gerenciamento dos itens de configuração.

\subsection{Siglas, abreviações e definições}

Devem ser definidos todos os termos, acrônimos e abreviações necessárias para a interpretação apropriada do Plano de Gestão de Configuração.

\section{Definição dos itens de configuração}

Devem ser selecionados pela Equipe de Qualidade da empresa os artefatos a serem controlados como itens de configuração do sistema a ser desenvolvido.

Normalmente, o plano de projeto, documento de requisitos, programas (códigofonte), modelos de dados e casos de teste são mantidos como itens de configuração. Entretanto, a equipe de qualidade tem a liberdade de definir quais outros artefatos, desenvolvidos em meio ao processo de desenvolvimento de software, são importantes serem colocados sob a gerência de configuração para auxiliar em uma futura manutenção do sistema (seja ela corretiva, evolutiva ou preditiva).

A seguir, são listados os itens de configuração que poderão compor a baseline de um projeto, organizados pelas fases do processo de venda e desenvolvimento de software. Uma baseline serve como uma fotografia capaz de descrever um projeto em um determinado instante de sua execução.

\section{- Fase Prospecção}

- Roteiro de Prospecção

- Modelo de Negócio

- Plano de Ação
- $\quad$ Fase Concepção

$\begin{array}{ll}\circ & \text { Modelo de Negócio } \\ \circ & \text { Documento de Requisitos } \\ \circ & \text { Plano de Projeto } \\ \circ & \text { Projeto IHM } \\ \circ & \text { Relatório de Análise dos Requisitos } \\ \circ & \text { Arquitetura do Software } \\ \circ & \text { Cronograma } \\ \circ & \text { Relatório de Viabilidade do Projeto } \\ \circ & \text { Fluxo de Caixa } \\ \circ & \text { Plano de Ação }\end{array}$

- $\quad$ Fase Negociação

Proposta Técnica

Proposta Comercial

Relatório de Viabilidade do Projeto

Cronograma

Documento de Requisitos

Contrato

Plano de Projeto

Cronograma

Documento de formalização do

projeto

Pedido de Compra

Plano de Ação

Relatório de Acompanhamento de

Projeto
- $\quad$ Fase Elaboração

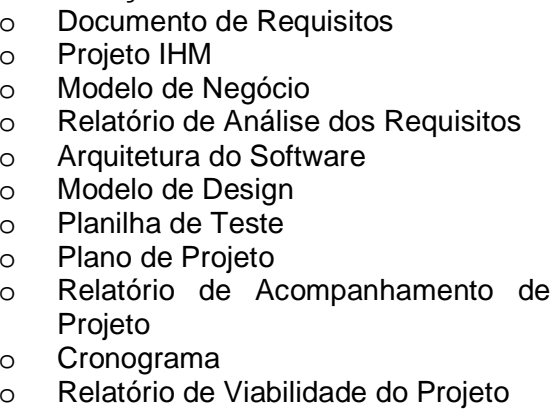


- $\quad$ Fase Construção

- Arquivo de Código

- Controle de Tarefas

- Planilha de Teste

- Relatório de Acompanhamento de Projeto

- Cronograma

- $\quad$ Fase Transição

$\begin{array}{ll}\circ & \text { Planilha de Teste } \\ \circ & \text { Versão do Produto } \\ \circ & \text { Documento de Aceite } \\ \circ & \text { Manual do Usuário } \\ \circ & \text { Relatório de Acompanhamento de Projeto } \\ \circ & \text { Cronograma }\end{array}$

\section{Papéis dos responsáveis pelos procedimentos de gestão de configuração}

A Equipe de Qualidade, responsável por definir o Plano de Gestão de Configuração para cada projeto a ser executado, pode ser composta pelos membros responsáveis em cada fase do processo de venda e desenvolvimento de software. Por exemplo:

- Equipe de Vendas: responsável pelo controle dos itens de configuração da fase Prospecção. Este papel consiste em criar novas versões de itens de configuração, criar novas baselines e colocar estes itens de configuração na ferramenta de controle de versões.

- Gerente de Projeto: responsável pela revisão, aprovação e autorização de mudança nos itens de configuração do processo de venda e desenvolvimento de software. Este papel consiste em analisar a relevância da mudança, controlar o planejamento, a implementação e os testes das mudanças nos itens de configuração, bem como a alteração de qualquer documento no projeto.

\section{Estratégia de identificação dos itens de configuração}

A estratégia de identificação dos itens de configuração é importante para manter a rastreabilidade de todas as informações pertinentes aos itens de configuração.

Deve ser atribuído um único nome para todos os artefatos sob controle de configuração. Este nome pode refletir o tipo do item, uma parte do sistema ao qual ele se aplica, o criador do item, etc.

E interessante que se evidencie a relação entre os itens de configuração para garantir que os artefatos relacionados possuam uma mesma raiz em seus nomes.

A identificação de um item de configuração pode ser realizada da seguinte maneira:

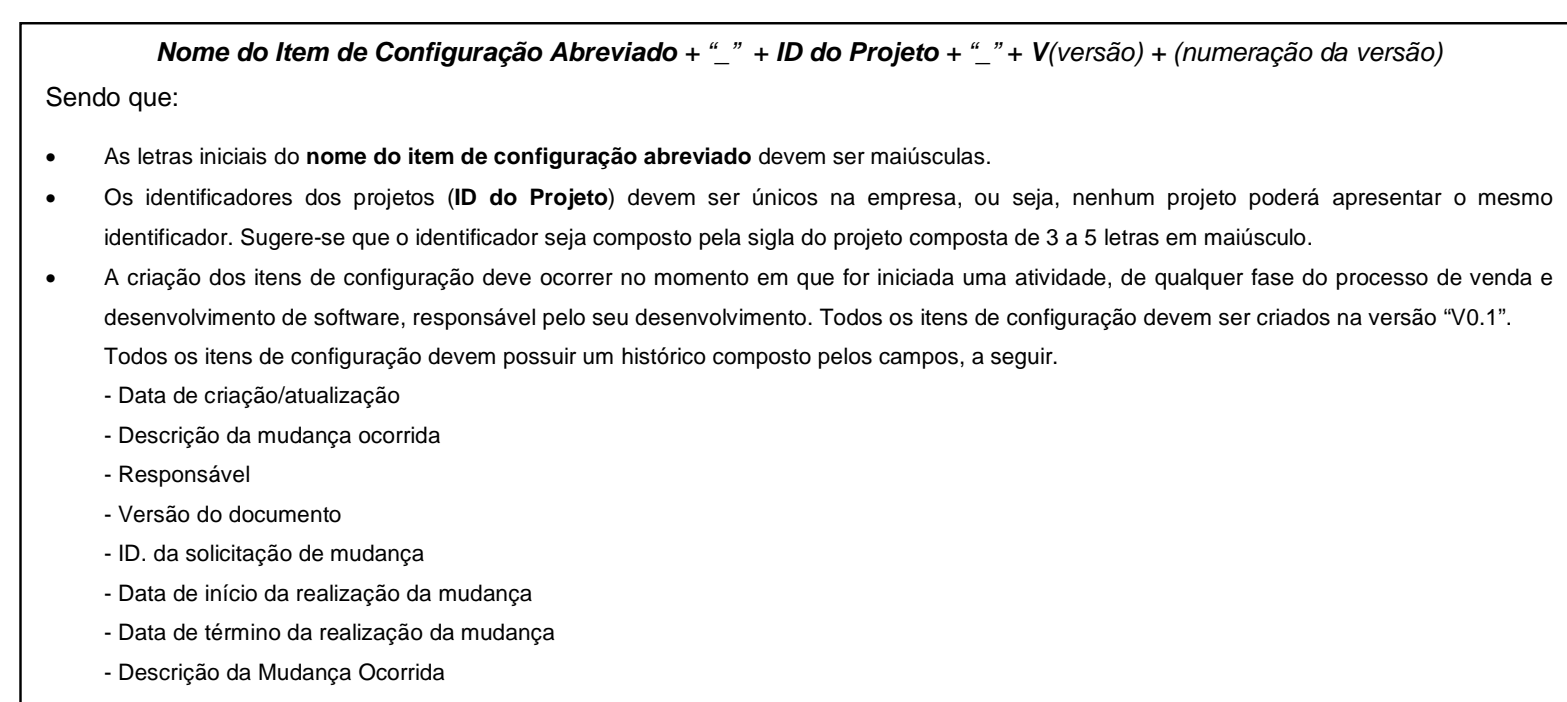




\section{Política de criação de baselines}

Baseline é uma linha de referência composta por todos os itens de configuração de um projeto. O objetivo de uma baseline é servir de referência para o gerenciamento de mudanças de um projeto. Ela deve ser como uma fotografia capaz de descrever um projeto em um determinado instante de sua execução.

A criação de baselines pode ser realizada de acordo com os marcos do projeto (milestones) ou de alguma outra forma definida pela gerência. A baseline é armazenada em um repositório de itens de configuração. E, a partir desse momento, só pode ser alterado por meio de uma solicitação de alteração formal para controle de mudança.

No modelo de processo genérico elaborado nessa pesquisa de doutorado, sugerese que quando é realizada tanto uma mudança simples em um ou mais itens de configuração quanto complexa deve ser criada uma nova baseline que incorpore os itens de configuração modificados, autorizada pelo Gerente de Projeto.

A fim de se ter um controle de baselines a cada término de fase do modelo de processo genérico, mesmo que não haja modificações, para cada uma das fases do modelo sugere-se a criação de baselines nos seguintes marcos:

- Fase Prospecção

- Milestone: Solicitação de uma proposta pelo cliente

- Fase Concepção

- Após a atividade do ciclo de desenvolvimento: Cp14. Conduzir revisão do milestone: Estudo de Viabilidade do Projeto

- Fase Negociação

- Após a atividade do ciclo de desenvolvimento: N09. Conduzir revisão do milestone: Contrato

- Fase Elaboração

- Após a atividade do ciclo de desenvolvimento: E08. Conduzir revisão do milestone: Arquitetura do Software

- Fase Construção

- Após a atividade do ciclo de desenvolvimento: Ct05. Conduzir revisão do milestone: Capacidade Operacional

- Fase Transição

- Após a atividade do ciclo de desenvolvimento: T06. Conduzir revisão do milestone: Entrega do Produto

A identificação da baseline pode ser constituída por:

“Baseline” + "_" + ID do Projeto + "_" + (numeração sequencial iniciada por 0001)

Sendo que:

- Os identificadores dos projetos (ID do Projeto) devem ser únicos na empresa, ou seja, nenhum projeto poderá apresentar o mesmo identificador. Sugere-se que o identificador seja composto pela sigla do projeto composta de 3 a 5 letras em maiúsculo.

\section{Políticas de gestão de configuração}

Nesta seção são definidas as políticas de gerenciamento de configuração que todos os membros da equipe do projeto devem adotar para o controle de mudanças e gerenciamento das versões.

A seguir, é mostrado um exemplo de políticas de gestão de configuração. Essas políticas estão inseridas no modelo de processo genérico. Caso queira modificá-las é preciso modificar as tarefas das atividades correspondentes no modelo.

Exemplo de políticas:

Os itens de configuração poderão ser modificados perante as seguintes situações:

- Enquanto o item de configuração não tiver uma primeira versão finalizada, determinada por um marco de projeto (milestone), ele será modificado sem alteração de versão. 
- Após o término de uma versão do item de configuração, ele só poderá ser alterado para outra versão mediante uma solicitação de mudança e análise da mudança para detectar a relevância e complexidade da mesma. Nesse caso, pode haver duas situações:

- Mudança simples: Deve ser realizada sem a necessidade de todo o processo de análise e planejamento da mudança. Devem ser realizados testes depois de finalizada a implementação da mudança. A realização de uma mudança simples deve ser registrada no próprio histórico do item de configuração que foi alterado.

- Mudança complexa: Caso uma mudança seja considerada complexa, devese então seguir todo o fluxo do processo de gestão de configuração: GCf04. Analisar/Autorizar e Planejar mudança(s), CGf05. Implementar mudança(s), CGf06. Validar e Liberar mudança(s). Uma mudança complexa também deve ser registrada no histórico do item de configuração.

- A identificação da solicitação de mudança pode ser constituída por:

"Mudança” + "_" + ID do Projeto + "_" + (numeração sequencial iniciada por 0001) Sendo que:

- Os identificadores dos projetos (ID do Projeto) devem ser únicos na empresa, ou seja, nenhum projeto poderá apresentar o mesmo identificador. Sugere-se que o identificador seja composto pela sigla do projeto composta de 3 a 5 letras em maiúsculo.

Quando realizada tanto uma mudança simples quanto uma complexa deve ser criada uma nova baseline que incorpore os itens de configuração modificados, de acordo com a política de criação de baselines descrita na seção 5.

Um release do sistema é uma versão distribuída ao cliente. Cada release deve incorporar novas funcionalidades ou ser planejado para uma plataforma diferente de hardware. Há, normalmente, muito mais versões de um sistema do que liberações. As versões são criadas no âmbito da organização, para desenvolvimentos ou testes internos, e não são previstas para serem liberadas para os clientes.

Um release do sistema não é somente um código executável do sistema. Ele pode incluir: arquivos de configuração que definem como o release pode ser configurado para instalações específicas; arquivo de dados necessário para a operação do sistema com sucesso; um programa de instalação usado para auxiliar a instalação do sistema no hardware-alvo; documentação eletrônica e em papel que descreve o sistema; empacotamento e publicidade associada projetados para release.

Para documentar um release, deve-se:

- registrar as versões específicas dos componentes de código-fonte usados para criar o código executável;

- manter cópias dos códigos-fonte, do código-executável, de todos os arquivos de dados e de configuração;

- registrar as versões do sistema operacional, as bibliotecas, os compiladores e outras ferramentas usadas para construir o software.

\section{Ferramentas utilizadas}

< aqui são descritas as ferramentas utilizadas para realizar o controle de mudanças e versões dos artefatos do projeto>

\section{Estrutura do Banco de Dados de Configuração}

O banco de dados de configuração é utilizado para registrar todas as informações relevantes sobre as configurações de sistema e os itens de configuração. Assim, ele auxilia a avaliação do impacto das mudanças de sistema e permite gerar relatórios para a gerência.

Referência Bibliográfica: SOMMERVILLE, I. Engenharia de Software. $8^{\underline{a}}$ ed. São Paulo: Pearson Addison Wesley, 2007. 


\section{A4.12 - PLANO DE MARKETING}

Título: Deve descrever o que o plano tem como objetivo

Data Inicial: Data de início do plano

Data Final: Data final do plano

\section{HISTÓRICO DE REVISÕES}

\begin{tabular}{|c|c|c|c|c|}
\hline $\begin{array}{c}\text { Data de } \\
\text { criação/ } \\
\text { atualização }\end{array}$ & $\begin{array}{c}\text { Descrição da(s) Mudança(s) } \\
\text { Ocorrida(s) }\end{array}$ & Autor & $\begin{array}{c}\text { Versão do } \\
\text { Documento }\end{array}$ & $\begin{array}{c}\text { ID. } \\
\text { Solicitação } \\
\text { de } \\
\text { Mudança }\end{array}$ \\
\hline & & & & \\
\hline & & & & \\
\hline
\end{tabular}

\section{Contextualização}

< É realizada a análise SWOT - trata-se da avaliação global das forças, fraquezas, oportunidades e ameaças (strengths, weaknesses, opportunities, threats). Em geral, uma empresa tem que monitorar importantes forças macroambientais (econômicodemográficas, tecnológicas, político-legais e socioculturais) e significativos agentes microambientais (clientes, concorrentes, distribuidores, fornecedores) que afetam sua capacidade de obter lucros. É realizada uma análise de mercado, considerando oportunidades e ameaças. Além disso, é feita uma análise dos pontos fortes e fracos da sua empresa e são considerados, também, os concorrentes.

A lista, a seguir, sugere itens a serem considerados na análise de forças/fraquezas:

- Marketing: reputação da empresa, participação de mercado, satisfação do cliente, retenção do cliente, qualidade do produto, qualidade de serviço, efetividade na determinação de preços, efetividade na distribuição, efetividade de promoções, efetividade da força de vendas, efetividade das inovações, cobertura geográfica.

- Finanças: custo ou disponibilidade de capital, fluxo de caixa, estabilidade financeira.

- Produção: instalações, economias de escala, capacidade, força de trabalho capaz e dedicada, capacidade de produzir no prazo, habilidades técnicas de fabricação.

- Organização: liderança visionária e capaz, funcionários dedicados, orientação empreendedora, flexibilidade ou boa capacidade de resposta.

Exemplo da Análise SWOT (forças, fraquezas, oportunidades e ameaças).

\begin{tabular}{|c|c|}
\hline $\begin{array}{l}\text { Potencialidades (Fatores Internos) } \\
\text { 1- } \quad \text { Fácil Implantação } \\
\text { 2- } \quad \text { Satisfação dos atuais clientes }\end{array}$ & $\begin{array}{l}\text { Fragilidades (Fatores Internos) } \\
\begin{array}{ll}1- & \text { Produto pouco conhecido pelo mercado } \\
2- & \text { Preço acima da capacidade de grande } \\
& \text { parte do mercado }\end{array}\end{array}$ \\
\hline $\begin{array}{l}\text { Oportunidades (Fatores Externos) } \\
\begin{array}{ll}\text { 1- } & \text { Baixa Concorrência } \\
2- & \text { Existência de recursos de órgãos de } \\
& \text { fomento para aquisição do sistema }\end{array}\end{array}$ & $\begin{array}{l}\text { Ameaças (Fatores Externos) } \\
1-\begin{array}{l}\text { Produto concorrente sem custo para } \\
\text { clientes }\end{array}\end{array}$ \\
\hline
\end{tabular}


O produto deve ser contextualizado (aproximadamente um parágrafo) e pode ser inserida a lista de atuais clientes atendidos e casos de sucesso. Além disso, é importante definir o público-alvo desse produto.

São, também, definidos o preço do produto e as condições de fornecimento do produto (no caso de ser algum produto já pronto da empresa, sem customizações). $>$

\section{Objetivos}

<Define as metas financeiras e de marketing do plano em relação ao volume de vendas, participação do mercado e lucros e índices de satisfação dos clientes.

Exemplos de objetivos quantitativos: aumentar vendas em 10\%; aumentar participação de mercado para $30 \%$.

Exemplos de objetivos qualitativos: treinar equipe de vendas; implantar filosofia de qualidade; melhorar o relacionamento com os fornecedores. $>$

\section{Operacionalização}

\subsection{Perfil de potenciais clientes}

< Aqui deve ser descrito o perfil dos potenciais clientes.>

\subsection{Estratégia para busca de potenciais clientes}

$<$ Aqui deve ser definido como buscar os potenciais clientes, conforme o perfil descrito no item anterior.

Exemplo:

Etapa 1 - E-mail marketing e/ou material marketing via correio

Etapa 2 - Contato Telefônico

Etapa 3 - Visita

Etapa 4 - Proposta

Etapa 5 - Fechamento

$>$

\section{Plano de Ação}

< O que será feito para atingir aos objetivos do plano? Como? Quando será feito? Quem fará? Quanto custará?

Aqui deverá ser definido um conjunto de etapas que coloque em prática a estratégia definida anteriormente, assim como cada uma dessas etapas deverá ser realizada (seqüência e ordem de prioridade). Quem será o responsável pela execução e qual o custo estimado. Para cada etapa desse plano deverá ser definido um conjunto de informações que deverão ser transmitidas aos potenciais clientes e outro conjunto de respostas que a empresa espera para que a próxima etapa possa ser iniciada.

Exemplo: As seguintes etapas serão abordadas nas fases prospecção, concepção e negociação:

$$
\begin{aligned}
& \text { Etapa } 1 \text { - E-mail marketing } \\
& \text { Etapa } 2 \text { - Contato Telefônico } \\
& \text { Etapa } 3 \text { - Visita } \\
& \text { Etapa } 4 \text { - Proposta } \\
& \text { Etapa } 5 \text { - Fechamento }
\end{aligned}
$$

Para cada etapa deverá ser definida a forma de abordagem. Ex: etapa 1 email marketing. Definir texto do email, layout e links. Definir o que é esperado como retorno dessa ação. Ex. telefonema, email de reposta manifestando interesse ou click no link $X$. > 


\section{Atividades de inicialização e infra-estrutura}

$<$ Aqui devem ser definidas as atividades necessárias para que seja iniciada a ação de vendas. Ex: Instalação de um novo ramal de telefone na sala Y.>

\section{Equipe}

<Aqui deverá ser definida a equipe que será responsável pelas ações de venda, percentual de alocação de cada recurso e horário de trabalho.>

\section{Metas de venda} pessoa.>

< Aqui deverá ser definida a meta de vendas geral e parcial por período e por

\section{Custos referentes à ação de venda}

< Aqui deverá ser descrito o orçamento relativo ao planejamento da ação de venda em questão. Pessoal, telefone, infra-estrutura, viagens, comissões, eventos, material de divulgação. Para que esse item seja feito com um mínimo de confiabilidade é necessário que o item 3 deste documento (Plano de ação) tenha um planejamento não só de como cada etapa deverá ser realizada, mas também o número de eventos por etapa por período. Ex: arquivo excell plano_de_acao.xls.>

\section{Acompanhamento do Plano de Ação}

$<$ Aqui deverá ser definida a forma de acompanhamento do plano. Isso deverá incluir periodicidade e itens para avaliação. Para que esse item seja realizado com sucesso é necessário que o item 3 (Definir Plano de ação) tenha um planejamento não só de como cada etapa deverá ser realizada, mas também o número de eventos por etapa e por período para que possa ser produzido uma planilha mostrando a comparação entre o planejado e o realizado.Ex: guia "Acompanhamento" do template "Plano de Ação.xls".>

\section{Referências:}

KOTLER, P. Administração de Marketing. 10 ed. São Paulo: Pearson Prentice Hall, 2000.

LAS CASAS, A. L. Plano de marketing para micro e pequena empresa. São Paulo: Atlas, 2001.

ROSA, C. A. Como elaborar um plano de negócio. Brasília: SEBRAE, 2007.

GOMES, I. M. Como elaborar um plano de marketing. Belo Horizonte: SEBRAE/MG, 2005.

CARVALHAIS, R. S.; PATTO, A. R. Como elaborar um plano de vendas. Belo Horizonte: SEBRAE/MG, 2007.

O planejamento estratégico é o processo gerencial de desenvolver e manter uma direção estratégica que alinhe as metas e os recursos da organização com suas mutantes oportunidades de mercado (KOTLER, 2000).

Segundo Kotler (2000), o planejamento estratégico de negócios consiste de oito etapas. São elas:

- Missão do Negócio: cada unidade de negócio precisa definir sua missão específica dentro da missão corporativa.

- Análise SWOT: trata-se da avaliação global das forças, fraquezas, oportunidades e ameaças (strengths, weaknesses, opportunities, threats). Em geral, uma unidade de negócios tem que monitorar importantes forças macroambientais (econômicodemográficas, tecnológicas, político-legais e socioculturais) e significativos agentes microambientais (clientes, concorrentes, distribuidores, fornecedores) que afetam 
sua capacidade de obter lucros. A unidade de negócios deve estabelecer um sistema de inteligência de marketing para acompanhar tendências e mudanças importantes. A administração precisa identificar as oportunidades e ameaças associadas a cada tendência ou desenvolvimento. Um objetivo importante da avaliação ambiental é o reconhecimento de novas oportunidades de marketing. Uma oportunidade de marketing existe quando a empresa pode lucrar ao atender às necessidades dos consumidores de um determinado segmento. Cada unidade de negócio, também precisa avaliar periodicamente suas forças e fraquezas internas. Isso pode ser feito pela gerência (ou consultor externo) que analisa as competências de marketing, financeiras, de fabricação e organizacionais. A lista, a seguir, sugere itens a serem considerados na análise de forças/fraquezas:

- Marketing: reputação da empresa, participação de mercado, satisfação do cliente, retenção do cliente, qualidade do produto, qualidade de serviço, efetividade na determinação de preços, efetividade na distribuição, efetividade de promoções, efetividade da força de vendas, efetividade das inovações, cobertura geográfica.

- Finanças: custo ou disponibilidade de capital, fluxo de caixa, estabilidade financeira.

- Produção: instalações, economias de escala, capacidade, força de trabalho capaz e dedicada, capacidade de produzir no prazo, habilidades técnicas de fabricação.

- Organização: liderança visionária e capaz, funcionários dedicados, orientação empreendedora, flexibilidade ou boa capacidade de resposta.

- Formulação de metas: a empresa deve desenvolver metas específicas para o período de planejamento. As metas indicam aquilo que uma unidade de negócios deve alcançar. Essas metas são utilizadas para descrever objetivos em termos de magnitude e prazo.

- Formulação de estratégias: a estratégia é o meio para atingir os fins (os objetivos da empresa); refere-se a como devem ser alcançadas as metas. Exemplos de estratégias: liderança total em custos (a empresa se esforça para conseguir os menores custos de produção e de distribuição, de modo a poder oferecer preços mais baixos do que os dos concorrentes e a obter uma grande participação de mercado).

- Formulação de programas: devem ser definidos planos de programas baseados na estratégia definida.

- Implementação: os programas devem ser executados.

- Feedback e Controle: à medida que se implementa a estratégia, deve-se realizar o acompanhamento dos resultados e monitoramente dos novos acontecimentos nos ambientes interno e externo.

O plano estratégico é composto pelo plano de marketing, plano de produção, plano financeiro e plano de recursos humanos (LAS CASAS, 2001). O plano de marketing, por sua vez, é composto pelo plano de vendas, plano de propaganda, plano de novos produtos e plano de merchandising.

O processo de marketing consiste em analisar oportunidades de marketing, pesquisando e selecionando mercados-alvo, delineando estratégias, planejando programas e organizando, implementando e controlando o esforço de marketing.

Para cada nível de produto (linha de produtos, marca) deve ser desenvolvido um plano de marketing para atingir suas metas. Esse plano é um dos produtos do processo de marketing. Um Plano de Marketing contém:

- Resumo executivo e sumário: apresenta uma rápida visão geral do plano proposto. 
- Situação atual de marketing: apresenta antecedentes relevantes sobre vendas, custos, lucros, mercado, concorrentes, distribuição e macroambiente.

- Análise de oportunidades e questões: identifica as principais oportunidades/ameaças, forças/fraquezas e questões relacionadas à linha de produtos.

- Objetivos: define as metas financeiras e de marketing do plano em relação ao volume de vendas, participação do mercado e lucros.

- Estratégia de marketing: apresenta a abordagem geral de marketing que será utilizada para alcançar os objetivos do plano. O gerente de produto, ao desenvolver a estratégia de marketing, conversa com o pessoal de compras e de fabricação, a fim de confirmas se são capazes de comprar material suficiente e produzir unidades suficientes para atender aos níveis-alvo de volume de vendas; também conversa com o gerente de vendas, para obter apoio da força de vendas, e com o gerente financeiro, para conseguir os recursos necessários para propaganda e promoção.

- Programas de ação: apresenta os programas especiais de marketing projetados para atingir aos objetivos do plano. O que será feito? Quando será feito? Quem fará? Quanto custará?

- Demonstrativo de resultados projetados: projeta os resultados financeiros esperados do plano. Os planos de ação permitem que o gerente de produto desenvolva um orçamento de apoio. Pelo lado da receita, esse orçamento mostra o volume esperado de vendas em unidades e seu preço médio. Pelo lado de despesas, mostra os custos de produção, de distribuição e de marketing. Uma vez aprovado, o orçamento é a base para desenvolver planos e programações de suprimento de materiais, de produção, de recrutamento de funcionários e de operações de marketing.

- Controles: indica como o plano será monitorado. As metas e orçamentos foram especificados detalhadamente para cada mês ou trimestre. A alta administração pode analisar os resultados a cada período. Algumas seções de controle incluem planos de contingência. Um plano de contingência descreve as atitudes que a gerência tomaria em resposta a eventos adversos específicos, como guerras de preço.

Um roteiro simplificado para um plano de marketing é apresentado por Las Casas (2001):

\section{Análise Ambiental}

a. Ameaças e oportunidades: análise do mercado como um todo. sugestões.

Para cada evento, descrever ameaças, oportunidades e

b. Pontos fortes e fracos: realizada com o propósito de identificar quais empresas concorrentes têm melhores condições de aproveitar as oportunidades ou se defender de eventuais ameaças.

Os aspectos que podem ser analisados são: pessoal (quantidade e qualificação), equipamentos (capacidade instalada, tecnologia), finanças (recursos financeiros, possibilidade de obtenção de empréstimos), marketing (produto, preço, distribuição, propaganda, equipe de vendas, promoção).

\section{Objetivos:}

a. Quantitativos

Exemplos: aumentar vendas em 10\%; aumentar participação de mercado para $30 \%$.

b. Qualitativos: 
Exemplos: treinar equipe de vendas; implantar filosofia de qualidade; melhorar o relacionamento com os fornecedores.

\section{Estratégia de Marketing}

a. Público-alvo

Exemplo: segmento de homens, faixa etária de 25 a 35 anos, renda entre $R \$ 1.500,00$ e $R \$ 3.000,00$.

b. Posicionamento

Exemplo: produto de boa qualidade e preço intermediário.

c. Estratégia do mix: produto, preço, distribuição e promoção.

Exemplo: o produto a ser comercializado será o relógio Champion, com qualidade suíça, modelo quartzo, linha esportiva, plástico resistente, à prova d'água e com pulseiras intercambiáveis de várias cores. A marca é Champion; o produto terá garantia de 4 anos; seu preço é de $R \$ 50,00$; será distribuído por varejistas, principalmente relojoarias e lojas de departamentos. Quanto à propaganda, será utilizado um outdoor no lançamento, filmes de 15" na TV e anúncios nas revistas. Quanto à promoção de vendas: promoção junto aos varejistas com uso de displays e cartazes; relações públicas: assessoria de imprensa.

4. Plano de Ação: para cada atividade, descrever encarregado, período e orçamento.

Exemplo:

\begin{tabular}{|l|l|l|l|}
\hline Atividades & Encarregado & Período & Orçamento \\
\hline $\begin{array}{l}\text { Promoção: uso de outdoor } \\
\text { no lançamento }\end{array}$ & José Silva & Jan a mar de 2008 & $\begin{array}{l}\text { (incluir } \\
\text { estimados) }\end{array}$ \\
\hline $\begin{array}{l}\text { Filmes de 15" na TV: } \\
\text { Globo e Bandeirantes }\end{array}$ & José Silva & Jan a jul de 2008 & $\begin{array}{l}\text { (incluir valores } \\
\text { estimados) }\end{array}$ \\
\hline $\begin{array}{l}\text { Anúncios em revistas: Veja } \\
\text { e Exame }\end{array}$ & Maria Silva & Mar de 2008 & $\begin{array}{l}\text { (incluir valores } \\
\text { estimados) }\end{array}$ \\
\hline
\end{tabular}

5. Projeção de vendas e lucros: para cada período, estabelecer vendas e lucros e fazer observações pertinentes. 
A4.13 - PLANO DE PROJETO

ID documento: Data: / / Versão :

Responsável pelo documento:

ID Projeto:

\section{HISTÓRICO DE REVISÕES}

\begin{tabular}{|l|c|c|c|c|}
\hline $\begin{array}{c}\text { Data de } \\
\text { criação/ } \\
\text { atualização }\end{array}$ & $\begin{array}{c}\text { Descrição da(s) Mudança(s) } \\
\text { Ocorrida(s) }\end{array}$ & Autor & $\begin{array}{c}\text { Versão do } \\
\text { Documento }\end{array}$ & $\begin{array}{c}\text { ID. } \\
\text { Solicitação } \\
\text { de } \\
\text { Mudança }\end{array}$ \\
\hline & & & & \\
\hline & & & & \\
\hline & & & & \\
\hline & & & & \\
\hline
\end{tabular}

\section{ESCOPO DO PROJETO}

1.1 Cenário

< Identificar as necessidades que motivaram o cliente a solicitar o projeto, definir os stakeholders e usuários do sistema (quem são e quais as necessidades de cada um) e descrever as expectativas que o projeto visa atender $>$ 


\subsection{Entregas do Projeto}

$<$ As entregas são desdobramentos do produto de projeto em resultados tangíveis. Podem ser físicas ou uma mudança de estado visível. A característica fundamental das entregas é a capacidade de serem medidas e avaliadas. Por ex: documento de requisitos, relatório de teste, etc.>

\subsection{Premissas, Limitações e Restrições do Projeto}

1.4 Critérios de aceitação do cliente

< Descrever como o projeto atenderá às expectativas do cliente e itens de sucesso para o cliente, tal como antecipação de prazos.>

\subsection{Estratégias}

\subsection{Prazos Máximos}

\subsection{Custo e Preço-Meta}

\section{PLANO DE RECURSOS}

$<$ Aqui devem ser descritos todos os recursos (equipamentos físicos, tais como hardware, impressora e outros periféricos) necessários para o desenvolvimento do software.>

\section{PLANO DE HABILIDADES E CONHECIMENTO}

$<$ Aqui devem ser descritos todos os conhecimentos e habilidades necessários para o desenvolvimento do software e na frente de cada um deles, sugerir colaboradores que possam participar como integrantes do projeto> 


\section{RISCOS}

\section{Tabela de Riscos}

\begin{tabular}{|l|l|l|l|l|l|l|}
\hline Descrição & Escala & $\begin{array}{l}\text { Probabi- } \\
\text { lidade }\end{array}$ & Impacto & Prioridade & Ações & $\begin{array}{l}\text { \% Risco } \\
\text { do projeto }\end{array}$ \\
\hline & & & & & & \\
\hline & & & & & & \\
\hline & & & & & & \\
\hline
\end{tabular}

< Lista de possíveis riscos: Horas extras; Rotatividade/perda de colaboradores; Necessidade de equipamentos; Falta de colaboração do cliente; Falta de conhecimento do domínio>

\section{PLANO DE TESTES}

Referência bibliográfica: Introducão ao Teste de Software

5.1 Critérios de Teste de Unidade

\subsection{Critérios de Teste de Integração}

\subsection{Teste de Validação}

Tempo máximo: 
5.4 Ferramentas de Teste

5.5 Equipamentos Necessários

APÊNDICE 1: PLANO DE CONTINGÊNCIA

<inserir aqui o plano de contingência>

ANEXO 1: CRONOGRAMA

ID:

ANEXO 2: FLUXO DE CAIXA (PARA MONITORAMENTO)

ID:

ANEXO 3: RELATÓRIO DE VIABILIDADE DO PROJETO

ID:

ANEXO 4: DOCUMENTO DE REQUISITOS

ID:

ANEXO 5: PLANILHA DE TESTE 


\section{A4.14 - PROJETO INTERFACE HOMEM-MÁQUINA}

ID documento:

Data: / /

Versão :

Responsável pelo documento:

\section{ID Projeto:}

Documento de requisitos:

\section{HISTÓRICO DE REVISÕES}

\begin{tabular}{|l|l|l|l|l|}
\hline $\begin{array}{c}\text { Data de } \\
\text { criação/ } \\
\text { atualização }\end{array}$ & $\begin{array}{c}\text { Descrição da(s) Mudança(s) } \\
\text { Ocorrida(s) }\end{array}$ & Autor & $\begin{array}{c}\text { Versão do } \\
\text { Documento }\end{array}$ & $\begin{array}{c}\text { ID. } \\
\text { Solicitação } \\
\text { de } \\
\text { Mudança }\end{array}$ \\
\hline & & & & \\
\hline & & & & \\
\hline & & & & \\
\hline
\end{tabular}

\section{Perfil do Usuário}

< Para cada tipo de usuário previsto, os projetistas devem conhecer seus atributos pessoais (faixa etária, sexo, limitações, motivação) e suas habilidades e competências (na tarefa, na organização e com sistemas informatizados).

\begin{tabular}{|l|l|l|l|l|l|l|}
\hline $\begin{array}{l}\text { Tipo de } \\
\text { Usuário }\end{array}$ & $\begin{array}{l}\text { Faixa } \\
\text { etária }\end{array}$ & Sexo & Limitações & Motivação & Habilidades & Competências \\
\hline & & & & & & \\
\hline & & & & & & \\
\hline
\end{tabular}

$>$

\section{Princípios Gerais para o Projeto}

< Pesquisa e catalogação do conhecimento ergonômico disponível para a concepção da interface no tipo de contexto de uso (usuário, tarefa, equipamento e ambiente) no qual o sistema está inserido. Podem ser utilizados como referência para a pesquisa e catalogação do conhecimento ergonômico, os critérios ergonômicos propostos por Scapin \& Bastien (1993). Esses critérios são apresentados no Apêndice 1.>

\section{Padrão de Telas}

<São definidas regras para a escolha de controles, para a definição do formato e localização das telas, para a terminologia empregada, para o uso de cores, tipos de fontes, etc. 
Deve-se construir o layout das telas com base nessas regras. Inclusive, pode-se construir uma maquete informatizada (considerada um protótipo executável com baixa fidelidade) de uma parte da interface, de modo que seja possível um diálogo com o usuário, sem uma base de dados. No que se refere à modelagem de websites, a ferramenta Denim é uma alternativa e pode ser obtida gratuitamente no site http://dub.washington.edu/projects/denim/download. Na falta de uma ferramenta especializada, é sempre possível usar um editor de apresentações, como o PowerPoint. >

\section{Mapa de Navegação}

< Para representar o mapa de navegação pode ser utilizado o diagrama de transição de estados, no qual os espaços de interação são representados por retângulos, e as transições são representadas por flechas conectando espaços.>

Referência: CYBIS, W.; BETIOL, A. H.; FAUST, R. Ergonomia e Usabilidade: Conhecimentos, Métodos e Aplicações. São Paulo: Novatec Editora, 2007.

\section{Ciclo de engenharia de usabilidade}

Este modelo, proposto por Mayhew (1999), tem a mesma estrutura do modelo proposto pela norma ISO 13407. Entretanto, o modelo de Mayhew fornece mais detalhes sobre o conteúdo das atividades a serem realizadas em cada fase do processo de desenvolvimento.

1) Análise de Requisitos: os resultados das atividades dessa fase são utilizados para especificar o contexto de uso e a usabilidade pretendida para o sistema. As atividades dessa fase são:

- Análise do perfil do usuário: para cada tipo de usuário previsto, os projetistas devem conhecer seus atributos pessoais (faixa etária, sexo, limitações, motivação) e suas habilidades e competências (na tarefa, na organização e com sistemas informatizados).

- Análise do contexto da tarefa: para cada tarefa a ser apoiada pelo sistema, os projetistas devem conhecer os objetivos e resultados, a estrutura, a duração, as dependências, os custos, a carga mental, as interrupções, os incidentes, etc.

- Análise das possibilidades e restrições da plataforma: são examinadas as possibilidades e restrições em termos de equipamentos, sistemas operacionais, ambientes de janelas, recursos de rede, a possibilidade de oferecer recursos em termos de manuais, suporte, treinamento, etc.

- Análise de princípios gerais para o projeto: atividade de pesquisa e catalogação do conhecimento ergonômico disponível para a concepção da interface no tipo de contexto de uso (usuário, tarefa, equipamento e ambiente) no qual o sistema está inserido. Podem ser utilizados como referência para a pesquisa e catalogação do conhecimento ergonômico, os oito critérios ergonômicos propostos por Scapin \& Bastien (1993). Esses critérios são apresentados no Apêndice 1.

- Especificação do contexto de uso: o projetista especifica que tipo de usuário irá operar o sistema para realizar que tipo de tarefa e em 
que condições ambientais (qual software, equipamento, ambiente físico e organizacional).

- Especificação das exigências para a usabilidade: são especificadas as exigências qualitativas para a interface e quantitativas para a usabilidade.

i. As exigências qualitativas referem-se às funções $e$ características da interface de modo a satisfazer o tipo de usuário. Por exemplo, se a maioria são idosos, então uma função de zoom deveria ser implementada e esses usuários deveriam fazer parte da população de testes do sistema.

ii. As exigências quantitativas referem-se ao nível de usabilidade esperado para o sistema. Essa especificação é realizada em termos de valores mínimos admissíveis para os fatores básicos de usabilidade: eficácia, eficiência e satisfação do usuário principalmente. Exemplo:

\begin{tabular}{|c|c|c|c|}
\hline $\begin{array}{l}\text { Objetivos da } \\
\text { usabilidade }\end{array}$ & $\begin{array}{l}\text { Medidas de } \\
\text { eficácia }\end{array}$ & $\begin{array}{l}\text { Medidas de } \\
\text { eficiência }\end{array}$ & $\begin{array}{l}\text { Medidas de } \\
\text { satisfação }\end{array}$ \\
\hline \multirow[t]{3}{*}{ Usabilidade global } & $\begin{array}{l}\text { \% de objetivos } \\
\text { alcançados }\end{array}$ & $\begin{array}{l}\text { Tempo para } \\
\text { completar a tarefa }\end{array}$ & $\begin{array}{l}\text { Escala de } \\
\text { satisfação }\end{array}$ \\
\hline & $\begin{array}{l}\text { \% de usuários } \\
\text { completando a } \\
\text { tarefa com } \\
\text { sucesso }\end{array}$ & $\begin{array}{l}\text { Tarefas } \\
\text { completadas por } \\
\text { unidade de tempo }\end{array}$ & Freqüência de uso \\
\hline & $\begin{array}{l}\text { Média da acurácia } \\
\text { de tarefas } \\
\text { completadas }\end{array}$ & $\begin{array}{l}\text { Custo monetário } \\
\text { de realização da } \\
\text { tarefa }\end{array}$ & $\begin{array}{l}\text { Freqüência de } \\
\text { reclamações }\end{array}$ \\
\hline
\end{tabular}

2) Projeto, Testes e Implementação: os sucessivos ciclos dessas fases envolvem três versões de uma mesma interface: modelo conceitual da interface, padrão de telas e projeto detalhado da interface.

- Modelo Conceitual da Interface: esse modelo pode ser definido como representações abstratas de alternativas de projeto, nas quais são especificadas as principais telas e componentes da interface, bem como a navegação entre elas. Para representar o modelo conceitual pode-se usar uma maquete (protótipo em papel). Para representar o mapa de navegação pode ser utilizado o diagrama de transição de estados, no qual os espaços de interação são representados por retângulos, e as transições são representadas por flechas conectando espaços.

- Padrão de Telas: são definidas regras para a escolha de controles, para a definição do formato e localização das telas, para a terminologia empregada, para o uso de cores, tipos de fontes, etc. Pode-se construir uma maquete informatizada (considerada um protótipo executável com baixa fidelidade) de uma parte da interface, de modo que seja possível um diálogo com o usuário, sem uma base de dados. No que se refere à modelagem de websites, a ferramenta Denim é uma alternativa e pode ser obtida gratuitamente no site http://dub.washington.edu/projects/denim/download. Na falta de uma ferramenta especializada, é sempre possível usar um editor de apresentações, como o PowerPoint.

- Projeto Detalhado da Interface: os aspectos definidos no modelo conceitual e no padrão de telas são integrados.

3) Instalação: depois que o usuário já está acostumado em utilizar o software, o seu feedback é valioso para: detectar e eliminar problemas e preparar um novo 
release do produto; detectar oportunidades para melhoria de novas versões do produto e elaborar requisitos para novos produtos similares. Para coletar esse feedback são utilizados testes de usabilidade no local de trabalho dos usuários ou métodos de análise, tais como observações, entrevistas e questionários.

As técnicas de avaliação, a seguir apresentadas, têm como foco duas qualidades: a ergonomia das interfaces e a usabilidade dos sistemas. A ergonomia é a qualidade da adaptação de um dispositivo a seu operador e à tarefa que este realiza. A usabilidade se revela quando usuários empregam o sistema para alcançar seus objetivos em um determinado contexto de operação, sendo caracterizada pelo nível de eficácia, eficiência e satisfação alcançado pelo usuário durante o seu uso (conforme ISO 9241:11). Algumas alternativas de questionário de satisfação podem ser encontradas em http://www.usabilitynet.org/tools/r questionnaire.htm, tais como: SUMI - Software Usability Measurement Inventory (5 fatores; 50 questões) http://www.ucc.ie/hfrg/questionnaires/sumi/index.html; SUS - System Usability Scale (10 questões). Uma alternativa interessante é a versão em português do questionário ISONORM, desenvolvida por Medeiros (1999), http://teses.eps.ufsc.br/defesa/pdf/1073.pdf.

As inspeções de ergonomia, por meio de listas de verificação, permitem que profissionais, não necessariamente especialistas em ergonomia, identifiquem problemas menores e repetitivos das interfaces. As normas ISO 9241, partes 10 a 17, fornecem listas de verificação de ergonomia bem-definidas, assim como as listas de verificação fornecidas pelo site ErgoList (http://www.labiutil.inf.ufsc.br/ergolist).

Os testes de usabilidade têm como foco de avaliação a qualidade das interações que se estabelecem entre usuários e o sistema. Um teste de usabilidade envolve usuários reais ou representativos da população-alvo do sistema interagindo com ele para realizar tarefas específicas em um contexto de operação real ou simulado.

\section{APÊNDICE 1 - Critérios Ergonômicos segundo Scapin \& Bastien (1993)}

- Condução: a interface deve aconselhar, orientar, informar e conduzir o usuário na interação com o sistema. Essa qualidade pode ser analisada a partir de quatro sub-critérios:

- Convite: engloba os meios utilizados para levar o usuário a realizar determinadas ações. Uma interface convidativa apresentará: títulos claros para as tarefas, janelas e caixas de diálogo; informações claras sobre o estado (disponível, em foco selecionado, etc) dos componentes do sistema; informações sobre o preenchimento de um formulário, sobre as entradas esperadas; opções de ajuda claramente indicadas.

- Agrupamento/Distinção de itens: a rápida compreensão de uma tela pelo usuário depende, dentre outros itens, do posicionamento, da ordenação e da forma dos objetos (imagens, textos, comandos, etc) apresentados. Esse critério é composto pelos seguintes sub-critérios: agrupamento/distinção por localização (quando o usuário percebe rapidamente os grupamentos a partir da localização das informações nas interfaces) e agrupamento/distinção por formato (quando o usuário percebe rapidamente as similaridades ou diferenças entre as informações, a partir da forma gráfica de componentes da interface, como tamanho, cor da figura e do fundo, estilo dos caracteres, etc). 
- Legibilidade: diz respeito às características que possam dificultar ou facilitar a leitura das informações textuais. Deve ser considerada, principalmente, quando os usuários são pessoas idosas ou com problemas de visão (baixa visão). Em uma interface legível: o texto longo que deve ser lido rapidamente aparece em letras maiúsculas e minúsculas naturalmente ao invés de somente com maiúsculas; o texto é apresentado em linhas com comprimento adequado e com um contraste efetivo com o fundo; o texto que deve ser lido por idosos ou pessoas com problemas de visão aparece em letras claras sobre um fundo escuro. Para essas pessoas, o fundo brilhante pode ofuscar completamente as letras escuras.

- Feedback imediato: está a serviço de todos, porém os mais novatos precisarão mais dessa qualidade. Uma interface que fornece feedback de qualidade: relata ao usuário o recebimento de todas as entradas por ele efetuadas (as entradas confidenciais são relatadas de modo a não revelar o seu conteúdo, por exemplo, com asteriscos); indica ao usuário que um tratamento demorado está sendo realizado, bem como a sua conclusão e o seu resultado.

- Carga de trabalho: esse critério se aplica, principalmente, a um contexto de trabalho intenso e repetitivo, no qual os profissionais que operam o sistema precisarão de interfaces econômicas sob o ponto de vista cognitivo e motor, ou seja, que lhes economizem leitura e memorização desnecessárias, assim como deslocamentos inúteis e repetição de entradas. Os sub-critérios desse são:

- Brevidade: as qualidades inerentes a esse são a concisão e as ações mínimas. Uma interface concisa apresenta títulos (de telas, janelas e caixas de diálogo), rótulos (de campos, de botões e de comandos) e denominações curtas; apresenta códigos arbitrários (nome de usuário, senha) curtos; fornece valores default (para os campos de dados, lista, check boxes) capazes de acelerar as entradas individuais e fornece o preenchimento automático de vírgulas, pontos decimais e zeros à direita da vírgula nos campos de dados. Uma interface ágil não solicita aos usuários dados que podem ser deduzidos pelo sistema; não força o usuário a percorrer em seqüência todas as páginas de um documento de modo a alcançar a página específica e não solicita o mesmo dado ao usuário diversas vezes em uma mesma seqüência de diálogo.

- Densidade informacional: critério a serviço principalmente de usuários iniciantes, os quais podem encontrar dificuldades para filtrar a informação de que necessitam em uma tela carregada. Uma interface minimalista apresenta somente os itens que estão relacionados à tarefa (o restante deve ser removido da tela); não força os usuários a transportar mentalmente dados de uma tela a outra; não força os usuários a realizar procedimentos complicados, como a transformação da unidade de medida; não coloca os usuários diante de tarefas cognitivas complexas, como as de especificação de buscas avançadas.

- Controle explícito: aplica-se em particular às tarefas longas seqüenciais e nas quais os processamentos são demorados. Seus sub-critérios são:

- Accões explícitas do usuário: refere-se à ligação explícita que deve existir entre uma ação do usuário e um processamento do sistema. A interface explicitamente comandada sempre solicita uma ação explícita do usuário de validação global em um formulário para entrada de diversos dados ou parâmetros; separa as ações de seleção de uma opção e de ativação dessa opção quando se referir a um tratamento demorado (exemplo: tela 
de assistente para novas conexões do windows); não coloca o usuário diante de comandos de dupla repercussão (por exemplo, salvar + fechar).

- Controle do usuário: em realização de ações longas seqüenciais e de tratamento demorado, os usuários devem estar no controle dos acontecimentos. Cada possível ação do usuário deve ser antecipada e as opções apropriadas devem ser oferecidas. Em uma interface controlada pelo usuário: a) o cursor não se desloca de um campo a outro em um formulário como efeito colateral das entradas dos usuários (validação [enter]) ou do preenchimento completo de um dado de comprimento controlado (campo senha, por exemplo); ele o faz como efeito do comando explícito de tabulação ([tab]); b) o usuário encontra as opções para comandar o avanço, o recuo, a interrupção, a retomada ou a finalização de um diálogo seqüencial (exemplo: tela de artigo publicado em periódico do currículo lattes); c) o usuário encontra as opções para comandar a interrupção, a retomada ou a finalização de tratamentos demorados.

- Adaptabilidade: qualidade esperada em sistemas em que o público-alvo é vasto e variado. Para que todos tenham direito ao mesmo nível de usabilidade, a interface deve propor maneiras variadas de realizar uma tarefa, deixando ao usuário a liberdade de escolher e dominar uma delas no curso de seu aprendizado. Deve permitir que o usuário adapte as apresentações e estilos de diálogo a suas necessidades. Os sub-critérios são:

- Flexibilidade: envolve duas qualidades diferenciadas - a flexibilidade estrutural e a personalização. Uma interface estruturalmente flexível fornece aos usuários diferentes maneiras de realizar a entrada de dados (por digitação, por seleção); diferentes caminhos para chegar a uma funcionalidade freqüentemente utilizada (ícone na barra de ferramenta, opção em um painel de menu, atalho de teclado) e diferentes opções de formato de arquivos e de unidades para os dados (exemplo: telas de configuração de cores do MS Office, nas quais o usuário pode selecionar uma cor padronizada ou definir uma outra personalizada digitando seu valor no sistema RGB ou clicando sobre um ponto na área de cores). Uma interface personalizável oferece a possibilidade de o usuário personalizar as telas, inserindo ou retirando ícones, dados ou comandos (exemplo: formatos de apresentação dos arquivos/diretórios pelo gerenciador de arquivos Explorer); definir seqüências de ações automáticas (macros); alterar os valores default oferecidos pelo sistema.

- Consideração da experiência do usuário: uma interface que considere a experiência do usuário fornece aos especialistas atalhos que permitem acesso rápido às funções do sistema e fornece aos usuários intermitentes diálogos passo a passo.

- Gestão de erros: esse critério se aplica a todas as situações. A gestão de erros diz respeito a todos os mecanismos que permitem evitar ou reduzir a ocorrência de erros que favoreçam sua correção. Seus sub-critérios são:

- Protecão contra os erros: diz respeito aos mecanismos empregados para detectar e prevenir os erros de entradas de dados ou de comandos, e impedir que ações de conseqüências desastrosas e/ou não recuperáveis ocorram. Uma interface que protege a interação contra erros informa ao usuário sobre o risco de perda de dados não-gravados ao final de uma sessão de trabalho; não oferece um comando destrutivo como opção default e detecta os erros já no momento da digitação de uma entrada individual em vez de fazê-lo apenas no momento da validação do formulário inteiro. 
- Qualidade das mensagens de erro: refere-se à pertinência, à legibilidade e à exatidão da informação dada ao usuário sobre a natureza do erro cometido e sobre as ações a serem executadas para corrigi-lo. Uma boa mensagem de erro indica ao usuário a razão ou a natureza do erro cometido, o que ele fez de errado, o que deveria ter feito e o que deve fazer para sair da situação de erro; é orientada para a tarefa, emprega termos específicos e é breve; tem um tom neutro (nem reprovador e nem humorístico).

- Correção dos erros: diz respeito aos meios colocados à disposição do usuário com o objetivo de permitir a correção de seus erros. Há facilidade na correção de erros quando a interface fornece funções desfazer e refazer, fornece a possibilidade de o usuário refazer apenas a parte errada de uma entrada (indica o dado errado em um formulário, mantendo todos os outros intactos); fornece ligação direta entre o relatório de erro e o local onde ele se produz.

- Homogeneidade/consistência: critério que se aplica de forma geral, mas em particular quando os usuários são novatos ou intermitentes. Este critério refere-se à forma na qual as escolhas no projeto da interface (códigos, denominações, formatos, procedimentos, etc) são conservadas idênticas em contextos idênticos e diferentes para contextos diferentes. Em uma interface homogênea os códigos e denominações são definidos pelos mesmos critérios em contextos idênticos; a distribuição, a apresentação e a denominação dos objetos nas telas são padronizadas; a sintaxe dos procedimentos é padronizada (utiliza os mesmos meios para obter os mesmos resultados).

- Significado de códigos e denominações: critério que se aplica de forma geral, mas em particular quando os usuários são novatos ou intermitentes. Em uma interface significativa os nomes de funções e objetos de interação são familiares para os usuários; os códigos são representativos do conteúdo que veiculam e são distintos (por exemplo: M - masculino / F - feminino, em vez de 1 - homens e 2 mulheres); as abreviações são de imediata interpretação.

- Compatibilidade: diz respeito ao grau de similaridade entre diferentes sistemas que são executados em um mesmo ambiente operacional (windows, mac, openlook). Trata-se de um tipo de consistência externa entre aplicativos de um mesmo ambiente. Em uma interface compatível a transferência de informações do contexto da tarefa para o do sistema é mais rápida e eficaz; os procedimentos e as tarefas são organizados de maneira a respeitar expectativas ou costumes do usuário; as traduções, as transposições, as interpretações ou referências à documentação são minimizadas (as telas são compatíveis com os documentos em papel, as denominações de comandos são compatíveis com o vocabulário do usuário, etc.); a informação é apresentada de forma diretamente utilizável.

Dentre algumas recomendações ergonômicas para Interface HomemComputador (IHC), coletadas da ISO 9241 (Requisitos Ergonômicos para o trabalho de escritório informatizado), serão apresentadas algumas referentes a cores utilizadas na interface. Os estereótipos naturais mais populares indicam os seguintes empregos para as cores:

- Vermelho: deve ser utilizada para perigo, alarme, atenção, alerta, calor e comandos de interrupção;

- Amarelo: para advertências, teste e lentidão.

- Verde: para passagem livre, normalidade, vegetação e segurança.

- Laranja: para valor-limite e radiação; 
- Azul: para frio, água, céu e calma;

- Cinza: para inatividade, neutralidade.

É importante lembrar que deve ser evitada a codificação de significado por meio de cores que não sejam vistas por pessoas que sofrem de daltonismo, uma alteração genética caracterizada pela falta de um tipo de célula perceptiva para as cores vermelha e/ou verde e/ou azul. O tipo de daltonismo mais freqüente impõe dificuldade para que os portadores façam a distinção entre o verde e o vermelho.

Recomenda-se que sejam usadas poucas cores, sendo cores neutras, com o mesmo brilho e que as cores brilhantes sejam usadas com cautela. Uma forma interessante de usar as cores é explorar as sensações que estas causam sobre as pessoas: o verde descansa, o vermelho atrai a atenção e pode causar irritação, o azul dá sono e o amarelo desperta.

Quanto às recomendações sobre o emprego de fontes, aconselha-se não usar serifa (caracterizada por uma terminação saliente nos caracteres) para vídeos de baixa resolução. Mas, serifas devem ser empregadas em textos longos, como forma de facilitar o reconhecimento rápido dos caracteres. Já nos títulos e rótulos curtos, deve-se empregas fontes sem serifa. Não utilize fontes menores que 12 pontos para telas e menores que 10 pontos para material impresso. Limite o uso de fontes diferentes para textos em até dois tipos. Evite fontes muito grandes que "gritem" com o usuário. Evite textos só com maiúsculas e não exagere com o sublinhado, o negrito e o itálico. As fontes mais populares e indicadas a serem usadas são:

- Arial: para títulos e cabeçalhos de documentos;

- Avant Garde: grandes títulos;

- Courrier: documentos impressos, cartas padronizadas, correspondência;

- Helvética: relatórios, títulos de capítulos, de seções, códigos de programas;

- Letter gothic: texto que deve ser simples e claro;

- Romano: correio padronizado;

- Times: documentos diversos, de múltiplo uso, comentários em programas;

- Ultraback: etiquetas de embalagens. 


\section{A4.15 - PROPOSTA COMERCIAL}

ID documento:

Data: / /

Versão :

Responsável pelo documento:

ID Projeto:

ID Proposta Técnica:

\section{HISTÓRICO DE REVISÕES}

\begin{tabular}{|l|l|l|l|l|}
\hline $\begin{array}{c}\text { Data de } \\
\text { criação/ } \\
\text { atualização }\end{array}$ & $\begin{array}{c}\text { Descrição da(s) Mudança(s) } \\
\text { Ocorrida(s) }\end{array}$ & Autor & $\begin{array}{c}\text { Versão do } \\
\text { Documento }\end{array}$ & $\begin{array}{c}\text { ID. } \\
\text { Solicitação } \\
\text { de } \\
\text { Mudança }\end{array}$ \\
\hline & & & & \\
\hline & & & & \\
\hline & & & & \\
\hline & & & & \\
\hline & & & & \\
\hline
\end{tabular}

\section{DADOS DO CLIENTE}

Razão Social:

CNPJ:

Contato:

Endereço:

Telefones:

\section{CRONOGRAMA DE ENTREGAS}

<inserir aqui o cronograma de entregas, com base na WBS>

\section{CONDIÇÕES DE PAGAMENTO}

Preço:

Cronograma de pagamentos

\section{VALIDADE DA PROPOSTA}

Data: 


\section{A4.16 - PROPOSTA TÉCNICA}

ID documento:

Data: / /

Versão :

Responsável pelo documento:

ID Projeto:

\section{HISTÓRICO DE REVISÕES}

\begin{tabular}{|l|l|l|l|l|}
\hline $\begin{array}{c}\text { Data de } \\
\text { criação/ } \\
\text { atualização }\end{array}$ & $\begin{array}{c}\text { Descrição da(s) Mudança(s) } \\
\text { Ocorrida(s) }\end{array}$ & Autor & $\begin{array}{c}\text { Versão do } \\
\text { Documento }\end{array}$ & $\begin{array}{c}\text { ID. } \\
\text { Solicitação } \\
\text { de } \\
\text { Mudança }\end{array}$ \\
\hline & & & & \\
\hline & & & & \\
\hline & & & & \\
\hline & & & & \\
\hline & & & & \\
\hline
\end{tabular}

\section{DADOS DA EMPRESA DE DESENVOLVIMENTO}

Razão Social:

CNPJ:

Endereço:

Telefones:

Contato:

\section{ID DO DOCUMENTO DE REQUISITOS}




\section{A4.17 - RELATÓRIO DE ACOMPANHAMENTO DO PROJETO}
ID documento:
Data: / /
Versão :

Responsável pelo documento:

ID Projeto:

\section{HISTÓRICO DE REVISÕES}

\begin{tabular}{|l|l|l|l|c|}
\hline $\begin{array}{c}\text { Data de } \\
\text { criação/ } \\
\text { atualização }\end{array}$ & $\begin{array}{c}\text { Descrição da(s) Mudança(s) } \\
\text { Ocorrida(s) }\end{array}$ & Autor & $\begin{array}{c}\text { Versão do } \\
\text { Documento }\end{array}$ & $\begin{array}{c}\text { ID. } \\
\text { Solicitação } \\
\text { de } \\
\text { Mudança }\end{array}$ \\
\hline & & & & \\
\hline & & & & \\
\hline & & & & \\
\hline
\end{tabular}

\section{DADOS DO RELATÓRIO}

\begin{tabular}{|l|l|l|l|l|}
\hline $\begin{array}{l}\text { Data da } \\
\text { avaliação }\end{array}$ & Entrega avaliada & Resultado da avaliação & Responsáveis & Ações Corretivas \\
\hline & & & & \\
\hline & & & & \\
\hline & & & & \\
\hline
\end{tabular}




\section{A4.18 -RELATÓRIO DE ANÁLISE DO CONTRATO}

ID documento:

Data: / /

Responsável pelo documento:

ID Contrato:

\section{HISTÓRICO DE REVISÕES}

\begin{tabular}{|l|l|l|l|c|}
\hline $\begin{array}{c}\text { Data de } \\
\text { criação/ } \\
\text { atualização }\end{array}$ & $\begin{array}{c}\text { Descrição da(s) Mudança(s) } \\
\text { Ocorrida(s) }\end{array}$ & Autor & $\begin{array}{c}\text { Versão do } \\
\text { Documento }\end{array}$ & $\begin{array}{c}\text { ID. } \\
\text { Solicitação } \\
\text { de } \\
\text { Mudança }\end{array}$ \\
\hline & & & & \\
\hline & & & & \\
\hline & & & & \\
\hline & & & & \\
\hline & & & & \\
\hline
\end{tabular}

ALTERAÇÕES SOLICITADAS PELO CLIENTE

\section{ALTERAÇÕES PROMOVIDAS NO CONTRATO}




\section{A4.19 - RELATÓRIO DE ANÁLISE DA PROPOSTA}

ID documento:

Data: / /

Responsável pelo documento:

ID Proposta:

\section{HISTÓRICO DE REVISÕES}

\begin{tabular}{|l|l|l|l|l|}
\hline $\begin{array}{c}\text { Data de } \\
\text { criação/ } \\
\text { atualização }\end{array}$ & $\begin{array}{c}\text { Descrição da(s) Mudança(s) } \\
\text { Ocorrida(s) }\end{array}$ & Autor & $\begin{array}{c}\text { Versão do } \\
\text { Documento }\end{array}$ & $\begin{array}{c}\text { ID. } \\
\text { Solicitação } \\
\text { de } \\
\text { Mudança }\end{array}$ \\
\hline & & & & \\
\hline & & & & \\
\hline & & & & \\
\hline & & & & \\
\hline & & & & \\
\hline
\end{tabular}

ALTERAÇÕES SOLICITADAS PELO CLIENTE

ALTERAÇÕES PROMOVIDAS NA PROPOSTA 


\section{A4.20 - RELATÓRIO DE ANÁLISE DOS REQUISITOS}

ID documento:

Data: / I

Responsável pelo documento:

ID Projeto:

\section{HISTÓRICO DE REVISÕES}

\begin{tabular}{|l|l|l|l|l|}
\hline $\begin{array}{c}\text { Data de } \\
\text { criação/ } \\
\text { atualização }\end{array}$ & $\begin{array}{c}\text { Descrição da(s) Mudança(s) } \\
\text { Ocorrida(s) }\end{array}$ & Autor & $\begin{array}{c}\text { Versão do } \\
\text { Documento }\end{array}$ & $\begin{array}{c}\text { ID. } \\
\text { Solicitação } \\
\text { de } \\
\text { Mudança }\end{array}$ \\
\hline & & & & \\
\hline & & & & \\
\hline & & & & \\
\hline & & & & \\
\hline & & & & \\
\hline
\end{tabular}

\section{Conflitos relacionados ao Modelo de Negócio}

< Inserir aqui os conflitos relacionados ao modelo de negócio (relacionado ao processo de negócio, às regras de negócio) e a solução adotada depois de esclarecido o conflito junto ao cliente.>

\section{Conflitos entre requisitos}

< Inserir aqui o identificador dos requisitos conflitantes (a partir do Documento de Requisitos), a descrição desses requisitos e a solução adotada depois de esclarecido o conflito junto ao cliente.>

ID. Requisitos conflitantes:

Descrição dos requisitos:

Solução:

ID. Requisitos conflitantes:

Descrição dos requisitos:

Solução:

ID. Requisitos conflitantes:

Descrição dos requisitos:

Solução: 


\subsection{1 - RELATÓRIO SOBRE GARANTIA DE QUALIDADE}

ID documento:

Data: / /

Responsável pelo documento:

ID Projeto:

\section{HISTÓRICO DE REVISÕES}

\begin{tabular}{|c|c|c|c|c|}
\hline $\begin{array}{c}\text { Data de } \\
\text { criação/ } \\
\text { atualização }\end{array}$ & $\begin{array}{c}\text { Descrição da(s) Mudança(s) } \\
\text { Ocorrida(s) }\end{array}$ & Autor & $\begin{array}{c}\text { Versão do } \\
\text { Documento }\end{array}$ & $\begin{array}{c}\text { ID. } \\
\text { Solicitação } \\
\text { de } \\
\text { Mudança }\end{array}$ \\
\hline & & & & \\
\hline & & & & \\
\hline
\end{tabular}

Avaliações

\begin{tabular}{|l|l|l|l|l|l|}
\hline $\begin{array}{l}\text { Data da } \\
\text { avaliação }\end{array}$ & $\begin{array}{l}\text { Objetivo } \\
\text { avaliado } \\
\text { (produto ou } \\
\text { processo. No caso } \\
\text { de produto, } \\
\text { discriminar) }\end{array}$ & $\begin{array}{l}\text { Responsáveis } \\
\text { pela avaliação }\end{array}$ & Não conformidades & Sugestões de melhoria & $\begin{array}{l}\text { Data de comunicação } \\
\text { aos interessados }\end{array}$ \\
\hline & & & & & \\
\hline
\end{tabular}




\section{A4.22 - RELATÓRIO DE VIABILIDADE DO PROJETO}

ID documento:

Data: / /

Versão :

Responsável pelo documento:

\section{ID Projeto:}

\section{HISTÓRICO DE REVISÕES}

\begin{tabular}{|l|l|l|l|l|}
\hline $\begin{array}{c}\text { Data de } \\
\text { criação/ } \\
\text { atualização }\end{array}$ & $\begin{array}{c}\text { Descrição da(s) Mudança(s) } \\
\text { Ocorrida(s) }\end{array}$ & Autor & $\begin{array}{c}\text { Versão do } \\
\text { Documento }\end{array}$ & $\begin{array}{c}\text { ID. } \\
\text { Solicitação } \\
\text { de } \\
\text { Mudança }\end{array}$ \\
\hline & & & & \\
\hline & & & & \\
\hline & & & & \\
\hline & & & & \\
\hline & & & & \\
\hline
\end{tabular}

< Apresentar a alternativa definida, considerando as viabilidades técnica, econômica e legal, destacando as vantagens/desvantagens da alternativa com base na relação custo $X$ benefício.>

\section{VIABILIDADE TÉCNICA E ECONÔMICA/FINANCEIRA}

Tabela de Custos

\begin{tabular}{|l|l|l|l|}
\hline COST DRIVER & \multicolumn{1}{|c|}{ Total } \\
\hline & Valor Unitário & Qtde & Tinção \\
\hline & & & \\
\hline & & & \\
\hline & & & \\
\hline & & TOTAL & $\mathrm{R} \$$ \\
\hline
\end{tabular}

\begin{tabular}{|c|c|c|c|}
\hline ESTIMATIVAS DE AQUISIÇÃO & \multicolumn{1}{|c|}{ Data } \\
\cline { 1 - 3 } Produto & $\begin{array}{c}\text { Data Previsão } \\
\text { Recebimento }\end{array}$ & \multicolumn{2}{c|}{ Preço } \\
\hline & & & \\
\hline & & $\begin{array}{c}\text { TOTAL EM } \\
\text { AQUISIÇÃo }\end{array}$ & R\$ \\
\hline
\end{tabular}




\section{RELAÇÃO CUSTO X BENEFÍCIO}

\section{SUGESTÃO DE PREÇO}

\section{CRONOGRAMA DE RECEBIMENTOS}

\begin{tabular}{|l|l|}
\hline Data de Recebimento & Valor \\
\hline & \\
\hline & \\
\hline & \\
\hline & \\
\hline
\end{tabular}

\section{Apêndice: Fluxo de caixa do projeto}

ID:

\section{Fonte: Wikipedia}

http://pt.wikipedia.org/wiki/Fluxo de caixa

http://pt.wikipedia.org/wiki/Dre

A Demonstração do Resultado do Exercício (DRE) é uma demonstração contábil dinâmica que se destina a evidenciar a formação do resultado líquido em um exercício, através do confronto das receitas, custos e despesas, apuradas segundo o princípio contábil do regime de competência.

A DRE oferece uma síntese financeira dos resultados operacionais e não operacionais de uma empresa em certo período. Embora sejam elaboradas anualmente para fins de legais de divulgação, em geral são feitas mensalmente para fins administrativos e trimestralmente para fins fiscais.

Receita é a entrada monetária que ocorre em uma Entidade (Contabilidade) ou patrimônio (Economia), em geral sob a forma de dinheiro ou de créditos representativos de direitos.

Custos são medidas monetárias dos sacrifícios financeiros com os quais uma organização, uma pessoa ou um governo, têm de arcar a fim de atingir seus objetivos, sendo considerados esses ditos objetivos, a utilização de um produto ou serviço qualquer, utilizados na obtenção de outros bens ou serviços. Custos são medidas monetárias resultantes da aplicação de bens e serviços na produção de outros bens e serviços durante o processo de fabricação.

Despesa, para a Contabilidade, é o gasto necessário para a obtenção de receita. As Despesas são gastos que não se identificam com o processo de transformação ou produção dos bens e produtos. 
As despesas estão relacionadas aos valores gastos com a estrutura administrativa e comercial da empresa. Ex: aluguel, salários e encargos, pró-labore, telefone, propaganda, impostos, comissões de vendedores etc. Elas ainda são classificadas em fixas e variáveis, sendo as fixas aquelas cujo valor a ser pago não depende do volume, ou do valor das vendas, enquanto que as variáveis são aquelas cujo valor a ser pago está diretamente relacionado ao valor vendido.

Em Finanças, o fluxo de caixa (designado em inglês por "cash flow"), refere-se ao montante de caixa recebido e gasto por uma empresa durante um período de tempo definido, algumas vezes ligado a um projeto específico.

$\mathrm{Na}$ Contabilidade, uma projeção de fluxo de caixa demonstra todos os pagamentos (direito) e recebimentos esperados em um determinado período de tempo. O controlador de fluxo de caixa necessita de uma visão geral sobre todas as funções da empresa, como: pagamentos, recebimentos, compras de matéria-prima, compras de materiais secundários, salários e outros, por que é necessário prever o que se poderá gastar no futuro dependendo do que se consome hoje.

O fluxo de caixa é uma ótima ferramenta para auxiliar o administrador de determinada empresa nas tomadas de decisões. É através deste "mapa" que os custos fixos e variáveis ficam evidentes, permitindo-se desta forma um controle efetivo sobre determinadas questões empresariais. 


\section{A4.23 - ROTEIRO DE PROSPECÇÃO}

ID documento:

Data: / /

Versão :

Responsável pelo documento:

\section{HISTÓRICO DE REVISÕES}

\begin{tabular}{|l|l|l|l|c|}
\hline $\begin{array}{c}\text { Data de } \\
\text { criação/ } \\
\text { atualização }\end{array}$ & $\begin{array}{c}\text { Descrição da(s) Mudança(s) } \\
\text { Ocorrida(s) }\end{array}$ & Autor & $\begin{array}{c}\text { Versão do } \\
\text { Documento }\end{array}$ & $\begin{array}{c}\text { ID. } \\
\text { Solicitação } \\
\text { de } \\
\text { Mudança }\end{array}$ \\
\hline & & & & \\
\hline & & & & \\
\hline & & & & \\
\hline & & & & \\
\hline & & & & \\
\hline
\end{tabular}

<Devem ser descritos os passos a serem seguidos para a prospecção do cliente, de acordo com as abordagens definidas no item 4 (plano de ação) do "Plano de Marketing".> 


\section{A4.24 - SISTEMA DE GESTÃO DE CONHECIMENTO}

ID documento:

Data: / I

Responsável pelo documento:

HISTÓRICO DE REVISÕES

\begin{tabular}{|l|l|l|l|l|}
\hline $\begin{array}{c}\text { Data de } \\
\text { criação/ } \\
\text { atualização }\end{array}$ & $\begin{array}{c}\text { Descrição da(s) Mudança(s) } \\
\text { Ocorrida(s) }\end{array}$ & Autor & $\begin{array}{c}\text { Versão do } \\
\text { Documento }\end{array}$ & $\begin{array}{c}\text { ID. } \\
\text { Solicitação } \\
\text { de } \\
\text { Mudança }\end{array}$ \\
\hline & & & & \\
\hline & & & & \\
\hline & & & & \\
\hline & & & & \\
\hline & & & & \\
\hline
\end{tabular}

\section{Infra-estrutura}

< Aqui é descrita a infra-estrutura para apoiar a realização das atividades de gestão de conhecimento. Por exemplo, a utilização de alguma ferramenta>

\section{Estratégia}

< Aqui é descrita a estratégia para captura, armazenamento, compartilhamento e utilização do conhecimento.>

\section{Tipologia do conhecimento}

< Aqui é descrita a tipologia do conhecimento, a fim do conhecimento ser classificado para facilitar a sua utilização> 


\section{A4.25 - BANCO DE DADOS DE CONFIGURAÇÃO}

Este template é composto por cinco planilhas: histórico de revisões, itens de configuração, controle de mudanças, planejamento de mudanças e baselines.

\begin{tabular}{|lr|}
\hline HISTORICO & DE \\
REVISÕES & DO \\
DOCUMENTO & \\
\hline
\end{tabular}

\begin{tabular}{|l|c|c|c|c|}
\hline Data de criação/ atualização & $\begin{array}{c}\text { Descrição da(s) Mudança(s) } \\
\text { Ocorrida(s) }\end{array}$ & Autor & Versão do Documento & $\begin{array}{c}\text { ID. Solicitação de } \\
\text { Mudança }\end{array}$ \\
\hline & & & & \\
\hline & & & & \\
\hline & & & & \\
\hline
\end{tabular}

Planilha - Histórico de Revisões

\begin{tabular}{|c|c|c|c|c|}
\hline Id. Item Configuração & DocReq_EMP & & & \\
\hline Responsável & Engenheiro de Requisitos (Pedro) & & & \\
\hline Data Criação/Atualização & $01 / 10 / 08$ & & & \\
\hline Versões do IC & V0.1 & & & \\
\hline Status da versão do IC & em desenvolvimento & & & \\
\hline Id. solicitação de mudança & Mudança_EMP_0001 & & & \\
\hline Data de início da realização da mudança & $5 / 10 / 2008$ & & & \\
\hline Data de término da realização da mudança & $6 / 10 / 2008$ & & & \\
\hline Descrição da Mudança Ocorrida & Foram adicionados novos requisitos & & & \\
\hline \multicolumn{5}{|l|}{ Verificação/Validação } \\
\hline \multicolumn{5}{|l|}{ Comentários } \\
\hline Id. Item Configuração & PlanoProj_EMP & & & \\
\hline \multicolumn{5}{|l|}{ Responsável } \\
\hline \multicolumn{5}{|l|}{ Data Criação/Atualização } \\
\hline Versões do IC & V0.1 & & & \\
\hline Status da versão do IC & em desenvolvimento & baselined & liberada & \\
\hline \multicolumn{5}{|l|}{ Id. solicitação de mudança } \\
\hline \multicolumn{5}{|l|}{ Data de início da realização da mudança } \\
\hline \multicolumn{5}{|l|}{ Data de término da realização da mudança } \\
\hline \multicolumn{5}{|l|}{ Descrição da Mudança Ocorrida } \\
\hline \multicolumn{5}{|l|}{ Verificação/Validação } \\
\hline Comentários & & & & \\
\hline
\end{tabular}

Planilha - Itens de Configuração

\begin{tabular}{|c|c|c|c|c|c|c|c|c|c|}
\hline $\begin{array}{l}\text { Id. Solicitação de } \\
\text { Mudança }\end{array}$ & $\begin{array}{c}\text { Descrição da } \\
\text { Mudança a ser } \\
\text { realizada }\end{array}$ & $\begin{array}{l}\text { Tipo de Mudança } \\
\text { (simples ou } \\
\text { complexa) }\end{array}$ & $\begin{array}{c}\text { Origem (interna ou } \\
\text { externa) }\end{array}$ & $\begin{array}{c}\text { Data de } \\
\text { solicitação }\end{array}$ & Solicitante & $\begin{array}{c}\text { Autorização } \\
\text { (sim/não) }\end{array}$ & $\begin{array}{c}\text { Data da } \\
\text { autorização/não } \\
\text { autorização }\end{array}$ & $\begin{array}{l}\text { Quem autorizou/ } \\
\text { não autorizou }\end{array}$ & $\begin{array}{l}\text { Id. do } \\
\text { Contrato }\end{array}$ \\
\hline & & & & & & & & & \\
\hline & & & & & & & & & \\
\hline & & & & & & & & & \\
\hline & & & & & & & & & \\
\hline & & & & & & & & & \\
\hline
\end{tabular}

Planilha - Controle de Mudanças

\begin{tabular}{|c|c|c|c|c|c|c|c|c|c|c|}
\hline $\begin{array}{l}\text { Id. Solicitação } \\
\text { de Mudança }\end{array}$ & $\begin{array}{c}\text { Responsável pelo } \\
\text { planejamento da } \\
\text { mudança }\end{array}$ & $\begin{array}{c}\text { Esforço Total } \\
\text { estimado }\end{array}$ & \begin{tabular}{|c|} 
Data Estimada \\
do Início da \\
realização da \\
mudança \\
\end{tabular} & \begin{tabular}{|c|} 
Data Estimada do \\
Término da \\
realização da \\
mudança
\end{tabular} & $\begin{array}{l}\text { Colaboradores } \\
\text { estimados }\end{array}$ & ID Cronograma & \begin{tabular}{|l|} 
ID dos itens de \\
configuraçáo a \\
serem afetados
\end{tabular} & $\begin{array}{c}\text { Custo para } \\
\text { efetivação da } \\
\text { mudança }\end{array}$ & \begin{tabular}{|c|} 
Alteração do \\
contrato? \\
("sim"/"não")
\end{tabular} & Comentários \\
\hline & & & & & & & & & & \\
\hline & & & & & & & & & & \\
\hline & & & & & & & & & & \\
\hline & & & & & & & & & & \\
\hline & & & & & & & & & & \\
\hline
\end{tabular}

Planilha - Planejamento de Mudanças 


\begin{tabular}{|l|l|}
\hline Identificador da Baseline & Baseline_EMP_0001 \\
\hline Gerente de Projeto que autorizou & Ana \\
\hline Data de autorização/criação & \\
\hline Status & liberada \\
\hline \multirow{4}{*}{ Itens de configuração e versões } & DocReq_EMP_V0.1 \\
\cline { 2 - 2 } & PlanoProj_EMP_V0.1 \\
\cline { 2 - 2 } & \\
\cline { 2 - 2 } & \\
\cline { 2 - 2 } & \\
\cline { 2 - 2 } & \\
\cline { 2 - 2 } & \\
\cline { 2 - 2 } & \\
\end{tabular}

\begin{tabular}{|l|l|}
\hline Identificador da Baseline & \\
\hline Gerente de Projeto que autorizou & \\
\hline Data de autorização/criação & \\
\hline Status & bloqueada \\
\hline \multirow{4}{*}{ Itens de configuração e versões } & \\
\cline { 2 - 2 } \cline { 2 - 2 } & \\
\cline { 2 - 2 } & \\
\cline { 2 - 2 } & \\
\cline { 2 - 2 } & \\
\cline { 2 - 2 } & \\
\cline { 2 - 2 } & \\
\end{tabular}

Planilha - Baselines 


\section{A4.26 - CONTROLE DE PROJETOS}

Este template é composto por nove planilhas: histórico de revisões, identificação de projetos, acompanhamento de projetos, identificação de recursos, alocação de recursos, identificação de colaboradores, alocação de colaboradores, notas fiscais e duplicatas.

\begin{tabular}{lr}
\hline HISTÓRICO & DE \\
REVISÕES & DO \\
DOCUMENTO & \\
\hline
\end{tabular}

\begin{tabular}{|l|c|c|c|c|}
\hline Data de criação/ atualização & $\begin{array}{c}\text { Descrição da(s) Mudança(s) } \\
\text { Ocorrida(s) }\end{array}$ & Autor & Versão do Documento & $\begin{array}{c}\text { ID. Solicitação de } \\
\text { Mudança }\end{array}$ \\
\hline & & & & \\
\hline & & & & \\
\hline & & & & \\
\hline
\end{tabular}

Planilha - Histórico de Revisões

\begin{tabular}{|c|c|c|c|}
\hline ID Projeto & Descrição & Pasta Física & Pasta Lógica \\
\hline projeto 1 & & sim & sim \\
\hline projeto 2 & & & \\
\hline projeto 3 & & & \\
\hline
\end{tabular}

Planilha - Identificação de Projetos

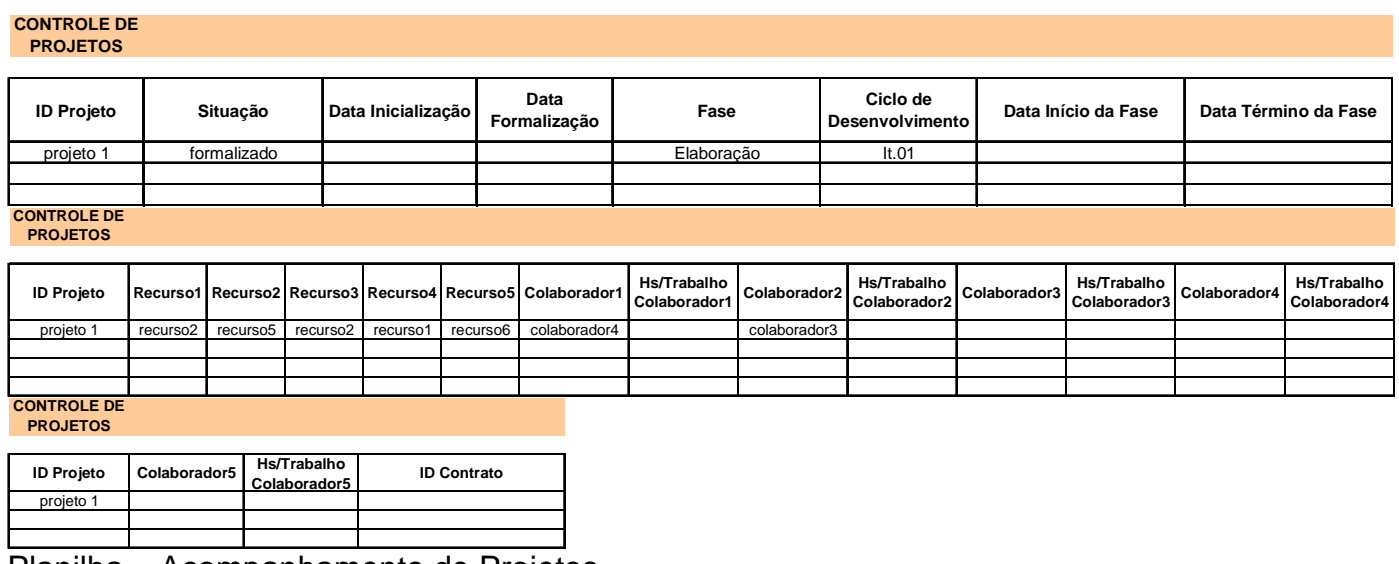

Planilha - Acompanhamento de Projetos

\begin{tabular}{|l|l|l|}
\hline Id. Recurso & Descrição & Tipo \\
\hline & recurso1 & hardware \\
\hline & recurso2 & hardware \\
\hline & recurso3 & plataforma \\
\hline & recurso4 & \\
\hline
\end{tabular}

Planilha - Identificação de Recursos

\begin{tabular}{|l|l|l|l|l|}
\hline \multicolumn{1}{|c|}{ Recurso } & Data de Alocação & $\begin{array}{c}\text { Previsão de término } \\
\text { da alocação }\end{array}$ & Status & Id. Projeto \\
\hline recurso1 & & & reservado & projeto 1 \\
\hline & & & & \\
\hline
\end{tabular}

Planilha - Alocação de Recursos 


\begin{tabular}{|l|l|l|l|l|}
\hline Id. Colaborador & Descrição & Categoria de Conhecimento & Conhecimento & Nível \\
\hline & colaborador1 & Design & Junior \\
\hline & colaborador2 & Requisitos & elicitar requisitos & Trainee \\
\hline & colaborador3 & & & \\
\hline & colaborador4 & & & \\
\hline & colaborador5 & & & \\
\hline
\end{tabular}

Planilha - Identificação de Colaboradores

\begin{tabular}{|l|l|l|l|l|}
\hline \multicolumn{1}{|c|}{ Colaborador } & Data de Alocação & $\begin{array}{c}\text { Previsão de término } \\
\text { da alocação }\end{array}$ & Status & Id. Projeto \\
\hline colaborador1 & & & alocado & projeto 2 \\
\hline colaborador3 & & & & \\
\hline & & & & \\
\hline & & & & \\
\hline
\end{tabular}

Planilha - Alocação de Colaboradores

\begin{tabular}{|l|l|l|l|l|l|}
\hline Cliente & Data de emissão & Valor & Valor da Alíquota & Valor Total da Nota & ID Projeto \\
\hline nome do cliente/empresa3 & & $\mathrm{R} \$ 5.000,00$ & & $\mathrm{R} \$$ & $5.000,00$ \\
\hline & & & & & projeto 1 \\
\hline & & & & & \\
\hline & & & & & \\
\hline
\end{tabular}

Planilha - Notas Fiscais

\begin{tabular}{|c|c|c|c|c|}
\hline Nr da Duplicata & Data de Vencimento & Valor & № da NF & Status \\
\hline 1 & $10 / 10 / 2008$ & $2.500,00$ & 1 & paga \\
\hline 2 & $10 / 11 / 2008$ & $2.500,00$ & 1 & emitida \\
\hline
\end{tabular}

Planilha - Duplicatas 


\section{A4.27 - CONTROLE DE TAREFAS}

Este template é composto por duas planilhas: histórico de revisões e lista de tarefas.

\begin{tabular}{|ll|}
\hline HISTÓRICO & DE \\
REVISÕES & DO \\
DOCUMENTO & \\
\hline
\end{tabular}

\begin{tabular}{|l|c|c|c|c|}
\hline Data de criação/ atualização & $\begin{array}{c}\text { Descrição da(s) Mudança(s) } \\
\text { Ocorrida(s) }\end{array}$ & Autor & Versão do Documento & $\begin{array}{c}\text { ID. Solicitação de } \\
\text { Mudança }\end{array}$ \\
\hline & & & & \\
\hline & & & & \\
\hline
\end{tabular}

Planilha - Histórico de Revisões

\begin{tabular}{|l|l|}
\hline ID Projeto: & \\
\hline
\end{tabular}

\begin{tabular}{|c|c|c|c|c|}
\hline Tarefas & $\begin{array}{c}\text { Tempo máximo (de } \\
\text { acordo com o } \\
\text { estabelecido no } \\
\text { cronograma) }\end{array}$ & Início & $\begin{array}{c}\text { Qtde de } \\
\text { hs/trabalhadas no dia }\end{array}$ & Término \\
\hline Tarefa1 & $16 \mathrm{hs}$ & $22 / 10 / 2008$ & $4 \mathrm{hs}$ & \\
\hline & & $23 / 10 / 2008$ & $8 \mathrm{hs}$ & \\
\hline & & $24 / 10 / 2008$ & $4 \mathrm{hs}$ & $24 / 10 / 2008$ \\
\hline Tarefa 2 & & & & \\
\hline & & & & \\
\hline & & & & \\
\hline & & & & \\
\hline
\end{tabular}

Planilha - Lista de Tarefas 


\section{A4.28 - CRONOGRAMA}

Este template é composto por duas planilhas: histórico de revisões e cronograma.

\begin{tabular}{|ll|}
\hline HISTÓRICO & DE \\
REVISÕES & DO \\
DOCUMENTO & \\
\hline
\end{tabular}

\begin{tabular}{|l|c|c|c|c|}
\hline Data de criação/ atualização & $\begin{array}{c}\text { Descrição da(s) Mudança(s) } \\
\text { Ocorrida(s) }\end{array}$ & Autor & Versão do Documento & $\begin{array}{c}\text { ID. Solicitação de } \\
\text { Mudança }\end{array}$ \\
\hline & & & & \\
\hline & & & & \\
\hline & & & & \\
\hline
\end{tabular}

Planilha - Histórico de Revisões

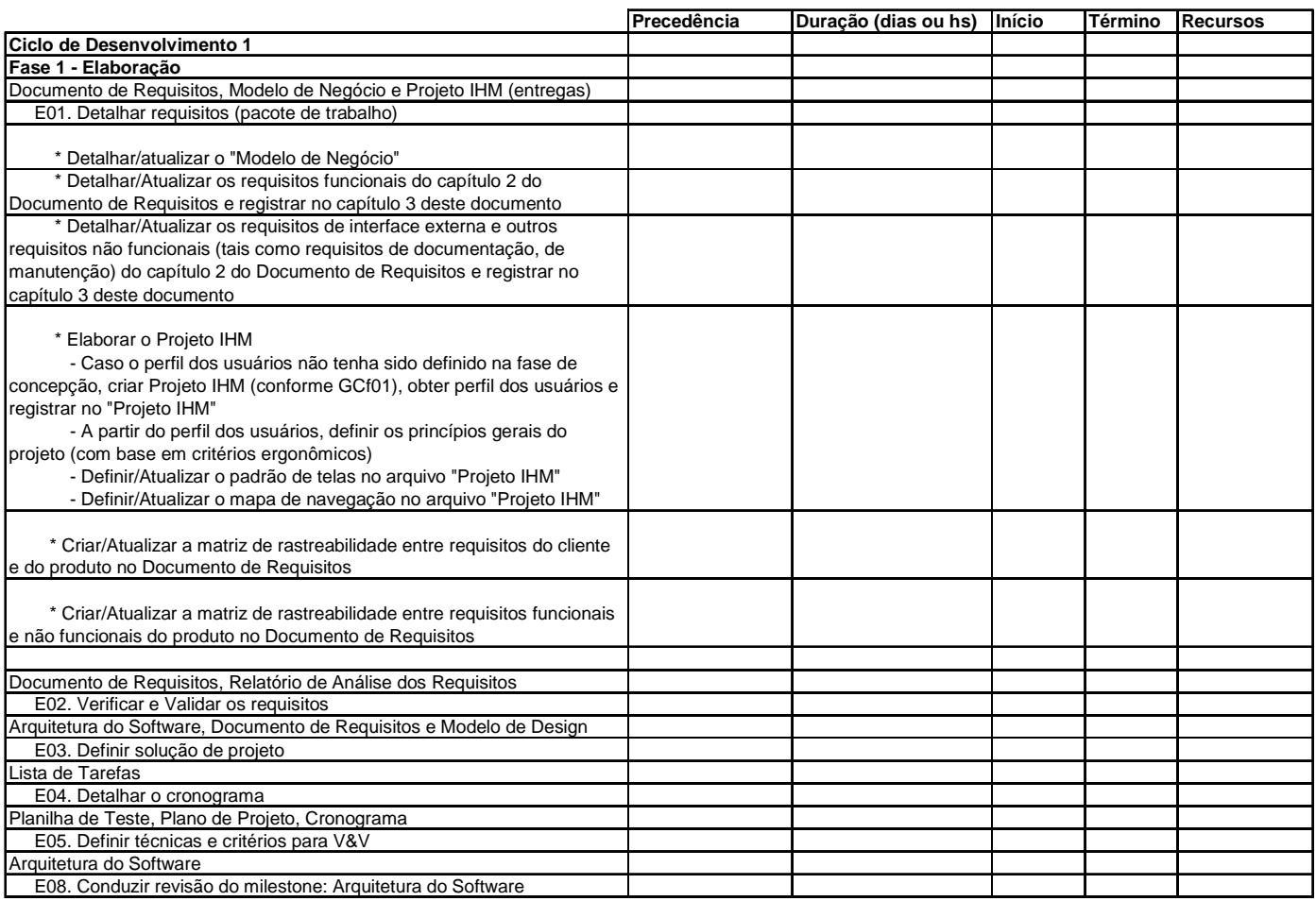

Planilha - Cronograma 
Este template é composto por dez planilhas: histórico de revisões, investimentos, despesas fixas, mão de obra, despesas variáveis, impostos, receitas, DRE, projeção de fluxo de caixa e demonstrativo de receita e despesas.

\begin{tabular}{ll}
\hline HISTORICO & DE \\
REVISÕES & DO \\
DOCUMENTO
\end{tabular}

\begin{tabular}{|l|c|c|c|c|}
\hline Data de criação/ atualização & $\begin{array}{c}\text { Descrição da(s) Mudança(s) } \\
\text { Ocorrida(s) }\end{array}$ & Autor & Versão do Documento & $\begin{array}{c}\text { ID. Solicitação de } \\
\text { Mudança }\end{array}$ \\
\hline & & & & \\
\hline & & & & \\
\hline & & & & \\
\hline
\end{tabular}

Planilha - Histórico de Revisões

\begin{tabular}{|l|l|l|l|}
\hline \multicolumn{1}{|c|}{ Descrição } & Qtde & Valor Unitário & Valor Total \\
\hline Infra-estrutura necessária & & & \\
\hline Hardware & & & \\
\hline Software & & & \\
\hline $\begin{array}{l}\text { Tempo necessário para } \\
\text { desenvolvimento do } \\
\text { produto padrão (se for o } \\
\text { caso) }\end{array}$ & & & \\
\hline $\begin{array}{l}\text { Outros tipos de } \\
\text { investimento inicial }\end{array}$ & & & \\
\hline
\end{tabular}

Planilha - Investimentos

\begin{tabular}{|c|c|c|c|c|c|c|c|c|c|c|c|c|}
\hline Descrição & Mês 1 & Mês 2 & Mês 3 & Mês 4 & Mês 5 & Mês 6 & Mês 7 & Mês 8 & Mês 9 & Mês 10 & Mês 11 & Mês 12 \\
\hline PRO-LABORE DOS SOCIOS & & & & & & & & & & & & \\
\hline 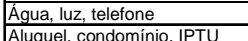 & & & & & & & & & & & & \\
\hline Escritório de Contabilidade & & & & & & & & & & & & \\
\hline Limpeza & & & & & & & & & & & & \\
\hline Tarifas Bancárias & & & & & & & & & & & & \\
\hline \begin{tabular}{|l} 
Marketing \& Publicidade \\
ard
\end{tabular} & & & & & & & & & & & & \\
\hline $\begin{array}{l}\text { Internet } \\
\text { Treinamentos e Viagens }\end{array}$ & & & & & & & & & & & & \\
\hline $\begin{array}{l}\text { Treinamentos e Viagens } \\
\text { Manutencão e Conservaçăo }\end{array}$ & & & & & & & & & & & & \\
\hline $\begin{array}{l}\mid \text { Monulençao e Conservaçao } \\
\text { Total }\end{array}$ & $R \$$ & $1 \mathrm{R} \$$ & $\mathrm{R} \$$ & $\mathrm{R} \$$ & $\mathrm{R} \$$ & $\mathrm{R} \$$ & $\mathrm{R} \$$ & $\mathrm{R} \$$ & $\mathrm{R} \$$ & $\mathrm{R} \$$ & $\mathrm{R} \$$ & $\mathrm{R} \$$ \\
\hline
\end{tabular}

Planilha - Despesas Fixas

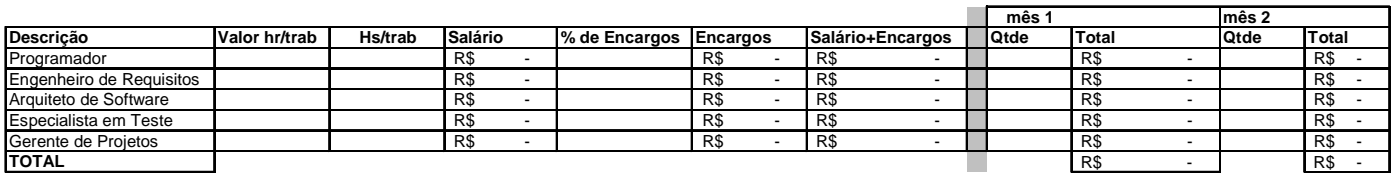

Planilha - Mão de obra

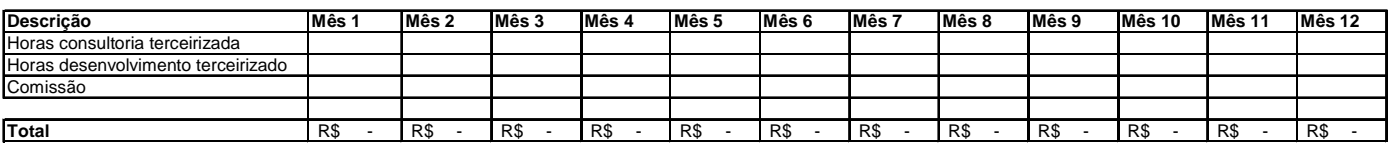

Planilha - Despesas Variáveis

\begin{tabular}{|l|l|c|}
\hline Descrição & Alíquota & Incidência \\
\hline Impostos Federais & & receita \\
\hline Impostos Estaduais & & receita \\
\hline Impostos Municipais & & receita \\
\hline
\end{tabular}

Planilha - Impostos 


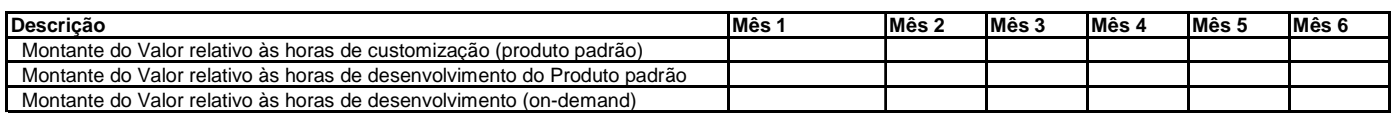

Planilha - Receitas

\section{DEMONSTRAÇÃO DE RESULTADO}

\begin{tabular}{|c|c|c|c|c|c|c|c|c|c|c|}
\hline & \multicolumn{2}{|c|}{ Mês 1} & \multicolumn{2}{|c|}{ Mês 2} & \multicolumn{2}{|c|}{ Mês 3} & \multicolumn{2}{|c|}{ Mês 4} & \multicolumn{2}{|c|}{ Mês 5} \\
\hline Receita Bruta & $\mathrm{R} \$$ & - & $\mathrm{R} \$$ & - & $\mathrm{R} \$$ & - & $\mathrm{R} \$$ & - & $\mathrm{R} \$$ & - \\
\hline $\begin{array}{l}\text { Montante do Valor relativo às horas de } \\
\text { customização (produto padrão) }\end{array}$ & $R \$$ & - & $\mathrm{R} \$$ & - & $\mathrm{R} \$$ & - & $\mathrm{R} \$$ & - & $\mathrm{R} \$$ & - \\
\hline $\begin{array}{l}\text { Montante do Valor relativo às horas de } \\
\text { desenvolvimento do Produto padrão }\end{array}$ & $R \$$ & - & $\mathrm{R} \$$ & - & $\mathrm{R} \$$ & - & $\mathrm{R} \$$ & - & $\mathrm{R} \$$ & - \\
\hline $\begin{array}{l}\text { Montante do Valor relativo às horas de } \\
\text { desenvolvimento (on-demand) }\end{array}$ & $R \$$ & - & $\mathrm{R} \$$ & - & $\mathrm{R} \$$ & - & $\mathrm{R} \$$ & - & $\mathrm{R} \$$ & - \\
\hline$(-)$ Impostos & $\mathrm{R} \$$ & - & $\mathrm{R} \$$ & - & $\mathrm{R} \$$ & - & $\mathrm{R} \$$ & - & $\mathrm{R} \$$ & - \\
\hline ( - ) Comissão & $\mathrm{R} \$$ & - & $\mathrm{R} \$$ & - & $\mathrm{R} \$$ & - & $\mathrm{R} \$$ & - & $\mathrm{R} \$$ & - \\
\hline ( - ) Demais Despesas Variáveis & $\mathrm{R} \$$ & - & $\mathrm{R} \$$ & - & $\mathrm{R} \$$ & - & $\mathrm{R} \$$ & - & $\mathrm{R} \$$ & - \\
\hline ( = ) Receita Líquida & $\mathrm{R} \$$ & - & $\mathrm{R} \$$ & - & $\mathrm{R} \$$ & - & $\mathrm{R} \$$ & - & $\mathrm{R} \$$ & - \\
\hline ( - ) Investimento Inicial & $\mathrm{R} \$$ & - & & & & & & & & \\
\hline $\begin{array}{l}\text { ( - ) Custo do trabalho de } \\
\text { customização/desenvolvimento }\end{array}$ & $\mathrm{R} \$$ & - & $\mathrm{R} \$$ & - & $\mathrm{R} \$$ & - & $\mathrm{R} \$$ & - & $\mathrm{R} \$$ & - \\
\hline $\begin{array}{l}\text { ( - ) Custo do desenvolvimento do produtc } \\
\text { padrão }\end{array}$ & & & & & & & & & & \\
\hline ( = ) Margem Contribuição & $\mathrm{R} \$$ & - & $\mathrm{R} \$$ & - & $\mathrm{R} \$$ & - & $\mathrm{R} \$$ & - & $R \$$ & - \\
\hline ( - ) Despesas Fixas & $\mathrm{R} \$$ & - & $\mathrm{R} \$$ & - & $\mathrm{R} \$$ & - & $\mathrm{R} \$$ & - & $R \$$ & - \\
\hline ( = ) Resultado Final & $\mathrm{R} \$$ & - & $\mathrm{R} \$$ & - & $\mathrm{R} \$$ & - & $\mathrm{R} \$$ & - & $\mathrm{R} \$$ & - \\
\hline
\end{tabular}

Planilha - DRE

\section{\begin{tabular}{|l|l|}
\hline ID PROJETO & \\
\hline
\end{tabular}}

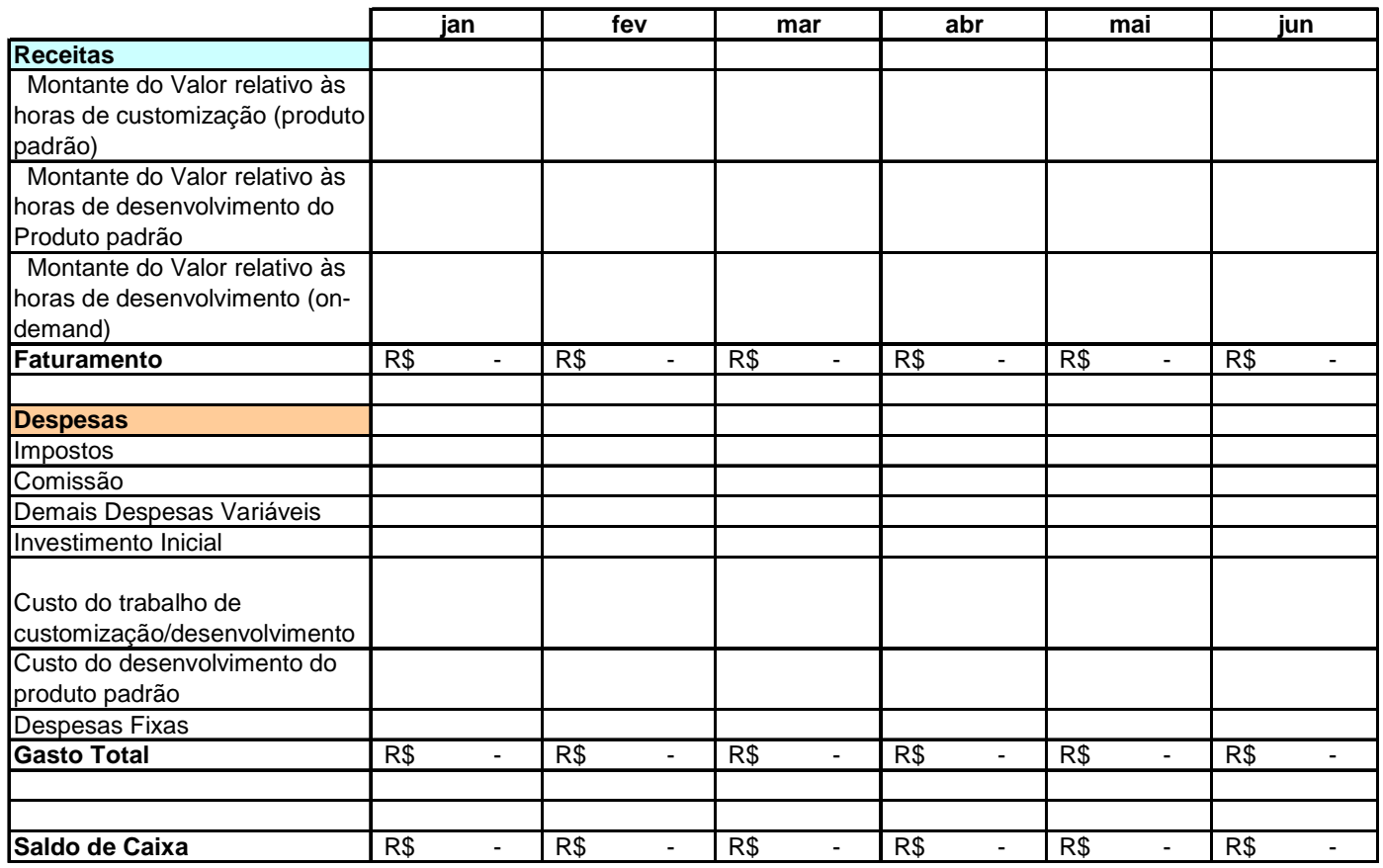

Planilha - Projeção de Fluxo de Caixa 
DEMONSTRATIVO DE RECEITAS E DESPESAS DO ANO DE 2008

\begin{tabular}{|c|c|c|c|c|c|c|}
\hline & \multicolumn{2}{|c|}{ Janeiro } & \multicolumn{2}{|c|}{ Fevereiro } & \multicolumn{2}{|c|}{ Março } \\
\hline & Valor & $\begin{array}{c}\text { \% Relação } \\
\text { (Receita X } \\
\text { Despesa) }\end{array}$ & Valor & $\begin{array}{c}\text { \% Relação } \\
\text { (Receita X } \\
\text { Despesa) }\end{array}$ & Valor & $\begin{array}{c}\text { \% Relação } \\
\text { (Receita X } \\
\text { Despesa) }\end{array}$ \\
\hline \multicolumn{7}{|l|}{ Receita } \\
\hline Venda de Software & $5.000,00$ & & $2.300,00$ & & $3.000,00$ & \\
\hline \multirow[t]{4}{*}{ Mensalidades } & $2.000,00$ & & $2.300,00$ & & $2.600,00$ & \\
\hline & ----------- & & 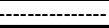 & & 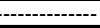 & \\
\hline & $7.000,00$ & & $4.600,00$ & & $5.600,00$ & \\
\hline & & & & & & \\
\hline \multicolumn{7}{|l|}{ Despesas } \\
\hline PRO-LABORE DOS SÓCIOS & 700,00 & 10,00 & 900,00 & 19,57 & $1.200,00$ & 21,43 \\
\hline Água, luz, telefone & 300,00 & 4,29 & 300,00 & 6,52 & 300,00 & 5,36 \\
\hline Aluguel, condomínio, IPTU & 200,00 & 2,86 & 200,00 & 4,35 & 200,00 & 3,57 \\
\hline Escritório de Contabilidade & 30,00 & 0,43 & 30,00 & 0,65 & 30,00 & 0,54 \\
\hline Limpeza & 20,00 & 0,29 & 20,00 & 0,43 & 20,00 & 0,36 \\
\hline Tarifas Bancárias & 50,00 & 0,71 & 50,00 & 1,09 & 50,00 & 0,89 \\
\hline Marketing \& Publicidade & 30,00 & 0,43 & 30,00 & 0,65 & 30,00 & 0,54 \\
\hline Internet & 50,00 & 0,71 & 50,00 & 1,09 & 50,00 & 0,89 \\
\hline Treinamentos e Viagens & 60,00 & 0,86 & 60,00 & 1,30 & 60,00 & 1,07 \\
\hline Manutenção e Conservação & 230,00 & 3,29 & 230,00 & 5,00 & 230,00 & 4,11 \\
\hline Folha de Pagemento & 800,00 & 11,43 & 800,00 & 17,39 & 800,00 & 14,29 \\
\hline \multirow[t]{3}{*}{ Investimentos } & 0,00 & 0,00 & 200,00 & 4,35 & 0,00 & 0,00 \\
\hline & $\begin{array}{ll}--\cdot- \\
-\cdots-\end{array}$ & & -------------- & & ------------ & \\
\hline & $1.670,00$ & 23,86 & $1.870,00$ & 40,65 & $2.170,00$ & 38,75 \\
\hline
\end{tabular}

\begin{tabular}{|l|r|c|c|}
\hline Lucro & $5.330,00$ & $2.730,00$ & $3.430,00$ \\
\hline
\end{tabular}

Planilha - Demonstrativo de Receitas e Despesas 


\section{A4.30 - LIÇÕES APRENDIDAS E CONHECIMENTO}

Este template é composto por duas planilhas: lições aprendidas e conhecimento.

\begin{tabular}{|l|l|l|}
\cline { 2 - 3 } \multicolumn{2}{c|}{} & \multicolumn{2}{c|}{ TIPO } \\
\hline Lições Aprendidas & Area de conhecimento & \\
\hline & & \\
\hline & & \\
\hline & & \\
\hline & & \\
\hline
\end{tabular}

Planilha - Lições Aprendidas

\begin{tabular}{|l|l|l|l|}
\hline Conhecimento & Área de conhecimento & Elemento \\
\hline & & & \\
\hline & & \\
\hline & & \\
\hline & & \\
\hline
\end{tabular}

Planilha - Conhecimento

Exemplo de Tipologia

Área de conhecimento

Engenharia de Requisitos

Planejamento de Projeto

Monitoramento e Controle de Projeto

Garantia da Qualidade

Medição

Design

Codificacão

Testes

Revisões Formais

Estimativas

Gestão de Mudanças e Configuração

Gestão de Requisitos

Templates

Atividades

Tarefas

Recursos 


\section{A4.31 - LISTA DE CONTATOS}

Este template é composto por três planilhas: histórico de revisões, lista de contatos e controle de visitas.

\begin{tabular}{|ll|}
\hline HISTÓRICO & DE \\
REVISÕES & DO \\
DOCUMENTO & \\
\hline
\end{tabular}

\begin{tabular}{|l|c|c|c|c|}
\hline Data de criação/ atualização & $\begin{array}{c}\text { Descrição da(s) Mudança(s) } \\
\text { Ocorrida(s) }\end{array}$ & Autor & Versão do Documento & $\begin{array}{c}\text { ID. Solicitação de } \\
\text { Mudança }\end{array}$ \\
\hline & & & & \\
\hline & & & & \\
\hline & & & & \\
\hline
\end{tabular}

Planilha - Histórico de Revisões

\begin{tabular}{|c|l|l|l|l|l|l|}
\hline Contatos Validados & Endereço Completo & Telefones & E-mails para contato & $\begin{array}{c}\text { Contato chave dentro } \\
\text { da empresa }\end{array}$ & $\begin{array}{c}\text { Gargalose } \\
\text { necessidades da } \\
\text { empresa }\end{array}$ & $\begin{array}{c}\text { Atividades e Soluçöes } \\
\text { Utilizadas na Empresa } \\
\text { e nivel de satisfação }\end{array}$ \\
\hline nome do cliente/empresa1 & & & & & & \\
\hline nome do cliente/empresa2 & & & & & & \\
\hline nome do cliente//mpresa3 & & & & & & \\
\hline nome do cliente/empresa4 & & & & & \\
\hline
\end{tabular}

Planilha - Lista de Contatos

\begin{tabular}{|l|c|c|c|c|c|c|c|}
\hline Contatos Validados & $\begin{array}{c}\text { Data de E- } \\
\text { mail } \\
\text { marketing }\end{array}$ & $\begin{array}{c}\text { Data do } \\
\text { Contato } \\
\text { Telefônico }\end{array}$ & $\begin{array}{c}\text { Interesse } \\
\text { por } \\
\text { proposta }\end{array}$ & $\begin{array}{c}\text { Data da } \\
\text { Visita }\end{array}$ & $\begin{array}{c}\text { Data de } \\
\text { Solicitação } \\
\text { pelo cliente da } \\
\text { Proposta }\end{array}$ & $\begin{array}{c}\text { Data de Envio } \\
\text { da Proposta } \\
\text { para o cliente }\end{array}$ & Data de Fechamento \\
\hline nome do cliente/empresa & $25 / 08 / 08$ & $30 / 08 / 08$ & sim & $05 / 09 / 08$ & $05 / 09 / 08$ & $07 / 09 / 08$ & cancelado - 20/09/2008 \\
\hline & & & & & & & \\
\hline
\end{tabular}

Planilha - Controle de Visitas 


\section{A4.32 - MEMÓRIA ORGANIZACIONAL}

Este template é composto pela planilha: memória organizacional.

\begin{tabular}{|l|l|l|l|}
\hline Conhecimento & Area de conhecimento & Elemento \\
\hline & & & \\
\hline & & & \\
\hline & & \\
\hline & & \\
\hline
\end{tabular}

Planilha - Memória Organizacional

Exemplo de Tipologia

Area de conhecimento

Engenharia de Requisitos

Planejamento de Projeto

Monitoramento e Controle de Projeto

Garantia da Qualidade

Medição

Design

Codificação

Testes

Revisões Formais

Estimativas

Gestão de Mudanças e Configuração

Gestão de Requisitos

\begin{tabular}{|l|}
\hline Elementos \\
\hline Templates \\
\hline Atividades \\
\hline Tarefas \\
\hline Recursos \\
\hline
\end{tabular}




\section{A4.33 - PLANILHA DE TESTE}

Este template é composto por quatro planilhas: histórico de revisões, casos de teste de unidade, casos de teste de integração e casos de teste de validação.

\begin{tabular}{|ll|}
\hline HISTÓRICO & DE \\
REVISÕES & DO \\
DOCUMENTO & \\
\hline
\end{tabular}

\begin{tabular}{|l|c|c|c|c|}
\hline Data de criação/ atualização & $\begin{array}{c}\text { Descrição da(s) Mudança(s) } \\
\text { Ocorrida(s) }\end{array}$ & Autor & Versão do Documento & $\begin{array}{c}\text { ID. Solicitação de } \\
\text { Mudança }\end{array}$ \\
\hline & & & & \\
\hline & & & & \\
\hline
\end{tabular}

Planilha - Histórico de Revisões

ID Projeto:
\begin{tabular}{|l|l|l|}
\hline Critério de Teste: & \multicolumn{2}{|c|}{} \\
\hline Casos de Teste Definidos & Resultado Esperado & Resultado Obtido \\
\hline & & \\
\hline & & \\
\hline & & \\
\hline & & \\
\hline & & \\
\hline & & \\
\hline
\end{tabular}

\begin{tabular}{|l|l|l|}
\hline Critério de Teste: & \multicolumn{2}{|c|}{} \\
\hline Casos de Teste Definidos & Resultado Esperado & Resultado Obtido \\
\hline & & \\
\hline & & \\
\hline & & \\
\hline & & \\
\hline & & \\
\hline & & \\
\hline
\end{tabular}

Testes de regressão

\begin{tabular}{|l|l|l|}
\hline Casos de Teste Definidos & Resultado Esperado & Resultado Obtido \\
\hline & & \\
\hline & & \\
\hline & & \\
\hline & & \\
\hline & & \\
\hline & & \\
\hline
\end{tabular}

Planilha - Casos de Teste de Unidade, de Teste de Integração e de Teste de Validação 


\section{A4.34 - PLANO DE AÇÃO}

Este template é composto por três planilhas: histórico de revisões, plano de ação e acompanhamento.

\begin{tabular}{|ll|}
\hline HISTÓRICO & DE \\
REVISÕES & DO \\
DOCUMENTO & \\
\hline
\end{tabular}

\begin{tabular}{|l|c|c|c|c|}
\hline Data de criação/ atualização & $\begin{array}{c}\text { Descrição da(s) Mudança(s) } \\
\text { Ocorrida(s) }\end{array}$ & Autor & Versão do Documento & $\begin{array}{c}\text { ID. Solicitação de } \\
\text { Mudança }\end{array}$ \\
\hline & & & & \\
\hline & & & & \\
\hline
\end{tabular}

Planilha - Histórico de Revisões

PLANO DE AÇÃO

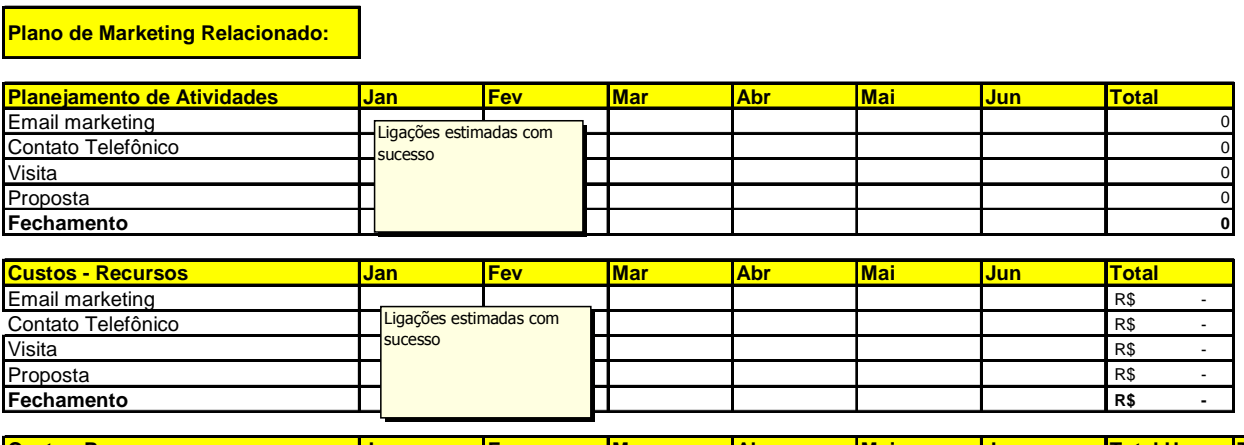

\begin{tabular}{|c|c|c|c|c|c|c|c|c|c|}
\hline Custo - Pessoas & Jan & Fev & Mar & $A b r$ & Mai & Jun & Total Hs & Total R\$ & \\
\hline Nome1 & & & & & & & & $\begin{array}{ll}0 \mathrm{R} \$ \\
\end{array}$ & - \\
\hline Nome2 & & & & & & & 0 & $\begin{array}{ll}0 & R \$ \\
\end{array}$ & - \\
\hline Nome3 & & & & & & & & \begin{tabular}{l|l}
0 & $R \$$ \\
\end{tabular} & - \\
\hline \begin{tabular}{|l|} 
Nome4 \\
\end{tabular} & & & & & & & & \begin{tabular}{l|l|}
0 & $R \$$ \\
\end{tabular} & - \\
\hline Total & 0 & 0 & 0 & 0 & 0 & 0 & & \begin{tabular}{l|l}
0 & $\mathbf{R} \$$ \\
\end{tabular} & - \\
\hline
\end{tabular}

\begin{tabular}{|l|l|}
\hline Pessoas & $\begin{array}{l}\text { Valor } \\
\text { hr/trab }\end{array}$ \\
\hline Nome1 & \\
\hline Nome2 & \\
\hline Nome3 & \\
\hline Nome4 & \\
\hline
\end{tabular}

Total Geral

R\$ -

Planilha - Plano de Ação

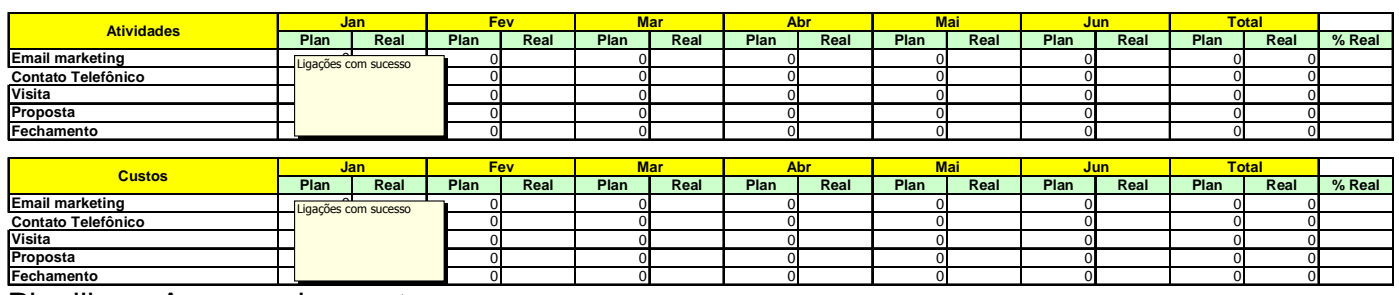

Planilha - Acompanhamento 


\section{Apêndice 5 - Modelo ProcSoftVD (Mapeamento com o CMMI e ISO/IEC 15504)}

O Quadro A5.1 apresenta uma legenda com os símbolos (e suas respectivas descrições), utilizados no mapeamento das atividades do Modelo ProcSoftVD com o CMMI-DEV e ISO/IEC 15504-5 (Quadros A5.2 a A5.7).

Quadro A5.1 - Legenda do Mapeamento das Atividades

\begin{tabular}{|l|}
\hline Fases \\
\hline P - Prospecção \\
\hline CP - Concepção \\
\hline N - Negociação \\
\hline - Elaboração \\
\hline Ct - Construção \\
\hline T - Transição \\
\hline Áreas de Conhecimento \\
\hline ACQ - Aquisição \\
\hline GqPP - Garantia de Qualidade de Produto e Processo \\
\hline GCf - Gestão de Mudanças e Configuração \\
\hline GCo - Gestão de Conhecimento \\
\hline CMMI - Capability Maturity Model Integration (DEV - Development) \\
\hline SP - Specific Practices (práticas específicas) \\
\hline RD - Requeriments Development (Desenvolvimento de Requisitos) \\
\hline REQM - Requeriments Management (Gestão de Requisitos) \\
\hline PP - Project Planning (Planejamento de Projeto) \\
\hline VER - Verification (Verificação) \\
\hline VAL - Validation (Validação) \\
\hline TS - Technical Solution (Solução Técnica) \\
\hline MA - Measurement and Analysis (Medição e Análise) \\
\hline SAM - Supplier Agreement Management (Gestão de Acordo com o Fornecedor) \\
\hline PMC - Project Monitoring and Control (Monitoramento e Controle de Projeto) \\
\hline PPQA - Process and Product Quality Assurance< (Garantia da Qualidade de Produto e \\
\hline Processo) \\
\hline PI - Product Integration (Integração do Produto) \\
\hline CM - Configuration Management (Gestão de Configuração) \\
\hline ISO/IEC 15504-5 - An exemplar Process Assessment Model \\
\hline BP - Base Practices (Práticas-base) \\
\hline ENG.1 - Requirements elicitation (Elicitação de Requisitos) \\
\hline ENG.2 - System requirements analysis (Análise de requisitos de sistema) \\
\hline ENG.3 - System architectural design (Projeto arquitetural de sistema) \\
\hline ENG.4 - Software requirements analysis (Análise de requisitos de software) \\
\hline ENG.5 - Software design (Projeto de Software) \\
\hline ENG.7 - Software construction (Construção de Software) \\
\hline ENG.8 - Software testing (Teste de Software) \\
\hline ENG.9 - System integration (Integração de sistema) \\
\hline ENG.10 - System testing (Teste de Sistema) \\
\hline
\end{tabular}


Quadro A5.1 - Legenda do Mapeamento das Atividades (Cont.)

ENG.11 - Software installation (Instalação do Software)

SUP.2 - Verification (Verificação)

SUP.3 - Validation (Validação)

SUP.7 - Documentation (Documentação)

SUP.8 - Configuration management (Gestão de Configuração)

MAN.3 - Project management (Gestão de Projeto)

MAN.6 - Measurement (Medição)

ACQ.1 - Acquisition preparation (Preparação da Aquisição)

ACQ.2 - Supplier selection (Seleção do Fornecedor)

ACQ.3 - Contract agreement (Acordo)

ACQ.4 - Supplier monitoring (Monitoramento do Fornecedor)

ACQ.5 - Customer acceptance (Aceitação do Cliente)

RIN.3 - Knowledge management (Gestão de Conhecimento)

Quadro A5.2 - Mapeamento das Atividades da Fase de Prospecção

\begin{tabular}{|c|c|}
\hline \multicolumn{2}{|l|}{ P01. Buscar contatos } \\
\hline CMMI-DEV & ISO/IEC 15504-5 \\
\hline- & - \\
\hline \multicolumn{2}{|l|}{ P02. Prospectar cliente } \\
\hline CMMI-DEV & ISO/IEC 15504-5 \\
\hline 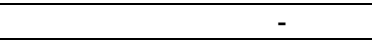 & - \\
\hline \multicolumn{2}{|l|}{ P03. Visitar cliente } \\
\hline CMMI-DEV & ISO/IEC 15504-5 \\
\hline RD - SP 1.1 Elicit Needs & $\begin{array}{l}\text { ENG.1.BP1: Obtain customer requirements and requests. } \\
\text { Obtain and define customer requirements and requests } \\
\text { through direct and continuous solicitation of customer and } \\
\text { user input. }\end{array}$ \\
\hline \multicolumn{2}{|c|}{ P04. Criar infra-estrutura do projeto } \\
\hline CMMI-DEV & ISO/IEC 15504-5 \\
\hline- & - \\
\hline \multicolumn{2}{|c|}{ P05. Controlar custos despendidos na fase de prospecção } \\
\hline CMMI-DEV & ISO/IEC 15504-5 \\
\hline- & - \\
\hline
\end{tabular}


QuAdRo A5.3 - MAPEAMENTO dAS ATIVIDADES dA FASE de ConcepçÃo

\begin{tabular}{|c|c|}
\hline \multicolumn{2}{|c|}{ Cp01. Entender o negócio e as necessidades do cliente } \\
\hline CMMI-DEV & ISO/IEC 15504-5 \\
\hline $\begin{array}{l}\text { RD - SP } 1.1 \text { Elicit Needs } \\
\text { RD - SP } 1.2 \text { Develop the Customer } \\
\text { Requirements }\end{array}$ & $\begin{array}{l}\text { ENG.1.BP1: Obtain customer requirements and requests. } \\
\text { Obtain and define customer requirements and requests } \\
\text { through direct and continuous solicitation of customer and } \\
\text { user input. }\end{array}$ \\
\hline \multicolumn{2}{|l|}{ Cp02. Definir escopo do projeto } \\
\hline CMMI-DEV & ISO/IEC 15504-5 \\
\hline $\begin{array}{l}\text { PP - SP 1.1 Estimate the Scope of the } \\
\text { Project } \\
\text { PP - SP 1.3 Define Project Lifecycle (este } \\
\text { objetivo específico é atendido ao ser } \\
\text { utilizado esse modelo de processo } \\
\text { proposto neste trabalho de pesquisa, } \\
\text { como ciclo de vida do projeto) } \\
\text { PP - SP 2.7 Establish the Project Plan } \\
\text { RD - SP } 1.1 \text { Elicit Needs } \\
\text { RD - SP } 1.2 \text { Develop the Customer } \\
\text { Requirements }\end{array}$ & $\begin{array}{l}\text { MAN.3.BP1: Define the scope of work. Identify the } \\
\text { project's objectives, motivation and boundaries and define } \\
\text { the work to be undertaken by the project. } \\
\text { MAN.3.BP2: Define project life cycle. Define a life cycle } \\
\text { and strategy for the project, appropriate to its scope, } \\
\text { context, magnitude and complexity. (esta prática base é } \\
\text { atendida ao ser utilizado esse modelo de processo } \\
\text { proposto neste trabalho de pesquisa, como ciclo de vida } \\
\text { do projeto) } \\
\text { MAN.3.BP10: Establish project plan. Define and maintain } \\
\text { project master plan and other relevant plans to cover the } \\
\text { project scope and goals, resources, infrastructure, } \\
\text { interfaces and communication mechanisms. } \\
\text { ENG.1.BP1: Obtain customer requirements and requests. } \\
\text { Obtain and define customer requirements and requests } \\
\text { through direct and continuous solicitation of customer and } \\
\text { user input. }\end{array}$ \\
\hline \multicolumn{2}{|l|}{ Cp03. Determinar requisitos do produto } \\
\hline CMMI-DEV & ISO/IEC 15504-5 \\
\hline $\begin{array}{l}\text { RD - SP } 2.1 \text { Establish Product and } \\
\text { Product Component Requirements }\end{array}$ & $\begin{array}{l}\text { ENG.2.BP1: Establish system requirements. Use the } \\
\text { stakeholder requirements as the basis for defining the } \\
\text { required functions and capabilities of the system and } \\
\text { document in a system requirements baseline. } \\
\text { ENG.4.BP1: Specify software requirements. Define and } \\
\text { prioritize functional and nonfunctional requirements of the } \\
\text { software elements of the system and their interfaces and } \\
\text { document them in a software requirements specification. } \\
\text { Analyze the software requirements for correctness, } \\
\text { completeness, consistency, feasibility and testability. } \\
\text { Identify any derived requirements. }\end{array}$ \\
\hline
\end{tabular}


Quadro A5.3 - MaPeamento das Atividades da FASE de Concepção (CONT.)

\begin{tabular}{|c|c|}
\hline \multicolumn{2}{|l|}{ Cp04. Verificar e Validar os requisitos } \\
\hline CMMI-DEV & ISO/IEC 15504-5 \\
\hline $\begin{array}{l}\text { RD - SP 3.3 Analyze Requirements } \\
\text { RD - SP 3.5 Validate Requirements } \\
\text { VER - SP 2.1 Prepare for Peer Reviews } \\
\text { VER - SP 2.2 Conduct Peer Reviews } \\
\text { VER - SP 2.3 Analyze Peer Review Data } \\
\text { VER - SP 3.1 Perform Verification } \\
\text { VER - SP 3.2 Analyze Verification Results } \\
\text { VAL - SP 2.1 Perform Validation } \\
\text { VAL - SP 2.2 Analyze Validation Results }\end{array}$ & $\begin{array}{l}\text { ENG.1.BP2: Understand customer expectations. Ensure } \\
\text { that both supplier and customer understand each } \\
\text { requirement in the same way. Review with customers their } \\
\text { requirements and requests to better understand their } \\
\text { needs and expectations and to check the feasibility and } \\
\text { appropriateness of their requirements. } \\
\text { ENG.1.BP3: Agree on requirements. Obtain agreement } \\
\text { across teams on the customer requirements, obtaining the } \\
\text { appropriate sign-offs by representatives of all teams and } \\
\text { other parties contractually bound to work to these } \\
\text { requirements. } \\
\text { ENG.2.BP3: Analyze system requirements. Prioritize } \\
\text { requirements and analyze the prioritized requirements for } \\
\text { correctness, completeness, consistency, feasibility and } \\
\text { testability, identifying the necessary elements of the } \\
\text { system. Identify changes to the operating environment. } \\
\text { SUP.2.BP3: Conduct verification. Verify identified work } \\
\text { products according to specified strategy. } \\
\text { SUP.2.BP4: Determine actions for verification results. } \\
\text { Defects detected by the verification should be identified, } \\
\text { recorded and entered into the Problem resolution process } \\
\text { (SUP.9). } \\
\text { SUP.3.BP3: Perform validation activities. Conduct } \\
\text { validation activities using identified techniques, processes, } \\
\text { and test cases against requirements and quality standards. } \\
\text { SUP.3.BP4: Identify problems. Issues detected by the } \\
\text { validation process should be identified, recorded and } \\
\text { entered into the Problem resolution management process } \\
\text { (SUP.9). }\end{array}$ \\
\hline \multicolumn{2}{|c|}{ Cp05. Estudar soluções alternativas de arquitetura do software } \\
\hline CMMI-DEV & ISO/IEC 15504-5 \\
\hline $\begin{array}{l}\text { RD - SP 2.2 Allocate Product Component } \\
\text { Requirements } \\
\text { RD - SP } 2.3 \quad \text { Identify Interface } \\
\text { Requirements } \\
\text { TS - SP } 1.1 \text { Develop Alternative Solutions } \\
\text { and Selection Criteria } \\
\text { TS - SP } 1.2 \text { Select Product Component } \\
\text { Solutions } \\
\text { TS - SP } 2.4 \text { Perform Make, Buy, or Reuse } \\
\text { Analyses }\end{array}$ & $\begin{array}{l}\text { ENG.3.BP1: Describe system architecture. Establish the } \\
\text { top-level system architecture that identifies elements of } \\
\text { hardware, software and manual-operations. } \\
\text { ENG.3.BP2: Allocate requirements. Allocate all system } \\
\text { requirements to the elements of the top-level system } \\
\text { architecture. } \\
\text { ENG.3.BP3: Define interfaces. Develop and document the } \\
\text { internal and external interfaces of each system element. } \\
\text { ENG.3.BP4: Verify system architecture. Ensure that the } \\
\text { system architecture meets all stakeholder and system } \\
\text { requirements. } \\
\text { ENG.3.BP5: Evaluate alternative system architectures. } \\
\text { Define evaluation criteria for architecture design. Evaluate } \\
\text { alternative system architectures according to the defined } \\
\text { criteria. Record the rationale for choosing the current } \\
\text { system architecture. } \\
\text { ENG.4.BP2: Determine operating environment impact. } \\
\text { Determine the interfaces between the software } \\
\text { requirements and other elements of the operating } \\
\text { environment, and the impact that the requirements will } \\
\text { have. } \\
\text { ENG.5.BP1: Describe software architecture. Transform the } \\
\text { software requirements into a software architecture design } \\
\text { that describes the top-level structure and identifies its } \\
\text { major software elements. } \\
\text { ENG.5.BP2: Define interfaces. Specify and document the } \\
\text { external and internal interfaces between the software } \\
\text { elements. }\end{array}$ \\
\hline
\end{tabular}


Quadro A5.3 - Mapeamento das Atividades da FASe de Concepção (Cont.)

\begin{tabular}{|c|c|}
\hline \multicolumn{2}{|c|}{ Cp06. Definir/Redefinir cronograma do projeto } \\
\hline CMMI-DEV & ISO/IEC 15504-5 \\
\hline $\begin{array}{l}\text { PP - SP } 2.1 \text { Establish the Budget and } \\
\text { Schedule } \\
\text { PP - SP 2.7 Establish the Project Plan }\end{array}$ & $\begin{array}{l}\text { MAN.3.BP5: Define project activities and tasks. Identify } \\
\text { project activities and tasks according to defined project } \\
\text { lifecycle, and define dependencies between them. } \\
\text { MAN.3.BP7: Define project schedule. Allocate resources to } \\
\text { activities and determine the sequence and schedule of } \\
\text { performance of activities within the project. } \\
\text { MAN.3.BP10: Establish project plan. Define and maintain } \\
\text { project master plan and other relevant plans to cover the } \\
\text { project scope and goals, resources, infrastructure, } \\
\text { interfaces and communication mechanisms. }\end{array}$ \\
\hline \multicolumn{2}{|c|}{ Cp07. Determinar estimativas de esforco e tempo } \\
\hline CMMI-DEV & ISO/IEC 15504-5 \\
\hline $\begin{array}{l}\text { PP - SP 1.2 Establish Estimates of Work } \\
\text { Product and Task Attributes } \\
\text { PP - SP 1.4 Determine Estimates of Effort } \\
\text { and Cost } \\
\text { PP - SP 2.7 Establish the Project Plan } \\
\text { MA - SP 2.1 Collect Measurement Data } \\
\text { MA - SP 2.2 Analyze Measurement Data } \\
\text { MA - SP 2.3 Store Data and Results }\end{array}$ & $\begin{array}{l}\text { MAN.3.BP4: Determine and maintain estimates for project } \\
\text { attributes. Define and maintain baselines for project } \\
\text { attributes. } \\
\text { NOTE 1: Project attributes may include 1) business and quality goals for the } \\
\text { project, 2) size and complexity of the project and 3) project effort, schedule } \\
\text { and budget. } \\
\text { NOTE 2: Project quality goals and risks should be considered when } \\
\text { estimating project attributes. See Quality management process (MAN.4) } \\
\text { and Risk management process (MAN.5) for details. } \\
\text { MAN.3.BP10: Establish project plan. Define and maintain } \\
\text { project master plan and other relevant plans to cover the } \\
\text { project scope and goals, resources, infrastructure, } \\
\text { interfaces and communication mechanisms. } \\
\text { MAN.6.BP5: Collect and store measurement data. Identify, } \\
\text { collect and store measurement data, including context } \\
\text { information necessary to verify, understand, or evaluate } \\
\text { the data. } \\
\text { MAN.6.BP6: Analyze measurement data. Analyze and } \\
\text { interpret measurement data, and develop information } \\
\text { products. } \\
\text { MAN.6.BP7: Use measurement information products for } \\
\text { decision-making. Make accurate and current measurement } \\
\text { information products accessible for any decision-making } \\
\text { processes for which it is relevant. }\end{array}$ \\
\hline \multicolumn{2}{|c|}{ Cp08. Verificar a viabilidade técnica e financeira do projeto } \\
\hline CMMI-DEV & ISO/IEC 15504-5 \\
\hline $\begin{array}{l}\text { PP - SP 1.4 Determine Estimates of Effort } \\
\text { and Cost } \\
\text { PP - SP 2.7 Establish the Project Plan } \\
\text { MA - SP 2.1 Collect Measurement Data } \\
\text { MA - SP 2.2 Analyze Measurement Data } \\
\text { MA - SP 2.3 Store Data and Results }\end{array}$ & $\begin{array}{l}\text { MAN.3.BP4: Determine and maintain estimates for project } \\
\text { attributes. Define and maintain baselines for project } \\
\text { attributes. } \\
\text { NOTE 1: Project attributes may include 1) business and quality goals for the } \\
\text { project, 2) size and complexity of the project and 3) project effort, schedule } \\
\text { and budget. } \\
\text { NOTE 2: Project quality goals and risks should be considered when } \\
\text { estimating project attributes. See Quality management process (MAN.4) } \\
\text { and Risk management process (MAN.5) for details. } \\
\text { MAN.3.BP10: Establish project plan. Define and maintain } \\
\text { project master plan and other relevant plans to cover the } \\
\text { project scope and goals, resources, infrastructure, } \\
\text { interfaces and communication mechanisms. } \\
\text { MAN.6.BP5: Collect and store measurement data. Identify, } \\
\text { collect and store measurement data, including context } \\
\text { information necessary to verify, understand, or evaluate } \\
\text { the data. } \\
\text { MAN.6.BP6: Analyze measurement data. Analyze and } \\
\text { interpret measurement data, and develop information } \\
\text { products. } \\
\text { MAN.6.BP7: Use measurement information products for } \\
\text { decision-making. Make accurate and current measurement } \\
\text { information products accessible for any decision-making } \\
\text { processes for which it is relevant. }\end{array}$ \\
\hline
\end{tabular}


Quadro A5.3 - Mapeamento das Atividades da FASe de Concepção (Cont.)

\begin{tabular}{|c|c|}
\hline \multicolumn{2}{|l|}{ Cp09. Planejar os recursos do projeto } \\
\hline CMMI-DEV & ISO/IEC 15504-5 \\
\hline $\begin{array}{l}\text { PP - SP 2.4 Plan for Project Resources } \\
\text { PP - SP 2.6 Plan Stakeholder Involvement } \\
\text { PP - SP 2.7 Establish the Project Plan } \\
\text { SAM - SP 1.1 Determine Acquisition Type }\end{array}$ & $\begin{array}{l}\text { MAN.3.BP10: Establish project plan. Define and maintain } \\
\text { project master plan and other relevant plans to cover the } \\
\text { project scope and goals, resources, infrastructure, } \\
\text { interfaces and communication mechanisms. } \\
\text { ACQ.1.BP1: Establish the need. Establish a need to } \\
\text { acquire, develop, or enhance a system, software product } \\
\text { or service. } \\
\text { ACQ.1.BP2: Define the requirements. Identify the } \\
\text { customer/stakeholder requirements for a system and/or } \\
\text { software product or service. } \\
\text { ACQ.1.BP3: Review requirements. Analyze and validate } \\
\text { the defined requirements against the identified needs. } \\
\text { Validate the requirements to reduce risk of } \\
\text { misunderstanding by the potential suppliers }\end{array}$ \\
\hline \multicolumn{2}{|c|}{ Cp10. Identificar conhecimentos e habilidades necessárias } \\
\hline CMMI-DEV & ISO/IEC 15504-5 \\
\hline $\begin{array}{l}\text { PP - SP 2.5 Plan for Needed Knowledge } \\
\text { and Skills } \\
\text { PP - SP 2.6 Plan Stakeholder Involvement } \\
\text { PP - SP 2.7 Establish the Project Plan }\end{array}$ & $\begin{array}{l}\text { MAN.3.BP6: Define needs for experience, knowledge and } \\
\text { skills. Identify the experience, knowledge and skill } \\
\text { requirements of the project and apply them to the selection } \\
\text { of individuals and teams. }\end{array}$ \\
\hline \multicolumn{2}{|c|}{ Cp11. Identificar riscos inerentes ao projeto } \\
\hline CMMI-DEV & ISO/IEC 15504-5 \\
\hline $\begin{array}{l}\text { RD - SP } 3.4 \text { Analyze Requirements to } \\
\text { Achieve Balance } \\
\text { PP - SP 2.2 Identify Project Risks } \\
\text { PP - SP 2.7 Establish the Project Plan } \\
\text { MA - SP 2.1 Collect Measurement Data } \\
\text { MA - SP 2.2 Analyze Measurement Data } \\
\text { MA - SP 2.3 Store Data and Results }\end{array}$ & $\begin{array}{l}\text { ENG.2.BP4: Evaluate and update system requirements. } \\
\text { Evaluate the impact of proposed changes and new } \\
\text { requirements for cost, schedule, risk and technical impact, } \\
\text { approve or reject changes and new requirements, and } \\
\text { update the system requirements baseline. } \\
\text { ENG.4.BP5: Evaluate and update software requirements. } \\
\text { Evaluate the requirements with the customer, evaluate the } \\
\text { impact of proposed changes for cost, schedule and } \\
\text { technical impact, approve or reject changes, and update } \\
\text { the software requirements specification. } \\
\text { MAN.3.BP10: Establish project plan. Define and maintain } \\
\text { project master plan and other relevant plans to cover the } \\
\text { project scope and goals, resources, infrastructure, } \\
\text { interfaces and communication mechanisms. } \\
\text { MAN.6.BP5: Collect and store measurement data. Identify, } \\
\text { collect and store measurement data, including context } \\
\text { information necessary to verify, understand, or evaluate } \\
\text { the data. } \\
\text { MAN.6.BP6: Analyze measurement data. Analyze and } \\
\text { interpret measurement data, and develop information } \\
\text { products. } \\
\text { MAN.6.BP7: Use measurement information products for } \\
\text { decision-making. Make accurate and current measurement } \\
\text { information products accessible for any decision-making } \\
\text { processes for which it is relevant. }\end{array}$ \\
\hline \multicolumn{2}{|c|}{ Cp12. Acompanhar o andamento do projeto } \\
\hline CMMI-DEV & ISO/IEC 15504-5 \\
\hline $\begin{array}{l}\text { PMC - SP 1.1 Monitor Project Planning } \\
\text { Parameters } \\
\text { PMC - SP 1.2 Monitor Commitments } \\
\text { PMC - SP 1.3 Monitor Project Risks }\end{array}$ & $\begin{array}{l}\text { MAN.3.BP12: Monitor project attributes. Monitor project } \\
\text { scope, budget, cost, resources and other necessary } \\
\text { attributes and document significant deviations of them } \\
\text { against the project baseline. }\end{array}$ \\
\hline \multicolumn{2}{|c|}{ Cp13. Controlar custos despendidos na fase de concepção } \\
\hline CMMI-DEV & ISO/IEC 15504-5 \\
\hline $\begin{array}{l}\text { PMC - SP 1.1 Monitor Project Planning } \\
\text { Parameters }\end{array}$ & $\begin{array}{l}\text { MAN.3.BP12: Monitor project attributes. Monitor project } \\
\text { scope, budget, cost, resources and other necessary } \\
\text { attributes and document significant deviations of them } \\
\text { against the project baseline. }\end{array}$ \\
\hline
\end{tabular}


Quadro A5.3 - Mapeamento das Atividades da Fase de Concepção (ConT.)

\begin{tabular}{|c|c|}
\hline \multicolumn{2}{|c|}{ Cp14. Conduzir revisão do milestone: Estudo de Viabilidade do Projeto } \\
\hline CMMI-DEV & ISO/IEC 15504-5 \\
\hline $\begin{array}{l}\text { PMC - SP 1.7 Conduct Milestone Reviews } \\
\text { PP - SP } 3.1 \text { Review Plans That Affect the } \\
\text { Project } \\
\text { PPQA - SP } 1.1 \text { Objectively Evaluate } \\
\text { Processes } \\
\text { PPQA - SP } 1.2 \text { Objectively Evaluate Work } \\
\text { Products and Services } \\
\text { PPQA - SP } 2.1 \text { Communicate and Ensure } \\
\text { Resolution of Noncompliance Issues } \\
\text { PPQA - SP } 2.2 \text { Establish Records } \\
\text { MA - SP 2.1 Collect Measurement Data } \\
\text { MA - SP 2.2 Analyze Measurement Data } \\
\text { MA - SP 2.3 Store Data and Results } \\
\text { MA - SP 2.4 Communicate Results }\end{array}$ & $\begin{array}{l}\text { SUP.1.BP2: Define quality records. Quality records are } \\
\text { defined that demonstrate conformance of process and } \\
\text { work products to their quality requirements. } \\
\text { SUP.1.BP3: Assure the quality of project process activities } \\
\text { and project work products. Carry out a series of activities } \\
\text { to provide assurance, with the required level of confidence, } \\
\text { that the project processes have followed specified } \\
\text { standards and that the work products meet the quality } \\
\text { requirements. } \\
\text { SUP.1.BP4: Identify and record problems and non- } \\
\text { conformances. Problems and nonconformances are } \\
\text { identified and recorded and then reported to appropriate } \\
\text { stakeholders for information and action. } \\
\text { SUP.1.BP5: Act on non-conformances. Deviations or non- } \\
\text { conformance with agreed requirements or organizational } \\
\text { quality goals are analyzed and resolved. } \\
\text { MAN.6.BP5: Collect and store measurement data. Identify, } \\
\text { collect and store measurement data, including context } \\
\text { information necessary to verify, understand, or evaluate } \\
\text { the data. } \\
\text { MAN.6.BP6: Analyze measurement data. Analyze and } \\
\text { interpret measurement data, and develop information } \\
\text { products. } \\
\text { MAN.6.BP7: Use measurement information products for } \\
\text { decision-making. Make accurate and current measurement } \\
\text { information products accessible for any decision-making } \\
\text { processes for which it is relevant. } \\
\text { MAN.6.BP8: Communicate measurement results. } \\
\text { Disseminate measurement information products to all } \\
\text { parties who will be using them and collect feedback to } \\
\text { evaluate the appropriateness for intended use. } \\
\text { MAN.6.BP9: Evaluate and communicate information } \\
\text { products and measurement activities to process owners. } \\
\text { Evaluate information products and measurement activities } \\
\text { against the identified information needs and measurement } \\
\text { strategy, identify potential improvements in measurements, } \\
\text { and communicate any identified potential improvement to } \\
\text { the process owners. }\end{array}$ \\
\hline
\end{tabular}

Quadro A5.4 - Mapeamento das Ativid ades da Fase de Negociação

\begin{tabular}{|c|c|}
\hline \multicolumn{2}{|l|}{ N01. Elaborar proposta } \\
\hline CMMI-DEV & ISO/IEC 15504-5 \\
\hline $\begin{array}{l}\text { PP - SP } 3.2 \text { Reconcile } \text { Work and } \\
\text { Resource Levels }\end{array}$ & $\begin{array}{l}\text { ENG.4.BP5: Evaluate and update software requirements. } \\
\text { Evaluate the requirements with the customer, evaluate the } \\
\text { impact of proposed changes for cost, schedule and } \\
\text { technical impact, approve or reject changes, and update } \\
\text { the software requirements specification. } \\
\text { MAN.3.BP3 Evaluate feasibility of the project. Evaluate the } \\
\text { feasibility of achieving the goals of the project with } \\
\text { available resources and constraints. }\end{array}$ \\
\hline \multicolumn{2}{|l|}{ N02. Analisar proposta } \\
\hline CMMI-DEV & ISO/IEC 15504-5 \\
\hline- & - \\
\hline \multicolumn{2}{|l|}{ N03. Elaborar contrato } \\
\hline CMMI-DEV & ISO/IEC 15504-5 \\
\hline
\end{tabular}


Quadro A5.4 - Mapeamento das Atividades da Fase de Negociação (Cont.)

\begin{tabular}{|c|c|}
\hline \multicolumn{2}{|l|}{ N04. Analisar contrato } \\
\hline CMMI-DEV & ISO/IEC 15504-5 \\
\hline- & - \\
\hline \multicolumn{2}{|l|}{ N05. Definir time do projeto } \\
\hline CMMI-DEV & ISO/IEC 15504-5 \\
\hline $\begin{array}{l}\text { PP - SP 2.5 Plan for Needed Knowledge } \\
\text { and Skills } \\
\text { PP - SP } 2.1 \text { Establish the Budget and } \\
\text { Schedule }\end{array}$ & $\begin{array}{l}\text { MAN.3.BP7: Define project schedule. Allocate resources to } \\
\text { activities and determine the sequence and schedule of } \\
\text { performance of activities within the project. } \\
\text { MAN.3.BP6: Define needs for experience, knowledge and } \\
\text { skills. Identify the experience, knowledge and skill } \\
\text { requirements of the project and apply them to the selection } \\
\text { of individuals and teams. }\end{array}$ \\
\hline \multicolumn{2}{|l|}{ N06. Formalizar início do projeto } \\
\hline CMMI-DEV & ISO/IEC 15504-5 \\
\hline PP - SP 3.3 Obtain Plan Commitment & $\begin{array}{l}\text { MAN.3.BP8: Identify and monitor project interfaces. } \\
\text { Identify and agree interfaces of the project with other } \\
\text { projects, organizational units and other affected parties } \\
\text { and monitor agreed commitments. } \\
\text { MAN.3.BP9: Allocate responsibilities. Identify the specific } \\
\text { individuals and groups contributing to, and impacted by, } \\
\text { the project, allocate them their specific responsibilities, and } \\
\text { ensure that the commitments are understood and } \\
\text { accepted, funded and achievable. }\end{array}$ \\
\hline \multicolumn{2}{|c|}{ N07. Acompanhar o andamento do projeto } \\
\hline CMMI-DEV & ISO/IEC 15504-5 \\
\hline $\begin{array}{l}\text { PMC - SP 1.1 Monitor Project Planning } \\
\text { Parameters } \\
\text { PMC - SP 1.2 Monitor Commitments } \\
\text { PMC - SP 1.3 Monitor Project Risks }\end{array}$ & $\begin{array}{l}\text { MAN.3.BP12: Monitor project attributes. Monitor project } \\
\text { scope, budget, cost, resources and other necessary } \\
\text { attributes and document significant deviations of them } \\
\text { against the project baseline. }\end{array}$ \\
\hline \multicolumn{2}{|c|}{ N08. Controlar custos despendidos na fase de negociação } \\
\hline CMMI-DEV & ISO/IEC 15504-5 \\
\hline $\begin{array}{l}\text { PMC - SP } 1.1 \text { Monitor Project Planning } \\
\text { Parameters }\end{array}$ & $\begin{array}{l}\text { MAN.3.BP12: Monitor project attributes. Monitor project } \\
\text { scope, budget, cost, resources and other necessary } \\
\text { attributes and document significant deviations of them } \\
\text { against the project baseline. }\end{array}$ \\
\hline
\end{tabular}


QuAdro A5.4 - MAPEAMENTo das Atividades da FASE de Negociação (CONT.)

N09. Conduzir revisão do milestone: Contrato

$$
\text { CMMI-DEV }
$$

PMC - SP 1.7 Conduct Milestone Reviews PP - SP 3.1 Review Plans That Affect the Project

PPQA - SP 1.1 Objectively Evaluate

Processes

PPQA - SP 1.2 Objectively Evaluate Work

Products and Services

PPQA - SP 2.1 Communicate and Ensure

Resolution of Noncompliance Issues

PPQA - SP 2.2 Establish Records

MA - SP 2.1 Collect Measurement Data

MA - SP 2.2 Analyze Measurement Data

MA - SP 2.3 Store Data and Results

MA - SP 2.4 Communicate Results
SUP.1.BP2: Define quality records. Quality records are defined that demonstrate conformance of process and work products to their quality requirements.

SUP.1.BP3: Assure the quality of project process activities and project work products. Carry out a series of activities to provide assurance, with the required level of confidence, that the project processes have followed specified standards and that the work products meet the quality requirements.

SUP.1.BP4: Identify and record problems and nonconformances. Problems and nonconformances are identified and recorded and then reported to appropriate stakeholders for information and action.

SUP.1.BP5: Act on non-conformances. Deviations or nonconformance with agreed requirements or organizational quality goals are analyzed and resolved.

MAN.6.BP5: Collect and store measurement data. Identify, collect and store measurement data, including context information necessary to verify, understand, or evaluate the data.

MAN.6.BP6: Analyze measurement data. Analyze and interpret measurement data, and develop information products.

MAN.6.BP7: Use measurement information products for decision-making. Make accurate and current measurement information products accessible for any decision-making processes for which it is relevant.

MAN.6.BP8: Communicate measurement results. Disseminate measurement information products to all parties who will be using them and collect feedback to evaluate the appropriateness for intended use.

MAN.6.BP9: Evaluate and communicate information products and measurement activities to process owners. Evaluate information products and measurement activities against the identified information needs and measurement strategy, identify potential improvements in measurements, and communicate any identified potential improvement to the process owners. 
Quadro A5.5 - MaPEAMENTo das ATIVIDADES da FASE de Elaboração

\begin{tabular}{|c|c|}
\hline \multicolumn{2}{|l|}{ E01. Detalhar requisitos } \\
\hline CMMI-DEV & ISO/IEC 15504-5 \\
\hline $\begin{array}{l}\text { RD - SP 2.1 Establish Product and } \\
\text { Product Component Requirements } \\
\text { RD - SP 3.1 Establish Operational } \\
\text { Concepts and Scenarios } \\
\text { RD - SP } 3.2 \text { Establish a Definition of } \\
\text { Required Functionality } \\
\text { REQM - SP 1.4 Maintain Bidirectional } \\
\text { Traceability of Requirements }\end{array}$ & $\begin{array}{l}\text { ENG.4.BP1: Specify software requirements. Define and } \\
\text { prioritize functional and nonfunctional requirements of the } \\
\text { software elements of the system and their interfaces and } \\
\text { document them in a software requirements specification. } \\
\text { Analyze the software requirements for correctness, } \\
\text { completeness, consistency, feasibility and testability. } \\
\text { Identify any derived requirements. }\end{array}$ \\
\hline \multicolumn{2}{|l|}{ E02. Verificar e Validar os requisitos } \\
\hline CMMI-DEV & ISO/IEC 15504-5 \\
\hline $\begin{array}{l}\text { RD - SP 3.3 Analyze Requirements } \\
\text { RD - SP } 3.5 \text { Validate Requirements } \\
\text { VER - SP 2.1 Prepare for Peer Reviews } \\
\text { VER - SP 2.2 Conduct Peer Reviews } \\
\text { VER - SP 2.3 Analyze Peer Review Data } \\
\text { VER - SP 3.1 Perform Verification } \\
\text { VER - SP 3.2 Analyze Verification Results } \\
\text { VAL - SP 2.1 Perform Validation } \\
\text { VAL - SP 2.2 Analyze Validation Results }\end{array}$ & $\begin{array}{l}\text { ENG.1.BP2: Understand customer expectations. Ensure } \\
\text { that both supplier and customer understand each } \\
\text { requirement in the same way. Review with customers their } \\
\text { requirements and requests to better understand their } \\
\text { needs and expectations and to check the feasibility and } \\
\text { appropriateness of their requirements. } \\
\text { ENG.1.BP3: Agree on requirements. Obtain agreement } \\
\text { across teams on the customer requirements, obtaining the } \\
\text { appropriate sign-offs by representatives of all teams and } \\
\text { other parties contractually bound to work to these } \\
\text { requirements. } \\
\text { ENG.2.BP3: Analyze system requirements. Prioritize } \\
\text { requirements and analyze the prioritized requirements for } \\
\text { correctness, completeness, consistency, feasibility and } \\
\text { testability, identifying the necessary elements of the } \\
\text { system. Identify changes to the operating environment. } \\
\text { SUP.2.BP3: Conduct verification. Verify identified work } \\
\text { products according to specified strategy. } \\
\text { SUP.2.BP4: Determine actions for verification results. } \\
\text { Defects detected by the verification should be identified, } \\
\text { recorded and entered into the Problem resolution process } \\
\text { (SUP.9). } \\
\text { SUP.3.BP3: Perform validation activities. Conduct } \\
\text { validation activities using identified techniques, processes, } \\
\text { and test cases against requirements and quality standards. } \\
\text { SUP.3.BP4: Identify problems. Issues detected by the } \\
\text { validation process should be identified, recorded and } \\
\text { entered into the Problem resolution management process } \\
\text { (SUP.9). }\end{array}$ \\
\hline
\end{tabular}


QuAdRo A5.5 - MAPEAMENTO dAS ATIVIDADES dA FASE de ElaboraÇão (CONT.)

\begin{tabular}{|c|c|}
\hline \multicolumn{2}{|l|}{ E03. Definir solução de projeto } \\
\hline CMMI-DEV & ISO/IEC 15504-5 \\
\hline $\begin{array}{l}\text { RD - SP } 2.2 \text { Allocate Product Component } \\
\text { Requirements } \\
\text { RD - SP } 2.3 \text { Identify Interface } \\
\text { Requirements } \\
\text { REQM - SP } 1.4 \text { Maintain Bidirectional } \\
\text { Traceability of Requirements } \\
\text { TS - SP 2.1 Design the Product or } \\
\text { Product Component } \\
\text { TS - SP } 2.2 \text { Establish a Technical Data } \\
\text { Package } \\
\text { TS - SP } 2.3 \text { Design Interfaces Using } \\
\text { Criteria }\end{array}$ & $\begin{array}{l}\text { ENG.3.BP2: Allocate requirements. Allocate all system } \\
\text { requirements to the elements of the top-level system } \\
\text { architecture. } \\
\text { ENG.3.BP3: Define interfaces. Develop and document the } \\
\text { internal and external interfaces of each system element. } \\
\text { ENG.3.BP1: Describe system architecture. Establish the } \\
\text { top-level system architecture that identifies elements of } \\
\text { hardware, software and manual-operations. } \\
\text { ENG.5.BP1: Describe software architecture. Transform the } \\
\text { software requirements into a software architecture design } \\
\text { that describes the top-level structure and identifies its } \\
\text { major software elements. } \\
\text { ENG.4.BP2: Determine operating environment impact. } \\
\text { Determine the interfaces between the software } \\
\text { requirements and other elements of the operating } \\
\text { environment, and the impact that the requirements will } \\
\text { have. } \\
\text { ENG.5.BP2: Define interfaces. Specify and document the } \\
\text { external and internal interfaces between the software } \\
\text { elements. } \\
\text { ENG.5.BP3: Develop detailed design. Decompose the } \\
\text { software architectural design into a detailed design for } \\
\text { each software element describing all software units to be } \\
\text { produced and tested. Document software units and } \\
\text { interfaces in a software design document. }\end{array}$ \\
\hline \multicolumn{2}{|l|}{ E04. Detalhar o cronograma } \\
\hline CMMI-DEV & ISO/IEC 15504-5 \\
\hline $\begin{array}{l}\text { PP - SP } 2.1 \text { Establish the Budget and } \\
\text { Schedule }\end{array}$ & $\begin{array}{l}\text { MAN.3.BP5: Define project activities and tasks. Identify } \\
\text { project activities and tasks according to defined project } \\
\text { lifecycle, and define dependencies between them. } \\
\text { MAN.3.BP7: Define project schedule. Allocate resources to } \\
\text { activities and determine the sequence and schedule of } \\
\text { performance of activities within the project. }\end{array}$ \\
\hline
\end{tabular}


Quadro A5.5 - MaPeamento das Atividades da FASE de Elaboração (Cont.)

\begin{tabular}{|c|c|}
\hline \multicolumn{2}{|c|}{ E05. Definir técnicas e critérios para V\&V } \\
\hline CMMI-DEV & ISO/IEC 15504-5 \\
\hline $\begin{array}{l}\text { PP - SP } 2.7 \text { Establish the Project Plan } \\
\text { PI - SP } 1.1 \text { Determine Integration } \\
\text { Sequence } \\
\text { PI - SP } 1.2 \text { Establish the Product } \\
\text { Integration Environment } \\
\text { PI - SP } 1.3 \text { Establish Product Integration } \\
\text { Procedures and Criteria } \\
\text { VER - SP } 1.1 \text { Select Work Products for } \\
\text { Verification } \\
\text { VER - SP } 1.2 \text { Establish the Verification } \\
\text { Environment } \\
\text { VER - SP } 1.3 \text { Establish Verification } \\
\text { Procedures and Criteria } \\
\text { VAL - SP } 1.1 \text { Select Products for } \\
\text { Validation } \\
\text { VAL - SP } 1.2 \text { Establish the Validation } \\
\text { Environment } \\
\text { VAL - SP } 1.3 \text { Establish Validation } \\
\text { Procedures and Criteria }\end{array}$ & 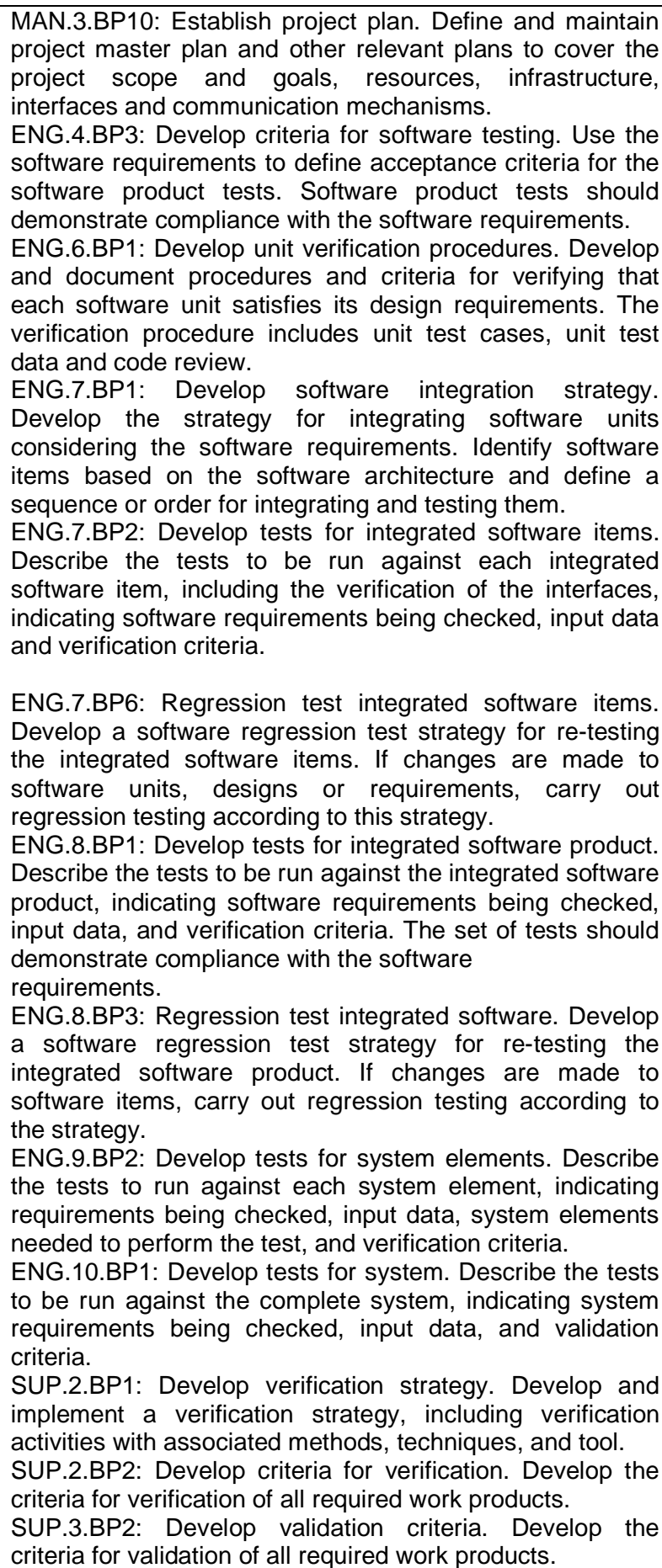 \\
\hline
\end{tabular}


QuadRo A5.5 - MAPEAmento das Atividades da FASE de Elaboração (CONT.)

\begin{tabular}{|c|c|}
\hline \multicolumn{2}{|l|}{ E06. Monitorar e controlar o projeto } \\
\hline CMMI-DEV & ISO/IEC 15504-5 \\
\hline $\begin{array}{l}\text { PMC - SP 1.1 Monitor Project Planning } \\
\text { Parameters } \\
\text { PMC - SP 1.2 Monitor Commitments } \\
\text { PMC - SP 1.3 Monitor Project Risks } \\
\text { PMC - SP 1.4 Monitor Data Management } \\
\text { PMC - SP } 1.5 \text { Monitor Stakeholder } \\
\text { Involvement } \\
\text { PMC - SP 1.6 Conduct Progress Reviews } \\
\text { PMC - SP 2.1 Analyze Issues } \\
\text { PMC - SP 2.2 Take Corrective Action } \\
\text { PMC - SP 2.3 Manage Corrective Action }\end{array}$ & $\begin{array}{l}\text { MAN.3.BP12: Monitor project attributes. Monitor project } \\
\text { scope, budget, cost, resources and other necessary } \\
\text { attributes and document significant deviations of them } \\
\text { against the project baseline. } \\
\text { MAN.3.BP13: Review progress of the project. Regularly } \\
\text { report and review the status of the project performance } \\
\text { against the project plan. } \\
\text { MAN.3.BP14: Act to correct deviations. Take action when } \\
\text { project goals are not achieved, to correct deviations from } \\
\text { the plan and to prevent recurrence of problems identified in } \\
\text { the project. Update project plans accordingly. }\end{array}$ \\
\hline \multicolumn{2}{|c|}{ E07. Monitorar e Controlar questões financeiras } \\
\hline CMMI-DEV & ISO/IEC 15504-5 \\
\hline $\begin{array}{l}\text { PMC - SP 1.1 Monitor Project Planning } \\
\text { Parameters } \\
\text { PMC - SP 1.2 Monitor Commitments } \\
\text { PMC - SP 1.3 Monitor Project Risks }\end{array}$ & $\begin{array}{l}\text { MAN.3.BP12: Monitor project attributes. Monitor project } \\
\text { scope, budget, cost, resources and other necessary } \\
\text { attributes and document significant deviations of them } \\
\text { against the project baseline. }\end{array}$ \\
\hline \multicolumn{2}{|c|}{ E08. Conduzir revisão do milestone: Arquitetura do Software } \\
\hline CMMI-DEV & ISO/IEC 15504-5 \\
\hline $\begin{array}{l}\text { PMC - SP 1.7 Conduct Milestone Reviews } \\
\text { PP - SP } 3.1 \text { Review Plans That Affect the } \\
\text { Project } \\
\text { PPQA - SP } 1.1 \text { Objectively Evaluate } \\
\text { Processes } \\
\text { PPQA - SP } 1.2 \text { Objectively Evaluate Work } \\
\text { Products and Services } \\
\text { PPQA - SP } 2.1 \text { Communicate and Ensure } \\
\text { Resolution of Noncompliance Issues } \\
\text { PPQA - SP 2.2 Establish Records } \\
\text { MA - SP 2.1 Collect Measurement Data } \\
\text { MA - SP 2.2 Analyze Measurement Data } \\
\text { MA - SP 2.3 Store Data and Results } \\
\text { MA - SP 2.4 Communicate Results }\end{array}$ & $\begin{array}{l}\text { SUP.1.BP2: Define quality records. Quality records are } \\
\text { defined that demonstrate conformance of process and } \\
\text { work products to their quality requirements. } \\
\text { SUP.1.BP3: Assure the quality of project process activities } \\
\text { and project work products. Carry out a series of activities } \\
\text { to provide assurance, with the required level of confidence, } \\
\text { that the project processes have followed specified } \\
\text { standards and that the work products meet the quality } \\
\text { requirements. } \\
\text { SUP.1.BP4: Identify and record problems and non- } \\
\text { conformances. Problems and nonconformances are } \\
\text { identified and recorded and then reported to appropriate } \\
\text { stakeholders for information and action. } \\
\text { SUP.1.BP5: Act on non-conformances. Deviations or non- } \\
\text { conformance with agreed requirements or organizational } \\
\text { quality goals are analyzed and resolved. } \\
\text { MAN.6.BP5: Collect and store measurement data. Identify, } \\
\text { collect and store measurement data, including context } \\
\text { information necessary to verify, understand, or evaluate } \\
\text { the data. } \\
\text { MAN.6.BP6: Analyze measurement data. Analyze and } \\
\text { interpret measurement data, and develop information } \\
\text { products. } \\
\text { MAN.6.BP7: Use measurement information products for } \\
\text { decision-making. Make accurate and current measurement } \\
\text { information products accessible for any decision-making } \\
\text { processes for which it is relevant. } \\
\text { MAN.6.BP8: Communicate measurement results. } \\
\text { Disseminate measurement information products to all } \\
\text { parties who will be using them and collect feedback to } \\
\text { evaluate the appropriateness for intended use. } \\
\text { MAN.6.BP9: Evaluate and communicate information } \\
\text { products and measurement activities to process owners. } \\
\text { Evaluate information products and measurement activities } \\
\text { against the identified information needs and measurement } \\
\text { strategy, identify potential improvements in measurements, } \\
\text { and communicate any identified potential improvement to } \\
\text { the process owners. }\end{array}$ \\
\hline
\end{tabular}


Quadro A5.6 - MaPeamento das Atividades da Fase de Construção

\begin{tabular}{|c|c|}
\hline \multicolumn{2}{|l|}{ Ct01. Codificar componentes } \\
\hline CMMI-DEV & ISO/IEC 15504-5 \\
\hline TS - SP 3.1 Implement the Design & $\begin{array}{l}\text { ENG.6.BP2: Develop software units. Develop and } \\
\text { document the executable representations of each software } \\
\text { unit. Update test requirements and user documentation. }\end{array}$ \\
\hline \multicolumn{2}{|l|}{ Ct02. Realizar teste de unidade } \\
\hline CMMI-DEV & ISO/IEC 15504-5 \\
\hline $\begin{array}{l}\text { VER - SP 3.1 Perform Verification } \\
\text { MA - SP 2.1 Collect Measurement Data } \\
\text { MA - SP 2.3 Store Data and Results }\end{array}$ & $\begin{array}{l}\text { ENG.6.BP4: Verify software units. Verify that each } \\
\text { software unit satisfies its design requirements by executing } \\
\text { the specified unit verification procedures and document the } \\
\text { results. } \\
\text { ENG.7.BP4: Test integrated software items. Test each } \\
\text { integrated software item on an operational platform or } \\
\text { suitable equivalent platform, against the verification } \\
\text { criteria, and record the results. Update user documentation } \\
\text { as necessary. } \\
\text { ENG.7.BP6: Regression test integrated software items. } \\
\text { Develop a software regression test strategy for re-testing } \\
\text { the integrated software items. If changes are made to } \\
\text { software units, designs or requirements, carry out } \\
\text { regression testing according to this strategy. } \\
\text { ENG.8.BP2: Test integrated software product. Test the } \\
\text { integrated software product against the verification criteria, } \\
\text { and record the results. Update user documentation as } \\
\text { necessary. } \\
\text { ENG.8.BP3: Regression test integrated software. Develop } \\
\text { a software regression test strategy for re-testing the } \\
\text { integrated software product. If changes are made to } \\
\text { software items, carry out regression testing according to } \\
\text { the strategy. } \\
\text { ENG.9.BP4: Test system elements. Test each system } \\
\text { element and ensure that it satisfies its requirements, and } \\
\text { document the results. } \\
\text { ENG.9.BP5: Regression test system elements. If changes } \\
\text { are made to system elements, carry out regression testing } \\
\text { as defined in the regression test strategy. } \\
\text { SUP.2.BP3: Conduct verification. Verify identified work } \\
\text { products according to specified strategy. } \\
\text { MAN.6.BP5: Collect and store measurement data. Identify, } \\
\text { collect and store measurement data, including context } \\
\text { information necessary to verify, understand, or evaluate } \\
\text { the data. }\end{array}$ \\
\hline \multicolumn{2}{|c|}{ Ct03. Analisar os resultados de teste } \\
\hline CMMI-DEV & ISO/IEC 15504-5 \\
\hline $\begin{array}{l}\text { VER - SP 3.2 Analyze Verification Results } \\
\text { MA - SP 2.2 Analyze Measurement Data }\end{array}$ & $\begin{array}{l}\text { SUP.2.BP4: Determine actions for verification results. } \\
\text { Defects detected by the verification should be identified, } \\
\text { recorded and entered into the Problem resolution process. } \\
\text { MAN.6.BP6: Analyze measurement data. Analyze and } \\
\text { interpret measurement data, and develop information } \\
\text { products. } \\
\text { MAN.6.BP7: Use measurement information products for } \\
\text { decision-making. Make accurate and current measurement } \\
\text { information products accessible for any decision-making } \\
\text { processes for which it is relevant. }\end{array}$ \\
\hline
\end{tabular}


Quadro A5.6 - Mapeamento das Atividades da Fase de Construção (Cont.)

\begin{tabular}{|c|c|}
\hline \multicolumn{2}{|c|}{ Ct04. Integrar e testar integração entre componentes } \\
\hline CMMI-DEV & ISO/IEC 15504-5 \\
\hline $\begin{array}{l}\text { PI - SP 1.1 Determine Integration } \\
\text { Sequence } \\
\text { PI - SP 2.1 Review Interface Descriptions } \\
\text { for Completeness } \\
\text { PI - SP 2.2 Manage Interfaces } \\
\text { PI - SP 3.1 Confirm Readiness of Product } \\
\text { Components for Integration } \\
\text { PI - SP 3.2 Assemble Product } \\
\text { Components } \\
\text { PI - SP } 3.3 \text { Evaluate Assembled Product } \\
\text { Components } \\
\text { VER - SP 3.1 Perform Verification } \\
\text { MA - SP 2.1 Collect Measurement Data } \\
\text { MA - SP 2.3 Store Data and Results }\end{array}$ & 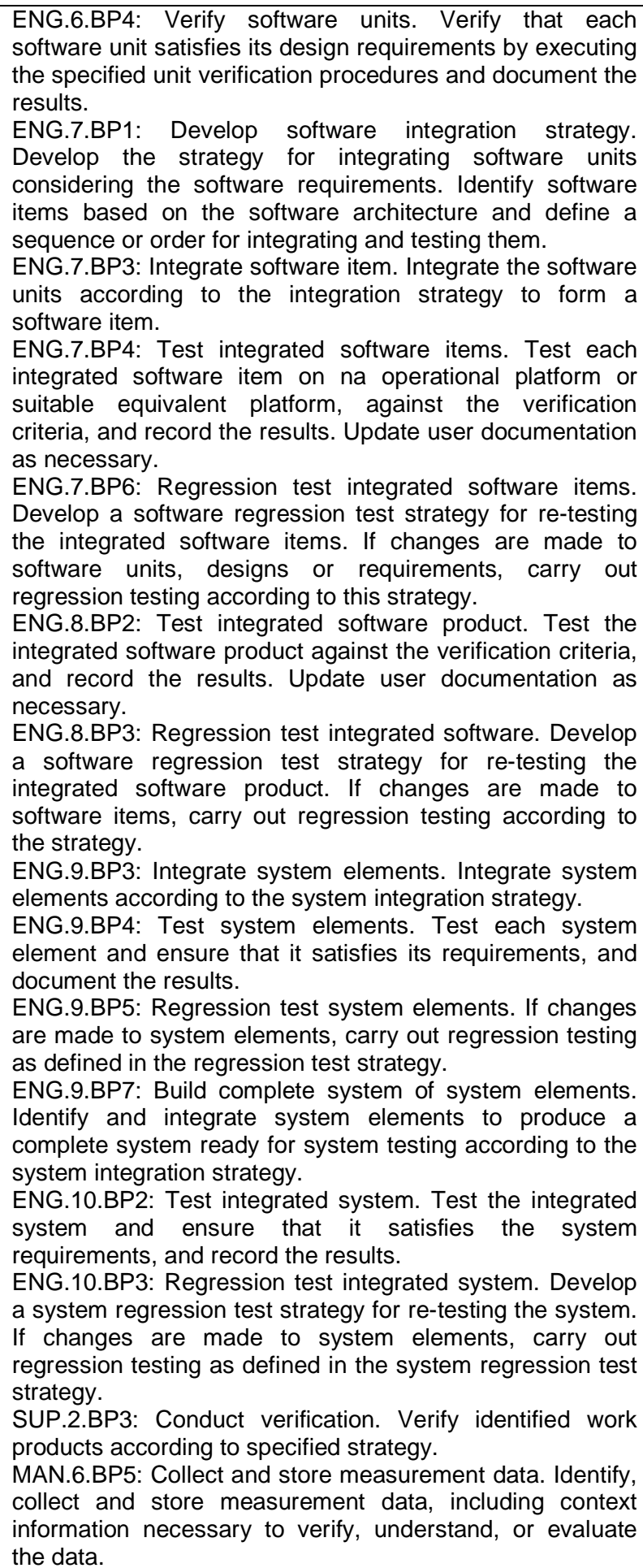 \\
\hline
\end{tabular}


Quadro A5.6 - Mapeamento das Atividades da FASe de Construção (CONT.)

\begin{tabular}{|c|c|}
\hline \multicolumn{2}{|l|}{ Ct05. Monitorar e controlar o projeto } \\
\hline CMMI-DEV & ISO/IEC 15504-5 \\
\hline $\begin{array}{l}\text { PMC - SP 1.1 Monitor Project Planning } \\
\text { Parameters } \\
\text { PMC - SP 1.2 Monitor Commitments } \\
\text { PMC - SP 1.3 Monitor Project Risks } \\
\text { PMC - SP 1.4 Monitor Data Management } \\
\text { PMC - SP } 1.5 \text { Monitor Stakeholder } \\
\text { Involvement } \\
\text { PMC - SP 1.6 Conduct Progress Reviews } \\
\text { PMC - SP 2.1 Analyze Issues } \\
\text { PMC - SP 2.2 Take Corrective Action } \\
\text { PMC - SP 2.3 Manage Corrective Action }\end{array}$ & $\begin{array}{l}\text { MAN.3.BP12: Monitor project attributes. Monitor project } \\
\text { scope, budget, cost, resources and other necessary } \\
\text { attributes and document significant deviations of them } \\
\text { against the project baseline. } \\
\text { MAN.3.BP13: Review progress of the project. Regularly } \\
\text { report and review the status of the project performance } \\
\text { against the project plan. } \\
\text { MAN.3.BP14: Act to correct deviations. Take action when } \\
\text { project goals are not achieved, to correct deviations from } \\
\text { the plan and to prevent recurrence of problems identified in } \\
\text { the project. Update project plans accordingly. }\end{array}$ \\
\hline \multicolumn{2}{|c|}{ Ct06. Monitorar e Controlar questões financeiras } \\
\hline CMMI-DEV & ISO/IEC 15504-5 \\
\hline $\begin{array}{l}\text { PMC - SP 1.1 Monitor Project Planning } \\
\text { Parameters } \\
\text { PMC - SP 1.2 Monitor Commitments } \\
\text { PMC - SP 1.3 Monitor Project Risks }\end{array}$ & $\begin{array}{l}\text { MAN.3.BP12: Monitor project attributes. Monitor project } \\
\text { scope, budget, cost, resources and other necessary } \\
\text { attributes and document significant deviations of them } \\
\text { against the project baseline. }\end{array}$ \\
\hline \multicolumn{2}{|c|}{ Ct07. Conduzir revisão do milestone: Capacidade Operacional } \\
\hline CMMI-DEV & ISO/IEC 15504-5 \\
\hline $\begin{array}{l}\text { PMC - SP 1.7 Conduct Milestone Reviews } \\
\text { PP - SP } 3.1 \text { Review Plans That Affect the } \\
\text { Project } \\
\text { PPQA - SP } 1.1 \text { Objectively Evaluate } \\
\text { Processes } \\
\text { PPQA - SP } 1.2 \text { Objectively Evaluate Work } \\
\text { Products and Services } \\
\text { PPQA - SP } 2.1 \text { Communicate and Ensure } \\
\text { Resolution of Noncompliance Issues } \\
\text { PPQA - SP 2.2 Establish Records } \\
\text { MA - SP 2.1 Collect Measurement Data } \\
\text { MA - SP 2.2 Analyze Measurement Data } \\
\text { MA - SP 2.3 Store Data and Results } \\
\text { MA - SP 2.4 Communicate Results }\end{array}$ & $\begin{array}{l}\text { SUP.1.BP2: Define quality records. Quality records are } \\
\text { defined that demonstrate conformance of process and } \\
\text { work products to their quality requirements. } \\
\text { SUP.1.BP3: Assure the quality of project process activities } \\
\text { and project work products. Carry out a series of activities } \\
\text { to provide assurance, with the required level of confidence, } \\
\text { that the project processes have followed specified } \\
\text { standards and that the work products meet the quality } \\
\text { requirements. } \\
\text { SUP.1.BP4: Identify and record problems and non- } \\
\text { conformances. Problems and nonconformances are } \\
\text { identified and recorded and then reported to appropriate } \\
\text { stakeholders for information and action. } \\
\text { SUP.1.BP5: Act on non-conformances. Deviations or non- } \\
\text { conformance with agreed requirements or organizational } \\
\text { quality goals are analyzed and resolved. } \\
\text { MAN.6.BP5: Collect and store measurement data. Identify, } \\
\text { collect and store measurement data, including context } \\
\text { information necessary to verify, understand, or evaluate } \\
\text { the data. } \\
\text { MAN.6.BP6: Analyze measurement data. Analyze and } \\
\text { interpret measurement data, and develop information } \\
\text { products. } \\
\text { MAN.6.BP7: Use measurement information products for } \\
\text { decision-making. Make accurate and current measurement } \\
\text { information products accessible for any decision-making } \\
\text { processes for which it is relevant. } \\
\text { MAN.6.BP8: Communicate measurement results. } \\
\text { Disseminate measurement information products to all } \\
\text { parties who will be using them and collect feedback to } \\
\text { evaluate the appropriateness for intended use. } \\
\text { MAN.6.BP9: Evaluate and communicate information } \\
\text { products and measurement activities to process owners. } \\
\text { Evaluate information products and measurement activities } \\
\text { against the identified information needs and measurement } \\
\text { strategy, identify potential improvements in measurements, } \\
\text { and communicate any identified potential improvement to } \\
\text { the process owners. }\end{array}$ \\
\hline
\end{tabular}


QuAdro A5.7 - MAPEAMENTO dAs Atividades da FASE de Transição

\begin{tabular}{|c|c|}
\hline \multicolumn{2}{|l|}{ T01. Validar a versão do produto } \\
\hline CMMI-DEV & ISO/IEC 15504-5 \\
\hline $\begin{array}{l}\text { VAL - SP 2.1 Perform Validation } \\
\text { MA - SP 2.1 Collect Measurement Data } \\
\text { MA - SP 2.3 Store Data and Results }\end{array}$ & $\begin{array}{l}\text { ENG.8.BP2: Test integrated software product. Test the } \\
\text { integrated software product against the verification criteria, } \\
\text { and record the results. Update user documentation as } \\
\text { necessary } \\
\text { ENG.10.BP2: Test integrated system. Test the integrated } \\
\text { system and ensure that it satisfies the system } \\
\text { requirements, and record the results. } \\
\text { SUP.3.BP3: Perform validation activities. Conduct } \\
\text { validation activities using identified techniques, processes, } \\
\text { and test cases against requirements and quality standards. } \\
\text { The results of validation activities are recorded. } \\
\text { MAN.6.BP5: Collect and store measurement data. Identify, } \\
\text { collect and store measurement data, including context } \\
\text { information necessary to verify, understand, or evaluate } \\
\text { the data. }\end{array}$ \\
\hline \multicolumn{2}{|c|}{ T02. Analisar e Ajustar a versão do produto } \\
\hline CMMI-DEV & ISO/IEC 15504-5 \\
\hline $\begin{array}{l}\text { VAL - SP 2.2 Analyze Validation Results } \\
\text { MA - SP 2.2 Analyze Measurement Data } \\
\text { TS - SP } 3.1 \text { Implement the Design }\end{array}$ & $\begin{array}{l}\text { ENG.11.BP3: Specify the requirements for adaptation. } \\
\text { Specify the requirements for adaptation of the system for } \\
\text { its intended environment. } \\
\text { MAN.6.BP6: Analyze measurement data. Analyze and } \\
\text { interpret measurement data, and develop information } \\
\text { products. } \\
\text { MAN.6.BP7: Use measurement information products for } \\
\text { decision-making. Make accurate and current measurement } \\
\text { information products accessible for any decision-making } \\
\text { processes for which it is relevant. } \\
\text { ENG.11.BP4: Adapt the system. Adapt the system to meet } \\
\text { the requirements for operation. } \\
\text { SUP.3.BP4: Identify problems. Issues detected by the } \\
\text { validation process should be identified, recorded and } \\
\text { entered into the Problem resolution management process } \\
\text { (SUP.9). }\end{array}$ \\
\hline \multicolumn{2}{|l|}{ T03. Realizar testes de regressão } \\
\hline CMMI-DEV & ISO/IEC 15504-5 \\
\hline $\begin{array}{l}\text { VER - SP } 3.1 \text { Perform Verification } \\
\text { VAL - SP 2.1 Perform Validation } \\
\text { MA - SP 2.1 Collect Measurement Data } \\
\text { MA - SP 2.3 Store Data and Results }\end{array}$ & $\begin{array}{l}\text { SUP.2.BP3: Conduct verification. Verify identified work } \\
\text { products according to specified strategy. } \\
\text { SUP.3.BP3: Perform validation activities. Conduct } \\
\text { validation activities using identified techniques, processes, } \\
\text { and test cases against requirements and quality standards. } \\
\text { The results of validation activities are recorded. } \\
\text { ENG.10.BP3: Regression test integrated system. Develop } \\
\text { a system regression test strategy for re-testing the system. } \\
\text { If changes are made to system elements, carry out } \\
\text { regression testing as defined in the system regression test } \\
\text { strategy. } \\
\text { MAN.6.BP5: Collect and store measurement data. Identify, } \\
\text { collect and store measurement data, including context } \\
\text { information necessary to verify, understand, or evaluate } \\
\text { the data. }\end{array}$ \\
\hline
\end{tabular}


Quadro A5.7 - MAPEAmento das Atividades da FASE de Transição (CONT.)

\begin{tabular}{|c|c|}
\hline \multicolumn{2}{|c|}{ T04. Entregar/Instalar a versão do produto } \\
\hline CMMI-DEV & ISO/IEC 15504-5 \\
\hline $\begin{array}{l}\text { TS - SP } 3.2 \text { Develop Product Support } \\
\text { Documentation } \\
\text { PI - SP } 3.4 \text { Package and Deliver the } \\
\text { Product or Product Component }\end{array}$ & $\begin{array}{l}\text { SUP.7.BP5: Develop documents. Develop documents at } \\
\text { required process points according to established standards } \\
\text { and policy. } \\
\text { ENG.11.BP5: Install software product. Install the software } \\
\text { product according to the software installation strategy. } \\
\text { Document the events and results. } \\
\text { ENG.11.BP6: Confirm product readiness. Assure that the } \\
\text { software product is ready for use in its intended } \\
\text { environment. } \\
\text { NOTE 2: Software installation process is linked to Product } \\
\text { acceptance support process (SPL.3). } \\
\text { ENG.11.BP1: Develop installation strategy. Develop a } \\
\text { software installation strategy to install the software product } \\
\text { in the target environment in agreement with the customer } \\
\text { and the operating organization. } \\
\text { NOTE 1: An important part of developing an installation } \\
\text { strategy is to develop a strategy to return to the last } \\
\text { working system version. In order to be able to re-install the } \\
\text { last working version, a complete backup of the system } \\
\text { should be made before starting the installation. } \\
\text { ENG.11.BP2: Establish installation criteria. Based on the } \\
\text { installation requirements, develop criteria for the } \\
\text { environment where the software will be installed. }\end{array}$ \\
\hline \multicolumn{2}{|l|}{ T05. Monitorar e controlar o projeto } \\
\hline CMMI-DEV & ISO/IEC 15504-5 \\
\hline $\begin{array}{l}\text { PMC - SP 1.1 Monitor Project Planning } \\
\text { Parameters } \\
\text { PMC - SP 1.2 Monitor Commitments } \\
\text { PMC - SP 1.3 Monitor Project Risks } \\
\text { PMC - SP 1.4 Monitor Data Management } \\
\text { PMC - SP 1.5 Monitor Stakeholder } \\
\text { Involvement } \\
\text { PMC - SP 1.6 Conduct Progress Reviews } \\
\text { PMC - SP 2.1 Analyze Issues } \\
\text { PMC - SP 2.2 Take Corrective Action } \\
\text { PMC - SP 2.3 Manage Corrective Action }\end{array}$ & $\begin{array}{l}\text { MAN.3.BP12: Monitor project attributes. Monitor project } \\
\text { scope, budget, cost, resources and other necessary } \\
\text { attributes and document significant deviations of them } \\
\text { against the project baseline. } \\
\text { MAN.3.BP13: Review progress of the project. Regularly } \\
\text { report and review the status of the project performance } \\
\text { against the project plan. } \\
\text { MAN.3.BP14: Act to correct deviations. Take action when } \\
\text { project goals are not achieved, to correct deviations from } \\
\text { the plan and to prevent recurrence of problems identified in } \\
\text { the project. Update project plans accordingly. }\end{array}$ \\
\hline \multicolumn{2}{|c|}{ T06. Monitorar e Controlar questões financeiras } \\
\hline CMMI-DEV & ISO/IEC 15504-5 \\
\hline $\begin{array}{l}\text { PMC - SP 1.1 Monitor Project Planning } \\
\text { Parameters } \\
\text { PMC - SP 1.2 Monitor Commitments } \\
\text { PMC - SP 1.3 Monitor Project Risks }\end{array}$ & $\begin{array}{l}\text { MAN.3.BP12: Monitor project attributes. Monitor project } \\
\text { scope, budget, cost, resources and other necessary } \\
\text { attributes and document significant deviations of them } \\
\text { against the project baseline. }\end{array}$ \\
\hline
\end{tabular}


Quadro A5.7 - Mapeamento das Atividades da Fase de Transição (Cont.)

T07. Conduzir revisão do milestone: Entrega do Produto

$$
\text { CMMI-DEV }
$$

PMC - SP 1.7 Conduct Milestone Reviews PP - SP 3.1 Review Plans That Affect the Project

PPQA - SP 1.1 Objectively Evaluate

Processes

PPQA - SP 1.2 Objectively Evaluate Work

Products and Services

PPQA - SP 2.1 Communicate and Ensure

Resolution of Noncompliance Issues

PPQA - SP 2.2 Establish Records

MA - SP 2.1 Collect Measurement Data

MA - SP 2.2 Analyze Measurement Data

MA - SP 2.3 Store Data and Results

MA - SP 2.4 Communicate Results
ISO/IEC 15504-5

SUP.1.BP2: Define quality records. Quality records are defined that demonstrate conformance of process and work products to their quality requirements.

SUP.1.BP3: Assure the quality of project process activities and project work products. Carry out a series of activities to provide assurance, with the required level of confidence, that the project processes have followed specified standards and that the work products meet the quality requirements.

SUP.1.BP4: Identify and record problems and nonconformances. Problems and nonconformances are identified and recorded and then reported to appropriate stakeholders for information and action.

SUP.1.BP5: Act on non-conformances. Deviations or nonconformance with agreed requirements or organizational quality goals are analyzed and resolved.

MAN.6.BP5: Collect and store measurement data. Identify, collect and store measurement data, including context information necessary to verify, understand, or evaluate the data.

MAN.6.BP6: Analyze measurement data. Analyze and interpret measurement data, and develop information products.

MAN.6.BP7: Use measurement information products for decision-making. Make accurate and current measurement information products accessible for any decision-making processes for which it is relevant.

MAN.6.BP8: Communicate measurement results. Disseminate measurement information products to all parties who will be using them and collect feedback to evaluate the appropriateness for intended use.

MAN.6.BP9: Evaluate and communicate information products and measurement activities to process owners. Evaluate information products and measurement activities against the identified information needs and measurement strategy, identify potential improvements in measurements, and communicate any identified potential improvement to the process owners. 


\section{Apêndice 6 - Aplicação do ProcSoftVD - Melhoria}

Ramo de atividade da empresa: Desenvolvimento de Sistemas de Informática Nicho: Comércio Varejista, oficinas mecânicas.

Quadro de funcionários: 3

\section{Fase 1. Diagnóstico do Processo de Software Atual e Definição do Perfil-Alvo}

\subsection{Descrição do Processo Atual}

- É efetuada uma análise inicial, com uma entrevista e anotações (em papel) do que o sistema fará.

- Durante uma semana (mais ou menos) é feita uma análise de todo o sistema, quais ferramentas serão usadas, e é fornecido ao cliente um prazo.

- Durante o processo de desenvolvimento, são efetuadas anotações em papéis e planilhas eletrônicas.

- É visto o que é mais prioritário e este incremento é desenvolvido e entregue. O próprio programador efetua os testes, também. Esses testes são relacionados à compartilhamento de recursos, carga de dados, impressões, e em relação ao software sem utilizar critérios de teste (erros de codificação).

- É efetuado um instalador para a versão, é marcado em uma planilha o número da versão e o que foi instalado ou não.

- Depois, realiza-se o próximo incremento e se refaz o processo novamente

- Nesse ínterim, existem modificações de outros sistemas.

- Um dos funcionários é responsável pelo relacionamento com o cliente, verificando qual será a mudança e se está sendo atendida.

- O outro programador auxilia em testes e alterações.

Quanto ao controle de pagamentos, existe uma planilha para controlar quem pagou o quê em cada mês, pois o produto executável é disponibilizado para o cliente por intermédio de mensalidades.

\subsection{Objetivos Estratégicos do Negócio da Empresa}

Objetivos Estratégicos:

- Hoje os clientes da empresa são pequenas empresas e um dos objetivos estratégicos é buscar e atender clientes de porte médio e grande, por meio do desenvolvimento de um sistema ERP

- Ter clientes de outras regiões

Metas de melhoria:

- Formalizar e padronizar o processo para desenvolvimento do software (necessária e importante)

- Melhorar a implantação no cliente, deixar explícito para o patrocinador, todas as modificações relevantes

- Desenvolver uma ferramenta de BI (business intelligence) que seja integrada ao sistema ERP para dar melhores resultados financeiros.

- Ter meios de suporte on-line para o cliente

\subsection{Definição dos Perfis-Alvo do Processo}




\section{Comercialização}

Sintomas da não execução do processo:

- O cliente faz solicitações de mudanças do sistema e pode cancelar a utilização.

- O cliente pode solicitar mais alterações, além do combinado verbalmente, Benefícios: extrapolando prazos, etc

- O contrato pode estipular multas em casos de solicitações de mudanças e desistência da utilização do sistema, por ex, e isso traz segurança para a empresa desenvolvedora.

- Ter controle das modificações solicitadas pelo cliente dentro um prazo estabelecido.

\section{Modelagem de Negócio}

Sintomas da não execução do processo:

Benefícios:

- Cada vez que tiver um novo funcionário dentro da softwarehouse, alguém terá que ser interrompido para explicar o modelo de negócio.

- Auxiliar na visão geral dos stakeholders do que se trata o negócio do cliente.

\section{Produção de Requisitos}

Sintomas da não execução do processo:

- Entendimento único dos processos do sistema (fica "na cabeça" de um participante do projeto)

- A não definição dos requisitos propicia até a inviabilidade do projeto, pois não é avaliado a sua dimensão.

Benefícios:

- Melhor entendimento das lógicas dos processos

- Visão macro de todo o sistema

- A definição dos requisitos ajuda na melhora também do sistema no futuro, pois tem se "um alicerce" de como realmente o sistema funciona

\section{Projeto, Codificação \& Integração de Produto}

Sintomas da não execução do processo:

- A falta de parâmetros de definição de codificação e integração do produto propicia uma instabilidade no projeto como um todo

Benefícios

- A definição em design, do software, podem levar a uma melhor verificação se o projeto como um todo está funcional ou não.

\section{$\mathbf{V} \& \mathbf{V}$}

Sintomas da não execução do processo:

- Podem surgir diversos erros, ainda mais, no cliente, proporcionando uma corrida pra "atender e resolver" os erros do cliente

Benefícios

- Maior "credibilidade" na versão que está no cliente

\section{Garantia da Qualidade}

Sintomas da não execução do processo:

- A falta de avaliação do processo (de forma imparcial) pode proporcionar comodismo no projeto como um todo ou em partes 
Benefícios

- Apuração dos resultados, e é possível verificar se está adiantando mesmo fazer todos os processos

\section{Implantação}

Sintomas da não execução do processo:

- Dúvidas e falta de credibilidade no ambiente do cliente

Benefícios

- Um controle da implantação propicia maior facilidade da instalação com o cliente

\section{Aquisição}

Sintomas da não execução do processo:

- Com as mudanças no software do cliente, uma falta de controle de aquisição, pode gerar erros na instalação de uma versão. (terceirização de parte do software)

\section{Benefícios}

- Controlando a aquisição de versões, a softwarehouse tem a noção do que está "rodando", em termos de sistema no cliente.

\section{Medição}

Sintomas da não execução do processo:

- A falta de medição pode levar a uma insatisfação do cliente, até porque não é avaliado como o cliente está se adaptando ao sistema

\section{Benefícios}

- Consegue-se "medir" um retorno do próprio produto de como ele está, e há várias formas de se medir ele. Ex: em categorias, por índice, etc

\section{Gestão de Requisitos}

Sintomas da não execução do processo:

- pode-se gerar uma falta de atualização entre requisitos e o software

\section{Benefícios}

- identificando as inconsistências pode evitar-se um desentendimento entre documentação do que é realmente o sistema (em relação a outras pessoas)

\section{Gestão de Projetos}

Sintomas da não execução do processo:

- a falta de definição de um plano no projeto como um todo, pode propiciar a que o projeto não chegue a lugar nenhum

\section{Benefícios}

- a definição do projeto como um todo, gera a idéia de começo, meio e fim do todo

\section{Gestão de Mudanças e Configuração}

Sintomas da não execução do processo:

- falta de parametrização no sistema dos produtos usados,como um todo, em relação a equipe de desenvolvimento 
Benefícios

- controle mais apurado de como desenvolver e uso do produto

\section{Gestão de Conhecimento}

Sintomas da não execução do processo:

- cada um do desenvolvimento (programadores, analistas) faz e refazem funções, procedimentos, etc, e se perde tempo no desenvolvimento e no projeto

Benefícios

- acho que uma equipe em constante conversação, evita-se e tem-se idéias de inovações no produto e resolução de problemas nos clientes

\section{Fase 2. Análise Estratégica e Planejamento da Mudança}

\subsection{Priorização das Áreas de Conhecimento}

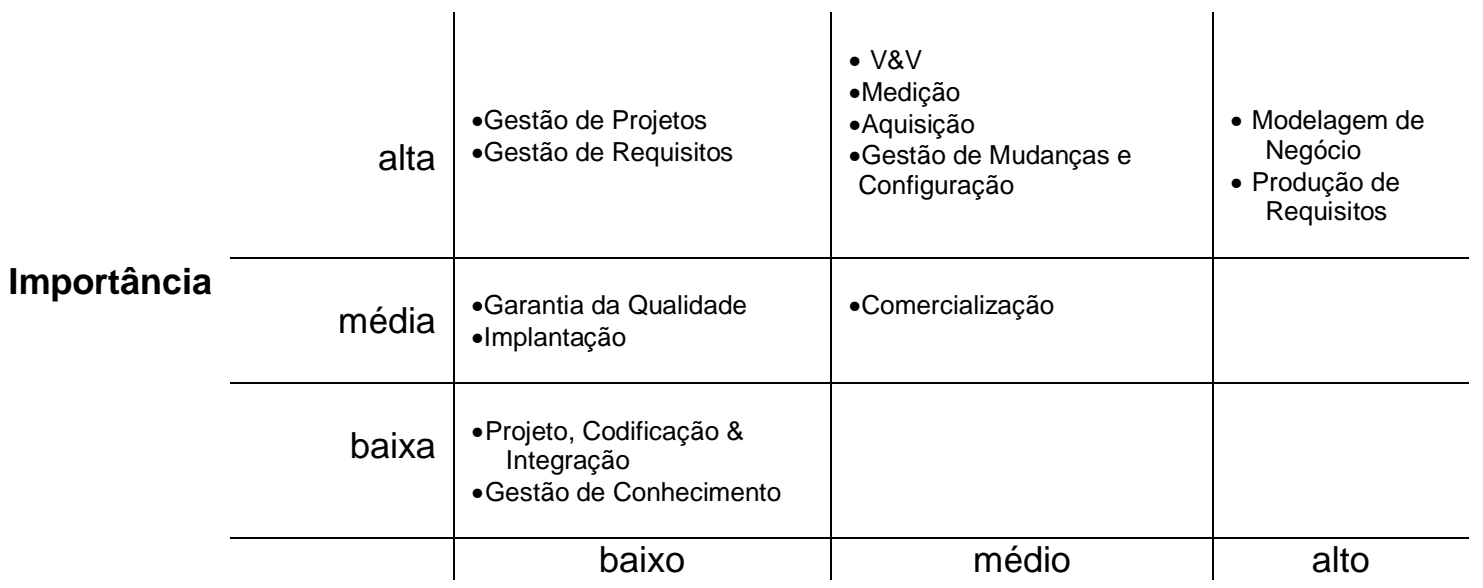

Risco

\section{Ciclos de Melhoria}

Ciclo de Melhoria 1: Modelagem de Negócios; Produção de Requisitos

Ciclo de Melhoria 2: V\&V

Ciclo de Melhoria 3: Aquisição; Gestão de Mudanças e Configuração

Ciclo de Melhoria 4: Medição

Ciclo de Melhoria 5: Gestão de Requisitos; Gestão de Projetos

Ciclo de Melhoria 6: Garantia da Qualidade; Implantação

Ciclo de Melhoria 7: Comercialização

Ciclo de Melhoria 8: Projeto, Codificação \& Integração; Gestão de Conhecimento

\subsection{Plano de Ação}

Foi definido um patrocinador na empresa, o escopo do projeto de mudança, a WBS, cronograma e avaliados os riscos do projeto de mudança.

Fase 3. Definição das atividades da(s) área(s) de conhecimento 
Nessa fase foi realizada a definição das atividades das áreas de conhecimento "Modelagem de Negócios" e "Produção de Requisitos", tendo como subsídio o Modelo ProcSoftVD.

Fase 4. Implantação da(s) área(s) de conhecimento

Nessa fase as áreas de conhecimento "Modelagem de Negócios" e "Produção de Requisitos" foram institucionalizadas e avaliadas. 


\section{Apêndice 7 - Questionário de Avaliação do ProcSoftVD}

\section{QUESTIONARIO}

\section{Identificação}

1.2 Seu nome (opcional):

1.2 E-mail pessoal para contato:

1.3 Qual é a sua formação acadêmica?

R.

1.4 Função que você exerce na empresa onde trabalha:

a. ( ) Gerente/Supervisor

b. ( ) Gerente de Projetos

c. ( ) Analista de Sistemas

d. ( ) Programador

e. ( ) Outra. Qual ?

Nesse caso, algum dia já exerceu a função de analista de sistema e/ou programador em alguma empresa? R:

\section{Validação do Modelo ProcSoftVD}

\subsection{Apresentação do Modelo}

Acesse o site http://www.numa.org.br/GProcSoftVD.

\subsection{Validação das Áreas de Conhecimento}

Para cada área de conhecimento será apresentada, a seguir, uma tabela com a sua descrição e espera-se que você defina os pontos fortes e fracos do modelo relacionado a essa área de conhecimento, após sua validação. 


\begin{tabular}{|c|c|c|}
\hline DESCRIÇÃO DA ÁREA DE CONHECIMENTO & $\begin{array}{l}\text { PONTOS } \\
\text { FORTES }\end{array}$ & $\begin{array}{l}\text { PONTOS } \\
\text { FRACOS }\end{array}$ \\
\hline $\begin{array}{l}\text { Comercialização: essa área de conhecimento foi criada } \\
\text { para abordar (1) atividades relacionadas à prospecção de } \\
\text { potenciais clientes para a empresa (o que não é coberto } \\
\text { pelo CMMI, nem pela ISO/IEC 15504-5); (2) atividades } \\
\text { relacionadas à elaboração/submissão de propostas ao } \\
\text { cliente e negociação e aprovação de contrato sem } \\
\text { ambigüidades que especifique as expectativas, } \\
\text { responsabilidades, entregas e compromissos de ambas as } \\
\text { partes cliente e fornecedor; (3) atividades relacionadas à } \\
\text { viabilidade financeira do projeto e relacionadas ao } \\
\text { pagamento dos produtos/serviços vendidos pela empresa. } \\
\text { As atividades do item (2) foram definidas com subsídio dos } \\
\text { processos "Prospecção do Fornecedor" e "Acordado } \\
\text { Contratual" da ISO/IEC 15504-5. }\end{array}$ & $\bullet$ & $\bullet$ \\
\hline $\begin{array}{l}\text { Modelagem de Negócio: o objetivo dessa área de } \\
\text { conhecimento é documentar os processos de negócio } \\
\text { usando casos de uso de negócio, a fim de assegurar um } \\
\text { entendimento comum entre todos os stakeholders } \\
\text { (envolvidos) sobre as necessidades existentes no processo } \\
\text { de negócio da organização cliente. Essa área de } \\
\text { conhecimento teve sua origem no Unified Process. }\end{array}$ & $\bullet$ & $\bullet$ \\
\hline $\begin{array}{l}\text { Produção de Requisitos: tem o objetivo de produzir e } \\
\text { analisar os requisitos do cliente, do produto e dos } \\
\text { componentes de produto. Essa área de conhecimento teve } \\
\text { sua origem relacionada à área de processo } \\
\text { "Desenvolvimento de Requisitos" do CMMI-DEV e aos } \\
\text { processos "Elicitação de Requisitos", "Análise de Requisitos } \\
\text { do Sistema" e "Análise de Requisitos do Software" da } \\
\text { ISO/IEC 15504-5. }\end{array}$ & $\bullet$ & - \\
\hline $\begin{array}{l}\text { Projeto, Codificação \& Integração de Produto: Engloba os } \\
\text { processos "Projeto do Software", "Integração do Software" e } \\
\text { "Integração do Sistema" da 15504-5, o workflow } \\
\text { "Implementação" do UP e as áreas de processo "Solução } \\
\text { Técnica" e "Integração de Produto" do CMMI-DEV. Segundo } \\
\text { a 15504-5, o processo "Projeto de Software" tem o objetivo } \\
\text { de fornecer um design para o software que é implementado } \\
\text { e pode ser verificado em confronto aos requisitos; o } \\
\text { processo "Integração de Software" tem o objetivo de } \\
\text { combinar as unidades de software, produzindo itens de } \\
\text { software integrados, consistentes com o projeto de software, } \\
\text { os quais demonstram que os requisitos funcionais e não- } \\
\text { funcionais foram satisfeitos; e o processo "Integração do } \\
\text { Sistema" tem como objetivo integrar os elementos do } \\
\text { sistema (incluindo os itens de software, itens de hardware, } \\
\text { operações manuais e outros sistemas, se necessário) para } \\
\text { produzir um sistema completo que satisfaça ao projeto do } \\
\text { sistema e às expectativas do cliente, expressadas em } \\
\text { requisitos do sistema. Segundo o modelo CMMI-DEV, a área } \\
\text { de processo "Solução Técnica" tem como objetivo projetar, } \\
\text { desenvolver e implementar soluções para os requisitos, } \\
\text { soluções essas que envolvem produtos, componentes de } \\
\text { produtos e processos de ciclo de vida relacionados ao } \\
\text { produto; e a área de processo "Integração do Produto" tem o } \\
\text { objetivo de montar o produto, a partir dos componentes de } \\
\text { produto, assegurar que o produto ao ser integrado funcione } \\
\text { adequadamente, e entregar o produto. }\end{array}$ & $\bullet$ & $\bullet$ \\
\hline V\&V: Engloba as áreas de processo (CMMI) e processos & $\bullet$ & $\bullet$ \\
\hline
\end{tabular}


(15504-5) "Validação" e "Verificação" e os processos "Teste de Software" e "Teste de Sistema" da 15504-5. O objetivo da área de processo/processo "Validação" é demonstrar que o produto ou componente do produto atenda ao uso pretendido quando colocado no ambiente destinado. Já o objetivo da área de processo/processo "Verificação" é assegurar que produtos de trabalho (e serviços, no caso do CMMI) selecionados alcancem seus requisitos especificados. Testes desempenham um papel extremamente importante em V\&V (Verificação e Validação). Segundo o modelo 15504-5, o processo "Teste" pode ser realizado tanto no software quanto no sistema. O processo "Teste de Software" tem como objetivo confirmar que o produto de software integrado atende aos requisitos definidos. E, o processo "Teste de Sistema" tem o objetivo de assegurar que a implementação de cada requisito de sistema seja testada quanto à sua conformidade e que o sistema esteja pronto para entrega.

Implantação: o objetivo é entregar o produto produzido para os usuários finais, por meio das atividades de codificação, teste, empacotamento e instalação do software. Essa área de conhecimento teve sua origem no UP e também está relacionada ao processo "Entrega de Produto" da 15504-5.

Aquisição: essa área de conhecimento tem o objetivo de gerenciar a aquisição de produtos de fornecedores, sejam equipamentos ou até mesmo componentes de software do produto (no caso de terceirização do serviço). Exemplos de produtos e componentes de produtos que podem ser adquiridos pelo projeto: subsistemas (por exemplo, um sistema navegacional de uma aeronave), software, hardware, documentação (como manuais de instalação, de operação e do usuário). A origem dessa área de conhecimento está relacionada ao grupo de processo "Aquisição" da 15504-5 à área de processo denominada "Gestão de Acordo com Fornecedor" do CMMI-DEV.

Medição: essa área de conhecimento tem o objetivo de coletar e analisar dados relacionados aos produtos desenvolvidos e aos processos implementados dentro da organização por meio de projetos, a fim de dar um suporte efetivo à gestão dos processos e demonstrar objetivamente a qualidade dos produtos. Sua origem está relacionada à área de processo "Análise e Medição" do CMMI-DEV e do processo "Medição" da 15504-5.

Garantia da Qualidade de Produto e Processo: o objetivo dessa área de conhecimento é fornecer a garantia de que processos e produtos de trabalho estejam em conformidade com planos e provisões pré-definidos. Sua origem está relacionada tanto ao CMMI quanto à ISO/IEC 15504.

Gestão de Requisitos: 0 objetivo dessa área de conhecimento, que teve sua origem no CMMI-DEV, é gerenciar os requisitos dos produtos e componentes de produtos dos projetos e identificar inconsistências entre esses requisitos e os planos e produtos de trabalho dos projetos. Para isso, essa área trata do rastreamento dos requisitos em meio ao projeto e das mudanças desses requisitos. As mudanças relacionadas aos requisitos utilizam algumas das atividades definidas pela área de conhecimento "Gestão de Mudanças e Configuração".

Gestão de Mudanças e Configuração: essa área de conhecimento engloba a área de processo "Gestão de 


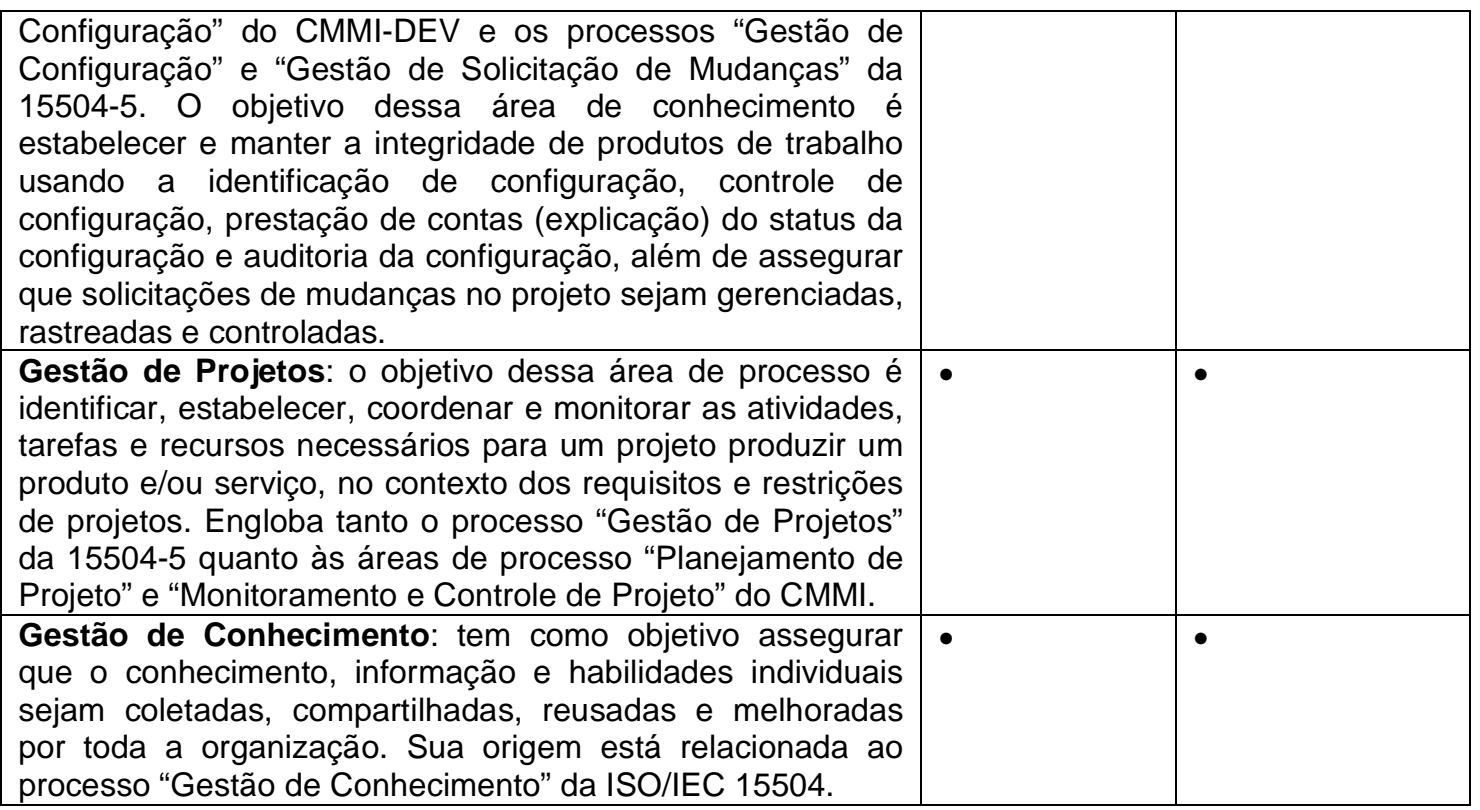

\subsection{Validação do Modelo como um todo}

2.3.1 Por gentileza, abra o arquivo "CMMI-v1-2.pdf". Aperte SHIFT+CTRL+N e digite 339. Você foi redirecionado para a área de processo do CMMI "Planejamento de Projeto". Nela você encontra o objetivo dessa área, os objetivos específicos e para cada um deles as sub-práticas e produtos de trabalho típicos. Todas as outras áreas de processo têm a mesma estrutura.

- Para uma MPE, o que é mais fácil: utilizar como modelo de referência para criar o seu processo padrão o CMMI ou um outro modelo com mais detalhes de como podem ser realizadas as atividades do processo, como o proposto nesse trabalho de pesquisa?

R:

2.3.2 Por gentileza, abra o arquivo "ISO-IEC_FDIS_15504-5.pdf". Aperte SHIFT+CTRL+N e digite 69 . Você foi redirecionado para o processo "Gestão de Projeto". Nele você encontra o objetivo desse processo, os resultados, as práticas-base e os produtos de trabalho típicos. Todos os outros processos têm a mesma estrutura.

- Para uma MPE, o que é mais fácil: utilizar como modelo de referência para criar o seu processo padrão a norma ISO/IEC 15504-5 ou um outro modelo com mais detalhes de como podem ser realizadas as atividades do processo, como o proposto nesse trabalho de pesquisa?

R:

2.3.3 Você enxerga o modelo proposto nesse trabalho de pesquisa como uma referência, um guia que poderia ser utilizado por uma MPE para, a partir dele, definir o seu processo padrão (mesmo que seja necessário fazer alguns ajustes para adequar à realidade da empresa)?

$\mathrm{R}$ :

2.3.4 De forma geral, quais os comentários você faria a respeito do modelo proposto?

$\mathrm{R}:$

2.3.5 Acesse a planilha "AvaliacaoQualidade.xls" e preencha a coluna "Qual nível de atendimento de cada sub-característica?" com as alternativas do combo-box (Alto, Médio, Baixo e NA (não se aplica). Por favor, envie a planilha preenchida junto a esse questionário. 


\section{Apêndice 8 - Pontos Fortes e Fracos Transcritos das Respostas do Questionário entregue aos Profissionais}

As respostas dos 6 (seis) profissionais que avaliaram o modelo quanto aos seus pontos fortes e fracos estão transcritas, por área de conhecimento, nos Quadros A8.1 a A8.13.

Quadro A8.1 - Transcrição das Respostas - Área de Conhecimento Produção de Requisitos

\begin{tabular}{|c|c|c|}
\hline \multirow{12}{*}{$\begin{array}{l}\text { Quanto à } \\
\text { Produção de } \\
\text { Requisitos }\end{array}$} & \multirow[t]{6}{*}{$\begin{array}{l}\text { Pontos } \\
\text { Fortes }\end{array}$} & $\begin{array}{l}\text { P1: "O template documento de requisitos é simplificado e fácil de ser colocado em } \\
\text { prática; muito bom". }\end{array}$ \\
\hline & & $\begin{array}{l}\text { P2: "a) Documentação muito bem definida; b) Contempla Exemplos/Sugestões; c) } \\
\text { Completo". }\end{array}$ \\
\hline & & P3: não comentou \\
\hline & & P4: não comentou \\
\hline & & $\begin{array}{l}\text { P5: "Tempo despendido em modelagem, análise e produção de requisitos é um } \\
\text { excelente investimento, e não um gasto". }\end{array}$ \\
\hline & & $\begin{array}{l}\text { P6: "a) Vasto material de apoio para a elicitação dos requisitos para o software; b) } \\
\text { Bem detalhado". }\end{array}$ \\
\hline & \multirow{6}{*}{$\begin{array}{l}\text { Pontos } \\
\text { Fracos }\end{array}$} & P1: não comentou \\
\hline & & P2: não comentou \\
\hline & & P3: não comentou \\
\hline & & P4: não comentou \\
\hline & & $\begin{array}{l}\text { P5: "Muito material para ser lido, analisado, documentado e empreendido, para } \\
\text { autônomos e equipes pequenas". }\end{array}$ \\
\hline & & P6: não comentou \\
\hline
\end{tabular}

Quadro A8.2 - Transcrição das Respostas - Área de Conhecimento Modelagem de Negócios

\begin{tabular}{|c|c|c|}
\hline \multirow{12}{*}{$\begin{array}{l}\text { Quanto à } \\
\text { Modelagem de } \\
\text { Negócios }\end{array}$} & \multirow{6}{*}{$\begin{array}{l}\text { Pontos } \\
\text { Fortes }\end{array}$} & P1: "As tarefas que incluem a modelagem de negócio estão claramente definidas". \\
\hline & & $\begin{array}{l}\text { P2: "a) Completo e eficiente; b) Foco e preocupação com aspectos fundamentais } \\
\text { dessa área de conhecimento; c) Clareza nas explicações; d) Contempla } \\
\text { Exemplos/Sugestões". }\end{array}$ \\
\hline & & P3: não comentou \\
\hline & & P4: não comentou \\
\hline & & P5: não comentou \\
\hline & & $\begin{array}{l}\text { P6: "Roteiro bem definido, enfatizando a importância da interação entre cliente e } \\
\text { desenvolvedor". }\end{array}$ \\
\hline & \multirow{6}{*}{$\begin{array}{l}\text { Pontos } \\
\text { Fracos }\end{array}$} & P1: não comentou \\
\hline & & P2: não comentou \\
\hline & & P3: não comentou \\
\hline & & P4: não comentou \\
\hline & & P5: não comentou \\
\hline & & P6: não comentou \\
\hline
\end{tabular}


Quadro A8.3 - Transcrição das Respostas - Área de Conhecimento Comercialização

\begin{tabular}{|c|c|c|}
\hline \multirow[t]{12}{*}{$\begin{array}{l}\text { Quanto à } \\
\text { Comercialização }\end{array}$} & \multirow[t]{6}{*}{$\begin{array}{l}\text { Pontos } \\
\text { Fortes }\end{array}$} & $\begin{array}{l}\text { P1: "As atividades prospectar clientes, visitar clientes e criar infra-estrutura do projeto } \\
\text { são pontos fortes do modelo". }\end{array}$ \\
\hline & & $\begin{array}{l}\text { P2: "a) Fornece plenas condições para o gerenciamento do contato inicial com o } \\
\text { cliente, transmitindo eficiência e credibilidade perante o cliente; b) Aspecto formal } \\
\text { abrangido sem exageros; ideal!; c) Contempla Exemplos/Sugestões". }\end{array}$ \\
\hline & & P3: não comentou \\
\hline & & $\begin{array}{l}\text { P4: "Cobertura de uma atividade cuja organização desenvolvedora deve se } \\
\text { preocupar". }\end{array}$ \\
\hline & & $\begin{array}{l}\text { P5: "a) O modelo contempla a viabilidade do projeto para a empresa; b) Com o } \\
\text { auxílio do Marketing pode-se aumentar o desenvolvimento de produtos, aumentando- } \\
\text { se os lucros". }\end{array}$ \\
\hline & & $\begin{array}{l}\text { P6: "a) Linguagem de fácil entendimento por parte da empresa envolvida; b) Roteiro } \\
\text { bem simplificado, a área de conhecimento é bem explicada e fácil de se seguir; c) } \\
\text { Elaboração do contrato de prestação de serviço junto ao cliente ou de venda do } \\
\text { software bem explicado e de acordo com a legislação". }\end{array}$ \\
\hline & \multirow{6}{*}{$\begin{array}{l}\text { Pontos } \\
\text { Fracos }\end{array}$} & P1: não comentou \\
\hline & & P2: não comentou \\
\hline & & P3: não comentou \\
\hline & & $\begin{array}{l}\text { P4: "É preciso considerar dois papéis claramente: cliente (consumidor de uma } \\
\text { solução computacional) e fornecedor (produtor dessa solução). A análise da } \\
\text { viabilidade financeira é uma atividade do cliente, não do fornecedor. Aliás, o cliente já } \\
\text { tem parâmetros para tal análise, o que torna essa atividade sem uma utilidade para } \\
\text { ele. E para o fornecedor? Por que uma MPE deveria usar essa atividade?" }\end{array}$ \\
\hline & & $\begin{array}{l}\text { P5: "No pós-venda a equipe de vendas não acompanha o andamento do cliente, } \\
\text { sendo que é necessário um acompanhamento mútuo de suporte". }\end{array}$ \\
\hline & & P6: não comentou \\
\hline
\end{tabular}

Quadro A8.4 - Transcrição das Respostas - Área de Conhecimento Projeto, Codificação \& INTEgração de Produto

\begin{tabular}{|c|c|c|}
\hline \multirow{12}{*}{$\begin{array}{l}\text { Quanto ao } \\
\text { Projeto, } \\
\text { Codificação \& } \\
\text { Integração de } \\
\text { Produto }\end{array}$} & \multirow{6}{*}{$\begin{array}{l}\text { Pontos } \\
\text { Fortes }\end{array}$} & P1: não comentou \\
\hline & & P2: não comentou \\
\hline & & P3: não comentou \\
\hline & & P4: não comentou \\
\hline & & $\begin{array}{l}\text { P5: "Um software deve ser bem projetado, desenvolvido e documentado de forma a } \\
\text { permitir uma fácil manutenção e evolução do mesmo. Os custos de manutenção são } \\
\text { muito superiores ao custo de desenvolvimento do sistema. O modelo apresenta } \\
\text { atividades e templates para a realização dessa área de conhecimento que podem } \\
\text { auxiliar". }\end{array}$ \\
\hline & & $\begin{array}{l}\text { P6: "a) Bem detalhado; b) Fornece subsídios para o início da codificação por parte } \\
\text { dos responsáveis pelo desenvolvimento do software". }\end{array}$ \\
\hline & \multirow{6}{*}{$\begin{array}{l}\text { Pontos } \\
\text { Fracos }\end{array}$} & P1: não comentou \\
\hline & & P2: não comentou \\
\hline & & P3: não comentou \\
\hline & & P4: não comentou \\
\hline & & P5: não comentou \\
\hline & & P6: não comentou \\
\hline
\end{tabular}


Quadro A8.5 - Transcrição das Respostas - Área de Conhecimento Aquisição

\begin{tabular}{|c|c|c|}
\hline \multirow{12}{*}{$\begin{array}{l}\text { Quanto à } \\
\text { Aquisição }\end{array}$} & \multirow{6}{*}{$\begin{array}{l}\text { Pontos } \\
\text { Fortes }\end{array}$} & P1: não comentou \\
\hline & & P2: "Clareza". \\
\hline & & P3: não comentou \\
\hline & & P4: "Parece coerente" \\
\hline & & P5: "Fazer cotações e análise de fornecedores é importante para viabilizar o projeto". \\
\hline & & $\begin{array}{l}\text { P6: "a) Auxilia o desenvolver no gerenciamento de aquisição de hardwares, por } \\
\text { exemplo, que estarão sendo usados para a implantação do software; b) Vasto material } \\
\text { de apoio; c) Bem detalhado". }\end{array}$ \\
\hline & \multirow{6}{*}{$\begin{array}{l}\text { Pontos } \\
\text { Fracos }\end{array}$} & P1: não comentou \\
\hline & & P2: não comentou \\
\hline & & P3: não comentou \\
\hline & & P4: não comentou \\
\hline & & $\begin{array}{l}\text { P5: "Sugiro inserir o Documento de requisitos do componente adquirido pelo } \\
\text { fornecedor, no caso de componente de software, como artefato do projeto que poderá } \\
\text { ser modificado e, por isso, precisa ser colocado sob gerência de requisitos também". }\end{array}$ \\
\hline & & P6: não comentou \\
\hline
\end{tabular}

\section{Quadro A8.6 - Transcrição das Respostas - Área de Conhecimento Medição}

\begin{tabular}{|c|c|c|}
\hline \multirow{12}{*}{$\begin{array}{l}\text { Quanto à } \\
\text { Medição }\end{array}$} & \multirow{6}{*}{$\begin{array}{l}\text { Pontos } \\
\text { Fortes }\end{array}$} & P1: não comentou \\
\hline & & P2: não comentou \\
\hline & & P3: não comentou \\
\hline & & P4: "Parece coerente" \\
\hline & & $\begin{array}{l}\text { P5: "É importantíssimo avaliar os processos como forma de aprimoramento e } \\
\text { diminuição de redundâncias nos processos". }\end{array}$ \\
\hline & & $\begin{array}{l}\text { P6: "O modelo fornece subsídios para se ter dados relacionados a todos os projetos da } \\
\text { empresa; dados como tempo estimado e concretizado, valor cobrado, etc, que serão } \\
\text { utilizados para estimativas em projetos futuros". }\end{array}$ \\
\hline & \multirow{6}{*}{$\begin{array}{l}\text { Pontos } \\
\text { Fracos }\end{array}$} & P1: não comentou \\
\hline & & P2: não comentou \\
\hline & & P3: não comentou \\
\hline & & P4: não comentou \\
\hline & & P5: não comentou \\
\hline & & P6: não comentou \\
\hline
\end{tabular}

\section{Quadro A8.7 - Transcrição das Respostas - Área de ConHecimento ImPLANTAÇão}

\begin{tabular}{|c|c|c|}
\hline \multirow{12}{*}{$\begin{array}{l}\text { Quanto à } \\
\text { Implantação }\end{array}$} & \multirow{6}{*}{$\begin{array}{l}\text { Pontos } \\
\text { Fortes }\end{array}$} & P1: não comentou \\
\hline & & P2: "a) Preocupação com a satisfação do cliente; b) Bem gerenciado". \\
\hline & & P3: não comentou \\
\hline & & P4: "Parece coerente" \\
\hline & & $\begin{array}{l}\text { P5: "O modelo apresenta atividades relacionadas à implantação dos releases do } \\
\text { produto ao cliente de forma completa". }\end{array}$ \\
\hline & & P6: "Cuida de todos os tópicos relacionados à implantação e a entrega do material." \\
\hline & \multirow{6}{*}{$\begin{array}{l}\text { Pontos } \\
\text { Fracos }\end{array}$} & P1: não comentou \\
\hline & & P2: não comentou \\
\hline & & P3: não comentou \\
\hline & & P4: não comentou \\
\hline & & P5: não comentou \\
\hline & & P6: não comentou \\
\hline
\end{tabular}


Quadro A8.8 - Transcrição das Respostas - Área de Conhecimento V\&V

\begin{tabular}{|c|c|c|}
\hline \multirow[t]{12}{*}{ Quanto à V\&V } & \multirow{6}{*}{$\begin{array}{l}\text { Pontos } \\
\text { Fortes }\end{array}$} & P1: não comentou \\
\hline & & $\begin{array}{l}\text { P2: "a) Muito bem distribuído e especificado nas fases; b) Presença marcante no } \\
\text { modelo proposto". }\end{array}$ \\
\hline & & P3: não comentou \\
\hline & & P4: não comentou \\
\hline & & $\begin{array}{l}\text { P5: "Teste é uma das tarefas mais importantes e que não deve ser negligenciada } \\
\text { durante o desenvolvimento, com apenas testes rápidos e sem critérios". }\end{array}$ \\
\hline & & $\begin{array}{l}\text { P6: "Muito importante, porque nem sempre as empresas de software testam e validam } \\
\text { seus produtos antes de entregar para o cliente". }\end{array}$ \\
\hline & \multirow{6}{*}{$\begin{array}{l}\text { Pontos } \\
\text { Fracos }\end{array}$} & P1: não comentou \\
\hline & & P2: não comentou \\
\hline & & P3: não comentou \\
\hline & & P4: não comentou \\
\hline & & P5: não comentou \\
\hline & & P6: não comentou \\
\hline
\end{tabular}

\section{Quadro A8.9 - Transcrição das Respostas - Área de Conhecimento GaRantia dA}

Qualidade de Produto e Processo

\begin{tabular}{|c|c|c|}
\hline \multirow{3}{*}{$\begin{array}{l}\text { Quanto à } \\
\text { Garantia da } \\
\text { Qualidade de }\end{array}$} & \multirow{6}{*}{$\begin{array}{l}\text { Pontos } \\
\text { Fortes }\end{array}$} & P1: não comentou \\
\hline & & P2: não comentou \\
\hline & & P3: não comentou \\
\hline \multirow{9}{*}{$\begin{array}{l}\text { Produto e } \\
\text { Processo }\end{array}$} & & P4: "Parece coerente" \\
\hline & & $\begin{array}{l}\text { P5: "A verificação de qualidade é um processo apontado aqui em todas as etapas de } \\
\text { desenvolvimento". }\end{array}$ \\
\hline & & P6: não comentou \\
\hline & \multirow{6}{*}{$\begin{array}{l}\text { Pontos } \\
\text { Fracos }\end{array}$} & P1: não comentou \\
\hline & & P2: não comentou \\
\hline & & P3: não comentou \\
\hline & & P4: não comentou \\
\hline & & P5: não comentou \\
\hline & & P6: não comentou \\
\hline
\end{tabular}

Quadro A8.10 - Transcrição das Respostas - Área de Conhecimento Gestão de Conhecimento

\begin{tabular}{|c|c|c|}
\hline \multirow{12}{*}{$\begin{array}{l}\text { Quanto à } \\
\text { Gestão de } \\
\text { Conhecimento }\end{array}$} & \multirow{6}{*}{$\begin{array}{l}\text { Pontos } \\
\text { Fortes }\end{array}$} & P1: não comentou \\
\hline & & P2: "Garantia de controle e disponibilidade do conhecimento". \\
\hline & & P3: não comentou \\
\hline & & P4: não comentou \\
\hline & & P5: não comentou \\
\hline & & $\begin{array}{l}\text { P6: "O modelo mostra uma forma de gerenciar o conhecimento de todos os } \\
\text { desenvolvedores da empresa, fazendo com que o conhecimento e experiência de um } \\
\text { desenvolvedor sejam disseminados para outros interessados". }\end{array}$ \\
\hline & \multirow{6}{*}{$\begin{array}{l}\text { Pontos } \\
\text { Fracos }\end{array}$} & P1: não comentou \\
\hline & & P2: não comentou \\
\hline & & P3: não comentou \\
\hline & & P4: não comentou \\
\hline & & P5: não comentou \\
\hline & & P6: não comentou \\
\hline
\end{tabular}


Quadro A8.11 - Transcrição das Respostas - Área de Conhecimento Gestão de Requisitos

\begin{tabular}{|c|c|c|}
\hline \multirow{12}{*}{$\begin{array}{l}\text { Quanto à } \\
\text { Gestão de } \\
\text { Requisitos }\end{array}$} & \multirow{6}{*}{$\begin{array}{l}\text { Pontos } \\
\text { Fortes }\end{array}$} & P1: não comentou \\
\hline & & P2: "Muito bem articulado e completo". \\
\hline & & P3: não comentou \\
\hline & & P4: não comentou \\
\hline & & $\begin{array}{l}\text { P5: "Importante para controlar qualquer tipo de requisito que possa influenciar na lógica } \\
\text { de processos". }\end{array}$ \\
\hline & & $\begin{array}{l}\text { P6: "O gerenciamento de todos os requisitos é muito importante e é contemplado pelo } \\
\text { modelo". }\end{array}$ \\
\hline & \multirow{6}{*}{$\begin{array}{l}\text { Pontos } \\
\text { Fracos }\end{array}$} & P1: não comentou \\
\hline & & P2: não comentou \\
\hline & & P3: não comentou \\
\hline & & P4: não comentou \\
\hline & & $\begin{array}{l}\text { P5: "Sugiro inserir o Documento de requisitos do componente adquirido pelo } \\
\text { fornecedor, no caso de componente de software, como artefato do projeto que poderá } \\
\text { ser modificado e, por isso, precisa ser colocado sob gerência de requisitos também". }\end{array}$ \\
\hline & & P6: não comentou \\
\hline
\end{tabular}

Quadro A8.12 - Transcrição das Respostas - Área de Conhecimento Gestão de Projetos

\begin{tabular}{|c|c|c|}
\hline \multirow{12}{*}{$\begin{array}{l}\text { Quanto à } \\
\text { Gestão de } \\
\text { Projetos }\end{array}$} & \multirow{6}{*}{$\begin{array}{l}\text { Pontos } \\
\text { Fortes }\end{array}$} & P1: não comentou \\
\hline & & P2: "Muito bem articulado e completo". \\
\hline & & P3: não comentou \\
\hline & & P4: não comentou \\
\hline & & $\begin{array}{l}\text { P5: "É importante entender o escopo do projeto e fazer o planejamento preliminar desse } \\
\text { escopo, a fim de ser ter uma visão macro em relação ao que se pretende atingir com o } \\
\text { produto resultante do projeto, quanto será gasto, quanto demorará para ser produzido e } \\
\text { qual o retorno financeiro desse projeto. E, também, é importante fazer o monitoramento } \\
\text { e controle desse projeto para que se possa tomar medidas reativas e até mesmo pró- } \\
\text { ativas. Esse modelo atende a esses requisitos". }\end{array}$ \\
\hline & & P6: "O Gerenciamento de Projetos é muito importante e é contemplado pelo modelo". \\
\hline & \multirow{6}{*}{$\begin{array}{l}\text { Pontos } \\
\text { Fracos }\end{array}$} & P1: não comentou \\
\hline & & P2: não comentou \\
\hline & & P3: não comentou \\
\hline & & P4: não comentou \\
\hline & & P5: não comentou \\
\hline & & P6: não comentou \\
\hline
\end{tabular}


Quadro A8.13 - Transcrição das Respostas - Área de Conhecimento Gestão de Mudanças e Configuração

\begin{tabular}{|c|c|c|}
\hline \multirow{12}{*}{$\begin{array}{l}\text { Quanto à } \\
\text { Gestão de } \\
\text { Mudanças e } \\
\text { Configuração }\end{array}$} & \multirow{6}{*}{$\begin{array}{l}\text { Pontos } \\
\text { Fortes }\end{array}$} & P1: não comentou \\
\hline & & P2: "Completo e detalhado". \\
\hline & & P3: não comentou \\
\hline & & P4: não comentou \\
\hline & & $\begin{array}{l}\text { P5: “Implementações e mudanças em sistemas são processos constantes e, portanto, é } \\
\text { necessário um controle dessas modificações". }\end{array}$ \\
\hline & & $\begin{array}{l}\text { P6: "O gerenciamento das versões dos softwares desenvolvidos pela empresa é muito } \\
\text { importante e o modelo fornece sugestões de como fazê-lo". }\end{array}$ \\
\hline & \multirow{6}{*}{$\begin{array}{l}\text { Pontos } \\
\text { Fracos }\end{array}$} & P1: não comentou \\
\hline & & P2: não comentou \\
\hline & & P3: não comentou \\
\hline & & P4: não comentou \\
\hline & & P5: "Acho importante um Controle para Help-Desk" \\
\hline & & P6: não comentou \\
\hline
\end{tabular}




\section{Apêndice 9 - Respostas do Questionário respondido pelos Profissionais}

Os Quadros A9.1 a A9.4 apresentam as respostas transcritas relacionadas a 4 (quatro) questões respondidas pelos 6 (seis) profissionais que avaliaram o modelo.

Quadro A9.1 - TranscriçÃo da Resposta Para A Questão 1

\begin{tabular}{|c|c|}
\hline Questão 1 & Respostas \\
\hline \multirow{6}{*}{$\begin{array}{l}\text { Para uma MPE, o } \\
\text { que é mais fácil: } \\
\text { utilizar como } \\
\text { modelo de } \\
\text { referência para } \\
\text { criar o seu } \\
\text { processo padrão o } \\
\text { CMMI ou um outro } \\
\text { modelo com mais } \\
\text { detalhes de como } \\
\text { podem ser } \\
\text { realizadas as } \\
\text { atividades do } \\
\text { processo, como o } \\
\text { proposto nesse } \\
\text { trabalho de } \\
\text { pesquisa? }\end{array}$} & P1: "Um outro modelo com mais detalhes". \\
\hline & $\begin{array}{l}\text { P2: "O melhor é utilizar um modelo como o proposto neste trabalho, pois uma MPE não } \\
\text { teria recursos financeiros, pessoas e tempo para criar um modelo com base no CMMI. } \\
\text { Além disso, os detalhes e as orientações de como e o que deve ser feito auxiliam muito. } \\
\text { Outro fator é a clareza e a riqueza de detalhes que tornam a adoção do modelo um } \\
\text { processo mais rápido e eficiente". }\end{array}$ \\
\hline & $\begin{array}{l}\text { P3: "A utilização do modelo apresentado nesse trabalho torna-se mais efetivo que o } \\
\text { CMMI, uma vez que sugere os templates e documentos de apoio. A aplicação de } \\
\text { qualquer modelo que cita diretrizes gerais dificulta a aplicação, pois deixa sem } \\
\text { direcionamento o procedimento de aplicação". }\end{array}$ \\
\hline & $\begin{array}{l}\text { P4: "Acredito que para uma MPE seria mais fácil iniciar com um modelo simplificado, e } \\
\text { não com um modelo com mais atividades. A estrutura organizacional é geralmente } \\
\text { pequena para tantas atividades. Dessa forma, à medida que a organização cresce, tem } \\
\text { condições de evoluir seu processo de desenvolvimento e comercialização". }\end{array}$ \\
\hline & $\begin{array}{l}\text { P5: "Na minha opinião, o modelo CMMI é muito complexo, e acho que o modelo } \\
\text { apresentando nesse trabalho poderia auxiliar mais (logicamente adaptado à realidade da } \\
\text { empresa)". }\end{array}$ \\
\hline & $\begin{array}{l}\text { P6: "É mais fácil utilizar um modelo com mais detalhes porque cada atividade de cada } \\
\text { área de conhecimento foi detalhada, fornecendo material suficiente para que cada } \\
\text { empresa utilize os modelos do jeito que lhe for mais útil". }\end{array}$ \\
\hline
\end{tabular}


QuAdro A9.2 - TrANSCRIÇÃo dA RESPOSTA PARA A QUESTÃo 2

\begin{tabular}{|c|c|}
\hline Questão 2 & Respostas \\
\hline \multirow{6}{*}{$\begin{array}{l}\text { Para uma MPE, o } \\
\text { que é mais fácil: } \\
\text { utilizar como } \\
\text { modelo de } \\
\text { referência para } \\
\text { criar o seu } \\
\text { processo padrão a } \\
\text { norma ISO/IEC } \\
\text { 15504-5 ou um } \\
\text { outro modelo com } \\
\text { mais detalhes de } \\
\text { como podem ser } \\
\text { realizadas as } \\
\text { atividades do } \\
\text { processo, como o } \\
\text { proposto nesse } \\
\text { trabalho de } \\
\text { pesquisa? }\end{array}$} & P1: "Um outro modelo com mais detalhes". \\
\hline & P2: "Um outro modelo com mais detalhes". \\
\hline & $\begin{array}{l}\text { P3: "Apesar da norma ISO/IEC 15504-5 ter mais detalhes com relação aos } \\
\text { procedimentos, ainda não contém os templates que podem ser o diferencial na hora de } \\
\text { uma aplicação real". }\end{array}$ \\
\hline & $\begin{array}{l}\text { P4: "Acredito que para uma MPE seria mais fácil iniciar com um modelo simplificado, e } \\
\text { não com um modelo com mais atividades. A estrutura organizacional é geralmente } \\
\text { pequena para tantas atividades. Dessa forma, à medida que a organização cresce, tem } \\
\text { condições de evoluir seu processo de desenvolvimento e comercialização". }\end{array}$ \\
\hline & $\begin{array}{l}\text { P5: "Na minha opinião, comparando o CMMI com a 15504-5, acredito que o último é } \\
\text { muito mais fácil de ser compreendido e com possibilidade de ser usado até mesmo por } \\
\text { uma MPE como subsídio para criar o seu processo padrão. Entretanto, apesar de } \\
\text { apresentar práticas base, resultados, produtos de trabalho típicos e até mesmo } \\
\text { sugestões de itens a serem abordados nesses produtos de trabalho, a ISO 15504-5 } \\
\text { (assim como o CMMI) não fornece templates mais detalhados a respeito desses } \\
\text { produtos, o que facilitaria e muito o entendimento de "como fazer" para realizar as } \\
\text { atividades em MPEs". }\end{array}$ \\
\hline & P6: "Um outro modelo com mais detalhes, como o apresentado nesse trabalho". \\
\hline
\end{tabular}




\section{QuAdRo A9.3 - Transcrição dA RESPOSTA PARA A QUESTÃo 3}

\begin{tabular}{|c|c|}
\hline Questão 3 & Respostas \\
\hline \multirow{6}{*}{$\begin{array}{l}\text { Você enxerga o } \\
\text { modelo proposto } \\
\text { nesse trabalho de } \\
\text { pesquisa como } \\
\text { uma referência, um } \\
\text { guia que poderia } \\
\text { ser utilizado por } \\
\text { uma MPE para, a } \\
\text { partir dele, definir o } \\
\text { seu processo } \\
\text { padrão (mesmo } \\
\text { que sejam } \\
\text { necessários alguns } \\
\text { ajustes para } \\
\text { adequar à } \\
\text { realidade da } \\
\text { empresa)? }\end{array}$} & 1: "Sim". \\
\hline & $\begin{array}{l}\text { P2: "Sim, pois o modelo aborda todos os aspectos relevantes do processo de } \\
\text { desenvolvimento de software para as MPEs, enfocando especificamente suas } \\
\text { características e necessidades (busca de clientes, agilidade, inexperiência na área de } \\
\text { Engenharia de Software, recursos limitados). É extremamente viável, pois além de } \\
\text { descrever cada fase do modelo proposto com um vocabulário de fácil entendimento, } \\
\text { ainda indica/sugere formas para sua aplicação na empresa. Além disso, possui } \\
\text { referências e anexos contendo a fundamentação teórica sobre cada assunto que pode } \\
\text { não ser trivial ao seu público-alvo". }\end{array}$ \\
\hline & $\begin{array}{l}\text { P3: "Sim. Acredito que as áreas podem ser instanciadas isoladamente para melhoria de } \\
\text { determinadas áreas de um processo, especialmente, em empresas que já detêm algum } \\
\text { procedimento organizado de concepção e construção de software. Entretanto, para MPE } \\
\text { ainda acredito ser necessário algumas simplificações, pois o modelo está complexo e } \\
\text { exige um grau de conhecimento técnico e de recursos humanos que pode inviabilizar } \\
\text { seu uso". }\end{array}$ \\
\hline & $\begin{array}{l}\text { P4: "Pelo que tenho visto, seria ideal. Mas a realidade é outra. Ele seria útil para } \\
\text { conscientizar uma MPE sobre a necessidade e vantagens de se ter um processo } \\
\text { padrão, e até mesmo considerar tarefas que podem não ser consideradas em tal } \\
\text { organização (até por não ter sentido a necessidade delas)". }\end{array}$ \\
\hline & $\begin{array}{l}\text { P5: "Sim. Aliás, se encaixa muito no atual processo organizacional de minha empresa de } \\
\text { software, com apenas pequenos ajustes, para adaptação do modelo à realidade da } \\
\text { empresa". }\end{array}$ \\
\hline & $\begin{array}{l}\text { P6: "Sim. Para a minha empresa que está iniciando suas atividades, onde eu serei } \\
\text { responsável por todas as áreas de conhecimento, o modelo será de muito auxílio, pois } \\
\text { seguirei normas estabelecidas e estarei de acordo com o que o mercado consumidor na } \\
\text { área de TI quer: softwares bem projetados e empresas de software com seus processos } \\
\text { de desenvolvimento bem definidos". }\end{array}$ \\
\hline
\end{tabular}




\section{QuAdro A9.4 - Transcrição da Resposta PaRA A QUESTÃo 4}

\begin{tabular}{|c|c|}
\hline Questão 4 & Respostas \\
\hline \multirow[t]{6}{*}{$\begin{array}{l}\text { De forma geral, } \\
\text { quais os } \\
\text { comentários você } \\
\text { faria a respeito do } \\
\text { modelo proposto? }\end{array}$} & $\begin{array}{l}\text { P1: "Este modelo é um guia de referência espetacular para uma MPE criar seus } \\
\text { processos de software. É um modelo genérico que serve para a empresa vender, } \\
\text { modelar e executar qualquer tipo de processo de software, sem a necessidade da } \\
\text { contratação de consultores especializados neste tipo de trabalho por um tempo muito } \\
\text { grande, o que seria inviável para uma MPE. O modelo proposto é fácil de entender, pois } \\
\text { contêm todas as atividades necessárias para a venda e desenvolvimento de software, } \\
\text { descritas de uma maneira simples e completa, com ênfase às tarefas de cada atividade, } \\
\text { bem como suas entradas e saídas, quem deve executá-las e os recursos que podem ser } \\
\text { utilizados, tornando o processo auto-explicativo e possível de ser conduzido por uma } \\
\text { MPE". }\end{array}$ \\
\hline & $\begin{array}{l}\text { P2: "Com eficiência e baixo custo, o modelo proporciona o gerenciamento de projetos, } \\
\text { auxilia na melhoria da qualidade dos produtos desenvolvidos. O detalhamento das fases } \\
\text { e as orientações sobre "o quê" e "como" realizar as tarefas é extremamente útil e } \\
\text { relevante, uma vez que facilita o uso e adaptação ao modelo. Outro ponto relevante é a } \\
\text { área de conhecimento "comercialização" que foi inserida no modelo e que é fundamental } \\
\text { para as empresas de desenvolvimento de software, pois envolve atividades de busca } \\
\text { por potenciais clientes, o que muitas vezes as empresas não dedicam o devido tempo. } \\
\text { Seria interessante que o modelo fosse testado/experimentado por alguma(s) empresa(s) } \\
\text { de desenvolvimento de software. Assim, várias opiniões e sugestões significativas } \\
\text { poderiam ser obtidas." }\end{array}$ \\
\hline & $\begin{array}{l}\text { P3: "Alguns exemplos estão em inglês e outros em português. Seria interessante definir } \\
\text { uma padronização, idealmente, em português. Seria também interessante explicitar em } \\
\text { todas as tarefas das atividades, que é possível consultar/atualizar a base de } \\
\text { conhecimento da empresa". }\end{array}$ \\
\hline & $\begin{array}{l}\text { P4: "A organização está um tanto confusa. Não fica claro como os ciclos do RUP (que é } \\
\text { baseado em modelo Espiral) ficariam nesse processo. Também não fica claro como uma } \\
\text { organização utilizaria tal processo para o primeiro projeto. Por exemplo, considere uma } \\
\text { proposta de uma empresa a ser incubada em uma Incubadora Tecnológica, que ainda } \\
\text { não tem cliente e não tem produto. Nesse caso, vários artefatos utilizados como } \\
\text { subsídios ainda não existem. Como fica o processo? Para melhorar, facilitando seu uso } \\
\text { por uma MPE, o uso de um modelo o processo para apoiar a definição de um processo } \\
\text { deveria ser evolutivo, iniciando com atividades fundamentais, com vistas ao crescimento } \\
\text { e facilidade de evolução do processo simplificado (inicial) para um processo mais } \\
\text { completo e maduro, conforme a organização evolui (cresce)". }\end{array}$ \\
\hline & $\begin{array}{l}\text { P5: "Achei muito interessante o modelo por se adequar realmente à realidade de uma } \\
\text { MPE, uma vez que é importante estudar tendências que o mercado direciona". }\end{array}$ \\
\hline & $\begin{array}{l}\text { P6: "Muito bom - o modelo fornece às MPEs uma orientação de como podem realizar as } \\
\text { atividades de um processo de venda e desenvolvimento de software, possibilitando que } \\
\text { a empresa adapte o modelo às suas necessidades". }\end{array}$ \\
\hline
\end{tabular}

